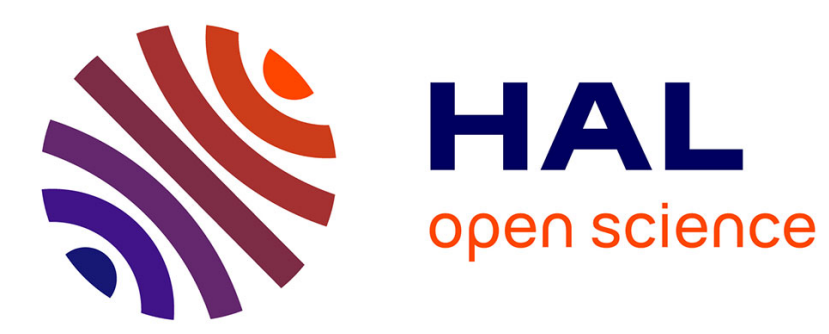

\title{
Promiscuous function of the prion protein gene family
}

\author{
Sophie Mouillet-Richard, Jean-Luc Vilotte
}

\section{To cite this version:}

Sophie Mouillet-Richard, Jean-Luc Vilotte. Promiscuous function of the prion protein gene family. Frontiers Media, 115 p., 2015, Frontiers in Cell and Developmental Biology, 978-2-88919-605-0. 10.3389/978-2-88919-605-0 . hal-01194141

\section{HAL Id: hal-01194141 \\ https://hal.science/hal-01194141}

Submitted on 5 Jun 2020

HAL is a multi-disciplinary open access archive for the deposit and dissemination of scientific research documents, whether they are published or not. The documents may come from teaching and research institutions in France or abroad, or from public or private research centers.
L'archive ouverte pluridisciplinaire HAL, est destinée au dépôt et à la diffusion de documents scientifiques de niveau recherche, publiés ou non, émanant des établissements d'enseignement et de recherche français ou étrangers, des laboratoires publics ou privés. 


\section{PROMISCUOUS FUNCTIONS OF THE PRION PROTEIN GENE FAMILY}

EDITED BY: Sophie Mouillet-Richard and Jean-Luc Vilotte PUBLISHED IN: Frontiers in Cell and Developmental Biology 


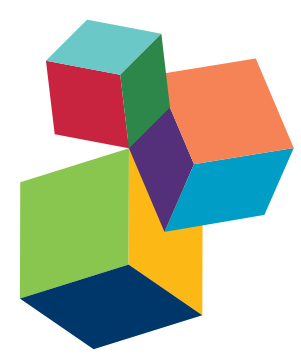

Frontiers Copyright Statement

(c) Copyright 2007-2015 Frontiers Media SA. All rights reserved.

All content included on this site, such as text, graphics, logos, button icons, images, video/audio clips, downloads, data compilations and software, is the property of or is licensed to Frontiers Media SA

("Frontiers") or its licensees and/or subcontractors. The copyright in the text of individual articles is the property of their respective authors, subject to a license granted to Frontiers.

The compilation of articles constituting

this e-book, wherever published,

as well as the compilation of all other content on this site, is the exclusive property of Frontiers. For the conditions for downloading and copying of e-books from Frontiers' website, please see the Terms for Website Use. If purchasing Frontiers e-books from other websites or sources, the conditions of the website concerned apply.

Images and graphics not forming part of user-contributed materials may not be downloaded or copied without permission.

Individual articles may be downloaded and reproduced in accordance with the principles of the $C C-B Y$ licence subject to any copyright or other notices. They may not be re-sold as an e-book.

As author or other contributor you grant a CC-BY licence to others to reproduce your articles, including any graphics and third-party materials supplied by you, in accordance with the Conditions for Website Use and subject to any copyright notices which you include in connection with your articles and materials.

All copyright, and all rights therein, are protected by national and international copyright laws.

The above represents a summary only. For the full conditions see the Conditions for Authors and the Conditions for Website Use.

ISSN 1664-8714 ISBN 978-2-88919-605-0

DOI 10.3389/978-2-88919-605-0

\section{About Frontiers}

Frontiers is more than just an open-access publisher of scholarly articles: it is a pioneering approach to the world of academia, radically improving the way scholarly research is managed. The grand vision of Frontiers is a world where all people have an equal opportunity to seek, share and generate knowledge. Frontiers provides immediate and permanent online open access to all its publications, but this alone is not enough to realize our grand goals.

\section{Frontiers Journal Series}

The Frontiers Journal Series is a multi-tier and interdisciplinary set of open-access, online journals, promising a paradigm shift from the current review, selection and dissemination processes in academic publishing. All Frontiers journals are driven by researchers for researchers; therefore, they constitute a service to the scholarly community. At the same time, the Frontiers Journal Series operates on a revolutionary invention, the tiered publishing system, initially addressing specific communities of scholars, and gradually climbing up to broader public understanding, thus serving the interests of the lay society, too.

\section{Dedication to Quality}

Each Frontiers article is a landmark of the highest quality, thanks to genuinely collaborative interactions between authors and review editors, who include some of the world's best academicians. Research must be certified by peers before entering a stream of knowledge that may eventually reach the public - and shape society; therefore, Frontiers only applies the most rigorous and unbiased reviews.

Frontiers revolutionizes research publishing by freely delivering the most outstanding research, evaluated with no bias from both the academic and social point of view. By applying the most advanced information technologies, Frontiers is catapulting scholarly publishing into a new generation.

\section{What are Frontiers Research Topics?}

Frontiers Research Topics are very popular trademarks of the Frontiers Journals Series: they are collections of at least ten articles, all centered on a particular subject. With their unique mix of varied contributions from Original Research to Review Articles, Frontiers Research Topics unify the most influential researchers, the latest key findings and historical advances in a hot research area! Find out more on how to host your own Frontiers Research Topic or contribute to one as an author by contacting the Frontiers Editorial Office: researchtopics@frontiersin.org 


\section{PROMISCUOUS FUNCTIONS OF THE PRION PROTEIN GENE FAMILY}

Topic Editors:

Sophie Mouillet-Richard, INSERM Unit 1124 Paris, France

Jean-Luc Vilotte, National Institute of Agronomical Research Jouy-en-Josas, France

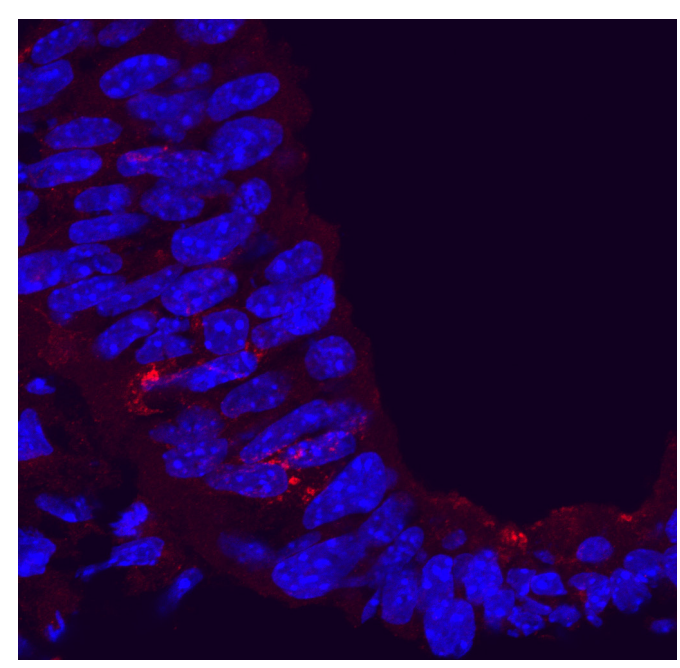

Confocal image of $\mathrm{PrP}^{\mathrm{C}}$ staining (red) in mouse embryo at E9.5 in the presumptive hindbrain region (courtesy of S. Halliez, INRA Jouy en Josas, France)
The cellular prion protein $\operatorname{PrP}^{\mathrm{C}}$ is a ubiquitous GPI-anchored protein. While $\operatorname{PrP}^{\mathrm{C}}$ has been the focus of intense research for its involvement in a group of neurodegenerative disorders known as transmissible spongiform encephalopathies (TSE), much less attention has been devoted to its physiological function. This notably relates to the lack of obvious abnormalities of mice, goat or cattle lacking $\mathrm{PrP}^{\mathrm{C}}$. This apparently normal phenotype in these $\operatorname{PrP}^{\mathrm{C}}$-deficient animals however contrasts with the very high degree of conservation of the prion protein gene (Prnp) in mammalian species (over $80 \%$ ), and the presence of genes with similarities to Prnp in birds, reptils, amphibians and fish. This high conservation together with its ubiquitous

expression, - albeit at highest levels in the brain-, suggest that $\operatorname{PrP}^{\mathrm{C}}$ has major physiological functions.

Dissecting $\operatorname{PrP}^{\mathrm{C}}$ function is further complicated by the occurrence, in mammals, of two potentially partially redundant homologues, Doppel, and Shadoo. The biological overlaps between members of the prion protein family are still under investigation and much debated. Similarly, although in vitro analyses have suggested various functions for $\operatorname{PrP}^{\mathrm{C}}$, notably in cell death and survival processes, some have yielded conflicting results and/or discrepancies with in vivo studies. This Research Topic brings together the accumulated knowledge regarding the biological roles of the prion protein family, from the animal to the molecular scale.

Citation: Mouillet-Richard, S., Vilotte, J.-L., eds. (2015). Promiscuous Functions of the Prion Protein Gene Family. Lausanne: Frontiers Media. doi: 10.3389/978-2-88919-605-0 


\section{Table of Contents}

04 Promiscuous functions of the prion protein family

Sophie Mouillet-Richard and Jean-Luc Vilotte

06 To develop with or without the prion protein

Sophie Halliez, Bruno Passet, Séverine Martin-Lannerée, Julia Hernandez-Rapp, Hubert Laude, Sophie Mouillet-Richard, Jean-Luc Vilotte and Vincent Béringue

16 The prion protein family: a view from the placenta

Samira Makzhami, Bruno Passet, Sophie Halliez, Johan Castille, Katayoun MoazamiGoudarzi, Amandine Duchesne, Marthe Vilotte, Hubert Laude, Sophie MouilletRichard, Vincent Béringue, Daniel Vaiman and Jean-Luc Vilotte

26 Role of the prion protein family in the gonads

Aurélie Allais-Bonnet and Eric Pailhoux

35 An emerging role of the cellular prion protein as a modulator of a morphogenetic program underlying epithelial-to-mesenchymal transition Mohadeseh Mehrabian, Sepehr Ehsani and Gerold Schmitt-Ulms

42 PrPc from stem cells to cancer

Séverine Martin-Lannerée, Théo Z. Hirsch, Julia Hernandez-Rapp, Sophie Halliez, Jean-Luc Vilotte, Jean-Marie Launay and Sophie Mouillet-Richard

49 Prion protein (PrP) gene-knockout cell lines: insight into functions of the PrP Akikazu Sakudo and Takashi Onodera

67 Regulation of $\mathrm{PrP}^{c}$ signaling and processing by dimerization Xavier Roucou

73 Common themes in PrP signaling: the Src remains the same Katharina Ochs and Edward Málaga-Trillo

81 Cellular prion protein and NMDA receptor modulation: protecting against excitotoxicity

Stefanie A. G. Black, Peter K. Stys, Gerald W. Zamponi and Shigeki Tsutsui

92 Lipid rafts: linking prion protein to zinc transport and amyloid- $\beta$ toxicity in Alzheimer's disease

Nicole T. Watt, Heledd H. Griffiths and Nigel M. Hooper

$98 \quad$ Prion protein and aging

Lisa Gasperini and Giuseppe Legname

106 Biochemical insight into the prion protein family

Danica Ciric and Human Rezaei 


\title{
Promiscuous functions of the prion protein family
}

\section{Sophie Mouillet-Richard ${ }^{1,2 *}$ and Jean-Luc Vilotte ${ }^{3}$}

\author{
Toxicology, Pharmacology, and Cellular Signaling, Institut National de la Santé et de la Recherche Médicale Unité Mixtes de Recherche-S1124, Université Paris \\ Descartes, Paris, France \\ 2 Toxicology, Pharmacology, and Cellular Signaling, Sorbonne Paris Cité, Unité Mixtes de Recherche-S1124, Université Paris Descartes, Paris, France \\ ${ }^{3}$ Unité Mixtes de Recherche1313 Génétique Animale et Biologie Intégrative, Institut National de la Recherche Agronomique, Jouy-en-Josas, France \\ *Correspondence: sophie.mouillet-richard@parisdescartes.fr
}

Edited and reviewed by:

Craig Michael Walsh, University of California, Irvine, USA

Keywords: prion protein, embryonic and fetal development, stem cells, aging, cell signaling, placenta, gonads, neuroprotection

From the discovery nearly 30 years ago of the cellular prion protein $\operatorname{PrP}^{\mathrm{C}}$, the founder of the prion protein family, there has been a constant quest to dissect its biological function and that of its two homologs, Doppel and Shadoo. While clues were greatly anticipated from the generation of PrP null mice, alterations appeared quite imperceptible at first examination, beyond the clear-cut resistance to prion infection. Taking a closer look at these knockout mice, together with the generation of mice invalidated for Doppel and Shadoo has in the end yielded much information on the -sometimes overlapping- roles of these proteins. These in-depth investigations have also explored functions of the prion protein family beyond the central nervous system, which was obviously the first focus of interest since prion diseases are neurodegenerative disorders. This Frontiers Research topic on the promiscuous functions of the prion protein family incorporates contributions ranging from the field of developmental biology to that of structure-function, including aspects related to cell biology, signal transduction, and neuronal homeostasis.

Starting from the embryo, the contribution by Halliez et al. provides a comprehensive review of the impact of $\operatorname{PrP}$ invalidation on embryonic development, compiling data from both mice and zebrafish and highlighting the key cellular pathways affected by $\operatorname{PrP}^{\mathrm{C}}$ deletion (Halliez et al., 2014). The review by Makzhami and colleagues is centered on the tissue with the second highest $\mathrm{PrP}^{\mathrm{C}}$ expression after the brain, i.e., the placenta (Makzhami et al., 2014). It summarizes the recent data obtained with the help of $\operatorname{PrP}$ invalidated mice and discusses the pathophysiological implications stemming from the aberrant $\mathrm{PrP}^{\mathrm{C}}$ expression in human gestational diseases. The review by AllaisBonnet and Pailhoux is dedicated to the gonads, a unique tissue where $\operatorname{PrP}^{\mathrm{C}}$, Shadoo and Doppel are all expressed, raising the question of a potential redundancy between the three proteins, as well as their roles in reproductive functions (Allais-Bonnet and Pailhoux, 2014). Mehrabian et al. provide a perspective on the potential relationship between $\operatorname{PrP}^{\mathrm{C}}$ and the pathways involved in epithelial to mesenchymal transition, a process associated with major changes in cell adhesion properties and that physiologically takes place during embryonic development, while also involved in cancer metastasis (Mehrabian et al., 2014). A further connection with cancer is highlighted in the mini-review by Martin-Lannerée et al, which focuses on the contribution of $\operatorname{PrP}^{\mathrm{C}}$ to stem cell biology and its recent association with tumor-initiating cells (Martin-Lanneree et al., 2014). At a cellular level, Sakudo and Onodera provide an overview of the data gathered by exploiting cell lines derived from PrP-null mice or constitutively knocked-down for $\operatorname{PrP}^{\mathrm{C}}$, with special emphasis on the protective role exerted by this protein (Sakudo and Onodera, 2014).

Several contributions go down to the molecular scale and focus on the relationship between $\mathrm{PrP}^{\mathrm{C}}$ and cell signaling. The minireview by Roucou elaborates on the connection between $\operatorname{PrP}^{\mathrm{C}}$ dimerization, proteolytic processing and the recruitment of cell signaling cascades (Roucou, 2014). Ochs and Málaga-Trillo provide a perspective on the recurrent link between $\operatorname{PrP}^{\mathrm{C}}$-related signaling and src family kinases, in contexts ranging from embryonic cell adhesion to regulation of NMDA activity (Ochs and Malaga-Trillo, 2014). The protective function of $\operatorname{PrP}^{\mathrm{C}}$ against NMDA-dependent excitotoxicity is the focus of the review by Black et al, which also discusses the pathophysiological implications of this regulation as to ischemic injury, neuroinflammation, and Alzheimer's disease (Black et al., 2014). This last issue relates to the identification of $\operatorname{PrP}^{\mathrm{C}}$ as a cell-surface receptor for Abeta oligomers, and follow-up investigations on the contribution of $\operatorname{PrP}^{\mathrm{C}}$ to Abeta toxicity, which is summarized in the review by Watt et al. (2014). This review additionally focuses on the contribution of $\operatorname{PrP}^{\mathrm{C}}$ to zinc homeostasis, and discusses how age-regulated deregulation of the interplay between $\operatorname{PrP}^{\mathrm{C}}$, lipid rafts and zinc may contribute to Alzheimer's disease. The fate of $\operatorname{PrP}^{\mathrm{C}}$ during aging is further discussed in the review by Gasperini and Legname, which notably highlights the changes in the biochemical properties and lipid raft association of $\mathrm{PrP}^{\mathrm{C}}$ in aged animals (Gasperini and Legname, 2014).

Further zooming on the molecule itself, the review by Rezaei provides a global view of the biochemical and structural similarities between $\operatorname{PrP}^{\mathrm{C}}$, Doppel and Shadoo, as well as their specificities, in relation with their propensity to misfold (Rezaei, 2015).

Collectively, these works underscore the advance in our understanding of the functions exerted by the prion protein family and underlines their versatile roles according to the cellular context and interacting partners involved. Finally, they provide some future directions for further dissecting how the deregulation of these proteins functions can cause or contribute to pathological conditions. 


\section{REFERENCES}

Allais-Bonnet, A., and Pailhoux, E. (2014). Role of the prion protein family in the gonads. Front. Cell Dev. Biol. 2:56. doi: 10.3389/fcell.2014.00056

Black, S. A., Stys, P. K., Zamponi, G. W., and Tsutsui, S. (2014). Cellular prion protein and NMDA receptor modulation: protecting against excitotoxicity. Front. Cell Dev. Biol. 2:45. doi: 10.3389/fcell.2014.00045

Gasperini, L., and Legname, G. (2014). Prion protein and aging. Front. Cell Dev. Biol. 2:44. doi: 10.3389/fcell.2014.00044

Halliez, S., Passet, B., Martin-Lanneree, S., Hernandez-Rapp, J., Laude, H., Mouillet-Richard, S., et al. (2014). To develop with or without the prion protein. Front. Cell Dev. Biol. 2:58. doi: 10.3389/fcell.2014.00058

Makzhami, S., Passet, B., Halliez, S., Castille, J., Moazami-Goudarzi, K., Duschene, A., et al. (2014). The prion protein family: a view from the placenta. Front. Cell Dev. Biol. 2:35. doi: 10.3389/fcell.2014.00035

Martin-Lanneree, S., Hirsch, T. Z., Hernandez-Rapp, J., Halliez, S., Vilotte, J. L., Launay, J. M., et al. (2014). PrPC from stem cells to cancer. Front. Cell Dev. Biol. 2:55. doi: $10.3389 /$ fcell.2014.00055

Mehrabian, M., Ehsani, S., and Schmitt-Ulms, G. (2014). An emerging role of the cellular prion protein as a modulator of a morphogenetic program underlying epithelial-to-mesenchymal transition. Front. Cell Dev. Biol. 2:53. doi: 10.3389/fcell.2014.00053

Ochs, K., and Malaga-Trillo, E. (2014). Common themes in PrP signaling: the Src remains the same. Front. Cell Dev. Biol. 2:63. doi: 10.3389/fcell.2014.00063

Rezaei, H. (2015). Biochemical insight in to the prion protein family. Front. Cell Dev. Biol. 3:5. doi: 10.3389/fcell.2015.00005
Roucou, X. (2014). Regulation of $\operatorname{PrP}(C)$ signaling and processing by dimerization. Front. Cell Dev. Biol. 2:57. doi: 10.3389/fcell.2014.00057

Sakudo, A., and Onodera, T. (2014). Prion protein (PrP) gene-knockout cell lines: insight into functions of the PrP. Front. Cell Dev. Biol. 2:75. doi: 10.3389/fcell.2014.00075

Watt, N. T., Griffiths, H. H., and Hooper, N. M. (2014). Lipid rafts: linking prion protein to zinc transport and amyloid-beta toxicity in Alzheimer's disease. Front. Cell Dev. Biol. 2:41. doi: 10.3389/fcell.2014.00041

Conflict of Interest Statement: The authors declare that the research was conducted in the absence of any commercial or financial relationships that could be construed as a potential conflict of interest.

Received: 20 January 2015; accepted: 23 January 2015; published online: 10 February 2015.

Citation: Mouillet-Richard S and Vilotte J-L (2015) Promiscuous functions of the prion protein family. Front. Cell Dev. Biol. 3:7. doi: 10.3389/fcell.2015.00007

This article was submitted to Cell Death and Survival, a section of the journal Frontiers in Cell and Developmental Biology.

Copyright (c) 2015 Mouillet-Richard and Vilotte. This is an open-access article distributed under the terms of the Creative Commons Attribution License (CC BY). The use, distribution or reproduction in other forums is permitted, provided the original author(s) or licensor are credited and that the original publication in this journal is cited, in accordance with accepted academic practice. No use, distribution or reproduction is permitted which does not comply with these terms. 


\title{
To develop with or without the prion protein
}

\section{Sophie Halliez ${ }^{1 *}$, Bruno Passet ${ }^{2}$, Séverine Martin-Lannerée ${ }^{3,4}$, Julia Hernandez-Rapp ${ }^{3,4}$, Hubert Laude $^{1}$, Sophie Mouillet-Richard ${ }^{3,4}$, Jean-Luc Vilotte ${ }^{2}$ and Vincent Béringue ${ }^{1 *}$}

\author{
${ }^{1}$ Institut National de la Recherche Agronomique, U892 Virologie et Immunologie Moléculaires, Jouy-en-Josas, France \\ 2 Institut National de la Recherche Agronomique, UMR1313 Génétique Animale et Biologie Intégrative, Jouy-en-Josas, France \\ ${ }^{3}$ Institut National de la Santé et de la Recherche Médicale, UMR-S1124, Paris, France \\ ${ }^{4}$ Université Paris Descartes, Sorbonne Paris Cité, UMR-S1124, Paris, France
}

\section{Edited by:}

Kim Newton, Genentech, Inc., USA

Reviewed by:

Peter Christian Kloehn, University

College London, UK

Joseph W. Lewcock, Genentech,

Inc., USA

*Correspondence:

Sophie Halliez and Vincent Béringue, Institut National de la Recherche

Agronomique, U892 Virologie et

Immunologie Moléculaires, Equipe

MAP2, Bâtiment 440, 78350

Jouy-en-Josas, France

e-mail:shalliez@jouy.inra.fr;

vincent.beringue@jouy.inra.fr
The deletion of the cellular form of the prion protein $\left(\mathrm{PrP}^{\mathrm{C}}\right)$ in mouse, goat, and cattle has no drastic phenotypic consequence. This stands in apparent contradiction with $\operatorname{Pr} P^{C}$ quasi-ubiquitous expression and conserved primary and tertiary structures in mammals, and its pivotal role in neurodegenerative diseases such as prion and Alzheimer's diseases. In zebrafish embryos, depletion of PrP ortholog leads to a severe loss-of-function phenotype. This raises the question of a potential role of $\mathrm{PrPC}^{\mathrm{C}}$ in the development of all vertebrates. This view is further supported by the early expression of the $\operatorname{PrP}^{\mathrm{C}}$ encoding gene (Prnp) in many tissues of the mouse embryo, the transient disruption of a broad number of cellular pathways in early $P_{r n p^{-/-}}$mouse embryos, and a growing body of evidence for $\operatorname{PrPC}^{\mathrm{C}}$ involvement in the regulation of cell proliferation and differentiation in various types of mammalian stem cells and progenitors. Finally, several studies in both zebrafish embryos and in mammalian cells and tissues in formation support a role for $\mathrm{PrPC}^{\mathrm{C}}$ in cell adhesion, extra-cellular matrix interactions and cytoskeleton. In this review, we summarize and compare the different models used to decipher $\operatorname{PrP}^{\mathrm{C}}$ functions at early developmental stages during embryo- and organo-genesis and discuss their relevance.

Keywords: prion protein, development, neural development, stem cells, cell adhesion, extra-cellular matrix, cytoskeleton

\section{INTRODUCTION}

Prion diseases are a group of fatal and transmissible neurodegenerative diseases affecting a broad range of mammals including humans. The causative agent (the prion) is primarily composed of abnormally folded and aggregated forms of a hostencoded protein, the cellular prion protein $\left(\mathrm{PrP}^{\mathrm{C}}\right) . \mathrm{PrP}^{\mathrm{C}}$ is a glycosyl-phosphatidyl-inositol anchored cell surface sialoglycoprotein associated with lipid rafts (Taylor et al., 2009). PrP primary sequence is highly conserved among mammals (Wopfner et al., 1999) and PrP putative functional domains are structurally conserved between mammals, avians, and fish (Wopfner et al., 1999; Rivera-Milla et al., 2006). $\operatorname{PrP}^{\mathrm{C}}$ is widely expressed in nearly all the organism, albeit at highest levels in the adult nervous system (Bendheim et al., 1992). Together, these data lend support for an essential role of $\mathrm{PrP}^{\mathrm{C}}$ in mammals and possibly in vertebrates in general. However, the production of mice, goat, and cattle lacking PrP did not lead to any obvious phenotype (Bueler et al., 1992; Manson et al., 1994a; Richt et al., 2007; Yu et al., 2009) except, for mice, a resistance to experimental prion diseases (Bueler et al., 1993; Prusiner et al., 1993; Manson et al., 1994b; Mallucci et al., 2003). Additionally, goats, naturally devoid of $\operatorname{Pr}^{C}$ due to a nonsense mutation, do not seem to present any abnormal phenotype (Benestad et al., 2012). Subtle behavioral and oxidative stressrelated alterations have been then reported in adult mice devoid of $\operatorname{PrP}^{\mathrm{C}}$ (see Table 1) (Tobler et al., 1996; Wong et al., 2001; Roucou et al., 2004; Meotti et al., 2007; Sanchez-Alavez et al., 2008; Le Pichon et al., 2009; Gadotti et al., 2012) although some of them are debated (Steele et al., 2007) and some may be related to Prnpflanking genes rather than to $\operatorname{PrP}^{\mathrm{C}}$ absence itself (Nuvolone et al., 2013). However, none of them seems, at first glance, so important to justify the conserved structure and broad expression of $\operatorname{PrP}^{\mathrm{C}}$. The physiological role of $\operatorname{PrP}^{\mathrm{C}}$ still remains highly uncertain despite more than two decades of research and numerous proposed functions (Nicolas et al., 2009; Martins et al., 2010). To conciliate these discrepant data, it has been hypothesized that $\operatorname{PrP}^{\mathrm{C}}$ function is either dispensable or redundant with that of other proteins. Yet, recent advances, notably in the developmental biology, shed a new light on $\operatorname{PrP}^{\mathrm{C}}$ functions and suggest that, perhaps, the quest for $\operatorname{PrP}^{\mathrm{C}}$ functions has been made at the wrong place and/or at the wrong period of time.

\section{EARLY DEVELOPMENTAL EXPRESSION OF THE PrP GENES IN SELECTED VERTEBRATES}

The apparent lack of a phenotype in mice invalidated for $\operatorname{PrP}^{\mathrm{C}}$ sounds at odds with the very early and quasi-ubiquitous expression pattern of the protein at embryonic and postnatal stages, respectively. Expression of the gene encoding PrP-Prnp-is detected in post-implantation embryo from embryonic day (E) 6.5 in extra-embryonic regions (Manson et al., 1992) and from E7.5 (late allantoic bud stage) in cardiac mesoderm (Hidaka et al., 2010). Prnp expression is then observed in the developing central nervous system and heart around $\mathrm{E} 8$ before extending rapidly almost to the entire embryo (Tremblay et al., 2007). Prnp may even be expressed earlier on as PrP mRNAs have been 
Table 1 | Phenotypes associated to PrP invalidation/ectopic activation.

\begin{tabular}{|c|c|c|c|c|}
\hline $\begin{array}{l}\text { Life } \\
\text { period/developmental } \\
\text { stage }\end{array}$ & Type of manipulation & Phenotype(s) & Comments & References \\
\hline Early embryo & & Lethal & & \\
\hline (zebrafish) & PrP-1 knockdown & $\begin{array}{l}\text { - gastrulation arrest due to } \\
\text { impaired cell adhesion }\end{array}$ & $\begin{array}{l}\text { - partial rescue of the } \\
\text { morphants by the } \\
\text { injection of PrP mRNA } \\
\text { including mammalian } \\
\text { sequence }\end{array}$ & Malaga-Trillo et al., 2009 \\
\hline
\end{tabular}

Early embryo (mouse)

\section{Moderately severe}

Prnp knockout embryos

- transcriptomic analysis shows differential expression of genes from multiple cell pathways
- transient phenotype

Khalife et al., 2011;

Passet et al., 2012
Early embryo (mouse) PrP and Shadoo co-invalidation obtained by: Sprn knockdown and Prnp knockout

Double knockout

\section{Controversial}

- impaired trophoblast development, lethality

- no phenotype reported but no assessment at embryonic stage
- discussed in Makhzami

et al. (2014)
Young et al., 2009;

Passet et al., 2012

Daude et al., 2012
Pharyngula stage (zebrafish)
PrP-2 knockdown

PrP-2 knockout

\section{Controversial}

- differential expression of genes involved in multiple cell pathways

- no obvious developmental abnormalities but no transcriptomic analysis performed
Larva (zebrafish)

PrP-2 knockdown

PrP-2 knockout

\section{Controversial}

- head malformations, missing neuronal structures

- no obvious abnormalities at larval stage
- no phenotype rescue of Nourizadeh-Lillabadi the morphants

et al., 2010

Fleisch et al., 2013

\section{Minor}

Late embryo/newborn (mouse)
Prnp knockout embryos
- increased proliferation and maturation delay of the oligodendrocyte precursor cell population in the brain

- earlier formation of dentin and enamel in the developing tooth
- no phenotype rescue of the morphants

Malaga-Trillo et al., 2009;

Nourizadeh-Lillabadi

et al., 2010

Fleisch et al., 2013
Juvenile (mouse)

Prnp knockout mice

\section{Moderately severe}

- functional abnormalities and persisting cell proliferation in the cerebellum, impaired locomotor abilities
Adult Brain (mouse)

\section{Minor}

Prnp knockout mice
- transcriptomic and proteomic analysis revealed no important differences

- increased protein oxidation, protein ubiquitination and lipid peroxidation

- increased proliferation and maturation delay of the oligodendrocyte precursor cells - delayed maturation of astrocytes
- no brain abnormalities

Bribian et al., 2012

or myelin defect

- no enamel defect but reduced hardness of dentin at adult stage
Zhang et al., 2011
- transient phenotype Prestori et al., 2008
- no brain abnormalities or myelin defect associated
Crecelius et al., 2008;

Chadi et al., 2010

Wong et al., 2001
Bribian et al., 2012

Arantes et al., 2009 


\section{Table 1 | Continued}

\begin{tabular}{|c|c|c|c|c|}
\hline $\begin{array}{l}\text { Life } \\
\text { period/developmental } \\
\text { stage }\end{array}$ & Type of manipulation & Phenotype(s) & Comments & References \\
\hline Adult brain (mouse) & Prnp overexpressing mice & $\begin{array}{l}\text { Minor } \\
\text { - increased cell proliferation in the } \\
\text { subventricular zone (adult } \\
\text { neurogenic region) } \\
\text { - shorten astrocyte maturation } \\
\text { phase }\end{array}$ & $\begin{array}{l}\text { - no brain abnormalities } \\
\text { associated }\end{array}$ & $\begin{array}{l}\text { Steele et al., } 2006 \\
\text { Hartmann et al., } 2013\end{array}$ \\
\hline Adult (mouse) & Prnp knockout mice & $\begin{array}{l}\text { Minor and/or partially } \\
\text { controversial } \\
\text { - depending of the study, no } \\
\text { phenotype observed to minor } \\
\text { alterations such as altered } \\
\text { olfactory behavior }\end{array}$ & $\begin{array}{l}\text { - few studies were } \\
\text { carried out using distinct } \\
\text { genetic background }\end{array}$ & $\begin{array}{l}\text { Bueler et al., 1992; } \\
\text { Collinge et al., 1994; } \\
\text { Tobler et al., 1996; Walz } \\
\text { et al., 1999; Nico et al., } \\
\text { 2005; Meotti et al., 2007; } \\
\text { Sanchez-Alavez et al., } \\
\text { 2008; Le Pichon et al., } \\
\text { 2009; Gadotti et al., } 2012 \\
\text { Rial et al., } 2014\end{array}$ \\
\hline Adult (zebrafish) & PrP-1 knockout & Unknown & $\begin{array}{l}\text { - no transgenic } \\
\text { (inducible) line } \\
\text { established }\end{array}$ & \\
\hline Aged animal (mouse) & Prnp knockout mice & $\begin{array}{l}\text { Minor } \\
\text { - behavior alterations }\end{array}$ & & $\begin{array}{l}\text { Rial et al., 2009; } \\
\text { Massimino et al., } 2013\end{array}$ \\
\hline $\begin{array}{l}\text { Aged animal nerves } \\
\text { (mouse) }\end{array}$ & $\begin{array}{l}\text { Prnp knockout and } \\
\text { conditional Prnp knockout }\end{array}$ & $\begin{array}{l}\text { Minor } \\
\text { - increased myelin abnormalities in } \\
\text { peripheral nerves }\end{array}$ & $\begin{array}{l}\text { - several genetic } \\
\text { background analyzed }\end{array}$ & Bremer et al., 2010 \\
\hline
\end{tabular}

found maternally expressed in the zygotes of Xenopus laevis and zebrafish (Danio rerio) (van Rosmalen et al., 2006; Malaga-Trillo et al., 2009).

Two PrP homologs, PrP-1, PrP-2 and a more divergent form, PrP-3, have been identified in zebrafish (Cotto et al., 2005;
Rivera-Milla et al., 2006). The expression patterns of the corresponding genes ( $P r P-1, \operatorname{Pr} P-2$, and $\operatorname{Pr} P-3$, respectively) in zebrafish embryos are partially conflicting (Cotto et al., 2005; Malaga-Trillo et al., 2009) although both studies agree on their spatio-temporal complementarity. Both studies describe early PrP 
gene expression from the mid-blastula stage although it is $\mathrm{PrP}-2$ according to the Cotto et al. study and $P r P-1$ according to MalagaTrillo et al. At pharyngula stage (24-48 h postfertilization), both studies show a strong and broad expression of $\mathrm{PrP}-2$ in the developing central nervous system. Additionally, the Cotto et al. study reports the expression of $\operatorname{PrP}-1$ in the floor plate, an essential organizing center of the central nervous system and in the peripheral nervous system around the same developmental period. The expression of $\mathrm{PrP}-2$ and $\mathrm{PrP}-3$ in the developing neuromasts (sensory organs) is also described at the larval stage. PrP-encoding genes are also expressed in developing organs or tissues outside the nervous system such as the heart ( $P r P-2$ and $P r P-3)$, the kidney $(P r P-2)$, the pectoral fins ( $P r P-2$ and $P r P-3)$ and the intestinal epithelium (PrP-2) (Cotto et al., 2005).

\section{THE EMBRYO SPILLS THE BEANS}

In sharp contrast with the situation in mammals, knockdown (KD) of $\operatorname{PrP}-1$ or $\operatorname{PrP}-2$ by morpholino injection led to severe biological phenotypes in zebrafish (see Table 1): gastrulation arrest for PrP-1 KD (Malaga-Trillo et al., 2009) and malformations of the brain and the eyes associated to a reduced number of peripheral neurons for PrP-2 KD (Malaga-Trillo et al., 2009; Nourizadeh-Lillabadi et al., 2010). However, PrP-2 KDinduced phenotype is subject to caution as $\operatorname{Pr} P-2$ knockout (KO) by zinc finger nuclease-induced targeted mutation did not lead to any obvious developmental phenotype (Fleisch et al., 2013). Additional and aspecific effects due to morpholino injection may have occurred. There is less concern about $\operatorname{Pr} P-1 \mathrm{KD}$ phenotype as partial rescue was obtained by the injection of $\operatorname{PrP}-1$ mRNA, PrP-2 mRNA and, remarkably, mouse Prnp mRNA (Malaga-Trillo et al., 2009), strongly suggesting that zebrafish and mammalian PrPs may share conserved functions.

$\operatorname{PrP}$ inactivation studies in zebrafish allow investigating $\operatorname{PrP}^{\mathrm{C}}$ functions. They also favor a more critical role of $\mathrm{PrP}^{\mathrm{C}}$ in early development rather than during postnatal stages (see Table 1). Accordingly, transcriptomic analyses (by RNAseq) of Prnp ${ }^{-1-}$ versus wild-type mouse embryos identified numerous genes differentially expressed (73 and 263 genes at E6.5 and E7.5, respectively) (Khalife et al., 2011), while only 1 gene was found differentially expressed in adult brains (Chadi et al., 2010). Proteomic analysis also failed to identify major alterations (Crecelius et al., 2008) although many cellular stress markers such as protein oxidation, protein ubiquitination, and lipid peroxidation were reportedly activated in the brains of $\operatorname{Prnp}^{-/-}$versus wild-type mice (Wong et al., 2001). This suggests either that $\mathrm{PrP}^{\mathrm{C}}$ is quite dispensable in the adult brain or that, in a Prnp $\mathrm{P}^{-/-}$ context, alternative mechanisms are activated during the brain development to compensate the absence of $\mathrm{PrP}^{\mathrm{C}}$. Supporting the second hypothesis, the number of genes differentially expressed in the adult Prnp ${ }^{-/-}$mouse brain was substantially higher upon postnatal depletion in neurons than embryonically (Chadi et al., 2010), albeit to a less extent than in the embryo. The genes differentially expressed in the embryo covered various cell functions including adhesion, apoptosis and proliferation and are related to heart formation and blood vessel development, vascular diseases, immune response, nervous system development, and prion diseases (Khalife et al., 2011). Interestingly and in line with the idea of evolutionary conserved functions of PrPs, similar biological functions were impacted by $\operatorname{Pr} P-2 \mathrm{KD}$ in zebrafish, as revealed by transcriptomic analyses: development including that of the cardiovascular and nervous systems specifically, cell death, cellular assembly, cell cycle, immunological, and neurological diseases (Nourizadeh-Lillabadi et al., 2010).

Finally, the KD of the Sprn gene encoding a PrP-related protein, Shadoo resulted in embryonic lethality between E8 and E11 specifically in $\mathrm{Prnp}^{-/-}$embryos, supporting a role for $\mathrm{PrP}^{\mathrm{C}}$ and Shadoo in mouse embryogenesis, notably cell adhesion and placenta development, and a possible functional redundancy between the two proteins (Young et al., 2009; Passet et al., 2012). However, the recent generation of viable $\mathrm{Prnp}^{-/-} ; \mathrm{Sprn}^{-/-}$animals is challenging this view (Daude et al., 2012). These apparently conflicting observations are discussed in Makhzami et al. (2014).

Thus, studying the consequences of PrP inactivation during developmental stages rather than in adult animals could be a more efficient, although not easier, strategy to decipher $\mathrm{PrP}^{\mathrm{C}}$ functions. Additionally, studying $\operatorname{PrP}^{\mathrm{C}}$ implications in regenerative processes and in renewing tissues could also be an informative approach (see Table 1).

\section{THE CURRENT LIMITS OF IN VIVO STUDIES IN MAMMALS}

As $\mathrm{PrP}^{\mathrm{C}}$ is mediating neuronal dysfunction and degeneration in prion diseases and reportedly in Alzheimer's disease (Lauren et al., 2009; Klyubin et al., 2014), it has been logically suspected to play a role in neuronal homeostasis and during neural development. As $\mathrm{PrP}^{\mathrm{C}}$ functions in mature neurons are not under the scope of the present review, we will not discuss them and only focus on developmental aspects. In vivo direct evidence supporting a role of $\mathrm{PrP}^{\mathrm{C}}$ in neural development is quite elusive and $\mathrm{PrP}^{\mathrm{C}}$ expression pattern remains one of the strongest pro arguments. Indeed, $\mathrm{PrP}^{\mathrm{C}}$ expression increases as neurons mature, although it is not detected in mitotically active neural progenitor cells (Steele et al., 2006; Peralta et al., 2011). Other experimental evidence was obtained from the comparative study of WT and Prnp ${ }^{-/-}$ and/or Prnp overexpressing animals (see Table 1). The levels of $\operatorname{PrP}^{\mathrm{C}}$ were found to positively regulate the proliferation in neurogenic regions in adult mice (Steele et al., 2006; Bribian et al., 2012) and the maturation of astrocytes in the developing brain (Arantes et al., 2009; Hartmann et al., 2013). Conversely, the absence of $\mathrm{PrP}^{\mathrm{C}}$ was associated with an increased proliferation in oligodendrocyte precursor cells both in embryos and adults (Bribian et al., 2012). However, no brain morphology abnormalities or myelin defects could be observed in $\operatorname{Prnp} p^{-/-}$animals, casting doubt on a crucial role of $\mathrm{PrP}^{\mathrm{C}}$ in cell proliferation and maturation during brain development or, at least, suggesting the occurrence of compensatory mechanisms. Yet, electrophysiological recordings on hippocampus from $\mathrm{Prnp}^{-/-}$mice (Collinge et al., 1994) and on cerebellum from juvenile $\operatorname{Prnp}^{-/-}$mice (Prestori et al., 2008) revealed functional alterations. However, no hippocampus-related behavioral or learning alterations were observed in Prnp ${ }^{-/-}$mice (Bueler et al., 1992) suggesting the hippocampus functional alterations are minor or at least compensated. Conversely, cerebellum functional alterations were found associated to a failure of juvenile $\operatorname{Prn} \mathrm{p}^{-/-}$mice in motor control 
test and to protracted cell proliferation in the cerebellum granular layer at the third week of postnatal development although all these abnormalities vanished in older animals (Prestori et al., 2008). Taken together, these arguments suggest a delay in the maturation of the cerebellar granule cells in $\operatorname{Pr} n p^{-/-}$mice.

Further dissecting the underlying mechanisms responsible for the subtle phenotypes in $P r n p^{-/-}$mice is a particularly arduous task in vivo. For example, determining whether the effects are cellautonomous would require the use of several transgenic lines or genetic chimeras to limit the expression of $\mathrm{PrP}^{\mathrm{C}}$ to a subset of cells. And this question is far from being irrelevant as $\operatorname{PrP}^{\mathrm{C}}$ is a cell surface protein. Such topology could elicit specific cell responses in neighboring cells. Additionally, $\operatorname{PrP}^{\mathrm{C}}$ may act at distance since secreted forms of have been described both in vitro and in vivo (Borchelt et al., 1993; Harris et al., 1993).

\section{CONTRIBUTIONS OF IN VITRO AND EX VIVO MODELS TO UNDERSTANDING THE ROLE OF PrPC IN NEURAL DEVELOPMENT}

The use of in vitro or ex vivo models has generated a wealth of data with regard to the involvement of $\mathrm{PrP}^{\mathrm{C}}$ in neural development and, importantly, has comforted the putative functions suggested by the in vivo approaches. Moreover they often allow pinpointing more precisely the cellular processes and signaling pathways involving $\mathrm{PrP}^{\mathrm{C}}$. Collectively, these experimental data argue that $\mathrm{PrP}^{\mathrm{C}}$ positively regulates (1) the differentiation of pluripotent progenitors cells toward the neural lineage (Peralta et al., 2011), (2) the proliferation of neural progenitor cells (Prodromidou et al., 2014) (3) the self-renewal of neural progenitor cells (Santos et al., 2011; Prodromidou et al., 2014) (4) the neuronal differentiation in terms of choice of cell fate (Steele et al., 2006) and (5) acquisition of neuronal features (Graner et al., 2000). However, how $\operatorname{PrP}^{\mathrm{C}}$ fulfills these different actions is only partially understood. The current idea is that $\operatorname{PrP}^{C}$ is part of multiprotein signaling complexes, able to bind various partners, and participate to signal transduction events along different cellular pathways depending on the cellular context (Caughey and Baron, 2006; Watts et al., 2009; Stuermer, 2011; Hirsch et al., 2014). Non-exhaustively, the interaction between $\operatorname{PrP}^{\mathrm{C}}$ and one of its identified ligand, Stress inducible protein 1 (STI1), has been shown to promote the self-renewal of the neural progenitor cells (Santos et al., 2011). Besides, interaction with the neural cell adhesion molecule (NCAM) can induce their neuronal differentiation (Prodromidou et al., 2014). In cultured neurons, STI1 binding to $\mathrm{PrP}^{\mathrm{C}}$ increases protein synthesis (Roffe et al., 2010), STI1 and Laminin- $\gamma 1$ binding promotes intracellular $\mathrm{Ca}^{2+}$ increase and axonogenesis (Santos et al., 2013), and vitronectin binding, axonal growth (Hajj et al., 2007). Experimental evidence also favors a role of $\mathrm{PrP}^{\mathrm{C}}$ in glia development since the lack of $\mathrm{PrP}^{\mathrm{C}}$ promotes the proliferation of oligodendrocyte precursor cells and delays their differentiation in culture (Bribian et al., 2012). Studies in astrocyte primary cultures revealed that the involvement of $\mathrm{PrP}^{\mathrm{C}}$ in astrocytes maturation is dependent upon its interaction with STI1 and the downstream activation of ERK1/2 (Arantes et al., 2009). Of note, $\operatorname{PrP}^{C}$ action does not necessarily rely on $\mathrm{PrP}^{\mathrm{C}}$ expression solely in the cell population considered. For instance, proper neuritogenesis has been shown to require $\mathrm{PrP}^{\mathrm{C}}$ expression in both neurons and surrounding astrocytes in co-cultures experiments (Lima et al., 2007). Beyond a role in the interactions between both populations, $\operatorname{PrP}^{\mathrm{C}}$ serves as a neuronal receptor for laminin (Graner et al., 2000) and is also involved in the organization of the extracellular matrix by the astrocytes, especially through laminin deposition (Lima et al., 2007).

It should also be stressed that $\operatorname{PrP}^{\mathrm{C}}$ partners and the cellular context could tightly determine the final consequences of $\mathrm{PrP}^{\mathrm{C}}$ stimulation. For example $\mathrm{PrP}^{\mathrm{C}}$ interaction with contactinassociated protein (Caspr) protects Caspr from proteolysis allowing it to inhibit more efficiently neurite outgrowth (Devanathan et al., 2010). On the opposite, $\operatorname{PrP}^{\mathrm{C}}$ and NCAM interactions allow stabilization of NCAM in lipid rafts allowing Fyn kinase activation and promoting neurite outgrowth (Santuccione et al., 2005).

In vitro, $\mathrm{PrP}^{\mathrm{C}}$ is thereby found involved in all the major steps of neural development. Since it notably regulates the self-renewal and differentiation processes in neural progenitor cells, the question arises as to whether this role can be extended to other cell types.

\section{WHAT THE STUDY OF STEM CELLS REVEALS}

The role of $\mathrm{PrP}^{\mathrm{C}}$ is far from being restricted to neural development and a growing body of evidence support its involvement in stem cell biology see also Martin-Lannerée et al. (2014). Whether $\mathrm{PrP}^{\mathrm{C}}$ is expressed in embryonic stem cells (ESC) at basal state remains unclear (Lee and Baskakov, 2010; Miranda et al., 2011), possibly due to limitations in the sensitivity of the detection methods, choice of the target (i.e., the gene or the protein itself) and methods of production and culture of the cells. Nevertheless, there is a consensus that $\operatorname{PrP}^{\mathrm{C}}$ expression progressively increases during stem cell differentiation (Miranda et al., 2011; Lee and Baskakov, 2013). To understand the role played by $\operatorname{PrP}^{\mathrm{C}}$ during early embryogenesis, the consequences of Prnp KD or overexpression were studied in human ESC (Lee and Baskakov, 2013). Forcing $\mathrm{PrP}^{\mathrm{C}}$ expression under self-renewal conditions was found to alter cell cycle regulation and to promote ESC differentiation. Blocking $\mathrm{PrP}^{\mathrm{C}}$ expression in differentiating ESC also impacts on cell cycle regulation and inhibits the differentiation toward ectodermal lineages, in line with $\operatorname{PrP}^{\mathrm{C}}$ functions in neural differentiation (Peralta et al., 2011) and the reduced expression of Nestin, an ectodermal marker, observed in ESC in the absence of $\operatorname{PrP}^{\mathrm{C}}$ (Miranda et al., 2011; Peralta et al., 2011). Mesodermal and endodermal differentiations were, however, not affected. Finally, overexpressing $\mathrm{PrP}^{\mathrm{C}}$ in differentiating ESC promotes proliferation and inhibits differentiation toward all the lineages (Lee and Baskakov, 2013).

Further supporting $\operatorname{PrP}^{\mathrm{C}}$ function in stem cell biology, $\mathrm{PrP}^{\mathrm{C}}$ is expressed in hematopoietic stem cells and promotes their selfrenewal (Zhang et al., 2006). $\mathrm{PrP}^{\mathrm{C}}$ is therefore involved in the self-renewal and differentiation of stem cells although its role and requirement seem to vary along the differentiation process and the cell lineage considered. Identifying the molecular mechanisms at play is a particularly challenging task since self-renewal, differentiation and proliferation are highly intertwined processes impacting each other. 


\section{THE ROLE OF PrPC IN DEVELOPING AND RENEWING TISSUES OUTSIDE THE NERVOUS SYSTEM}

Looking outside the central nervous system in newborn to full-grown animals allowed pinpointing subtle phenotypes in the absence of $\operatorname{PrP}^{\mathrm{C}}$ (see Table 1), in perfect consistency with $\mathrm{PrP}^{\mathrm{C}}$ widespread expression. $\mathrm{PrP}^{\mathrm{C}}$ is expressed in developing human and murine teeth and study of dental cell cultures and teeth from $\operatorname{Prnp}^{-/-}$animals revealed multiple alterations during tooth formation (Schneider et al., 2007; Zhang et al., 2011). In vitro, embryonic dental mesenchymal cells from Prnp ${ }^{-/-}$ embryos proliferate more rapidly and differentiate earlier and coherently, Prnp ${ }^{-/-}$newborn mice exhibit earlier formation of mesenchymally- and epithelially-derived dentin and enamel, respectively (Zhang et al., 2011).

$\mathrm{PrP}^{\mathrm{C}}$ is also abundantly expressed in muscles and, although no abnormalities could be observed in a physiological context, it is involved in the regeneration of skeletal muscles in adult mice. Regeneration of locally damaged muscle fibers occurs at slower pace in Prnp ${ }^{-/-}$animals. Yet total recovery is finally achieved (Stella et al., 2010). This is associated with a longer phase of proliferation and a delayed maturation of muscle precursors, likely due to a reduced level of released myogenic factors (Stella et al., 2010). However, the identity of the releasing cells is difficult to establish, showing again the limits of the in vivo paradigm.

Another extra-neural tissue where $\operatorname{PrP}^{\mathrm{C}}$ depletion induces alterations is the intestinal epithelium, a constantly renewing tissue. $\operatorname{PrP}^{\mathrm{C}}$ is expressed by human enterocytes (Morel et al., 2004) and Prnp ${ }^{-/-}$animals exhibit shorter intestinal villi associated to an increased number of mitotic cells (Morel et al., 2008).

Collectively, these observations support a role of $\mathrm{PrP}^{\mathrm{C}}$ in the regulation of cell cycle and cell differentiation extraneurally. But how can these functions be exerted?

\section{PrPC REGULATES CELLULAR ADHESION, EXTRA-CELLULAR MATRIX INTERACTIONS, AND CYTOSKELETON REMODELING}

$\operatorname{PrP}-1$ KD-induced gastrulation arrest in zebrafish embryos is due to impaired morphogenetic cell movements. This defect is, at least partially, caused by the disruption of cellular adhesion (Malaga-Trillo et al., 2009). The study revealed that PrP-1 normally accumulates at cell-cell contacts at early embryonic stages and regulates cell adhesion, including E-cadherin processing and/or storage, in a cell-autonomous way. Such functions may be conserved in mammals as injection of mouse mRNA Prnp partially rescued the $\mathrm{PrP}-1 \mathrm{KD}$-induced phenotype (Malaga-Trillo et al., 2009). Consistent with this idea, a number of experimental evidence have linked $\mathrm{PrP}^{\mathrm{C}}$ to cell adhesion and intimately associated processes such as cytoskeleton remodeling and interactions with extra-cellular matrix (Petit et al., 2013): (i) the expression pattern of $\mathrm{PrP}^{\mathrm{C}}$. $\mathrm{PrP}^{\mathrm{C}}$ is expressed at the cell-to-cell contacts, growth cone, and other extending process tips in cultured neural progenitors and neurons (Santuccione et al., 2005; Devanathan et al., 2010; Miyazawa et al., 2010), cell-to-cell junctions in human intestinal epithelium villi (Morel et al., 2004), cell-to-cell contacts in primary cultured endothelial cells (Viegas et al., 2006), focal adhesions in HeLa cell lines (Schrock et al., 2009) and the apical face of ameloblasts of developing teeth (Zhang et al.,
2011); (ii) relevant $\operatorname{PrP}^{\mathrm{C}}$ partners and ligands, such as cell junction proteins including integrins, the cytoskeleton protein actin and components of the extra-cellular matrix (Graner et al., 2000; Schmitt-Ulms et al., 2001; Morel et al., 2004, 2008; Nieznanski et al., 2005; Hajj et al., 2007; Watts et al., 2009); (iii) alterations in cell adhesion, cytoskeleton dynamics, and extra-cellular matrix interactions upon ectopic expression or deletion of $\mathrm{PrP}^{\mathrm{C}}$ in different cell systems. Prnp KD leads to alterations in the actin cytoskeleton, remodeling of focal adhesions and over-production of fibronectin in neuronal progenitors (Loubet et al., 2012), to disruption of adherens junctions in carcinoma cells (Solis et al., 2012) and to miss-localization of cell junction-related proteins in enterocytes (Morel et al., 2008). As for Prnp overexpression, it promotes aggregation and filopodia formation as well as alterations of the focal adhesion dynamics in neuroblastoma N2a cells (Mange et al., 2002; Schrock et al., 2009). Subtle changes were even noticed in vivo such as a decrease in the length of desmosomes in the intestinal epithelium of $\operatorname{Prnp}^{-/-}$mice (Morel et al., 2008).

Interestingly, the alterations induced by the deletion of $\mathrm{PrP}^{\mathrm{C}}$ can be partially rescued by neutralizing antibodies to specific integrins: use of $\beta 1$ and $\beta 5$ integrins was found to restore neuritogenesis in differentiating PrP-deficient neuronal progenitors (Loubet et al., 2012) and Nanog expression in differentiating PrP-deficient ESC (Miranda et al., 2011), respectively. Moreover, modulation of integrin activity was suspected to be a spontaneous compensatory mechanism occurring in the absence of $\operatorname{PrP}^{\mathrm{C}}$ (Hajj et al., 2007). This last observation supports an involvement of $\mathrm{PrP}^{\mathrm{C}}$ in extra-cellular matrix interactions and suggests a possible adaptive mechanism to the absence of $\operatorname{PrP}^{\mathrm{C}}$, which may account for the lack of drastic phenotypes in $\operatorname{Prnp}^{-/-}$animals.

Taken together, these observations demonstrate a clear involvement of $\mathrm{PrP}^{\mathrm{C}}$ in the regulation of cell adhesion, the interactions with the extra-cellular matrix and the cytoskeleton dynamics. The links between these functions and the role of $\mathrm{PrP}^{\mathrm{C}}$ in the regulation of cell proliferation and differentiation have been the focus of few studies (Miranda et al., 2011; Loubet et al., 2012). Are they under-estimated? And are these functions still ongoing in adult organism?

\section{STUDYING PrPC FUNCTIONS DURING AGING}

Little attention has been devoted to the potential functions of $\mathrm{PrP}^{\mathrm{C}}$ during aging (see Table $\mathbf{1}$ and also Gasperini and Legname, 2014). It is commonly accepted that the cellular machinery deteriorates or, at least, evolves with aging. As the potential development of adaptive mechanisms to the absence of $\mathrm{PrP}^{\mathrm{C}}$ is assumed to complicate the study of $\operatorname{PrP}^{\mathrm{C}}$ functions in $\operatorname{Prnp}^{-/-}$mice, the study of aged animals could be a way to bypass such difficulty: because of the age-related alterations accumulation, the tolerance to $\operatorname{PrP}^{\mathrm{C}}$ depletion could partially break. In line with this scenario, behavioral differences between WT and Prnp ${ }^{-/-}$mice seem more pronounced when performed on aged animals (Rial et al., 2009; Massimino et al., 2013). Age-related physiological traits can also be found amplified in absence of $\operatorname{PrP}^{\mathrm{C}}$. Myelin abnormalities in the peripheral nervous system accumulate with aging (Verdu et al., 2000) and sciatic nerves from moderately aged mice devoid of $\mathrm{PrP}^{\mathrm{C}}$ (in selected or all cell populations) showed 
highly precocious and increased demyelination in the absence of neuronal $\operatorname{PrP}^{\mathrm{C}}$ (Bremer et al., 2010). If the axons-glia interactions are known to play a key role in myelination during development (Sherman and Brophy, 2005), their role in myelin maintenance in adulthood is less well-understood. However, myelin maintenance is clearly established as an active process (Bremer et al., 2011). The early demyelination observed in the absence of neuronal $\mathrm{PrP}^{\mathrm{C}}$ suggests axonal $\mathrm{PrP}^{\mathrm{C}}$ participates in myelin maintenance and is likely required, directly or indirectly, in axons-Schwann cells communication.

Thus, aging may perhaps be the ultimate stage to unravel the mystery of $\mathrm{PrP}^{\mathrm{C}}$ function(s). However, it has to be considered that aging could also impact on $\mathrm{PrP}^{\mathrm{C}}$ and/or its function(s). For instance, the age-related change in the cholesterol/sphingolipids ratio in lipid rafts is suspected to alter $\mathrm{PrP}^{\mathrm{C}}$ compartmentalization (Agostini et al., 2013), which could ultimately impact on its functions. A functional study of $\mathrm{PrP}^{\mathrm{C}}$ during aging could therefore be difficult to analyse due to the numerous changes occurring at the same time.

\section{CONCLUDING REMARKS}

A major function of $\mathrm{PrP}^{\mathrm{C}}$, consistent with its cell surface expression consists in the modulation of signaling pathways in response to various cues. The panel of putative $\mathrm{PrP}^{\mathrm{C}}$ ligands is quite large, including soluble ligands, extra-cellular matrix components, and adhesion molecules. Their modes of interaction with $\mathrm{PrP}^{\mathrm{C}}$ are variable, including cooperation (Santos et al., 2013) and both cis- and trans-interactions for a same ligand (Santuccione et al., 2005). The cellular context can strongly influence the composition of the $\mathrm{PrP}^{\mathrm{C}}$-multiprotein complexes and the sub-cellular localization of $\mathrm{PrP}^{\mathrm{C}}$ is highly dynamic: it can cycle rapidly from the plasma membrane to internal membranes (Griffiths et al., 2007) possibly in response to a given stimulus (Lee et al., 2001; Brown and Harris, 2003; Caetano et al., 2008). All these elements taken together may allow a specific response to a given signal with regard to the cell type and differentiation state. This may explain why $\operatorname{PrP}^{\mathrm{C}}$ appears to be involved in a multitude of functions. Regarding development, this view perfectly fits the requirement of different stem and progenitor cells by eliciting appropriate cell responses to adapt efficiently to different microenvironments. But how $\operatorname{PrP}^{\mathrm{C}}$ precisely impacts on stemness maintenance and differentiation processes remains unresolved. The potential implication of $\mathrm{PrP}^{\mathrm{C}}$ in cell polarization and cytoskeleton remodeling in differentiating stem cells is a very attractive hypothesis and should obviously deserve further investigation. Cell polarity and cytoskeleton dynamics are life-long important cell processes, notably during cell fate determination. They have been studied more particularly during drosophilia neurogenesis and in mammalian neuroepithelial cells (Fietz and Huttner, 2011), but they are fundamental processes for all sort of stem and progenitor cells such as hematopoietic progenitor cells (Bullock et al., 2007). Our unpublished data (Halliez et al., in preparation) reveal a polarized expression of $\mathrm{PrP}^{\mathrm{C}}$ in neural and cardiovascular progenitor cells of the developing mouse embryo and therefore are compatible with such idea.

If $\mathrm{PrP}^{\mathrm{C}}$ is involved in so many cell lineages, understanding the lack of drastic phenotype in $\mathrm{PrP}^{\mathrm{C}}$-depleted animals remains an ongoing issue. Yet, a modulation of the cell maturation phase (generally delayed but also shortened) is consistently observed in different models (Prnp KO but also KD and overexpression) and may therefore be the general price to pay for the loss of $\operatorname{PrP}^{\mathrm{C}}$ (see Table 1). This may have a more selective impact on free-range than on laboratory animals (for example acquisition of perfect motor control) and justify the high degree of PrP conservation through evolution. Moreover, building an organism is a highly complex task requiring spatial and temporal finetuning of a broad number of biological processes via multiple regulatory networks. Cells, tissues and organs do not develop separately along each other but rely on multiple interactions to develop in a concerted, interconnected, and time-scheduled manner. Partial redundancies into and between signaling pathways ensure robustness to the system. That two or more proteins may exert overlapping functions during development and therefore allow tolerance to the loss of one of them is not unprecedented (Yoon et al., 2005; Santamaria and Ortega, 2006; Nicolae et al., 2007). Moreover, it is not unheard-of, notably in plants where environment adaptation is largely studied, that redundant genes in a regular context allow survival under environmental modifications and stress (Wu et al., 2002). Interestingly, $\operatorname{PrP} \mathrm{KO}$ animals seem to react differentially than WT animals to stressful situations (Nico et al., 2005) and to alcohol (Rial et al., 2014) and show increased susceptibility to convulsant agents (Walz et al., 1999; Fleisch et al., 2013) (see Table 1). The general function of $\mathrm{PrP}^{\mathrm{C}}$ could be to facilitate responses to external stimulus/factors at the cell- and at the organism-scale. Yet, laboratory animals are raised in standardized and protective environment and are often homogenous genetically. In such conditions, the time window to apprehend the cell specific functions of $\mathrm{PrP}^{\mathrm{C}}$ may be restricted to the developmental and perinatal phases, with so much information provided and so much transformation occurring at the same time.

\section{REFERENCES}

Agostini, F., Dotti, C. G., Perez-Canamas, A., Ledesma, M. D., Benetti, F., and Legname, G. (2013). Prion protein accumulation in lipid rafts of mouse aging brain. PLoS ONE 8:e74244. doi: 10.1371/journal.pone.0074244

Arantes, C., Nomizo, R., Lopes, M. H., Hajj, G. N., Lima, F. R., and Martins, V. R. (2009). Prion protein and its ligand stress inducible protein 1 regulate astrocyte development. Glia 57, 1439-1449. doi: 10.1002/glia.20861

Bendheim, P. E., Brown, H. R., Rudelli, R. D., Scala, L. J., Goller, N. L., Wen, G. Y., et al. (1992). Nearly ubiquitous tissue distribution of the scrapie agent precursor protein. Neurology 42, 149-156. doi: 10.1212/WNL.42.1.149

Benestad, S. L., Austbo, L., Tranulis, M. A., Espenes, A., and Olsaker, I. (2012). Healthy goats naturally devoid of prion protein. Vet. Res. 43, 87. doi: 10.1186/1297-9716-43-87

Borchelt, D. R., Rogers, M., Stahl, N., Telling, G., and Prusiner, S. B. (1993). Release of the cellular prion protein from cultured cells after loss of its glycoinositol phospholipid anchor. Glycobiology 3, 319-329. doi: 10.1093/glycob/ 3.4.319

Bremer, J., Baumann, F., Tiberi, C., Wessig, C., Fischer, H., Schwarz, P., et al. (2010). Axonal prion protein is required for peripheral myelin maintenance. Nat. Neurosci. 13, 310-318. doi: 10.1038/nn.2483

Bremer, M., Frob, F., Kichko, T., Reeh, P., Tamm, E. R., Suter, U., et al. (2011). Sox10 is required for Schwann-cell homeostasis and myelin maintenance in the adult peripheral nerve. Glia 59, 1022-1032. doi: 10.1002/glia.21173

Bribian, A., Fontana, X., Llorens, F., Gavin, R., Reina, M., Garcia-Verdugo, J. M., et al. (2012). Role of the cellular prion protein in oligodendrocyte precursor cell proliferation and differentiation in the developing and adult mouse CNS. PLoS ONE 7:e33872. doi: 10.1371/journal.pone.0033872 
Brown, L. R., and Harris, D. A. (2003). Copper and zinc cause delivery of the prion protein from the plasma membrane to a subset of early endosomes and the Golgi. J. Neurochem. 87, 353-363. doi: 10.1046/j.1471-4159.2003.01996.x

Bueler, H., Aguzzi, A., Sailer, A., Greiner, R. A., Autenried, P., Aguet, M., et al. (1993). Mice devoid of PrP are resistant to scrapie. Cell 73, 1339-1347. doi: 10.1016/0092-8674(93)90360-3

Bueler, H., Fischer, M., Lang, Y., Bluethmann, H., Lipp, H. P., DeArmond, S. J., et al. (1992). Normal development and behaviour of mice lacking the neuronal cell-surface PrP protein. Nature 356, 577-582. doi: 10.1038/356577a0

Bullock, T. E., Wen, B., Marley, S. B., and Gordon, M. Y. (2007). Potential of CD34 in the regulation of symmetrical and asymmetrical divisions by hematopoietic progenitor cells. Stem Cells 25, 844-851. doi: 10.1634/stemcells.2006-0346

Caetano, F. A., Lopes, M. H., Hajj, G. N., Machado, C. F., Pinto Arantes, C., Magalhaes, A. C., et al. (2008). Endocytosis of prion protein is required for ERK1/2 signaling induced by stress-inducible protein 1. J. Neurosci. 28, 6691-6702. doi: 10.1523/JNEUROSCI.1701-08.2008

Caughey, B., and Baron, G. S. (2006). Prions and their partners in crime. Nature 443, 803-810. doi: 10.1038/nature05294

Chadi, S., Young, R., Le Guillou, S., Tilly, G., Bitton, F., Martin-Magniette, M. L., et al. (2010). Brain transcriptional stability upon prion protein-encoding gene invalidation in zygotic or adult mouse. BMC Genomics 11:448. doi: 10.1186/1471-2164-11-448

Collinge, J., Whittington, M. A., Sidle, K. C., Smith, C. J., Palmer, M. S., Clarke, A. R., et al. (1994). Prion protein is necessary for normal synaptic function. Nature 370, 295-297. doi: 10.1038/370295a0

Cotto, E., Andre, M., Forgue, J., Fleury, H. J., and Babin, P. J. (2005). Molecular characterization, phylogenetic relationships, and developmental expression patterns of prion genes in zebrafish (Danio rerio). FEBS J. 272, 500-513. doi: 10.1111/j.1742-4658.2004.04492.x

Crecelius, A. C., Helmstetter, D., Strangmann, J., Mitteregger, G., Frohlich, T., Arnold, G. J., et al. (2008). The brain proteome profile is highly conserved between Prnp-/- and Prnp+/+ mice. Neuroreport 19, 1027-1031. doi: 10.1097/WNR.0b013e3283046157

Daude, N., Wohlgemuth, S., Brown, R., Pitstick, R., Gapeshina, H., Yang, J., et al. (2012). Knockout of the prion protein (PrP)-like Sprn gene does not produce embryonic lethality in combination with $\operatorname{PrP}(\mathrm{C})$-deficiency. Proc. Natl. Acad. Sci. U.S.A. 109, 9035-9040. doi: 10.1073/pnas.1202130109

Devanathan, V., Jakovcevski, I., Santuccione, A., Li, S., Lee, H. J., Peles, E., et al. (2010). Cellular form of prion protein inhibits Reelin-mediated shedding of Caspr from the neuronal cell surface to potentiate Caspr-mediated inhibition of neurite outgrowth. J. Neurosci. 30, 9292-9305. doi: 10.1523/JNEUROSCI.565709.2010

Fietz, S. A., and Huttner, W. B. (2011). Cortical progenitor expansion, self-renewal and neurogenesis-a polarized perspective. Curr. Opin. Neurobiol. 21, 23-35. doi: 10.1016/j.conb.2010.10.002

Fleisch, V. C., Leighton, P. L., Wang, H., Pillay, L. M., Ritzel, R. G., Bhinder, G., et al. (2013). Targeted mutation of the gene encoding prion protein in zebrafish reveals a conserved role in neuron excitability. Neurobiol. Dis. 55, 11-25. doi: 10.1016/j.nbd.2013.03.007

Gadotti, V. M., Bonfield, S. P., and Zamponi, G. W. (2012). Depressive-like behaviour of mice lacking cellular prion protein. Behav. Brain Res. 227, 319-323. doi: 10.1016/j.bbr.2011.03.012

Gasperini, L., and Legname, G. (2014). Prion protein and aging. Front. Cell Dev. Biol. 2:44. doi: 10.3389/fcell.2014.00044

Graner, E., Mercadante, A. F., Zanata, S. M., Forlenza, O. V., Cabral, A. L., Veiga, S. S., et al. (2000). Cellular prion protein binds laminin and mediates neuritogenesis. Brain Res. Mol. Brain Res. 76, 85-92. doi: 10.1016/S0169-328X(99) 00334-4

Griffiths, R. E., Heesom, K. J., and Anstee, D. J. (2007). Normal prion protein trafficking in cultured human erythroblasts. Blood 110, 4518-4525. doi: 10.1182/blood-2007-04-085183

Hajj, G. N., Lopes, M. H., Mercadante, A. F., Veiga, S. S., da Silveira, R. B., Santos, T. G., et al. (2007). Cellular prion protein interaction with vitronectin supports axonal growth and is compensated by integrins. J. Cell Sci. 120, 1915-1926. doi: $10.1242 /$ jcs. 03459

Harris, D. A., Huber, M. T., van Dijken, P., Shyng, S. L., Chait, B. T., and Wang, R. (1993). Processing of a cellular prion protein: identification of N- and C-terminal cleavage sites. Biochemistry 32, 1009-1016. doi: 10.1021/bi00055a003
Hartmann, C. A., Martins, V. R., and Lima, F. R. (2013). High levels of cellular prion protein improve astrocyte development. FEBS Lett. 587, 238-244. doi: 10.1016/j.febslet.2012.11.032

Hidaka, K., Shirai, M., Lee, J. K., Wakayama, T., Kodama, I., Schneider, M. D., et al. (2010). The cellular prion protein identifies bipotential cardiomyogenic progenitors. Circ. Res. 106, 111-119. doi: 10.1161/CIRCRESAHA.109. 209478

Hirsch, T. Z., Hernandez-Rapp, J., Martin-Lannerée, S., Launay, J. M., and Mouillet-Richard, S. (2014). PrP signalling in neurons: from basics to clinical challenges. Biochimie. 104, 2-11. doi: 10.1016/j.biochi.2014.06.009

Khalife, M., Young, R., Passet, B., Halliez, S., Vilotte, M., Jaffrezic, F., et al. (2011). Transcriptomic analysis brings new insight into the biological role of the prion protein during mouse embryogenesis. PLOS ONE 6:e23253. doi: 10.1371/journal.pone.0023253

Klyubin, I., Nicoll, A. J., Khalili-Shirazi, A., Farmer, M., Canning, S., Mably, A., et al. (2014). Peripheral administration of a humanized anti-PrP antibody blocks Alzheimer's disease abeta synaptotoxicity. J. Neurosci. 34, 6140-6145. doi: 10.1523/JNEUROSCI.3526-13.2014

Lauren, J., Gimbel, D. A., Nygaard, H. B., Gilbert, J. W., and Strittmatter, S. M. (2009). Cellular prion protein mediates impairment of synaptic plasticity by amyloid-beta oligomers. Nature 457, 1128-1132. doi: 10.1038/nature 07761

Lee, K. S., Magalhaes, A. C., Zanata, S. M., Brentani, R. R., Martins, V. R., and Prado, M. A. (2001). Internalization of mammalian fluorescent cellular prion protein and N-terminal deletion mutants in living cells. J. Neurochem. 79, 79-87. doi: 10.1046/j.1471-4159.2001.00529.x

Lee, Y. J., and Baskakov, I. V. (2010). Treatment with normal prion protein delays differentiation and helps to maintain high proliferation activity in human embryonic stem cells. J. Neurochem. 114, 362-373. doi: 10.1111/j.14714159.2010.06601.x

Lee, Y. J., and Baskakov, I. V. (2013). The cellular form of the prion protein is involved in controlling cell cycle dynamics, self-renewal, and the fate of human embryonic stem cell differentiation. J. Neurochem. 124, 310-322. doi: 10.1111/j.1471-4159.2012.07913.x

Le Pichon, C. E., Valley, M. T., Polymenidou, M., Chesler, A. T., Sagdullaev, B. T., Aguzzi, A., et al. (2009). Olfactory behavior and physiology are disrupted in prion protein knockout mice. Nat. Neurosci. 12, 60-69. doi: 10.1038/nn.2238

Lima, F. R., Arantes, C. P., Muras, A. G., Nomizo, R., Brentani, R. R., and Martins, V. R. (2007). Cellular prion protein expression in astrocytes modulates neuronal survival and differentiation. J. Neurochem. 103, 2164-2176. doi: 10.1111/j.14714159.2007.04904.x

Loubet, D., Dakowski, C., Pietri, M., Pradines, E., Bernard, S., Callebert, J., et al. (2012). Neuritogenesis: the prion protein controls betal integrin signaling activity. FASEB J. 26, 678-690. doi: 10.1096/fj.11-185579

Makhzami, S., Passet, B., Halliez, S., Castille, J., Moazami-Goudarzi, K., Duchesne, A., et al. (2014). The prion protein family: a view from the placenta. Front. Cell Dev. Biol. 2:35. doi: 10.3389/fcell.2014.00035

Malaga-Trillo, E., Solis, G. P., Schrock, Y., Geiss, C., Luncz, L., Thomanetz, V., et al. (2009). Regulation of embryonic cell adhesion by the prion protein. PLoS Biol. 7:e55. doi: 10.1371/journal.pbio. 1000055

Mallucci, G., Dickinson, A., Linehan, J., Klohn, P. C., Brandner, S., and Collinge, J. (2003). Depleting neuronal PrP in prion infection prevents disease and reverses spongiosis. Science 302, 871-874. doi: 10.1126/science.1090187

Mange, A., Milhavet, O., Umlauf, D., Harris, D., and Lehmann, S. (2002). PrPdependent cell adhesion in N2a neuroblastoma cells. FEBS Lett. 514, 159-162. doi: 10.1016/S0014-5793(02)02338-4

Manson, J. C., Clarke, A. R., Hooper, M. L., Aitchison, L., McConnell, I., and Hope, J. (1994a). 129/Ola mice carrying a null mutation in $\operatorname{PrP}$ that abolishes mRNA production are developmentally normal. Mol. Neurobiol. 8, 121-127. doi: 10.1007/BF02780662

Manson, J. C., Clarke, A. R., McBride, P. A., McConnell, I., and Hope, J. (1994b). PrP gene dosage determines the timing but not the final intensity or distribution of lesions in scrapie pathology. Neurodegeneration 3, 331-340.

Manson, J., West, J. D., Thomson, V., McBride, P., Kaufman, M. H., and Hope, J. (1992). The prion protein gene: a role in mouse embryogenesis? Development $115,117-122$.

Martin-Lannerée, S., Hirsch, T. Z., Hernandez-Rapp, J., Halliez, S., Vilotte, J.-L., Launay, J.-M., et al. (2014). $\operatorname{PrP}^{\mathrm{C}}$ from stem cells to cancer. Front. Cell Dev. Biol. 2:55. doi: $10.3389 /$ fcell.2014.00055 
Martins, V. R., Beraldo, F. H., Hajj, G. N., Lopes, M. H., Lee, K. S., Prado, M. A., et al. (2010). Prion protein: orchestrating neurotrophic activities. Curr. Issues Mol. Biol. 12, 63-86.

Massimino, M. L., Redaelli, M., Bertoli, A., Sorgato, M. C., and Mucignat-Caretta, C. (2013). Altered behavioral aspects of aged mice lacking the cellular prion protein. Physiol. Behav. 119, 86-91. doi: 10.1016/j.physbeh.2013.06.006

Meotti, F. C., Carqueja, C. L., Gadotti Vde, M., Tasca, C. I., Walz, R., and Santos, A. R. (2007). Involvement of cellular prion protein in the nociceptive response in mice. Brain Res. 1151, 84-90. doi: 10.1016/j.brainres.2007.03.024

Miranda, A., Pericuesta, E., Ramirez, M. A., and Gutierrez-Adan, A. (2011). Prion protein expression regulates embryonic stem cell pluripotency and differentiation. PLoS ONE 6:e18422. doi: 10.1371/journal.pone.0018422

Miyazawa, K., Emmerling, K., and Manuelidis, L. (2010). Proliferative arrest of neural cells induces prion protein synthesis, nanotube formation, and cell-to-cell contacts. J. Cell. Biochem. 111, 239-247. doi: 10.1002/jcb.22723

Morel, E., Fouquet, S., Chateau, D., Yvernault, L., Frobert, Y., Pincon-Raymond, M., et al. (2004). The cellular prion protein PrPc is expressed in human enterocytes in cell-cell junctional domains. J. Biol. Chem. 279, 1499-1505. doi: 10.1074/jbc.M308578200

Morel, E., Fouquet, S., Strup-Perrot, C., Pichol Thievend, C., Petit, C., Loew, D., et al. (2008). The cellular prion protein $\operatorname{PrP}(c)$ is involved in the proliferation of epithelial cells and in the distribution of junction-associated proteins. PLoS ONE 3:e3000. doi: 10.1371/journal.pone.0003000

Nico, P. B., de-Paris, F., Vinade, E. R., Amaral, O. B., Rockenbach, I., Soares, B. L., et al. (2005). Altered behavioural response to acute stress in mice lacking cellular prion protein. Behav. Brain Res. 162, 173-181. doi: 10.1016/j.bbr.2005.02.003

Nicolae, C., Ko, Y. P., Miosge, N., Niehoff, A., Studer, D., Enggist, L., et al. (2007). Abnormal collagen fibrils in cartilage of matrilin-1/matrilin-3-deficient mice. J. Biol. Chem. 282, 22163-22175. doi: 10.1074/jbc.M610994200

Nicolas, O., Gavin, R., and del Rio, J. A. (2009). New insights into cellular prion protein $(\mathrm{PrPc})$ functions: the "ying and yang" of a relevant protein. Brain Res. Rev. 61, 170-184. doi: 10.1016/j.brainresrev.2009.06.002

Nieznanski, K., Nieznanska, H., Skowronek, K. J., Osiecka, K. M., and Stepkowski, D. (2005). Direct interaction between prion protein and tubulin. Biochem. Biophys. Res. Commun. 334, 403-411. doi: 10.1016/j.bbrc.2005.06.092

Nourizadeh-Lillabadi, R., Seilo Torgersen, J., Vestrheim, O., Konig, M., Alestrom, P., and Syed, M. (2010). Early embryonic gene expression profiling of zebrafish prion protein (Prp2) morphants. PLoS ONE 5:e13573. doi: 10.1371/journal.pone.0013573

Nuvolone, M., Kana, V., Hutter, G., Sakata, D., Mortin-Toth, S. M., Russo, G., et al. (2013). SIRPalpha polymorphisms, but not the prion protein, control phagocytosis of apoptotic cells. J. Exp. Med. 210, 2539-2552. doi: 10.1084/jem.20131274

Passet, B., Young, R., Makhzami, S., Vilotte, M., Jaffrezic, F., Halliez, S., et al. (2012). Prion protein and Shadoo are involved in overlapping embryonic pathways and trophoblastic development. PLoS ONE 7:e41959. doi: 10.1371/journal.pone.0041959

Peralta, O. A., Huckle, W. R., and Eyestone, W. H. (2011). Expression and knockdown of cellular prion protein (PrPC) in differentiating mouse embryonic stem cells. Differentiation 81, 68-77. doi: 10.1016/j.diff.2010.09.181

Petit, C. S., Besnier, L., Morel, E., Rousset, M., and Thenet, S. (2013). Roles of the cellular prion protein in the regulation of cell-cell junctions and barrier function. Tissue Barriers 1:e24377. doi: 10.4161/tisb.24377

Prestori, F., Rossi, P., Bearzatto, B., Laine, J., Necchi, D., Diwakar, S., et al. (2008). Altered neuron excitability and synaptic plasticity in the cerebellar granular layer of juvenile prion protein knock-out mice with impaired motor control. J. Neurosci. 28, 7091-7103. doi: 10.1523/JNEUROSCI.040908.2008

Prodromidou, K., Papastefanaki, F., Sklaviadis, T., and Matsas, R. (2014). Functional cross-talk between the cellular prion protein and the neural cell adhesion molecule is critical for neuronal differentiation of neural stem/precursor cells. Stem Cells 32, 1674-1687. doi: 10.1002/stem.1663

Prusiner, S. B., Groth, D., Serban, A., Koehler, R., Foster, D., Torchia, M., et al. (1993). Ablation of the prion protein (PrP) gene in mice prevents scrapie and facilitates production of anti-PrP antibodies. Proc. Natl. Acad. Sci. U.S.A. 90, 10608-10612. doi: 10.1073/pnas.90.22.10608

Rial, D., Duarte, F. S., Xikota, J. C., Schmitz, A. E., Dafre, A. L., Figueiredo, C. P., et al. (2009). Cellular prion protein modulates age-related behavioral and neurochemical alterations in mice. Neuroscience 164, 896-907. doi: 10.1016/j.neuroscience.2009.09.005
Rial, D., Pandolfo, P., Bitencourt, R. M., Pamplona, F. A., Moreira, K. M., Hipolide, D., et al. (2014). Cellular prion protein $(\operatorname{PrP}(C))$ modulates ethanol-induced behavioral adaptive changes in mice. Behav. Brain Res. 271, 325-332. doi: 10.1016/j.bbr.2014.05.067

Richt, J. A., Kasinathan, P., Hamir, A. N., Castilla, J., Sathiyaseelan, T., Vargas, F., et al. (2007). Production of cattle lacking prion protein. Nat. Biotechnol. 25, 132-138. doi: 10.1038/nbt1271

Rivera-Milla, E., Oidtmann, B., Panagiotidis, C. H., Baier, M., Sklaviadis, T., Hoffmann, R., et al. (2006). Disparate evolution of prion protein domains and the distinct origin of Doppel- and prion-related loci revealed by fish-to-mammal comparisons. FASEB J. 20, 317-319. doi: 10.1096/fj.054279fje

Roffe, M., Beraldo, F. H., Bester, R., Nunziante, M., Bach, C., Mancini, G., et al. (2010). Prion protein interaction with stress-inducible protein 1 enhances neuronal protein synthesis via mTOR. Proc. Natl. Acad. Sci. U.S.A. 107, 13147-13152. doi: 10.1073/pnas. 1000784107

Roucou, X., Gains, M., and LeBlanc, A. C. (2004). Neuroprotective functions of prion protein. J. Neurosci. Res. 75, 153-161. doi: 10.1002/jnr.10864

Sanchez-Alavez, M., Criado, J. R., Klein, I., Moroncini, G., and Conti, B. (2008). Hypothalamic-pituitary-adrenal axis disregulation in PrPC-null mice. Neuroreport 19, 1473-1477. doi: 10.1097/WNR.0b013e32830f1e90

Santamaria, D., and Ortega, S. (2006). Cyclins and CDKS in development and cancer: lessons from genetically modified mice. Front. Biosci. 11, 1164-1188. doi: $10.2741 / 1871$

Santos, T. G., Beraldo, F. H., Hajj, G. N., Lopes, M. H., Roffe, M., Lupinacci, F. C., et al. (2013). Laminin-gammal chain and stress inducible protein 1 synergistically mediate PrPC-dependent axonal growth via Ca2+ mobilization in dorsal root ganglia neurons. J. Neurochem. 124, 210-223. doi: 10.1111/jnc.12091

Santos, T. G., Silva, I. R., Costa-Silva, B., Lepique, A. P., Martins, V. R., and Lopes, M. H. (2011). Enhanced neural progenitor/stem cells self-renewal via the interaction of stress-inducible protein 1 with the prion protein. Stem Cells 29, 1126-1136. doi: 10.1002/stem.664

Santuccione, A., Sytnyk, V., Leshchyns'ka, I., and Schachner, M. (2005). Prion protein recruits its neuronal receptor NCAM to lipid rafts to activate p59fyn and to enhance neurite outgrowth. J. Cell Biol. 169, 341-354. doi: 10.1083/jcb.200409127

Schmitt-Ulms, G., Legname, G., Baldwin, M. A., Ball, H. L., Bradon, N., Bosque, P. J., et al. (2001). Binding of neural cell adhesion molecules (N-CAMs) to the cellular prion protein. J. Mol. Biol. 314, 1209-1225. doi: 10.1006/jmbi. 2000.5183

Schneider, K., Korkmaz, Y., Addicks, K., Lang, H., and Raab, W. H. (2007). Prion protein $(\mathrm{PrP})$ in human teeth: an unprecedented pointer to PrP's function. J. Endod. 33, 110-113. doi: 10.1016/j.joen.2006.11.010

Schrock, Y., Solis, G. P., and Stuermer, C. A. (2009). Regulation of focal adhesion formation and filopodia extension by the cellular prion protein (PrPC). FEBS Lett. 583, 389-393. doi: 10.1016/j.febslet.2008.12.038

Sherman, D. L., and Brophy, P. J. (2005). Mechanisms of axon ensheathment and myelin growth. Nat. Rev. Neurosci. 6, 683-690. doi: 10.1038/nrn1743

Solis, G. P., Schrock, Y., Hulsbusch, N., Wiechers, M., Plattner, H., and Stuermer, C. A. (2012). Reggies/flotillins regulate E-cadherin-mediated cell contact formation by affecting EGFR trafficking. Mol. Biol. Cell 23, 1812-1825. doi: 10.1091/mbc.E11-12-1006

Steele, A. D., Emsley, J. G., Ozdinler, P. H., Lindquist, S., and Macklis, J. D. (2006). Prion protein $(\mathrm{PrPc})$ positively regulates neural precursor proliferation during developmental and adult mammalian neurogenesis. Proc. Natl. Acad. Sci. U.S.A. 103, 3416-3421. doi: 10.1073/pnas.0511290103

Steele, A. D., Lindquist, S., and Aguzzi, A. (2007). The prion protein knockout mouse: a phenotype under challenge. Prion 1, 83-93. doi: 10.4161/pri.1.2.4346

Stella, R., Massimino, M. L., Sandri, M., Sorgato, M. C., and Bertoli, A. (2010). Cellular prion protein promotes regeneration of adult muscle tissue. Mol. Cell. Biol. 30, 4864-4876. doi: 10.1128/MCB.01040-09

Stuermer, C. A. (2011). Reggie/flotillin and the targeted delivery of cargo. J. Neurochem. 116, 708-713. doi: 10.1111/j.1471-4159.2010.07007.x

Taylor, D. R., Whitehouse, I. J., and Hooper, N. M. (2009). Glypican-1 mediates both prion protein lipid raft association and disease isoform formation. PLoS Pathog. 5:e1000666. doi: 10.1371/journal.ppat.1000666

Tobler, I., Gaus, S. E., Deboer, T., Achermann, P., Fischer, M., Rulicke, T., et al. (1996). Altered circadian activity rhythms and sleep in mice devoid of prion protein. Nature 380, 639-642. doi: 10.1038/380639a0 
Tremblay, P., Bouzamondo-Bernstein, E., Heinrich, C., Prusiner, S. B., and DeArmond, S. J. (2007). Developmental expression of PrP in the postimplantation embryo. Brain Res. 1139, 60-67. doi: 10.1016/j.brainres.2006. 12.055

van Rosmalen, J. W., Born, J. M., and Martens, G. J. (2006). Prion protein mRNA expression in Xenopus laevis: no induction during melanotrope cell activation. Brain Res. 1075, 20-25. doi: 10.1016/j.brainres.2005.12.105

Verdu, E., Ceballos, D., Vilches, J. J., and Navarro, X. (2000). Influence of aging on peripheral nerve function and regeneration. J. Peripher. Nerv. Syst. 5, 191-208. doi: 10.1046/j.1529-8027.2000.00026.x

Viegas, P., Chaverot, N., Enslen, H., Perriere, N., Couraud, P. O., and Cazaubon, S. (2006). Junctional expression of the prion protein PrPC by brain endothelial cells: a role in trans-endothelial migration of human monocytes. J. Cell Sci. 119, 4634-4643. doi: 10.1242/jcs.03222

Walz, R., Amaral, O. B., Rockenbach, I. C., Roesler, R., Izquierdo, I., Cavalheiro, E. A., et al. (1999). Increased sensitivity to seizures in mice lacking cellular prion protein. Epilepsia 40, 1679-1682. doi: 10.1111/j.1528-1157.1999. tb01583.x

Watts, J. C., Huo, H., Bai, Y., Ehsani, S., Jeon, A. H., Shi, T., et al. (2009). Interactome analyses identify ties of PrP and its mammalian paralogs to oligomannosidic N-glycans and endoplasmic reticulum-derived chaperones. PLoS Pathog. 5:e1000608. doi: 10.1371/annotation/9eb11869-6acb-49b0-978eabedc3cc545a

Wong, B. S., Liu, T., Li, R., Pan, T., Petersen, R. B., Smith, M. A., et al. (2001). Increased levels of oxidative stress markers detected in the brains of mice devoid of prion protein. J. Neurochem. 76, 565-572. doi: 10.1046/j.14714159.2001.00028.x

Wopfner, F., Weidenhofer, G., Schneider, R., von Brunn, A., Gilch, S., Schwarz, T. F., et al. (1999). Analysis of 27 mammalian and 9 avian PrPs reveals high conservation of flexible regions of the prion protein. J. Mol. Biol. 289, 1163-1178. doi: 10.1006/jmbi.1999.2831

Wu, Z., Liang, F., Hong, B., Young, J. C., Sussman, M. R., Harper, J. F., et al. (2002). An endoplasmic reticulum-bound $\mathrm{Ca}(2+) / \mathrm{Mn}(2+)$ pump, ECA1, supports plant growth and confers tolerance to $\mathrm{Mn}(2+)$ stress. Plant Physiol. 130, 128-137. doi: 10.1104/pp.004440
Yoon, B. S., Ovchinnikov, D. A., Yoshii, I., Mishina, Y., Behringer, R. R., and Lyons, K. M. (2005). Bmprla and Bmprlb have overlapping functions and are essential for chondrogenesis in vivo. Proc. Natl. Acad. Sci. U.S.A. 102, 5062-5067. doi: 10.1073/pnas.0500031102

Young, R., Passet, B., Vilotte, M., Cribiu, E. P., Béringue, V., Le Provost, F., et al. (2009). The prion or the related Shadoo protein is required for early mouse embryogenesis. FEBS Lett. 583, 3296-3300. doi: 10.1016/j.febslet.2009.09.027

Yu, G., Chen, J., Xu, Y., Zhu, C., Yu, H., Liu, S., et al. (2009). Generation of goats lacking prion protein. Mol. Reprod. Dev. 76, 3. doi: 10.1002/mrd.20960

Zhang, C. C., Steele, A. D., Lindquist, S., and Lodish, H. F. (2006). Prion protein is expressed on long-term repopulating hematopoietic stem cells and is important for their self-renewal. Proc. Natl. Acad. Sci. U.S.A. 103, 2184-2189. doi: 10.1073/pnas.0510577103

Zhang, Y., Kim, S. O., Opsahl-Vital, S., Ho, S. P., Souron, J. B., Kim, C., et al. (2011). Multiple effects of the cellular prion protein on tooth development. Int. J. Dev. Biol. 55, 953-960. doi: 10.1387/ijdb.113348yz

Conflict of Interest Statement: The authors declare that the research was conducted in the absence of any commercial or financial relationships that could be construed as a potential conflict of interest.

Received: 28 July 2014; accepted: 22 September 2014; published online: 13 October 2014.

Citation: Halliez S, Passet B, Martin-Lannerée S, Hernandez-Rapp J, Laude H, Mouillet-Richard S, Vilotte J-L and Béringue V (2014) To develop with or without the prion protein. Front. Cell Dev. Biol. 2:58. doi: 10.3389/fcell.2014.00058

This article was submitted to Cell Death and Survival, a section of the journal Frontiers in Cell and Developmental Biology.

Copyright (c) 2014 Halliez, Passet, Martin-Lannerée, Hernandez-Rapp, Laude, Mouillet-Richard, Vilotte and Béringue. This is an open-access article distributed under the terms of the Creative Commons Attribution License (CC BY). The use, distribution or reproduction in other forums is permitted, provided the original author(s) or licensor are credited and that the original publication in this journal is cited, in accordance with accepted academic practice. No use, distribution or reproduction is permitted which does not comply with these terms. 


\title{
The prion protein family: a view from the placenta
}

\section{Samira Makzhami ${ }^{1}$, Bruno Passet ${ }^{1}$, Sophie Halliez ${ }^{2}$, Johan Castille ${ }^{1}$, Katayoun Moazami-Goudarzi ${ }^{1}$, Amandine Duchesne ${ }^{1}$, Marthe Vilotte ${ }^{1}$, Hubert Laude ${ }^{2}$, Sophie Mouillet-Richard ${ }^{3}$, Vincent Béringue ${ }^{2}$, Daniel Vaiman ${ }^{4}$ and Jean-Luc Vilotte ${ }^{1 *}$}

\author{
1 INRA, UMR1313 Génétique Animale et Biologie Intégrative, Jouy-en-Josas, France \\ 2 INRA, U892 Virologie et Immunologie Moléculaires, Jouy-en-Josas, France \\ 3 INSERM, UMR-S1124 Signalisation et Physiopathologie Neurologique, Université Paris Descartes, Paris, France \\ ${ }^{4}$ Faculté Paris Descartes, UMR8104 CNRS, U1016 INSERM, Institut Cochin, Paris, France
}

Edited by:

Craig Michael Walsh, University of California, Irvine, USA

\section{Reviewed by:}

Chunying Li, Wayne State University

School of Medicine, USA

Panagiotis N. Moschou, Swedish

University of Agricultural Sciences,

Sweden

*Correspondence:

Jean-Luc Vilotte, INRA, UMR1313

Génétique Animale et Biologie

Intégrative, Equipe MoDiT- Batiment

440, 78350 Jouy-en-Josas, France

e-mail: jean-luc.vilotte@jouy.inra.fr
Based on its developmental pattern of expression, early studies suggested the implication of the mammalian Prion protein PrP, a glycosylphosphatidylinositol-anchored ubiquitously expressed and evolutionary conserved glycoprotein encoded by the Prnp gene, in early embryogenesis. However, gene invalidation in several species did not result in obvious developmental abnormalities and it was only recently that it was associated in mice with intra-uterine growth retardation and placental dysfunction. A proposed explanation for this lack of easily detectable developmental-related phenotype is the existence in the genome of one or more gene (s) able to compensate for the absence of PrP. Indeed, two other members of the Prnp gene family have been recently described, Doppel and Shadoo, and the consequences of their invalidation alongside that of PrP tested in mice. No embryonic defect was observed in mice depleted for Doppel and PrP. Interestingly, the co-invalidation of PrP and Shadoo in two independent studies led to apparently conflicting observations, with no apparent consequences in one report and the observation of a developmental defect of the ectoplacental cone that leads to early embryonic lethality in the other. This short review aims at summarizing these recent, apparently conflicting data highlighting the related biological questions and associated implications in terms of animal and human health.

Keywords: prion, shadoo, doppel, placenta, development, mammals

\section{INTRODUCTION}

Studies on the neuropathology of transmissible spongiform encephalopathy (TSE) revealed that misfolded, aggregated conformers of the host-encoded cellular protein PrP are the major if not the sole constituent of the infectious agent termed prion (Prusiner, 1982). Prion pathologies affect humans, with the Creutzfeldt-Jakob and Kuru diseases for example, and animals, with for instance the bovine spongiform encephalopathy and sheep scrapie. PrP is a glycosylphosphatidylinositol-anchored, ubiquitously expressed, glycoprotein encoded by the Prnp gene. The PrP primary and tertiary structures are well conserved among mammals. Although many studies focused on PrP potential role in the central nervous system in association with prion neurotoxicity, the evolutionary conservation of this protein and the Prnp gene expression pattern suggested that PrP may exert important biological roles. Numerous functions were attributed to PrP such as its implication in various signal transductions, cell adhesion, neuroprotection, basic biology of embryonic and tissue-specific stem cells, T-cell regulation and immune function, oxidative stress homeostasis and synaptic function (Westergard et al., 2007; Linden et al., 2008; Zomosa-Signoret et al., 2008; Haigh et al., 2010; Resenberger et al., 2011; Schneider et al., 2011; Lopes and Santos, 2012, for recent reviews as well as associated reviews from this special issue). However, the precise PrP biological role remains rather elusive. It may relate to the multiplicity of partners with which PrP appears to interact, with noticeable differences according to the cell type considered and/or the physiological condition assessed. These diverse cellular proteins include transmembrane receptors, metal ion transporters, signaling molecules, cytoskeleton-associated proteins which could suggest that $\mathrm{PrP}$ is a key component of a versatile signaling scaffold complex that allows the activation of various biological pathways.

One further difficulty in understanding PrP physiological function relates to the lack of obvious phenotype in Prnpknockout mice, apart from resistance to TSE and the disappearance of the neurotoxicity associated with prions (Büeler et al., 1992, 1993; Manson et al., 1994). This absence of a strong phenotype could have various, non-mutually exclusive, origins such as (i) the lack of a crucial function of this protein in non-challenging breeding conditions, (ii) genetic adaptation of the animals to the lack of this protein, (iii) biological functional redundancy with other host-encoded proteins able to take over at least some of the PrP roles, and (iv) genetic robustness with PrP being involved in biological functions for which several pathways naturally exist. As mentioned above, the evolutionary conservation of the PrP protein during evolution, at least in mammals, and its involvement in the homeostasis of various stem cells appear somehow contradictory with an absence of important function(s). However, 
such function could be crucial only to allow adaptation of the animal against stressful conditions, situations that have not been yet really tested, or only in a few occasions, for Prnp-knockout mice. The second hypothesis has been challenged by the observation that invalidation only in adult neurons of the Prnp locus did not induce histopathological changes but resulted in a modulation of neuronal excitability (Mallucci et al., 2002), with very limited associated transcriptional alteration at a global brain level (Chadi et al., 2010). However, despite its high level of expression in the adult nervous system, PrP biological role might be crucial at earlier developmental stages in this and/or other tissues of the animal. Two other members of the prion gene family, that share with PrP some structural features (Figure 1), were recently described in the mammalian genomes, Prnd which encodes Doppel and Sprn which encodes Shadoo. These three genes are supposedly evolutionary derived from the retro-insertion event of a gene belonging to one of the four subfamilies of the Zinc transporter containing protein-encoding genes, the ZIP LIV-1 branch (Schmitt-Ulms et al., 2009; Ehsani et al., 2011). The existence of these two related proteins could be seen as being in favor of the existence of a biological redundant mechanism. Investigations toward testing this hypothesis led to apparently contradictory observations that have yet to be conciliated (Young et al., 2009; Daude et al., 2012; Passet et al., 2012).

Besides the understanding of the precise mechanism leading to the lack of strong phenotypes in Prnp-knockout mammals, a related and yet unsolved question is the tissue where and the developmental stage at which this phenotype would be the more likely to occur. Because of its involvement in TSE and of its higher level of expression in the adult nervous system, many studies first focused on this tissue. However, accumulating evidences associate PrP with stem cell biology and early developmental and regenerative processes. Of specific interest is thus the potential involvement of these proteins in the regulation of the extraembryonic annexes and more precisely the placenta, based on the observation of the developmental regulation of this gene family in such normal or pathological tissues and on the association of alleles, including experimental gene knockouts, with phenotypes involving or at least recalling placental functional failures. This review summarizes our current knowledge on this specific topic.

\section{PRION PROTEIN GENE FAMILY EXPRESSION IN EXTRA-EMBRYONIC TISSUES}

Available data on the regulation of the prion protein gene family in extra-embryonic tissues are limited and mostly related to the Prnp gene. Both in situ hybridization (Manson et al., 1992; Alfaidy et al., 2013) and uses of a Prnp-promoter/LacZ reporter transgene (Tremblay et al., 2007) allowed to identify mouse Prnp-gene expression in extra-embryonic membranes as early as 6.5 days post-coïtum, E6.5, the earliest analyzed developmental stage in these studies. This stage corresponds to a transition toward oxidative metabolism and is associated with an increase of the Prnp gene expression level (Miele et al., 2003). A similar early extraembryonic expression of Prnp was reported in human (Donadio et al., 2007), rat (Tanji et al., 1995), and ruminant (Kubosaki et al., 2000; O'Rourke et al., 2011) placentas. However, this gene developmental regulation might differ between species, as observed for example in human where the high level of Prnp expression was restricted to the first trimester of pregnancy.

Transcription of members of the prion protein gene family was also detected at earlier developmental stages (Table 1). Mouse embryonic stem cells were reported to express the three genes (Miranda et al., 2011) and human embryonic stem cells to express at least the Prnp one (Krejciova et al., 2011; Lee and Baskakov, 2013). Prnp gene expression was also observed in human trophoblast cells (Alfaidy et al., 2013) and that of Sprn indirectly suspected to occur in mouse trophectoderm (Passet et al., 2012). We have detected Sprn and Prnd gene expressions in extraembryonic tissues of mouse embryos at E10.5 and E13.5 (our unpublished observation and Young et al., 2011). In sheep, Prnp

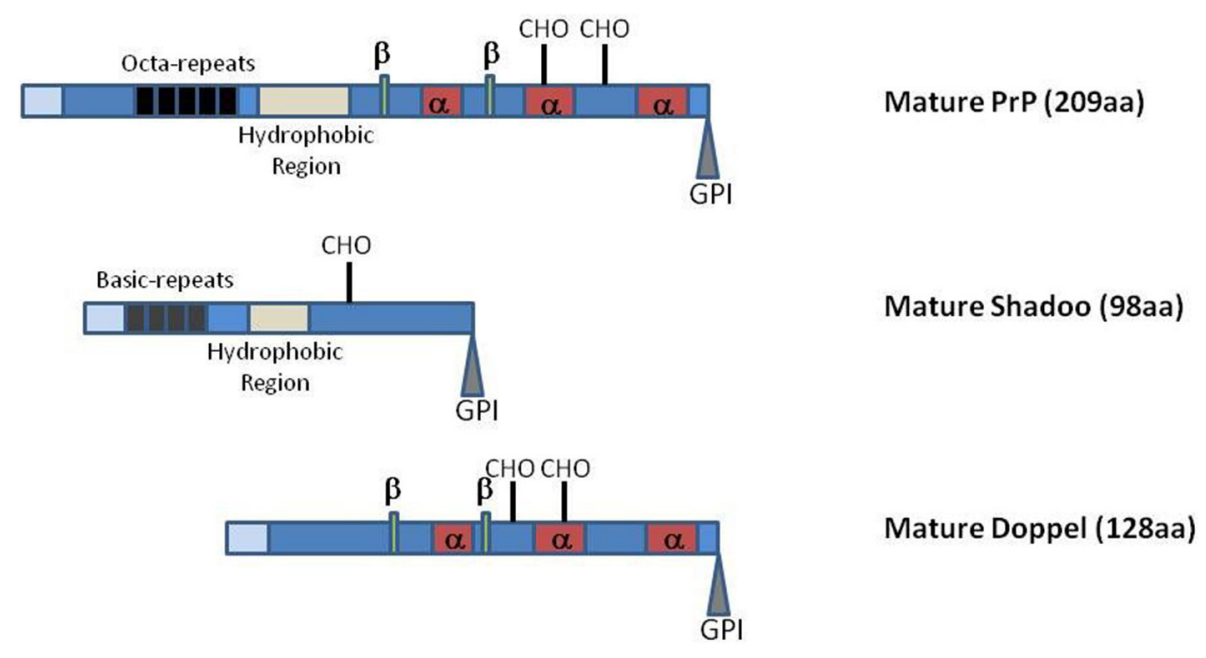

FIGURE 1 | Schematic representation of PrP, Shadoo and Doppel mature proteins. Representations are not at scale. Light blue boxes: $\mathrm{N}$-terminal charged regions of the mature proteins. $\alpha$, $\alpha$-helices; $\beta, \beta$-strands; $\mathrm{CHO}$,
N-glycosylation sites. GPI glycosylphosphatidylinositol. The PrP octa-repeat region and the Shadoo basic repeat region are indicated as well as the two protein hydrophobic domains. 
Table 1 | Summary on prion protein family expression in placenta and knockout phenotypes.

\begin{tabular}{|c|c|c|c|}
\hline $\begin{array}{l}\text { Gene } \\
\text { (Protein) }\end{array}$ & $\begin{array}{l}\text { Expression in } \\
\text { embryonic } \\
\text { stem cells }\end{array}$ & $\begin{array}{l}\text { Expression } \\
\text { in placenta }\end{array}$ & $\begin{array}{l}\text { Placental and related } \\
\text { phenotype in knockout } \\
\text { mice }\end{array}$ \\
\hline Prnp (PrP) & Published & Published & $\begin{array}{l}\text { Fetal and post-natal } \\
\text { growth retardation. } \\
\text { Placental abnormalities } \\
\text { (weight, structure). } \\
\text { Transcriptomic } \\
\text { alterations. (Khalifé et al., } \\
\text { 2011; Alfaidy et al., 2013) }\end{array}$ \\
\hline $\begin{array}{l}\text { Sprn } \\
\text { (Shadoo) }\end{array}$ & Published & Published & $\begin{array}{l}\text { Post-natal growth } \\
\text { retardation (Daude et al., } \\
\text { 2012). } \\
\text { Transcriptomic alterations } \\
\text { to be confirmed } \\
\text { (knockdown experiments } \\
\text { only, Passet et al., 2012) }\end{array}$ \\
\hline $\begin{array}{l}\text { Prnd } \\
\text { (Doppel) }\end{array}$ & Published & $\begin{array}{l}\text { Our } \\
\text { observation }\end{array}$ & $\begin{array}{l}\text { No described effect but } \\
\text { no reported specific } \\
\text { analysis. }\end{array}$ \\
\hline
\end{tabular}

Data on gene expression analyses are derived from various sources, origin of which can be found in the article.

transcripts were also detected in mature and immature oocytes and at the morula stage (Thumdee et al., 2007) while in mouse, the recent sequencing of single oocytes revealed that the three genes are potentially expressed at very low amounts in such cells (Reich et al., 2012).

Overall, these studies suggest that in most mammalian species, the prion family genes are transcribed very early in embryogenesis, in totipotent cells, and that this expression remains both in embryonic and extra-embryonic tissues at early differentiation stages (Table 1). At later developmental times, more restricted and cell-specific expression patterns have been reported, but only few studies focused on these loci. Nevertheless, these observations suggest a potential involvement of this gene family in early mammalian developmental stages and highlight its potential implication in the differentiation of the extra-embryonic tissues.

\section{POTENTIAL INCIDENCE OF SINGLE PRION PROTEIN FAMILY GENE ON PLACENTA \\ THE Prnp LOCUS}

In sheep, PrP variants are strongly associated with differences in animal susceptibility to prion. The observation that some of these PrP variants confer a stronger resistance of the animal to some prion strains resulted in selection breeding strategies aiming at reducing the prevalence of the disease in the sheep population through the selection of so-called resistant Prnp alleles, such as ARR vs. VRQ at codons 136, 154, and 171, respectively (Clouscard et al., 1995; Jeffrey et al., 2014). While selecting ARR animals seems efficient against scrapie development, it could have negative consequences should Prnp or closely related genes be involved in important economical traits, since it would force the breeder not to consider selecting for interesting traits if they are associated to a sensitive (VRQ) genotype. Indeed, several articles described a potential association between the Prnp genotype and specific traits such as lamb birth weight (Sawalha et al., 2007b) and (post-natal) survival (Sawalha et al., 2007a; Gubbins et al., 2009). Although these are complex traits with several potential origins, a correlation between these observations and a role of $\mathrm{PrP}$ during placentation/early development could be suspected.

Potential implication of PrP in the placental physiology was also suggested by the observation of the deregulation of its gene expression in pathological situations. In human, one of the most studied albeit still mysterious gestational disease is preeclampsia. Preeclampsia is characterized by a de novo gestational hypertension and proteinuria. It is a major source of maternal and neonatal morbidity and mortality (Sibai et al., 2005). In one third of the cases, preeclampsia is accompanied with Intra-Uterine Growth Restriction (IUGR), a disease where the fetus fails to reach its genetic growth potential, often through placental dysfunction. Oxidative stress is associated with preeclampsia (Shaker and Sadik, 2013) and abnormal placenta levels of zinc and copper with preterm gestations and IUGR both in humans (Zadrozna et al., 2009; Uriu-Adams and Keen, 2010; Kambe et al., 2014) and mouse (Andrews et al., 2004; Tian et al., 2014). Placental tissues deriving from preeclamptic pregnancies were found to overexpress both the Prnp gene mRNA and the PrP protein (Nishizawa et al., 2007; Hwang et al., 2010). However, this over-expression was not equally distributed within the tissue and appeared to be restricted to the syncytiotrophoblast (the external layer of the placental villi) and to the cytotrophoblasts (the layer of cells that underline the syncytiotrophoblast). Both in human (Bilodeau, 2014) and in a recently published preeclamptic mouse model (Doridot et al., 2013, 2014), strong links between preeclampsia and oxidative stress were described. The octapeptide region and adjacent sites, around histidines 96 and 111, of the PrP protein localized in its amino-terminal region bind several divalent metals (Jackson et al., 2001; Kramer et al., 2001; Walter et al., 2009). This ability has been associated with putative PrP functions in the binding and internalizations of ions, ferrireductase and superoxide dismutase-like activities, signal transduction and protection against oxidative stress (Brown et al., 2001; Choi et al., 2007; Bertuchi et al., 2012; Watt et al., 2012; Singh et al., 2013). Concurrently, a recent study by Alfaidy et al. depicted an involvement of $\mathrm{PrP}$ in the response to oxidative stress in the placenta (Alfaidy et al., 2013). It was thus hypothesized that these increased protein and mRNA PrP levels could be part of a compensatory mechanism induced by a preeclamptic status. However, beside this protective function, $\operatorname{PrP}$ could also play an active role in the establishment of preeclampsia as signaling pathways involving PrP have been proposed to participate or to worsen this disease. The TGF $\beta$ pathway, modulated by the prion protein (Wurm and Wechselberger, 2006), is suspected to contribute to the preeclamptic etiopathology (Stanczuk et al., 2007; Feizollahzadeh et al., 2012; Ozkan et al., 2013), possibly by altering Treg cells equilibrium (Laresgoiti-Servitje et al., 2010; Robertson et al., 2013). Alteration of the Notch-signaling pathway leads to a defect of trophoblast invasion that contributes to the pathogenesis of preeclampsia (Hunkapiller et al., 2011). Interestingly, invalidation of the PrP appears to modulate the placental Notch signaling 
pathway through alteration of the expression of the Jagged 1 ligand (SMR et al., unpublished observation). Thus, PrP could coordinate various signal pathways in response to an oxidative stress that lead to the development of preeclampsia.

Another indirect evidence of PrP implication in placentation came from comparative transcriptomic studies of E6.5 and E7.5 FVB/N and FVB/N Prnp ${ }^{-/-}$embryos (Khalifé et al., 2011). These data revealed that in Prnp gene-invalidated embryos several major metabolic pathways such as angiogenesis, cell proliferation, adhesion and movement were affected at these early developmental stages. Such pathways are important in placental physiology. Furthermore, some of the identified deregulated genes were previously described as key actors of mammalian placentation, such as Adam12 (Huppertz et al., 2006) and activin receptors (Munir et al., 2004).

A direct implication of $\mathrm{PrP}$ in regulating placental function and pregnancy outcomes was recently documented (Alfaidy et al., 2013). This study comparatively analyzed the reproductive performances of transgenic mice either over-expressing mouse $\operatorname{PrP}$ (Tga20) or knockout for Prnp (Prn $\left.p^{-/-}\right)$with those of their wild type (WT) counterpart. The litter size was decreased in Tga20 comparatively to that of Prnp $p^{-/-}$or WT mice. At E17.5, the fetal and placental weights of the $\operatorname{Prn} \mathrm{p}^{-/-}$mice were lower than that of the two other genotypes and in their adulthood, both the Prnp ${ }^{-/-}$and Tga20 mice had lower body weights compared to their WT counterparts. This study further highlighted a role of $\mathrm{PrP}$ in placental $\mathrm{Cu}$ homeostasis and protection against oxidative stress as well as its involvement in placental angiogenesis, two of the altered metabolic pathways identified in the abovementioned embryonic transcriptomic study (Khalifé et al., 2011). Phenotypic analysis of Prnp ${ }^{-/-}$mice revealed a compacted placental labyrinth structure and a disorganization of the vascular tree, disorganization also observed in Tga20 placentas. Alteration of the expression of genes specific of spongiotrophoblasts, invasive trophoblasts or related to the labyrinth branching were noticed. Trophoblastic cell mobility is an important physiological process that allows placental cells to invade uterine tissue, contributing to the anchorage of the placenta, to the regulation of decidual angiogenesis and to the remodeling of the maternal spiral arteries. This mechanism is complex and involves different cell types and signaling pathways (Gasperowicz and Otto, 2008; Knofler, 2010, for recent reviews). PrP might also be directly involved in angiogenesis (Turu et al., 2008) and hematopoiesis (Palmqvist et al., 2007). This might be related to its localization in caveolae and interaction with Caveolin-1, known to be involved in angiogenesis (Griffoni et al., 2000; Massimino et al., 2002).

Overall these studies highlighted a role of PrP during placentation. Deregulation of the expression of the gene and differences in $\operatorname{PrP}$ genotypes were associated with placental perturbations (Table 1). However, these events did not result in overt phenotypes, suggesting either that PrP function in this tissue is not crucial enough for its development to induce embryonic distress or that compensatory mechanisms exist.

\section{THE Prnd AND Sprn LOCI}

The Prnd gene has been invalidated in two different mouse genetic backgrounds, 129/Ola (Paisley et al., 2004) and a mixed
C57BL6/CBA one (Behrens et al., 2002). In both experiments, knockout males suffered from severe subfertility involving a defect in acrosome biogenesis. These males also suffered from other sperm abnormalities that varied between the two reports probably in relation with the different genetic background. Because of this male phenotype, a knockout transgenic line could not be propagated by classical breeding and homozygous knockout animals were only routinely obtained using heterozygous males. In both articles, reproduction of the knockout females were reported to be normal in terms of fertility and litter sizes. Although not specifically studied, none of these reports described other associated phenotypes, suggesting either that Doppel has no role during early embryogenesis or that, should it be involved in placentation, its gene invalidation does not induce drastic alterations (Table 1). However, as Doppel is expressed in mouse extra-embryonic tissues (our unpublished observation), more dedicated analyses should probably be conducted before formally excluding it from the list of proteins involved in the physiology of the placenta. The $\alpha$-helical region of the Doppel protein binds copper (Qin et al., 2003), but this interaction does not appear to induce the protein internalization, as it is observed for $\operatorname{PrP}$ (Cereghetti et al., 2004). It was also reported that Doppel expression might exacerbate oxidative damage (Wong et al., 2001), but this property is discussed (Qin et al., 2003). Thus, analysis of a putative role of Doppel in oxidative stress homeostasis during placental development would be worth looking at.

The Sprn gene invalidation was also recently obtained by homologous recombination in 129Pas ES cells (Daude et al., 2012). These cells were used to derive C57BL/129 and $\mathrm{FVB} / \mathrm{NCr} / 129 \mathrm{Sprn}^{-/-}$mice that were reported to have no gross morphological alterations and to be fertile (Daude et al., 2012). However, 8-16 days old knockout females from the first genetic background were found to have slightly lighter body weights compared to their wild-type counterparts, while knockout males of both genetic backgrounds had a similar weight phenotype at older ages, from day 28 till 42 for C57BL/129 and from day 22 to 50

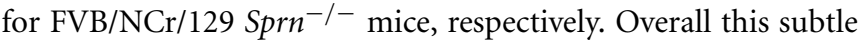
alteration resulted in a weight decrement of about $9 \%$. In a following up review, the authors suggested that the origin of this phenotype could be related to the natural expression of Shadoo in hypothalamic neurons, a structure associated with the control of feeding behavior (Daude and Westaway, 2012). Several other explanations could also be proposed. A mammary defect resulting in modified lactation ability of the knockout females would also induce growth retardations; however such a phenotype would probably affect all pups similarly. Interestingly, uteroplacental insufficiency and altered maternal nutrition during gestation have also been associated with sex-specific post-natal development defects of rat offsprings (Howie et al., 2012; Wadley et al., 2013). It could thus be also hypothesized that the body weight phenotype described for the Sprn ${ }^{-/-}$pups arises from a defect in the placentation process. In line with this suggestion is the observation that the mean litter size of these $\mathrm{Sprn}^{-/}$females is smaller than that of their Sprn ${ }^{+/-}$counterparts (Table S1 in Daude et al., 2012). Transcriptomic analyses performed on FVB/N Sprn-knockdown embryos at E6.5 and E7.5 also revealed the differential expression of around 60 transcripts associated 
with cellular movement and development and with differentiation of the hematological system. Interestingly, some of them, such as the prolactin-related genes, pointed to a transcriptomic deregulation affecting precisely the trophectoderm-derived compartment (Passet et al., 2012, 2013). Regulation of cellular metal uptake by $\operatorname{PrP}$ is probably regulated through the interaction of this protein with other membrane-bound partners such as the lipoprotein-receptor-related protein LRP1 (Taylor and Hooper, 2007) or the glutamate receptor AMPA (Watt et al., 2012) and, as already discussed, this function was shown to be important for placentation (Alfaidy et al., 2013). Although not known to bind divalent metals, Shadoo might also indirectly regulate oxidative stress homeostasis regulatory processes through interaction with $\mathrm{PrP}$ and/or other proteins from their shared interactome (Watts et al., 2009). This hypothesis has yet to be substantiated by experimental evidences. Overall, these observations are compatible with a gene dosage effect of Sprn expression on the ectoplacental cone differentiation and of a potential incidence of the genetic background on the resulting phenotype, as already mentioned for Prnd (Table 1).

\section{CO-INVALIDATION OF SEVERAL MEMBERS OF THE PRION PROTEIN GENE FAMILY}

As already mentioned, the absence of a strong phenotype in mammals invalidated for a single member of the prion protein gene family has led to the hypothesis of the existence of a biological functional redundancy with another host-encoded protein. This model was first developed for the implication of $\operatorname{PrP}$ in the central nervous system (Shmerling et al., 1998). Such proteins should share with PrP an overlapping pattern of expression, at least at some developmental time points, and related biological properties. The two PrP related proteins, Shadoo and Doppel, were suspected to play this role.

\section{Prnd AND Prnp CO-INVALIDATION}

Doppel is unlikely to compensate for the lack of PrP based on its adult pattern of expression, mainly restricted to non-nervous tissues and the male gonads, and on its biological properties in terms of neurotoxicity. Indeed, induced ectopic activation of the Prnd gene expression in the adult nervous system of some Prnp-knockout mice was shown to be neurotoxic (Moore et al., 1999, 2001; Rossi et al., 2001; Anderson et al., 2004) and antagonized by full length PrP expression (Yamaguchi et al., 2004). However, because Doppel and PrP are both expressed during embryogenesis, it remained possible that these two proteins share crucial properties at earlier developmental stages. To investigate a potential compensation by Doppel for the absence of PrP, both loci were co-invalidated in ES cells, taking advantage of their physical close linkage (Paisley et al., 2004). The resulting animals were reported to develop normally into adulthood with no overt phenotype beside an infertility syndrome in the double-knockout males indistinguishable from that observed in their single Prnd-knockout counterparts. Thus, this experiment strongly suggests that Doppel and PrP share no obvious compensatory mechanisms. The reproductive performances of these mice, apart that of the males, were however not specifically assessed.

\section{Sprn AND Prnp CO-INVALIDATION}

The co-invalidation of Sprn and Prnp was achieved using transgenic lines derived from targeted 129Sv/Pas ES cells. Double knockout animals were obtained by crossing $S p r n^{-/}$with FVB.129-Prnp ${ }^{-/-}$mice (Daude et al., 2012). The resulting mice were viable, fertile and produced at expected Mendelian ratios. No overt phenotype was reported, even in aged individuals, and the above-discussed lighter body-weight of the single Sprn ${ }^{-/-}$ mice not mentioned in these animals (Daude et al., 2012). Altogether, this work strongly argued against compensation or redundancy between Shadoo and PrP in the adult nervous system and during embryogenesis (Daude and Westaway, 2012).

However, this conclusion drastically contrasts with previous experiments aimed at lowering the expression of the Sprn gene in various genetic backgrounds by RNA interference, RNAi (Young et al., 2009; Passet et al., 2012). Indeed, using lentiviral ShRNAdelivery in mouse embryos, Sprn gene knockdown resulted in early embryonic lethality, between E8 and E11, in an FVB/N.129Prnp $^{-/-}$genetic background that was not observed in FVB/N mice (Young et al., 2009). This lethality was associated with a developmental defect of the ectoplacental cone and with important hemorrhage surrounding the embryos (Passet et al., 2012). The restriction of the lentiviral infection to the trophoblastic cell lineage resulted in a similar lethal phenotype (Passet et al., 2012). Consistently, embryos invalidated for Prnp and/or knockdown for Sprn (Khalifé et al., 2011; Passet et al., 2013) display alterations of the expression of genes involved in placental angiogenesis, such as angiopoietin genes (Geva et al., 2005), cathepsins (Screen et al., 2008) and matrix metalloproteinases (Fontana et al., 2012). It would be of interest to assess in which extent, inactivation of Shadoo and co-inactivation with PrP affects Notch signaling in regards of $\operatorname{PrP}$ invalidation alone and consistently with the crucial role of this pathway for mouse placental fetal angiogenesis and proper trophoblast cell type specification (Gasperowicz and Otto, 2008). PrP expression is positively regulated by MEK and p38 MAPK kinases (Wang et al., 2005) and it is noteworthy that Mek-1 deficient mice die at early embryonic stages, around E10.5, from an angiogenesis defect of the placenta (Giroux et al., 1999). This age is reminiscent of that of the lethality occurring in Prnp ${ }^{-/-}$Sprn-knockdown embryos (Young et al., 2009) and it would be of interest to also assess the effect of Mek-1 on the transcriptional regulation of Sprn in a regular context and in the absence of PrP.

It remains that this RNAi strategy yielded seemingly contradictory result compared to the classical knockout approach. Several explanations were proposed to conciliate these observations (Daude and Westaway, 2012; Passet et al., 2013). It was suggested that the RNAi approach may induce a potential artifact resulting from either an off target effect of the two used shRNA only phenotypically visible in Prnp-knockout embryos or a toxicity associated with an shRNA over expression in single Prnp or double Prnp/Sprn knockout genotypes, linked to the role of $\mathrm{PrP}$ and potentially Shadoo in the regulation of the RISC complex (Gibbings et al., 2012). Alternative hypotheses may also be proposed, such as a higher susceptibility of the double knockout genotype to external stresses, such as lentiviral infection. Furthermore, even if the knockdown of a gene can result 
in phenotypic outcomes comparable to that of the knockout (De Souza et al., 2006), haplo-insufficiency may on the opposite induce stronger phenotypes than the complete gene loss, as described for Dicer1, a key regulator of microRNA biogenesis (Lambertz et al., 2010).

The use of different genetic backgrounds is also known to greatly influence the phenotype of genetically engineered mouse (Doetschman, 2009). Although cautions were taken in that respect in the knockout experiments (see comments in Daude and Westaway, 2012), this strategy involves inbreeding crosses over several generations. Doing so, starting from different genetic backgrounds [129Pas for the ES cells, C57BL6 for the first established knockout line that was then backcrossed in $\mathrm{FVB} / \mathrm{NCr}$ (Daude et al., 2012)], a selection process might take place that progressively eliminates unfavorable allelic combinations. This could also lead to potential miss-association between (absence of) a phenotype and the targeted gene, as recently exemplified in the case of PrP where abnormalities suspected to result from this gene invalidation actually originated from co-segregating $129 \mathrm{~Sv}$ derived loci (Nuvolone et al., 2013; Striebel et al., 2013). Such a mechanism will not occur using an RNAi approach, potentially leading to stronger associated phenotypes. One way to avoid these potential artifacts would be to use the new custom-designed DNA scissors to invalidate these loci in pure genetic backgrounds ( $\mathrm{Gaj}$ et al., 2013).

On this basis, we have engineered Sprn knockout mice through the use of the Zinc Finger Nuclease (ZFN) technology. Our preliminary results indicate that, as reported by Daude et al. (2012), FVB/N Sprn ${ }^{-/-}$and FVB/N.129 Prnp P $/-/ S p r n^{-/-}$mice are viable. However, these transgenic mice suffer from various defects that are under scrutiny. In both cases, pups exhibit a growth retardation that can be attributed, for part of it, to a mammary defect of the knockout females, probably associated with Sprn invalidation. The FVB/N.129 Prnp $^{-/-} /$Sprn $^{-/-}$mice are also characterized by increased embryonic and perinatal lethality rates compared to FVB/N or FVB/N.129 Prnp $^{-/-}$controls, the extent of which is under analysis. Finally, some phenotypic differences in the survival of the mice at the past weaning stage between FVB/N Sprn ${ }^{-/-}$and FVB/N.129 Prnp ${ }^{-/-} / S_{P r n}{ }^{-/-}$mice appear to result from the 129 genetic contribution in the double knockout mice. Altogether, these preliminary and unpublished observations are consistent with a role of these two related proteins in placentation. They further reassert the importance of the influence of the genetic background and suggest the contribution of other yet unknown loci in the phenotypic consequences of the Prnp and Sprn invalidations.

A remaining issue concerns the discrepancy observed between the knockout and the knockdown experiments. We could exclude a specific susceptibility of the FVB/N.129 Prnp $\mathrm{P}^{-/-} / \mathrm{Sprn}^{-/-}$mice toward lentiviral infection per se. Three other hypothesis are currently tested: (i) an impact of ShRNA over-expression in FVB/N.129 Prnp - $^{-/} / S p r n^{-/-}$embryos in relation with a potential function of these proteins in miRNA regulation, (ii) an offtarget effect of the anti-Sprn ShRNAs used in Young et al. (2009) that would down-regulate the expression of a protein leading to a detrimental effect on the development of the ecoplacental cone in FVB/N.129 Prnp I- $^{-/}$and/or FVB/N.129 Prnp ${ }^{-/-} / S p r n^{-/-}$mice or (iii) a genetic adaptation of the double-knockout embryos to the lack of these two proteins highlighting other loci able to compensate for the lack of them. Pursuing this analysis will thus undoubtedly increase our knowledge on early mammalian embryogenesis.

\section{SIMILARITIES OF THE SIGNALING PATHWAYS ASSOCIATED WITH THE PRION PROTEIN FAMILY IN PLACENTATION AND IN ZEBRAFISH EARLY EMBRYOGENESIS}

As mentioned before, the biological roles of the $\operatorname{PrP}$, of the related Shadoo and to a lesser extend of the Doppel proteins still remain elusive in mammals. Investigations on the PrP biological role were also performed on more distantly species such as Zebrafish. Again, the outcome of these studies surprisingly differed according to the experimental approaches used, morpholinos or knockout, somehow recalling the situation described in mouse. Morpholino-induced downregulation of PrP1 or PrP2 resulted in high mortality of the depleted early embryos. Lethality occurred at developmental stages related to the respective two genes' spatio-temporal patterns of expression, and was associated with deficient morphogenic cell movements and induced apoptotic cell death (Malaga-Trillo et al., 2009; Nourizadeh-Lillabadi et al., 2010). Surviving PrP2- (Nourizadeh-Lillabadi et al., 2010) or PrP1- (Kaiser et al., 2012) depleted embryos also highlighted a neuroprotective role of these proteins. In contrast to PrP-2 morpholino experiments, the knockout of this gene by a ZFN-based approach resulted in no overt developmental phenotypes (Fleisch et al., 2013). This apparent discrepancy was attributed in part to an off target effect of the used morpholinos. In contrast, PrP1knockdown by morpholinos can be considered as specific as the phenotype can be partially rescued by the injection of PrP1 or PrP2 mRNA.

Interestingly, the function of PrP1 in early embryonic development of the Zebrafish could be partly rescued in depleted embryos by the injection of mammalian PrP-encoding mRNAs, suggesting evolutionary conservation of some of the protein functions (Chiesa and Harris, 2009; Malaga-Trillo and Sempou, 2009; Malaga-Trillo et al., 2009; Solis et al., 2013). Besides, in mouse Prnp ${ }^{-/-}$embryos, transcriptomic analyses revealed similarities with PrP1-depleted Zebrafish eggs by highlighting the overexpression of genes encoding proteins with proteolysis activities that could modulate cellular adhesion and proliferation as well as extracellular matrix deposition (Khalifé et al., 2011). The same pathways were also deregulated in Shadoo-depleted embryos, suggesting that this protein shares some of these PrP-functions at least in mammals (Passet et al., 2012). In Zebrafish, the PrP1depleted phenotype is associated with an abnormal intracellular processing and/or transport of E-cadherin, potentially resulting from a modulation of the Fyn signaling pathway (Malaga-Trillo et al., 2009). Similarly in mammals, PrP has been linked to the activation of Src kinases, including Fyn (Mouillet-Richard et al., 2000), while in early mouse embryos, both Prnp and Sprn downregulations induced protocadherin and cadherin transcriptomic alterations (Khalifé et al., 2011; Passet et al., 2012). In mouse embryos, the trophectoderm is the first differentiated tissue to form, with cells requiring complex adhesive structures and invasive capacities. Migrating trophoblast cells are first observed at 
E6.5 (Croy et al., 2012). Thus, the alterations of cell adhesion pathways in Sprn and Prnp invalidated mice, similar to the alterations exhibited by PrP1-depleted zebrafish, are very likely to affect this specialized tissue at these early embryonic stages.

\section{CONCLUSION-ONGOING OR POTENTIAL FUTURE DIRECTIONS}

Current data clearly indicate that the PrP protein has an important role in early mammalian embryogenesis through its implication in placental physiology. The mechanistic behind these observations has yet to be clearly deciphered and could involve several, not mutually exclusive, processes such as an involvement in cell adhesion and angiogenesis as well as a role in the control and response to oxidative stress. A similar implication of Shadoo has also been suggested by several studies but whether this protein acts through identical, complementary or unrelated biological pathways with those of PrP remains a debatable question. The properties of Doppel and its pattern of expression make it an interesting potential partner, but no evidence so far has pointed to this protein as being a key actor of placental physiology. Taking into account the phenotypes observed through the modulation of the expression of these genes in placenta and the affected pathways, the knowledge accumulated on the function of these proteins in this tissue could be of particular interest in regards with their more and more recognized implication in cancers. A crosstalk between these so far independent studies would be of great interest with potential benefits for human and animal health.

A yet poorly investigated question is the relation between these proteins and the biology of mitochondria. PrP depletion was shown to result in reduced mitochondrial numbers and unusual mitochondrial morphology with increased diameters and poorly defined and sparse cristae in several mouse tissues (Miele et al., 2002). PrP depletion induced elevated mitochondrial manganese superoxide dismutase activity, manganese-induced mitochondrial depolarization and reactive oxygen species generation. Brains of Prion-infected mice have reduced cytochrome $\mathrm{C}$ oxidase and manganese superoxide dismutase activities and contain swelling mitochondria. Oxidative stress conditions can induce PrP localization in raft-like microdomains of the mitochondria membranes, resulting in loss of this membrane potential. Impaired mitochondrial function is associated with perturbations of mouse placental (Wakefield et al., 2011) and potentially with preeclampsia (Shi et al., 2013; Doridot et al., 2014) developments. Thus, it is tempting to suggest that oxidative stress conditions and preeclampsia through its induced over-expression of $\mathrm{PrP}$, might trigger the delocalization of some PrP proteins in sub-domains of the mitochondria membrane resulting in induced mitochondria dysfunctions and placentation defects. Similar implication of the other prion protein family members is a yet-to-be explored direction for future experimentations.

One difficulty to delineate the role of these proteins might be related with their mode of action. As nicely highlighted by Alfaidy et al. (2013), these proteins may act as gatekeeper of cellular integrity and thus, in the absence of specific insults such as oxidative stress conditions, their absence might not yield strong phenotypes. Challenging through diverse approaches the existing panel of created animal models with altered expression of these genes would reveal such roles.

It was also suggested that these proteins, which have diverse and large interactomes, may participate to versatile signaling scaffold complexes, allowing activation of various biological pathways. As such, one might expect this function to be revealed by invalidation of their encoding genes unless (i) biological redundancy exists, (ii) the involved biological pathways are associated with non-essential functions or related to response to various stress as discussed just before, (iii) their absence may be, at least partially, compensated through selection of specific genetic environment. This latter hypothesis is attractive as it would explain the different outcomes of the knockout of these genes according to the genetic background, as observed for Doppel, and/or to the methodology used, as observed for Shadoo. It would also reconcile the discrepancy between in vitro data, suggesting that these proteins have key biological functions in crucial pathways such as stem cell homeostasis, with in vivo observations, which appear to deny or limit their importance. The classical knockout process involves the establishment of transgenic lines in mixed genetic backgrounds, allowing the selection process of the less detrimental genetic combinations. New approaches now exist to assess gene invalidation in controlled genetic backgrounds, such as the use of endonucleases (Wijshake et al., 2014). The implementation of this approach to target the prion gene family in different mouse strains might help us to better understand the role of each of these proteins and their potential biological redundancy. Such experiments are currently ongoing and their conclusions much awaited.

\section{AUTHOR CONTRIBUTIONS}

All authors contributed to the conception of this review, revised the manuscript and approved the submitted version.

\section{REFERENCES}

Alfaidy, N., Chauvet, S., Donadio-Andrei, S., Salomon, A., Saoudi, Y., Richaud, P., et al. (2013). Prion protein expression and functional importance in developmental angiogenesis: role in oxidative stress and copper homeostasis. Antioxid. Redox Signal. 18, 400-411. doi: 10.1089/ars.2012.4637

Anderson, L., Rossi, D., Linehan, J., Brandner, S., and Weissmann, C. (2004). Transgene-driven expression of the Doppel protein in Purkinje cells causes Purkinje cell degeneration and motor impairment. Proc. Natl. Acad. Sci. U.S.A. 101, 3644-3649. doi: 10.1073/pnas.0308681101

Andrews, G. K., Wang, H., Dey, S. K., and Palmiter, R. D. (2004). Mouse zinc transporter 1 gene provides an essential function during early embryonic development. Genesis 40, 74-81. doi: 10.1002/gene.20067

Behrens, A., Genoud, N., Naumann, H., Rulicke, T., Janett, F., Heppner, F. L., et al. (2002). Absence of the prion protein homologue Doppel causes male sterility. EMBO J. 21, 3652-3658. doi: 10.1093/emboj/cdf386

Bertuchi, F. R., Bourgeon, D. M., Landemberger, M. C., Martins, V. R., and Cerchiaro, G. (2012). PrPC displays an essential protective role from oxidative stress in an astrocyte cell line derived from PrPC knockout mice. Biochem. Biophys. Res. Commun. 418, 27-32. doi: 10.1016/j.bbrc.2011.12.098

Bilodeau, J. F. (2014). Review: maternal and placental antioxidant response to preeclampsia —impact on vasoactive eicosanoids. Placenta 35(Suppl.), S32S38. doi: 10.1016/j.placenta.2013.11.013

Brown, D. R., Clive, C., and Haswell, S. J. (2001). Antioxidant activity related to copper binding of native prion protein. J. Neurochem. 76, 69-76. doi: 10.1046/j.1471-4159.2001.00009.x

Büeler, H., Aguzzi, A., Sailer, A., Greiner, R. A., Autenried, P., Aguet, M., et al. (1993). Mice devoid of PrP are resistant to scrapie. Cell 73, 1339-1347. doi: 10.1016/0092-8674(93)90360-3 
Büeler, H., Fischer, M., Lang, Y., Bluethmann, H., Lipp, H. P., Dearmond, S. J., et al. (1992). Normal development and behaviour of mice lacking the neuronal cell-surface PrP protein. Nature 356, 577-582. doi: 10.1038/356577a0

Cereghetti, G. M., Negro, A., Vinck, E., Massimino, M. L., Sorgato, M. C., and Van Doorslaer, S. (2004). Copper(II) binding to the human Doppel protein may mark its functional diversity from the prion protein. J. Biol. Chem. 279, 36497-36503. doi: 10.1074/jbc.M404341200

Chadi, S., Young, R., Le Guillou, S., Tilly, G., Bitton, F., Martin-Magniette, M. L., et al. (2010). Brain transcriptional stability upon prion protein-encoding gene invalidation in zygotic or adult mouse. BMC Genomics 11:448. doi: 10.1186/1471-2164-11-448

Chiesa, R., and Harris, D. A. (2009). Fishing for prion protein function. PLoS Biol. 7:e75. doi: 10.1371/journal.pbio.1000075

Choi, C. J., Anantharam, V., Saetveit, N. J., Houk, R. S., Kanthasamy, A., and Kanthasamy, A. G. (2007). Normal cellular prion protein protects against manganese-induced oxidative stress and apoptotic cell death. Toxicol. Sci. 98, 495-509. doi: 10.1093/toxsci/kfm099

Clouscard, C., Beaudry, P., Elsen, J. M., Milan, D., Dussaucy, M., Bounneau, C., et al. (1995). Different allelic effects of the codons 136 and 171 of the prion protein gene in sheep with natural scrapie. J. Gen. Virol. 76(Pt 8), 2097-20101. doi: 10.1099/0022-1317-76-8-2097

Croy, B. A., Chen, Z., Hofmann, A. P., Lord, E. M., Sedlacek, A. L., and Gerber, S. A. (2012). Imaging of vascular development in early mouse decidua and its association with leukocytes and trophoblasts. Biol. Reprod. 87, 125. doi: 10.1095/biolreprod.112.102830

Daude, N., and Westaway, D. (2012). Shadoo/PrP (Sprn(0/0)/Prnp(0/0)) double knockout mice: more than zeroes. Prion 6, 420-424. doi: 10.4161/pri.21867

Daude, N., Wohlgemuth, S., Brown, R., Pitstick, R., Gapeshina, H., Yang, J., et al. (2012). Knockout of the prion protein (PrP)-like Sprn gene does not produce embryonic lethality in combination with $\operatorname{PrP}(\mathrm{C})$-deficiency. Proc. Natl. Acad. Sci. U.S.A. 109, 9035-9040. doi: 10.1073/pnas. 1202130109

De Souza, A. T., Dai, X., Spencer, A. G., Reppen, T., Menzie, A., Roesch, P. L., et al. (2006). Transcriptional and phenotypic comparisons of Ppara knockout and siRNA knockdown mice. Nucleic Acids Res. 34, 4486-4494. doi: 10.1093/nar/gkl609

Doetschman, T. (2009). Influence of genetic background on genetically engineered mouse phenotypes. Methods Mol. Biol. 530, 423-433. doi: 10.1007/978-1-59745471-1_23

Donadio, S., Alfaidy, N., De Keukeleire, B., Micoud, J., Feige, J. J., Challis, J. R., et al. (2007). Expression and localization of cellular prion and COMMD1 proteins in human placenta throughout pregnancy. Placenta 28, 907-911. doi: 10.1016/j.placenta.2006.11.006

Doridot, L. D., Chatre, L. D., Ducat, A., Vilotte, J. L., Lombes, A., Mehats, C., et al. (2014). Nitroso-redox balance and mitochondrial homeostasis are regulated by Stox1, a pre-eclampsia associated gene. Antioxid. Redox Signal. 21, 819-834. doi: 10.1089/ars.2013.5661

Doridot, L., Passet, B., Méhats, C., Rigourd, V., Barbaux, S., Ducat, A., et al. (2013). Preeclampsia-like symptoms induced in mice by fetoplacental expression of STOX1 are reversed by aspirin treatment. Hypertension 61, 662-668. doi: 10. 1161/HYPERTENSIONAHA.111.202994

Ehsani, S., Tao, R., Pocanschi, C. L., Ren, H., Harrison, P. M., and Schmitt-Ulms, G. (2011). Evidence for retrogene origins of the prion gene family. PLoS ONE 6:e26800. doi: 10.1371/journal.pone.0026800

Feizollahzadeh, S., Taheripanah, R., Khani, M., Farokhi, B., and Amani, D. (2012). Promoter region polymorphisms in the transforming growth factor beta-1 (TGFbetal) gene and serum TGFbetal concentration in preeclamptic and control Iranian women. J. Reprod. Immunol. 94, 216-221. doi: 10.1016/j.jri.2012.02.006

Fleisch, V. C., Leighton, P. L., Wang, H., Pillay, L. M., Ritzel, R. G., Bhinder, G., et al. (2013). Targeted mutation of the gene encoding prion protein in zebrafish reveals a conserved role in neuron excitability. Neurobiol. Dis. 55, 11-25. doi: 10.1016/j.nbd.2013.03.007

Fontana, V., Coll, T. A., Sobarzo, C. M., Tito, L. P., Calvo, J. C., and Cebral, E. (2012). Matrix metalloproteinase expression and activity in trophoblastdecidual tissues at organogenesis in CF-1 mouse. J. Mol. Histol. 43, 487-496. doi: 10.1007/s10735-012-9429-8

Gaj, T., Gersbach, C. A., and Barbas, C. F. 3rd. (2013). ZFN, TALEN, and CRISPR/Cas-based methods for genome engineering. Trends Biotechnol. 31, 397-405. doi: 10.1016/j.tibtech.2013.04.004
Gasperowicz, M., and Otto, F. (2008). The notch signalling pathway in the development of the mouse placenta. Placenta 29, 651-659. doi: 10.1016/j.placenta.2008.06.004

Geva, E., Ginzinger, D. G., Moore, D. H. 2nd., Ursell, P. C., and Jaffe, R. B. (2005). In utero angiopoietin-2 gene delivery remodels placental blood vessel phenotype: a murine model for studying placental angiogenesis. Mol. Hum. Reprod. 11, 253-260. doi: 10.1093/molehr/gah159

Gibbings, D., Leblanc, P., Jay, F., Pontier, D., Michel, F., Schwab, Y., et al. (2012). Human prion protein binds Argonaute and promotes accumulation of microRNA effector complexes. Nat. Struct. Mol. Biol. 19, 517-524. doi: 10.1038/nsmb.2273

Giroux, S., Tremblay, M., Bernard, D., Cardin-Girard, J. F., Aubry, S., Larouche, L., et al. (1999). Embryonic death of Mek1-deficient mice reveals a role for this kinase in angiogenesis in the labyrinthine region of the placenta. Curr. Biol. 9, 369-372. doi: 10.1016/S0960-9822(99)80164-X

Griffoni, C., Spisni, E., Santi, S., Riccio, M., Guarnieri, T., and Tomasi, V. (2000). Knockdown of caveolin-1 by antisense oligonucleotides impairs angiogenesis in vitro and in vivo. Biochem. Biophys. Res. Commun. 276, 756-761. doi: 10.1006/bbrc. 2000.3484

Gubbins, S., Cook, C. J., Hyder, K., Boulton, K., Davis, C., Thomas, E., et al. (2009). Associations between lamb survival and prion protein genotype: analysis of data for ten sheep breeds in Great Britain. BMC Vet. Res. 5:3. doi: 10.1186/17466148-5-3

Haigh, C. L., Marom, S. Y., and Collins, S. J. (2010). Copper, endoproteolytic processing of the prion protein and cell signalling. Front. Biosci. (Landmark Ed). 15, 1086-1104. doi: 10.2741/3663

Howie, G. J., Sloboda, D. M., and Vickers, M. H. (2012). Maternal undernutrition during critical windows of development results in differential and sex-specific effects on postnatal adiposity and related metabolic profiles in adult rat offspring. Br. J. Nutr. 108, 298-307. doi: 10.1017/S000711451 $100554 \mathrm{X}$

Hunkapiller, N. M., Gasperowicz, M., Kapidzic, M., Plaks, V., Maltepe, E., Kitajewski, J., et al. (2011). A role for Notch signaling in trophoblast endovascular invasion and in the pathogenesis of pre-eclampsia. Development 138, 2987-2998. doi: 10.1242/dev.066589

Huppertz, B., Bartz, C., and Kokozidou, M. (2006). Trophoblast fusion: fusogenic proteins, syncytins and ADAMs, and other prerequisites for syncytial fusion. Micron 37, 509-517. doi: 10.1016/j.micron.2005.12.011

Hwang, H. S., Park, S. H., Park, Y. W., Kwon, H. S., and Sohn, I. S. (2010). Expression of cellular prion protein in the placentas of women with normal and preeclamptic pregnancies. Acta Obstet. Gynecol. Scand. 89, 1155-1161. doi: $10.3109 / 00016349.2010 .498497$

Jackson, G. S., Murray, I., Hosszu, L. L., Gibbs, N., Waltho, J. P., Clarke, A. R., et al. (2001). Location and properties of metal-binding sites on the human prion protein. Proc. Natl. Acad. Sci. U.S.A. 98, 8531-8535. doi: 10.1073/pnas. 151038498

Jeffrey, M., Martin, S., Chianini, F., Eaton, S., Dagleish, M. P., and González, L. (2014). Incidence of infection in Prnp ARR/ARR sheep following experimental inoculation with or natural exposure to classical scrapie. PLoS ONE 9:e91026. doi: 10.1371/journal.pone.0091026

Kaiser, D. M., Acharya, M., Leighton, P. L., Wang, H., Daude, N., Wohlgemuth, S., et al. (2012). Amyloid beta precursor protein and prion protein have a conserved interaction affecting cell adhesion and CNS development. PLoS ONE 7:e51305. doi: 10.1371/journal.pone.0051305

Kambe, T., Hashimoto, A., and Fujimoto, S. (2014). Current understanding of ZIP and $\mathrm{ZnT}$ zinc transporters in human health and diseases. Cell. Mol. Life Sci. doi: 10.1007/s00018-014-1617-0. [Epub ahead of print].

Khalifé, M., Young, R., Passet, B., Halliez, S., Vilotte, M., Jaffrezic, F., et al. (2011). Transcriptomic analysis brings new insight into the biological role of the prion protein during mouse embryogenesis. PLOS ONE 6:e23253. doi: 10.1371/journal.pone. 0023253

Knofler, M. (2010). Critical growth factors and signalling pathways controlling human trophoblast invasion. Int. J. Dev. Biol. 54, 269-280. doi: 10.1387/ijdb.082769mk

Kramer, M. L., Kratzin, H. D., Schmidt, B., Romer, A., Windl, O., Liemann, S., et al. (2001). Prion protein binds copper within the physiological concentration range. J. Biol. Chem. 276, 16711-16719. doi: 10.1074/jbc.M006554200

Krejciova, Z., Pells, S., Cancellotti, E., Freile, P., Bishop, M., Samuel, K., et al. (2011). Human embryonic stem cells rapidly take up and then clear exogenous human and animal prions in vitro. J. Pathol. 223, 635-645. doi: 10.1002/path.2832 
Kubosaki, A., Ueno, A., Matsumoto, Y., Doi, K., Saeki, K., and Onodera, T. (2000). Analysis of prion protein mRNA by in situ hybridization in brain and placenta of sheep. Biochem. Biophys. Res. Commun. 273, 890-893. doi: 10.1006/bbrc.2000.3035

Lambertz, I., Nittner, D., Mestdagh, P., Denecker, G., Vandesompele, J., Dyer, M. A., et al. (2010). Monoallelic but not biallelic loss of Dicer1 promotes tumorigenesis in vivo. Cell Death Differ. 17, 633-641. doi: 10.1038/cdd.2009.202

Laresgoiti-Servitje, E., Gómez-López, N., and Olson, D. M. (2010). An immunological insight into the origins of pre-eclampsia. Hum. Reprod. Update 16, 510-524. doi: 10.1093/humupd/dmq007

Lee, Y. J., and Baskakov, I. V. (2013). The cellular form of the prion protein is involved in controlling cell cycle dynamics, self-renewal, and the fate of human embryonic stem cell differentiation. J. Neurochem. 124, 310-322. doi: 10.1111/j.1471-4159.2012.07913.x

Linden, R., Martins, V. R., Prado, M. A., Cammarota, M., Izquierdo, I., and Brentani, R. R. (2008). Physiology of the prion protein. Physiol. Rev. 88, 673-728. doi: 10.1152/physrev.00007.2007

Lopes, M. H., and Santos, T. G. (2012). Prion potency in stem cells biology. Prion 6, 142-146. doi: 10.4161/pri.19035

Malaga-Trillo, E., and Sempou, E. (2009). PrPs: proteins with a purpose: lessons from the zebrafish. Prion 3, 129-133. doi: 10.4161/pri.3.3.9651

Malaga-Trillo, E., Solis, G. P., Schrock, Y., Geiss, C., Luncz, L., Thomanetz, V., et al. (2009). Regulation of embryonic cell adhesion by the prion protein. PLoS Biol. 7:e55. doi: 10.1371/journal.pbio. 1000055

Mallucci, G. R., Ratte, S., Asante, E. A., Linehan, J., Gowland, I., Jefferys, J. G., et al. (2002). Post-natal knockout of prion protein alters hippocampal CA1 properties, but does not result in neurodegeneration. EMBO J. 21, 202-210. doi: 10.1093/emboj/21.3.202

Manson, J. C., Clarke, A. R., McBride, P. A., Mcconnell, I., and Hope, J. (1994). PrP gene dosage determines the timing but not the final intensity or distribution of lesions in scrapie pathology. Neurodegeneration 3, 331-340.

Manson, J., West, J. D., Thomson, V., McBride, P., Kaufman, M. H., and Hope, J. (1992). The prion protein gene: a role in mouse embryogenesis? Development $115,117-122$.

Massimino, M. L., Griffoni, C., Spisni, E., Toni, M., and Tomasi, V. (2002). Involvement of caveolae and caveolae-like domains in signalling, cell survival and angiogenesis. Cell. Signal. 14, 93-98. doi: 10.1016/S0898-6568(01) 00232-7

Miele, G., Alejo Blanco, A. R., Baybutt, H., Horvat, S., Manson, J., and Clinton, M. (2003). Embryonic activation and developmental expression of the murine prion protein gene. Gene Expr. 11, 1-12. doi: 10.3727/000000003783992324

Miele, G., Jeffrey, M., Turnbull, D., Manson, J., and Clinton, M. (2002). Ablation of cellular prion protein expression affects mitochondrial numbers and morphology. Biochem. Biophys. Res. Commun. 291, 372-377. doi: 10.1006/bbrc.2002.6460

Miranda, A., Pericuesta, E., Ramirez, M. A., and Gutierrez-Adan, A. (2011). Prion protein expression regulates embryonic stem cell pluripotency and differentiation. PLoS ONE 6:e18422. doi: 10.1371/journal.pone.0018422

Moore, R. C., Lee, I. Y., Silverman, G. L., Harrison, P. M., Strome, R., Heinrich, C., et al. (1999). Ataxia in prion protein (PrP)-deficient mice is associated with upregulation of the novel PrP-like protein doppel. J. Mol. Biol. 292, 797-817. doi: 10.1006/jmbi.1999.3108

Moore, R. C., Xiang, F., Monaghan, J., Han, D., Zhang, Z., Edstrom, L., et al. (2001). Huntington disease phenocopy is a familial prion disease. Am. J. Hum. Genet. 69, 1385-1388. doi: 10.1086/324414

Mouillet-Richard, S., Ermonval, M., Chebassier, C., Laplanche, J. L., Lehmann, S., Launay, J. M., et al. (2000). Signal transduction through prion protein. Science 289, 1925-1928. doi: 10.1126/science.289.5486.1925

Munir, S., Xu, G., Wu, Y., Yang, B., Lala, P. K., and Peng, C. (2004). Nodal and ALK7 inhibit proliferation and induce apoptosis in human trophoblast cells. J. Biol. Chem. 279, 31277-31286. doi: 10.1074/jbc.M400641200

Nishizawa, H., Pryor-Koishi, K., Kato, T., Kowa, H., Kurahashi, H., and Udagawa, Y. (2007). Microarray analysis of differentially expressed fetal genes in placental tissue derived from early and late onset severe pre-eclampsia. Placenta 28, 487-497. doi: 10.1016/j.placenta.2006.05.010

Nourizadeh-Lillabadi, R., Seilo Torgersen, J., Vestrheim, O., Konig, M., Alestrom, P., and Syed, M. (2010). Early embryonic gene expression profiling of zebrafish prion protein (Prp2) morphants. PLoS ONE 5:e13573. doi: 10.1371/journal.pone.0013573
Nuvolone, M., Kana, V., Hutter, G., Sakata, D., Mortin-Toth, S. M., Russo, G., et al. (2013). SIRPalpha polymorphisms, but not the prion protein, control phagocytosis of apoptotic cells. J. Exp. Med. 210, 2539-2552. doi: 10.1084/jem. 20131274

O'Rourke, K. I., Zhuang, D., Truscott, T. C., Yan, H., and Schneider, D. A. (2011). Sparce $\mathrm{PrP}^{\mathrm{Sc}}$ accumulation in the placentas of goats with naturally acquired scrapie. BMC Vet. Res. 7:7. doi: 10.1186/1746-6148-7-7

Ozkan, Z. S., Simsek, M., Ilhan, F., Deveci, D., Godekmerdan, A., and Sapmaz, E. (2013). Plasma IL-17, IL-35, interferon-gamma, SOCS3 and TGF-beta levels in pregnant women with preeclampsia, and their relation with severity of disease. J. Matern. Fetal Neonatal Med. doi: 10.3109/14767058.2013. 861415. [Epub ahead of print].

Paisley, D., Banks, S., Selfridge, J., McLennan, N. F., Ritchie, A. M., McEwan, C., et al. (2004). Male infertility and DNA damage in Doppel knockout and prion protein/Doppel double-knockout mice. Am. J. Pathol. 164, 2279-2288. doi: 10.1016/S0002-9440(10)63784-4

Palmqvist, L., Pineault, N., Wasslavik, C., and Humphries, R. K. (2007). Candidate genes for expansion and transformation of hematopoietic stem cells by NUP98HOX fusion genes. PLoS ONE 2:e768. doi: 10.1371/journal.pone.0000768

Passet, B., Halliez, S., Beringue, V., Laude, H., and Vilotte, J. L. (2013). The prion protein family: looking outside the central nervous system. Prion 7, 127-130. doi: $10.4161 /$ pri.22851

Passet, B., Young, R., Makhzami, S., Vilotte, M., Jaffrezic, F., Halliez, S., et al. (2012). Prion protein and Shadoo are involved in overlapping embryonic pathways and trophoblastic development. PLoS ONE 7:e41959. doi: 10.1371/journal.pone.0041959

Prusiner, S. B. (1982). Novel proteinaceous infectious particles cause scrapie Science 216, 136-144. doi: 10.1126/science.6801762

Qin, K., Coomaraswamy, J., Mastrangelo, P., Yang, Y., Lugowski, S., Petromilli, C., et al. (2003). The PrP-like protein Doppel binds copper. J. Biol. Chem. 278, 8888-8896. doi: 10.1074/jbc.M210875200

Reich, A., Neretti, N., Freiman, R. N., and Wessel, G. M. (2012). Transcriptome variance in single oocytes within, and between, genotypes. Mol. Reprod. Dev. 79, 502-503. doi: 10.1002/mrd.22061

Resenberger, U. K., Harmeier, A., Woerner, A. C., Goodman, J. L., Muller, V., Krishnan, R., et al. (2011). The cellular prion protein mediates neurotoxic signalling of beta-sheet-rich conformers independent of prion replication. EMBO J. 30, 2057-2070. doi: 10.1038/emboj.2011.86

Robertson, S. A., Prins, J. R., Sharkey, D. J., and Moldenhauer, L. M. (2013). Seminal fluid and the generation of regulatory T cells for embryo implantation. Am. J. Reprod. Immunol. 69, 315-330. doi: 10.1111/aji.12107

Rossi, D., Cozzio, A., Flechsig, E., Klein, M. A., Rulicke, T., Aguzzi, A., et al. (2001). Onset of ataxia and Purkinje cell loss in PrP null mice inversely correlated with Dpl level in brain. EMBO J. 20, 694-702. doi: 10.1093/emboj/20.4.694

Sawalha, R. M., Brotherstone, S., Conington, J., and Villanueva, B. (2007a). Lambs with scrapie susceptible genotypes have higher postnatal survival. PLoS ONE 2:e1236. doi: 10.1371/journal.pone.0001236

Sawalha, R. M., Brotherstone, S., Man, W. Y., Conington, J., Bunger, L., Simm, G., et al. (2007b). Associations of polymorphisms of the ovine prion protein gene with growth, carcass, and computerized tomography traits in Scottish Blackface lambs. J. Anim. Sci. 85, 632-640. doi: 10.2527/jas. 2006-372

Schmitt-Ulms, G., Ehsani, S., Watts, J. C., Westaway, D., and Wille, H. (2009). Evolutionary descent of prion genes from the ZIP family of metal ion transporters. PLoS ONE 4:e7208. doi: 10.1371/journal.pone.0007208

Schneider, B., Pietri, M., Pradines, E., Loubet, D., Launay, J. M., Kellermann, O., et al. (2011). Understanding the neurospecificity of Prion protein signaling. Front. Biosci. (Landmark Ed). 16:169-186. doi: 10.2741/3682

Screen, M., Dean, W., Cross, J. C., and Hemberger, M. (2008). Cathepsin proteases have distinct roles in trophoblast function and vascular remodelling. Development 135, 3311-3320. doi: 10.1242/dev.025627

Shaker, O. G., and Sadik, N. A. (2013). Pathogenesis of preeclampsia: implications of apoptotic markers and oxidative stress. Hum. Exp. Toxicol. 32, 1170-1178. doi: $10.1177 / 0960327112472998$

Shi, J., Feng, H., Lee, J., and Ning Chen, W. (2013). Comparative proteomics profile of lipid-cumulating oleaginous yeast: an iTRAQ-coupled 2-D LC-MS/MS analysis. PLoS ONE 8:e85532. doi: 10.1371/journal.pone.0085532

Shmerling, D., Hegyi, I., Fischer, M., Blattler, T., Brandner, S., Gotz, J., et al. (1998). Expression of amino-terminally truncated PrP in the mouse leading 
to ataxia and specific cerebellar lesions. Cell 93, 203-214. doi: 10.1016/S00928674(00)81572-X

Sibai, B., Dekker, G., and Kupferminc, M. (2005). Pre-eclampsia. Lancet 365, 785-799. doi: 10.1016/S0140-6736(05)17987-2

Singh, A., Haldar, S., Horback, K., Tom, C., Zhou, L., Meyerson, H., et al. (2013). Prion protein regulates iron transport by functioning as a ferrireductase. J. Alzheimers. Dis. 35, 541-552. doi: 10.3233/JAD-130218

Solis, G. P., Radon, Y., Sempou, E., Jechow, K., Stuermer, C. A., and MalagaTrillo, E. (2013). Conserved roles of the prion protein domains on subcellular localization and cell-cell adhesion. PLOS ONE 8:e70327. doi: 10.1371/journal.pone. 0070327

Stanczuk, G. A., McCoy, M. J., Hutchinson, I. V., and Sibanda, E. N. (2007). The genetic predisposition to produce high levels of TGF-betal impacts on the severity of eclampsia/pre-eclampsia. Acta Obstet. Gynecol. Scand. 86, 903-908. doi: 10.1080/00016340701416945

Striebel, J. F., Race, B., Pathmajeyan, M., Rangel, A., and Chesebro, B. (2013). Lack of influence of prion protein gene expression on kainate-induced seizures in mice: studies using congenic, coisogenic and transgenic strains. Neuroscience 238, 11-18. doi: 10.1016/j.neuroscience.2013.02.004

Tanji, K., Saeki, K., Matsumoto, Y., Takeda, M., Hirasawa, K., Doi, K., et al. (1995). Analysis of PrPc mRNA by in situ hybridization in brain, placenta, uterus and testis of rats. Intervirology 38, 309-315.

Taylor, D. R., and Hooper, N. M. (2007). The low-density lipoprotein receptorrelated protein 1 (LRP1) mediates the endocytosis of the cellular prion protein. Biochem. J. 402, 17-23. doi: 10.1042/BJ20061736

Thumdee, P., Ponsuksili, S., Murani, E., Nganvongpanit, K., Gehrig, B., Tesfaye, D., et al. (2007). Expression of the prion protein gene (PRNP) and cellular prion protein $(\mathrm{PrPc})$ in cattle and sheep fetuses and maternal tissues during pregnancy. Gene Expr. 13, 283-297. doi: 10.3727/000000006780666984

Tian, X., Anthony, K., Neuberger, T., and Diaz, F. J. (2014). Preconception zinc deficiency disrupts postimplantation fetal and placental development in mice. Biol. Reprod. 90, 83. doi: 10.1095/biolreprod.113.113910

Tremblay, P., Bouzamondo-Bernstein, E., Heinrich, C., Prusiner, S. B., and Dearmond, S. J. (2007). Developmental expression of PrP in the post-implantation embryo. Brain Res. 1139, 60-67. doi: 10.1016/j.brainres.2006.12.055

Turu, M., Slevin, M., Ethirajan, P., Luque, A., Elasbali, A., Font, A., et al. (2008). The normal cellular prion protein and its possible role in angiogenesis. Front. Biosci. 13, 6491-6500. doi: 10.2741/3169

Uriu-Adams, J. Y., and Keen, C. L. (2010). Zinc and reproduction: effects of zinc deficiency on prenatal and early postnatal development. Birth Defects Res. B Dev. Reprod. Toxicol. 89, 313-325. doi: 10.1002/bdrb.20264

Wadley, G. D., McConell, G. K., Goodman, C. A., Siebel, A. L., Westcott, K. T., and Wlodek, M. E. (2013). Growth restriction in the rat alters expression of metabolic genes during postnatal cardiac development in a sexspecific manner. Physiol. Genomics 45, 99-105. doi: 10.1152/physiolgenomics. 00095.2012

Wakefield, S. L., Lane, M., and Mitchell, M. (2011). Impaired mitochondrial function in the preimplantation embryo perturbs fetal and placental development in the mouse. Biol. Reprod. 84, 572-580. doi: 10.1095/biolreprod.110. 087262

Walter, E. D., Stevens, D. J., Spevacek, A. R., Visconte, M. P., Dei Rossi, A., and Millhauser, G. L. (2009). Copper binding extrinsic to the octarepeat region in the prion protein. Curr. Protein Pept. Sci. 10, 529-535. doi: 10.2174/138920309789352056

Wang, V., Chuang, T. C., Hsu, Y. D., Chou, W. Y., and Kao, M. C. (2005). Nitric oxide induces prion protein via MEK and p38 MAPK signaling. Biochem. Biophys. Res. Commun. 333, 95-100. doi: 10.1016/j.bbrc.2005.05.091
Watt, N. T., Taylor, D. R., Kerrigan, T. L., Griffiths, H. H., Rushworth, J. V., Whitehouse, I. J., et al. (2012). Prion protein facilitates uptake of zinc into neuronal cells. Nat. Commun. 3, 1134. doi: 10.1038/ncomms2135

Watts, J. C., Huo, H., Bai, Y., Ehsani, S., Jeon, A. H., Shi, T., et al. (2009). Interactome analyses identify ties of $\operatorname{PrP}$ and its mammalian paralogs to oligomannosidic $\mathrm{N}$-glycans and endoplasmic reticulum-derived chaperones. PLoS Pathog. 5:e1000608. doi: 10.1371/annotation/9eb11869-6acb-49b0-978eabedc3cc545a

Westergard, L., Christensen, H. M., and Harris, D. A. (2007). The cellular prion protein $(\operatorname{PrP}(\mathrm{C}))$ : its physiological function and role in disease. Biochim. Biophys. Acta 1772, 629-644. doi: 10.1016/j.bbadis.2007.02.011

Wijshake, T., Baker, D. J., and Van De Sluis, B. (2014). Endonucleases: new tools to edit the mouse genome. Biochim. Biophys. Acta. doi: 10.1016/j.bbadis.2014.04.020. [Epub ahead of print].

Wong, B. S., Liu, T., Paisley, D., Li, R., Pan, T., Chen, S. G., et al. (2001). Induction of HO-1 and NOS in doppel-expressing mice devoid of PrP: implications for doppel function. Mol. Cell. Neurosci. 17, 768-775. doi: 10.1006/mcne. 2001.0963

Wurm, S., and Wechselberger, C. (2006). Prion protein modifies TGF-beta induced signal transduction. Biochem. Biophys. Res. Commun. 349, 525-532. doi: 10.1016/j.bbrc.2006.08.074

Yamaguchi, N., Sakaguchi, S., Shigematsu, K., Okimura, N., and Katamine, S. (2004). Doppel-induced Purkinje cell death is stoichiometrically abrogated by prion protein. Biochem. Biophys. Res. Commun. 319, 1247-1252. doi: 10.1016/j.bbrc.2004.05.115

Young, R., Bouet, S., Polyte, J., Le Guillou, S., Passet, B., Vilotte, M., et al. (2011). Expression of the prion-like protein Shadoo in the developing mouse embryo. Biochem. Biophys. Res. Commun. 416, 184-187. doi: 10.1016/j.bbrc.2011.11.021

Young, R., Passet, B., Vilotte, M., Cribiu, E. P., Beringue, V., Le Provost, F., et al. (2009). The prion or the related Shadoo protein is required for early mouse embryogenesis. FEBS Lett. 583, 3296-3300. doi: 10.1016/j.febslet.2009. 09.027

Zadrozna, M., Gawlik, M., Nowak, B., Marcinek, A., Mrowiec, H., Walas, S., et al. (2009). Antioxidants activities and concentration of selenium, zinc and copper in preterm and IUGR human placentas. J. Trace Elem. Med. Biol. 23, 144-148. doi: 10.1016/j.jtemb.2009.02.005

Zomosa-Signoret, V., Arnaud, J. D., Fontes, P., Alvarez-Martinez, M. T., and Liautard, J. P. (2008). Physiological role of the cellular prion protein. Vet. Res. 39, 9. doi: $10.1051 /$ vetres: 2007048

Conflict of Interest Statement: The authors declare that the research was conducted in the absence of any commercial or financial relationships that could be construed as a potential conflict of interest.

Received: 10 June 2014; accepted: 22 July 2014; published online: 08 August 2014. Citation: Makzhami S, Passet B, Halliez S, Castille J, Moazami-Goudarzi K, Duchesne A, Vilotte M, Laude H, Mouillet-Richard S, Béringue V, Vaiman D and Vilotte J-L (2014) The prion protein family: a view from the placenta. Front. Cell Dev. Biol. 2:35. doi: $10.3389 /$ fcell.2014.00035

This article was submitted to Cell Death and Survival, a section of the journal Frontiers in Cell and Developmental Biology.

Copyright (c) 2014 Makzhami, Passet, Halliez, Castille, Moazami-Goudarzi, Duchesne, Vilotte, Laude, Mouillet-Richard, Béringue, Vaiman and Vilotte. This is an open-access article distributed under the terms of the Creative Commons Attribution License (CC BY). The use, distribution or reproduction in other forums is permitted, provided the original author(s) or licensor are credited and that the original publication in this journal is cited, in accordance with accepted academic practice. No use, distribution or reproduction is permitted which does not comply with these terms. 


\title{
Role of the prion protein family in the gonads
}

\author{
Aurélie Allais-Bonnet and Eric Pailhoux* \\ Institut National de la Recherche Agronomique, UMR 1198, Biologie du Développement et Reproduction, Jouy-en-Josas, France
}

\section{Edited by:}

Jean-Luc Vilotte, National Institute of Agronomical Research, France

\section{Reviewed by:}

Rafael Linden, Federal University of

Rio de Janeiro, Brazil

Reiner A. Veitia, Paris

Diderot, France

${ }^{*}$ Correspondence:

Eric Pailhoux, Institut National de la Recherche Agronomique, UMR

1198, Biologie du Développement et Reproduction, Bâtiment 440,

F-78350 Jouy-en-Josas, France e-mail: eric.pailhoux@jouy.inra.fr
The prion-gene family comprises four members named PRNP (PRPC), PRND (Doppel), PRNT (PRT), and SPRN (Shadoo). According to species, PRND is located $16-52 \mathrm{~kb}$ downstream from the PRNP locus, whereas SPRN is located on another chromosome. The fourth prion-family gene, $P R N T$, belongs to the same genomic cluster as PRNP and $P R N D$ in humans and bovidae. PRNT and PRND possibly resulted from a duplication event of $P R N D$ and $P R N P$, respectively, that occurred early during eutherian species divergence. Although most of the studies concerning the prion-family has been done on $\mathrm{PRP}^{\mathrm{C}}$ and its involvement in transmissible neurodegenerative disorders, different works report some potential roles of these proteins in the reproductive function of both sexes. Among them, a clear role of $P R N D$, that encodes for the Doppel protein, in male fertility has been demonstrated through gene targeting studies in mice. In other species, Doppel seems to play a role in testis and ovary development but its cellular localization is variable according to the gonadal developmental stage and to the mammalian species considered. For the other three genes, their roles in reproductive function appear ill-defined and/or controversial. The present review aimed to synthesize all the available data on these prion-family members and their relations with reproductive processes, mainly in the gonad of both sexes.

\section{Keywords: prion, Doppel, Shadoo, PRT, reproduction, gonads}

\section{INTRODUCTION}

In Eutherian mammals, the reproductive system is composed by gonads (testes and ovaries) and the genital tract (male: penis, prostate, seminal vesicle, vas deferens, epididymis; female: vulva, vagina, uterus, and oviduct). Gonads produce sex hormones and gametes (sperms and oocytes), whereas the genital tract provides a suitable environment for the maturation and transport of gametes, the fertilization and implantation of the eggs. The differentiation of reproductive organs follows a specific and variable chronology according to species. In every case, the sex determination occurs immediately at fertilization with the addition of male and female gamete genomes. This step determines the genetic sex of the embryo and induces latter on the differentiation of gonads (arising from mesonephros, a transient embryonic kidney) toward a testicular (XY) or an ovarian (XX) differentiating pathway (DeFalco and Capel, 2009; for review; Figure 1). The undifferentiated gonad is composed by a germinal and two somatic cell-lineages. Each somatic line presents a double potentiality and will be turned toward a specific gonadal fate depending of the genes involved in sex determination, with SRY (Sexdetermining Region of Y) being at the top of them (Kashimada and Koopman, 2010; for review). In somatic cell populations, we distinguish: (1) the supporting cells, which will differentiate into Sertoli cells in males and into follicular (also called granulosa) cells in females (these cells are responsible for the growth and the maturation of the germ line); (2) the steroidogenic cells, which will differentiate in Leydig cells in male and theca cells in female (Figure 1). The phenotypic sex, which depends on the gonadal sex and its hormonal production, is set up in many successive steps during development from early gonad differentiation until adulthood. Testes produce androgens and $\mathrm{AMH}$ (Anti-Müllerian Hormone) which are responsible for the differentiation of the genital tract toward the male pathway. Without these hormones the genital tract will differentiate into the female pathway.

Most of the major genes involved in gonad differentiation have been discovered through human genetic studies of DSD (Disorders of Sex Differentiation) cases, but many other genes were found to be expressed in gonads following high throughput mRNA sequencing or other expressional studies. Most of the genes of this last category could putatively be involved in gonadal processes but their role remains to be defined. Among these genes are those of the prion-family. Notably, $P R N D$ has been shown to be essential for testicular function in several species (Behrens et al., 2002; Paisley et al., 2004; Kocer et al., 2007). The most studied gene in the prion family is $P R N P$ which encodes a cell surface glycoprotein, the prion protein $\left(\mathrm{PRP}^{\mathrm{C}}\right)$. An infectious isoform of PRP ${ }^{c}\left(\mathrm{PRP}^{\mathrm{sc}}\right)$ has been shown to be the major component of "Prion," the etiological agent of transmissible spongiform encephalopathies (TSEs). These fatal neurodegenerative disorders include Creutzfelt-Jacob disease (CJD) in humans, bovine spongiform encephalopathy and scrapie in bovidae (Prusiner, 1998).

\section{THE PRION GENE FAMILY COMPRISES FOUR MEMBERS}

The "prion gene complex" encompasses four members named $P R N P, P R N D$ (downstream prion protein-like gene), PRNT (prion protein testis-specific gene), and SPRN (shadow of the 


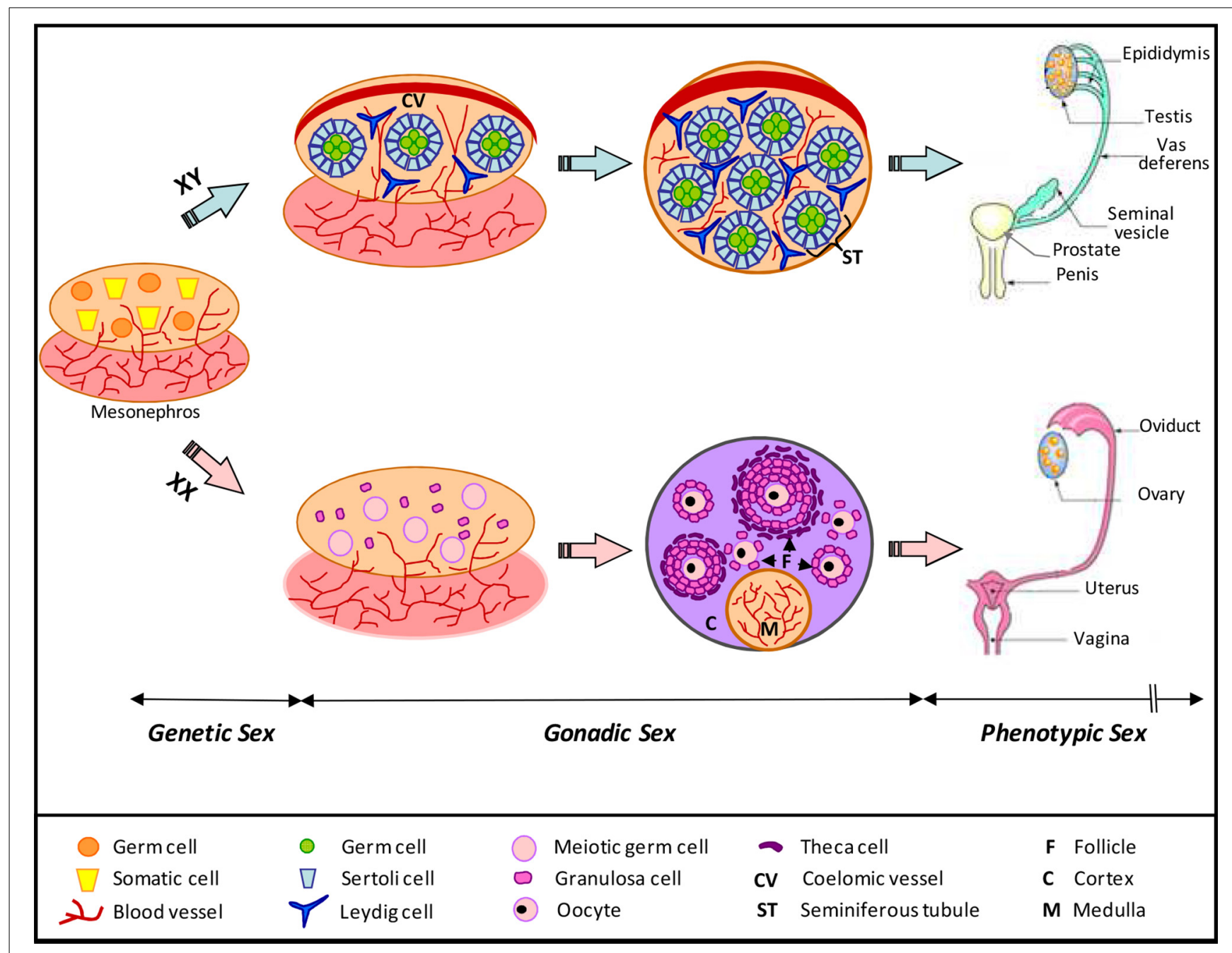

FIGURE 1 | Schematic representation of mammalian gonad differentiation. The genetic sex directs the development of the bipotential gonad toward a male or female gonadal fate. Three cellular types are present in differentiating gonad: somatic supporting cells, somatic steroid-producing cells, and germinal cells. Male and female somatic supporting cells have a common origin and differentiate respectively in Sertoli and granulosa cells. Steroidogenic cells will differentiate in Leydig cells in testis and theca cells in ovary. Testicular-specific features include the formation of the coelomic arterial vessel and of the seminiferous tubules formed by germ and Sertoli cells. Ovarian-specific features are in a chronological order: (i) entry of germ cells into meiosis, (ii) establishment of cortical and medullar compartments, and (iii) formation of follicles, which contain oocytes surrounded by granulosa cells. In agreement with the genetic sex, the development of the phenotypic sex is achieved with the differentiation of the genital tract: epididymis, vas deferens, seminal vesicle, prostate, and penis in males; oviduct, uterus and vagina in female (Adapted from DeFalco and Capel, 2009; for review). prion protein gene). In mouse, sheep, cattle, and rat, the PRNP gene is composed of three exons, whereas only two are present in humans (Yoshimoto et al., 1992; Saeki et al., 1996; Lee et al., 1998; Figure 2). Depending on the studied species, $P R N D$ is located $16-52 \mathrm{~kb}$ downstream of PRNP and PRNT 3 and $6 \mathrm{~kb}$ downstream of human and cattle PRND, respectively (Moore et al., 1999; Comincini et al., 2001; Essalmani et al., 2002; Makrinou et al., 2002; Kocer et al., 2007). PRND and PRNT share with PRNP the same genomic cluster and possibly result from a duplication, that occurred early during eutherian species divergence, of $P R N P$ and $P R N D$, respectively. As $P R N P, P R N D$ structure can vary from two to three exons between species, whereas $P R N T$ has two exons in humans (Comincini et al., 2001; Makrinou et al., 2002; Figure 2). The same organization of PRNT was predicted in cow, sheep, horse, dog and primates whereas this gene seems to be absent in rodents (Premzl et al., 2004; Harrison et al., 2010; Figure 2). SPRN is not part of the PRNP genomic locus, and is located on another chromosome. SPRN comprises two exons and its structure is conserved in fishes and mammals (Premzl et al., 2003; Figure 2). Some of the prion-family genes produce different transcripts of variable compositions and numbers according to the species.

The mammalian PRNP encodes the PRP protein $\left(\mathrm{PRP}^{\mathrm{c}}\right)$ that contains several distinct domains, including an $\mathrm{N}$-terminal signal peptide, an octapeptide repeat domain, a highly conserved hydrophobic segment and a C-terminal hydrophobic region which contains a glycosylphosphatidylinisitol (GPI) anchor (Figure 3A). This glycoprotein possesses two N-linked 

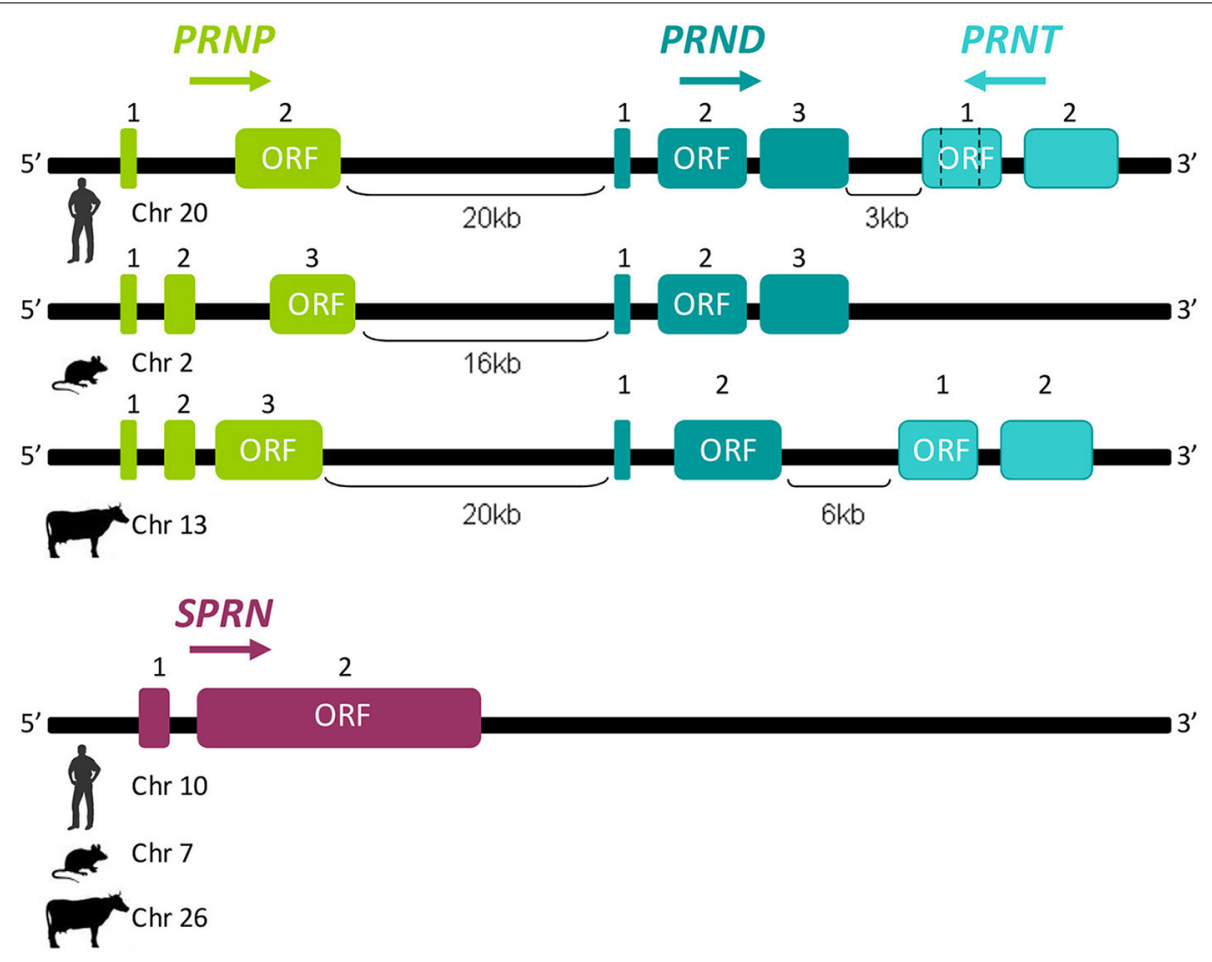

FIGURE 2 | Schematic structural representation of prion genes family members. PRNP, PRND, and PRNT are clustered on the same genomic locus. The distance between PRNP, PRND, and PRNT are given in kilobases $(\mathrm{kb})$; according to species, the number of exons could be variable. SPRN consist of two exons and is located on another chromosome in all studied species. Arrows indicate the relative orientation of the genes. Chromosomes carrying these genes are annotated near each species symbols. For each gene, the open reading frame (ORF) is indicated on relevant exons. glycosylation sites and exists in bi-, mono-, and un-glycosylated forms (Figure 3A). Its secondary structure is defined by the presence of three $\alpha$-helices and two $\beta$-strands (Harris, 1999; for review; Figures 3A,B). The mature Doppel protein (DPL) encoded by $P R N D$ is a protein which resembles a N-terminally truncated $\mathrm{PRP}^{\mathrm{C}}$ protein lacking the octamer repeats (Figure 3 ). In contrast, SPRN encodes the Shadoo protein (SHO) which shares with $\mathrm{PRP}^{\mathrm{c}}$ a similar N-terminal region with a basic repeat region and a hydrophobic domain (Watts and Westaway, 2007; for review; Figure 3). Few data are available concerning the structure of PRT, the PRNT-encoded protein (Makrinou et al., 2002). No signal peptide was predicted for the 94 aa PRT protein, suggesting it could be an intracellular protein (Premzl and Gamulin, 2007). In bovine, PRNT encodes for an N-terminally truncated protein of 55 aa in length, sharing 55\% identity with its human counterpart (Kocer et al., 2007).

Although $\mathrm{PRP}^{\mathrm{c}}$ and $\mathrm{SHO}$ are mainly expressed in the central nervous system (CNS), these two proteins were also detected in male and female gonads (Bendheim et al., 1992; Tanji et al., 1995; Young et al., 2011). DPL and PRT are described as testis-specific proteins (Moore et al., 1999; Tranulis et al., 2001; Makrinou et al., 2002; Kocer et al., 2007). Nevertheless, a transient expression of DPL has been observed in brain of neonatal mice, but this protein is absent in the CNS of adult healthy animals (Li et al., 2000).

Many studies have been conducted on the role of DPL in testis differentiation but the implication of the other prion proteins in reproduction still remains subjective.

\section{TESTIS-SPECIFIC PRION PROTEINS}

In order to comment on the role of a testis-specific protein, it is necessary to introduce the spermatogenesis process allowing the production of male germ cells, spermatozoa (spz). Three different generations of germ cells are visible at any given time among the epithelial cells of the seminiferous tubule: spermatogonia (sg), spermatocytes (spc), and spermatids (std; Figure 4). During spermatogenesis, developing germ cells undergo several mitotic divisions and two meiotic divisions after translocation through the blood-testis barrier, to the luminal side of the epithelium, that is defined by tight junctions between non-dividing Sertoli cells. The final stage of spermatogenesis, known as spermiogenesis, consists of the complex differentiation of round spermatids into spermatozoa (cell elongation, nucleus condensation, acrosome formation, cytoplasm reduction; Figure 4). Throughout spermatogenesis each cluster of germ cells, derived from a single spermatogonium, is interconnected by cytoplasmic bridges that are important for synchronizing the developing process. Thus, the germ cells can be considered as being isolated cells only after they are released as spermatozoa into the lumen of the seminiferous tubule. Upon release, spermatozoa leave behind excess cytoplasm, in the form of interconnected syncytial chains called cytoplasmic lobes (Sprando and Russell, 1987; Weber and Russell, 1987), which are subsequently engulfed and degraded as residual bodies by the Sertoli cells (Espenes et al., 2006). Then spermatozoa are stored in epididymis and undergo maturation processes necessary to acquire motility and capacity to fertilize. Final maturation is 


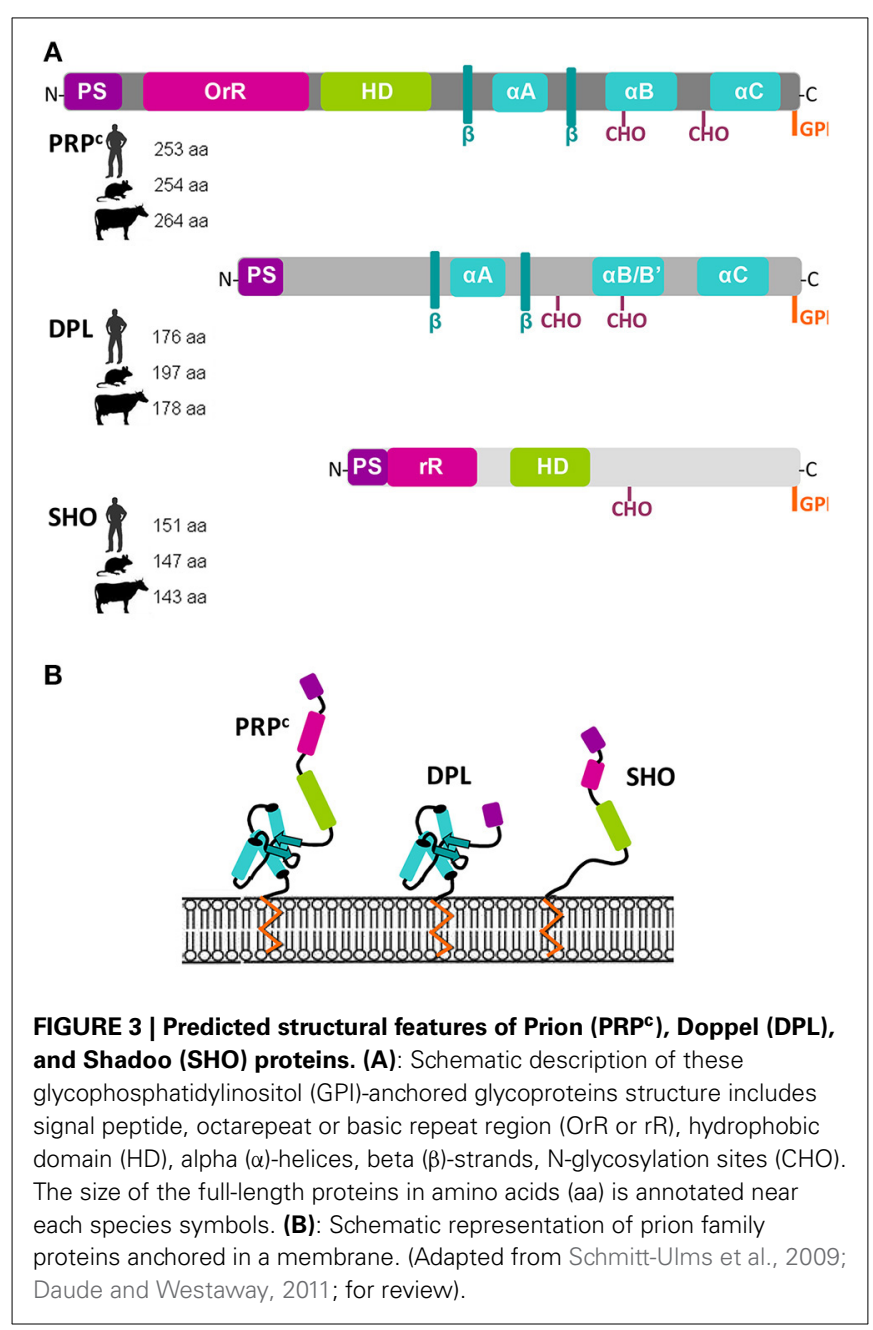

completed in the female reproductive tract where spermatozoa acquire the capacities to fertilize oocytes. This last step called capacitation ended with acrosome reaction which consists on the fusion of the acrosome and oocyte membranes, allowing fertilization.

Two members of the prion-gene family could be considered as testis-specific proteins, $P R N D$ and PRNT. PRND/DPL expression has been studied mainly during spermatogenesis in many species. The first common observation is that DPL is expressed in Sertoli cells at various concentrations according to the species (Westaway, 2004; Rondena et al., 2005; Serres et al., 2006; Kocer et al., 2007; Figure 5). Nevertheless, in germ cells, the localization of DPL is less comparable between animals. For example in bovidae, DPL is present early in primordial germ cells in goat fetal gonads (Kocer et al., 2007) and in bovine, this protein is expressed in all stages of male germ cell development during spermatogenesis (spermatogones to ejaculated spermatozoa, Rondena et al., 2005; Figure 5). In contrast, DPL is only detected in spermatids at final stages of spermiogenesis in ovine, human and mice, (Behrens et al., 2002; Espenes et al., 2006; Serres et al., 2006; Figure 5). Interestingly in ram, DPL is observed in spermatids during the elongation process, in Sertoli cells after sperm release and is completely absent in spermatozoa (Espenes et al.,
2006). Authors suggest that DPL is present in cytoplasmic lobes of maturing spermatids that culminate in DPL concentration in residual bodies which are subsequently released by spermatids then engulfed by Sertoli cells. DPL seems not to be detected in spermatozoa. However, sperm supplementation with recombinant ovine DPL protein during in vitro capacitation, significantly improves spermatozoa motility, vigor, viability and fertilization rate (Pimenta et al., 2012a). At this step we can proposed that DPL expression in ovine ejaculated sperm may be under the threshold of the detection limit of the method and the antibodies used. Otherwise, DPL could be produced by another cell type in the genital tract thus influencing the behavior of spermatozoa. This hypothesis was also suggested in human by Peoc'h and collaborators which completed previous studies by the localization of DPL on the flagella of epididymal and mature spermatozoa, and in seminal plasma (Peoc'h et al., 2002). As DPL seems to be transiently expressed in spermatids but is not detected in differentiated testicular spermatozoa, these authors considered that DPL could be acquired during the maturation of spermatozoa through the epididymis, as it has been described for other GPIanchored proteins on spermatozoa (Peoc'h et al., 2002). Serres and collaborators reinforced this hypothesis by the observation of a DPL-staining in epithelial cells of the boar epididymis, suggesting a possible epididymal origin of DPL and a potential role during spermatozoa maturation (Serres et al., 2006). The transient presence of DPL in the final stages of spermiogenesis points an important role of this protein in the final remodeling of spermatids prior to their release into the testicular seminiferous lumen. The role of DPL in this spermiogenesis process was completely demonstrated by the analysis of mouse Prnd knock-out lines. Indeed, ablation of Prnd (Prnd $\left.{ }^{-/-}\right)$in two different mouse lines lead to infertile males with different sperm phenotypes.

The Prnd $^{-/-}$mouse line with a 129/Ola genetic background produced low numbers of spermatozoa with poor motility and abnormal nuclei and acrosomes, greatly affecting the fertilization process. Indeed, sperm from DPL-deficient mice appears to be unable to undergo the normal acrosome reaction that is necessary to penetrate the zona pellucida of the ovum and $\mathrm{Prnd}^{-/-}$males are completely sterile (Behrens et al., 2002).

The second $\mathrm{Prnd}^{-/-}$mouse line produced on a mixed C57BL6/CBA genetic background produced a normal number of motile spermatozoa but these spermatozoa had an altered chromatin structure and DNA damages that induce an early arrest of embryo development (Paisley et al., 2004). A common phenotype between both $\mathrm{Prnd}^{-/-}$mice is a loss of sperm head integrity.

In conclusion, the localization of DPL on both somatic (Sertoli cells) and germinal cells strongly suggests that this protein plays a major role in male fertility. In most species, its expression in testicular germ cells was detected at late stage of spemiogenesis, principally in spermatids with a transient presence in acrosome. These data show that DPL is implicated in normal acrosome genesis and thus in spermatozoa fertilizing ability. Supplemental roles could be attributing to DPL by its presence at earliest stages of testis development in bovine and goats, suggesting an involvement in germinal cell ontogeny. Moreover, DPL has also been detected in goat fetal Leydig cells (steroidogenic cells) where its role remains to be defined (Kocer et al., 2007). Finally some roles 


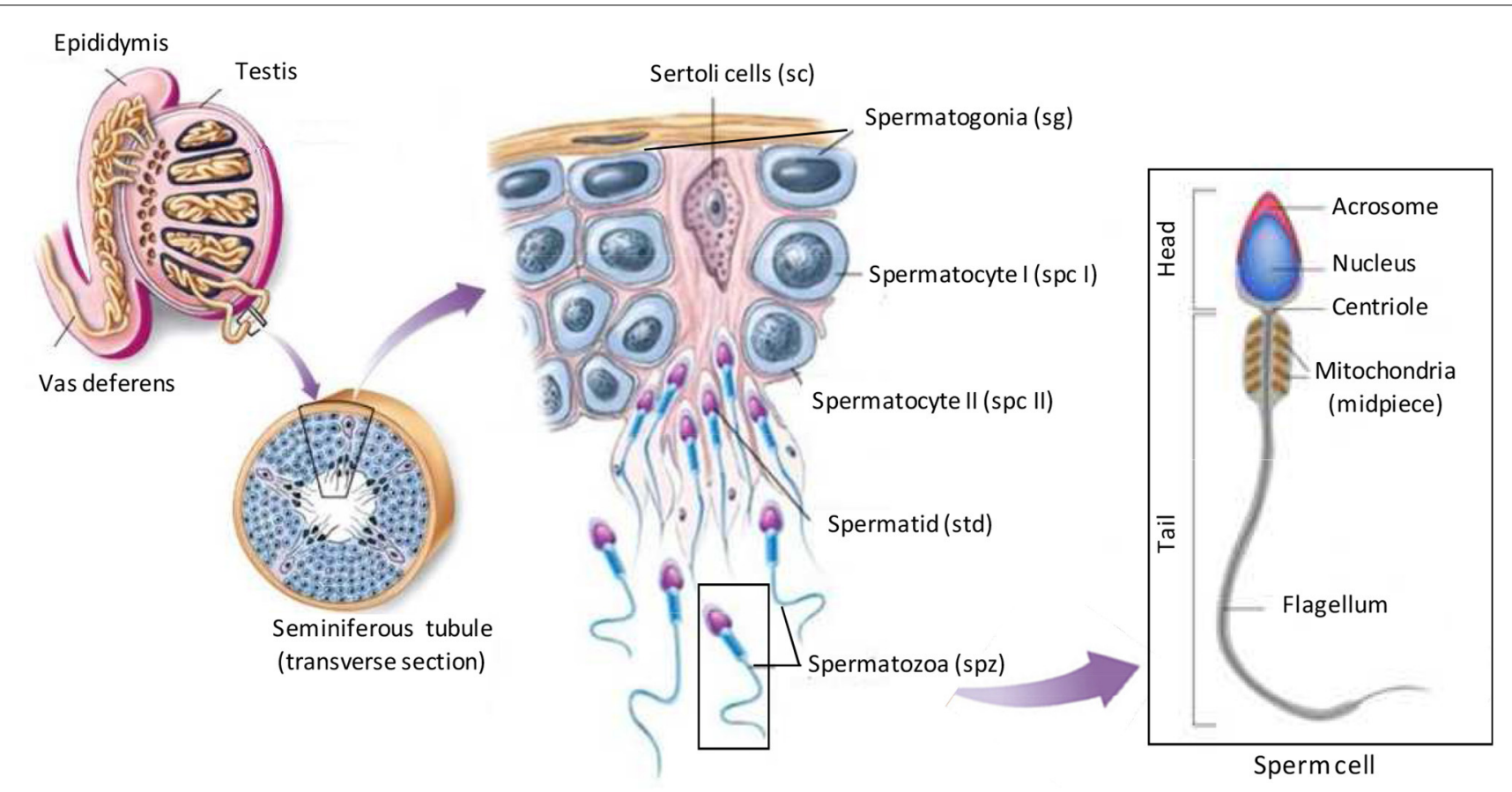

FIGURE 4 | Illustration of spermatogenesis. Spermatogenesis occurs within the seminiferous tubules of the testes of a post pubescent male. Diploid primordial germ cells (also called spermatogonia; sg) near the basal lamina of the seminiferous tubules undergo an initial mitotic division to produce diploid primary spermatocytes (spc I). Nearly half the primary spermatocytes produced remain near the basal lamina to continue to divide mitotically, thus allowing spermatogenesis to be continuous during male's reproductive lifespan. Other primary spermatocytes migrate toward the lumen of the seminiferous tubules and begin to undergo meiosis I, resulting in haploid secondary spermatocytes (spc II). These secondary spermatocytes further divide through meiosis II, producing haploid spermatids (std). Mature sperm cells (spermatozoa; spz) capable of fertilizing an egg develop from spermatids through the final stage called spermiogenesis. In this stage specific regions of the spermatid differentiate into the head, mid-piece, and the tail of the sperm cell. Within the head, an acrosomal space is developed which houses specific enzymes required for fertilization. Specialized acrosomal membranes that are pertinent for fertilization also differentiate in the head of the sperm. A

flagellum develops as a means of motility near the posterior aspect which is fuelled by the abundance of mitochondria in the mid-piece of the sperm cell. (Adapted from buffonescience9.wikispaces website). of DPL in ovarian differentiation couldn't be discarded since DPL has been detected in female germ cells of goat fetuses and in granulosa cells and follicular fluid in bovine (Rondena et al., 2005; Kocer et al., 2007). This last observation reinforces the idea that DPL may contribute to regulate fertility, since follicular fluid has been shown to influence sperm mobility and fertility (Rodriguez et al., 2001).

In order to pinpoint putative other reproductive roles of DPL, it will be of great interest to engineer PRND mutant animals in mammalian species other than mice. For the sex-differentiating process, it is know that the mouse species remains less sensible to gene dosage and haplo-insufficiency than humans. Furthermore, $P R N D$ expression profiles suggest additional roles for DPL in goat testis differentiation compare to mice (Kocer et al., 2007). Accordingly, $P R N D$ gene ablation in goats is currently under investigation in our laboratory that has recently succeeded in such technologies (Boulanger et al., 2014).

Three isoforms of human PRNT have been described and are exclusively expressed in the adult testis, thus absent in fetal tissues including testis (Makrinou et al., 2002). In goats, PRNT is weakly and stochastically expressed in both testes and ovaries at various developmental stages, suggesting that the expression pattern of this gene differs between ruminant and human or, most probably, that ruminant PRNT is a pseudogene (Kocer et al., 2007). By contrast, recent results demonstrate that PRT is found in the ram germinal cells. Notably, PRT expression is localized in the nuclei of spermatogonia, spermatocytes, spermatids and in the sperm acrosome. These observations suggest that ovine PRNT could be a translated protein-coding gene, pointing to a role for PRT in the ram spermatogenesis, throughout spermatogenic cell proliferation and sperm maturation (Pimenta et al., 2012b). However, it is difficult to conclude on a real role of PRT during spermatogenesis. The lack of PRT detection in others species, supports the hypothesis that PRT could be a pseudogene.

\section{PRPC AND ITS SHADOW}

In the $\mathrm{CNS}, \mathrm{PRP}^{\mathrm{c}}$, and $\mathrm{SHO}$ present a partially reciprocal pattern of expression, suggesting a common function of these two proteins in neuronal cells. This overlapping expression leads to Shadoo protein designation (Shadoo is the Japanese word for shadow) and this protein was considered as the putative hostencoded protein that compensates for the lack of $\mathrm{PRP}^{\mathrm{c}}$. Although $\mathrm{PRP}^{\mathrm{C}}$ and $\mathrm{SHO}$ are present in gonads, their single and/or common roles are not established in reproductive biology.

$\mathrm{PRP}^{\mathrm{c}}$ has been more studied and was detected on spermatozoa of different species including human, cattle and mouse 


\begin{tabular}{|c|c|c|c|c|c|c|}
\hline \multicolumn{7}{|l|}{ TESTIS } \\
\hline fetuses germ cells & $\checkmark$ & & & & & \\
\hline Spermatogones & & $\checkmark$ & & & & \\
\hline Spermatocytes & & $\checkmark$ & & & & \\
\hline Spermatids & & $\checkmark$ & $\checkmark$ & $\checkmark$ & $\checkmark$ & \\
\hline Spermatozoa (spz) & & $\checkmark$ & & & & \\
\hline Sertoli cells & $\checkmark$ & $\checkmark$ & $\checkmark$ & $\checkmark$ & $r$ & $\checkmark$ \\
\hline Leydig cells & $\checkmark$ & & & & & \\
\hline \multicolumn{7}{|l|}{ EPIDIDYMIS } \\
\hline Epididymal epithelial cells & & & $?$ & $?$ & & $\checkmark$ \\
\hline Epididymal spz & & & & $\checkmark$ & & \\
\hline EJACULATED SPZ & & $\checkmark$ & & $\checkmark$ & $\checkmark$ & \\
\hline SEMINAL PLASMA & & & & $\checkmark$ & & \\
\hline \multicolumn{7}{|l|}{ OVARY } \\
\hline fetuses germ cells & $\checkmark$ & & & & & \\
\hline \multicolumn{7}{|l|}{ Qocytes } \\
\hline Granulosa cells & & $r$ & & & & \\
\hline Folicular fluid & & $\checkmark$ & & & & \\
\hline
\end{tabular}

FIGURE 5 | Table summarizing the cellular localization of Dopple (DPL) in gonads of various species.

(Shaked et al., 1999) but the nature of $\mathrm{PRP}^{\mathrm{c}}$ isoforms on spermatozoa is debated and appears different according to antibodies. A first study showed the presence of $\mathrm{PRP}^{\mathrm{c}}$ on epididymal sperm extracts from epididymis of mouse and bovine and from ejaculated spermatozoa from bovine and human (Figure 6). The molecular weight of $\mathrm{PRP}^{\mathrm{c}}$ in epididymal sperm cells was similar to that of the brain (control tissue) whereas in mature sperm cells, the $\mathrm{PRP}^{\mathrm{c}}$ isoform detected is smaller and C-terminallytruncated. Authors suggested that the C-terminal portion of the $\mathrm{PRP}^{\mathrm{c}}$ is removed during the process of sperm maturation in epididymis and that the protein is inserted via its $\mathrm{N}$-terminal part in the membrane of ejaculated sperm (Shaked et al., 1999). In contrast, Peoc'h group demonstrated that $\mathrm{PRP}^{\mathrm{c}}$ was recognized on sperm membranes by antibodies binding to the C-terminus part of the protein, suggesting that only $\mathrm{N}$-terminally truncated fragments of $\mathrm{PRP}^{\mathrm{c}}$ are present in these cells in the human species. In addition in human testes, 3 isoforms of $\mathrm{PRP}^{\mathrm{c}}$, an unglycosylated full-length and two N-terminally truncated proteins, are also detected in spermatocytes and spermatids (Peoc'h et al., 2002; Figure 6). Differences in the nature of $\mathrm{PRP}^{\mathrm{c}}$ truncated (C- or Nterm) could be due to differences in the protocol for preparing spermatozoa extracts that could affect proteolysis differentially, or to the antibodies used. Studies in ram supports the work of Shaked and collaborators by demonstrating that one major glycosylated C-terminally truncated $\mathrm{PRP}^{\mathrm{c}}$ isoform is associated with sperm from testis, cauda epididymis and semen and also in sperm cytoplasmic droplets that are released during maturation (Ecroyd et al., 2004; Figure 6). Other $\mathrm{PRP}^{\mathrm{c}}$ isoforms were compartmentalized within cauda epididymal fluid and semina plasma (Ecroyd et al., 2004). Indeed, Gatti and colleagues demonstrated the synthesis and secretion of soluble $\mathrm{PRP}^{\mathrm{c}}$ by the epithelial cells lining the ram epididymis (Figure 6). These cells produce large quantities of a specific isoform of $\mathrm{PRP}^{\mathrm{c}}$ that seems to be processed post-secretion in different ways during epididymal transit. In ovine spermatozoa, different forms of $\mathrm{PRP}^{\mathrm{C}}$ have been found, as reported previously for others species (Shaked et al., 1999), that seem to be inserted into the sperm membrane mainly during ejaculation (Gatti et al., 2002). In summary, both glycosylated and proteolytic isoforms of $\mathrm{PRP}^{\mathrm{c}}$ are present in the male reproductive tract. However, the main isoforms differ between the sperm and the reproductive fluid, suggesting only a low extend of exchange between these two compartments. By studying Prnp deficient mice, a protective role of $\mathrm{PRP}^{\mathrm{c}}$ against copper toxicity has been proposed since sperm cells originating from $\mathrm{Prnp}^{-/-}$mice were significantly more susceptible to high copper concentrations than sperm from wild-type mice (Shaked et al., 1999). The presence of an anti-oxidant defense in the sperm-surrounding media is highly important, especially during passage and storage in the epididymis, since these germinal cells lack the molecular machinery to regenerate damaged lipids and proteins. Nevertheless, Prnp null mice are fully fertile and the ablation of Prnp in Prnd ${ }^{-/-}$ mice has no additional effect on the phenotype described for 


\begin{tabular}{|l|c|c|c|c|}
\hline \multicolumn{1}{|c|}{} & P P & P & & \\
\hline TESTIS & $\checkmark$ & & & \\
\hline Spermatogonia & $\checkmark$ & & & \\
\hline Spermatocytes & & & & $\checkmark$ \\
\hline Spermatids & & & & \\
\hline Spermatozoa (spz) & & & & \\
\hline Sertoli cells & & & & \\
\hline Leydig cells & & & & $\checkmark$ \\
\hline EPIDIDYMIS & $\checkmark$ & $\checkmark$ & & $\checkmark$ \\
\hline Epididymal epithelial cells & & & & $\checkmark$ \\
\hline Epididymal spz & & & \\
\hline EJACULATED SPZ & $\checkmark$ & & & $\checkmark$ \\
\hline SEMINAL PLASMA & $\checkmark$ & & \\
\hline OVARY & & & & \\
\hline Oocytes & & & & \\
\hline Granulosa cells & & $\checkmark$ & & \\
\hline Theca cells & & & & \\
\hline Folicular fluid & & & & \\
\hline OVIDUCT & & & & \\
\hline UTERUS & & & & \\
\hline
\end{tabular}

FIGURE 6 | Table summarizing the cellular localization of Prion protein (PRPc) in gonads of various species.

Prnd ${ }^{-1-}$ males, suggesting that $\mathrm{PRP}^{\mathrm{c}}$ is not involved in fertilizing capacity of mice spermatozoa, at least under normal breeding conditions (Büeler et al., 1992; Manson et al., 1994; Paisley et al., 2004).

$\mathrm{PRP}^{\mathrm{c}}$ is also present in the female reproductive tract. This protein has been detected in the ovary, oviduct and uterus of pregnant and cyclic ewes (Moudjou et al., 2001; Tuo et al., 2001; Figure 6). In bovine, PRNP is expressed in both theca and granulosa cells of ovarian follicles notably in developing follicles suggesting that it could promote the growth of dominant follicles (Forde et al., 2008; Figure 6). Again, invalidation of this gene did not induce any noticeable fertility defect in the studied females. However, these animals were kept under control breeding conditions and not challenged, through induction of oxidative stresses for example. Such challenges revealed yet undiscovered function of PrP in other organs, such as placenta (Alfaidy et al., 2013), and such experiments would be of interest to further assess the function of $\mathrm{PrP}$ in the gonads.

Although no biological role of SHO has been defined in reproduction, few data are available in mice. Generation of transgenic reporter mice for the gene encoding SHO protein (Sprn) has permitted to show a Sprn-LacZ expression in the male and female gonads. In both cases, staining was cell-specific, in the interstitial Leydig cells in testis and in granulosa cells of ovarian follicle (Young et al., 2011). Leydig cells are the site of testosterone biosynthesis that is required for the development of the male reproductive system, and the initiation and maintenance of spermatogenesis. Deregulation of some genes expressed in Leydig cells such as proliferin-related protein (PRP) result in decreased testosterone production and has an impact on development of male reproductive system and fertility (Zhao et al., 2011). If we consider the testicular SHO localization, could this protein have the same function in male fertility? Another way to determine the function of a protein is to study the ablation of its coding gene. The lack of Sprn in mice has no effect on fertility, as judged by the measurement of the litter size (Daude et al., 2012). Given that DPL is implicated in spermiogenesis and $\mathrm{PRP}^{\mathrm{C}}$ is present on spermatozoa, one can imagine that these close proteins can compensate each other. Sprn invalidation in Prnd ${ }^{-1-}$ mice does not increase the testicular phenotype associated with single Prnd knockout (our unpublished data). In the same way, mice deficient for both SHO and $\mathrm{PRP}^{\mathrm{c}}$ were also found to be viable and fertile (Daude et al., 2012). By contrast, the Sprn knockdown in Prnp ${ }^{-/-}$mice presents an embryonic lethal phenotype at developmental stage E7.5 (Passet et al., 2012). Discordant results between $S p r n^{\mathrm{KO}} / \operatorname{Prnp}^{\mathrm{KO}}$ and $S p r n^{\mathrm{KD}} / \operatorname{Prnp}^{\mathrm{KO}}$ could be due to different mice genetic backgrounds used in these studies or to a genetic adaptation of the double knockout animals. Nevertheless, gene-targeting experiments in mice do not allow yet defining a putative role of $\mathrm{SHO}$ in reproduction. 


\section{CONCLUSION}

Among the prion-gene family members, $P R N D$ is yet the sole to have been clearly linked to reproductive biology with a crucial function during the late steps of spermatogenesis. Indeed its gene ablation in mice leads to male infertility. Although expression of the other three members PRNP, PRNT, and SPRN has been demonstrated at mRNA and protein levels in gonads and/or reproductive tracts, their specific reproductive functions, if any, remain to be elucidated. The fact that these putative functions haven't been pointed on by human genetics or gene-targeting in other mammalian species may suggest that these proteins by alone have no critical reproductive functions or that their functions aren't hugely affected by mutational events. Indeed, even if the physiological role of $\mathrm{PRP}^{\mathrm{c}}$ remains unclear in the central nervous system, according to the fact that $P r n p^{-/-}$mice or goats seem to be unaffected and well-being, it is a mis-folding of $\mathrm{PRP}^{\mathrm{c}}$ $\left(\mathrm{PRP}^{\mathrm{sc}}\right)$ that remains highly detrimental for the central nervous system physiology (a sort of gain-of-function mutation). This means that we cannot exclude some detrimental reproductive effects of these proteins without any mutational changes, but with post-translational and/or conformational changes remaining very difficult to pin-point.

\section{ACKNOWLEDGMENTS}

The authors want to thank Sophie Mouillet-Richard and JeanLuc Vilotte for their invitation to submit this manuscript. We also thank Jean-Luc Vilotte for his constructive criticisms. The authors are supported by the French ANR-09-BLAN-0015-01 and ANR-09-GENM-009.

\section{REFERENCES}

Alfaidy, N., Chauvet, S., Donadio-Andrei, S., Salomon, A., Saoudi, Y., Richaud, P., et al. (2013). Prion protein expression and functional importance in developmental angiogenesis: role in oxidative stress and copper homeostasis. Antioxid. Redox Signal. 18, 400-411. doi: 10.1089/ars.2012.4637

Behrens, A., Genoud, N., Naumann, H., Rülicke, T., Janett, F., Heppner, F. L., et al. (2002). Absence of the prion protein homologue Doppel causes male sterility. EMBO J. 21, 3652-3658. doi: 10.1093/emboj/cdf386

Bendheim, P. E., Brown, H. R., Rudelli, R. D., Scala, L. J., Goller, N. L., Wen, G. Y., et al. (1992). Nearly ubiquitous tissue distribution of the scrapie agent precursor protein. Neurology 42, 149-156. doi: 10.1212/WNL.42.1.149

Boulanger, L., Pannetier, M., Gall, L., Allais-Bonnet, A., El Zaiat, M., Le Bourhis, D., et al. (2014). FOXL2 is a female sex-determining gene in the goat. Curr. Biol. 24, 404-408. doi: 10.1016/j.cub.2013.12.039

Büeler, H., Fischer, M., Lang, Y., Bluethmann, H., Lipp, H. P., DeArmond, S. J., et al. (1992). Normal development and behaviour of mice lacking the neuronal cell-surface PrP protein. Nature 356, 577-582. doi: 10.1038/356577a0

Comincini, S., Foti, M. G., Tranulis, M. A., Hills, D., Di Guardo, G., Vaccari, G., et al. (2001). Genomic organization, comparative analysis, and genetic polymorphisms of the bovine and ovine prion Doppel genes (PRND). Mamm. Genome 12, 729-733. doi: 10.1007/s00335-001-2064-4

Daude, N., and Westaway, D. (2011). Biological properties of the PRP-like Shadoo protein. Front. Biosci. 16, 1505-1516. doi: 10.2741/3801

Daude, N., Wohlgemuth, S., Brown, R., Pitstick, R., Gapeshina, H., Yang, J., et al. (2012). Knockout of the prion protein (PrP)-like Sprn gene does not produce embryonic lethality in combinaison with $\mathrm{PrP}^{\mathrm{c}}$-deficiency. Proc. Natl. Acad. Sci. U.S.A. 109, 9035-9040. doi: 10.1073/pnas.1202130109

DeFalco, T., and Capel, B. (2009). Gonad morphogenesis in vertebrates: divergent means to a convergent end. Annu. Rev. Cell Dev. Biol. 25, 457-482. doi: 10.1146/annurev.cellbio.042308.13350

Ecroyd, H., Sarradin, P., Dacheux, J. L., and Gatti, J. L. (2004). Compartmentalization of prion isoforms within the reproductive tract of the ram. Bio. Reprod. 71, 993-1001. doi: 10.1095/biolreprod.104.029801
Espenes, A., Harbitz, I., Skogtvedt, S., Fuglestveit, R., Berg, K. A., Dick, G., et al. (2006). Dynamic expression of the prion-like protein Doppel in ovine testicular tissue. Int. J. Androl. 29, 400-408. doi: 10.1111/j.1365-2605.2005. 00618.x

Essalmani, R., Taourit, S., Besnard, N., and Vilotte, J. L. (2002). Sequence determination and expression of the ovine doppel-encoding gene in transgenic mice. Gene 285, 287-290. doi: 10.1016/S0378-1119(02)00391-8

Forde, N., Rogers, M., Canty, M. J., Lonergan, P., Smith, G. W., Coussens, P. M., et al. (2008). Association of the prion protein and its expression with ovarian follicle development in cattle. Mol. Reprod. Dev. 75, 243-249. doi: 10.1002/mrd.20807

Gatti, J. L., Métayer, S., Moudjou, M., Andréoletti, O., Lantier, F., Dacheux, J. L., et al. (2002). Prion protein is secreted in soluble forms in the epididymal fluid and proteolytically processed and transported in seminal plasma. Biol. Reprod. 67, 393-400. doi: 10.1095/biolreprod67.2.393

Harris, D. A. (1999). Cell biological studies of the prion protein. Curr. Issues Mol. Biol. 1, 65-75.

Harrison, P. M., Khachane, A., and Kumar, M. (2010). Genomic assessment of the evolution of the prion protein gene family in vertebrates. Genomics 95, 268-277. doi: 10.1016/j.ygeno.2010.02.008

Kashimada, K., and Koopman, P. (2010). Sry: the master switch in mammalian sex determination. Development 137:3921-3930 doi: 10.1242/dev.048983

Kocer, A., Gallozzi, M., Renault, L., Tilly, G., Pinheiro, L., Le Provost, F., et al. (2007). Goat PRND expression pattern suggests its involvement in early sex differentiation. Dev. Dyn. 236, 836-842. doi: 10.1002/dvdy.21066

Lee, I. Y., Westaway, D., Smit, A. F., Wang, K., Seto, J., Chen, L., et al. (1998). Complete genomic sequence and analysis of the prion protein gene region from three mammalian species. Genome Res. 8, 1022-1037.

Li, A., Sakaguchi, S., Shigematsu, K., Atarashi, R., Roy, B.C., Nakaoke, R., et al. (2000). Physiological expression of the gene for PrP-like protein, PrPLP/Dpl, by brain endothelial cells and its ectopic expression in neurons of PrP-deficient mice ataxic due to Purkinje cell degeneration. Am. J. Pathol.157, 1447-1452. doi: 10.1016/S0002-9440(10)64782-7

Makrinou, E., Collinge, J., and Antoniou, M. (2002). Genomic characterization of the human protein (PrP) gene locus. Mamm. Genome 13, 696-703. doi: 10.1007/s00335-002-3043-0

Manson, J. C., Clarke, A. R., Hopper, M. L., Aitchison, L., McConnell, I., and Hope, J. (1994). 129/Ola mice carrying a null mutation in PrP that abolishes mRNA production are developmentally normal. Mol. Neurobiol. 8, 121-127. doi: 10.1007/BF02780662

Moore, R. C., Lee, I. Y., Silverman, G. L., Harrison, P. M., Strome, R., Heinrich, C., et al. (1999). Ataxia in prion protein (PrP)-deficient mice is associated with upregulation of the novel PrP-like protein doppel. J. Mol. Biol. 292, 797-817. doi: 10.1006/jmbi.1999.3108

Moudjou, M., Frobert, Y., Grassi, J., and La Bonnardière, C. (2001). Cellular prion protein status in sheep: tissue-specific biochemical signatures. J. Gen. Virol. 82, 2017-2024. doi: 10.1099/vir.0.17776-0

Paisley, D., Banks, S., Selfridge, J., McLennan, N. F., Ritchie, A. M., McEwan, C., et al. (2004). Male infertility and DNA damage in Doppel knockout and prion protein/Doppel double-knoukout mice. Am. J. Pathol. 164, 2279-2288. doi: 10.1016/S0002-9440(10)63784-4

Passet, B., Young, R., Makhzami, S., Vilotte, M., Jaffrezic, F., Halliez, S., et al. (2012). Prion protein and Shadoo are involved in overlapping embryonic pathways and trophoblastic development. PLOS ONE 7:e41959. doi: 10.1371/journal.pone.0041959.

Peoc'h, K., Serres, C., Frobert, Y., Martin, C., Lehmann, S., Chasseigneaux, S., et al. (2002). The human "prion-like" protein Doppel is expressed in both Sertoli cells ans spermatozoa. J. Biol. Chem. 277, 43071-43078. doi: 10.1074/jbc.M206357200

Pimenta, J., Dias, F. M., Marques, C. C., Baptista, M. C., Vasques, M. I., Horta, A. E., et al. (2012a). The prion-like protein Doppel enhances ovine spermatozoa fertilizing ability. Reprod. Domest. Anim. 47, 196-202. doi: 10.1111/j.14390531.2011.01827.x

Pimenta, J., Domingos, A., Santos, P., Marques, C. C., Cantante, C., Santos, A., et al. (2012b). Is prnt a pseudogene? Identification of ram Prt in testis and ejaculated spermatozoa. PLoS ONE 7:e42957. doi: 10.1371/journal.pone. 0042957

Premzl, M., and Gamulin, V. (2007). Comparative genomic analysis of prion genes. BMC Genomics 8:1. doi: 10.1186/1471-2164-8-1 
Premzl, M., Gready, J. E., Jermiin, L. S., Simonic, T., and Marshall Graves, J. A. (2004). Evolution of vertebrate genes related to prion and shadoo proteinsclues from comparative genomic analysis. Mol. Bio. Evol. 21, 2210-2231. doi: $10.1093 / \mathrm{molbev} / \mathrm{msh} 245$

Premzl, M., Sangiorgio, L., Strumbo, B., Marshall Graves, J. A., Simonic, T., and Gready, J. E. (2003). Shadoo, a new protein highly conserved from fish to mammals and with similarity to prion protein. Gene 314, 89-102. doi: 10.1016/S0378-1119(03)00707-8

Prusiner, S. B. (1998). Prions. Proc. Natl. Acad. Sci. U.S.A. 95, 13363-13383. doi: 10.1073/pnas.95.23.13363

Rodriguez, H., Torres, C., Valdes, X., Guerra, H., Pastor, L. M., Maccallini, G., et al. (2001). The acrosomic reaction in stallion spermatozoa: inductive effect of the mare preovulatory follicular fluid. Biocell. 25, 115-120.

Rondena, M., Ceciliani, F., Comazzi, S., Pocacqua, V., Bazzocchi, C., Luvoni, C., et al. (2005). Identification of bovine doppel protein in testis, ovary and ejaculated spermatozoa. Theriogenology 63, 1195-1206. doi: 10.1016/j.theriogenology.2004.06.009

Saeki, K., Matsumoto, Y., Hirota, Y., Matsumoto, Y., and Onodera, T. (1996). Threeexon structure of the gene encoding the rat prion protein and its expression in tissues. Virus Genes 12, 15-20. doi: 10.1007/BF00369996

Schmitt-Ulms, G., Ehsani, S., Watts, J. C., Westaway, D., and Wille, H. (2009). Evolutionary descent of prion genes from the ZIP family of metal ion transporters. PLoS ONE 4:e7208. doi: 10.1371/journal.pone.0007208.

Serres, C., Peoc'h, K., Courtot, A. M., Lesaffre, C., Jouannet, P., and Laplanche, J. L. (2006). Spatio-developmental distribution of the prion-like protein doppel in Mammalian testis: a comparative analysis focusing on its presence in the acrosome of spermatids. Biol. Reprod. 74, 816-823. doi: 10.1095/biolreprod.105.047829

Shaked, Y., Rosenmann, H., Talmor, G., and Gabizon, R. (1999). A C-terminaltruncated $\operatorname{PrP}$ isoform is present in mature sperm. J. Biol. Chem. 274, 32153-32158. doi: 10.1074/jbc.274.45.32153

Sprando, R. L., and Russell, L. D. (1987). Comparative study of cytoplasmic elimination in spermatids of selected mammalian species. Am. J. Anat. 178, 72-80. doi: 10.1002/aja.1001780109

Tanji, K., Saeki, K., Matsumoto, Y., Takeda, M., Hirasawa, K., Doi, K., et al. (1995). Analysis of PRPc mRNA by in situ hybridization in brain, placenta, uterus and testis of rats. Intervirology 38, 309-315.

Tranulis, M. A., Espenes, A., Comincini, S., Skretting, G., and Harbitz, I. (2001). The PrP-like protein Doppel gene in sheep and cattle: cDNA sequence and expression. Mamm. Genome 12, 376-379. doi: 10.1007/s0033500 10285

Tuo, W., Zhuang, D., Knowles, D. P., Cheevers, W. P., Sy, M. S., and O’Rourke, K. I. (2001). Prp-c and Prp-sc at the fetal maternal interface. J. Biol. Chem. 276, 18229-18234. doi: 10.1074/jbc.M008887200

Watts, J. C., and Westaway, D. (2007). The prion protein family: diversity, rivalry, and dysfunction. Biochim. Biophys. Acta 1772, 654-672. doi: 10.1016/j.bbadis.2007.05.001

Weber, J. E., and Russell, L. D. (1987). A study of intercellular bridges during spermatogenesis in the rat. Am. J. Anat. 180, 1-24. doi: 10.1002/aja.1001800102 Westaway, D. (2004). "Inherited prion diseases," in Prion Biology and Diseases, ed S. B. Prusiner (New York, NY: Cold Spring Harbor Laboratory Press), 673-775.

Yoshimoto, J., Iinuma, T., Ishiguro, N., Horiuchi, M., Imamura, M., and Shinagawa M. (1992). Comparative sequence analysis and expression of bovine PrP gene in mouse L-929 cells. Virus Genes 6, 343-356. doi: 10.1007/BF01703083

Young, R., Le Guillou, S., Tilly, G., Passet, B., Castille, J., Beringue, V., et al. (2011). Generation of Sprn-regulated reporter mice reveals gonadic spatial expression of the prion-like protein Shadoo in mice. Biochem. Biophys. Res. Commun. 412, 752-756. doi: 10.1016/j.bbrc.2011.08.049

Zhao, L., Hao, J., Hu, J., Wang, Q., Lü, Z., Wang, L., et al. (2011). Expression of proliferin-related protein in testis and the biological significance in testosterone production. Mol. Cell. Endocrinol. 343, 25-31 doi: 10.1016/j.mce.2011.05.046

Conflict of Interest Statement: The authors declare that the research was conducted in the absence of any commercial or financial relationships that could be construed as a potential conflict of interest.

Received: 18 July 2014; accepted: 12 September 2014; published online: 02 October 2014.

Citation: Allais-Bonnet A and Pailhoux E (2014) Role of the prion protein family in the gonads. Front. Cell Dev. Biol. 2:56. doi: 10.3389/fcell.2014.00056

This article was submitted to Cell Death and Survival, a section of the journal Frontiers in Cell and Developmental Biology.

Copyright (c) 2014 Allais-Bonnet and Pailhoux. This is an open-access article distributed under the terms of the Creative Commons Attribution License (CC BY). The use, distribution or reproduction in other forums is permitted, provided the original author(s) or licensor are credited and that the original publication in this journal is cited, in accordance with accepted academic practice. No use, distribution or reproduction is permitted which does not comply with these terms. 


\title{
An emerging role of the cellular prion protein as a modulator of a morphogenetic program underlying epithelial-to-mesenchymal transition
}

\author{
Mohadeseh Mehrabian ${ }^{1,2}$, Sepehr Ehsani ${ }^{1,2+}$ and Gerold Schmitt-UIms ${ }^{1,2 *}$ \\ ${ }^{1}$ Tanz Centre for Research in Neurodegenerative Diseases, University of Toronto, Toronto, ON, Canada \\ ${ }^{2}$ Department of Laboratory Medicine and Pathobiology, University of Toronto, Toronto, ON, Canada
}

Edited by:

Sophie Mouillet-Richard, INSERM

Unit 1124, France

Reviewed by:

Séverine Martin-Lannerée,

Université Paris Descartes,

UMR-S1124, France

Edward Málaga-Trillo, University of

Konstanz, Germany

*Correspondence:

Gerold Schmitt-UIms, Tanz Centre for Research in Neurodegenerative Diseases, University of Toronto,

Krembil Discovery Tower, 60

Leonard Avenue, Toronto, ON M5T

2S8, Canada

e-mail:g.schmittulms@utoronto.ca

${ }^{t}$ Present address:

Sepehr Ehsani, Whitehead Institute

for Biomedical Research

Cambridge, MA, USA
Knowledge of phenotypic changes the cellular prion protein $\left(\operatorname{Pr} \mathrm{P}^{\mathrm{C}}\right)$ contributes to may provide novel avenues for understanding its function. Here we consider data from functional knockout/down studies and protein-protein interaction analyses from the perspective of PrP's relationship to its ancestral ZIP metal ion transporting proteins. When approached in this manner, a role of $\mathrm{PrPC}^{\mathrm{C}}$ as a modulator of a complex morphogenetic program that underlies epithelial-to-mesenchymal transition (EMT) emerges. To execute EMT, cells have to master the challenge to shift from cell-cell to cell-substrate modes of adherence. During this process, cell-cell junctions stabilized by E-cadherins are replaced by focal adhesions that mediate cell-substrate contacts. A similar reprogramming occurs during distinct organogenesis events that have been shown to rely on ZIP transporters. A model is presented that sees ZIP transporters, and possibly also PrPC, affect this balance of adherence modes at both the transcriptional and post-translational levels.

Keywords: epithelial-to-mesenchymal transition, function, phenotype, prion protein, ZIP transporter

\section{INTRODUCTION}

To someone new to the prion literature, it might be confusing that on the one hand some researchers lament the absence of a known function of the cellular prion protein $\left(\mathrm{PrP}^{\mathrm{C}}\right)$, while on the other hand, there seems to be a myriad of roles assigned to this protein (Steele et al., 2007; Aguzzi et al., 2008; ZomosaSignoret et al., 2008). Indeed, over the past few decades, mouse models harboring a deletion of the prion gene have revealed some interesting and highly diverse phenotypes, including (i) defects in the circadian rhythm (Tobler et al., 1996), (ii) abnormal development of infrapyramidal mossy fibers (Colling et al., 1997), (iii) a reduced capacity to generate hematopoietic stem cells (Zhang et al., 2006), and (iv) a peripheral neuropathy that is most conspicuously characterized by a myelin maintenance defect (Bremer et al., 2010). Due to the complex nature of the biology underlying any of these phenotypic changes, none of them immediately suggest how $\operatorname{PrP}^{\mathrm{C}}$ might be involved. It also does not help that each of them requires a unique environment not easily accessible by experimental means. The only phenotype for which a wealth of available data has provided a near-complete

Abbreviations: CRISPR, clustered regularly interspaced short palindromic repeats; EMT, epithelial-to-mesenchymal transition; FOI, Fear-Of-Intimacy; GSK$3 \beta$, glycogen synthase kinase 3 beta; MAP, mitogen-activated protein; NCAM, neural cell adhesion molecule; PL, PrP-like; $\operatorname{PrP}^{\mathrm{C}}$, cellular prion protein; SFK, $\mathrm{Src}$ family kinase; TGF $\beta$, transforming growth factor beta; ZIP, Zrt-, Irt-like Protein. molecular explanation constitutes the well-known resistance of PrP-knockout mice to infection with prion disease (Sailer et al., 1994).

This mini-review will add to this body of literature by shining a spotlight on the possibility that the prion protein may, in some cellular contexts, operate in signaling events that influence a shift from cell-cell to cell-substrate modes of adherence and play, for example, a critical role during EMT. In light of the emphasis of this special issue on research that explores the function of the prion protein, a brief clarification of terms and concepts may be helpful.

\section{THE PHYSIOLOGICAL ROLE OF A PROTEIN—PHENOTYPIC CHANGE vs. FUNCTION}

Although intuitively appealing, applying the concept of "function" to a protein can be a difficult undertaking. Any protein that emerges from ribosome-mediated translation enters into a unique molecular life-cycle that ultimately comes to an end when the protein is degraded. During this cycle, a protein encounters many other molecules that may impact its own biology. Some of these may, for instance, facilitate its post-translational maturation and folding or influence its sorting and trafficking. The consequences of molecular interactions may be equidirectional, orthogonal or opposite with regard to a specific outcome. They may also possess other characteristics that complicate their 
study; for example, they can be transient or long-lasting, and can qualitatively or quantitatively change over time. The net effect of these molecular interactions will not only depend on the physicochemical properties of the protein of interest itself, but also on the status of the cell or multicellular entity into which it was born. The latter will, in turn, be influenced by the characteristics and locations of all other molecules present at a given time. For example, there are several proteins (e.g., WNT5A, RACK1, SIRT1 and several F-box proteins) whose expression levels appear to correlate with the risk to acquire certain cancers, yet the same proteins have been observed to confer protection against cancers in other paradigms (McDonald and Silver, 2009; Lin and Fang, 2013; Li and Xie, 2014; Wang et al., 2014).

A phenotypic change caused by a protein can be discerned if its molecular interactions cumulatively change the biology of the experimental paradigm in a way that is detectable (Crusio, 2002). It follows that the description of such a phenotypic change only becomes meaningful if a precise account of the experimental paradigm is also provided.

What is the relationship between phenotypic change and function? The term "function" seems overused in the protein literature in general and the prion literature in particular. Here, the use of this term will be restricted to an immediate and contextindependent role of a protein (e.g., the capacity of substrate phosphorylation by a kinase) and will not be employed to capture the contribution of a protein to a broad and indirect phenotypic change (e.g., mitosis).

When viewed in this light, the body of literature dealing with functional assignments of the prion protein begins to look considerably less controversial. It comes as no surprise that a protein studied as extensively as $\operatorname{PrP}^{\mathrm{C}}$ has been observed to contribute to several biological processes that give rise to diverse phenotypes. While the phenotypic changes a protein causes are not to be confused with its function, once the function is known, it will hopefully reconcile a majority of these phenotypic changes with a consistent molecular and mechanistic explanation.

\section{EMT, YET ANOTHER PHENOTYPIC CHANGE THE PRION PROTEIN MAY CONTRIBUTE TO-BUT NOT ITS FUNCTION}

The term EMT refers to a complex morphogenetic reprogramming of cells observed during their transition from epithelial to mesenchymal phenotypes. EMT is naturally initiated in cells during distinct stages of development and wound healing (Lim and Thiery, 2012). Similar morphogenetic changes also take place during organogenesis and in pathological conditions, including fibrosis and cancers, where their occurrence most often correlates with a higher metastasis propensity (Thiery et al., 2009). During the EMT process, strong epithelial cell-to-cell contacts in the form of adherens junctions gradually give way to more transient cell-to-matrix connections evident in cultured cells (referred to as focal adhesions). As adherens junctions are dissolved, functional levels of E-cadherin, their main molecular constituent, are also reduced. Consequently, cells acquire a more fibroblastlike morphology and gradually rely on a more dynamic molecular network involving integrins for cell-matrix interactions (Lamouille et al., 2014). During the cellular reprogramming that accompanies EMT, the levels and/or activities of many molecules change (Figure 1).

The notion of an involvement of $\mathrm{PrP}^{\mathrm{C}}$ in the morphogenetic program underlying EMT emerged recently from several independent strands of investigation, including (1) observations in cancer paradigms that predominantly see a role of $\mathrm{PrP}^{\mathrm{C}}$ as a promoter of cellular invasiveness and malignancy; (2) morpholinobased manipulations of PrP levels undertaken in zebrafish; (3) a subset of available PrP protein-protein interaction data; and (4) commonalities between PrP and the subbranch of ZIP transporters from which it descended. Finally, pilot data generated in mammalian cells in which the expression of $\mathrm{PrP}^{\mathrm{C}}$ was eliminated using CRISPR/Cas gene editing tools (Hsu et al., 2014) are also consistent with a role of $\mathrm{PrP}^{\mathrm{C}}$ as a modulator of a cellular program that defines the balance between cell-cell and cell-substrate adhesion (unpublished observations, Schmitt-Ulms laboratory). Therefore, when asked to contribute to this special issue, we decided to take the opportunity to further investigate the merits of an involvement of $\mathrm{PrP}^{\mathrm{C}}$ in EMT based on published reports.

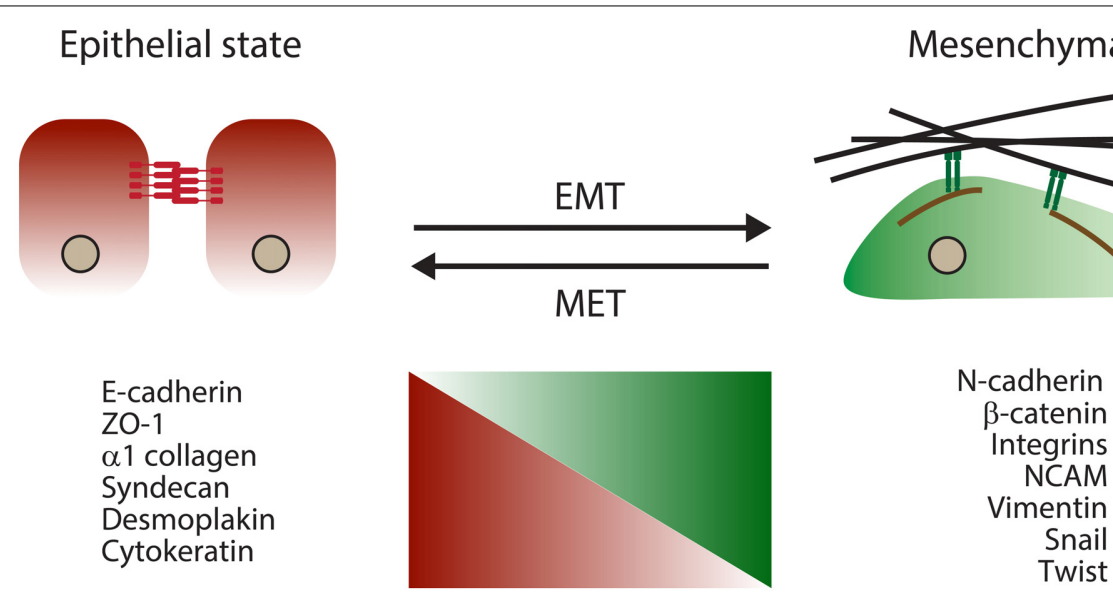

FIGURE 1 | Schematic outlining key morphological and molecular changes that accompany EMT. 
Needless to say, no claim is made that an involvement of $\mathrm{PrP}^{\mathrm{C}}$ in EMT, even if further substantiated experimentally, would represent its physiological function. Instead, it is hoped that this contribution might further stimulate research that may uncover the function of $\mathrm{PrP}^{\mathrm{C}}$.

\section{EVIDENCE FOR A ROLE OF PrPC IN EMT IN THE CANCER LITERATURE}

In light of the central role that EMT plays in the cellular biology that governs tumor malignancy, it may not be surprising that some support for a possible role of $\mathrm{PrP}^{\mathrm{C}}$ in $\mathrm{EMT}$ can be found in the cancer literature. Several groups have reported that the prion protein is upregulated in a subset of human cancers ranging from colorectal and gastric cancers to breast cancer and glioblastomas (Mehrpour and Codogno, 2010). Furthermore, a positive correlation has been reported between the upregulation of $\mathrm{PrP}^{\mathrm{C}}$ and the tumorigenicity of some cancer cells, suggestive of a more causative involvement. For instance, in one of the first reports that tied $\mathrm{PrP}^{\mathrm{C}}$ to cancer biology, the overexpression of $\mathrm{PrP}^{\mathrm{C}}$ was observed to promote invasive and metastatic properties of gastric cancer cell lines (Pan et al., 2006), and a more recent report suggested that high $\mathrm{PrP}^{\mathrm{C}}$ levels can be predictive of disease recurrence in colorectal cancers (Antonacopoulou et al., 2010). Overall, a broad consensus seems to be emerging that $\mathrm{PrP}^{\mathrm{C}}$ can promote key indicators of malignancy in several cancer paradigms. However, less information and agreement exist at this time on the signaling pathways and molecular events involved. Several observations suggest that $\operatorname{PrP}^{\mathrm{C}}$ may modulate signaling downstream of TGF $\beta$. For example, it was reported that $\mathrm{PrP}^{\mathrm{C}}$ promotes the release of certain matrix metalloproteinases (Pan et al., 2006; Wurm and Wechselberger, 2006) that are activated during TGF $\beta$ signaling and are known to promote the breakdown of the extracellular matrix, thereby leading to cell detachment. Also, researchers have proposed that the serine/threonine kinases Erk1/2 may play a critical role in the cancer-related signaling cascade emanating from $\operatorname{PrP}^{C}$. This conclusion was drawn on the basis of data documenting that small-molecule inhibitors against key components of the mitogen-activated protein (MAP) kinase signaling pathway were able to rescue invasive and metastatic characteristics contributed by $\operatorname{PrP}^{\mathrm{C}}$ (Pan et al., 2006; Du et al., 2013). Although an inverse relationship between $\mathrm{E}$-cadherin and $\mathrm{PrP}^{\mathrm{C}}$ levels has been observed (Du et al., 2013), whether this relationship is merely correlative or if $\mathrm{PrP}^{\mathrm{C}}$ causally influences E-cadherin biology has, to our knowledge, not yet been addressed in the aforementioned cancer paradigms.

\section{ZEBRAFISH PrP KNOCKDOWN MODELS}

To date, the most dramatic phenotypic change associated with PrP deficiency was not reported for the mouse prion protein but for one of its two orthologs in zebrafish (Malaga-Trillo et al., 2009). More specifically, the morpholino-based knockdown of PrP1 (but not PrP2) was observed to cause an arrest of zebrafish embryogenesis at the gastrula stage in the course of cellular rearrangements that rely on EMT. Interestingly, the PrP1-deficient embryos do not appear to suffer from an inability to initiate EMT; rather, they are impaired in their ability to fully execute a cell migration program that is limited to a small number of cells and requires re-establishing cellular contacts following their migration (Malaga-Trillo et al., 2009). Whereas in normal embryos PrP1 was shown to activate Src family kinases (SFKs) and modulate the post-transcriptional E-cadherin biology, both of these activities were impaired in PrP1-deficient embryos. A follow-up investigation revealed that several features within PrP1, including the repeat domain, globular domain, $\mathrm{N}$-glycosylation sites and GPI anchor attachment signal, influence the proper positioning of $\mathrm{PrP} 1$ at cell-cell contacts (Solis et al., 2013). Importantly, the phenotype does not appear to reflect a functional specialization or idiosyncrasy of zebrafish PrP1 because it could be rescued by the introduction of mammalian $\operatorname{PrP}^{\mathrm{C}}$ (Malaga-Trillo and Sempou, 2009; Malaga-Trillo et al., 2009).

\section{PROTEIN-PROTEIN INTERACTIONS OF PrPC WITH A KNOWN EMT CONNECTION}

Although there are divergent views regarding the significance of protein-protein interactions of $\mathrm{PrP}^{\mathrm{C}}$ (Watts and Westaway, 2007; Aguzzi et al., 2008; Rubenstein, 2012), there appears to be a broad consensus that $\mathrm{PrP}^{\mathrm{C}}$ exerts some of its biological role through its affiliation with caveolae and specialized membrane domains referred to as lipid rafts (Naslavsky et al., 1997; Mouillet-Richard et al., 2000). Furthermore, there is agreement that the molecular microenvironment of $\mathrm{PrP}^{\mathrm{C}}$ in neurons is dominated by cell adhesion molecules that include neural cell adhesion molecule (NCAM) (Walsh et al., 1989), L1, integrins and non-integrin laminin receptors known to modulate cell-to-substrate contacts (Gauczynski et al., 2001; Watts et al., 2009). Finally, there is a broad consensus that signals emanating from $\mathrm{PrP}^{\mathrm{C}}$ can lead to Fyn activation (Mouillet-Richard et al., 2000; Santuccione et al., 2005; Toni et al., 2006; Pantera et al., 2009; Tomasi, 2010; Um et al., 2012).

Several of these physiological interactors of the prion protein have been implicated in EMT. NCAM, for example, has recently been shown to be a critical regulator of EMT (Lehembre et al., 2008; Evseenko et al., 2010). Specifically, (i) increases in the levels of NCAM and (ii) a redistribution of NCAM that may involve its detachment from fibroblast growth factor (FGF) receptors and recruitment into caveolae and/or raft-like domains (Niethammer et al., 2002; Santuccione et al., 2005), have been recognized as early steps during EMT (Lehembre et al., 2008). Not surprisingly, these changes to the cellular NCAM pool and the concomitant upregulation of functional integrins occurring during EMT lead to increases in signaling through Fyn (Lehembre et al., 2008). Moreover, $\alpha \mathrm{V}$-containing integrins, another family of $\operatorname{PrP}^{\mathrm{C}}$ interactors (Watts et al., 2009), are critical for activation of the EMT master regulator TGF $\beta 1$ (Munger et al., 1999; Mu et al., 2002). Mice harboring point mutations in the $\alpha \mathrm{V}$ integrin "RGD" recognition motif within the TGF $\beta 1$ preprotein (TGF $\beta 1^{\mathrm{RGE} / \mathrm{RGE}}$ ) were shown to phenocopy TGF $\beta 1$-null mice (Yang et al., 2007). As an additional example, $\beta 1$ integrin- $\mathrm{L} 1$ complexes have long been known to play a role in controlling cellular migration processes. More recently, L1 has been linked to EMT and a molecular biology that determines cancer invasiveness (Kiefel et al., 2012). Thus, the stage, players and activities that $\operatorname{PrP}^{\mathrm{C}}$ is surrounded by are familiar to the research community studying EMT. 


\section{FUNCTION OF CLOSEST EVOLUTIONARY RELATIVES OF PrP}

Members of the mammalian prion protein family $\left(\mathrm{PrP}^{\mathrm{C}}, \mathrm{Dpl}\right.$ and Sho) were recently shown to have evolved from the family of ZIP (Zrt-, Irt-like Protein) metal ion transporters (SchmittUlms et al., 2009), with up to $30 \%$ amino acid sequence identity observed in some pair-wise comparisons of $\operatorname{PrP}$ and ZIP sequences. Subsequent work established that the founding event of the prion gene family coincided with the speciation of early vertebrates around 500 million years ago. This event relied on a genomic rearrangement that involved the retroinsertion of an ancient ZIP transcript and, probably, was mediated by retrotransposition elements (Ehsani et al., 2011). Amino acid sequence comparisons revealed that PrP is most similar to ZIPs 5, 6 and 10 , which constitute a distinct sub-branch within this gene family that consists of 14 paralogs in humans (Schmitt-Ulms et al., 2009). The primary cellular function of ZIP transporters is the import of zinc and other divalent cations into the cytosol (Lichten and Cousins, 2009). The PrP-like (PL) domains within ZIPs 5, 6 and 10 represent their $\mathrm{N}$-terminal ectodomains and resemble PrP with regard to orientation and relative distance to their downstream membrane anchorage sites. The PL domain most likely fulfills a role as a modulator of the cation import channel to which it is attached (Ehsani et al., 2012).

Interestingly, ZIP6 deficiency in zebrafish embryos has been reported to give rise to a gastrulation defect that is similar to the aforementioned defect observed in PrP1-deficient zebrafish (Yamashita et al., 2004). Subsequent work documented that manipulation of ZIP6 expression levels in mammalian cells leads to equidirectional changes in levels of E-cadherin expression (Shen et al., 2009). The close Drosophila ZIP ortholog Fear-OfIntimacy (FOI) (Mathews et al., 2005) has similarly been shown to play a role in EMT-like morphogenetic cell movements underlying both gonad and trachea formation (Godt and Tepass, 2003; Van Doren et al., 2003). More specifically, the zinc transport activity of FOI was shown to be essential for post-transcriptional stabilization of E-cadherin expression, with loss-of-function mutants of FOI leading to strongly reduced levels of functional E-cadherin. This did not preclude initiation of cell migration, but interfered with the coalescence of cells following their migration (Mathews et al., 2006). Additional support for the notion that ZIP proteins may affect EMT-like signaling came from a recent genetic report of a family afflicted with a subtype of myopia, a leading cause of blindness in humans, which identified a nonsense mutation in the ZIP5 gene to co-segregate with the phenotype (Guo et al., 2014). Follow-up biochemical work led the authors to observe that ZIP5 deficiency interfered with signaling downstream of TGF $\beta$.

\section{MODEL OF PrP/ZIP E-CADHERIN MODULATION}

Given that the knockdown of PrP1 or its molecular cousin ZIP6 gives rise to similar gastrulation defects in zebrafish, the question arises as to whether a primary role of the prion protein is to modulate ZIP-dependent cation import. The evolutionary relationship of PrP and ZIPs and the ability of ZIPs to interact with $\mathrm{PrP}^{\mathrm{C}}$ are consistent with such a model (Schmitt-Ulms et al., 2009). However, close scrutiny of the precise E-cadherin deficiencies in the respective knockdown phenotypes may suggest a more complex scenario. Whereas the zinc import function of the aforementioned ZIPs appears to reduce E-cadherin levels at the transcriptional level (Yamashita et al., 2004), PrP deficiency in zebrafish does not seem to interfere with E-cadherin transcription but may prevent E-cadherin from reaching the plasma membrane (Malaga-Trillo et al., 2009; Solis et al., 2013). Thus, PrP/ZIPs may influence functional E-cadherin levels by a coordinated transcriptional and post-translational regulation. A plausible scenario (Figure 2) sees the zinc import function of ZIPs regulate E-cadherin gene transcription, possibly by controlling the zinc-dependent nuclear translocation of certain transcription factors such as the zinc finger EMT master regulator Snail (Yamashita et al., 2004). This signaling pathway may involve glycogen synthase kinase 3 beta (GSK-3 $\beta$ ) (Hogstrand et al., 2013). PrP may also act as a modulator of this ZIP-dependent zinc import by acting as a scavenger or sensor of zinc ions (Watt et al., 2013), or on account of its ability to acquire alternative Nterminal folds in response to changes in its surrounding cation milieu (Chattopadhyay et al., 2005). Metal-dependent conformational changes of PrP could, for instance, modulate access of divalent cations to the ion channel present in a nearby ZIP protein, either by sterically blocking the channel or by exerting an influence on the arrangement of the channel transmembrane domains. On the other hand, PrP may serve a role in controlling functional E-cadherin levels post-translationally through the activation of Fyn (Lilien and Balsamo, 2005; Smyth et al., 2012). Assuming that PrP inherited this property from its ZIP ancestor, and that it can still be found in contemporary ZIP transporters equipped with a PL ectodomain, these ZIP molecules may operate as highly specialized regulators of EMT. It will be interesting to explore if the PL ectodomain of ZIPs can influence Fyn activation similar to PrP, and if such dual capability is at play in EMT paradigms that lack the prion protein. An example could be the process of gonad formation in Drosophila, where the ZIP para$\log$ FOI is known to play a critical role in modulating E-cadherin expression and stability (Jenkins et al., 2003; Van Doren et al., 2003; Mathews et al., 2006). Indeed, a first indication that FOI might influence E-cadherin biology at the transcriptional and post-translational levels emerged from elegant in vivo functional rescue experiments conducted with FOI-knockout flies. In contrast to the aforementioned ZIP6 zebrafish gastrulation paradigm, mutant zinc import-defective derivatives of FOI were, observed to exhibit reduced DE-cadherin expression. Significantly, forced expression of DE-cadherin from an unrelated tubulin promoter still did not lead to a functional rescue unless FOI was also present to ensure the post-translational stabilization of DE-cadherin (Mathews et al., 2006).

\section{CONCLUSIONS}

During the course of EMT, cells have to master the feat of gradually shifting their cell-cell and cell-substrate contacts from a stably adherent to a more transient and focal mode of attachment. The cellular program underlying these changes requires the concerted action of many molecules. Here we reviewed evidence consistent with the notion that members of the ZIP/PrP protein family may influence this program by affecting E-cadherin biology at multiple levels. It is likely that the cellular context will play a 


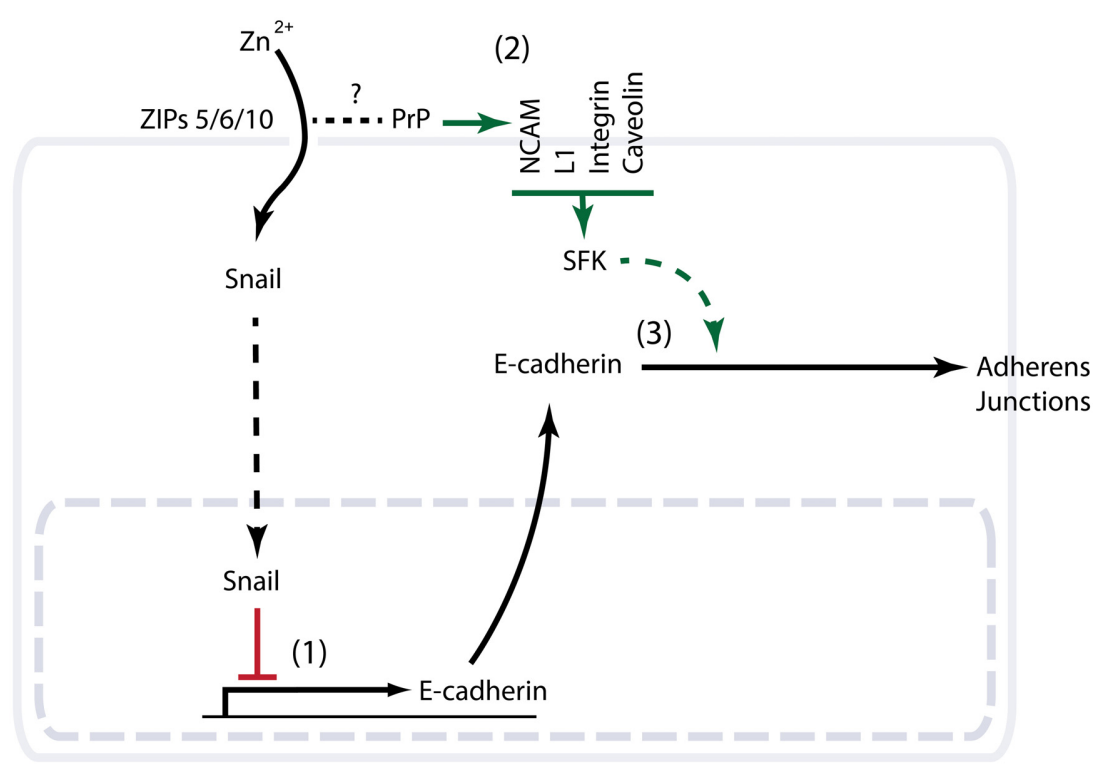

FIGURE 2 | Schematic summarizing evidence consistent with a role of

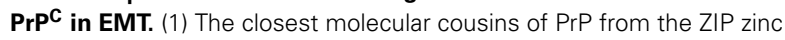
transporter family possess a documented role in EMT. Knockout or knockdown phenotypes of the respective ZIPs in zebrafish, Drosophila or mammalian cells demonstrate a critical role of ZIP-dependent zinc import in the transcriptional control of the E-cadherin gene. Note that whereas in the zebrafish EMT paradigm this transcriptional control is orchestrated by the
EMT master regulator Snail and suppresses E-cadherin expression, the zinc import function of the Drosophila FOI gene was observed to promote E-cadherin transcription during gonad organogenesis (not shown). (2) Multiple interactors of $\mathrm{PrPC}^{\mathrm{C}}$ with a known ability to modulate the activity of Fyn (a SrC family kinase) are independently known to play a role in EMT. (3) PrP knockdown in zebrafish is characterized by a gastrulation arrest phenotype with cytoplasmic accumulation of E-cadherin. critical role for the direction and extent to which the expression of ZIPs/PrP affects this biology. With the advent of novel genome editing technologies and advances in quantitative protein mass spectrometry, the involvement of PrP in EMT and related cellular processes can now be studied much more elegantly. It is to be expected that these efforts will in the not-too-distant future lead to a much more detailed understanding of the cellular pathways that underlie phenotypic changes observed in PrP knockout paradigms and, ultimately, reveal the molecular function of this protein.

\section{ACKNOWLEDGMENTS}

Work on this project was funded through support by the Canadian Institutes of Health Research and The W. Garfield Weston Foundation.

\section{REFERENCES}

Aguzzi, A., Baumann, F., and Bremer, J. (2008). The Prion's elusive reason for being. Annu. Rev. Neurosci. 31, 439-477. doi: 10.1146/annurev.neuro.31.060407. 125620

Antonacopoulou, A. G., Palli, M., Marousi, S., Dimitrakopoulos, F. I., Kyriakopoulou, U., Tsamandas, A. C., et al. (2010). Prion protein expression and the M129V polymorphism of the PRNP gene in patients with colorectal cancer. Mol. Carcinog. 49, 693-699. doi: 10.1002/mc.20642

Bremer, J., Baumann, F., Tiberi, C., Wessig, C., Fischer, H., Schwarz, P., et al. (2010). Axonal prion protein is required for peripheral myelin maintenance. Nat. Neurosci. 13, 310-318. doi: 10.1038/nn.2483

Chattopadhyay, M., Walter, E. D., Newell, D. J., Jackson, P. J., Aronoff-Spencer, E., Peisach, J., et al. (2005). The octarepeat domain of the prion protein binds $\mathrm{Cu}$ (II) with three distinct coordination modes at pH 7.4. J. Am. Chem. Soc. 127, 12647-12656. doi: 10.1021/ja053254z
Colling, S. B., Khana, M., Collinge, J., and Jefferys, J. G. (1997). Mossy fibre reorganization in the hippocampus of prion protein null mice. Brain Res. 755, 28-35. doi: 10.1016/S0006-8993(97)00087-5

Crusio, W. E. (2002). My mouse has no phenotype. Genes Brain Behav. 1, 71. doi: 10.1034/j.1601-183X.2002.10201.x

Du, L., Rao, G., Wang, H., Li, B., Tian, W., Cui, J. T., et al. (2013). CD44-positive cancer stem cells expressing cellular prion protein contribute to metastatic capacity in colorectal cancer. Cancer Res. 73, 2682-2694. doi: 10.1158/00085472.CAN-12-3759

Ehsani, S., Mehrabian, M., Pocanschi, C. L., and Schmitt-Ulms, G. (2012). The ZIP-prion connection. Prion 6, 317-321. doi: 10.4161/pri.20196

Ehsani, S., Tao, R., Pocanschi, C. L., Ren, H., Harrison, P. M., and Schmitt-Ulms, G. (2011). Evidence for retrogene origins of the prion gene family. PLoS ONE 6:e26800. doi: 10.1371/journal.pone.0026800

Evseenko, D., Zhu, Y., Schenke-Layland, K., Kuo, J., Latour, B., Ge, S., et al. (2010). Mapping the first stages of mesoderm commitment during differentiation of human embryonic stem cells. Proc. Natl. Acad. Sci. U.S.A. 107, 13742-13747. doi: 10.1073/pnas.1002077107

Gauczynski, S., Peyrin, J. M., Haik, S., Leucht, C., Hundt, C., Rieger, R., et al. (2001). The $37-\mathrm{kDa} / 67-\mathrm{kDa}$ laminin receptor acts as the cell-surface receptor for the cellular prion protein. EMBO J. 20, 5863-5875. doi: 10.1093/emboj/20. 21.5863

Godt, D., and Tepass, U. (2003). Organogenesis: keeping in touch with the germ cells. Curr. Biol. 13, R683-R685. doi: 10.1016/S0960-9822(03) 00609-2

Guo, H., Jin, X., Zhu, T., Wang, T., Tong, P., Tian, L., et al. (2014). SLC39A5 mutations interfering with the BMP/TGF-beta pathway in non-syndromic high myopia. J. Med. Genet. 51, 518-525. doi: 10.1136/jmedgenet-2014-102351

Hogstrand, C., Kille, P., Ackland, M. L., Hiscox, S., and Taylor, K. M. (2013). A mechanism for epithelial-mesenchymal transition and anoikis resistance in breast cancer triggered by Zinc channel zip 6 and signal transducer and activator of transcription 3 (STAT3). Biochem. J. 455, 229-237. doi: 10.1042/bj20130483

Hsu, P. D., Lander, E. S., and Zhang, F. (2014). Development and applications of CRISPR-Cas9 for genome engineering. Cell 157, 1262-1278. doi: 10.1016/j.cell.2014.05.010 
Jenkins, A. B., McCaffery, J. M., and Van Doren, M. (2003). Drosophila E-cadherin is essential for proper germ cell-soma interaction during gonad morphogenesis. Development 130, 4417-4426. doi: 10.1242/dev.00639

Kiefel, H., Bondong, S., Pfeifer, M., Schirmer, U., Erbe-Hoffmann, N., Schafer, H., et al. (2012). EMT-associated up-regulation of L1CAM provides insights into L1CAM-mediated integrin signalling and NF-kappaB activation. Carcinogenesis 33, 1919-1929. doi: 10.1093/carcin/bgs220

Lamouille, S., Xu, J., and Derynck, R. (2014). Molecular mechanisms of epithelial-mesenchymal transition. Nat. Rev. Mol. Cell Biol. 15, 178-196. doi: $10.1038 / \mathrm{nrm} 3758$

Lehembre, F., Yilmaz, M., Wicki, A., Schomber, T., Strittmatter, K., Ziegler, D., et al. (2008). NCAM-induced focal adhesion assembly: a functional switch upon loss of E-cadherin. EMBO J. 27, 2603-2615. doi: 10.1038/emboj.2008.178

Li, J. J., and Xie, D. (2014). RACK1, a versatile hub in cancer. Oncogene. doi: 10.1038/onc.2014.127. [Epub ahead of print].

Lichten, L. A., and Cousins, R. J. (2009). Mammalian zinc transporters: nutritional and physiologic regulation. Annu. Rev. Nutr. 29, 153-176. doi: 10.1146/annurevnutr-033009-083312

Lilien, J., and Balsamo, J. (2005). The regulation of cadherin-mediated adhesion by tyrosine phosphorylation/dephosphorylation of beta-catenin. Curr. Opin. Cell Biol. 17, 459-465. doi: 10.1016/j.ceb.2005.08.009

Lim, J., and Thiery, J. P. (2012). Epithelial-mesenchymal transitions: insights from development. Development 139, 3471-3486. doi: 10.1242/dev.071209

Lin, Z., and Fang, D. (2013). The Roles of SIRT1 in Cancer. Genes Cancer 4, 97-104. doi: $10.1177 / 1947601912475079$

Malaga-Trillo, E., and Sempou, E. (2009). PrPs: proteins with a purpose: lessons from the zebrafish. Prion 3, 129-133. doi: 10.4161/pri.3.3.9651

Malaga-Trillo, E., Solis, G. P., Schrock, Y., Geiss, C., Luncz, L., Thomanetz, V., et al. (2009). Regulation of embryonic cell adhesion by the prion protein. PLoS Biol. 7:e55. doi: 10.1371/journal.pbio.1000055

Mathews, W. R., Ong, D., Milutinovich, A. B., and Van Doren, M. (2006). Zinc transport activity of fear of Intimacy is essential for proper gonad morphogenesis and DE-cadherin expression. Development 133, 1143-1153. doi: $10.1242 /$ dev. 02256

Mathews, W. R., Wang, F., Eide, D. J., and Van Doren, M. (2005). Drosophila fear of intimacy encodes a Zrt/IRT-like protein (ZIP) family zinc transporter functionally related to mammalian ZIP proteins. J. Biol. Chem. 280, 787-795. doi: 10.1074/jbc.M411308200

McDonald, S. L., and Silver, A. (2009). The opposing roles of Wnt-5a in cancer. Br. J. Cancer 101, 209-214. doi: 10.1038/sj.bjc.6605174

Mehrpour, M., and Codogno, P. (2010). Prion protein: from physiology to cancer biology. Cancer Lett. 290, 1-23. doi: 10.1016/j.canlet.2009.07.009

Mouillet-Richard, S., Ermonval, M., Chebassier, C., Laplanche, J. L., Lehmann, S., Launay, J. M., et al. (2000). Signal transduction through prion protein. Science 289, 1925-1928. doi: 10.1126/science.289.5486.1925

Mu, D., Cambier, S., Fjellbirkeland, L., Baron, J. L., Munger, J. S., Kawakatsu, H., et al. (2002). The integrin alpha(v)beta8 mediates epithelial homeostasis through MT1-MMP-dependent activation of TGF-beta1. J. Cell Biol. 157, 493-507. doi: 10.1083/jcb.200109100

Munger, J. S., Huang, X., Kawakatsu, H., Griffiths, M. J., Dalton, S. L., Wu, J., et al. (1999). The integrin alpha v beta 6 binds and activates latent TGF beta 1: a mechanism for regulating pulmonary inflammation and fibrosis. Cell 96 , 319-328. doi: 10.1016/S0092-8674(00)80545-0

Naslavsky, N., Stein, R., Yanai, A., Friedlander, G., and Taraboulos, A. (1997). Characterization of detergent-insoluble complexes containing the cellular prion protein and its scrapie isoform. J. Biol. Chem. 272, 6324-6331. doi: $10.1074 /$ jbc. 272.10 .6324

Niethammer, P., Delling, M., Sytnyk, V., Dityatev, A., Fukami, K., and Schachner, M. (2002). Cosignaling of NCAM via lipid rafts and the FGF receptor is required for neuritogenesis. J. Cell Biol. 157, 521-532. doi: 10.1083/jcb.200109059

Pan, Y., Zhao, L., Liang, J., Liu, J., Shi, Y., Liu, N., et al. (2006). Cellular prion protein promotes invasion and metastasis of gastric cancer. FASEB J. 20, 1886-1888. doi: 10.1096/fj.06-6138fje

Pantera, B., Bini, C., Cirri, P., Paoli, P., Camici, G., Manao, G., et al. (2009). PrPc activation induces neurite outgrowth and differentiation in PC12 cells: role for caveolin-1 in the signal transduction pathway. J. Neurochem. 110, 194-207. doi: 10.1111/j.1471-4159.2009.06123.x

Rubenstein, R. (2012). Proteomic analysis of prion diseases: creating clarity or causing confusion? Electrophoresis 33, 3631-3643. doi: 10.1002/elps.201200310
Sailer, A., Bueler, H., Fischer, M., Aguzzi, A., and Weissmann, C. (1994). No propagation of prions in mice devoid of PrP. Cell 77, 967-968. doi: 10.1016/00928674(94)90436-7

Santuccione, A., Sytnyk, V., Leshchyns'ka, I., and Schachner, M. (2005). Prion protein recruits its neuronal receptor NCAM to lipid rafts to activate p59fyn and to enhance neurite outgrowth. J. Cell Biol. 169, 341-354. doi: 10.1083/jcb.200409127

Schmitt-Ulms, G., Ehsani, S., Watts, J. C., Westaway, D., and Wille, H. (2009). Evolutionary descent of prion genes from the ZIP family of metal ion transporters. PLOS ONE 4:e7208. doi: 10.1371/journal.pone.0007208

Shen, H., Qin, H., and Guo, J. (2009). Concordant correlation of LIV-1 and Ecadherin expression in human breast cancer cell MCF-7. Mol. Biol. Rep. 36, 653-659. doi: 10.1007/s11033-008-9225-4

Smyth, D., Leung, G., Fernando, M., and McKay, D. M. (2012). Reduced surface expression of epithelial E-cadherin evoked by interferon-gamma is Fyn kinasedependent. PLoS ONE 7:e38441. doi: 10.1371/journal.pone.0038441

Solis, G. P., Radon, Y., Sempou, E., Jechow, K., Stuermer, C. A., and MalagaTrillo, E. (2013). Conserved roles of the prion protein domains on subcellular localization and cell-cell adhesion. PLOS ONE 8:e70327. doi: 10.1371/journal.pone.0070327

Steele, A. D., Lindquist, S., and Aguzzi, A. (2007). The prion protein knockout mouse: a phenotype under challenge. Prion 1, 83-93. doi: 10.4161/pri.1.2.4346

Thiery, J. P., Acloque, H., Huang, R. Y., and Nieto, M. A. (2009). Epithelialmesenchymal transitions in development and disease. Cell 139, 871-890. doi: 10.1016/j.cell.2009.11.007

Tobler, I., Gaus, S. E., Deboer, T., Achermann, P., Fischer, M., Rulicke, T., et al. (1996). Altered circadian activity rhythms and sleep in mice devoid of prion protein. Nature 380, 639-642. doi: 10.1038/380639a0

Tomasi, V. (2010). Signal transduction in neurons: effects of cellular prion protein on fyn kinase and ERK1/2 kinase. Immun. Ageing 7, S5. doi: 10.1186/1742-49337-S1-S5

Toni, M., Spisni, E., Griffoni, C., Santi, S., Riccio, M., Lenaz, P., et al. (2006). Cellular prion protein and caveolin-1 interaction in a neuronal cell line precedes Fyn/Erk 1/2 signal transduction. J. Biomed. Biotechnol. 2006, 1-13. doi: 10.1155/JBB/2006/69469

Um, J. W., Nygaard, H. B., Heiss, J. K., Kostylev, M. A., Stagi, M., Vortmeyer, A., et al. (2012). Alzheimer amyloid-beta oligomer bound to postsynaptic prion protein activates Fyn to impair neurons. Nat. Neurosci. 15, 1227-1235. doi: 10.1038/nn.3178

Van Doren, M., Mathews, W. R., Samuels, M., Moore, L. A., Broihier, H. T., and Lehmann, R. (2003). Fear of intimacy encodes a novel transmembrane protein required for gonad morphogenesis in Drosophila. Development 130, 2355-2364. doi: 10.1242/dev.00454

Walsh, F. S., Parekh, R. B., Moore, S. E., Dickson, G., Barton, C. H., Gower, H. J., et al. (1989). Tissue specific O-linked glycosylation of the neural cell adhesion molecule (N-CAM). Development 105, 803-811.

Wang, Z., Liu, P., Inuzuka, H., and Wei, W. (2014). Roles of F-box proteins in cancer. Nat. Rev. Cancer 14, 233-247. doi: 10.1038/nrc3700

Watt, N. T., Griffiths, H. H., and Hooper, N. M. (2013). Neuronal zinc regulation and the prion protein. Prion 7, 203-208. doi: 10.4161/pri.24503

Watts, J. C., Huo, H., Bai, Y., Ehsani, S., Jeon, A. H., Shi, T., et al. (2009). Interactome analyses identify ties of $\mathrm{PrP}$ and its mammalian paralogs to oligomannosidic N-glycans and endoplasmic reticulum-derived chaperones. PLoS Pathog. 5:e1000608. doi: 10.1371/journal.ppat.1000608

Watts, J. C., and Westaway, D. (2007). The prion protein family: diversity, rivalry, and dysfunction. Biochim. Biophys. Acta 1772, 654-672. doi: 10.1016/j.bbadis.2007.05.001

Wurm, S., and Wechselberger, C. (2006). Prion protein modifies TGF-beta induced signal transduction. Biochem. Biophys. Res. Commun. 349, 525-532. doi: 10.1016/j.bbrc.2006.08.074

Yamashita, S., Miyagi, C., Fukada, T., Kagara, N., Che, Y. S., and Hirano, T. (2004). Zinc transporter LIVI controls epithelial-mesenchymal transition in zebrafish gastrula organizer. Nature 429, 298-302. doi: 10.1038/nature02545

Yang, Z., Mu, Z., Dabovic, B., Jurukovski, V., Yu, D., Sung, J., et al. (2007). Absence of integrin-mediated TGFbetal activation in vivo recapitulates the phenotype of TGFbeta1-null mice. J. Cell Biol. 176, 787-793. doi: 10.1083/jcb.2006 11044

Zhang, C. C., Steele, A. D., Lindquist, S., and Lodish, H. F. (2006). Prion protein is expressed on long-term repopulating hematopoietic stem cells and is 
important for their self-renewal. Proc. Natl. Acad. Sci. U.S.A. 103, 2184-2189. doi: $10.1073 /$ pnas. 0510577103

Zomosa-Signoret, V., Arnaud, J. D., Fontes, P., Alvarez-Martinez, M. T., and Liautard, J. P. (2008). Physiological role of the cellular prion protein. Vet. Res, 39, 9. doi: $10.1051 /$ vetres:2007048

Conflict of Interest Statement: The authors declare that the research was conducted in the absence of any commercial or financial relationships that could be construed as a potential conflict of interest.

Received: 27 June 2014; paper pending published: 16 July 2014; accepted: 03 September 2014; published online: 18 September 2014.
Citation: Mehrabian M, Ehsani S and Schmitt-Ulms G (2014) An emerging role of the cellular prion protein as a modulator of a morphogenetic program underlying epithelial-to-mesenchymal transition. Front. Cell Dev. Biol. 2:53. doi: 10.3389/fcell. 2014.00053

This article was submitted to Cell Death and Survival, a section of the journal Frontiers in Cell and Developmental Biology.

Copyright () 2014 Mehrabian, Ehsani and Schmitt-Ulms. This is an open-access article distributed under the terms of the Creative Commons Attribution License (CC BY). The use, distribution or reproduction in other forums is permitted, provided the original author(s) or licensor are credited and that the original publication in this journal is cited, in accordance with accepted academic practice. No use, distribution or reproduction is permitted which does not comply with these terms. 


\title{
PrPC from stem cells to cancer
}

\author{
Séverine Martin-Lannerée ${ }^{1,2}$, Théo Z. Hirsch ${ }^{1,2}$, Julia Hernandez-Rapp ${ }^{1,2,3}$, Sophie Halliez ${ }^{4}$, \\ Jean-Luc Vilotte ${ }^{5}$, Jean-Marie Launay ${ }^{6,7}$ and Sophie Mouillet-Richard ${ }^{1,2 *}$ \\ Toxicology, Pharmacology and Cellular Signaling, INSERM UMR-S1124, Paris, France \\ 2 Toxicology, Pharmacology and Cellular Signaling, Université Paris Descartes, Sorbonne Paris Cité, UMR-S1124, Paris, France \\ ${ }^{3}$ Université Paris Sud 11, ED419 Biosigne, Orsay, France \\ ${ }^{4}$ U892 Virologie et Immunologie Moléculaires, INRA, Jouy-en-Josas, France \\ ${ }^{5}$ UMR1313 Génétique Animale et Biologie Intégrative, INRA, Jouy-en-Josas, France \\ ${ }^{6}$ AP-HP Service de Biochimie, Fondation FondaMental, INSERM U942 Hôpital Lariboisière, Paris, France \\ 7 Pharma Research Department, F. Hoffmann-La-Roche Ltd., Basel, Switzerland
}

\section{Edited by:}

Craig Michael Walsh, University of California, Irvine, USA

\section{Reviewed by:}

Mario Cioce, New York University

Langone Medical Center, USA

Han-Ming Shen, National University

of Singapore, Singapore

*Correspondence:

Sophie Mouillet-Richard, Toxicology, Pharmacology and Cellular

Signaling, INSERM U-1124,

Université Paris Descartes, 45, rue des Saints Pères, 75006 Paris,

France

e-mail: sophie.mouillet-richard@ parisdescartes.fr
The cellular prion protein $\mathrm{PrP}^{\mathrm{C}}$ was initially discovered as the normal counterpart of the pathological scrapie prion protein PrPSc, the main component of the infectious agent of Transmissible Spongiform Encephalopathies. While clues as to the physiological function of this ubiquitous protein were greatly anticipated from the development of knockout animals, PrP-null mice turned out to be viable and to develop without major phenotypic abnormalities. Notwithstanding, the discovery that hematopoietic stem cells from PrP-null mice have impaired long-term repopulating potential has set the stage for investigating into the role of $\operatorname{PrP}^{C}$ in stem cell biology. A wealth of data have now exemplified that $\mathrm{PrP}^{\mathrm{C}}$ is expressed in distinct types of stem cells and regulates their self-renewal as well as their differentiation potential. A role for $\mathrm{PrPC}^{\mathrm{C}}$ in the fate restriction of embryonic stem cells has further been proposed. Paralleling these observations, an overexpression of $\operatorname{PrPC}$ has been documented in various types of tumors. In line with the contribution of $\operatorname{PrP}^{\mathrm{C}}$ to stemness and to the proliferation of cancer cells, $\operatorname{PrPC}^{\mathrm{C}}$ was recently found to be enriched in subpopulations of tumor-initiating cells. In the present review, we summarize the current knowledge of the role played by $\mathrm{PrPC}$ in stem cell biology and discuss how the subversion of its function may contribute to cancer progression.

Keywords: cellular prion protein, stem cell, cancer, self-renewal, cell fate specification, prion infection

\section{INTRODUCTION}

The discovery of the cellular prion protein $\operatorname{PrP}^{\mathrm{C}}$ dates back to 1985 with the identification that the scrapie prion protein $\mathrm{PrP}^{\mathrm{Sc}}$, the main component of the infectious agent responsible for Transmissible Spongiform Encephalopathies (TSEs) was encoded by a gene of the host, termed Prnp (Oesch et al., 1985). $\mathrm{PrP}^{\mathrm{C}}$ has been extensively scrutinized as the endogenous substrate for conversion into its pathogenic $\mathrm{PrP}^{\mathrm{Sc}}$ counterpart (Aguzzi and Calella, 2009), while studies on its physiological function have long been overlooked. At the molecular and cellular levels, it is well established that $\operatorname{PrP}^{\mathrm{C}}$ is anchored to the outer leaflet of the plasma membrane through a glycosyl-phosphatidylinositol (GPI) moiety (Linden et al., 2008). It may exist under a great diversity of isoforms as a result of heterogeneous glycosylation (Ermonval et al., 2003) and proteolytic cleavage (McDonald et al., 2014). Although it is suspected that the wide repertoire of $\operatorname{PrP}^{\mathrm{C}}$ species may endow the protein with the capacity to interact with multiple soluble ligands, extracellular matrix components or cell-surface proteins, the specific tissue distribution, and function of each isoform remain elusive (Linden et al., 2008). That research on $\mathrm{PrP}^{\mathrm{C}}$ function has lagged behind that of TSE pathophysiology may notably be explained by the lack of major abnormalities in PrP-null mice (Steele et al., 2007), whose most obvious phenotype is their resistance to TSE agents (Bueler et al., 1993). Because PrP is ubiquitously expressed and very much conserved in mammals, with Prnp orthologs identified in fish, birds, and reptiles (Premzl and Gamulin, 2007), the apparent normal phenotype of PrP null mice was quite unexpected and proposed to reflect the occurrence of compensatory mechanisms. One major contribution of these mice, however, was the demonstration that $\operatorname{PrP}^{\mathrm{C}}$ is mandatory for the long-term repopulating activity of hematopoietic stem cells (HSCs) (see below) (Zhang et al., 2006). This seminal report set the stage for investigating into the role exerted by $\operatorname{PrP}^{\mathrm{C}}$ in stem cell biology. Here, we provide an overview of the recent advances regarding the contribution of $\mathrm{PrP}^{\mathrm{C}}$ to stem cell biology and their pathophysiological implications.

\section{PrPC EXPRESSION AND ROLE DURING DEVELOPMENT}

Studies on $\operatorname{PrP}^{\mathrm{C}}$ have initially focused on the adult central nervous system (CNS), since it is the only target of $\mathrm{PrP}^{\mathrm{Sc}}$-associated toxicity (Aguzzi and Calella, 2009). Further, $\operatorname{PrP}^{\mathrm{C}}$ is most abundantly found in neurons (Linden et al., 2008). Notwithstanding, $\operatorname{PrP}^{\mathrm{C}}$ is highly expressed during embryonic development, as first shown by Manson et al. over two decades ago (Manson et al., 1992). This in situ hybridization analysis revealed widespread expression of Prnp transcripts in the developing central and 
peripheral nervous system at embryonic days E13.5 and E16.5, as well as in other tissues such as the intestine or the dental lamina (Manson et al., 1992). Prnp mRNA was also detected in extra-embryonic tissues from E6.5, pointing for the first time to a potential role for $\mathrm{PrP}^{\mathrm{C}}$ in the placenta, which has started to be accurately assessed recently (Alfaidy et al., 2012; Passet et al., 2012). These first data were refined with the detection of Prnp mRNA starting at E8.5-E9 in the differentiating neuroepithelium (Miele et al., 2003). The induction of Prnp expression at this stage in the developing CNS and heart was confirmed in a study using Prnp-LacZ reporter mice (Tremblay et al., 2007).

Based on this developmental pattern of expression, transcriptomic analyses were carried out on early Prnp knockout vs. wildtype (WT) embryos and revealed prominent alterations, with a total number of 263 genes differentially expressed at day E7.5 (Khalife et al., 2011). The array of genes with altered expression notably includes a set of growth factors and growth factor receptors, supporting the notion that $\mathrm{PrP}^{\mathrm{C}}$ plays an important role in the regulation of cascades associated with embryonic development (Khalife et al., 2011). Interestingly, the pattern of pathways affected overlaps with that obtained after early embryonic gene expression profiling of zebrafish PrP2 morphants (NourizadehLillabadi et al., 2010).

The zebrafish model actually allowed bringing to light a vital function for $\mathrm{PrP}^{\mathrm{C}}$ since morpholino-mediated knockdown of the PrP ortholog PrP1 in this species leads to loss of embryonic cell adhesion and gastrulation arrest (Malaga-Trillo et al., 2009). Of note, the defects observed could be rescued with mouse Prnp mRNA, indicating that this function is evolutionary conserved (Malaga-Trillo et al., 2009). Thus, the overall data gained at the animal scale argue that $\mathrm{PrP}^{\mathrm{C}}$ fulfills an important function during embryogenesis and that its ablation in mice triggers the implementation of yet-to-be-deciphered compensatory mechanisms.

\section{PrPC REgULATES THE SELF-RENEWAL OF STEM/PROGENITOR CELLS}

The link between $\mathrm{PrP}^{\mathrm{C}}$ and stem cell biology was first uncovered in HSCs. Investigations of $\mathrm{PrP}^{\mathrm{C}}$ in the hematopoietic system were initially prompted by the observation that $\mathrm{PrP}^{\mathrm{Sc}}$ accumulates in lymphoid organs and by the quest to understand the cellular mechanisms sustaining prion propagation in the periphery (Mabbott and MacPherson, 2006). These studies demonstrated that $\mathrm{PrP}^{\mathrm{C}}$ is highly expressed at the surface of various hematopoietic cells, including B and T lymphocytes, monocytes, dendritic cells, megakaryocytes and platelets, but not erythrocytes or granulocytes (Linden et al., 2008). In the human bone marrow, $\mathrm{PrP}^{\mathrm{C}}$ was found to be present in the $\mathrm{CD}_{3} 4^{+}$stem / progenitor cell population (Dodelet and Cashman, 1998) and to be preferentially expressed on murine $\mathrm{CD}_{4} 3^{+}, \mathrm{B} 220^{-}, \mathrm{IL}_{-} 7 \mathrm{R}^{-}$cells, enriched in immature progenitors (Liu et al., 2001). A major advance was the discovery by the team of Lodish that $\operatorname{PrP}^{\mathrm{C}}$ is very abundant at the surface of mouse bone marrow $\mathrm{Lin}^{-} \mathrm{Sca}^{+}$Endoglin ${ }^{+}$cells, a population comprising immature HSCs (Zhang et al., 2006). These authors then assessed the ability of bone marrow-derived $\mathrm{Lin}^{-} \mathrm{Sca}^{+}$Endoglin ${ }^{+}$cells from Prnp knockout mice to reconstitute the hematopoietic system of lethally irradiated mice in serial transplantation assays, and demonstrated that HSCs from Prnp null mice lack long-term repopulating activity (see Table 1) (Zhang et al., 2006). These experiments further allowed substantiating that the $\mathrm{Lin}^{-} \mathrm{Sca}^{+}$Endoglin ${ }^{+}$cell population endowed with long-term repopulating activity is $\mathrm{PrP}^{\mathrm{C}}$ positive (Zhang et al., 2006).

Much like HSCs, neuroepithelial stem cells have the capacity to proliferate through repeated symmetric divisions and generate radial glial cells, which then undergo asymmetric division and give rise to neurons, oligodendrocytes, and astrocytes (Gotz and Huttner, 2005). The proper proceeding of these expansive and neurogenic phases is crucial for the development of the CNS. By comparing neural stem cells isolated from Prnp knockout, WT or PrP overexpressing mice at embryonic day 13.5, Steele et al. documented that $\mathrm{PrP}^{\mathrm{C}}$ levels directly increase the differentiation rate of multipotent neural precursor cells (Steele et al., 2006). In the same study, $\operatorname{PrP}^{\mathrm{C}}$ expression levels were further found to correlate with the proliferation rate in the two adult neurogenic regions, the subventricular zone (SVZ) or the dentate gyrus (DG) (Steele et al., 2006). The latter finding was corroborated by two independent studies showing that the formation of neurospheres from fetal (Santos et al., 2011) or postnatal (Prodromidou et al., 2014) brains is less efficient with Prnp knockout than WT mice.

The notion that $\mathrm{PrP}^{\mathrm{C}}$ contributes to the proliferation of stem cells extends beyond hematopoietic and neural stem cells. Indeed, the level of $\mathrm{PrP}^{\mathrm{C}}$ was found to serve as an effective cell surface marker for self-renewing mammary gland stem cells in mice (Liao et al., 2007). More recently, $\operatorname{PrP}^{\mathrm{C}}$ was further shown to promote the expansion and engraftment of bone marrow-derived human mesenchymal stem cells (MSCs) (Mohanty et al., 2012). Finally, $\mathrm{PrP}^{\mathrm{C}}$ was shown to exert either an anti- or a pro-proliferative effect in human embryonic stem (ES) cells, depending on whether they are grown under self-renewing or differentiating conditions, respectively (Lee and Baskakov, 2012).

\section{PrPC INFLUENCES STEM CELL FATE}

The identification of $\mathrm{PrP}^{\mathrm{C}}$ as a broad cell surface marker for stem / progenitor cells raises the question as to whether the expression of $\mathrm{PrP}^{\mathrm{C}}$ is a determinant of the stem cell fate. In this respect, we (Mouillet-Richard et al., 1999) and others (Peralta et al., 2011) have provided evidence that $\operatorname{PrP}^{C}$ is upregulated following the cell fate restriction of multipotential ES or embryonic carcinoma (EC) cells toward the neuronal lineage. Similarly, $\operatorname{PrP}^{\mathrm{C}}$ is induced in ES-derived cardiomyogenic progenitors obtained after embryoid body (EB) formation (Hidaka et al., 2010). In line with this, the expression of $\mathrm{PrP}^{\mathrm{C}}$ was found to be increased during spontaneous differentiation of mouse and human ES cells (Lee and Baskakov, 2010; Miranda et al., 2011) and, reciprocally, induction of $\mathrm{PrP}^{\mathrm{C}}$ in human $\mathrm{ES}$ cells grown under self-renewal conditions was shown to promote their differentiation (Lee and Baskakov, 2012). Intriguingly, exposure of ES cells to recombinant PrP delays their spontaneous differentiation (Lee and Baskakov, 2010). In view of the early expression of $\operatorname{PrP}^{C}$ in extra-embryonic tissues, it is tempting to speculate that placentaderived $\mathrm{PrP}^{\mathrm{C}}$ may serve as a paracrine signal to maintain the self-renewal of inner mass cells, until their appropriate induction toward either of the three lineages. 
Table 1 | Summary of effects of PrPC depletion on stem and progenitor cells.

\begin{tabular}{|c|c|c|}
\hline Cell type/tissue & $\mathrm{PrP}^{\mathrm{C}}$-null/KD vs. wt & References \\
\hline ES & Increased apoptosis in embryoid bodies & Miranda et al., 2011 \\
\hline Multipotent neural precursors E13.5 (telencephalon) & Delayed neuronal differentiation & Steele et al., 2006 \\
\hline $\begin{array}{l}\text { E16.5 oligodendrocyte precursor cells (OPC) in optic } \\
\text { nerve explants }\end{array}$ & Increased proliferation (BrdU incorporation) & Bribian et al., 2012 \\
\hline E16.5 neocortex & Increased $\mathrm{NG}^{+}{ }^{+} \mathrm{Olig}^{+}{ }^{+} \mathrm{OPC}$ & Bribian et al., 2012 \\
\hline P0-P2 cortical OPC primary culture & Delayed differentiation & Bribian et al., 2012 \\
\hline P5 neurospheres isolated from SVZ & $\begin{array}{l}\text { Reduced proliferation (BrdU incorporation) and } \\
\text { secondary neurosphere formation }\end{array}$ & Prodromidou et al., 2014 \\
\hline Neocortex & Increased $\mathrm{NG}^{+}{ }^{+} \mathrm{Olig}_{2}+\mathrm{OPC}$ & Bribian et al., 2012 \\
\hline SVZ & $\begin{array}{l}\text { Reduction of cycling GFAP }{ }^{+} \text {neural stem cells } \\
\text { Decreased Mash }{ }^{+} \text {progenitors and accumulation } \\
\text { of proliferating neuroblasts } \mathrm{DCX}^{+}\end{array}$ & Prodromidou et al., 2014 \\
\hline HSC & $\begin{array}{l}\text { Loss of long-term repopulating activity in serial } \\
\text { transplantation assays }\end{array}$ & Zhang et al., 2006 \\
\hline Skeletal muscle & $\begin{array}{l}\text { Delayed regeneration after injury (retarded exit } \\
\text { from the cell cycle of myogenic precursor cells) }\end{array}$ & Stella et al., 2010 \\
\hline Human MSC & $\begin{array}{l}\text { Reduced clonogenic potential, proliferation and } \\
\text { differentiation }\end{array}$ & Mohanty et al., 2012 \\
\hline
\end{tabular}

Beyond lineage specification, the regulation of $\mathrm{PrP}^{\mathrm{C}}$ expression also accompanies differentiation toward a given fate. Along the hematopoietic lineage, $\operatorname{PrP}^{\mathrm{C}}$ appears to be downregulated upon differentiation of $\mathrm{CD}_{3} 4^{+}$progenitors toward a granulocytic fate, while its expression is retained in $\mathrm{B}$ and $\mathrm{T}$ lymphocytes as well as monocytes (Dodelet and Cashman, 1998). In addition, $\mathrm{PrP}^{\mathrm{C}}$ is absent from erythrocytes (Dodelet and Cashman, 1998) and abundant in megakaryocytes and platelets (Starke et al., 2005), suggesting that the expression of $\mathrm{PrP}^{\mathrm{C}}$ is switched off with the commitment of megakaryocytic-erythrocytic progenitors toward the erythroid fate, or is decreased along erythroid differentiation, in line with (Panigaj et al., 2011).

As for neural progenitor cells, the expression of $\operatorname{PrP}^{\mathrm{C}}$ was reported to be increased along neuronal differentiation, while barely detected in astrocytes or oligodendrocytes (Steele et al., 2006). This high neuronal $\operatorname{PrP}^{C}$ expression is in line with the well-documented contribution of $\mathrm{PrP}^{\mathrm{C}}$ to neuronal differentiation, including neurite outgrowth (Chen et al., 2003; Santuccione et al., 2005; Loubet et al., 2012; Santos et al., 2013) or synapse maturation (Kanaani et al., 2005). The lack of $\operatorname{PrP}^{\mathrm{C}}$ detection in differentiating oligodendrocytes and astrocytes in the study by Steele et al. (2006) is, however, in contrast with several reports documenting an abundant $\mathrm{PrP}^{\mathrm{C}}$ expression in these two cell types in late embryos or in the postnatal brain (Moser et al., 1995; Lima et al., 2007; Bribian et al., 2012). Interestingly, both oligodendrocytic (Bribian et al., 2012) and astrocytic (Arantes et al., 2009) differentiation kinetics appear to be delayed in Prnp knockout mice. These observations recall the delay in neuronal differentiation, as initially reported by Steele et al. (2006), as well as the slower regeneration of muscle after injury (Stella et al., 2010) in a PrP null context. Whether $\mathrm{PrP}^{\mathrm{C}}$ expression affects the balance from one fate to another remains, however, to be investigated. In this regard, it is worth noting that prion infection in adult neural stem cells (NSCs) favors the differentiation toward the glial lineage at the expense of neuronal differentiation (Relaño-Ginés et al., 2013).

\section{STEM CELLS AND PRION REPLICATION}

Whether stem cells are susceptible to prion infection may at first seem a question without relevance, since TSEs are neurodegenerative diseases. However, as rightly underlined in the study by Relaño-Ginés (Relaño-Ginés et al., 2013), exploiting the potential of adult NSCs is currently considered as a promising avenue to mitigate neurodegeneration (Bellenchi et al., 2013). While several studies had reported an efficient replication of $\mathrm{PrP}^{\mathrm{Sc}}$ in neurospheres isolated from fetal brain (Milhavet et al., 2006; Herva et al., 2010), the susceptibility of adult NSC toward prion infection has been evaluated only recently. In line with the results obtained with embryonic-derived cultures, neurospheres isolated from the SVZ or the DG of adult mice were shown to support prion replication (Relaño-Ginés et al., 2013). The same study further documented the presence of dense $\mathrm{PrP}^{\mathrm{Sc}}$ deposits in the 
DG and the SVZ of prion-infected mice, indicating that prions colonize adult NSCs, the brain's endogenous repair machinery (Relaño-Ginés et al., 2013, 2014). Of note, prion replication of adult NSCs was found to impair neuronal differentiation, both in vitro and in vivo (Relaño-Ginés et al., 2013). Thus, in addition to constituting a reservoir of $\mathrm{PrP}^{\mathrm{Sc}}$, the replication of prions in adult NSCs may also compromise the regeneration of damaged neurons. Finally, because $\mathrm{PrP}^{\mathrm{Sc}}$ is known to deviate the normal function of $\operatorname{PrP}^{\mathrm{C}}$ (Westergard et al., 2007; Pradines et al., 2013), these observations suggest that studying the impact of prion infection on the self-renewal and fate of NSCs may improve our understanding of the physiological role exerted by $\operatorname{PrP}^{\mathrm{C}}$ in these processes.

\section{PrPC ${ }_{\text {-DEPENDENT CONTROL OF STEM CELL SELF-RENEWAL }}$ AND FATE: MECHANISTIC INSIGHT}

Notwithstanding the well-established involvement of $\mathrm{PrP}^{\mathrm{C}}$ in the self-renewal of diverse types of stem /progenitor cells, the molecular mechanisms at play remain obscure. One possible mode of action of $\mathrm{PrP}^{\mathrm{C}}$ would be through the interaction with one of its ligands. This view is clearly supported by the demonstration that the binding of $\mathrm{PrP}^{\mathrm{C}}$ with STI-1 is critical for the formation and proliferation of neurospheres cultured from fetal forebrain (Santos et al., 2011). While several signaling cascades elicited by the interaction of STI- 1 with $\operatorname{PrP}^{\mathrm{C}}$ have been described in a neuronal context (Hirsch et al., 2014), the pathways mobilized to sustain neurosphere self-renewal and proliferation have not been analyzed so far (Santos et al., 2011). On another hand, the presence of $\mathrm{PrP}^{\mathrm{C}}$ on neurospheres was recently shown to be required for NCAM-induced neuronal differentiation (Prodromidou et al., 2014). These two sets of observations raise the question as to the $\mathrm{PrP}^{\mathrm{C}}$ isoforms that respectively bind STI-1 and NCAM, since these two molecules instruct distinct responses. Another $\mathrm{PrP}^{\mathrm{C}}$ partner that may have relevance to stem cell biology is the amyloid precursor protein APP, whose functional interaction with PrP in the zebrafish modulates cell adhesion and CNS development (Kaiser et al., 2012). Whether the APP-PrPC interaction is involved in the regulation of E-cadherin-dependent adhesion in zebrafish embryos deserves further investigation (Malaga-Trillo et al., 2009). Interestingly, our own studies on a neuroectodermal stem cell line also substantiate a disruption of cadherinmediated cell contacts upon $\mathrm{PrP}^{\mathrm{C}}$ depletion (Martin-Lannerée et al., unpublished observations). It is of note that cell adhesion processes are now recognized as major determinants of stem cell biology in relation with their local microenvironment (stem cell niche) (Marthiens et al., 2010). By affecting adhesion properties of stem cells, the depletion of $\mathrm{PrP}^{\mathrm{C}}$ may thus in turn impact on their retention, self-renewal or exit from their niche.

\section{A ROLE FOR PrPC IN CANCER STEM CELLS?}

The contribution of $\mathrm{PrP}^{\mathrm{C}}$ to cell proliferation appears to apply to many cell types beyond stem/progenitor cells. These notably include cancer cells, as first demonstrated in gastric tumor cell lines (Liang et al., 2007a). In these cells, $\mathrm{PrP}^{\mathrm{C}}$ was shown to accelerate the G1 to $S$ phase transition in the cell cycle and to sustain proliferation by inducing the expression of Cyclin D1 through a PI3K/Akt pathway (Liang et al., 2007a). The $\mathrm{PrP}^{\mathrm{C}}$-interacting protein(s) involved in this cascade remain(s), however, to be identified. Beyond proliferation, $\operatorname{PrP}^{\mathrm{C}}$ overexpression in cancer cells was further shown to confer resistance to various cytotoxic agents (Mehrpour and Codogno, 2010) as well as invasive properties (Pan et al., 2006). For instance, $\mathrm{PrP}^{\mathrm{C}}$ levels were shown to correlate with resistance to $\mathrm{TNF} \alpha$-induced cell death in the MCF-7 breast cancer cell line (Diarra-Mehrpour et al., 2004). Very recently, $\operatorname{PrP}^{\mathrm{C}}$ was found to interact with the cell surface protein CD44 in adriamycin-resistant breast cancer cells, and to promote their proliferation and migration (Cheng et al., 2013). Interestingly, CD44 has been reported to be enriched at the cell surface of various types of tumor-initiating cells, which bear similarities with embryonic or adult stem cells and are often referred to as cancer stem cells (CSCs) (Medema, 2013). It is also noteworthy that CSCs have been associated with increased resistance to antitumor treatments (Singh and Settleman, 2010). In line with the above-mentioned role of $\mathrm{PrP}^{\mathrm{C}}$ in the self-renewal of stem cells, $\mathrm{Du}$ et al. depicted a population of $\mathrm{CD} 44^{+} \mathrm{PrP}^{\mathrm{C}+}$ cells from primary colorectal tumors endowed with enhanced tumor-initiating and metastatic capacity (Du et al., 2013). At a mechanistic level, $\mathrm{PrP}^{\mathrm{C}}$ was shown to promote an epithelial to mesenchymal transition (EMT) through the regulation of the Twist transcription factor (Du et al., 2013). These observations are in agreement with the notion that the emergence of CSCs and EMT are intimately connected (Singh and Settleman, 2010).

A still unresolved question concerns the molecular mechanisms sustaining the enhanced expression of $\operatorname{PrP}^{\mathrm{C}}$ in cancer cells. $\mathrm{PrP}^{\mathrm{C}}$ expression has been shown to be increased in response to hypoxia in gastric cancer cell lines (Liang et al., 2007b). Other $\mathrm{PrP}^{\mathrm{C}}$-inducing signals include oxidative (Sauer et al., 1999) and endoplasmic-reticulum (Dery et al., 2013) stresses. Some deregulation of $\mathrm{PrP}^{\mathrm{C}}$ function may also arise with aging. Indeed, $\mathrm{PrP}^{\mathrm{C}}$ was recently shown to accumulate in lipid rafts in the mouse aging brain (Agostini et al., 2013). Whether this change in $\operatorname{PrP}^{C}$ distribution also occurs in other tissues with aging is worth considering, since it would potentially impact on the recruitment of downstream signaling cascades. As observed in the context of neurodegeneration (Hirsch et al., 2014), the subversion of $\operatorname{PrP}^{C}$ function may over-activate src kinases and further promote alterations in lipid raft-initiated signaling pathways, known to be detrimental in cancer (Patra, 2008). Such changes may in turn have consequences on the cell local environment, and, in the case of stem cells, deregulate the interactions with their niche. This scenario is considered as a potential cause of CSCs emergence (Rezza et al., 2014), and this may have particular relevance with respect to aging.

\section{OPEN QUESTIONS AND THERAPEUTIC PROSPECTS}

Harnessing the self-renewal and differentiation potential of stem cells represents a major challenge for regenerative medicine. The recent accumulation of data regarding the involvement of $\mathrm{PrP}^{\mathrm{C}}$ in stem cell biology warrants further studying the molecular and cellular mechanisms sustaining the contribution of this protein to the proliferation of stem cells, their maintenance in an undifferentiated state, their capacity to respond to fate determination inputs and to implement a given differentiation program. Achieving this task is complicated by the multiplicity of $\mathrm{PrP}^{\mathrm{C}}$ isoforms and 
partners, which may fulfill promiscuous functions. That $\operatorname{PrP}^{\mathrm{C}}$ is required for efficient tissue repair after injury is clearly indicated in the context of bone-marrow reconstitution (Zhang et al., 2006) or muscle regeneration (Stella et al., 2010), which suggest that the mobilization of $\mathrm{PrP}^{\mathrm{C}}$-dependent cascades via appropriate ligands may provide a fruitful approach to enhance the regeneration of lesionned tissues. As a prerequisite, manipulating conditions would need to be carefully adjusted in order to control activating signals, given the pathological implications that may ensue from $\operatorname{PrP}^{\mathrm{C}}$ over-activation.

Finally, the emerging roles of $\mathrm{PrP}^{\mathrm{C}}$ in stemness on the one hand and in various aspects of cancer cell biology on the other hand bring new light on this already fascinating molecule. Given the relationship between stem cells and oncogenesis, advance in the understanding of the role played by $\operatorname{PrP}^{\mathrm{C}}$ in stem cells is likely to illuminate the issue of its contribution to tumorigenesis and vice-versa. One major remaining challenge is to decipher the mechanisms controlling the expression levels of $\operatorname{PrP}^{\mathrm{C}}$ in normal and cancer stem cells. While the cues underlying the induction of $\operatorname{PrP}^{\mathrm{C}}$ during embryonic development are elusive, several cancer-associated conditions, including hypoxia (Liang et al., 2007b), oxidative (Sauer et al., 1999) or endoplasmic reticulum (Dery et al., 2013) stresses have been reported to activate $\operatorname{PrP}^{\mathrm{C}}$ transcription. More broadly, increasing our knowledge of the regulation of PrP gene expression may help design novel strategies for therapeutic intervention in cancer, beyond directly targeting $\mathrm{PrP}^{\mathrm{C}}$ through antisense oligonucleotides (Meslin et al., 2007) or monoclonal antibodies (Du et al., 2013).

To conclude, progress in the stem cell and cancer fields should increase our knowledge of how $\mathrm{PrP}^{\mathrm{C}}$, as a cell surface receptor or co-receptor, connects cells with their environment to drive adaptive, homeostatic responses and how this function is corrupted in disease-associated states.

\section{ACKNOWLEDGMENTS}

We apologize to colleagues in the field whose work we were unable to cite owing to space limitations. We acknowledge financial support from the ARC, INSERM, as well as the Region Ile de France (DIM-Stem Pôle).

\section{REFERENCES}

Agostini, F., Dotti, C. G., Perez-Canamas, A., Ledesma, M. D., Benetti, F., and Legname, G. (2013). Prion protein accumulation in lipid rafts of mouse aging brain. PLoS ONE 8:e74244. doi: 10.1371/journal.pone.0074244

Aguzzi, A., and Calella, A. M. (2009). Prions: protein aggregation and infectious diseases. Physiol. Rev. 89, 1105-1152. doi: 10.1152/physrev.00006.2009

Alfaidy, N., Chauvet, S., Andrei, S., Salomon, A., Saoudi, Y., Richaud, P., et al. (2012). Prion protein expression and functional importance in developmental angiogenesis: role in oxidative stress and copper homeostasis. Antioxid. Redox Signal. 18, 400-411. doi: 10.1089/ars.2012.4637

Arantes, C., Nomizo, R., Lopes, M. H., Hajj, G. N., Lima, F. R., and Martins, V. R. (2009). Prion protein and its ligand stress inducible protein 1 regulate astrocyte development. Glia 57, 1439-1449. doi: 10.1002/glia.20861

Bellenchi, G. C., Volpicelli, F., Piscopo, V., Perrone-Capano, C., and di Porzio, U. (2013). Adult neural stem cells: an endogenous tool to repair brain injury? J. Neurochem. 124, 159-167. doi: 10.1111/jnc.12084

Bribian, A., Fontana, X., Llorens, F., Gavin, R., Reina, M., Garcia-Verdugo, J. M., et al. (2012). Role of the cellular prion protein in oligodendrocyte precursor cell proliferation and differentiation in the developing and adult mouse CNS. PLoS ONE 7:e33872. doi: 10.1371/journal.pone.0033872
Bueler, H., Aguzzi, A., Sailer, A., Greiner, R. A., Autenried, P., Aguet, M., et al. (1993). Mice devoid of PrP are resistant to scrapie. Cell 73, 1339-1347. doi: 10.1016/0092-8674(93)90360-3

Chen, S., Mange, A., Dong, L., Lehmann, S., and Schachner, M. (2003). Prion protein as trans-interacting partner for neurons is involved in neurite outgrowth and neuronal survival. Mol. Cell. Neurosci. 22, 227-233. doi: 10.1016/S10447431(02)00014-3

Cheng, Y., Tao, L., Xu, J., Li, Q., Yu, J., Jin, Y., et al. (2013). CD44/Cellular prion protein interact in multidrug resistant breast cancer cells and correlate with responses to neoadjuvant chemotherapy in breast cancer patients. Mol. Carcinog. 53, 686-697. doi: 10.1002/mc.22021

Dery, M. A., Jodoin, J., Ursini-Siegel, J., Aleynikova, O., Ferrario, C., Hassan, S., et al. (2013). Endoplasmic reticulum stress induces PRNP prion protein gene expression in breast cancer. Breast Cancer Res. 15, R22. doi: 10.1186/bcr3398

Diarra-Mehrpour, M., Arrabal, S., Jalil, A., Pinson, X., Gaudin, C., Pietu, G., et al. (2004). Prion protein prevents human breast carcinoma cell line from tumor necrosis factor alpha-induced cell death. Cancer Res. 64, 719-727. doi: 10.1158/0008-5472.CAN-03-1735

Dodelet, V. C., and Cashman, N. R. (1998). Prion protein expression in human leukocyte differentiation. Blood 91, 1556-1561.

Du, L., Rao, G., Wang, H., Li, B., Tian, W., Cui, J., et al. (2013). CD44-positive cancer stem cells expressing cellular prion protein contribute to metastatic capacity in colorectal cancer. Cancer Res. 73, 2682-2694. doi: 10.1158/0008-5472.CAN12-3759

Ermonval, M., Mouillet-Richard, S., Codogno, P., Kellermann, O., and Botti, J. (2003). Evolving views in prion glycosylation: functional and pathological implications. Biochimie 85, 33-45. doi: 10.1016/S0300-9084(03)00040-3

Gotz, M., and Huttner, W. B. (2005). The cell biology of neurogenesis. Nat. Rev. Mol. Cell Biol. 6, 777-788. doi: 10.1038/nrm1739

Herva, M. E., Relaño-Ginés, A., Villa, A., and Torres, J. M. (2010). Prion infection of differentiated neurospheres. J. Neurosci. Methods 188, 270-275. doi: 10.1016/j.jneumeth.2010.02.022

Hidaka, K., Shirai, M., Lee, J. K., Wakayama, T., Kodama, I., Schneider, M. D., et al. (2010). The cellular prion protein identifies bipotential cardiomyogenic progenitors. Circ. Res. 106, 111-119. doi: 10.1161/CIRCRESAHA.109. 209478

Hirsch, T. Z., Hernandez-Rapp, J., Martin-Lanneree, S., Launay, J. M., and Mouillet-Richard, S. (2014). PrPC signalling in neurons: from basics to clinical challenges. Biochimie 104C, 2-11. doi: 10.1016/j.biochi.2014.06.009

Kaiser, D. M., Acharya, M., Leighton, P. L., Wang, H., Daude, N., Wohlgemuth, S. et al. (2012). Amyloid beta precursor protein and prion protein have a conserved interaction affecting cell adhesion and CNS development. PLoS ONE 7:e51305. doi: 10.1371/journal.pone.0051305

Kanaani, J., Prusiner, S. B., Diacovo, J., Baekkeskov, S., and Legname, G. (2005). Recombinant prion protein induces rapid polarization and development of synapses in embryonic rat hippocampal neurons in vitro. J. Neurochem. 95, 1373-1386. doi: 10.1111/j.1471-4159.2005.03469.x

Khalife, M., Young, R., Passet, B., Halliez, S., Vilotte, M., Jaffrezic, F., et al. (2011). Transcriptomic analysis brings new insight into the biological role of the prion protein during mouse embryogenesis. PLoS ONE 6:e23253. doi: 10.1371/journal.pone.0023253

Lee, Y. J., and Baskakov, I. V. (2010). Treatment with normal prion protein delays differentiation and helps to maintain high proliferation activity in human embryonic stem cells. J. Neurochem. 114, 362-373. doi: 10.1111/j.14714159.2010.06601.x

Lee, Y. J., and Baskakov, I. V. (2012). The cellular form of the prion protein is involved in controlling cell cycle dynamics, self-renewal, and the fate of human embryonic stem cell differentiation. J. Neurochem. 124, 310-322. doi: 10.1111/j.1471-4159.2012.07913.x

Liang, J., Bai, F., Luo, G., Wang, J., Liu, J., Ge, F., et al. (2007b). Hypoxia induced overexpression of $\operatorname{PrP}(\mathrm{C})$ in gastric cancer cell lines. Cancer Biol. Ther. 6, 769-774. doi: 10.4161/cbt.6.5.4001

Liang, J., Pan, Y., Zhang, D., Guo, C., Shi, Y., Wang, J., et al. (2007a). Cellular prion protein promotes proliferation and G1/S transition of human gastric cancer cells SGC7901 and AGS. FASEB J. 21, 2247-2256. doi: 10.1096/fj.06-7799com

Liao, M. J., Zhang, C. C., Zhou, B., Zimonjic, D. B., Mani, S. A., Kaba, M., et al. (2007). Enrichment of a population of mammary gland cells that form mammospheres and have in vivo repopulating activity. Cancer Res. 67, 8131-8138. doi: 10.1158/0008-5472.CAN-06-4493 
Lima, F. R., Arantes, C. P., Muras, A. G., Nomizo, R., Brentani, R. R., and Martins, V. R. (2007). Cellular prion protein expression in astrocytes modulates neuronal survival and differentiation. J. Neurochem. 103, 2164-2176. doi: 10.1111/j.14714159.2007.04904.x

Linden, R., Martins, V. R., Prado, M. A., Cammarota, M., Izquierdo, I., and Brentani, R. R. (2008). Physiology of the prion protein. Physiol. Rev. 88, 673-728. doi: 10.1152/physrev.00007.2007

Liu, T., Li, R., Wong, B. S., Liu, D., Pan, T., Petersen, R. B., et al. (2001). Normal cellular prion protein is preferentially expressed on subpopulations of murine hemopoietic cells. J. Immunol. 166, 3733-3742. doi: 10.4049/jimmunol.166.6.3733

Loubet, D., Dakowski, C., Pietri, M., Pradines, E., Bernard, S., Callebert, J., et al. (2012). Neuritogenesis: the prion protein controls betal integrin signaling activity. FASEB J. 26, 678-690. doi: 10.1096/fj.11-185579

Mabbott, N. A., and MacPherson, G. G. (2006). Prions and their lethal journey to the brain. Nat. Rev. Microbiol. 4, 201-211. doi: 10.1038/nrmicro1346

Malaga-Trillo, E., Solis, G. P., Schrock, Y., Geiss, C., Luncz, L., Thomanetz, V., et al. (2009). Regulation of embryonic cell adhesion by the prion protein. PLoS Biol. 7:e55. doi: 10.1371/journal.pbio.1000055

Manson, J., West, J. D., Thomson, V., McBride, P., Kaufman, M. H., and Hope, J. (1992). The prion protein gene: a role in mouse embryogenesis? Development 115, 117-122.

Marthiens, V., Kazanis, I., Moss, L., Long, K., and Ffrench-Constant, C. (2010). Adhesion molecules in the stem cell niche-more than just staying in shape? J. Cell Sci. 123, 1613-1622. doi: 10.1242/jcs.054312

McDonald, A. J., Dibble, J. P., Evans, E. G., and Millhauser, G. L. (2014). A new paradigm for enzymatic control of alpha-cleavage and beta-cleavage of the prion protein. J. Biol. Chem. 289, 803-813. doi: 10.1074/jbc.M113.502351

Medema, J. P. (2013). Cancer stem cells: the challenges ahead. Nat. Cell Biol. 15, 338-344. doi: 10.1038/ncb2717

Mehrpour, M., and Codogno, P. (2010). Prion protein: from physiology to cancer biology. Cancer Lett. 290, 1-23. doi: 10.1016/j.canlet.2009.07.009

Meslin, F., Hamai, A., Gao, P., Jalil, A., Cahuzac, N., Chouaib, S., et al. (2007). Silencing of prion protein sensitizes breast adriamycin-resistant carcinoma cells to TRAIL-mediated cell death. Cancer Res. 67, 10910-10919. doi: 10.1158/00085472.CAN-07-0512

Miele, G., Alejo Blanco, A. R., Baybutt, H., Horvat, S., Manson, J., and Clinton, M. (2003). Embryonic activation and developmental expression of the murine prion protein gene. Gene Expr. 11, 1-12. doi: 10.3727/0000000037839 92324

Milhavet, O., Casanova, D., Chevallier, N., McKay, R. D., and Lehmann, S. (2006). Neural stem cell model for prion propagation. Stem Cells 10, 2284-2291. doi: 10.1634/stemcells.2006-0088

Miranda, A., Pericuesta, E., Ramirez, M. A., and Gutierrez-Adan, A. (2011). Prion protein expression regulates embryonic stem cell pluripotency and differentiation. PLoS ONE 6:e18422. doi: 10.1371/journal.pone.0018422

Mohanty, S. T., Cairney, C. J., Chantry, A. D., Madan, S., Fernandes, J. A., Howe, S. J., et al. (2012). A small molecule modulator of prion protein increases human mesenchymal stem cell lifespan, ex vivo expansion, and engraftment to bone marrow in NOD/SCID mice. Stem Cells 30, 1134-1143. doi: 10.1002/ stem. 1065

Moser, M., Colello, R. J., Pott, U., and Oesch, B. (1995). Developmental expression of the prion protein gene in glial cells. Neuron 14, 509-517. doi: 10.1016/08966273(95)90307-0

Mouillet-Richard, S., Laurendeau, I., Vidaud, M., Kellermann, O., and Laplanche, J. L. (1999). Prion protein and neuronal differentiation: quantitative analysis of prnp gene expression in a murine inducible neuroectodermal progenitor. Microbes Infect. 1, 969-976. doi: 10.1016/S1286-4579(99) 80514-0

Nourizadeh-Lillabadi, R., Seilo Torgersen, J., Vestrheim, O., Konig, M., Alestrom, P., and Syed, M. (2010). Early embryonic gene expression profiling of zebrafish prion protein (Prp2) morphants. PLOS ONE 5:e13573. doi: 10.1371/journal.pone.0013573

Oesch, B., Westaway, D., Walchli, M., McKinley, M. P., Kent, S. B., Aebersold, R., et al. (1985). A cellular gene encodes scrapie PrP 27-30 protein. Cell 40, 735-746. doi: 10.1016/0092-8674(85)90333-2

Pan, Y., Zhao, L., Liang, J., Liu, J., Shi, Y., Liu, N., et al. (2006). Cellular prion protein promotes invasion and metastasis of gastric cancer. FASEB J. 20, 1886-1888. doi: 10.1096/fj.06-6138fje
Panigaj, M., Glier, H., Wildova, M., and Holada, K. (2011). Expression of prion protein in mouse erythroid progenitors and differentiating murine erythroleukemia cells. PLoS ONE 6:e24599. doi: 10.1371/journal.pone. 0024599

Passet, B., Young, R., Makhzami, S., Vilotte, M., Jaffrezic, F., Halliez, S., et al. (2012). Prion protein and Shadoo are involved in overlapping embryonic pathways and trophoblastic development. PLOS ONE 7:e41959. doi: 10.1371/journal.pone.0041959

Patra, S. K. (2008). Dissecting lipid raft facilitated cell signaling pathways in cancer. Biochim. Biophys. Acta 1785, 182-206. doi: 10.1016/j.bbcan.2007.11.002

Peralta, O. A., Huckle, W. R., and Eyestone, W. H. (2011). Expression and knockdown of cellular prion protein (PrPC) in differentiating mouse embryonic stem cells. Differentiation 81, 68-77. doi: 10.1016/j.diff.2010.09.181

Pradines, E., Hernandez-Rapp, J., Villa-Diaz, A., Dakowski, C., Ardila-Osorio, H., Haik, S., et al. (2013). Pathogenic prions deviate $\operatorname{PrP}(C)$ signaling in neuronal cells and impair A-beta clearance. Cell Death Dis. 4, e456. doi: $10.1038 /$ cddis. 2012.195

Premzl, M., and Gamulin, V. (2007). Comparative genomic analysis of prion genes. BMC Genomics 8:1. doi: 10.1186/1471-2164-8-1

Prodromidou, K., Papastefanaki, F., Sklaviadis, T., and Matsas, R. (2014). Functional cross-talk between the cellular prion protein and the neural cell adhesion molecule is critical for neuronal differentiation of neural stem/precursor cells. Stem Cells 32, 1674-1687. doi: 10.1002/stem.1663

Relaño-Ginés, A., Gabelle, A., Hamela, C., Belondrade, M., Casanova, D., Mourton-Gilles, C., et al. (2013). Prion replication occurs in endogenous adult neural stem cells and alters their neuronal fate: involvement of endogenous neural stem cells in prion diseases. PLoS Pathog. 9:e1003485. doi: 10.1371/journal.ppat. 1003485

Relaño-Ginés, A., Lehmann, S., and Crozet, C. (2014). Prion diseases and adult neurogenesis: how do prions counteract the brain's endogenous repair machinery? Prion 8, 1-7. doi: 10.4161/pri.29021

Rezza, A., Sennett, R., and Rendl, M. (2014). Adult stem cell niches: cellular and molecular components. Curr. Top. Dev. Biol. 107, 333-372. doi: 10.1016/B9780-12-416022-4.00012-3

Santos, T. G., Beraldo, F. H., Hajj, G. N., Lopes, M. H., Roffe, M., Lupinacci, F. C., et al. (2013). Laminin-gammal chain and stress inducible protein 1 synergistically mediate PrPC-dependent axonal growth via $\mathrm{Ca} 2+$ mobilization in dorsal root ganglia neurons. J. Neurochem. 124, 210-223. doi: 10.1111/jnc. 12091

Santos, T. G., Silva, I. R., Costa-Silva, B., Lepique, A. P., Martins, V. R., and Lopes, M. H. (2011). Enhanced neural progenitor/stem cells self-renewal via the interaction of stress-inducible protein 1 with the prion protein. Stem Cells 29, 1126-1136. doi: 10.1002/stem.664

Santuccione, A., Sytnyk, V., Leshchyns'ka, I., and Schachner, M. (2005). Prion protein recruits its neuronal receptor NCAM to lipid rafts to activate p59fyn and to enhance neurite outgrowth. J. Cell Biol. 169, 341-354. doi: $10.1083 /$ jcb. 200409127

Sauer, H., Dagdanova, A., Hescheler, J., and Wartenberg, M. (1999). Redoxregulation of intrinsic prion expression in multicellular prostate tumor spheroids. Free Radic. Biol. Med. 27, 1276-1283. doi: 10.1016/S08915849(99)00164-1

Singh, A., and Settleman, J. (2010). EMT, cancer stem cells and drug resistance: an emerging axis of evil in the war on cancer. Oncogene 29, 4741-4751. doi: 10.1038/onc. 2010.215

Starke, R., Harrison, P., Mackie, I., Wang, G., Erusalimsky, J. D., Gale, R., et al. (2005). The expression of prion protein $(\operatorname{PrP}(C))$ in the megakaryocyte lineage. J. Thromb. Haemost. 3, 1266-1273. doi: 10.1111/j.1538-7836.2005. 01343.x

Steele, A. D., Emsley, J. G., Ozdinler, P. H., Lindquist, S., and Macklis, J. D. (2006). Prion protein $(\mathrm{PrPc})$ positively regulates neural precursor proliferation during developmental and adult mammalian neurogenesis. Proc. Natl. Acad. Sci. U.S.A. 103, 3416-3421. doi: 10.1073/pnas.0511290103

Steele, A. D., Lindquist, S., and Aguzzi, A. (2007). The prion protein knockout mouse: a phenotype under challenge. Prion 1, 83-93. doi: 10.4161/pri.1.2.4346

Stella, R., Massimino, M. L., Sandri, M., Sorgato, M. C., and Bertoli, A. (2010). Cellular prion protein promotes regeneration of adult muscle tissue. Mol. Cell. Biol. 30, 4864-4876. doi: 10.1128/MCB.01040-09

Tremblay, P., Bouzamondo-Bernstein, E., Heinrich, C., Prusiner, S. B., and DeArmond, S. J. (2007). Developmental expression of PrP in the 
post-implantation embryo. Brain Res. 1139, 60-67. doi: 10.1016/j.brainres. 2006.12.055

Westergard, L., Christensen, H. M., and Harris, D. A. (2007). The cellular prion protein $(\operatorname{PrP}(\mathrm{C}))$ : its physiological function and role in disease. Biochim. Biophys. Acta 1772, 629-644. doi: 10.1016/j.bbadis.2007. 02.011

Zhang, C. C., Steele, A. D., Lindquist, S., and Lodish, H. F. (2006). Prion protein is expressed on long-term repopulating hematopoietic stem cells and is important for their self-renewal. Proc. Natl. Acad. Sci. U.S.A. 103, 2184-2189. doi: 10.1073/pnas.0510577103

Conflict of Interest Statement: The authors declare that the research was conducted in the absence of any commercial or financial relationships that could be construed as a potential conflict of interest.
Received: 30 June 2014; accepted: 11 September 2014; published online: 29 September 2014.

Citation: Martin-Lannerée S, Hirsch TZ, Hernandez-Rapp J, Halliez S, Vilotte J-L, Launay J-M and Mouillet-Richard S (2014) PrP $\mathrm{P}^{\mathrm{C}}$ from stem cells to cancer. Front. Cell Dev. Biol. 2:55. doi: 10.3389/fcell.2014.00055

This article was submitted to Cell Death and Survival, a section of the journal Frontiers in Cell and Developmental Biology.

Copyright () 2014 Martin-Lannerée, Hirsch, Hernandez-Rapp, Halliez, Vilotte, Launay and Mouillet-Richard. This is an open-access article distributed under the terms of the Creative Commons Attribution License (CC BY). The use, distribution or reproduction in other forums is permitted, provided the original author(s) or licensor are credited and that the original publication in this journal is cited, in accordance with accepted academic practice. No use, distribution or reproduction is permitted which does not comply with these terms. 


\title{
Prion protein (PrP) gene-knockout cell lines: insight into functions of the PrP
}

\author{
Akikazu Sakudo ${ }^{1 *}$ and Takashi Onodera ${ }^{2}$ \\ ${ }^{1}$ Laboratory of Biometabolic Chemistry, Faculty of Medicine, School of Health Sciences, University of the Ryukyus, Nishihara, Japan \\ ${ }^{2}$ Research Center for Food Safety, School of Agricultural and Life Sciences, University of Tokyo, Tokyo, Japan
}

\section{Edited by:}

Sophie Mouillet-Richard, Institut

National de la Santé et de la

Recherche Médicale, France

Reviewed by:

Sophie Mouillet-Richard, Institut

National de la Santé et de la

Recherche Médicale, France

Yong-Sun Kim, Hallym University,

South Korea

Marilene Hohmuth Lopes,

University of Sao Paulo, Brazil

*Correspondence:

Akikazu Sakudo, Laboratory of

Biometabolic Chemistry, Faculty of

Medicine, School of Health

Sciences, University of the

Ryukyus, 207 Uehara, Nishihara,

Okinawa 903-0215, Japan

e-mail:sakudo@med.u-ryukyu.ac.jp
Elucidation of prion protein (PrP) functions is crucial to fully understand prion diseases. A major approach to studying PrP functions is the use of PrP gene-knockout $\left(\mathrm{Prnp}^{-/-}\right)$mice. So far, six types of $\mathrm{Prnp}^{-/-}$mice have been generated, demonstrating the promiscuous functions of PrP. Recently, other PrP family members, such as Doppel and Shadoo, have been found. However, information obtained from comparative studies of structural and functional analyses of these PrP family proteins do not fully reveal PrP functions. Recently, varieties of $\mathrm{Prnp}^{-/-}$cell lines established from $\mathrm{Prnp}^{-/-}$mice have contributed to the analysis of PrP functions. In this mini-review, we focus on Prnp ${ }^{-1-}$ cell lines and summarize currently available Prnp ${ }^{-/-}$cell lines and their characterizations. In addition, we introduce the recent advances in the methodology of cell line generation with knockout or knockdown of the PrP gene. We also discuss how these cell lines have provided valuable insights into PrP functions and show future perspectives.

Keywords: prion protein, Prnp ${ }^{-/-}$cell line, Doppel, Shadoo, knockout mouse

\section{INTRODUCTION}

Prion diseases, also called transmissible spongiform encephalopathies (TSE), are a group of neurodegenerative disorders that affect both humans and animals (Prusiner, 1998). Examples of these disorders in humans include Creutzfeldt-Jakob disease (CJD), Gerstmann-Sträussler-Scheinker syndrome (GSS), kuru and fatal familial insomnia (FFI). TSEs found in animals include scrapie, bovine spongiform encephalopathy (BSE) and chronic wasting disease (CWD). The representative characteristics of prion diseases are spongiform changes, which are associated with neuronal loss, vacuolation, astrocytosis, formation of amyloid plaques and a failure to induce an inflammatory response (Sakudo and Ikuta, 2009a,b). A common characteristic of prion diseases is rapid symptom progression after a prolonged incubation period. The damaged region of the brain differs among each prion disease and determines the clinical signs and symptoms of the specific disease. Although the incidence of prion diseases is rare, it is fatal because of a lack of effective treatment to either cure or delay disease progression. Furthermore, the risk of prion transmission is a serious threat to public health due to the high resistance of prion agents to standard sterilization techniques (Sakudo et al., 2011a).

Prion protein $(\mathrm{PrP})$ is the most important factor for prion infection. This finding has been verified by experiments using PrP gene (Prnp)-knockout $\left(\mathrm{Pr} \mathrm{p}^{-/-}\right)$mice and cells derived from these mice (Sakudo et al., 2006, 2007a,b). The first important finding was that $\mathrm{Prnp}^{-/-}$mice are resistant to infection with prion agents (Bueler et al., 1993; Prusiner et al., 1993; Manson et al., 1994a,b). Secondly, Prnp $^{-/-}$primary culture neurons are not killed by the toxicity of prion agents or $\operatorname{PrP}(106-126)$
(Brandner et al., 1996a; Giese et al., 1998). Thirdly, prions cannot proliferate in the brain of $\mathrm{Prnp}^{-/-}$mice (Brandner et al., 1996b). Therefore, it is apparent that PrP plays an important role in the mechanisms of infection and contributes to the pathogenesis of prion diseases. This is also consistent with the notion that the conversion of cellular $\operatorname{PrP}\left(\operatorname{PrP}^{\mathrm{C}}\right)$ into abnormal $\operatorname{PrP}\left(\mathrm{PrP}^{\mathrm{Sc}}\right)$ constitutes a fundamental feature of prion diseases (Prusiner, 1998). It seems that $\operatorname{PrP}^{\mathrm{C}}$ acts as a cellular receptor of $\operatorname{PrP}^{\mathrm{Sc}}$. Because $\operatorname{PrP}^{\mathrm{C}}$ is thought to function as a dimeric form (Meyer et al., 2000; Kaimann et al., 2008), $\operatorname{PrP}^{\mathrm{C}}{ }_{-} \mathrm{PrP}^{\mathrm{Sc}}$ interaction might alternate between $\operatorname{PrP}^{\mathrm{C}}-\mathrm{PrP}^{\mathrm{Sc}}$ and $\mathrm{PrP}^{\mathrm{Sc}} \mathrm{PrP}^{\mathrm{Sc}}$ after prion infection. As shown above, $\operatorname{Prnp}^{-/-}$mice and the derived cells have confirmed the importance of PrP in the pathogenicity of prion diseases and have greatly contributed to the understanding of these disorders.

However, despite the numerous studies on $\operatorname{Prnp}^{-/-}$mice, the biological functions of $\operatorname{PrP}^{\mathrm{C}}$, which are crucial for understanding prion diseases, remain elusive. Cell lines are useful for detailed analysis of gene function. Therefore, to investigate $\mathrm{PrP}^{\mathrm{C}}$ functions in detail, $\mathrm{Prnp}^{-/-}$cell lines derived from $\mathrm{Prnp}^{-/-}$mice have been established. The present review will summarize currently available $\mathrm{Prnp}^{-/-}$cell lines. In addition, recent advances in strategies for producing cell lines in which Prnp is knocked out or knocked down will be presented. Valuable insights into $\mathrm{PrP}^{\mathrm{C}}$ functions made possible by the availability of these cell lines will be introduced as well.

\section{THE ANALYSIS OF Prnp ${ }^{-/-}$MICE FOR UNDERSTANDING PrPC FUNCTION}

One approach to studying protein function is to analyze the effect of knocking out the corresponding gene. In the case of $\operatorname{PrP}^{\mathrm{C}}$, 
Prnp ${ }^{-1-}$ mice have been widely used for this purpose. Therefore, studies using $\operatorname{Prnp}^{-/-}$mice should be mentioned before we discuss Prnp ${ }^{-/-}$cell lines. Prnp ${ }^{-/-}$mice have been used for elucidating the functions of $\mathrm{PrP}^{\mathrm{C}}$ via analysis of the phenotype of Prnp ${ }^{-/-}$mice (Weissmann and Flechsig, 2003). Six lines of Prnp ${ }^{-1-}$ mice, designated Zrch I (Bueler et al., 1992), Zrch II (Rossi et al., 2001), Npu (Manson et al., 1994a), Ngsk (Sakaguchi et al., 1996), Rcm0 (Moore et al., 1999) and Rikn (Yokoyama et al., 2001), have been generated (Figure 1). However, there were some discrepancies among the phenotypes of the knockout mice. The first and second knockout lines, Zrch I and Npu, were generated by disrupting the PrP coding region located in exon 3 of the Prnp (Bueler et al., 1992; Manson et al., 1994a). Studies on these lines did not show any severe abnormality. Subsequently, Ngsk, Rikn, $\mathrm{Rcm} 0$, and Zrch II mouse lines were generated in which the entire coding region and part of intron 2 was deleted (Sakaguchi et al., 1996; Moore et al., 1999; Rossi et al., 2001; Yokoyama et al., 2001). Because of the structure of the targeted Prnp allele, intergenic splicing between Prnp and the surrounding gene led to ectopic expression of the surrounding gene in the brains of these mice. This prompted the discovery of the gene Prnd located $16 \mathrm{kbp}$ downstream of Prnp, encoding the prion-related protein Doppel (Dpl) (Moore et al., 1999), which shares $\sim 25 \%$ identity with two-thirds of the C-terminal region of PrP. Ectopic expression

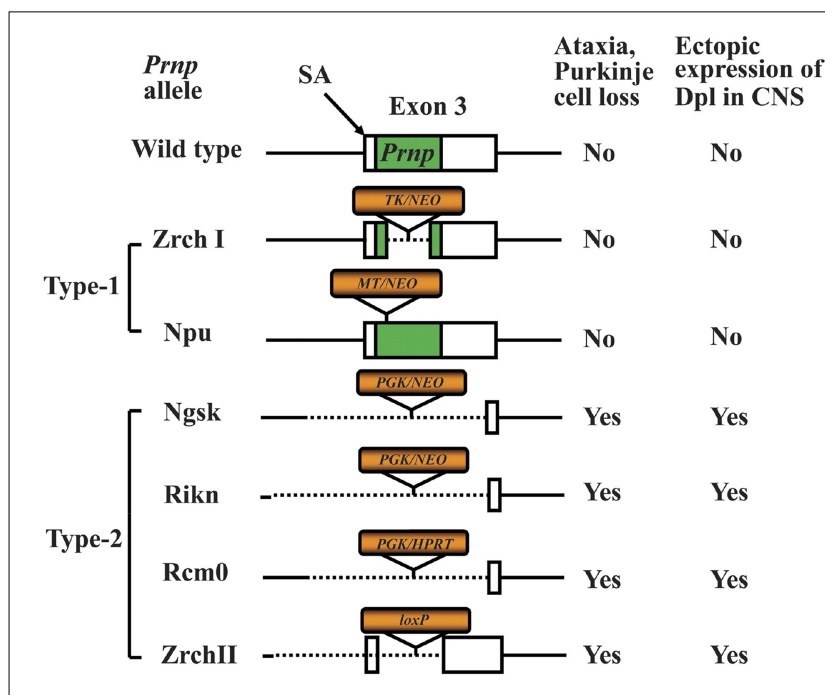

FIGURE 1 | Knockout constructs of type-1 and type-2 of prion protein gene (Prnp)-knockout (Prnp ${ }^{-/-}$) mice. Structures of the constructs used to produce six lines of $P r n p^{-/-}$mice. The $P_{r n p^{-/-}}$mice are divided into type-1 and type-2 Prnp-/- mice depending on whether the splicing acceptor of exon 3 is disrupted. The disruption of exon 3 is correlated with the development of late-onset ataxia and Purkinje cell loss, which is induced by ectopic expression of Doppel (Dpl) in the central nervous system (CNS). The structure of wild-type (WT) Prnp exon 3 and prion protein (PrP) coding region (green box) is shown at the top. The selection markers are indicated by orange boxes. The presence and absence of the exon 3 splicing acceptor (SA) is correlated with the development of late-onset ataxia. The selection markers were PGK, mouse phosphoglycerate kinase promoter; NEO, neomycin phosphotransferase; HPRT, mouse hypoxanthine phosphoribosyltransferase; TK, human herpes simplex virus type 1 thymidine kinase promoter; MT, mouse metallothionein promoter; loxP, a 34-bp recombination site from phage P1. of Dpl leads to the development of late-onset ataxia in Prnp ${ }^{-/-}$ mice. Therefore, the ataxic phenotype of some lines of Prnp ${ }^{-/-}$ mice (Ngsk, Rikn, Rcm0, ZrchII) is due to ectopic expression of Dpl (derived from Prnp/Prnd chimeric mRNAs through intergenic splicing) as a result of the disruption of the splicing acceptor of Prnp exon 3 (Moore et al., 1999; Li et al., 2000a; Rossi et al., 2001). In this review article, to discriminate between Prnp ${ }^{-/-}$ mice with and without ectopic expression of Dpl, we term the former ataxic Prnp ${ }^{-/-}$mice (Ngsk, Rikn, Rcm0, Zrch II) as type 2, while the latter non-ataxic Prnp ${ }^{-/-}$mice (Zrch I, Npu) as type-1 (Figure 1).

The type-1 Prnp $^{-/-}$mice display no major abnormalities. Indeed, only small abnormalities could be found in type-1 Prnp-knockout mice. These include deficits related to neuronal and other cellular functions such as abnormal learning and sleep patterns, olfactory deficits, susceptibility to seizures, abnormal neuromuscular function and depressive disorder as well as abnormal glucose tolerance and deficits related to protection against pathophysiological stress (e.g., abnormal inflammatory responses, decreased protection against viral bacterial infection, accelerated symptoms of experimental autoimmune encephalomyelitis (EAE) and susceptibility to ischemic brain injury (Onodera et al., 2014). In addition, the most consistent phenotype of $\mathrm{Prnp}^{-/-}$mice is myelin degeneration (Nishida et al., 1999; Baumann et al., 2007; Bremer et al., 2010). Some of these abnormalities may be due to the genetic background (Steele et al., 2007). Therefore, experiments using backcrossed mice should be performed to confirm whether the observed phenotypes are attributable to PrP. There are also possibilities of synergistic phenotypes in a combination of mouse strain genetic backgrounds and knockout constructs. In addition, the breeding condition of the mice may affect emergence of some phenotypes. For knockout mouse studies, confirmation of findings using mice with distinct knockout constructs and genetic backgrounds in an independent laboratory will be required to firmly establish conclusions regarding PrP function. Indeed, we have recently reviewed the topic of different $\operatorname{Prnp}^{-/-}$mouse phenotypes to assess the physiological function of $\operatorname{PrP}^{\mathrm{C}}$ (Onodera et al., 2014).

\section{PrP FAMILY PROTEINS AND THEIR KNOCKOUT MICE}

Recently, new members of the PrP family of proteins have been identified; namely, Dpl, encoded by Prnd, and Shadoo (Sho), encoded by Sprn. These PrP family proteins are all subject to endoproteolytic processing (Mays et al., 2014) and localize to similar membrane environments (Li et al., 2013). Dpl and Sho pose interesting and important questions concerning $\mathrm{PrP}$ function. Given that the function of $\mathrm{PrP}$ remains elusive, information obtained from comparative structural and functional studies of these PrP family proteins are of great interest. Specifically, complementary, overlapping or interference of function among PrP family members might be found from these analyses.

There are reports indicating functional interaction between PrP and Dpl. It has been shown that the ataxic phenotype observed in type-2 Prnp ${ }^{-/-}$mice can be neutralized by crossing the mice with those overexpressing wild-type mouse PrP 
(Nishida et al., 1999; Rossi et al., 2001). These findings suggest that $\operatorname{PrP}$ has a neuroprotective role and functionally interacts with Dpl. Another report showed that the toxicity of Dpl overexpression in mice and cells is inhibited by PrP expression. In a separate report, using immortalized $\operatorname{Prnp}^{-/-}$neuronal cells, a decrease of cellular copper levels brought about by serum deprivation was also inhibited by PrP. However, the inhibitory effect of PrP on decreased copper levels was prevented by Dpl overexpression (Sakudo et al., 2004). A further study demonstrated that endoproteolysis of PrP was affected by Dpl overexpression in Prnp $^{-1-}$ cells (Sakudo and Onodera, 2011b). Therefore, PrP-Dpl interaction functions both in vitro and in vivo.

Dpl is localized in the brain for only a limited duration in the developmental process ( $\mathrm{Li}$ et al., 2000b), whereas analysis of Prnd $^{-/-}$mice showed that Dpl deficiency did not interfere with embryonic and postnatal development (Behrens et al., 2002; Genoud et al., 2003). Dpl was produced at a late stage of spermatogenesis. Spermatids of Prnd $^{-/-}$mice were reduced in numbers, immobile, malformed and unable to fertilize oocytes, resulting in male sterility. $\operatorname{PrP}$ is also expressed in testis, but unlike other cells the PrP is expressed as N-terminally truncated isoforms (Peoc'h et al., 2002) or a C-terminally truncated isoform (Shaked et al., 1999). The C-terminal region of PrP resembles Dpl, suggesting that these proteins share a common function in testis in the case of N-terminally truncated PrP (Peoc'h et al., 2002) or show a complementary function to each other in the case of C-terminally truncated $\operatorname{PrP}$ (Shaked et al., 1999). Currently, there is no evidence that $\mathrm{Dpl}$ is associated with the pathogenesis of prion diseases. For example, the level of Dpl expression does not correlate with the onset of prion disease (Weissmann and Aguzzi, 1999; Tuzi et al., 2002).

By contrast, there is evidence that Sho is implicated in prion diseases. For example, the expression of Sho decreases with the accumulation of $\mathrm{PrP}^{\mathrm{Sc}}$ after prion infection (Watts et al., 2007a, 2011). Sho protein levels were decreased in the brains of Prnp $p^{\mathrm{a}}$ and Prnp ${ }^{\mathrm{b}}$ mice (Westaway et al., 2011), hamsters, meadow, voles and sheep infected with natural and experimental prion strains (Watts et al., 2011). In addition, time course experiments showed that the levels of $\mathrm{PrP}^{\mathrm{Sc}}$ vs. Sho protein were inversely proportional (Watts et al., 2011). Membrane anchoring and the N-terminal domain of PrP both influenced the inverse relationship between $\mathrm{PrP}^{\mathrm{Sc}}$ and Sho (Watts et al., 2011). By contrast, increased expression of Sho did not influence prion replication (Watts et al., 2011), suggesting Sho merely acts as a marker for prion disease. Therefore, it remains unclear how Sho contributes to the pathogenesis of prion diseases. Indeed, depletion of Sho appears to be unimportant in terms of triggering prion diseases and in the processing and degradation of $\mathrm{PrP}^{\mathrm{Sc}}$.

In terms of physiological action, Sho can exhibit neuroprotective properties similar to $\operatorname{PrP}^{\mathrm{C}}$ (Watts and Westaway, 2007b; Watts et al., 2007a) and share a number of binding partners common with $\operatorname{PrP}^{\mathrm{C}}$ (Watts et al., 2009). In addition, as Sho has a similar structure to the N-terminal region of PrP (Watts and Westaway, 2007b), the relationships between the structural similarity and functional similarity of PrP and Sho are interesting. Sprn ${ }^{-/-}$mice underwent a subtle alteration of body weight (Passet et al., 2013), which was not noted in the case of double-knockout (Sprn and
Prnp) mice. In addition, Prnp/Sprn knockout mice survived to over 600 days of age without any severe abnormality, suggesting the existence of a discrete signaling pathway of Prnp and Sprn to maintain neuronal survival. Sho was also found to be expressed in the trophoblast cells of the placenta (Passet et al., 2012). Comparative transcriptomic analyses performed between E6.5 and E7.5 Sprn-knockdown (using RNAi) embryo and their wild-type counterparts suggested that Sho has functions complementary, not necessary overlapping, with those of PrP, associated with cellular movement and hematological system development and differentiation (Passet et al., 2012). Interestingly, the expression profile of Sprn in testis and ovary resemble that of Prnp. Thus, interaction among three PrP family members may play important roles in reproductive tissues. Although the contribution of PrP family members to embryogenesis is suggested, Prnp/Sprn knockout mice are healthy and fertile (Daude and Westaway, 2012a; Daude et al., 2012b). Therefore, further studies on reproductive tissues are required to resolve the apparent discrepancy in the data. The topic of Sho is also discussed in detail in a review article in this research topic (Makzhami et al., 2014). As mentioned above, analysis of the phenotypes of knockout mice and comparison of PrP family members does not fully elucidate the functions of PrP. Therefore, other approaches to analyze PrP function are required. Next, we discuss the use of $\operatorname{Prnp}^{-/-}$cell lines to study the role of PrP.

\section{CHALLENGES TO INVESTIGATING PrPC FUNCTIONS IN VITRO}

Cells have been classified into approximately 200 different types (Obinata, 2007). Through development and maintenance during adult life, cells are differentiated and obtain characteristics to elicit specialized functions. Differentiation can be chemically induced by various stimuli such as growth factors, cytokines, and hormones (Alberts et al., 2008). Histological location of the cells also influences cell differentiation. In order to study each cell type possessing a specialized function, the cells need to be separated from each other. Examination of large, pure populations of specific cell types is extremely valuable in advancing our understanding of the cells. Primary cultures are composed of a heterogeneous cell population and can be maintained only for a limited period of time. Although $\operatorname{PrP}^{\mathrm{C}}$ is highly expressed in neurons, primary neuron cultures can be maintained for just a few weeks. Moreover, cells belonging to a rare cell type are often difficult to isolate and culture. For detailed functional gene analysis, an efficient transfection procedure is required. However, the transfection efficiency of primary cultures is generally low, especially when using primary neurons. If gene transfer to a primary culture of neurons or other cell types with low efficiency is necessary, a viral vector is required for the introduction of inducible genes. In this respect, cell lines are useful for detailed analysis of gene function because the transfection efficiency is usually high compared to that of primary cultures. In addition, cell lines can be maintained almost indefinitely.

However, studying pure cell lines has the disadvantage that it can only reflect a cell-autonomous condition, whereas biological processes in an organism involve a heterogeneous cell population. 
Co-cultures of multiple cell populations may help to mimic the heterogeneous condition. Additionally, because there are a lot of cell types in an organism, it is very difficult to match cell types between cell lines when a comparison is required. Thus, comparisons between a wild-type and a knockout cell line are suboptimal for analyzing a target gene. Alternatively, a cloned knockout cell line should be compared in the absence and presence of the target gene.

\section{PrPC EXPRESSION AND PrPC -INTERACTING PROTEINS}

$\mathrm{PrP}^{\mathrm{C}}$ is expressed in a variety of tissues. Northern blot analysis has shown that the levels of PrP mRNA vary among tissues, with the highest levels found in the brain and placenta; moderate levels in the testis, heart, and lung; and lower levels in the spleen and kidney (Horiuchi et al., 1995; Saeki et al., 1996). In sheep, 3-5 $\mu \mathrm{g} \mathrm{PrPC} / \mathrm{g}$ of tissue is present in the brain, whereas the level of $\mathrm{PrP}^{\mathrm{C}}$ per gram of tissue is $100 \mathrm{ng}$ in the heart and skeletal muscle, $200 \mathrm{ng}$ in the lung, $40 \mathrm{ng}$ in the spleen, and $3 \mathrm{ng}$ in the liver (Moudjou et al., 2001). Thus, the quantity of $\mathrm{PrP}^{\mathrm{C}}$ in the brain is 20- to 50-fold higher than in the other tissues. This observation suggests that $\mathrm{PrP}^{\mathrm{C}}$ plays an important role in several tissues, particularly in the brain.

Recently, it has been shown that $\operatorname{PrP}^{\mathrm{C}}$ binds a variety of partner molecules. Using radioisotope or enzyme-labeled PrP, interaction of PrP with glial fibrillary acidic protein (GFAP), a NF-E2 related factor 2 (Nrf2), amyloid precursor protein 1 (Aplp1), F-box protein-6, neural F-box protein $42 \mathrm{kDa}$ (NFB42), postsynaptic density $95 \mathrm{kDa}$ (PSD-95)/ SAP-90 associated protein, protein tyrosine phosphatase non-receptor type-21, and predicted protein KIAA0443 was reported (Yehiely et al., 1997). A two hybrid system showed that laminin (Graner et al., 2000), 37-kDa/67$\mathrm{kDa}$ laminin receptor (Gauczynski et al., 2001), 37-kDa laminin receptor precursor (Rieger et al., 1997), heat shock protein $60 \mathrm{kDa}$ (Hsp60) (Edenhofer et al., 1996) and Bcl-2 (Kurschner and Morgan, 1995) all bind PrP. Co-immunoprecipitation experiments were used to identify PrP-interacting molecules, which included prion interactor 1 (Pint1) (Spielhaupter and Schatzl, 2001), synapsin Ib (Spielhaupter and Schatzl, 2001), growth factor receptor-bound protein 2 (Grb2) (Spielhaupter and Schatzl, 2001), and neurotrophin receptor interacting MAGE (melanoma-associated antigens) homolog (NRAGE) (Bragason and Palsdottir, 2005), dystroglycan (Keshet et al., 2000), the neuronal isoform of nitric oxide synthase (nNOS) (Keshet et al., 2000), glucose regulated protein 94 (Grp94) (Capellari et al., 1999), protein disulphide isomerase (Capellari et al., 1999), calnexin (Capellari et al., 1999), calreticulin (Capellari et al., 1999) and zeta-associated protein-70 (ZAP-70) (Mattei et al., 2004). A cross-linking method demonstrated interaction of PrP with tubulin (Nieznanski et al., 2005) and neural adhesion molecule (N-CAM) (Schmitt-Ulms et al., 2001). Complementary hydropathy and pull-down assays were able to show the interaction of $\operatorname{PrP}$ with stress inducible protein 1 (STI1) (Martins et al., 1997) and Hsp60 of Brucella abortus (Watarai et al., 2003). Intriguingly, PrP interacts with caveolin-1 (Toni et al., 2006), while cross-linking of cell-surface PrP stimulated caveolin-1-dependent interaction with Fyn tyrosine kinase (Mouillet-Richard et al., 2000), resulting in neurite outgrowth and differentiation of neuronal cells
(Mouillet-Richard et al., 2000; Pantera et al., 2009). Thus, PrP contributes to the control of the cellular redox state and homeostasis of neuronal cells (Mouillet-Richard et al., 2007). Because Fyn is involved in various signaling pathways, the interaction implies that $\operatorname{PrP}^{\mathrm{C}}$ has diverse functions. Most interestingly, a wealth of recent studies has established that PrP interacts with Amyloid $\beta$ protein $(A \beta)$, which is generated by the abnormal processing of the amyloid precursor protein (APP) by $\beta$-secretase, $\beta$-site APP cleaving enzyme (BACE1) and involved in the pathogenesis of Alzheimer's disease (Larson et al., 2012; Um et al., 2012; Um and Strittmatter, 2013; Dohler et al., 2014). In addition, several reports have shown that $\mathrm{PrP}^{\mathrm{C}}$ interacts with APP (Yehiely et al., 1997; Kaiser et al., 2012). Several reports have further demonstrated an involvement of PrP in the toxicity of $\mathrm{A} \beta$, although the use of different in vitro or transgenic models has yielded contrasting results (Schwarze-Eicker et al., 2005; Laurén et al., 2009; Balducci et al., 2010; Calella et al., 2010; Chung et al., 2010; Kessels et al., 2010; Morales et al., 2010; Ordóñez-Gutiérrez et al., 2013; Gasperini and Legname, 2014). Some groups have also reported that Fyn kinase mediates signal transduction downstream of the $\operatorname{PrP}^{\mathrm{C}}-\mathrm{A} \beta$ complex (Larson et al., 2012; Um et al., 2012; Um and Strittmatter, 2013). Because $\mathrm{PrP}^{\mathrm{C}}$ inhibits BACE1 either by direct interaction (Griffiths et al., 2011) or indirectly without interaction (Parkin et al., 2007; McHugh et al., 2012), reduction of the $\operatorname{PrP}^{\mathrm{C}}$ level may increase $\mathrm{A} \beta$. Therefore, $\operatorname{PrP}^{\mathrm{C}}$ may be involved in the pathogenesis of Alzheimer's disease not only by transducing $A \beta$ toxic signals but also via regulation of neurotoxic $\mathrm{A} \beta$ production. Taken together, most of the interacting proteins are important factors involved in survival, proliferation, differentiation, development, and stress response. However, it should be mentioned that this interaction may depend on the specific cell type and/or the surrounding tissue environment.

Currently, Prnp ${ }^{-/-}$cell lines have predominantly been established from brain as well as fibroblast and macrophage cell lines (Figure 2). Next, we will introduce the $\operatorname{Prn} \mathrm{p}^{-/-}$cell lines established so far.

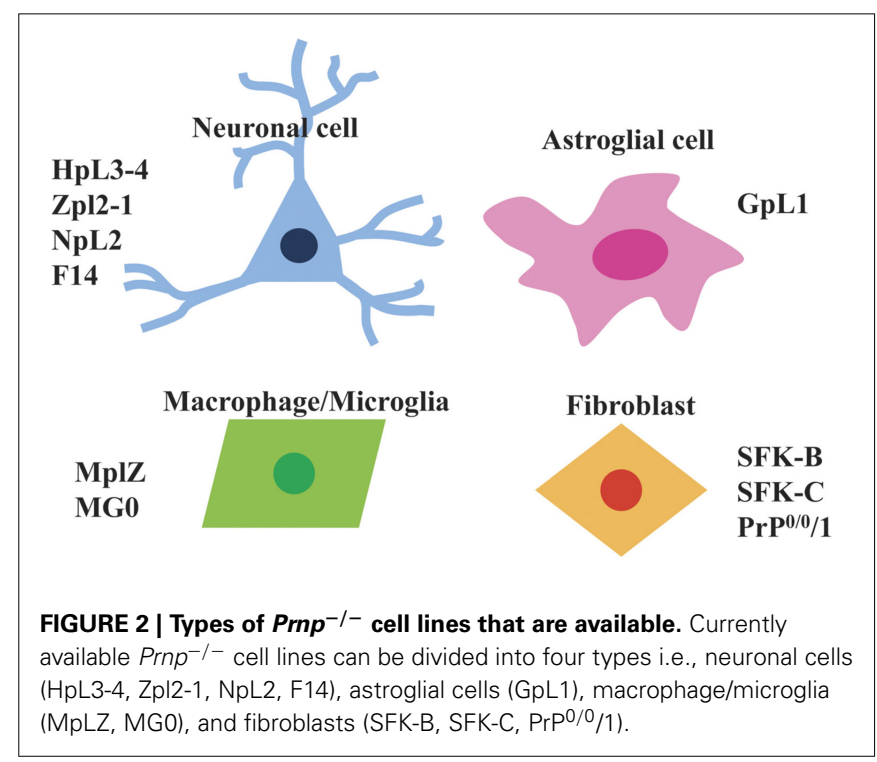




\section{HpL, Prnp ${ }^{-/-}$NEURONAL CELL LINES}

To gain further insights into $\mathrm{PrP}$ functions, cell lines $(\mathrm{HpL}$ and $\mathrm{HW}$ ) were established using the gene transfer of oncogenes by our group (Kuwahara et al., 1999). HpL was the first Prnp ${ }^{-/-}$cell line, while HW is the wild-type counterpart. These cell lines were from the hippocampal area of Rikn $\operatorname{Prnp}^{-/-}$mice and $\operatorname{Prnp} \mathrm{p}^{+/+}$mice using a target for infection with a recombinant retrovirus vector containing the simian virus 40 (SV40) T-antigen gene (Ryder et al., 1990). The virus vector was used for transfection of $\psi 2$ packaging cells, which are stable cells containing all of the structural retroviral protein genes ( $g a g$, pol, and env). The retrovirus particles produced from the transfected $\psi 2$ packaging cells were used for immortalization by introduction of the SV40 large T antigen gene. The hippocampal primary cultures derived from $\operatorname{Prnp}^{-/-}$and Prnp ${ }^{+/+}$mice were infected with the above retrovirus, then incubated, selected, expanded and finally subjected to limiting dilution to obtain cloned cell lines. Three $\operatorname{Prnp} \mathrm{p}^{-/}$cell lines, HpL2-1, HpL-3-2 and HpL3-4, and 3 Prnp ${ }^{+/+}$cell lines HW8, HW9, HW19, were thereby obtained (Kuwahara et al., 1999).

The HpL and HW cells were exposed to dibutyl cyclic AMP (dcAMP) at $0.4-6 \mathrm{mM}$, retinoic acid (RA) at $0.1-10 \mu \mathrm{M}$, and phorbol 12-myristate 13-acetate (PMA) at 160-1600 nM, for up to 10 days of culture. These compounds all induced morphological changes, i.e., elongation of neurite-like processes, in both $\mathrm{HpL}$ and HW cells. Among the tested compounds, the morphological change was best observed by stimulating the $\mathrm{HpL}$ and HW cells in medium with dcAMP or PMA without fetal calf serum (FCS). To further characterize the cell types of the cell lines, reverse transcription polymerase chain reaction (RT-PCR) was applied to monitor the expression of neurofilament genes. Treatment with PMA resulted in the amplification of the predicted size products corresponding to neurofilament (NF)-68K and NF-200K genes. The NF-68K gene was transcribed in all $3 \mathrm{HpL}$ and $3 \mathrm{HW}$ cell lines with or without PMA treatment. After treatment with PMA, the NF-200K gene was transcribed in all three HW cell lines and in only one of the HpL cell lines (HpL2-1). The transcription of GFAP, a glial cell marker, was not detected in $\mathrm{HpL}$ or HW cells. Taken together, the results suggest that all six of these cell lines belong to the neuronal precursor cell lineage.

Next, the characteristics of $\mathrm{HpL}$ cells were compared to those of HW cells. The most remarkable feature of HpL cells by comparison to HW cells was observed when the serum was removed from the culture medium (Kuwahara et al., 1999). Serum deprivation caused comparable morphological changes within $1 \mathrm{~h}$ in all cell lines whether or not they were treated with dcAMP. However, within 4 days the HpL cells had died in the serum-free culture. The process started by the rounding up of the cells, cytoplasmic condensation and neurite retraction. By contrast, all three HW cell lines maintained their structural integrity under the same culture conditions. DNA fragmentation, a characteristic of apoptosis, was firstly observed at $12 \mathrm{~h}$ and peaked at $24 \mathrm{~h}$ after serum deprivation in the $\mathrm{HpL}$ cells, whether or not they were treated with PMA or cAMP. However, no such DNA fragmentation was detected in any of the HW cells after serum deprivation. Cultured cells in serum-free medium for 6,12 , or $24 \mathrm{~h}$ were ethanol-fixed and stained with propidium iodide before analysis by flow cytometry (Sakudo et al., 2003a). A significant peak in the fluorescence low-intensity area (hypodiploid cells), which corresponds to the fraction of apoptotic cells, was detected only in the samples from HpL cells at 6, 12, and $24 \mathrm{~h}$ after serum withdrawal. Because HpL3-4 cells started to generate superoxide anion at $6 \mathrm{~h}$ after serum deprivation, superoxide anion generation seems to induce apoptosis of the HpL3-4 cells (Sakudo et al., 2003b). To investigate whether the abnormality observed in $\mathrm{HpL}$ cells was due to the absence of PrP, the HpL cell lines (HpL2-1 and HpL3-4) were transfected with PrP expression vector. Cells transfected with PrP-expressing vector, designated HpL2-1TR and HpL3-4TR, survived under serum-free conditions (Kuwahara et al., 1999). In contrast, HpL2-1 and HpL3-4 cells transfected with empty vector showed apoptotic features similar to those of HpL2-1 and HpL3-4 cells under serum-free conditions. These results suggest that $\mathrm{HpL}$ cells are susceptible to serum deprivation and that apoptotic cell death is suppressed by reintroduction of Prnp. Moreover, levels of superoxide anion generated from HpL34 cells after serum deprivation were suppressed by reintroduction of Prnp (Sakudo et al., 2003b). Therefore, these results suggest that PrP functions by displaying anti-oxidative and anti-apoptotic activity. Recent studies have shown that the anti-apoptotic activity of $\operatorname{PrP}$ is species specific, as indicated by evidence that apoptosis was suppressed by mouse PrP but not by bovine or hamster $\operatorname{PrP}$ (Wu et al., 2008). Moreover, as serum-free supernatants of HW cell cultures could not rescue the HpL cells from apoptosis, molecules secreted from HW cells do not appear to be involved in the neuroprotective mechanism of PrP (Kuwahara et al., 1999). In addition to the cell death, HpL cell lines show significantly shorter neurite extension in comparison with HW cell lines after treatment with PMA, suggesting that PrP is involved not only in survival but also in differentiation (Kuwahara et al., 1999).

Recently, in addition to our group, several other groups have independently confirmed the neuroprotective function of $\mathrm{PrP}$ using the above-mentioned PrP-deficient cell lines or other cell lines. Kim et al. reproduced our findings using HpL3-4 cells, and detected significantly greater changes in the calcium ion level, transmembrane potential and cytochrome c level in the mitochondria of HpL3-4 cells over those observed in Prnpreintroduced HpL3-4 cells after serum deprivation (Kim et al., 2004). Mange et al. also confirmed that cell viability was increased by the reintroduction of Prnp into HpL3-4 cells (Mange et al., 2004). By contrast, Christensen et al. confirmed a moderate but significant cytoprotective effect of PrP in serum-deprived HpL34 cells, but concluded the degree of neuroprotection offered by $\operatorname{PrP}$ was either not physiologically relevant or that the cell culture systems cannot adequately model the situation in vivo (Christensen and Harris, 2008). However, we believe the HpL3-4 cells used in these experiments were not appropriate for this analysis because they did not express neuronal markers (i.e., neuronal nuclear antigen $(\mathrm{NeuN})$, microtubule-associated protein 2 (MAP2) or NF-L) (Christensen and Harris, 2008). This opinion is also supported by the evidence that Prnp-Prnd chimeric mRNA transcribed from the Prnp promoter was not detected by RT-PCR and immunofluorescence analysis in the cells used by Christensen et al. By contrast, our results were confirmed by 
Prnp-Prnd chimeric mRNA expression in HpL3-4 cells (Sakudo et al., 2005b).

HpL3-4 cells are susceptible to various forms of stress. For example, Vassallo et al. showed HpL3-4 cells are prone to cell death induced by 3-morpholinosydnonimine (SIN-1) (Vassallo et al., 2005). Vassallo et al. further investigated the signal cascade of apoptosis induced by serum deprivation and SIN-1, and showed that recruitment of phosphatidylinositol 3-kinase by $\operatorname{PrP}$ contributes to cellular survival under conditions of oxidative stress imposed by SIN-1 or serum deprivation in HpL3-4 cells. Prnp-transfected HpL3-4 cells show autophagy after amyloid $\beta$ treatment. Amyloid $\beta_{1-42}\left(\mathrm{~A} \beta_{42}\right)$ enhanced autophagic flux, such as the formation of autophagic vacuoles, was observed in HpL34 cells in which Prnp was reintroduced. However, autophagy was impaired in HpL3-4 cells transfected with empty vector (Nah et al., 2013). In addition, PrP-dependent recruitment of Beclin1 (BECN1) into lipid rafts was observed in the HpL3-4 cell line. Because BECN1 is associated with phosphatidylinositol 3-kinase catalytic subunit type 3 (PIK3C3), there will be recruitment of BECN1-PIK3C3 complex into the lipid raft, which is an essential step for autophagy. The observed autophagy could be due to interaction of PrP and BECN1. Therefore, studies using HpL3-4 cells revealed that $\operatorname{PrP}$ is involved in $A \beta_{42}$ induced autophagy.

HpL3-4 cells were also susceptible to a monomeric, highly $\alpha$-helical form of PrP known as toxic PrP (Zhou et al., 2012). Toxic PrP was identified as a recombinant form of PrP that was subjected to denaturation, fractionation and dilution refolding. However, there is no information on the comparative effect of toxic PrP on PrP-expressing and non-expressing HpL3-4 cells. Similarly, in another report, although treatment with $A \beta_{42}$ showed a cytotoxic effect and increased levels of reactive oxygen species (ROS) in HpL3-4 cells, there was no comparison with the HpL3-4 counterpart in which Prnp was reintroduced (Hyeon et al., 2012).

It has also been reported that treatment of HpL3-4 cells with hydrogen peroxide increases intracellular calcium levels in a $\operatorname{PrP}$ expression dependent manner, suggesting PrP functions as a sensor of hydrogen peroxide (Krebs et al., 2007). Therefore, it appears that $\mathrm{PrP}^{\mathrm{C}}$ plays an important role in anti-oxidative stress. As such, the signaling cascade and oxidative metabolism were investigated in HpL3-4 cells after serum deprivation (Sakudo et al., 2003a,b). The studies revealed decreased expression of anti-apoptotic proteins Bcl-2 and Bcl- $\mathrm{x}_{\mathrm{L}}$ in HpL3-4 cells during apoptosis induced by serum deprivation. Suppression of apoptosis by overexpression of Bcl-2 and Bcl- $\mathrm{x}_{\mathrm{L}}$, suggested that cell death in this model system is apoptotic, and $\mathrm{Bcl}-2$ and $\mathrm{Bcl}-\mathrm{x}_{\mathrm{L}}$ play important roles in the apoptosis of HpL3-4 cells (Sakudo et al., 2003a). Furthermore, HpL3-4 cells subjected to serum deprivation showed a more marked decrease in intracellular copper concentration, greater increases of intracellular superoxide anion and caspase-3/9 activation, and a smaller increase in intracellular hydrogen peroxide levels by comparison to HpL3-4 cells in which Prnp was reintroduced (Sakudo et al., 2003b). HpL3-4 cells also showed a decrease of cellular superoxide dismutase (SOD) activity and cellular copper content compared to $\mathrm{HpL} 3-4$ cells expressing $\mathrm{PrP}$ (Sakudo et al., 2003b). By contrast, levels of Prnp-Prnd chimeric
mRNA and Prnd mRNA were unchanged in HpL3-4 cells after serum deprivation (Sakudo et al., 2005c). Higher coxsackievirus B3 and poliovirus production in HpL3-4 cells showed that PrP may be involved not only in the inhibition of virus replication but also anti-apoptotic functions against virus-induced apoptosis (Nakamura et al., 2003b; Baj et al., 2005). Taken together, our studies of $\mathrm{HpL}$ cell lines have revealed that PrP plays important roles in differentiation, proliferation and cell survival (i.e., roles in anti-apoptosis, anti-oxidative and anti-viral effect via regulating a variety of cell signal cascades). The results obtained from the study of $\mathrm{HpL}$ cell lines are consistent with those derived from other studies using primary cultures and other cell lines, which also showed the involvement of $\mathrm{PrP}$ in neuroprotection and differentiation (Milhavet and Lehmann, 2002; Roucou et al., 2004).

Studies using HpL cells have contributed to identifying PrPinteracting molecules or PrP-regulated genes because $\mathrm{HpL}$ does not express PrP. Moreover, Prnp-transfected $\mathrm{HpL}$ cells are an ideal counterpart for PrP analysis. Zafar et al. used HpL3-4 cells in combination with STrEP-Tactin chromatography and quadrupole time-of-flight tandem mass spectrometry (Q-TOF MS/MS) analysis to search for PrP-interacting proteins and identified 28 new hits (Zafar et al., 2011). Among them, Rab7a, a regulator of vesicular transport located in a specific intracellular compartment (early to late endosome) and involved in vesicle biogenesis and vesicle fusion to lysosomes, was found to interact with $\operatorname{PrP}$ and regulate $\mathrm{PrP}$ trafficking in $\mathrm{HpL} 3-4$ cells. Furthermore, $23 \mathrm{PrP}-$ interacting proteins were identified by using deletion mutants of $\operatorname{PrP}[\operatorname{PrP}(\Delta 23-230)]$, which lack the N-terminal signal peptide sequence and C-terminal glycosylphoshatidylinositol (GPI) anchor site (Zafar et al., 2014). Among them, one novel protein (pyruvate kinase isozymes M1/M2) (PKM2) was found to bind $\operatorname{PrP}(\Delta 23-230)$. In addition, $\operatorname{PrP}(\Delta 23-230)$ exhibits reduced antiapoptotic activity against staurosporine-induced cell stress with higher expression of PKM2 than full length PrP in HpL3-4 cells, suggesting that $\operatorname{PrP}(\Delta 23-230)$ regulates $\mathrm{PKM} 2$ and renders the cells susceptible to stress.

Taking advantage of the absence of Prnp, HpL3-4 cells have been used for the analysis of exogenous PrP. Hachiya et al. reported an N-terminal PrP fragment and C-terminal fragment showed distinct intracellular distribution using transfection of double-labeled fluorescent PrP into HpL3-4 cells (Hachiya et al., 2004). The N-terminal PrP fragment was associated with microtubules and had an intracellular localization, but did not co-localize with any intracellular organelle markers.

\section{OTHER Prnp-/- NEURONAL CELL LINES}

As described earlier, PrP exhibits a neuroprotective effect against apoptosis induced by serum deprivation in HpL3-4 cells, which are derived from type-2 $\operatorname{Prnp}^{-/-}$mice (Rikn) with ectopic $\mathrm{Dpl}$ expression. To investigate whether PrP inhibits apoptotic neuronal cell death in the absence of Dpl, neuronal cell lines were established from the brain of type-1 Prnp ${ }^{-/-}$mice (Zrch I), which did not show ectopic Dpl expression (Nishimura et al., 2007). The results showed that reintroduction of Prnp potently inhibited serum-withdrawal apoptotic cell death in 
a Zrch I neuronal $\operatorname{Prnp}^{-/-}$cell line (NpL2). Moreover, PrP expression was found to upregulate cellular SOD activity in NpL2 cells. Therefore, we concluded that ectopic Dpl production did not affect the anti-apoptotic and anti-oxidative functions of PrP. Thus, it was confirmed that the presence of $\mathrm{PrP}$ is directly correlated with protection against oxidative stress.

Kim et al. established neuronal cell lines from hippocampal neurons of Zrch I Prnp ${ }^{-/-}$mice by lipofection of SV40 large $\mathrm{T}$ antigen-expressing vector and found higher proliferation of neuronal cell lines from $\operatorname{Prnp}^{-/-}$mice $(\mathrm{Zpl})$ than those derived from Prnp ${ }^{+/+}$mice (ZW) (Kim et al., 2005). Zpl cells do not express $D$ pl because the cells are derived from type 1 Prnp ${ }^{-/-}$mice (Zrch I). Moreover, Zpl cells showed higher levels of apoptosis and autophagy compared to ZW cells after serum deprivation (Oh et al., 2008). The neuroprotective activity of $\operatorname{PrP}$ in Zpl cells was confirmed by reintroduction of Prnp into Zpl cells. Cleaved caspase-3 levels for apoptotic index and LC3-II levels for autophagy index were correlated with the expression of PrP. Furthermore, $\operatorname{PrP}(\Delta 53-94)$, octapeptide repeat (OR)deficient $\mathrm{PrP}$, did not display a protective activity in $\mathrm{Zpl}$ cells, indicating the importance of the OR region in the neuroprotective activity of PrP. These results are consistent with the HpL3-4 studies using deletion PrP mutants as described in the following section.

The F14 neuronal cell line is another Prnp ${ }^{-/-}$derived cell line, obtained by fusion of Prnp ${ }^{-/-}$cerebellar cells and mouse neuroblastoma cells (Holme et al., 2003). The cells were used for investigating the effect of PrP mutations on PrP membrane orientation, although the characteristics of PrP-expressing cells and PrP-deficient cells have not been compared.

Although not Prnp-knockout cells, Loubet et al. used the $1 \mathrm{C} 11$ cell line, a neuroepithelial progenitor for shRNA (short hairpin RNA)-mediated knockdown of Prnp, to investigate the gene silencing effect of Prnp (Loubet et al., 2012). 1C11 cells lack neuron-associated functions and acquire, upon differentiation, the functions of serotogenic or noradrenergic neuronal cells associated with cytoskeleton remodeling along neuritogenesis. The results showed that Prnp knockdown caused impaired neuronal polarization with inhibition of the initial sprouting of neurite. Further analysis of the signaling pathway suggests that $\mathrm{PrP}^{\mathrm{C}}$ contributes to neurite polarization by modulating integrin interactions with the extracellular matrix.

\section{ASTROGLIAL Prnp-/- CELL LINES}

$\mathrm{PrP}^{\mathrm{C}}$ is expressed not only in neuronal cells but also in nonneuronal cells such as glial cells. Therefore, studies on $\mathrm{PrP}^{\mathrm{C}}$ functions using non-neuronal cell lines are necessary. To address this issue, the Prnp ${ }^{-/-}$astroglial cell line GpL1 from hippocampal cells of Zrch I Prnp $p^{-/-}$mice were established by retrovirusmediated SV40 large T antigen-immortalization using a retrovirus vector employing methods described above (Nishimura et al., 2008). GpL1 cells were confirmed to express GFAP but not MAP-2, indicating that GpL1 is an astroglial cell line. Transfection of Prnp suppressed cell death in GpL1 cells under serum-free conditions. This finding is similar to the results of $\operatorname{Prnp}^{-/-}$neuronal cell lines HpL3-4 and NpL2. The Prnp-transfected GpL1 cells (GpL1-PrP) showed increased SOD activity compared to control GpL1 cells transfected with empty vector (GpL1-EM). Thus, this study extended the notion that $\operatorname{PrP}^{\mathrm{C}}$ prevents apoptosis by its anti-oxidative function in not only a $\operatorname{Prnp}^{-/-}$neuronal cell line but also a $\operatorname{Prn} \mathrm{p}^{-/-}$astroglial cell line after serum withdrawal.

In addition to $\mathrm{PrP}^{\mathrm{C}}$ function in independent cells, we have investigated whether PrP expression on the cell surface of astroglia influences neuronal survival because neurons and astroglia are closely coupled in their metabolic activities (Verkhratsky et al., 2014). Thus, the effect of PrP expression on cell viability of NpL2 cells under co-culture with GpL1-EM or GpL1-PrP cells in the absence of serum was investigated (Onodera and Sakudo, unpublished results). For co-culture experiments, GpL1-EM and GpL1-PrP cells were prepared and replaced with a serum-free DMEM. NpL2-EM and NpL2-PrP cells were plated onto coverslips, which were then transferred to a dish containing GpL1-EM or GpL1-PrP cells. After 4 days of co-culture, the coverslips were retracted and cell viability measured. The results showed that the NpL2 cell viability was significantly increased under co-culture with GpL1 cells transfected with Prnp (GpL1-PrP) compared to GpL1 cells transfected with empty vector (GpL1-EM). Similar results were observed when we used both NpL2 cells transfected with Prnp (NpL2-PrP) and NpL2 cells transfected with empty vector (NpL2-EM). These findings suggest that the neuronal cell viability depended on the PrP expression in feeder astroglia in the co-culture system. Taken together, astroglial cell lines are useful for revealing the mechanism of $\mathrm{PrP}^{\mathrm{C}}$ not only in independent astroglial cells but also in the function of the neuron-glia relationship.

\section{MACROPHAGE/MICROGLIA Prnp-/- CELL LINES}

Recent studies have shown that cells of the immune system, such as macrophages, dendritic cells (DCs) or lymphocytes, can act as a replication site or as a reservoir for prions (Aucouturier and Carnaud, 2002). Follicular dendritic cells (FDCs) in the germinal centers of lymphoid organs are reported to be sites of $\mathrm{PrP}^{\mathrm{Sc}}$ accumulation (Mcbride et al., 1992; Hill et al., 1999; Aucouturier and Carnaud, 2002). Current data suggest that the prion agent might be acquired by migratory DCs and macrophages (Maignien et al., 2005). However, the function of $\operatorname{PrP}^{C}$ in macrophages remains unclear.

Macrophages express $\operatorname{PrP}^{\mathrm{C}}$ at a very low level. To study $\mathrm{PrP}^{\mathrm{C}}$ functions in macrophage, the mouse bone marrow-derived macrophages (BMM) from FVB/N Prnp ${ }^{+/+}$and Zrch I Prnp ${ }^{-/-}$ mice were transformed with a replication-defective retrovirus encoding SV40 large $\mathrm{T}$ antigen by a similar method previously used for the establishment of $\mathrm{HpL}, \mathrm{NpL}$, and GpL cell lines (Uraki et al., 2010). The cells were then selected and cloned. Among the obtained clones, we used MWF3-3 (from FVB/N Prnp ${ }^{+/+}$ mice) and MplZ4-3 (from Zrch I Prnp ${ }^{-1-}$ mice) for comparison, because these cells expressed macrophage specific proteins (F4/80 and MOMA-2) and displayed phagocytotic properties. Because it was previously reported that $\mathrm{Prnp}^{-/-}$neuronal $\mathrm{HpL}$ and $\mathrm{NpL}$ cells and astroglial GpL cells are sensitive to oxidative stress in serum-free conditions, MWF3-3 and MplZ4-3 cells were subjected to serum deprivation. The MplZ4-3 cells died after 
withdrawal of serum, whereas most MWF3-3 cells survived under the same culture conditions. These findings suggest that $\operatorname{PrP}^{\mathrm{C}}$ increases the survival rate of macrophages.

With regard to the characteristics of the Prnp $p^{-1-}$ macrophage cell line, we have analyzed their cell morphology and phagocytotic activity. The Prnp ${ }^{-/-}$macrophage cell line (MplZ4-3) showed shorter pseudopodium extension and less phagocytotic activity of latex beads than a $\operatorname{Prnp}{ }^{+/+}$macrophage cell line (MWF3-3). These findings are consistent with the results using peritoneal macrophages from $\operatorname{Prnp}^{-/-}$and $P r n p^{+/+}$mice using latex beads (Nitta et al., 2009). However, the findings are inconsistent with a previous study showing that primary cultures of Zrch I Prnp ${ }^{-/-}$macrophages have increased rates of phagocytosis of zymosan particles, suggesting $\operatorname{PrP}$ negatively regulates this process (De Almeida et al., 2005). One possible explanation for this discrepancy may be the different mouse strains used in these experiments. Whereas the previous report examined primary cells derived from $\mathrm{C} 57 \mathrm{BL} / 6$, we used a macrophage cell line derived from FVB/N. Similarly, Prnp ${ }^{-/-}$mice are resistant to infection by Brucella abortus, which is supported in the report by De Almeida et al. implying that the deletion of $\operatorname{PrP}$ contributes to host defense against bacterial infection (Watarai et al., 2003). However, this was not confirmed in the case of Brucella suis in another laboratory (Fontes et al., 2005). In addition, a recent report by Nuvolone et al. suggests that the increased phagocytosis of apoptotic cells, which was reported as attributable to the absence of Prnp in Prnp ${ }^{-/-}$mice, has been shown instead to be caused by differences in a linked locus encoding signal regulatory protein- $\alpha$ (Sirpa) (Nuvolone et al., 2013). Thus, further studies would be required for investigating whether Sirpa-polymorphism influences the responses to zymosan or phagocytosis of latex beads.

Microglia are the primary immune cells of the central nervous system (CNS), and are highly similar to peripheral macrophages. These cells play important roles as the major inflammatory cell type in the brain, and respond to pathogens and injury and contribute to destroying pathogens as well as removing damaged cells. Several studies have indicated that microglia are implicated in the pathogenic events of prion diseases (Williams et al., 1994; Brown, 2001b). However, the pathophysiological function of $\operatorname{PrP}^{\mathrm{C}}$ in microglia remains unclear. Iwamaru and Kitani et al. obtained the MG0 Prnp ${ }^{-/-}$microglial cell line, which is derived from the brains of Rikn Prnp ${ }^{-/-}$mice (Iwamaru et al., 2007). To immortalize these microglial cells for establishing the MG0 cell line, $c$-myc-containing retroviral vector was used. The MG0 cells were confirmed to be positive for the microglial markers Mac-1 and F4/80 and negative for the astroglial marker GFAP and neuronal marker MAP2. Moreover, these cells were shown to have phagocytotic activity and to produce inflammatory cytokines, such as tumor necrosis factor $\alpha$, interleukin- $1 \alpha$ and interleukin-6, when stimulated with lipopolysaccharide. However, there are no reports on the comparison between MG0 and the wild-type counterpart MG6 cell line or PrP-overexpressed microglial cell line MG20. Persistent infection of scrapie and BSE in these cells has been reported. Further analysis of PrP function in microglia using the MG0 cell line is keenly awaited.

\section{FIBROBLAST Prnp-/- CELL LINES}

Satoh et al. established skin fibroblast $\operatorname{Prnp}^{-/-}$cell lines (SFK) derived from continuous cultures of abdominal skin explants of Ngsk Prnp ${ }^{-/-}$mice. SFK cells showed decreased expression of Ras- and Rac-related proteins compared to Prnp ${ }^{+/+}$skin fibroblast cell lines (SFH) (Satoh et al., 1998, 2000), while heat shock proteins were expressed at the same level in SFK and SFH cells in the presence and absence of heat stress (Satoh et al., 1998). Other groups established $\mathrm{Prnp}^{-/-}$fibroblasts $\left(\mathrm{PrP}^{0 / 0} / 1\right.$ cell line) from Ngsk Prnp ${ }^{-/-}$mice by immortalization with the chemical mutagen 3-methylcholanthrene (Prcina et al., 2010). The proliferation rate of $\mathrm{PrP}^{0 / 0} / 1$ cells expressing human $\mathrm{PrP}$ was lower those of non-transfected $\mathrm{PrP}^{0 / 0} / 1$ cells, and was negatively correlated with the PrP expression level. However, the authors also stated that these observations may be due to the antibiotic selection marker on the vector.

\section{MECHANISMS BY WHICH PrP PREVENTS APOPTOSIS IN THE HpL CELL LINE}

One way to identify the important regions of $\operatorname{PrP}$ is to generate partially deleted or mutated forms of PrP and transfect them into the Prnp ${ }^{-/-}$cell line. Endogenous PrP expression in the $\operatorname{Prnp}^{+/+}$cell line may interfere with these experiments. Hence, the $\operatorname{Prnp}^{-/-}$cell line is particularly useful for this approach. Here, we introduce our studies using HpL3-4 cells for investigating the important regions for PrP function (Figure 3).

PrP contains disulfide links (S-S), Asn-linked glycosylation sites $(\mathrm{CHO})$, a signal peptide sequence (SP) and a GPI anchor attached to its C-terminus (Brown, 2001a). In addition, $\operatorname{PrP}^{\mathrm{C}}$ contains two domains evolutionarily conserved among mammals; viz., the OR (amino acid residue 51-90 in mouse PrP) and the hydrophobic region (HR) (amino acid residue 112-145 in mouse PrP) domains.

OR, which is composed of five octapeptide repeats, $\mathrm{P}(\mathrm{Q} / \mathrm{H}) \mathrm{GGG}(\mathrm{G} /-)$ WGQ, is highly conserved among mammals and can selectively bind copper (Hornshaw et al., 1995; Brown et al., 1997; Miura et al., 1999; Viles et al., 1999; Kramer et al., 2001). Zinc, manganese, and nickel also bind to PrP but with lower affinity (Pan et al., 1992; Brown et al., 2000; Jackson et al., 2001). The binding of metals occurs via histidine residues located in the OR domain. The binding of copper to PrP is thought to be indispensable for the SOD activity of PrP (Brown et al., 1999; Cui et al., 2003). In addition, as metals such as copper are essential for myelin formation and maintenance (Skripuletz et al., 2008; Benetti et al., 2010), regulation of copper by $\operatorname{PrP}^{\mathrm{C}}$ may be involved in demyelination of $\operatorname{Prnp}^{-/-}$mice (Nishida et al., 1999; Baumann et al., 2007; Bremer et al., 2010).

HR, which contains the highly conserved sequence motif AGAAAAGA (Gasset et al., 1992; Schatzl et al., 1995), has been shown to be critical for PrP topology in the endoplasmic reticulum membrane (Hegde et al., 1998), STI1 binding (Zanata et al., 2002) as well as normal metabolic cleavage (Chen et al., 1995; Mange et al., 2004) such as $\alpha$-cleavage and $\beta$-cleavage.

To investigate the roles of OR and HR in the anti-apoptotic function of PrP, several deletions within these domains of mouse $\operatorname{PrP}$ or fusions with mouse $\operatorname{PrP}$ and Dpl have been 


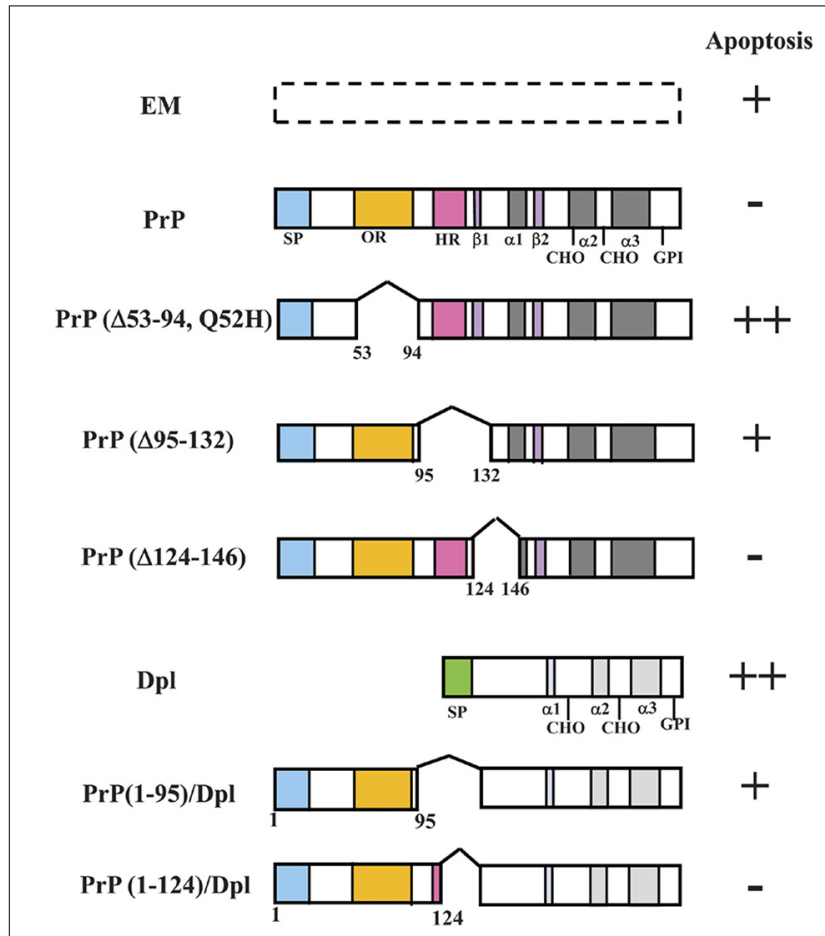

FIGURE 3 | Schematic representations of PrP deletion mutants or PrP-Dpl fusion proteins and Prnp ${ }^{-/-}$cells (HpL3-4) expressing these mutants that undergo apoptosis under serum deprivation. Schematic representations of deletion mutants of mouse PrP and PrP-Dpl fusion protein are shown. Mutants of mouse PrP [PrP: wild-type PrP; $\Delta \# 1$, $\operatorname{PrP}(\Delta 53-94, \mathrm{Q} 52 \mathrm{H}) ; \Delta \# 2, \operatorname{PrP}(\Delta$ 95-132); $\Delta \# 3, \operatorname{PrP}(\Delta 124-146)]$ were prepared using restriction digestion/ligation. Schematic locations of the deletions as compared with the wild-type protein are shown by a space within the bar next to the indicated protein. Dpl lacks sequences homologous to the octapeptide repeat (OR) and hydrophobic regions (HR) of PrP. ORDpl [PrP(1-95)-Dpl] is Dpl fused with amino acid residues 1-95 of PrP containing the OR. ORHRDpl [PrP(1-124)-Dpl] is Dpl fused with amino acid residues 1-124 of PrP containing the OR and $\mathrm{N}$-terminal half of $\mathrm{HR}$. The numbers refer to the amino acid residues in the mouse PrP sequence or Dpl sequence. The Asn-linked glycosylation sites ( $\mathrm{CHO}$ ), signal peptide sequence (SP), octapeptide repeat region (OR) and hydrophobic region (HR) are shown. The regions forming an $\alpha$-helix secondary structure are shown as $\alpha 1-\alpha 3$, whereas those forming a $\beta$-sheet are shown as $\beta 1$ and $\beta 2$. Both PrP and Dpl have a glycosylphosphatidylinositol (GPI) anchor attached to its C-terminus. HpL3-4 cells expressing wild-type $\operatorname{PrP}(\operatorname{PrP}), \operatorname{PrP}(\Delta 53-94$, $\mathrm{Q} 52 \mathrm{H})(\Delta \# 1), \operatorname{PrP}(\Delta 95-132)(\Delta \# 2), \operatorname{PrP}(\Delta 124-146)(\Delta \# 3), \mathrm{Dpl}(\mathrm{Dpl})$, $\operatorname{PrP}(1-95)-D p l$ (ORDpl), $\operatorname{PrP}(1-124)-D p l$ (ORHRDpl) or the empty vector alone (EM) were serum-deprived. The rate of apoptosis of the cells after serum deprivation for $24 \mathrm{~h}$ is shown on the right. The number of pluses $(+)$ indicates the degree of apoptosis. Minus (-) indicates a lesser degree of apoptosis. Updated from Figure 4 in Sakudo et al. (2006) and Figure 3 in Sakudo et al. (2007b) with permission from Bentham Science Publishers, Ltd. and John Wiley \& Sons, Inc., respectively.

made (Figure 3). The anti-apoptotic function of three PrP deletion constructs and PrP-Dpl fusion constructs as well as the control constructs was tested following stable transfection into Prnp ${ }^{-/-}$neuronal cells HpL3-4 [HpL3-4 cells expressing wildtype $\operatorname{PrP}(\operatorname{PrP}: \mathrm{HpL} 3-4-\mathrm{PrP}), \operatorname{PrP}(\Delta 53-94, \mathrm{Q} 52 \mathrm{H})(\Delta \# 1: \mathrm{HpL} 3-$ 4- $\Delta \# 1), \operatorname{PrP}(\Delta 95-132)(\Delta \# 2: \mathrm{HpL} 3-4-\Delta \# 2), \operatorname{PrP}(\Delta 124-146)$ ( $\Delta \# 3$ : HpL3-4- $\Delta \# 3), \operatorname{PrP}(1-95)-\mathrm{Dpl}$ (ORDpl: HpL3-4-ORDpl),
PrP(1-124)-Dpl (ORHRDpl: HpL3-4-ORHRDpl) or empty vector alone (EM: HpL3-4-EM)]. Western blotting confirmed that the cell clones expressed the deletion mutants and fusions at similar levels to those of clones expressing the full-length protein. In the absence of serum, HpL3-4 cells undergo cell death with features of apoptosis, whereas $\mathrm{Prnp}^{-/-}$cells transfected with Prnp are resistant to serum deprivation (Kuwahara et al., 1999; Sakudo et al., 2003b, 2005a). Serum deprivation showed that the control transfectants (HpL3-4-EM) underwent rapid cell death, while the full-length PrP-transfected cells were significantly protected. In contrast, the cells expressing OR-deficient $\operatorname{PrP}(\mathrm{HpL} 3-4-\triangle \# 1)$ showed higher levels of cell death compared with HpL3-4-EM cells. Interestingly, the cells expressing the $\mathrm{N}$ terminal half of HR-deficient $\operatorname{PrP}(\mathrm{HpL} 3-4-\Delta \# 2)$ underwent cell death at equivalent levels to HpL3-4-EM cells. In contrast, the cells expressing the C-terminal half of HR-deficient PrP (HpL34- $\Delta \# 3$ ) underwent cell death at equivalent levels to HpL3-4-PrP cells. The cells expressing Dpl fused to OR (HpL3-4-ORDpl) died at slightly higher levels compared to HpL3-4-EM cells, while the cells expressing Dpl fused to OR and N-terminal half of HR (HpL3-4-ORHRDpl) displayed elevated levels of survival over HpL3-4-EM cells (Lee et al., 2006).

Therefore, the data suggest that the anti-apoptotic function of $\mathrm{PrP}^{\mathrm{C}}$ can be regulated by not only the OR domain but also the N-terminal half of HR. In addition, a fusion protein containing $\mathrm{OR}$ of PrP did not protect the cells against stress, whereas extending the fusion to the N-terminal half of HR did provide some protection. These findings support the notion that both the $\mathrm{OR}$ and $\mathrm{HR}$ are important domains for PrP function. Moreover, measurement of cellular SOD activity showed that OR and the $\mathrm{N}$-terminal half of HR are necessary for the activation of cellular SOD in HpL3-4 cells (Sakudo et al., 2005c). Therefore, regulation of the anti-oxidative defense systems, such as SOD activity, by $\operatorname{PrP}$ suggests this domain contributes to the anti-oxidative and anti-apoptotic activity during serum deprivation in HpL3-4 cells.

Mouse $\operatorname{PrP}$ is cleaved at the $\beta$ site located in OR and near His96 as well as the $\alpha$ site located at position 111/112 (Mange et al., 2004). A PrP fragment was immunocaptured from HpL34 cells expressing wild-type PrP using an antibody recognizing the N-terminal region of PrP. This fragment mainly includes the $\mathrm{N}$-terminal portion of the protein generated after cleavage at the $\beta$ site. Interestingly, $\beta$ cleavage was observed after oxidative stress treatment in vitro (Mcmahon et al., 2001). Furthermore, HpL34 cells expressing $\operatorname{PrP}(\Delta 110-119)$ lacking the $\alpha$ cleavage site were more protected against stress than those expressing an equivalent level of wild-type PrP (Mange et al., 2004). These observations suggest that $\operatorname{PrP}(\Delta 110-119)$ is the dominant positive form of $\operatorname{PrP}$. Because the absence of $\alpha$ cleavage was found to enhance cell viability, $\alpha$ cleavage appears to suppress the protective activity of PrP. By contrast, $\beta$ cleavage may contribute to protection. Further studies are required to analyze the effect of $\beta$ cleavage on the neuroprotection mechanism of PrP.

Regarding $\mathrm{OR}$ and $\mathrm{HR}$, several potential interactors of $\mathrm{PrP}$ have been reported. Copper specifically binds the OR of $\operatorname{PrP}$ (Hornshaw et al., 1995; Brown et al., 1997; Viles et al., 1999; Kramer et al., 2001). STI1, binds with amino acid residues 
113-128 located in the N-terminal half of the HR of PrP (Zanata et al., 2002). Indeed, immunoprecipitation studies suggest that STI1 interacts with PrP in HpL3-4-PrP cells (Sakudo et al., 2005a). Therefore, we performed additional studies using HpL3-4 cells in order to determine how STI1 and copper might contribute to PrP-dependent anti-oxidative signaling. To investigate whether the STI1 is important for the biological activities displayed by PrP, the effect of the inhibitory peptides against PrP-STI1 on HpL3-4EM cells was compared to that on HpL3-4-PrP cells under serumfree conditions (Sakudo et al., 2005a). The inhibitory peptides are toxic to HpL3-4-PrP cells due to inhibiting the SOD activity, although this is not the case for HpL3-4-EM cells (Sakudo et al., 2005a). Regarding copper, the cellular copper concentration was decreased in HpL3-4-EM cells, but not in HpL3-4-PrP cells under serum deprivation (Sakudo et al., 2004). Therefore, it is proposed that STI1 and copper might be involved in PrP-dependent SOD activation that can inhibit apoptosis via the OR and N-terminal half of $\operatorname{PrP}$.

By considering the data reported using $\mathrm{HpL}$ cell lines, it is further proposed that the susceptibility of HpL3-4 cells to cell death is probably due to reduced SOD activity, induced, at least in part, by the absence of PrP-STI1 signals and the abnormality of copper homeostasis as well as the lack of $\beta$ cleavage. Taken together, these findings suggest that PrP plays an anti-oxidative role and functions only under extreme stress such as oxidative conditions.

\section{CONCLUSIONS AND FUTURE PERSPECTIVES}

The list of abnormalities caused by PrP-deficiency from the results of phenotype analysis of $P r n p^{-/-}$mice and from comparison between PrP-non-expressing cells and PrP-expressing cells continues to grow. Nonetheless, there has been little consensus from these studies regarding the overall main cellular function of $\operatorname{PrP}^{\mathrm{C}}$. To enable us to analyse $\operatorname{PrP}^{\mathrm{C}}$ in detail, $\operatorname{Prnp}{ }^{-/-}$cell lines have been established. Recently, the number of available Prnp $p^{-/-}$ cell lines has increased, including neuronal cells, astroglial cells, microglia, macrophages, and fibroblasts (Table 1). Rescue of Prnp by reintroducing into $P r n p^{-/-}$cell lines will provide convincing data. If further evidence is required, genetic complementation using the PrP transgene should be performed using a vector driven Prnp promoter. Indeed, $\operatorname{PrP}^{\mathrm{C}}$ function may differ depending on its expression level. As a consequence, levels of $\mathrm{PrP}^{\mathrm{C}}$ expression that are either too high or too low may mask the true biological function of the protein. Indeed, overexpression may cause the emergence of different functions from the real physiological function. Thus, if possible, analysis should be performed using physiological expression levels of $\mathrm{PrP}^{\mathrm{C}}$ in each cell type. However, in the case of low $\mathrm{PrP}^{\mathrm{C}}$ expressing cells, it becomes very difficult to detect the $\operatorname{PrP}^{\mathrm{C}}$ expression and analyse $\operatorname{PrP}^{\mathrm{C}}$ function (Raeber et al., 1999; Prinz et al., 2004).

The use of the Prnp ${ }^{-/-}$cell lines has facilitated the identification of abnormalities caused by PrP-deficiency at the cellular level (Table 2). Establishment of more Prnp ${ }^{-/-}$cell lines will further contribute to our understanding of $\mathrm{PrP}^{\mathrm{C}}$ function. For example, PrP family members are known to be expressed in reproductive tissues, such as testis, ovary, and placenta (Bonnet and Pailhoux, 2014; Makzhami et al., 2014). Thus, cells derived from reproductive tissues should also be used for the establishment of Prnp ${ }^{-/-}$cell lines. The importance of $\mathrm{PrP}^{\mathrm{C}}$ in leukocyte function has also been suggested because $\operatorname{Prn} p^{-/-}$lymphocytes show a reduction of mitogen response, cytokine production and proliferation (Kubosaki et al., 2003; Bainbridge and Walker, 2005). Recent studies have also demonstrated that $\operatorname{PrP}^{\mathrm{C}}$ plays a role in $\mathrm{T}$ cell and dendritic cell interactions (Ballerini et al., 2006). Therefore, the establishment of a Prnp ${ }^{-/-}$leukocyte cell line would be interesting.

As knockout animals lack all $\operatorname{PrP}$ expression, it is unclear whether the alteration and phenotypes in $\mathrm{Prnp}^{-/-}$mice are attributable to defects in cell function or development. Function of $\mathrm{PrP}^{\mathrm{C}}$ in the maturation process is feasible (Martin-Lannerée et al., 2014). Recent developments in regenerative medicine enable us to use various stem cells, such as embryonic stem (ES) cells and induced pluripotent stem (iPS) cells (Yamanaka, 2007). Establishment of Prnp ${ }^{-/-}$ES or iPS cells would open the opportunity for detailed analysis of $\mathrm{PrP}^{\mathrm{C}}$ function in reprogramming, expansion, isolation and differentiation.

The most studied phenotype of Prnp ${ }^{-/-}$mice is myelin degeneration. This phenotype is seen in both type 1 and type 2 Prnp $^{-/-}$ mice (Nishida et al., 1999; Baumann et al., 2007; Bremer et al., 2010). The myelin degeneration phenotype is caused by a deficiency of $\operatorname{PrP}^{\mathrm{C}}$, suggesting that myelin maintenance may be a representative physiological function of $\mathrm{PrP}^{\mathrm{C}}$. The process of demyelination is usually related to an abnormality of the immune system (Ramesh et al., 2013). The abnormal activity of immune cells may cause demyelination. Indeed, defects of immune cells in $\operatorname{Prnp} \mathrm{P}^{-1-}$ mice have been reported in several papers. Myelin sheath is composed of Schwann cells and oligodendrocytes (Alberts et al., 2008). As Schwann cell and oligodendroglia is one of glial cells, the study using glial Prnp ${ }^{-/-}$cell line GpL1might reveal some characteristics of $\operatorname{PrP}^{\mathrm{C}}$ related to myelin maintenance.

If knockout of Prnp is not required, suppression of Prnp is relatively easily achieved by gene silencing technology using siRNA (small interference RNA), miRNA (micro-RNA), bishRNA (bifunctional short hairpin RNA), or shRNA (Kubowicz et al., 2013). Indeed, shRNA of Prnp has been used for producing $\mathrm{PrP}^{\mathrm{C}}$-depleted 1C11 neuroectodermal cells (Loubet et al., 2012). If a knockout of Prnp is required, the relevant $P r n p^{-/-}$cell line should be generated (Figure 4). Recent development of immortalization techniques enables cells derived from $\mathrm{Prnp}^{-/-}$mice to be immortalized using oncogene transfection, radiation, fusion with cancer cells or treatment with chemical mutagens. In other cases, cells derived from transgenic mice with an oncogene (e.g., temperature sensitive SV40 largeT or p53) that is overexpressed, mutated or deleted can proliferate and be maintained in culture medium, resulting in the establishment of a cell line (Obinata, 2007). Alternatively, gene editing techniques such as CRISPR (Clustered Regularly Interspaced Short Palindromic Repeat) (Hsu et al., 2014), ZFN (Zinc Finger Nuclease) (Swarthout et al., 2011) or TALEN (Transcription activator-like effector nuclease) (Wright et al., 2014) can be used to knockout Prnp, resulting in the production of $\operatorname{Pr} n p^{+/-}$or $\operatorname{Pr} n p^{-/-}$cell lines.

Prnp ${ }^{-1-}$ cell lines are mainly used for two experimental purposes; analysis of $\operatorname{PrP}^{\mathrm{C}}$ function and the study of prions. 
Table 1 | Prnp ${ }^{-/-}$cell lines and their characteristics.

\begin{tabular}{|c|c|c|c|c|c|c|}
\hline Names & $\begin{array}{l}\text { Method of production } \\
\text { of cell lines }\end{array}$ & Cell type & $\begin{array}{l}\text { Prnp }^{-/-} \\
\text {mouse origin }\end{array}$ & Culture medium & $\begin{array}{l}\text { Main characterization } \\
\text { compared to PrP } \\
\text { expressing cells }\end{array}$ & References \\
\hline $\begin{array}{l}\text { HpL2-1, } \\
\text { HpL3-2, } \\
\text { HpL4-3 }\end{array}$ & $\begin{array}{l}\text { Retrovirus-mediated } \\
\text { method by SV40 large T } \\
\text { antigen expressing } \\
\text { vector }\end{array}$ & $\begin{array}{l}\text { Neuronal-precursor } \\
\text { cells (expessing NF- } \\
68 \mathrm{~K} \text { ) }\end{array}$ & Rikn & 10\% FCS-DMEM & $\begin{array}{l}\text { Susceptible to serum } \\
\text { deprivation }\end{array}$ & $\begin{array}{l}\text { Kuwahara et al., } \\
1999\end{array}$ \\
\hline $\begin{array}{l}\text { Zpl2-1, } \\
\text { Zpl2-4, } \\
\text { Zpl3-4 }\end{array}$ & $\begin{array}{l}\text { Lipofection of SV40 large } \\
\text { T antigen expressing } \\
\text { vector }\end{array}$ & $\begin{array}{l}\text { Neuronal cells } \\
\text { (expressing NeuN) }\end{array}$ & Zrchl & DMEM & Higher prolifertion rate & Kim et al., 2005 \\
\hline $\begin{array}{l}\text { SFK-B, } \\
\text { SFK-C }\end{array}$ & $\begin{array}{l}\text { Continuous culture of } \\
\text { abdominal skin explants }\end{array}$ & Skin fibroblast cells & Ngsk & $10 \%$ FCS-DMEM & $\begin{array}{l}\text { Decreased expression of } \\
\text { Ras and Rac related } \\
\text { proteins }\end{array}$ & $\begin{array}{l}\text { Satoh et al., } \\
\text { 1998, } 2000\end{array}$ \\
\hline F14 & $\begin{array}{l}\text { Fusion of PrP-knockout } \\
\text { cerebellar cells and } \\
\text { mouse neuroblastoma } \\
\text { cells }\end{array}$ & $\begin{array}{l}\text { Neuronal cells } \\
\text { (expressing NeuN, } \\
\text { MAP-2, and } \\
\text { synaptophysin) }\end{array}$ & $\mathrm{Npu}$ & $\begin{array}{l}\text { Serum containing } \\
\text { DMEM }\end{array}$ & $\begin{array}{l}\text { Similar distribution of } \\
\text { GFP-PrP fusion protein }\end{array}$ & $\begin{array}{l}\text { Holme et al., } \\
2003\end{array}$ \\
\hline $\mathrm{NpL2}$ & $\begin{array}{l}\text { Retrovirus-mediated } \\
\text { method by SV40 large T } \\
\text { antigen expressing } \\
\text { vector }\end{array}$ & $\begin{array}{l}\text { Neuronal cells } \\
\text { (expressing NF-L, } \\
\text { NF-M, NF-H, and } \\
\text { MAP-2) }\end{array}$ & Zrchl & $\begin{array}{l}10 \% \text { FCS-NB/B27 } \\
\text { medium }\end{array}$ & $\begin{array}{l}\text { Susceptible to serum } \\
\text { deprivation }\end{array}$ & $\begin{array}{l}\text { Nishimura et al., } \\
2007\end{array}$ \\
\hline MGO & $\begin{array}{l}\text { Retrovirus-mediated } \\
\text { method by c-myc } \\
\text { expressing vector }\end{array}$ & $\begin{array}{l}\text { Microglial cell } \\
\text { (expressing Mac-1 } \\
\text { and F4/80) }\end{array}$ & Rikn & $\begin{array}{l}10 \% \text { FCS-DMEM } \\
\text { supplemented with } \\
100 \mu \mathrm{M} \\
\beta \text {-mercaptoethanol, } \\
10 \mu \mathrm{g} / \mathrm{ml} \text { insulin }\end{array}$ & $\begin{array}{l}\text { Comparison has not } \\
\text { been performed }\end{array}$ & $\begin{array}{l}\text { Iwamaru et al., } \\
2007\end{array}$ \\
\hline MpLZ4-3 & $\begin{array}{l}\text { Retrovirus-mediated } \\
\text { method by SV40 large T } \\
\text { antigen expressing } \\
\text { vector }\end{array}$ & $\begin{array}{l}\text { Macrophage } \\
\text { (expressing } \\
\text { MOMA-2 and F4/80) }\end{array}$ & Zrchl & $10 \%$ FCS-DMEM & $\begin{array}{l}\text { Shorter pseudopodium } \\
\text { extension and less } \\
\text { phagocytotic activity }\end{array}$ & Uraki et al., 2010 \\
\hline $\operatorname{PrP}^{0 / 0} / 1$ & $\begin{array}{l}\text { Treatment with chemical } \\
\text { mutagen } \\
\text { (3-methylcholanthrene) }\end{array}$ & $\begin{array}{l}\text { Embryonic fibroblast } \\
\text { (expressing } \\
\text { fibronectin) }\end{array}$ & Ngsk & $\begin{array}{l}10 \% \text { FCS-MEMD } \\
\text { supplemented with } \\
2 \text { mM-glutamine }\end{array}$ & $\begin{array}{l}\text { Higher prolifertion rate } \\
\text { (probably artificial) }\end{array}$ & $\begin{array}{l}\text { Prcina et al., } \\
2010\end{array}$ \\
\hline GpL1 & $\begin{array}{l}\text { Retrovirus-mediated } \\
\text { method by SV40 large T } \\
\text { antigen expressing } \\
\text { vector }\end{array}$ & $\begin{array}{l}\text { Glial cells } \\
\text { (expressing GFAP) }\end{array}$ & Zrchl & $10 \%$ FCS-DMEM & $\begin{array}{l}\text { Susceptible to serum } \\
\text { deprivation }\end{array}$ & $\begin{array}{l}\text { Nishimura et al., } \\
2008\end{array}$ \\
\hline
\end{tabular}

DMEM, Dulbecco's modified Eagle's medium.

MCA, Methylcholanthrene, which is a highly carcinogenic polycyclic aromatic hydrocarbon produced by burning organic compounds at very high temperatures. NB/B27 medium, neurobasal medium (NB) (Gibco BRL, Gaithersburg, MD, USA) supplemented with B27 supplement (B27) (Gibco) and glutamine.

Updated from Table 3 in Sakudo et al. (2006) with permission from Bentham Science Publishers, Ltd.

For example, there are several reports of the successful production of monoclonal and polyclonal antibodies against PrP by immunizing $\operatorname{Prnp}^{-/-}$mice with recombinant murine PrP (Zanusso et al., 1998), human recombinant PrP folded into $\alpha$ or $\beta$ (Beringue et al., 2003), purified $\operatorname{PrP}^{\mathrm{C}}$ and $\operatorname{PrP}^{\mathrm{Sc}}$ (Prusiner et al., 1993; Tayebi et al., 2011), scrapie-infected mouse neuroblastoma cells (Nakamura et al., 2003a), DNA plasmids encoding Prnp (Krasemann et al., 1996a,b), PrP-displaying retrovirus particles (Nikles et al., 2005), and PrP-coated microbeads (Tayebi et al., 2011). Thus, by immunizing Prnp ${ }^{-1-}$ mice with the derived $P r n p^{-/-}$cell lines transfected with Prnp or mutated Prnp, specific antibodies to wild-type or mutated $\operatorname{PrP}$ could be readily obtained. Furthermore, to obtain specific antibodies to $\mathrm{PrP}^{\mathrm{Sc}}$, immunization of $\mathrm{Prnp}^{-/-}$mice with prion-infected $\mathrm{Prnp} \mathrm{P}^{-/-}$ cells transfected with Prnp could be a promising approach.

There is a species barrier in prion susceptibility, which is determined by the difference between the species of the host expressing PrP and species of prion agent (Beringue et al., 2008). 
Table 2 | Abnormality of PrP gene-deficient cell lines.

\begin{tabular}{|c|c|c|}
\hline Names & Main characterization compared to PrP expressing cells & References \\
\hline $\begin{array}{l}\text { HpL2-1, HpL3-2, } \\
\text { HpL4-3 }\end{array}$ & Higher rate of apoptosis by serum deprivation & $\begin{array}{l}\text { Kuwahara et al., 1999; Sakudo et al., 2003a, 2005a,b,c; } \\
\text { Kim et al., 2004; Vassallo et al., 2005; Wu et al., } 2008\end{array}$ \\
\hline HpL3-4 & $\begin{array}{l}\text { Decrease of intracellular copper concentration after serum } \\
\text { deprivation }\end{array}$ & Sakudo et al., 2004 \\
\hline HpL3-4 & Decrease of cellular SOD activity & Sakudo et al., 2003a \\
\hline HpL3-4 & $\begin{array}{l}\text { Bigger increase of intracellular superoxide anion after serum } \\
\text { deprivation }\end{array}$ & Sakudo et al., 2003a \\
\hline HpL3-4 & $\begin{array}{l}\text { Reduced increase of intracellular hydrogen peroxide after serum } \\
\text { deprivation }\end{array}$ & Sakudo et al., 2003a \\
\hline HpL3-4 & Bigger increase of caspase-3/9 activation after serum deprivation & Sakudo et al., 2003a \\
\hline HpL3-4 & Increased sensitivity of poliovirus infection & Baj et al., 2005 \\
\hline HpL3-4 & Increased coxsackievirus B3 production and apoptotic cell death & Nakamura et al., 2003a \\
\hline HpL3-4 & $\begin{array}{l}\text { Alteration of } \mathrm{Ca}^{2+} \text { concentration in mitochondria after serum } \\
\text { deprivation }\end{array}$ & Kim et al., 2004 \\
\hline HpL3-4 & $\begin{array}{l}\text { Alteration of transmembrane potentials in mitochondria after serum } \\
\text { deprivation }\end{array}$ & Kim et al., 2004 \\
\hline HpL3-4 & $\begin{array}{l}\text { Alteration of cytochrome c level in mitochondria after serum } \\
\text { deprivation }\end{array}$ & Kim et al., 2004 \\
\hline HpL3-4 & Higher rate of apoptosis by SIN-1 & Vassallo et al., 2005 \\
\hline HpL3-4 & Reduced PI 3-kinase activity & Vassallo et al., 2005 \\
\hline HpL3-4 & Decrease of cellular viability & Mange et al., 2004; Christensen and Harris, 2008 \\
\hline HpL3-4 & Shorter neurite extension after differentiation & Kuwahara et al., 1999 \\
\hline HpL3-4 & $\begin{array}{l}\text { Suceptible to amyloid beta toxicity and amyloid beta-inducing } \\
\text { autophagy }\end{array}$ & Nah et al., 2013 \\
\hline HpL3-4 & $\begin{array}{l}\text { Decreased rise in intracellular calcium following hydrogen peroxide } \\
\text { treatment }\end{array}$ & Krebs et al., 2007 \\
\hline HpL3-4 & Neutralization of Dpl toxicity & Sakudo et al., $2005 c$ \\
\hline $\mathrm{NpL2}$ & Decrease of SOD activity & Nishimura et al., 2007 \\
\hline NpL2 & Higher rate of apoptosis by serum deprivation & Nishimura et al., 2007 \\
\hline Zpl2-1, Zpl2-4, Zpl3-4 & Higher prolifertion rate & Kim et al., 2005 \\
\hline Zpl3-4 & Increased autophagy induced by serum deprivation & Oh et al., 2008 \\
\hline Zpl3-4 & Higher rate of apoptosis and autophagy by serum deprivation & Oh et al., 2008 \\
\hline GpL1 & Decrease of SOD activity & Nishimura et al., 2008 \\
\hline GpL1 & Higher rate of apoptosis by serum deprivation & Nishimura et al., 2008 \\
\hline GpL1 & Decrease of cellular viability of co-cultured neuronal cells & Onodera and Sakudo, unpublished results \\
\hline MplZ3-4 & Shorter pseudopedium extension and reduced phagocytotic activity & Uraki et al., 2010 \\
\hline $\operatorname{PrP} 0 / 0 / 1$ & Higher proliferation rate (may be non-specific) & Prcina et al., 2010 \\
\hline SFK-B, SFK-C & Decreased expression of Ras and Rac related proteins & Satoh et al., 1998, 2000 \\
\hline
\end{tabular}

PI3, phosphatidylinositol 3.

SIN-1, 3-morpholinosydnonimine.

SOD, superoxide dismutase.

Updated from Table 4 in Sakudo et al. (2006) with permission from Bentham Science Publishers, Ltd.

Prnp ${ }^{-/-}$cell lines are useful for producing susceptible cells to target species of prion agent after Prnp transfection of the target species. Importantly, endogenous $\mathrm{PrP}$ is not present in the Prnp ${ }^{-/-}$cell line. Thus, interference by endogenous PrP does not occur in a Prnp ${ }^{-/-}$cell line. The Prnp ${ }^{-/-}$cell line transfected with deletion mutants of $\operatorname{PrP}$ can be used for investigating important regions of PrP for prion infection. Previous results using the HpL3-4 cell line and chandler scrapie strain showed that OR is an essential region for the production of $\mathrm{PrP}^{\mathrm{Sc}}$ during the early stage of infection (Sakudo et al., 2008). This was supported by other reports using the HpL3-4 cell line and 22L scrapie strain, indicating that substitution of amino acid residues of mouse PrP at position 96, located in the region between OR and HR, decreased $\mathrm{PrP}^{\mathrm{Sc}}$ formation (Maas et al., 2007). The report also showed that the C-terminal half of PrP impacts on conversion efficiency. The C-terminal half of PrP includes regions forming a secondary structure of $\alpha$-helix, termed $\alpha 1-\alpha 3$, while that of $\beta$-sheet is termed $\beta 1$ and $\beta 2$. Substitution of amino acid residues of mouse $\operatorname{PrP}$ at position 132 (located between $\beta 1$ and $\alpha 1$ ), 150 ( $\alpha 1$ region), 167 (located between $\beta 2$ and $\alpha 2$ ), 189 ( $\alpha 2$ region) and 204 ( $\alpha 3$ region) 


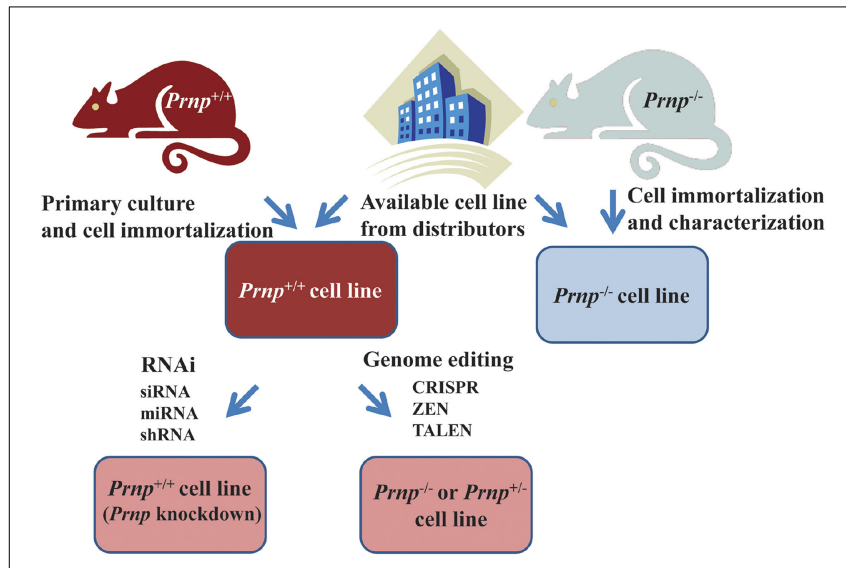

FIGURE 4 | Strategies for obtaining cell lines in which Prnp is suppressed or knocked out. Established $P_{r n p^{-1-}}$ cell lines can be obtained from a number of distributors. If suppression of Prnp is required, rather than a knockout of Prnp, gene silencing technology using siRNA (small interference RNA), miRNA (micro-RNA) bi-shRNA (bifunctional short hairpin RNA) or shRNA (short hairpin RNA) is applicable. In other cases, when a new Prnp ${ }^{-/-}$cell line is generated, immortalization of cells derived from Prnp ${ }^{-/-}$mice is usually performed. Alternatively, gene editing techniques such as CRISPR (Clustered Regularly Interspaced Short Palindromic Repeat), ZFN (Zinc Finger Nuclease), or TALEN (Transcription activator-like effector nuclease) can be used to knockout Prnp, resulting in the production of $\mathrm{Prnp}^{+/-}$or $\mathrm{Prnp}^{-/-}$cell lines. Cells can be immortalized using oncogene transfection, radiation, fusion with cancer cells, or treatment with chemical mutagens. In other cases, cells derived from transgenic mice with an oncogene (e.g., temperature sensitive SV40 (Simian virus 40) large T, p53 etc.) that is overexpressed, mutated or deleted can proliferate and be maintained in culture medium. Continuous fibroblast culture can also be used. A cell line may be established after cloning and selection of these cells.

abolished the efficient conversion of $\operatorname{PrP}^{\mathrm{Sc}}$. Taken together, these results suggest OR, $\alpha$-helices and the surrounding region contributes to the susceptibility of prion infection. Newly generated $\mathrm{PrP}^{\mathrm{C}}$ and $\mathrm{PrP}^{\mathrm{Sc}}$ antibodies together with cell lines that are susceptible or non-susceptible to target species of prion agents will be extremely useful for exploring prion biology.

Finally, we would like to emphasize that development of "OMICS" such as genomics, epigenomics, proteomics, metabolomics and transcriptomics will enable us to obtain a global view of the network of processes that are regulated by $\operatorname{PrP}^{\mathrm{C}}$. By exploiting the combination of $\operatorname{Prnp}^{-/-}$cell lines, comparison of PrP-expressing and PrP-non-expressing cells by OMICS will provide invaluable information on the effect of PrP-deficiency and fundamental differences caused by PrP-deficiency. The accumulated knowledge using these systems will be of great help in understanding $\operatorname{PrP}^{\mathrm{C}}$ functions, which is also important in terms of clarifying the etiology of prion diseases.

\section{AUTHOR CONTRIBUTIONS}

All authors contributed to the conception of this review and approved the submitted version.

\section{ACKNOWLEDGMENTS}

This work was supported by Grant-in-Aids for Scientific Research from the Ministry of Education, Science, Culture and Technology of Japan $(25450447,23780299,20780219,17780228)$, Grants-inAid from the Research Committee of Prion disease and Slow Virus Infection, the Ministry of Health, Labour and Welfare of Japan.

\section{REFERENCES}

Alberts, B., Johnson, A., Lewis, J., Raff, M., Roberts, K., and Walter, P. (2008). Molecular Biology of the Cell, 5th Edn. New York, NY: Garland Science.

Aucouturier, P., and Carnaud, C. (2002). The immune system and prion diseases: a relationship of complicity and blindness. J. Leukoc. Biol. 72, 1075-1083.

Bainbridge, J., and Walker, K. B. (2005). The normal cellular form of prion protein modulates $\mathrm{T}$ cell responses. Immunol. Lett. 96, 147-150. doi: 10.1016/j.imlet.2004.08.006

Baj, A., Bettaccini, A., Nishimura, T., Onodera, T., and Toniolo, A. (2005). Poliovirus type 1 infection of murine PRNP-knockout neuronal cells. J. Neurovirol. 11, 237-246. doi: 10.1080/13550280590952745

Balducci, C., Beeg, M., Stravalaci, M., Bastone, A., Sclip, A., Biasini, E., et al. (2010). Synthetic amyloid-beta oligomers impair long-term memory independently of cellular prion protein. Proc. Natl. Acad. Sci. U.S.A. 107, 2295-2300. doi: 10.1073/pnas.0911829107

Ballerini, C., Gourdain, P., Bachy, V., Blanchard, N., Levavasseur, E., Gregoire, S., et al. (2006). Functional implication of cellular prion protein in antigen-driven interactions between $\mathrm{T}$ cells and dendritic cells. J. Immunol. 176, 7254-7262. doi: 10.4049/jimmunol.176.12.7254

Baumann, F., Tolnay, M., Brabeck, C., Pahnke, J., Kloz, U., Niemann, H. H., et al. (2007). Lethal recessive myelin toxicity of prion protein lacking its central domain. EMBO J. 26, 538-547. doi: 10.1038/sj.emboj.7601510

Behrens, A., Genoud, N., Naumann, H., Rulicke, T., Janett, F., Heppner, F. L., et al. (2002). Absence of the prion protein homologue Doppel causes male sterility. EMBO J. 21, 3652-3658. doi: 10.1093/emboj/cdf386

Benetti, F., Ventura, M., Salmini, B., Ceola, S., Carbonera, D., Mammi, S., et al. (2010). Cuprizone neurotoxicity, copper deficiency and neurodegeneration. Neurotoxicology 31, 509-517. doi: 10.1016/j.neuro.2010.05.008

Beringue, V., Mallinson, G., Kaisar, M., Tayebi, M., Sattar, Z., Jackson, G., et al. (2003). Regional heterogeneity of cellular prion protein isoforms in the mouse brain. Brain 126, 2065-2073. doi: 10.1093/brain/awg205

Beringue, V., Vilotte, J. L., and Laude, H. (2008). Prion agent diversity and species barrier. Vet. Res. 39, 47. doi: 10.1051/vetres:2008024

Bonnet, A., and Pailhoux, E. (2014). Role of the prion protein family in the gonads. Front. Cell Dev. Biol. 2:56. doi: 10.3389/fcell.2014.00056

Bragason, B. T., and Palsdottir, A. (2005). Interaction of PrP with NRAGE, a protein involved in neuronal apoptosis. Mol. Cell. Neurosci. 29, 232-244. doi: 10.1016/j.mcn.2005.02.013

Brandner, S., Isenmann, S., Raeber, A., Fischer, M., Sailer, A., Kobayashi, Y., et al. (1996a). Normal host prion protein necessary for scrapie-induced neurotoxicity. Nature 379, 339-343. doi: 10.1038/379339a0

Brandner, S., Raeber, A., Sailer, A., Blattler, T., Fischer, M., Weissmann, C., et al. (1996b). Normal host prion protein $\left(\mathrm{PrP}^{\mathrm{C}}\right)$ is required for scrapie spread within the central nervous system. Proc. Natl. Acad. Sci. U.S.A. 93, 13148-13151. doi: 10.1073/pnas.93.23.13148

Bremer, J., Baumann, F., Tiberi, C., Wessig, C., Fischer, H., Schwarz, P., et al. (2010). Axonal prion protein is required for peripheral myelin maintenance. Nat. Neurosci. 13, 310-318. doi: 10.1038/nn.2483

Brown, D. R. (2001a). Copper and prion disease. Brain Res. Bull. 55, 165-173. doi: 10.1016/S0361-9230(01)00453-1

Brown, D. R. (2001b). Microglia and prion disease. Microsc. Res. Tech. 54, 71-80. doi: 10.1002/jemt.1122

Brown, D. R., Hafiz, F., Glasssmith, L. L., Wong, B. S., Jones, I. M., Clive, C., et al. (2000). Consequences of manganese replacement of copper for prion protein function and proteinase resistance. $E M B O ~ J .19,1180-1186$. doi: 10.1093/emboj/19.6.1180

Brown, D. R., Qin, K., Herms, J. W., Madlung, A., Manson, J., Strome, R., et al. (1997). The cellular prion protein binds copper in vivo. Nature 390, 684-687. doi: $10.1038 / 37733$

Brown, D. R., Wong, B. S., Hafiz, F., Clive, C., Haswell, S. J., and Jones, I. M. (1999). Normal prion protein has an activity like that of superoxide dismutase. Biochem. J. 344(Pt 1), 1-5. doi: 10.1042/0264-6021:3440001 
Bueler, H., Aguzzi, A., Sailer, A., Greiner, R. A., Autenried, P., Aguet, M., et al. (1993). Mice devoid of PrP are resistant to scrapie. Cell 73, 1339-1347. doi: 10.1016/0092-8674(93)90360-3

Bueler, H., Fischer, M., Lang, Y., Bluethmann, H., Lipp, H. P., Dearmond, S. J., et al. (1992). Normal development and behaviour of mice lacking the neuronal cell-surface PrP protein. Nature 356, 577-582. doi: 10.1038/ $356577 \mathrm{a} 0$

Calella, A. M., Farinelli, M., Nuvolone, M., Mirante, O., Moos, R., Falsig, J., et al. (2010). Prion protein and Abeta-related synaptic toxicity impairment. EMBO Mol. Med. 2, 306-314. doi: 10.1002/emmm.201000082

Capellari, S., Zaidi, S. I., Urig, C. B., Perry, G., Smith, M. A., and Petersen, R. B. (1999). Prion protein glycosylation is sensitive to redox change. J. Biol. Chem. 274, 34846-34850. doi: 10.1074/jbc.274.49.34846

Chen, S. G., Teplow, D. B., Parchi, P., Teller, J. K., Gambetti, P., and AutilioGambetti, L. (1995). Truncated forms of the human prion protein in normal brain and in prion diseases. J. Biol. Chem. 270, 19173-19180. doi: $10.1074 /$ jbc. 270.32 .19173

Christensen, H. M., and Harris, D. A. (2008). Prion protein lacks robust cytoprotective activity in cultured cells. Mol. Neurodegener. 3:11. doi: 10.1186/17501326-3-11

Chung, E., Ji, Y., Sun, Y., Kascsak, R. J., Kascsak, R. B., Mehta, P. D., et al. (2010). Anti-PrP ${ }^{\mathrm{C}}$ monoclonal antibody infusion as a novel treatment for cognitive deficits in an Alzheimer's disease model mouse. BMC Neurosci. 11:130. doi 10.1186/1471-2202-11-130

Cui, T., Daniels, M., Wong, B. S., Li, R., Sy, M. S., Sassoon, J., et al. (2003). Mapping the functional domain of the prion protein. Eur. J. Biochem. 270, 3368-3376. doi: 10.1046/j.1432-1033.2003.03717.x

Daude, N., and Westaway, D. (2012a). Shadoo/PrP $(\operatorname{Sprn}(0 / 0) / \operatorname{Prnp}(0 / 0))$ double knockout mice: more than zeroes. Prion 6, 420-424. doi: 10.4161/pri. 21867

Daude, N., Wohlgemuth, S., Brown, R., Pitstick, R., Gapeshina, H., Yang, J., et al. (2012b). Knockout of the prion protein (PrP)-like Sprn gene does not produce embryonic lethality in combination with $\operatorname{PrP}(\mathrm{C})$-deficiency. Proc. Natl. Acad. Sci. U.S.A. 109, 9035-9040. doi: 10.1073/pnas.1202130109

De Almeida, C. J., Chiarini, L. B., Da Silva, J. P., Pm, E. S., Martins, M. A., and Linden, R. (2005). The cellular prion protein modulates phagocytosis and inflammatory response. J. Leukoc. Biol. 77, 238-246. doi: 10.1189/jlb. 1103531

Dohler, F., Sepulveda-Falla, D., Krasemann, S., Altmeppen, H., Schlüter, H., Hildebrand, D., et al. (2014). High molecular mass assemblies of amyloid- $\beta$ oligomers bind prion protein in patients with Alzheimer's disease. Brain 137, 873-886. doi: 10.1093/brain/awt375

Edenhofer, F., Rieger, R., Famulok, M., Wendler, W., Weiss, S., and Winnacker, E. L. (1996). Prion protein $\mathrm{PrP}^{\mathrm{C}}$ interacts with molecular chaperones of the Hsp60 family. J. Virol. 70, 4724-4728.

Fontes, P., Alvarez-Martinez, M. T., Gross, A., Carnaud, C., Kohler, S., and Liautard, J. P. (2005). Absence of evidence for the participation of the macrophage cellular prion protein in infection with Brucella suis. Infect. Immun. 73, 6229-6236. doi: 10.1128/IAI.73.10.6229-6236.2005

Gasperini, L., and Legname, G. (2014). Prion protein and aging. Front. Cell Dev. Biol. 2:44. doi: 10.3389/fcell.2014.00044

Gasset, M., Baldwin, M. A., Lloyd, D. H., Gabriel, J. M., Holtzman, D. M., Cohen, F., et al. (1992). Predicted alpha-helical regions of the prion protein when synthesized as peptides form amyloid. Proc. Natl. Acad. Sci. U.S.A. 89, 10940-10944. doi: 10.1073/pnas.89.22.10940

Gauczynski, S., Peyrin, J. M., Haik, S., Leucht, C., Hundt, C., Rieger, R., et al. (2001). The $37-\mathrm{kDa} / 67-\mathrm{kDa}$ laminin receptor acts as the cell-surface receptor for the cellular prion protein. EMBO J. 20, 5863-5875. doi: 10.1093/emboj/20. 21.5863

Genoud, N., Behrens, A., Arrighi, I., and Aguzzi, A. (2003). Prion proteins and infertility: insight from mouse models. Cytogenet. Genome Res. 103, 285-289. doi: $10.1159 / 000076814$

Giese, A., Brown, D. R., Groschup, M. H., Feldmann, C., Haist, I., and Kretzschmar, H. A. (1998). Role of microglia in neuronal cell death in prion disease. Brain Pathol. 8, 449-457. doi: 10.1111/j.1750-3639.1998.tb00167.x

Graner, E., Mercadante, A. F., Zanata, S. M., Forlenza, O. V., Cabral, A. L., Veiga, S. S., et al. (2000). Cellular prion protein binds laminin and mediates neuritogenesis. Brain Res. Mol. Brain Res. 76, 85-92. doi: 10.1016/S0169-328X(99) 00334-4
Griffiths, H. H., Whitehouse, I. J., Baybutt, H., Brown, D., Kellett, K. A., Jackson, C. D., et al. (2011). Prion protein interacts with BACE1 protein and differentially regulates its activity toward wild type and Swedish mutant amyloid precursor protein. J. Biol. Chem. 286, 33489-33500. doi: 10.1074/jbc.M111. 278556

Hachiya, N. S., Watanabe, K., Sakasegawa, Y., and Kaneko, K. (2004). Microtubulesassociated intracellular localization of the NH2-terminal cellular prion protein fragment. Biochem. Biophys. Res. Commun. 313, 818-823. doi: 10.1016/j.bbrc.2003.11.167

Hegde, R. S., Mastrianni, J. A., Scott, M. R., Defea, K. A., Tremblay, P., Torchia, M., et al. (1998). A transmembrane form of the prion protein in neurodegenerative disease. Science 279, 827-834. doi: 10.1126/science.279.5352.827

Hill, A. F., Butterworth, R. J., Joiner, S., Jackson, G., Rossor, M. N., Thomas, D. J., et al. (1999). Investigation of variant Creutzfeldt-Jakob disease and other human prion diseases with tonsil biopsy samples. Lancet 353, 183-189. doi: 10.1016/S0140-6736(98)12075-5

Holme, A., Daniels, M., Sassoon, J., and Brown, D. R. (2003). A novel method of generating neuronal cell lines from gene-knockout mice to study prion protein membrane orientation. Eur. J. Neurosci. 18, 571-579. doi: 10.1046/j.14609568.2003.02780.x

Horiuchi, M., Yamazaki, N., Ikeda, T., Ishiguro, N., and Shinagawa, M. (1995). A cellular form of prion protein $\left(\mathrm{PrP}^{\mathrm{C}}\right)$ exists in many non-neuronal tissues of sheep. J. Gen. Virol. 76 (Pt 10), 2583-2587. doi: 10.1099/0022-1317-7610-2583

Hornshaw, M. P., Mcdermott, J. R., and Candy, J. M. (1995). Copper binding to the N-terminal tandem repeat regions of mammalian and avian prion protein. Biochem. Biophys. Res. Commun. 207, 621-629. doi: 10.1006/bbrc. 1995.1233

Hsu, P. D., Lander, E. S., and Zhang, F. (2014). Development and applications of CRISPR-Cas9 for genome engineering. Cell 157, 1262-1278. doi: 10.1016/j.cell.2014.05.010

Hyeon, J. W., Kim, S. Y., Park, J. S., Choi, B. Y., Lee, S. M., Ju, Y. R., et al. (2012) The association between prion proteins and $\operatorname{Abeta}(1)(-)(4)(2)$ oligomers in cytotoxicity and apoptosis. Biochem. Biophys. Res. Commun. 424, 214-220. doi: 10.1016/j.bbrc.2012.06.056

Iwamaru, Y., Takenouchi, T., Ogihara, K., Hoshino, M., Takata, M., Imamura, M., et al. (2007). Microglial cell line established from prion protein-overexpressing mice is susceptible to various murine prion strains. J. Virol. 81, 1524-1527. doi: 10.1128/JVI.01379-06

Jackson, G. S., Murray, I., Hosszu, L. L., Gibbs, N., Waltho, J. P., Clarke, A. R., et al. (2001). Location and properties of metal-binding sites on the human prion protein. Proc. Natl. Acad. Sci. U.S.A. 98, 8531-8535. doi: 10.1073/pnas.1510 38498

Kaimann, T., Metzger, S., Kuhlmann, K., Brandt, B., Birkmann, E., Holtje, H. D., et al. (2008). Molecular model of an alpha-helical prion protein dimer and its monomeric subunits as derived from chemical crosslinking and molecular modeling calculations. J. Mol. Biol. 376, 582-596. doi: 10.1016/j.jmb.2007.11.035

Kaiser, D. M., Acharya, M., Leighton, P. L., Wang, H., Daude, N., Wohlgemuth, S. et al. (2012). Amyloid beta precursor protein and prion protein have a conserved interaction affecting cell adhesion and CNS development. PLoS ONE 7:e51305. doi: 10.1371/journal.pone.0051305

Keshet, G. I., Bar-Peled, O., Yaffe, D., Nudel, U., and Gabizon, R. (2000). The cellular prion protein colocalizes with the dystroglycan complex in the brain. J. Neurochem. 75, 1889-1897. doi: 10.1046/j.1471-4159.2000. 0751889.x

Kessels, H. W., Nguyen, L. N., Nabavi, S., and Malinow, R. (2010). The prion protein as a receptor for amyloid-beta. Nature 466, E3-E4. doi: 10.1038/nature09217

Kim, B. H., Kim, J. I., Choi, E. K., Carp, R. I., and Kim, Y. S. (2005). A neuronal cell line that does not express either prion or doppel proteins. Neuroreport 16, 425-429. doi: 10.1097/00001756-200504040-00002

Kim, B. H., Lee, H. G., Choi, J. K., Kim, J. I., Choi, E. K., Carp, R. I., et al. (2004). The cellular prion protein $\left(\mathrm{PrP}^{\mathrm{C}}\right)$ prevents apoptotic neuronal cell death and mitochondrial dysfunction induced by serum deprivation. Brain Res. Mol. Brain Res. 124, 40-50. doi: 10.1016/j.molbrainres.2004.02.005

Kramer, M. L., Kratzin, H. D., Schmidt, B., Romer, A., Windl, O., Liemann, S. et al. (2001). Prion protein binds copper within the physiological concentration range. J. Biol. Chem. 276, 16711-16719. doi: 10.1074/jbc.M006554200 
Krasemann, S., Groschup, M. H., Harmeyer, S., Hunsmann, G., and Bodemer, W. (1996b). Generation of monoclonal antibodies against human prion proteins in $\operatorname{PrP}^{0 / 0}$ mice. Mol. Med. 2, 725-734.

Krasemann, S., Groschup, M., Hunsmann, G., and Bodemer, W. (1996a). Induction of antibodies against human prion proteins ( $\mathrm{PrP}$ ) by DNA-mediated immunization of $\mathrm{PrP}^{0 / 0}$ mice. J. Immunol. Methods 199, 109-118. doi: 10.1016/S00221759(96)00165-2

Krebs, B., Wiebelitz, A., Balitzki-Korte, B., Vassallo, N., Paluch, S., Mitteregger, G., et al. (2007). Cellular prion protein modulates the intracellular calcium response to hydrogen peroxide. J. Neurochem. 100, 358-367. doi: 10.1111/j.1471-4159.2006.04256.x

Kubosaki, A., Nishimura-Nasu, Y., Nishimura, T., Yusa, S., Sakudo, A., Saeki, K., et al. (2003). Expression of normal cellular prion protein $(\operatorname{PrP}(c))$ on $\mathrm{T}$ lymphocytes and the effect of copper ion: analysis by wild-type and prion protein gene-deficient mice. Biochem. Biophys. Res. Commun. 307, 810-813. doi 10.1016/S0006-291X(03)01263-4

Kubowicz, P., Zelaszczyk, D., and Pekala, E. (2013). RNAi in clinical studies. Curr. Med. Chem. 20, 1801-1816. doi: 10.2174/09298673113209990118

Kurschner, C., and Morgan, J. I. (1995). The cellular prion protein (PrP) selectively binds to Bcl-2 in the yeast two-hybrid system. Brain Res. Mol. Brain Res. 30 165-168. doi: 10.1016/0169-328X(95)00013-I

Kuwahara, C., Takeuchi, A. M., Nishimura, T., Haraguchi, K., Kubosaki, A., Matsumoto, Y., et al. (1999). Prions prevent neuronal cell-line death. Nature 400, 225-226. doi: 10.1038/22241

Larson, M., Sherman, M. A., Amar, F., Nuvolone, M., Schneider, J. A., Bennett, D. A., et al. (2012). The complex $\operatorname{PrP}(\mathrm{c})$-Fyn couples human oligomeric $A \beta$ with pathological tau changes in Alzheimer's disease. J. Neurosci. 32, 16857-16871. doi: 10.1523/JNEUROSCI.1858-12.2012

Laurén, J., Gimbel, D. A., Nygaard, H. B., Gilbert, J. W., and Strittmatter, S. M. (2009). Cellular prion protein mediates impairment of synaptic plasticity by amyloid-beta oligomers. Nature 457, 1128-1132. doi: 10.1038/nature 07761

Lee, D. C., Sakudo, A., Kim, C. K., Nishimura, T., Saeki, K., Matsumoto, Y., et al. (2006). Fusion of Doppel to octapeptide repeat and N-terminal half of hydrophobic region of prion protein confers resistance to serum deprivation. Microbiol. Immunol. 50, 203-209. doi: 10.1111/j.1348-0421.2006. tb03787.x

Li, A., Sakaguchi, S., Atarashi, R., Roy, B. C., Nakaoke, R., Arima, K., et al. (2000a). Identification of a novel gene encoding a PrP-like protein expressed as chimeric transcripts fused to $\operatorname{PrP}$ exon $1 / 2$ in ataxic mouse line with a disrupted PrP gene. Cell. Mol. Neurobiol. 20, 553-567. doi: 10.1023/A:10070598 27541

Li, A., Sakaguchi, S., Shigematsu, K., Atarashi, R., Roy, B. C., Nakaoke, R., et al. (2000b). Physiological expression of the gene for PrP-like protein, PrPLP/Dpl, by brain endothelial cells and its ectopic expression in neurons of PrP-deficient mice ataxic due to Purkinje cell degeneration. Am. J. Pathol. 157, 1447-1452. doi: 10.1016/S0002-9440(10)64782-7

Li, Q., Chevalier, C., Henry, C., Richard, C. A., Moudjou, M., and Vidic, J. (2013). Shadoo binds lipid membranes and undergoes aggregation and fibrillization. Biochem. Biophys. Res. Commun. 438, 519-525. doi: 10.1016/j.bbrc.2013. 07.104

Loubet, D., Dakowski, C., Pietri, M., Pradines, E., Bernard, S., Callebert, J., et al. (2012). Neuritogenesis: the prion protein controls $\beta 1$ integrin signaling activity FASEB J. 26, 678-690. doi: 10.1096/fj.11-185579

Maas, E., Geissen, M., Groschup, M. H., Rost, R., Onodera, T., Schatzl, H., et al. (2007). Scrapie infection of prion protein-deficient cell line upon ectopic expression of mutant prion proteins. J. Biol. Chem. 282, 18702-18710. doi: 10.1074/jbc.M701309200

Maignien, T., Shakweh, M., Calvo, P., Marce, D., Sales, N., Fattal, E., et al. (2005). Role of gut macrophages in mice orally contaminated with scrapie or BSE. Int. J. Pharm. 298, 293-304. doi: 10.1016/j.ijpharm.2005.02.042

Makzhami, S., Passet, B., Halliez, S., Castille, J., Moazami-Goudarzi, K., Duchesne, A., et al. (2014). The prion protein family: a view from the placenta. Front. Cell Dev. Biol. 2:35. doi: 10.3389/fcell.2014.00035

Mange, A., Beranger, F., Peoc'h, K., Onodera, T., Frobert, Y., and Lehmann, S. (2004). Alpha- and beta- cleavages of the amino-terminus of the cellular prion protein. Biol. Cell 96, 125-132. doi: 10.1016/j.biolcel.2003.11.007

Manson, J. C., Clarke, A. R., Hooper, M. L., Aitchison, L., Mcconnell, I., and Hope, J. (1994a). 129/Ola mice carrying a null mutation in PrP that abolishes
mRNA production are developmentally normal. Mol. Neurobiol. 8, 121-127. doi: 10.1007/BF02780662

Manson, J. C., Clarke, A. R., Mcbride, P. A., Mcconnell, I., and Hope, J. (1994b). PrP gene dosage determines the timing but not the final intensity or distribution of lesions in scrapie pathology. Neurodegeneration 3, 331-340.

Martin-Lannerée, S., Hirsch, T. Z., Hernandez-Rapp, J., Halliez, S., Vilotte, J., Launay, J., et al. (2014). $\operatorname{PrP}^{\mathrm{C}}$ from stem cells to cancer. Front. Cell Dev. Biol. 2:55. doi: $10.3389 /$ fcell.2014.00055

Martins, V. R., Graner, E., Garcia-Abreu, J., De Souza, S. J., Mercadante, A. F., Veiga, S. S., et al. (1997). Complementary hydropathy identifies a cellular prion protein receptor. Nat. Med. 3, 1376-1382. doi: 10.1038/nm1297-1376

Mattei, V., Garofalo, T., Misasi, R., Circella, A., Manganelli, V., Lucania, G., et al. (2004). Prion protein is a component of the multimolecular signaling complex involved in T cell activation. FEBS Lett. 560, 14-18. doi: 10.1016/S00145793(04)00029-8

Mays, C. E., Coomaraswamy, J., Watts, J. C., Yang, J., Ko, K. W., Strome, B., et al. (2014). Endoproteolytic processing of the mammalian prion glycoprotein family. FEBS J. 281, 862-876. doi: 10.1111/febs.12654

Mcbride, P. A., Eikelenboom, P., Kraal, G., Fraser, H., and Bruce, M. E. (1992). PrP protein is associated with follicular dendritic cells of spleens and lymph nodes in uninfected and scrapie-infected mice. J. Pathol. 168, 413-418. doi: $10.1002 /$ path. 1711680412

McHugh, P. C., Wright, J. A., Williams, R. J., and Brown, D. R. (2012). Prion protein expression alters APP cleavage without interaction with BACE-1. Neurochem. Int. 61, 672-680. doi: 10.1016/j.neuint.2012.07.002

Mcmahon, H. E., Mange, A., Nishida, N., Creminon, C., Casanova, D., and Lehmann, S. (2001). Cleavage of the amino terminus of the prion protein by reactive oxygen species. J. Biol. Chem. 276, 2286-2291. doi: 10.1074/jbc.M007243200

Meyer, R. K., Lustig, A., Oesch, B., Fatzer, R., Zurbriggen, A., and Vandevelde, M. (2000). A monomer-dimer equilibrium of a cellular prion protein $\left(\mathrm{PrP}^{\mathrm{C}}\right)$ not observed with recombinant PrP. J. Biol. Chem. 275, 38081-38087. doi: 10.1074/jbc.M007114200

Milhavet, O., and Lehmann, S. (2002). Oxidative stress and the prion protein in transmissible spongiform encephalopathies. Brain Res. Brain Res. Rev. 38, 328-339. doi: 10.1016/S0165-0173(01)00150-3

Miura, T., Hori-i, A., Mototani, H., and Takeuchi, H. (1999). Raman spectroscopic study on the copper(II) binding mode of prion octapeptide and its $\mathrm{pH}$ dependence. Biochemistry 38, 11560-11569. doi: 10.1021/bi99 09389

Moore, R. C., Lee, I. Y., Silverman, G. L., Harrison, P. M., Strome, R., Heinrich, C., et al. (1999). Ataxia in prion protein (PrP)-deficient mice is associated with upregulation of the novel PrP-like protein doppel. J. Mol. Biol. 292, 797-817. doi: 10.1006/jmbi.1999.3108

Morales, R., Estrada, L. D., Diaz-Espinoza, R., Morales-Scheihing, D., Jara, M. C., Castilla, J., et al. (2010). Molecular cross talk between misfolded proteins in animal models of Alzheimer's and prion diseases. J. Neurosci. 30, 4528-4535. doi: 10.1523/JNEUROSCI.5924-09.2010

Moudjou, M., Frobert, Y., Grassi, J., and La Bonnardiere, C. (2001). Cellular prion protein status in sheep: tissue-specific biochemical signatures. J. Gen. Virol. 82, 2017-2024.

Mouillet-Richard, S., Ermonval, M., Chebassier, C., Laplanche, J. L., Lehmann, S., Launay, J. M., et al. (2000). Signal transduction through prion protein. Science 289, 1925-1928. doi: 10.1126/science.289.5486.1925

Mouillet-Richard, S., Schneider, B., Pradines, E., Pietri, M., Ermonval, M., Grassi, J., et al. (2007). Cellular prion protein signaling in serotonergic neuronal cells. Ann. N. Y. Acad. Sci. 1096, 106-119. doi: 10.1196/annals.1397.076

Nah, J., Pyo, J. O., Jung, S., Yoo, S. M., Kam, T. I., Chang, J., et al. (2013). BECN1/Beclin 1 is recruited into lipid rafts by prion to activate autophagy in response to amyloid beta 42. Autophagy 9, 2009-2021. doi: 10.4161/auto. 26118

Nakamura, N., Miyamoto, K., Shimokawa, M., Nishida, N., Mohri, S., Kitamoto, T., et al. (2003a). Generation of antibodies against prion protein by scrapieinfected cell immunization of $\operatorname{PrP}(0 / 0)$ mice. Hybrid. Hybridomics 22, 263-266. doi: 10.1089/153685903322328992

Nakamura, Y., Sakudo, A., Saeki, K., Kaneko, T., Matsumoto, Y., Toniolo, A., et al. (2003b). Transfection of prion protein gene suppresses coxsackievirus B3 replication in prion protein gene-deficient cells. J. Gen. Virol. 84, 3495-3502. doi: 10.1099/vir.0.19222-0 
Nieznanski, K., Nieznanska, H., Skowronek, K. J., Osiecka, K. M., and Stepkowski, D. (2005). Direct interaction between prion protein and tubulin. Biochem. Biophys. Res. Commun. 334, 403-411. doi: 10.1016/j.bbrc.2005.06.092

Nikles, D., Bach, P., Boller, K., Merten, C. A., Montrasio, F., Heppner, F. L., et al. (2005). Circumventing tolerance to the prion protein $(\mathrm{PrP})$ : vaccination with PrP-displaying retrovirus particles induces humoral immune responses against the native form of cellular PrP. J. Virol. 79, 4033-4042. doi 10.1128/JVI.79.7.4033-4042.2005

Nishida, N., Tremblay, P., Sugimoto, T., Shigematsu, K., Shirabe, S., Petromilli, C., et al. (1999). A mouse prion protein transgene rescues mice deficient for the prion protein gene from purkinje cell degeneration and demyelination. $L a b$. Invest. 79, 689-697.

Nishimura, T., Sakudo, A., Hashiyama, Y., Yachi, A., Saeki, K., Matsumoto, Y. et al. (2007). Serum withdrawal-induced apoptosis in ZrchI prion protein (PrP) gene-deficient neuronal cell line is suppressed by PrP, independent of Doppel. Microbiol. Immunol. 51, 457-466. doi: 10.1111/j.1348-0421.2007. tb03920.x

Nishimura, T., Sakudo, A., Xue, G., Ikuta, K., Yukawa, M., Sugiura, K., et al. (2008). Establishment of a new glial cell line from hippocampus of prion protein gene-deficient mice. Biochem. Biophys. Res. Commun. 377, 1047-1050. doi: 10.1016/j.bbrc.2008.10.087

Nitta, K., Sakudo, A., Masuyama, J., Xue, G., Sugiura, K., and Onodera, T. (2009). Role of cellular prion proteins in the function of macrophages and dendritic cells. Protein Pept. Lett. 16, 239-246. doi: 10.2174/092986609787 601705

Nuvolone, M., Kana, V., Hutter, G., Sakata, D., Mortin-Toth, S. M., Russo, G., et al. (2013). SIRP $\alpha$ polymorphisms, but not the prion protein, control phagocytosis of apoptotic cells. J. Exp. Med. 210, 2539-2552. doi: 10.1084/jem.20131274

Obinata, M. (2007). The immortalized cell lines with differentiation potentials: their establishment and possible application. Cancer Sci. 98, 275-283. doi: 10.1111/j.1349-7006.2007.00399.x

Oh, J. M., Shin, H. Y., Park, S. J., Kim, B. H., Choi, J. K., Choi, E. K., et al. (2008). The involvement of cellular prion protein in the autophagy pathway in neuronal cells. Mol. Cell. Neurosci. 39, 238-247. doi: 10.1016/j.mcn.2008.07.003

Onodera, T., Sakudo, A., Tsubone, H., and Itohara, S. (2014). Review of studies that have used knockout mice to assess normal function of prion protein under immunological or pathophysiological stress. Microbiol. Immunol. 58, 361-374. doi: 10.1111/1348-0421.12162

Ordóñez-Gutiérrez, L., Torres, J. M., Gavín, R., Antón, M., Arroba-Espinosa, A. I., Espinosa, J. C., et al. (2013). Cellular prion protein modulates $\beta$-amyloid deposition in aged APP/PS1 transgenic mice. Neurobiol. Aging 34, 2793-2804. doi: 10.1016/j.neurobiolaging.2013.05.019

Pan, K. M., Stahl, N., and Prusiner, S. B. (1992). Purification and properties of the cellular prion protein from Syrian hamster brain. Protein Sci. 1, 1343-1352. doi: 10.1002/pro.5560011014

Pantera, B., Bini, C., Cirri, P., Paoli, P., Camici, G., Manao, G., et al. (2009). PrPC activation induces neurite outgrowth and differentiation in PC12 cells: role for caveolin-1 in the signal transduction pathway. J. Neurochem. 110, 194-207. doi: 10.1111/j.1471-4159.2009.06123.x

Parkin, E. T., Watt, N. T., Hussain, I., Eckman, E. A., Eckman, C. B., Manson, J. C., et al. (2007). Cellular prion protein regulates beta-secretase cleavage of the Alzheimer's amyloid precursor protein. Proc. Natl. Acad. Sci. U.S.A. 104, 11062-11067. doi: 10.1073/pnas.0609621104

Passet, B., Halliez, S., Beringue, V., Laude, H., and Vilotte, J. L. (2013). The prion protein family: looking outside the central nervous system. Prion 7, 127-130. doi: $10.4161 /$ pri.22851

Passet, B., Young, R., Makhzami, S., Vilotte, M., Jaffrezic, F., Halliez, S., et al. (2012). Prion protein and Shadoo are involved in overlapping embryonic pathways and trophoblastic development. PLoS ONE 7:e41959. doi: 10.1371/journal.pone.0041959

Peoc'h, K., Serres, C., Frobert, Y., Martin, C., Lehmann, S., Chasseigneaux, S., et al. (2002). The human "prion-like" protein Doppel is expressed in both Sertoli cells and spermatozoa. J. Biol. Chem. 277, 43071-43078. doi: 10.1074/jbc.M206357200

Prcina, M., Filipcik, P., and Kontsekova, E. (2010). Establishment of the cell line expressing human prion protein on $\mathrm{PrP}^{0 / 0}$ background. Acta Virol. 54, 297-302. doi: 10.4149/av_2010_04_297

Prinz, M., Montrasio, F., Furukawa, H., Van Der Haar, M. E., Schwarz, P., Rulicke, T., et al. (2004). Intrinsic resistance of oligodendrocytes to prion infection. J. Neurosci. 24, 5974-5981. doi: 10.1523/JNEUROSCI.012204.2004

Prusiner, S. B. (1998). Prions. Proc. Natl. Acad. Sci. U.S.A. 95, 13363-13383. doi: 10.1073/pnas.95.23.13363

Prusiner, S. B., Groth, D., Serban, A., Koehler, R., Foster, D., Torchia, M., et al. (1993). Ablation of the prion protein $(\operatorname{PrP})$ gene in mice prevents scrapie and facilitates production of anti-PrP antibodies. Proc. Natl. Acad. Sci. U.S.A. 90, 10608-10612. doi: 10.1073/pnas.90.22.10608

Raeber, A. J., Sailer, A., Hegyi, I., Klein, M. A., Rulicke, T., Fischer, M., et al. (1999). Ectopic expression of prion protein $(\mathrm{PrP})$ in $\mathrm{T}$ lymphocytes or hepatocytes of PrP knockout mice is insufficient to sustain prion replication. Proc. Natl. Acad. Sci. U.S.A. 96, 3987-3992. doi: 10.1073/pnas.96.7.3987

Ramesh, G., Maclean, A. G., and Philipp, M. T. (2013). Cytokines and chemokines at the crossroads of neuroinflammation, neurodegeneration, and neuropathic pain. Mediators Inflamm. 2013:480739. doi: 10.1155/2013/480739

Rieger, R., Edenhofer, F., Lasmezas, C. I., and Weiss, S. (1997). The human 37-kDa laminin receptor precursor interacts with the prion protein in eukaryotic cells. Nat. Med. 3, 1383-1388. doi: 10.1038/nm1297-1383

Rossi, D., Cozzio, A., Flechsig, E., Klein, M. A., Rulicke, T., Aguzzi, A., et al. (2001). Onset of ataxia and Purkinje cell loss in PrP null mice inversely correlated with Dpl level in brain. EMBO J. 20, 694-702. doi: 10.1093/emboj/20. 4.694

Roucou, X., Gains, M., and Leblanc, A. C. (2004). Neuroprotective functions of prion protein. J. Neurosci. Res. 75, 153-161. doi: 10.1002/jnr. 10864

Ryder, E. F., Snyder, E. Y., and Cepko, C. L. (1990). Establishment and characterization of multipotent neural cell lines using retrovirus vector-mediated oncogene transfer. J. Neurobiol. 21, 356-375. doi: 10.1002/neu.480210209

Saeki, K., Matsumoto, Y., Hirota, Y., and Onodera, T. (1996). Three-exon structure of the gene encoding the rat prion protein and its expression in tissues. Virus Genes 12, 15-20. doi: 10.1007/BF00369996

Sakaguchi, S., Katamine, S., Nishida, N., Moriuchi, R., Shigematsu, K., Sugimoto, T., et al. (1996). Loss of cerebellar Purkinje cells in aged mice homozygous for a disrupted PrP gene. Nature 380, 528-531. doi: 10.1038/380528a0

Sakudo, A., Ano, Y., Onodera, T., Nitta, K., Shintani, H., Ikuta, K., et al. (2011a). Fundamentals of prions and their inactivation (review). Int. J. Mol. Med. 27, 483-489. doi: 10.3892/ijmm.2011.605

Sakudo, A., and Ikuta, K. (2009a). Fundamentals of prion diseases and their involvement in the loss of function of cellular prion protein. Protein Pept. Lett. 16, 217-229. doi: 10.2174/092986609787601732

Sakudo, A., and Ikuta, K. (2009b). Prion protein functions and dysfunction in prion diseases. Curr. Med. Chem. 16, 380-389. doi: 10.2174/0929867097870 02673

Sakudo, A., Lee, D. C., Li, S., Nakamura, T., Matsumoto, Y., Saeki, K., et al. (2005a). PrP cooperates with STI1 to regulate SOD activity in PrPdeficient neuronal cell line. Biochem. Biophys. Res. Commun. 328, 14-19. doi: 10.1016/j.bbrc.2004.12.132

Sakudo, A., Lee, D. C., Nakamura, I., Taniuchi, Y., Saeki, K., Matsumoto, Y., et al. (2005b). Cell-autonomous PrP-Doppel interaction regulates apoptosis in PrP gene-deficient neuronal cells. Biochem. Biophys. Res. Commun. 333, 448-454. doi: 10.1016/j.bbrc.2005.05.128

Sakudo, A., Lee, D. C., Nishimura, T., Li, S., Tsuji, S., Nakamura, T., et al. (2005c). Octapeptide repeat region and N-terminal half of hydrophobic region of prion protein ( $\mathrm{PrP})$ mediate PrP-dependent activation of superoxide dismutase. Biochem. Biophys. Res. Commun. 326, 600-606. doi: 10.1016/j.bbrc.2004. 11.092

Sakudo, A., Lee, D. C., Saeki, K., Matsumoto, Y., Itohara, S., and Onodera, T. (2003a). Tumor necrosis factor attenuates prion protein-deficient neuronal cell death by increases in anti-apoptotic Bcl-2 family proteins. Biochem. Biophys. Res. Commun. 310, 725-729. doi: 10.1016/j.bbrc.2003.09.068

Sakudo, A., Lee, D. C., Saeki, K., Nakamura, Y., Inoue, K., Matsumoto, Y., et al. (2003b). Impairment of superoxide dismutase activation by $\mathrm{N}$ terminally truncated prion protein (PrP) in PrP-deficient neuronal cell line. Biochem. Biophys. Res. Commun. 308, 660-667. doi: 10.1016/S0006-291X(03) 01459-1

Sakudo, A., Lee, D. C., Yoshimura, E., Nagasaka, S., Nitta, K., Saeki, K., et al. (2004). Prion protein suppresses perturbation of cellular copper homeostasis under oxidative conditions. Biochem. Biophys. Res. Commun. 313, 850-855. doi: 10.1016/j.bbrc.2003.12.020 
Sakudo, A., Nakamura, I., Ikuta, K., and Onodera, T. (2007a). Recent developments in prion disease research: diagnostic tools and in vitro cell culture models. J. Vet. Med. Sci. 69, 329-337. doi: 10.1292/jvms.69.329

Sakudo, A., and Onodera, T. (2011b). Tissue- and cell type-specific modification of prion protein (PrP)-like protein Doppel, which affects PrP endoproteolysis. Biochem. Biophys. Res. Commun. 404, 523-527. doi: 10.1016/j.bbrc.2010. 12.016

Sakudo, A., Onodera, T., and Ikuta, K. (2007b). Prion protein gene-deficient cell lines: powerful tools for prion biology. Microbiol. Immunol. 51, 1-13. doi: 10.1111/j.1348-0421.2007.tb03877.x

Sakudo, A., Onodera, T., Suganuma, Y., Kobayashi, T., Saeki, K., and Ikuta, K. (2006). Recent advances in clarifying prion protein functions using knockout mice and derived cell lines. Mini Rev. Med. Chem. 6, 589-601. doi: 10.2174/138955706776876159

Sakudo, A., Wu, G., Onodera, T., and Ikuta, K. (2008). Octapeptide repeat region of prion protein $(\mathrm{PrP})$ is required at an early stage for production of abnormal prion protein in PrP-deficient neuronal cell line. Biochem. Biophys. Res. Commun. 365, 164-169. doi: 10.1016/j.bbrc.2007.10.158

Satoh, J., Kuroda, Y., and Katamine, S. (2000). Gene expression profile in prion protein-deficient fibroblasts in culture. Am. J. Pathol. 157, 59-68. doi 10.1016/S0002-9440(10)64517-8

Satoh, J., Yukitake, M., Kurohara, K., Nishida, N., Katamine, S., Miyamoto, T., et al. (1998). Cultured skin fibroblasts isolated from mice devoid of the prion protein gene express major heat shock proteins in response to heat stress. Exp. Neurol. 151, 105-115. doi: 10.1006/exnr.1998.6796

Schatzl, H. M., Da Costa, M., Taylor, L., Cohen, F. E., and Prusiner, S. B. (1995). Prion protein gene variation among primates. J. Mol. Biol. 245, 362-374. doi: 10.1006/jmbi.1994.0030

Schmitt-Ulms, G., Legname, G., Baldwin, M. A., Ball, H. L., Bradon, N., Bosque, P. J., et al. (2001). Binding of neural cell adhesion molecules (N-CAMs) to the cellular prion protein. J. Mol. Biol. 314, 1209-1225. doi: 10.1006/jmbi. 2000.5183

Schwarze-Eicker, K., Keyvani, K., Görtz, N., Westaway, D., Sachser, N., and Paulus, W. (2005). Prion protein $\left(\mathrm{PrP}^{\mathrm{C}}\right)$ promotes beta-amyloid plaque formation. Neurobiol. Aging 26, 1177-1182. doi: 10.1016/j.neurobiolaging.2004. 10.004

Shaked, Y., Rosenmann, H., Talmor, G., and Gabizon, R. (1999). A C-terminaltruncated $\operatorname{PrP}$ isoform is present in mature sperm. J. Biol. Chem. 274 32153-32158. doi: 10.1074/jbc.274.45.32153

Skripuletz, T., Lindner, M., Kotsiari, A., Garde, N., Fokuhl, J., Linsmeier, F., et al. (2008). Cortical demyelination is prominent in the murine cuprizone model and is strain-dependent. Am. J. Pathol. 172, 1053-1061. doi: 10.2353/ajpath.2008.070850

Spielhaupter, C., and Schatzl, H. M. (2001). $\mathrm{PrP}^{\mathrm{C}}$ directly interacts with proteins involved in signaling pathways. J. Biol. Chem. 276, 44604-44612. doi 10.1074/jbc.M103289200

Steele, A. D., Lindquist, S., and Aguzzi, A. (2007). The prion protein knockout mouse: a phenotype under challenge. Prion 1, 83-93. doi: 10.4161/pri.1.2.4346

Swarthout, J. T. P. D., Raisinghani, M., and Cui, X. (2011). Zinc Finger nucleases: a new era for transgenic animals. Ann. Neurosci. 18, 25-28. doi 10.5214/ans.0972.7531.1118109

Tayebi, M., Jones, D. R., Taylor, W. A., Stileman, B. F., Chapman, C., Zhao, D., et al. (2011). $\operatorname{PrP}(\mathrm{Sc})$-specific antibodies with the ability to immunodetect prion oligomers. PLOS ONE 6:e19998. doi: 10.1371/journal.pone. 0019998

Toni, M., Spisni, E., Griffoni, C., Santi, S., Riccio, M., Lenaz, P., et al. (2006). Cellular prion protein and caveolin-1 interaction in a neuronal cell line precedes Fyn/Erk 1/2 signal transduction. J. Biomed. Biotechnol. 2006:69469. doi: 10.1155/JBB/2006/69469

Tuzi, N. L., Gall, E., Melton, D., and Manson, J. C. (2002). Expression of doppel in the CNS of mice does not modulate transmissible spongiform encephalopathy disease. J. Gen. Virol. 83, 705-711.

Um, J. W., Nygaard, H. B., Heiss, J. K., Kostylev, M. A., Stagi, M., Vortmeyer, A., et al. (2012). Alzheimer amyloid- $\beta$ oligomer bound to postsynaptic prion protein activates Fyn to impair neurons. Nat. Neurosci. 15, 1227-1235. doi: 10.1038/nn.3178

Um, J. W., and Strittmatter, S. M. (2013). Amyloid- $\beta$ induced signaling by cellular prion protein and Fyn kinase in Alzheimer disease. Prion 7, 37-41. doi: $10.4161 /$ pri.22212
Uraki, R., Sakudo, A., Ando, S., Kitani, H., and Onodera, T. (2010). Enhancement of phagocytotic activity by prion protein in PrP-deficient macrophage cells. Int. J. Mol. Med. 26, 527-532. doi: 10.3892/ijmm_00000495

Vassallo, N., Herms, J., Behrens, C., Krebs, B., Saeki, K., Onodera, T., et al. (2005). Activation of phosphatidylinositol 3-kinase by cellular prion protein and its role in cell survival. Biochem. Biophys. Res. Commun. 332, 75-82. doi: 10.1016/j.bbrc.2005.04.099

Verkhratsky, A., Parpura, V., Pekna, M., Pekny, M., and Sofroniew, M. (2014). Glia in the pathogenesis of neurodegenerative diseases. Biochem. Soc. Trans. 42, 1291-1301. doi: 10.1042/BST20140107

Viles, J. H., Cohen, F. E., Prusiner, S. B., Goodin, D. B., Wright, P. E., and Dyson, H. J. (1999). Copper binding to the prion protein: structural implications of four identical cooperative binding sites. Proc. Natl. Acad. Sci. U.S.A. 96, 2042-2047. doi: $10.1073 /$ pnas.96.5.2042

Watarai, M., Kim, S., Erdenebaatar, J., Makino, S., Horiuchi, M., Shirahata, T., et al. (2003). Cellular prion protein promotes Brucella infection into macrophages J. Exp. Med. 198, 5-17. doi: 10.1084/jem.20021980

Watts, J. C., Drisaldi, B., Ng, V., Yang, J., Strome, B., Horne, P., et al. (2007a). The CNS glycoprotein Shadoo has $\operatorname{PrP}(\mathrm{C})$-like protective properties and displays reduced levels in prion infections. EMBO J. 26, 4038-4050. doi: 10.1038/sj.emboj.7601830

Watts, J. C., Huo, H., Bai, Y., Ehsani, S., Jeon, A. H., Shi, T., et al. (2009) Interactome analyses identify ties of $\operatorname{PrP}$ and its mammalian paralogs to oligomannosidic N-glycans and endoplasmic reticulum-derived chaperones. PLoS Pathog. 5:e1000608. doi: 10.1371/annotation/9eb11869-6acb-49b0-978eabedc3cc545a

Watts, J. C., Stohr, J., Bhardwaj, S., Wille, H., Oehler, A., Dearmond, S. J., et al. (2011). Protease-resistant prions selectively decrease Shadoo protein. PLoS Pathog. 7:e1002382. doi: 10.1371/journal.ppat.1002382

Watts, J. C., and Westaway, D. (2007b). The prion protein family: diversity, rivalry, and dysfunction. Biochim. Biophys. Acta 1772, 654-672. doi: 10.1016/j.bbadis.2007.05.001

Weissmann, C., and Aguzzi, A. (1999). Perspectives: neurobiology. PrP’s double causes trouble. Science 286, 914-915. doi: 10.1126/science.286.5441.914

Weissmann, C., and Flechsig, E. (2003). PrP knock-out and PrP transgenic mice in prion research. Br. Med. Bull. 66, 43-60. doi: 10.1093/bmb/66.1.43

Westaway, D., Genovesi, S., Daude, N., Brown, R., Lau, A., Lee, I., et al. (2011). Down-regulation of Shadoo in prion infections traces a pre-clinical event inversely related to $\operatorname{PrP}(\mathrm{Sc})$ accumulation. PLoS Pathog. 7:e1002391. doi: 10.1371/journal.ppat.1002391

Williams, A. E., Lawson, L. J., Perry, V. H., and Fraser, H. (1994). Characterization of the microglial response in murine scrapie. Neuropathol. Appl. Neurobiol. 20, 47-55. doi: 10.1111/j.1365-2990.1994.tb00956.x

Wright, D. A., Li, T., Yang, B., and Spalding, M. H. (2014). TALEN-mediated genome editing: prospects and perspectives. Biochem. J. 462, 15-24. doi: 10.1042/BJ20140295

Wu, G., Nakajima, K., Takeyama, N., Yukawa, M., Taniuchi, Y., Sakudo, A., et al. (2008). Species-specific anti-apoptotic activity of cellular prion protein in a mouse PrP-deficient neuronal cell line transfected with mouse, hamster, and bovine Prnp. Neurosci. Lett. 446, 11-15. doi: 10.1016/j.neulet.2008.09.020

Yamanaka, S. (2007). Strategies and new developments in the generation of patient-specific pluripotent stem cells. Cell Stem Cell 1, 39-49. doi: 10.1016/j.stem.2007.05.012

Yehiely, F., Bamborough, P., Da Costa, M., Perry, B. J., Thinakaran, G., Cohen, F. E., et al. (1997). Identification of candidate proteins binding to prion protein. Neurobiol. Dis. 3, 339-355. doi: 10.1006/nbdi.1997.0130

Yokoyama, T., Kimura, K. M., Ushiki, Y., Yamada, S., Morooka, A., Nakashiba, T., et al. (2001). In vivo conversion of cellular prion protein to pathogenic isoforms, as monitored by conformation-specific antibodies. J. Biol. Chem. 276, 11265-11271. doi: 10.1074/jbc.M008734200

Zafar, S., Asif, A. R., Ramljak, S., Tahir, W., Schmitz, M., and Zerr, I. (2014) Anchorless 23-230 $\mathrm{PrP}^{\mathrm{C}}$ interactomics for elucidation of $\mathrm{PrP}^{\mathrm{C}}$ protective role. Mol. Neurobiol. 49, 1385-1399. doi: 10.1007/s12035-013-8616-2

Zafar, S., Von Ahsen, N., Oellerich, M., Zerr, I., Schulz-Schaeffer, W. J., Armstrong, V. W., et al. (2011). Proteomics approach to identify the interacting partners of cellular prion protein and characterization of Rab7a interaction in neuronal cells. J. Proteome Res. 10, 3123-3135. doi: 10.1021/pr2001989

Zanata, S. M., Lopes, M. H., Mercadante, A. F., Hajj, G. N., Chiarini, L. B., Nomizo, R., et al. (2002). Stress-inducible protein 1 is a cell surface ligand 
for cellular prion that triggers neuroprotection. EMBO J. 21, 3307-3316. doi: 10.1093/emboj/cdf325

Zanusso, G., Liu, D., Ferrari, S., Hegyi, I., Yin, X., Aguzzi, A., et al. (1998). Prion protein expression in different species: analysis with a panel of new mAbs. Proc. Natl. Acad. Sci. U.S.A. 95, 8812-8816. doi: 10.1073/pnas.95. 15.8812

Zhou, M., Ottenberg, G., Sferrazza, G. F., and Lasmezas, C. I. (2012). Highly neurotoxic monomeric alpha-helical prion protein. Proc. Natl. Acad. Sci. U.S.A. 109, 3113-3118. doi: 10.1073/pnas.1118090109

Conflict of Interest Statement: The authors declare that the research was conducted in the absence of any commercial or financial relationships that could be construed as a potential conflict of interest.
Received: 30 September 2014; accepted: 22 December 2014; published online: 15 January 2015.

Citation: Sakudo A and Onodera T (2015) Prion protein (PrP) gene-knockout cell lines: insight into functions of the PrP. Front. Cell Dev. Biol. 2:75. doi: 10.3389/fcell. 2014.00075

This article was submitted to Cell Death and Survival, a section of the journal Frontiers in Cell and Developmental Biology.

Copyright $\odot 2015$ Sakudo and Onodera. This is an open-access article distributed under the terms of the Creative Commons Attribution License (CC BY). The use, distribution or reproduction in other forums is permitted, provided the original author $(s)$ or licensor are credited and that the original publication in this journal is cited, in accordance with accepted academic practice. No use, distribution or reproduction is permitted which does not comply with these terms. 


\title{
Regulation of $\mathrm{PrPC}^{\mathrm{C}}$ signaling and processing by dimerization
}

\author{
Xavier Roucou* \\ Department of Biochemistry, Faculty of Medicine, Université de Sherbrooke, Sherbrooke, OC, Canada
}

\section{Edited by:}

Sophie Mouillet-Richard, Institut

National de la Santé et de la

Recherche Médicale, France

\section{Reviewed by:}

Markus Glatzel, University Medical

Center Hamburg-Eppendorf,

Germany

Joel Watts, University of Toronto,

Canada

*Correspondence:

Xavier Roucou, Département de Biochimie (Z8-2001), Faculté de

Médecine, Université de

Sherbrooke, 3201 Jean Mignault,

Sherbrooke, OC J1E4K8, Canada

e-mail:xavier.roucou@

usherbrooke.ca
The cellular prion protein $\left(\mathrm{PrP}^{\mathrm{C}}\right)$ is a glycosylphosphatidylinositol (GPI)-anchored protein present at the cell surface. PrPC N-terminal moiety is intrinsically disordered and is able to interact with a variety of ligands. Physiological ligands have neurotrophic activity, whilst others, including protein toxic oligomers, have neurotoxic functions. These two opposite activities involve different interacting partners and result from different $\mathrm{PrPC}^{\mathrm{C}}$-activated signaling pathways. Remarkably, $\operatorname{PrPC}$ may be inactivated either by physiological endoproteolysis and release of the $\mathrm{N}$-terminal domain, or by ectodomain shedding. Ligand-induced $\operatorname{PrPC}$ dimerization or enforced dimerization of $\operatorname{Pr} \mathrm{PC}^{\mathrm{C}}$ indicate that $\mathrm{PrP}^{\mathrm{C}}$ dimerization represents an important molecular switch for both intracellular signaling and inactivation by the release of $\mathrm{PrPC} N$-terminal domain or shedding. In this review, we summarize evidence that cell surface receptor activity of $\operatorname{PrPC}^{C}$ is finely regulated by dimerization.

Keywords: prion protein trafficking, dimerization, signaling, neuroprotection, neurodegeneration

\section{INTRODUCTION}

$\operatorname{PrP}^{\mathrm{C}}$ is a cell surface protein with a bipartite structure: the $\mathrm{N}$-terminal domain is disordered and the C-terminal domain is structured and contains three $\alpha$-helices and two short $\beta$-strands (Wuthrich and Riek, 2001). The physiological function of $\operatorname{PrP}^{\mathrm{C}}$ is unclear, but a large body of evidence indicates that $\operatorname{PrP}^{\mathrm{C}}$ is a neuroprotective and neurotrophic protein (Linden et al., 2008). The neuroprotective function of $\operatorname{PrP}^{\mathrm{C}}$ against different insults was demonstrated in vitro in primary neurons and in cell lines, and in vivo (Roucou and LeBlanc, 2005; Lo et al., 2007). In these studies, $\operatorname{PrP}^{\mathrm{C}}$ expression was able to slow or halt cell death whilst $\mathrm{PrP}^{\mathrm{C}}$ absence did not prevent cell death. In a pioneer investigation, $\mathrm{PrP}^{\mathrm{C}}$ expression prevented cell death triggered by serum deprivation of immortalized hippocampal neurons (Kuwahara et al., 1999). Subsequent studies provided significant evidence for the implication of $\operatorname{PrP}^{\mathrm{C}}$ in cell survival. In addition to these neuroprotective effects, $\mathrm{PrP}^{\mathrm{C}}$ regulates cell proliferation, differenciation, growth, and $\mathrm{PrP}^{\mathrm{C}}$ is also important for the expansion of stem cells in culture (Martins et al., 2010; Miranda et al., 2013). Some of these trophic mechanisms have been addressed and involve the assembly of protein complexes at the cell surface.

Most of neuroprotective and neurotrophic activities result from $\operatorname{PrP}^{\mathrm{C}}$-mediated signaling (Martins et al., 2010; Schneider et al., 2011). Thus, a large body of data indicate that GPIanchored $\mathrm{PrP}^{\mathrm{C}}$ is a cell surface receptor or co-receptor and that its engagement with one of its numerous ligands or with antibodies activates different intracellular pathways. Cell surface receptors are generally activated by dimerization (Heldin, 1995), and this may also be valid for $\operatorname{PrP}^{\mathrm{C}}$ which forms dimers in native conditions and can be experimentally engaged with cross-linking antibodies (Mouillet-Richard et al., 2000; Rambold et al., 2008).
In prion diseases, $\operatorname{Pr}^{\mathrm{C}}$ changes conformation into a pathological conformer termed $\operatorname{PrP}^{\mathrm{Sc}}$ (Prusiner, 1998). The exact mechanism of this conformational change or prion conversion is unclear but may involve the initial formation of dimers. During the process of prion conversion, $\mathrm{PrP}^{\mathrm{Sc}}$ oligomerizes and form toxic oligomers that interact with $\mathrm{PrP}^{\mathrm{C}}$ and switch its neuroprotective/neurotrophic signaling to a neurotoxic signaling (Rambold et al., 2008; Resenberger et al., 2011).

In this review, I will summarize some of the most important studies on the role of dimerization on the physiological and pathological function of $\operatorname{PrP}^{\mathrm{C}}$ and $\mathrm{PrP}^{\mathrm{Sc}}$, respectively.

\section{PrPC DIMERIZATION AND CELL SIGNALING (FIGURE 1) DETECTION OF PrPC DIMERS IN NATIVE CONDITIONS AND CYTOPROTECTION}

$\operatorname{PrP}^{\mathrm{C}}$ dimers were detected in solution in a partially purified fraction from normal bovine brain thalamus (Meyer et al., 2000), and in murine neuroblastoma N2a cells expressing Syrian hamster $\operatorname{PrP}^{\mathrm{C}}$ (Priola et al., 1995). Syrian hamster, human and bovine $\mathrm{PrP}^{\mathrm{C}}$ expressed in baculovirus and purified under native conditions spontaneously form dimers (Hundt et al., 2003). Dimerization of human $\operatorname{PrP}^{\mathrm{C}}$ was confirmed in BHK cells overexpressing $\operatorname{PrP}^{\mathrm{C}}$ and in yeast two-hybrid assays (Hundt et al., 2003). More recently, endogenous $\operatorname{PrP}^{\mathrm{C}}$ dimers were also detected by blue native PAGE in N2a cells and the dimerization domain mapped to a hydrophobic domain of the protein (amino acids 112-MAGAAAAGAVVGGLGGYMLGSA-133) (Rambold et al., 2008). Finally, $\operatorname{PrP}^{\mathrm{C}}$ dimers were detected after chemical crosslinking in crude membranes from human neuroblastoma SH-SY5Y cells and mouse brains (Rambold et al., 2008). These results convincingly demonstrate that $\operatorname{Pr}^{C}$ has an 
intrinsic tendency to dimerize in native conditions and suggest that dimerization is important for the physiological function of $\operatorname{PrP}^{\mathrm{C}}$.

The assembly of natural $\operatorname{PrP}^{\mathrm{C}}$ dimers at the plasma membrane is associated with protective activity against the excitotoxin kainate and altering dimer formation results in cell death (Rambold et al., 2008). Based on their own data and previous data showing $\operatorname{PrP}^{\mathrm{C}}$-mediated signaling using anti-PrP $\mathrm{P}^{\mathrm{C}}$ antibodies (see below), the authors proposed that cell surface $\operatorname{PrP}^{\mathrm{C}}$ dimers induce protective signaling through an unknown transmembrane receptor. This study did not elucidate whether the formation of dimers is constitutive or depends on an unknown ligand. Also, the proportion of $\mathrm{PrP}^{\mathrm{C}}$ dimers is unknown.

\section{ANTIBODY-INDUCED PrPC DIMERIZATION REVEALS THE SIGNALING PATHWAY CONTROLLED BY PrPC}

Antibody-induced dimerization (also termed antibody-induced ligation or -cross-linking) is used to mimic an extracellular signal on cell surface receptors and trigger signal transduction. Although it is unclear if such strategy mimics the interaction with a partner or dimerization of the receptor, antibody-induced dimerization is largely used to engage a receptor in the absence of its ligand and relays intracellular signals. GPI-anchored proteins associate with raft domains in the plasma membrane and activate signal transduction pathways upon engagement with ligands or via antibody-induced dimerization (Robinson, 1991; Suzuki et al., 2012). For GPI-anchored proteins, signal transduction occurs through activation of intracellular tyrosine kinases including the Src-family kinases (Stefanova et al., 1991; Chen et al., 2006). Mouillet-Richard et al were the first to show that engagement of $\mathrm{PrP}^{\mathrm{C}}$ using an antibody-induced dimerization approach activates a Fyn-dependent signaling pathway in serotonergic and noradrenergic mouse cells differenciated from the murine neuroectodermal progenitor $1 \mathrm{C} 11$ clone (Mouillet-Richard et al., 2000). Similar results were obtained with two different antibodies, $1 \mathrm{~A} 8$ and SAF61 targeting C-terminal epitopes. Using 4 different antibodies to induce $\operatorname{PrP}^{\mathrm{C}}$ dimerization, SAF61, Bar221, and 1A8 that target C-terminal epitopes, and SAF32 which targets epitope 79-92, NADPH oxidase was subsequently identified as the main primary target of $\mathrm{PrP}^{\mathrm{C}}$-mediated signaling. $\mathrm{NADPH}$ oxidase-dependent reactive oxygen species production stimulated the phosphorylation of extracellular regulated kinases $1 / 2$ $($ Erk1/2) in the 1C11 neuroectodermal precursor and its neuronal differentiated progenies, the hypothalamic GT1-7 cells, and the T lymphoid BW5147 cells (Schneider et al., 2003). $\mathrm{PrP}^{\mathrm{C}}$ signaling was dependent on Fyn in neuronal cells only, indicating specificity in the control of $\mathrm{PrP}^{\mathrm{C}}$ function. $\mathrm{PrP}^{\mathrm{C}}$-mediated phosphorylation of Erk1/2 was independently confirmed in GT1-7 neuronal cells (Monnet et al., 2004) and in human neuroblastoma SH-SY5Y cells (Rambold et al., 2008). $\mathrm{PrP}^{\mathrm{C}}$-induced ROS production and Erk1/2 phosphorylation was confirmed using an inducible dimerization strategy (Beland et al., 2012).

These studies lend support for a role of $\mathrm{PrP}^{\mathrm{C}}$ in signal transduction and further investigations provided more insight into the physiological consequence of $\mathrm{PrP}^{\mathrm{C}}$ signaling in neuronal $1 \mathrm{C} 11$ cells. In $1 \mathrm{C} 11$ serotonergic cells expressing $5-\mathrm{HT}_{2 \mathrm{~B}}, 5-\mathrm{HT}_{1 \mathrm{~B} / \mathrm{D}}$, and $5-\mathrm{HT}_{2 \mathrm{~A}}$ receptor subtypes. $\mathrm{PrP}^{\mathrm{C}}$ dimerization interfered with the signaling activity of these three serotonergic receptors belonging to the GPCR family likely by modulating the recruitment of G-proteins (Mouillet-Richard et al., 2005). $\operatorname{PrP}^{\mathrm{C}}$ dimerization promoted the recruitment of the cAMP responsive element binding protein (CREB) transcription factor and the transcription of several genes with important function in cellular protection and neuronal plasticity (Pradines et al., 2008). In addition, $\operatorname{PrP}^{\mathrm{C}}$ dimerization inactivated the Glycogen Synthase Kinase $3 \beta$ and activated serotonergic signaling through inhibition of the serotonin $1 \mathrm{~B}$ receptor (Hernandez-Rapp et al., 2014). CREB recruitment and GSK3 $\beta$ are generally associated with cytoprotection, suggesting an important function of $\mathrm{PrP}^{\mathrm{C}}$ in cell survival and homeostasis.

For several years, these data were in contradiction with previous results indicating that antibody-induced $\operatorname{PrP}^{\mathrm{C}}$ dimerization is neurotoxic in vivo (Solforosi et al., 2004). However, these results were later invalidated with similar and other antibodies (Klohn et al., 2012). This debate is still ongoing since a recent study demonstrated that anti- $\mathrm{PrP}^{\mathrm{C}}$ antibodies induce rapid neurotoxicity in mice and cerebellar organotypic cultured slices (Sonati et al., 2012). Importantly, $\operatorname{PrP}^{C}$ dimerization is unlikely to be involved in neuronal toxicity since single-chain antibodies were also toxic.

\section{PrPC SIGNALING ACTIVATED BY DIFFERENT LIGANDS}

At the cell surface, $\mathrm{PrP}^{\mathrm{C}}$ interacts directly or indirectly with a variety of ligands as diverse as metals, lipids, nucleic acids, glycosaminoglycans, and other proteins (Linden et al., 2008; Beland and Roucou, 2012). In physiological conditions, it was proposed that $\mathrm{PrP}^{\mathrm{C}}$ is a scaffolding protein providing essential molecular interactions and signaling neurotrophic activities (Martins et al., 2010). $\operatorname{PrP}^{\mathrm{C}}$ ligands promoting neurotrophic activity include laminin, the $37-\mathrm{kDa} / 67-\mathrm{kDa}$ laminin receptor precursor/laminin receptor, vitronectin, the neural cell adhesion molecule, and the Stress Inducible Protein 1 (Martins et al., 2010).

In pathological conditions, binding of $\mathrm{PrP}^{\mathrm{Sc}}$ to cell surface $\mathrm{PrP}^{\mathrm{C}}$ corrupts $\mathrm{PrP}^{\mathrm{C}}$ signaling and results in cellular toxicity (Rambold et al., 2008; Resenberger et al., 2011). This finding is particularly important as it provides a simple explanation for the observation that $\mathrm{PrP}^{\mathrm{C}}$ on the cell surface is critical for the neurotoxicity of $\mathrm{PrP}^{\mathrm{Sc}}$ in prion diseases (Brandner et al., 1996; Chesebro et al., 2005). $\operatorname{PrP}^{\mathrm{C}}$ dimerization is essential for the toxicity of $\mathrm{PrP}^{\mathrm{Sc}}$ (Rambold et al., 2008). $\operatorname{PrP}^{\mathrm{C}}$ is also a receptor for other toxic $\beta$-sheet oligomers, including $A \beta$ in Alzheimer's disease (Lauren et al., 2009; Gunther and Strittmatter, 2010; Resenberger et al., 2011).

\section{PrPC INTEGRITY AT THE CELL SURFACE IS REGULATED BY PROTEOLYSIS AND DIMERIZATION: PrPC METABOLITES AND NEUROPROTECTION (FIGURE 1) PrPC IS A TARGET FOR SEVERAL POSTTRANSLATIONAL ENDOPROTEOLYTIC EVENTS}

Following translocation into the endoplasmic reticulum, signal peptidase removes a $\mathrm{N}$-terminal signal peptide, and a C-terminal peptide is removed prior to the attachment of the GPI anchor. Thus, human $\mathrm{PrP}^{\mathrm{C}}$ is translated as an immature 253 amino acids protein and mature $\mathrm{PrP}^{\mathrm{C}}$ is a 208 residues protein. After trafficking through the secretory pathway, a fraction of $\mathrm{PrP}^{\mathrm{C}}$ may 
undergo three proteolytic cleavages (Altmeppen et al., 2012). An $\alpha$-cleavage between residues $110-111$ and 112 in a late compartment of the secretory pathway produces $\mathrm{PrPC1}$, a $17 \mathrm{kDa}$ GPI-anchored C-terminal polypeptide, and a $11 \mathrm{kDa}$-terminal polypeptide released in the extracellular space. The identity of the protease responsible for $\alpha$-cleavage, termed the $\alpha$-PrPase (Oliveira-Martins et al., 2010), is still unclear. A $\beta$-cleavage at amino acids 89/90 generates PrPC2, a $20 \mathrm{kDa}$ GPI-anchored polypeptide, and the corresponding $8 \mathrm{kDa}$ PrPN2 fragment. $\beta$ cleavage occurs at the cell surface mainly in pathological conditions; calpains execute $\beta$-cleavage in prion diseases whilst reactive oxygen species perform $\beta$-cleavage under conditions of oxidative stress. In addition, a fraction of $\operatorname{PrP}^{\mathrm{C}}$ is constitutively shed from the cell surface after proteolytic cleavage close to the GPI anchor. In vivo, the main protease responsible for $\mathrm{PrP}^{\mathrm{C}}$ shedding is the zinc metalloproteinase ADAM10 (Altmeppen et al., 2012).

\section{NEUROPROTECTIVE PRPC -DERIVED PRPN1 AND PRPC1 METABOLITES}

In recent years, $\alpha$-cleavage attracted a lot of attention because it results in the production of $\operatorname{PrPN1}$, a natural $\mathrm{PrP}^{C}$ metabolite with a clear neuroprotective activity against different insults in vivo, in primary neuronal cultures and in cell lines (GuillotSestier et al., 2009, 2012; Resenberger et al., 2011; Beland et al., 2012; Fluharty et al., 2013; Beland and Roucou, 2013a). In particular, the neuroprotection against soluble $A \beta$ oligomers that may be the culprit species in Alzheimer's disease may pave the way for the discovery of a new class of therapeutic molecules (Beland et al., 2012; Fluharty et al., 2013). There is also some evidence that $\alpha$-cleavage is increased in post-mortem brain tissues of Alzheimer's disease patients, and that PrPN1 traps $A \beta$ into amorphous aggregates unable to transform into soluble and toxic $A \beta$ oligomers, and that $\alpha$-cleavage decrease promotes neurotoxicity in prion and Alzheimer's diseases (Pietri et al., 2013; Beland et al., 2014). PrPN1 also binds to and antagonizes the toxicity of other $\beta$-sheet rich oligomers, including $\operatorname{PrP}^{\mathrm{Sc}}$ oligomers, and PrPN1-derived therapeutic molecules may help treat different neurodegenerative disorders (Resenberger et al., 2011).

The GPI-anchored PrPC1 fragment after $\alpha$-cleavage of $\operatorname{PrP}^{C}$ protects against prion infection of neuronal and non-neuronal cell lines and acts as a dominant-negative inhibitor of prion conversion in vivo (Lewis et al., 2009; Westergard et al., 2011). The mechanism of action of PrPC1 is unclear, but since PrPC1 is resistant to prion conversion, the authors proposed that PrPC1 competes with $\operatorname{PrP}^{C}$ for binding to infectious $\operatorname{PrP}^{S c}$ (Westergard et al., 2011). Thus, PrPC1-derived peptides may have therapeutic benefits in prion diseases.

\section{PRPC DIMERIZATION STIMULATES ITS TRAFFICKING TO THE PLASMA MEMBRANE AND THE PRODUCTION OF PRPN1 AND PRPC1}

As many experimental data converge to support the proposition that PrPN1 and PrPC1 are neuroprotective metabolites, two therapeutic avenues could be proposed in prion diseases: to provide exogenous PrPN1- or PrPC1-derived molecules, or to increase the natural production of PrPN1 and PrPC1 by stimulating the $\alpha$-cleavage. The $\alpha$-cleavage mechanism is nebulous and only two elements are known: it occurs in the late secretory pathway but the enzyme is still unknown, and the hydrophobic domain is essential for this cleavage (Bremer et al., 2010; Oliveira-Martins et al., 2010). This domain is also essential for the physiological dimerization of $\operatorname{PrP}^{\mathrm{C}}$ (Rambold et al., 2008), supporting the hypothesis of a possible connection between dimerization and $\alpha$-cleavage. Using an inducible dimerization strategy with a permeable dimerizer, we were able to show that $\operatorname{PrP}^{\mathrm{C}}$ dimerization in cell lines and primary neurons increase $\operatorname{PrP}^{\mathrm{C}}$ trafficking to the plasma membrane and largely increase the production of PrPN1, PrPC1, and shed $\operatorname{PrP}^{\mathrm{C}}$ (Beland et al., 2012). After dimerization, conditioned medium containing these three metabolites strongly protected cells against toxic $A \beta$ oligomers.

Since levels of the products of both $\alpha$-cleavage and shedding rose after dimerization, we concluded that the large increase of $\mathrm{PrP}^{\mathrm{C}}$ trafficking to the plasma membrane was sufficient to explain the high levels of its metabolites. This effect was fast and occurred $4 \mathrm{~h}$ post-dimerization. Deletion of the hydrophobic domain, the natural dimerization domain, does not prevent $\mathrm{PrP}^{\mathrm{C}}$ trafficking to the plasma membrane (Winklhofer et al., 2003). Thus, dimerization is not essential for $\mathrm{PrP}^{\mathrm{C}}$ trafficking. We proposed a model with a constitutive and dimerization-independent pathway for $\operatorname{PrP}^{\mathrm{C}}$ secretion, and a pathway regulated by dimerization. This regulated pathway would allow the cells to quickly respond to toxic insults by increasing the levels of protective $\operatorname{PrP}^{\mathrm{C}}$ metabolites (Beland and Roucou, 2013a,b).

\section{THE DARK SIDE OF PrPC DIMERIZATION REVEALED FROM IN VITRO PRION CONVERSION ASSAYS}

$\mathrm{PrP}^{\mathrm{C}} \rightarrow \operatorname{PrP}^{\mathrm{Sc}}$ conversion or prion conversion is central to prion diseases; this process is neurotoxic and $\mathrm{PrP}^{\mathrm{Sc}}$ molecules assemble into infectious particles responsible for the transmission of the disease (Prusiner, 1998; Mallucci et al., 2003). Not surprisingly, numerous mechanistic studies have addressed this process using recombinant $\operatorname{PrP}(\mathrm{rec} P r \mathrm{P})$ and several experimental data have indicated an intrinsic tendency of the protein to form dimers during the initial steps of prion conversion. A fraction of Syrian hamster recPrP(90-231) forms alpha-helical dimers in solution in the presence of submicellar concentrations of SDS (Jansen et al., 2001). These dimers believed to be intermediates in prion conversion were observed by size exclusion chromatography, chemical crosslinking and analytical ultracentrifugation (Kaimann et al., 2008; Stöhr et al., 2008; Jansen et al., 2001). In these studies, non-denaturing concentrations of SDS were used to mimic membrane-like features. Using a reduction-oxidation protocol to induce the fibrillar assembly of Syrian hamster $\operatorname{PrP}(90-231)$, Lee and Eisenberg also observed the presence of dimeric intermediates in polyacrylamide native gels (Lee and Eisenberg, 2003). A similar conclusion was obtained with murine recPrP(23-231). During the conversion of murine $\operatorname{PrP}(23-231)$, an intermediate water-soluble $\beta$-sheet isoform termed $\operatorname{PrP}^{\beta}$ was identified (Luhrs et al., 2006). The kinetics of $\operatorname{PrP}^{\mathrm{C}} \rightarrow \operatorname{PrP}^{\beta}$ conversion suggest that dimerization is the rate-limiting step for the transition. The dimerization of murine rec $\operatorname{PrP}(23-231)$ as a key molecular step during the conversion was confirmed in a subsequent study (Hafner-Bratkovic et al., 2011). Additionally, 3D reconstruction of murine $\operatorname{rec} \operatorname{PrP}(91-230)$ amyloid fibrils led to the proposition that dimers represent building units of such fibrils (Tattum et al., 2006). 
These experiments were performed with nonposttranslationally modified $\mathrm{PrP}^{\mathrm{C}}$. Yet in vivo, $\operatorname{PrP}^{\mathrm{C}}$ carries two N-glycosylations and a GPI anchor and these complex posttranslational modifications may play an important role in prion conversion. To address this issue, posttranslationally modified $\mathrm{PrP}^{\mathrm{C}}$ was purified from Chinese hamster ovary cells overexpressing Syrian hamster $\operatorname{PrP}^{\mathrm{C}}$. This native $\operatorname{PrP}^{\mathrm{C}}$ spontaneously formed dimers stabilized by intermolecular $\beta$-sheets after insertion into artificial membranes (Elfrink et al., 2008).

Altogether, these studies support the hypothesis that dimerization is an important step for prion conversion but they did not directly test this hypothesis. To address this issue, two strategies have been used. First, two monomeric mouse $\operatorname{PrP}$ (23-231) were covalently linked with a linker and recombinantly purified. This tandem protein oligomerized after purification, and thioflavine $\mathrm{T}$ staining indicated that such oligomers were likely on the pathway of amyloid formation, although this was not demonstrated (Simoneau et al., 2007). In a second strategy, we used a conditional dimerization approach to induce chemical dimerization of mouse $\operatorname{rec} \operatorname{PrP}(23-231)$ and human recPrP (23-231). $\alpha$-helical PrP dimers spontaneously converted into $\beta$-sheet oligomers and amyloid fibrils were detected by electron microscopy and thioflavinT staining (Roostaee et al., 2009). Importantly, these experiments were performed in physiological-like conditions in the absence of any detergent or chaotropic agents.

Models of PrP dimers and the role of dimers in prion conversion are available (Warwicker, 2000; Gauczynski et al., 2001; Tompa et al., 2002). However, in all the above studies, prion conversion was assessed by the formation of PrP amyloid fibrils and/or partial resistance to proteinase $\mathrm{K}$ rather than by the formation of infectious $\mathrm{PrP}^{\mathrm{Sc}}$ in animal bioassays. Hence, the biological significance of $\mathrm{PrP}^{\mathrm{C}}$ dimerization for the formation of infectious $\mathrm{PrP}^{\mathrm{Sc}}$ remains speculative.

\section{CONCLUSION}

$\operatorname{PrP}^{\mathrm{C}}$ forms dimers in native conditions and cell surface dimerization clearly regulates $\mathrm{PrP}^{\mathrm{C}}$-mediated signaling and the resulting physiological neuroprotective/neurotrophic activities (Rambold et al., 2008). Intracellular dimerization also drastically increases its trafficking to the plasma membrane and the production of its natural metabolites PrPN1 and PrPC1 (Beland et al., 2012). The combination of these two effects of $\mathrm{PrP}^{C}$ dimerization likely provides $\mathrm{PrP}^{\mathrm{C}}$ with a powerful neuroprotective/neurotrophic function (Figure 1). However, the flip side of the coin is that unwanted dimerization may initiate prion conversion and result in neuronal toxicity (Tompa et al., 2002). Regulating $\mathrm{PrP}^{\mathrm{C}}$ dimerization may help translate these findings into

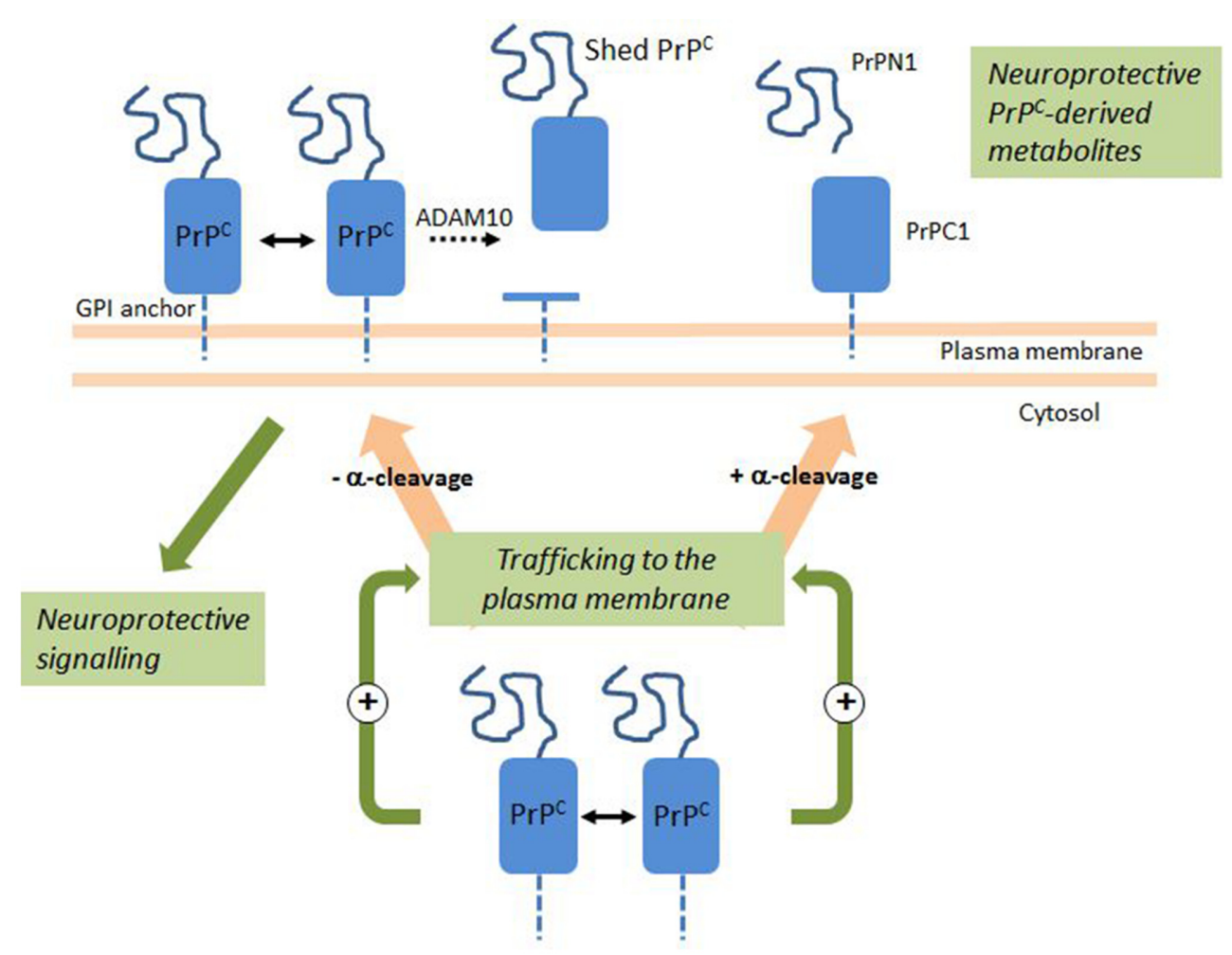

FIGURE 1 | PrPC Dimerization activates a neuroprotective signaling pathway and the production of neuroprotective $\mathrm{PrPC}^{\mathrm{C}}$-derived metabolites. En route to the plasma membrane, a fraction of PrPC undergoes a physiological cleavage termed $\alpha$-cleavage. Intracellular PrPC dimerization stimulates trafficking to the plasma membrane and the release of PrPN1 and PrPC1 at the cell surface. PrPC dimerization at the cell surface activates an intracellular signaling pathway with a neuroprotective outcome. At the cell surface, a fraction of $\operatorname{PrPC}$ undergoes ADAM10-mediated shedding. Double arrows indicate dimerization; dotted arrow indicates shedding. See text for details. 
novel therapeutic interventions in neurodegenerative diseases (Beland and Roucou, 2013b).

\section{REFERENCES}

Altmeppen, H. C., Puig, B., Dohler, F., Thurm, D. K., Falker, C., Krasemann, S., et al. (2012). Proteolytic processing of the prion protein in health and disease. Am. J. Neurodegener. Dis. 1, 15-31.

Beland, M., Bedard, M., Tremblay, G., Lavigne, P., and Roucou, X. (2014). Abeta induces its own prion protein N-terminal fragment (PrPN1)-mediated neutralization in amorphous aggregates. Neurobiol. Aging 35, 1537-1548. doi: 10.1016/j.neurobiolaging.2014.02.001

Beland, M., Motard, J., Barbarin, A., and Roucou, X. (2012). PrP(C) homodimerization stimulates the production of PrPC cleaved fragments PrPN1 and PrPC1. J. Neurosci. 32, 13255-13263. doi: 10.1523/JNEUROSCI.223612.2012

Beland, M., and Roucou, X. (2012). The prion protein unstructured N-terminal region is a broad-spectrum molecular sensor with diverse and contrasting potential functions. J. Neurochem. 120, 853-868. doi: 10.1111/j.14714159.2011.07613.x

Beland, M., and Roucou, X. (2013a). Homodimerization as a molecular switch between low and high efficiency PrP C cell surface delivery and neuroprotective activity. Prion 7, 170-174. doi: 10.4161/pri.23583

Beland, M., and Roucou, X. (2013b). Taking advantage of physiological proteolytic processing of the prion protein for a therapeutic perspective in prion and Alzheimer diseases. Prion 8, 106-110. doi: 10.4161/pri.27438

Brandner, S., Isenmann, S., Raeber, A., Fischer, M., Sailer, A., Kobayashi, Y., et al. (1996). Normal host prion protein necessary for scrapie-induced neurotoxicity. Nature 379, 339-343. doi: 10.1038/379339a0

Bremer, J., Baumann, F., Tiberi, C., Wessig, C., Fischer, H., Schwarz, P., et al. (2010). Axonal prion protein is required for peripheral myelin maintenance. Nat. Neurosci. 13, 310-318. doi: 10.1038/nn.2483

Chen, Y., Thelin, W. R., Yang, B., Milgram, S. L., and Jacobson, K. (2006). Transient anchorage of cross-linked glycosyl-phosphatidylinositol-anchored proteins depends on cholesterol, Src family kinases, caveolin, and phosphoinositides. J. Cell Biol. 175, 169-178. doi: 10.1083/jcb.200512116

Chesebro, B., Trifilo, M., Race, R., Meade-White, K., Teng, C., LaCasse, R., et al. (2005). Anchorless prion protein results in infectious amyloid disease without clinical scrapie. Science 308, 1435-1439. doi: 10.1126/science.1110837

Elfrink, K., Ollesch, J., Stohr, J., Willbold, D., Riesner, D., and Gerwert, K. (2008). Structural changes of membrane-anchored native $\operatorname{PrP}(\mathrm{C})$. Proc. Natl. Acad. Sci. U.S.A. 105, 10815-10819. doi: 10.1073/pnas.0804721105

Fluharty, B. R., Biasini, E., Stravalaci, M., Sclip, A., Diomede, L., Balducci, C., et al. (2013). An N-terminal fragment of the prion protein binds to amyloid-beta oligomers and inhibits their neurotoxicity in vivo. J. Biol. Chem. 288, 7857-7866. doi: 10.1074/jbc.M112.423954

Gauczynski, S., Hundt, C., Leucht, C., and Weiss, S. (2001). Interaction of prion proteins with cell surface receptors, molecular chaperones, and other molecules. Adv. Protein Chem. 57, 229-272. doi: 10.1016/S0065-3233(01)57024-2

Guillot-Sestier, M. V., Sunyach, C., Druon, C., Scarzello, S., and Checler, F. (2009). The alpha-secretase-derived N-terminal product of cellular prion, N1, displays neuroprotective function in vitro and in vivo. J. Biol. Chem. 284, 35973-35986. doi: 10.1074/jbc.M109.051086

Guillot-Sestier, M. V., Sunyach, C., Ferreira, S. T., Marzolo, M. P., Bauer, C., Thevenet, A., et al. (2012). alpha-Secretase-derived fragment of cellular prion, N1, protects against monomeric and oligomeric amyloid beta (Abeta)-associated cell death. J. Biol. Chem. 287, 5021-5032. doi: 10.1074/jbc.M111.323626

Gunther, E. C., and Strittmatter, S. M. (2010). Beta-amyloid oligomers and cellular prion protein in Alzheimer's disease. J. Mol. Med. 88, 331-338. doi: 10.1007/s00109-009-0568-7

Hafner-Bratkovic, I., Bester, R., Pristovsek, P., Gaedtke, L., Veranic, P., Gaspersic, J., et al. (2011). Globular domain of the prion protein needs to be unlocked by domain swapping to support prion protein conversion. J. Biol. Chem. 286, 12149-12156. doi: 10.1074/jbc.M110.213926

Heldin, C. H. (1995). Dimerization of cell surface receptors in signal transduction. Cell 80, 213-223. doi: 10.1016/0092-8674(95)90404-2

Hernandez-Rapp, J., Martin-Lanneree, S., Hirsch, T. Z., Pradines, E., AlleaumeButaux, A., Schneider, B., et al. (2014). A PrP(C)-caveolin-Lyn complex negatively controls neuronal GSK3beta and serotonin $1 \mathrm{~B}$ receptor. Sci. Rep. 4:4881. doi: 10.1038/srep04881

Hundt, C., Gauczynski, S., Leucht, C., Riley, M. L., and Weiss, S. (2003). Intra- and interspecies interactions between prion proteins and effects of mutations and polymorphisms. Biol. Chem. 384, 791-803. doi: 10.1515/BC.2003.088

Jansen, K., Schafer, O., Birkmann, E., Post, K., Serban, H., Prusiner, S. B., et al. (2001). Structural intermediates in the putative pathway from the cellular prion protein to the pathogenic form. Biol. Chem. 382, 683-691. doi: 10.1515/BC.2001.081

Kaimann, T., Metzger, S., Kuhlmann, K., Brandt, B., Birkmann, E., Höltje, H. D., et al. (2008). Molecular model of an alpha-helical prion protein dimer and its monomeric subunits as derived from chemical cross-linking and molecular modeling calculations. J. Mol. Biol. 376, 582-596. doi: 10.1016/j.jmb.2007. 11.035

Klohn, P. C., Farmer, M., Linehan, J. M., O’Malley, C., Fernandez de Marco, M., Taylor, W., et al. (2012). PrP antibodies do not trigger mouse hippocampal neuron apoptosis. Science 335, 52. doi: 10.1126/science.1215579

Kuwahara, C., Takeuchi, A. M., Nishimura, T., Haraguchi, K., Kubosaki, A., Matsumoto, Y., et al. (1999). Prions prevent neuronal cell-line death. Nature 400, 225-226. doi: 10.1038/22241

Lauren, J., Gimbel, D. A., Nygaard, H. B., Gilbert, J. W., and Strittmatter, S. M. (2009). Cellular prion protein mediates impairment of synaptic plasticity by amyloid-beta oligomers. Nature 457, 1128-1132. doi: 10.1038/nature07761

Lee, S., and Eisenberg, D. (2003). Seeded conversion of recombinant prion protein to a disulfide-bonded oligomer by a reduction-oxidation process. Nat. Struct. Biol. 10, 725-730. doi: 10.1038/nsb961

Lewis, V., Hill, A. F., Haigh, C. L., Klug, G. M., Masters, C. L., Lawson, V. A., et al. (2009). Increased proportions of C1 truncated prion protein protect against cellular M1000 prion infection. J. Neuropathol. Exp. Neurol. 68, 1125-1135. doi: 10.1097/NEN.0b013e3181b96981

Linden, R., Martins, V. R., Prado, M. A., Cammarota, M., Izquierdo, I., and Brentani, R. R. (2008). Physiology of the prion protein. Physiol. Rev. 88, 673-728. doi: 10.1152/physrev.00007.2007

Lo, R. Y., Shyu, W. C., Lin, S. Z., Wang, H. J., Chen, S. S., and Li, H. (2007). New molecular insights into cellular survival and stress responses: neuroprotective role of cellular prion protein (PrPC). Mol. Neurobiol. 35, 236-244. doi: $10.1007 /$ s12035-007-8003-y

Luhrs, T., Zahn, R., and Wuthrich, K. (2006). Amyloid formation by recombinant full-length prion proteins in phospholipid bicelle solutions. J. Mol. Biol. 357, 833-841. doi: 10.1016/j.jmb.2006.01.016

Mallucci, G., Dickinson, A., Linehan, J., Klöhn, P. C., Brandner, S., and Collinge, J. (2003). Depleting neuronal PrP in prion infection prevents disease and reverses spongiosis. Science 302, 871-874. doi: 10.1126/science.1090187

Martins, V. R., Beraldo, F. H., Hajj, G. N., Lopes, M. H., Lee, K. S., Prado, M. A., et al. (2010). Prion protein: orchestrating neurotrophic activities. Curr. Issues Mol. Biol. 12, 63-86.

Meyer, R. K., Lustig, A., Oesch, B., Fatzer, R., Zurbriggen, A., and Vandevelde, M. (2000). A monomer-dimer equilibrium of a cellular prion protein (PrPC) not observed with recombinant PrP. J. Biol. Chem. 275, 38081-38087. doi: 10.1074/jbc.M007114200

Miranda, A., Ramos-Ibeas, P., Pericuesta, E., Ramirez, M. A., and Gutierrez-Adan, A. (2013). The role of prion protein in stem cell regulation. Reproduction 146, R91-R99. doi: 10.1530/REP-13-0100

Monnet, C., Gavard, J., Mege, R. M., and Sobel, A. (2004). Clustering of cellular prion protein induces ERK1/2 and stathmin phosphorylation in GT1-7 neuronal cells. FEBS Lett. 576, 114-118. doi: 10.1016/j.febslet.2004.08.076

Mouillet-Richard, S., Ermonval, M., Chebassier, C., Laplanche, J. L., Lehmann, S., Launay, J. M., et al. (2000). Signal transduction through prion protein. Science 289, 1925-1928. doi: 10.1126/science.289.5486.1925

Mouillet-Richard, S., Pietri, M., Schneider, B., Vidal, C., Mutel, V., Launay, J. M., et al. (2005). Modulation of serotonergic receptor signaling and cross-talk by prion protein. J. Biol. Chem. 280, 4592-4601. doi: 10.1074/jbc.M406199200

Oliveira-Martins, J. B., Yusa, S., Calella, A. M., Bridel, C., Baumann, F., Dametto, P., et al. (2010). Unexpected tolerance of alpha-cleavage of the prion protein to sequence variations. PLOS ONE 5:e9107. doi: 10.1371/journal.pone.0009107

Pietri, M., Dakowski, C., Hannaoui, S., Alleaume-Butaux, A., Hernandez-Rapp, J., Ragagnin, A., et al. (2013). PDK1 decreases TACE-mediated $\alpha$-secretase activity and promotes disease progression in prion and Alzheimer's diseases. Nat. Med. 19, 1124-1131. doi: 10.1038/nm.3302 
Pradines, E., Loubet, D., Schneider, B., Launay, J. M., Kellermann, O., and Mouillet-Richard, S. (2008). CREB-dependent gene regulation by prion protein: impact on MMP-9 and beta-dystroglycan. Cell. Signal. 20, 2050-2058. doi 10.1016/j.cellsig.2008.07.016

Priola, S. A., Caughey, B., Wehrly, K., and Chesebro, B. (1995). A 60-kDa prion protein $(\mathrm{PrP})$ with properties of both the normal and scrapie-associated forms of PrP. J. Biol. Chem. 270, 3299-3305. doi: 10.1074/jbc.270.7.3299

Prusiner, S. B. (1998). Prions. Proc. Natl. Acad. Sci. U.S.A. 95, 13363-13383. doi: 10.1073/pnas.95.23.13363

Rambold, A. S., Muller, V., Ron, U., Ben-Tal, N., Winklhofer, K. F., and Tatzelt, J. (2008). Stress-protective signalling of prion protein is corrupted by scrapie prions. EMBO J. 27, 1974-1984. doi: 10.1038/emboj.2008.122

Resenberger, U. K., Harmeier, A., Woerner, A. C., Goodman, J. L., Muller, V., Krishnan, R., et al. (2011). The cellular prion protein mediates neurotoxic signalling of beta-sheet-rich conformers independent of prion replication. $E M B O$ J. 30, 2057-2070. doi: 10.1038/emboj.2011.86

Robinson, P. J. (1991). Phosphatidylinositol membrane anchors and T-cell activation. Immunol. Today 12, 35-41. doi: 10.1016/0167-5699(91)90110-F

Roostaee, A., Cote, S., and Roucou, X. (2009). Aggregation and amyloid fibril formation induced by chemical dimerization of recombinant prion protein in physiological-like conditions. J. Biol. Chem. 284, 30907-30916. doi: 10.1074/jbc.M109.057950

Roucou, X., and LeBlanc, A. C. (2005). Cellular prion protein neuroprotective function: implications in prion diseases. J. Mol. Med. 83, 3-11. doi: 10.1007/s00109-004-0605-5

Schneider, B., Mutel, V., Pietri, M., Ermonval, M., Mouillet-Richard, S., and Kellermann, O. (2003). NADPH oxidase and extracellular regulated kinases $1 / 2$ are targets of prion protein signaling in neuronal and nonneuronal cells. Proc. Natl. Acad. Sci. U.S.A. 100, 13326-13331. doi: 10.1073/pnas.2235648100

Schneider, B., Pietri, M., Pradines, E., Loubet, D., Launay, J. M., Kellermann, O., et al. (2011). Understanding the neurospecificity of Prion protein signaling. Front. Biosci. (Landmark Ed.) 16, 169-186. doi: 10.2741/3682

Simoneau, S., Rezaei, H., Sales, N., Kaiser-Schulz, G., Lefebvre-Roque, M., Vidal, C., et al. (2007). In vitro and in vivo neurotoxicity of prion protein oligomers. PLoS Pathog. 3:e125. doi: 10.1371/journal.ppat.0030125

Solforosi, L., Criado, J. R., McGavern, D. B., Wirz, S., Sanchez-Alavez, M., Sugama, S., et al. (2004). Cross-linking cellular prion protein triggers neuronal apoptosis in vivo. Science 303, 1514-1516. doi: 10.1126/science.1094273

Sonati, T., Reimann, R. R., Falsig, J., Baral, P. K., O’Connor, T., Hornemann, S., et al. (2012). The toxicity of antiprion antibodies is mediated by the flexible tail of the prion protein. Nature 501, 102-106. doi: 10.1038/nature12402

Stefanova, I., Horejsi, V., Ansotegui, I. J., Knapp, W., and Stockinger, H. (1991). GPI-anchored cell-surface molecules complexed to protein tyrosine kinases. Science 254, 1016-1019. doi: 10.1126/science.1719635
Stöhr, J., Weinmann, N., Wille, H., Kaimann, T., Nagel-Steger, L., Birkmann, E., et al. (2008). Mechanisms of prion protein assembly into amyloid. Proc. Natl. Acad. Sci. U.S.A. 105, 2409-2414. doi: 10.1073/pnas.0712036105

Suzuki, K. G., Kasai, R. S., Hirosawa, K. M., Nemoto, Y. L., Ishibashi, M., Miwa, Y., et al. (2012). Transient GPI-anchored protein homodimers are units for raft organization and function. Nat. Chem. Biol. 8, 774-783. doi: 10.1038/nchembio. 1028

Tattum, M. H., Cohen-Krausz, S., Thumanu, K., Wharton, C. W., Khalili-Shirazi, A., Jackson, G. S., et al. (2006). Elongated oligomers assemble into mammalian PrP amyloid fibrils. J. Mol. Biol. 357, 975-985. doi: 10.1016/j.jmb.2006. 01.052

Tompa, P., Tusnady, G. E., Friedrich, P., and Simon, I. (2002). The role of dimerization in prion replication. Biophys. J. 82, 1711-1718. doi: 10.1016/S00063495(02)75523-9

Warwicker, J. (2000). Modeling a prion protein dimer: predictions for fibril formation. Biochem. Biophys. Res. Commun. 278, 646-652. doi: $10.1006 /$ bbrc 2000.3829

Westergard, L., Turnbaugh, J. A., and Harris, D. A. (2011). A naturally occurring C-terminal fragment of the prion protein $(\operatorname{PrP})$ delays disease and acts as a dominant-negative inhibitor of PrPSc formation. J. Biol. Chem. 286, 44234-44242. doi: 10.1074/jbc.M111.286195

Winklhofer, K. F., Heske, J., Heller, U., Reintjes, A., Muranyi, W., Moarefi, I., et al. (2003). Determinants of the in vivo folding of the prion protein. A bipartite function of helix 1 in folding and aggregation. J. Biol. Chem. 278, 14961-14970. doi: 10.1074/jbc.M209942200

Wuthrich, K., and Riek, R. (2001). Three-dimensional structures of prion proteins. Adv. Protein Chem. 57, 55-82. doi: 10.1016/S0065-3233(01)57018-7

Conflict of Interest Statement: The author declares that the research was conducted in the absence of any commercial or financial relationships that could be construed as a potential conflict of interest.

Received: 04 August 2014; paper pending published: 25 August 2014; accepted: 19 September 2014; published online: 09 October 2014.

Citation: Roucou X (2014) Regulation of $\mathrm{Pr} \mathrm{P}^{\mathrm{C}}$ signaling and processing by dimerization. Front. Cell Dev. Biol. 2:57. doi: 10.3389/fcell.2014.00057

This article was submitted to Cell Death and Survival, a section of the journal Frontiers in Cell and Developmental Biology.

Copyright (C) 2014 Roucou. This is an open-access article distributed under the terms of the Creative Commons Attribution License (CC BY). The use, distribution or reproduction in other forums is permitted, provided the original author(s) or licensor are credited and that the original publication in this journal is cited, in accordance with accepted academic practice. No use, distribution or reproduction is permitted which does not comply with these terms. 


\title{
Common themes in PrP signaling: the Src remains the
} same

\author{
Katharina Ochs and Edward Málaga-Trillo *t
}

Department of Biology, University of Konstanz, Konstanz, Germany

Edited by:

Jean-Luc Vilotte, National Institute of Agronomical Research, France

Reviewed by:

Mario Cioce, NYU Langone Medical

Center, USA

Husheng Ding, Mayo Clinic, USA

*Correspondence:

Edward Málaga-Trillo, Laboratorios de Investigación y Desarrollo,

Facultad de Ciencias y Filosofía,

Universidad Peruana Cayetano

Heredia, Av. Honorio Delgado 430,

Lima 31, Perú

e-mail:edward.malaga@upch.pe

${ }^{\dagger}$ Present address:

Edward Málaga-Trillo, Laboratorios de Investigación y Desarrollo,

Facultad de Ciencias y Filosofía, Universidad Peruana Cayetano

Heredia, Lima, Perú
The ability of the cellular prion protein $\left(\mathrm{Pr}^{\mathrm{C}}\right)$ to trigger intracellular signals appears central to neurodegeneration pathways, yet the physiological significance of such signals is rather puzzling. For instance, $\operatorname{PrPC}$ deregulation disrupts phenomena as diverse as synaptic transmission in mammals and cell adhesion in zebrafish. Although unrelated, the key proteins in these events -the NMDA receptor (NMDAR) and E-cadherin, respectively- are similarly modulated by the Src family kinase (SFK) Fyn. These observations highlight the importance of $\mathrm{PrPC}^{\mathrm{C}}$-mediated Fyn activation, a finding reported nearly two decades ago. Given their complex functions and regulation, SFKs may hold the key to intriguing aspects of PrP biology such as its seemingly promiscuous functions and the lack of strong phenotypes in knockout mice. Here we provide a mechanistic perspective on how SFKs might contribute to the uncertain molecular basis of neuronal PrP phenotypes affecting ion channel activity, axon myelination and olfactory function. In particular, we discuss SFK target proteins involved in these processes and the role of tyrosine phosphorylation in the regulation of their activity and cell surface expression.

Keywords: prion protein, Src family kinases, ion channels, myelination, tyrosine phosphorylation, endocytosis, knockout mice, zebrafish
Yes, there are two paths you can go by but in the long run

There's still time to change the road you're on

(R. Plant and J. Page)

\section{INTRODUCTION}

The abnormal accumulation of misfolded proteins is a defining molecular landmark of neurodegenerative conditions like prion, Alzheimer's and Parkinson's diseases. Interestingly, the identity of the pathogenic protein is different in each of these illnesses, suggesting that neurotoxicity may result from the excess of virtually any rogue protein in neuronal tissue. On the other hand, at least some of these proteins may play physiological roles in their nonaggregated state, which are key to neuronal survival and disease. For instance, the amyloid precursor protein and $\alpha$-synucleinthe protein culprits of Alzheimer's and Parkinson's disease-are enriched in neuronal synapses and nerve terminals (Maroteaux et al., 1988; Schubert et al., 1991). Likewise, expression of $\operatorname{PrP}^{\mathrm{C}}$ on neuronal cell surfaces is required for pathogenic prions and a $\beta$ oligomers to trigger cellular damage (Chesebro et al., 2005; Um et al., 2012). Beyond their propensity to misfold and aggregate, little is known about how exactly these proteins contribute to neuronal physiology and disease. For PrP, the quest for a gene/protein function has been particularly challenging because of the paucity of clear knockout phenotypes in mice (Steele et al., 2007). While this phenomenon may be explained by compensatory mechanisms (Málaga-Trillo and Sempou, 2009), the actual extent to which other genes can functionally replace PrP is only partly understood (Passet et al., 2013). More recent analyses of
PrP knockout mice have revealed subtle defects in axon myelination and olfactory function as well as in the proliferation of neural precursors and self-renewal of hematopoietic stem cells (Steele et al., 2006; Zhang et al., 2006; Le Pichon et al., 2009; Bremer et al., 2010). Unfortunately, the precise molecular basis of these phenotypes remains unclear. Adding complexity to the matter, many of the dissimilar functions and interaction partners proposed for $\operatorname{PrP}^{\mathrm{C}}$ cannot easily be accounted for by a single biological activity.

Among the various molecular roles ascribed to $\operatorname{PrP}^{\mathrm{C}}$, its ability to elicit intracellular signals is in good correspondence with its cell surface localization and involvement in physiological processes as diverse and complex as cell adhesion, lymphocyte activation, neuroprotection, and synaptic function (Aguzzi et al., 2008). That PrP signaling is pathophysiologically relevant was elegantly shown by Chesebro and colleagues, who demonstrated that without anchoring to the plasma membrane, PrP may misfold and aggregate but not induce neuronal damage (Chesebro et al., 2005). Presently, a number of transmembrane and intracellular molecules are known to help $\operatorname{PrP}^{\mathrm{C}}$ transduce signals into the cell's interior (Linden et al., 2008). Among the latter, SFKs have gathered renewed interest because of their connection to prionand $\mathrm{a} \beta$-induced neurotoxicity as well as for their contribution to PrP-mediated cell communication in vivo. The purpose of this article is to revisit putative functions of $\operatorname{PrP}$ in the context of SFK signaling.

\section{SFKs, A MULTIFUNCTIONAL PROTEIN FAMILY}

The Src family of non-receptor protein tyrosine kinases comprises nine members in vertebrates, five of which are active in 
mammalian CNS neurons, namely the ubiquitously expressed Src, Fyn, and Yes, and the tissue-restricted Lck and Lyn (Thomas and Brugge, 1997; Salter and Kalia, 2004). Their association to the cytoplasmic face of the plasma membrane via myristoylation and palmytoylation enables them to receive extracellular stimuli and transduce them into the cell interior (Silverman et al., 1993). SFK enzymatic activity is triggered by autophosphorylation at tyrosine residue 416 and inhibited by phosphorylation of tyrosine residue 527 (Roskoski, 2005). Owing to their interaction with a diverse array of transmembrane receptors and downstream targets, SFKs can regulate a broad range of cellular processes, including cell differentiation, proliferation, adhesion, migration, apoptosis, and immunity (Thomas and Brugge, 1997; Roskoski, 2004). Because of their strong structural conservation, SFK members are functionally redundant and can often compensate for each other, encumbering analysis of their individual roles via gene knockout approaches (Lowell and Soriano, 1996). Given their expression and multiple functions in neurons, it is not surprising that SFK deregulation should contribute to neurodegeneration. In fact, prion infection triggers increased levels of Src and phosphotyrosine proteins in cultured cells and mice (Nixon, 2005; Gyllberg et al., 2006). Moreover, Fyn is selectively upregulated in Alzheimer's brains (Shirazi and Wood, 1993), where it mediates hyperphosphorylation of the aggregation-prone, microtubuleassociated protein Tau (Lee et al., 2004). Fittingly, Fyn overexpression triggers synaptic damage in mouse models of Alzheimer's disease (Chin et al., 2005) whereas Fyn knockdown leads to decreased Tau phosphorylation, increased a $\beta$ levels and impaired spatial learning (Minami et al., 2012). Together, these findings imply a direct involvement of SFKs in neurotoxic pathways that are common to multiple neurodegenerative conditions.

\section{SFKs AS FUNCTIONAL HUBS OF PrP}

Being tethered to the outer leaflet of the plasma membrane via a short glycosylphosphatidylinositol- (GPI) anchor, PrP is unlikely to physically associate with cytosolic SFKs. Nevertheless, co-immunoprecipitation data indicate that, in epithelial cells, PrP and SFKs interact at least indirectly within a larger protein complex (Morel et al., 2004, 2008). In addition, plenty of evidence supports the notion that $\operatorname{PrP}$ and SFKs are functional partners in neurons. Using antibody-mediated crosslinking, Mouillet-Richard and colleagues were the first to show that PrP clustering at neuronal cell surfaces triggers caveolindependent activation of Fyn (Mouillet-Richard et al., 2000). Related experiments in neuron-like PC12 cells corroborated the contribution of caveolin to $\mathrm{PrP}^{\mathrm{C}}$-mediated Fyn activation, along with the downstream activation of the Ras-Raf/ERK pathway and the negative regulation of the entire cascade by phosphocaveolin (Pantera et al., 2009). In cultured mouse hippocampal neurons, $\operatorname{PrP}^{\mathrm{C}}$ was found to indirectly activate Fyn via cis or trans associations with the neural cell adhesion molecule (NCAM) within lipid rafts, thereby stimulating neurite outgrowth (Santuccione et al., 2005). Importantly, in vivo data from a wide range of animal models underscore the relevance of the PrP/SFK pathway in physiology and disease. For instance, expression of a pathogenic PrP mutant in Caenorhabditis elegans induced neuronal dysfunction in a Fyn-dependent manner
(Bizat et al., 2010), a remarkable result since nematodes do not possess endogenous PrPs. In early zebrafish embryos, exogenously added mouse PrP mimicks the positive regulation of E-cadherin-mediated cell adhesion by endogenous PrPs, an effect that requires Fyn and Yes activity (Málaga-Trillo et al., 2009; Sempou et al., submitted). In undoubtedly one of the most sensational developments in the recent field of neurodegeneration, neuronal $\operatorname{PrP}^{\mathrm{C}}$ was reported to act as a receptor for $\mathrm{a} \beta$ oligomers. Notably, the resulting synaptic impairment was mediated by Fyn (Um et al., 2012).

At first glance, some of these findings have no apparent connection with each other, aside from the common involvement of SFKs. However, closer scrutiny reveals mechanistic similarities pertinent to our understanding of $\operatorname{PrP}$ function. This is particularly manifest in two of the aforementioned models, where the downstream targets of PrP turned out to be transmembrane proteins modulated by tyrosine phosphorylation. In the study by the Strittmatter lab, binding of a $\beta$ oligomers to $\mathrm{PrP}^{\mathrm{C}}$ triggered Fyn activation and hyperphosphorylation of the NR2B subunit of the NMDAR at tyrosine residue 1472 (Um et al., 2012). As a result, NMDARs became overstabilized at the plasma membrane and glutamate excitotoxicity ensued. Under non-pathological conditions, phosphorylation of NR2B at this C-terminal regulatory site promotes its normal cell surface expression by preventing the binding of AP-2 adaptor complexes, which would otherwise initiate its internalization via clathrin- and dynamin-dependent endocytosis (Salter and Kalia, 2004). Similarly, postsynaptic density protein 95 (PSD-95) prevents NR2B endocytosis by binding a site adjacent to tyrosine 1472 and thereby blocking access to AP-2 (Lavezzari et al., 2003). Overall, the phosphorylation state of NMDAR subunits is controlled by the dynamic interplay between SFKs and protein tyrosine phosphatases (PTPs), as well as by the input from various upstream signaling molecules (Salter and Kalia, 2004). In addition, NMDAR function is further regulated via differential transcription, translation and trafficking of specific subunits as well as through protein-protein interactions (Sanz-Clemente et al., 2013). Notably, the regulation of protein endocytosis by molecules that competitively bind target motifs at cytoplasmic tails is also pivotal to the modulation of E-cadherin cell surface expression (Ishiyama et al., 2010). Thus, association of p120 catenin to the C-terminal juxtamembrane domain (JMD) of E-cadherin sterically blocks binding of AP-2 and the E3 ubiquitin ligase Hakai, thereby preventing its clathrinmediated or ubiquitination-dependent endocytosis, respectively (Thoreson et al., 2000; Fujita et al., 2002; Miyashita and Ozawa, 2007; Ishiyama et al., 2010). Importantly, SFK-mediated phosphorylation of the JMD and/or p120 catenin triggers E-cadherin internalization (Reynolds, 2010). Additionally, SFKs phosphorylate and modulate components of the endocytic machinery like clathrin, dynamin and AP-2 (Ahn et al., 1999, 2002; Wilde et al., 1999; Zimmerman et al., 2009). In our zebrafish model, $\operatorname{PrP}^{\mathrm{C}}$ promotes embryonic cell adhesion by stabilizing E-cadherin at the cell-surface (Málaga-Trillo et al., 2009). Crucially, this activity entails the SFK-dependent inhibition of E-cadherin endocytosis (Sempou et al., submitted). Therefore, the roles of $\mathrm{PrP}^{\mathrm{C}}$ as a modulator of cell-cell adhesion in zebrafish and synaptic transmission in mammals converge at a common mechanism, 
namely the ability of SFKs to control the internalization of transmembrane proteins by phosphorylating their endocytic signals and/or the corresponding binding molecules. Given the functional diversity of SFK target proteins, we reasoned that altered SFK activity may account for at least some of the distinct neuronal phenotypes observed in PrP knockout and transgenic mice (Figure 1, Table 1). To address this possibility, we examined three compelling, yet poorly understood paradigms of $\operatorname{PrP}$ function.

\section{PrP AND ION CHANNELS}

The NMDAR-mediated glutamate excitotoxicity induced by a $\beta$ oligomers and $\mathrm{PrP}^{\mathrm{C}}$ clearly shows that the latter can influence the activity of ion channels (Um et al., 2012). Intriguingly, while this effect relies on the PrP-dependent overactivation of NR2B subunits, a different study found that $\operatorname{PrP}^{\mathrm{C}}$ suppresses NMDAR activity and glutamate excitotoxicity via the inhibition of NR2D subunits (Khosravani et al., 2008). How PrP may influence this pathway under physiological conditions remains to be established. Nonetheless, a general role of $\operatorname{PrP}$ as a modulator of ion channel activity and neurotransmission is consistent with its synaptic localization (Moya et al., 2000; Um et al., 2012) and the common occurrence of electrophysiological alterations in $\operatorname{PrP}$ knockout mice (Aguzzi et al., 2008; Biasini et al., 2012). Moreover, transgenic mice expressing neurotoxic PrP mutants show distinct neurological phenotypes related to ion channel dysfunction. One of these mutants, $\operatorname{PrP} \Delta \mathrm{CR}$, has 21 aa deleted from its central region and triggers neonatal lethality characterized by the spontaneous degeneration of cerebellar granule neurons (CGNs) (Li et al., 2007). Subsequent work in cultured cells and cerebellar slices revealed that $\operatorname{PrP} \Delta \mathrm{CR}$ induces spontaneous currents that increase neuronal susceptibility to glutamate-dependent, $\mathrm{Ca}^{2+}$. mediated excitotoxicity (Solomon et al., 2010; Biasini et al., 2013). Based on these data, the authors suggested that $\operatorname{PrP} \Delta C R$ might either activate an endogenous ion channel or form itself an ion channel. A second PrP mutant, PG14, causes age-related degeneration of CGNs owing to defective glutamate exocytosis and impaired calcium dynamics (Senatore et al., 2012). This phenotype was explained by the ability of PG14 to bind the voltage-gated calcium channel (VGCC) $\alpha_{2} \delta-1$ subunit and retain

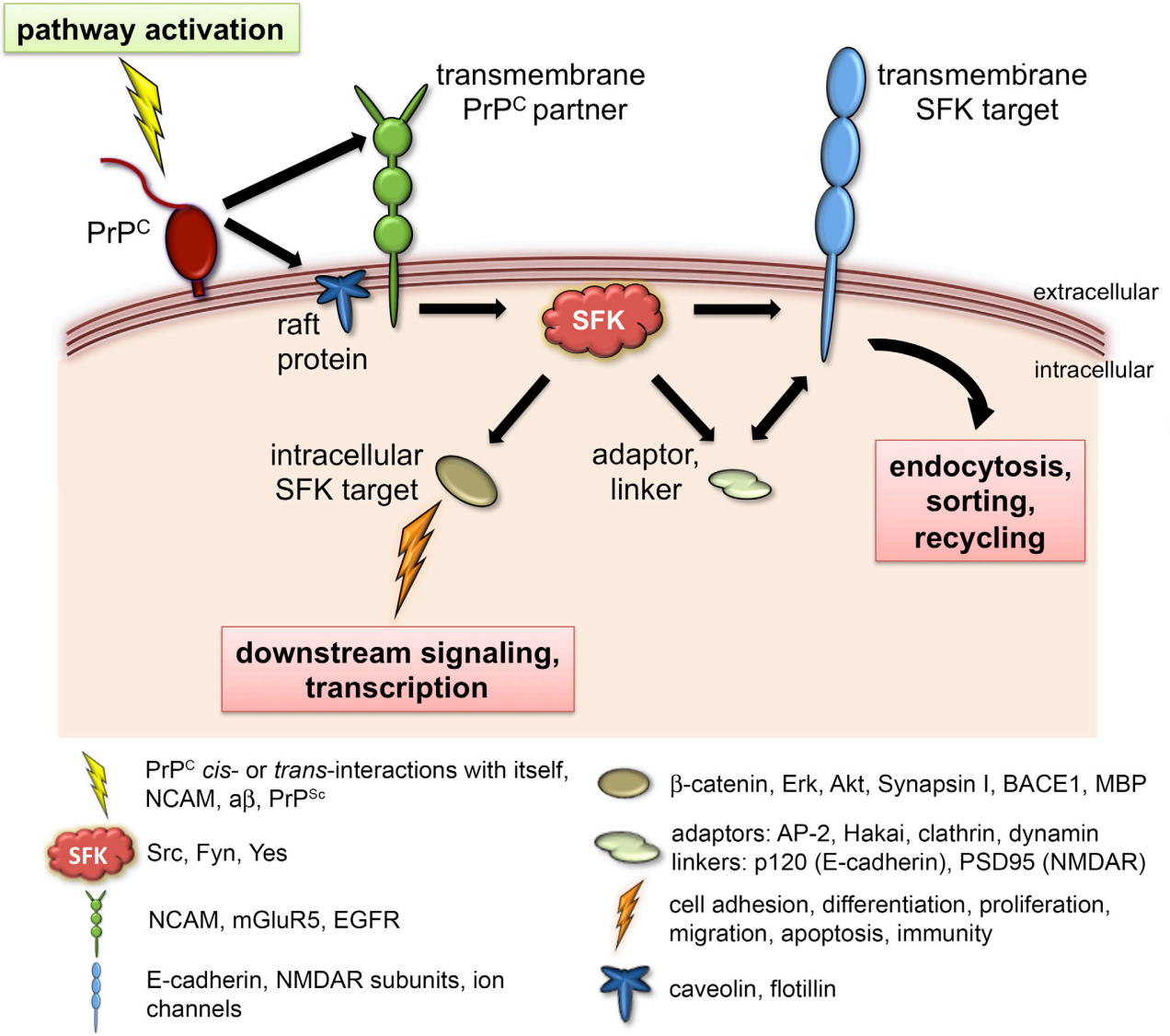

FIGURE 1 | PrPC signaling via SFKs. Known physiological roles of $\mathrm{PrP}^{\mathrm{C}}$ such as neurotransmission, embryonic cell adhesion, olfactory function, and myelination converge at the use of SFKs as intracellular signaling partners. In this model, engagement of $\mathrm{PrPC}$ in various cis- or trans-interactions (depicted as "pathway activation") elicits the catalytic activity of SFKs, leading to the modulation of diverse downstream targets that include ion channels, adhesion complexes, and cytosolic signaling molecules. Phosphorylation of transmembrane SFK targets controls their cell surface expression and/or signaling properties, whereas phosphorylation of intracellular SFK targets regulates the activation of additional downstream pathways, gene transcription, and protein translation. The caption below provides concrete examples of documented components of this cascade. 
Table 1 | SFKs and downstream events involved in PrP activities.

\begin{tabular}{|c|c|c|c|}
\hline PrP activities reported & SFKs involved & SFK target events affected & References \\
\hline $\begin{array}{l}\text { Regulation of embryonic cell } \\
\text { adhesion (zebrafish) }\end{array}$ & Fyn, Yes & Endocytosis of E-cadherin & Ishiyama et al., 2010 \\
\hline $\operatorname{PrP} \Delta \mathrm{CR}$ neurotoxicity & Fyn & Gating and/or endocytosis of NMDARs & Salter and Kalia, 2004 \\
\hline PrP PG14 neurotoxicity & Src & Gating and/or endocytosis of VGCCs & Davis et al., 2001 \\
\hline & Fyn & Gating and/or endocytosis of NMDARs & $\begin{array}{l}\text { Chen et al., 2000; Halabisky et al., } \\
2000\end{array}$ \\
\hline \multirow[t]{3}{*}{ Molecular control of myelination } & $\mathrm{Src}$ & Activation of Akt/PKB & $\begin{array}{l}\text { Chen et al., 2001; Jiang and Qiu, } \\
2003\end{array}$ \\
\hline & unknown & Endocytosis of MAG and MOG & $\begin{array}{l}\text { Bo et al., 1995; Kroepfl and } \\
\text { Gardinier, 2001a,b }\end{array}$ \\
\hline & Src, Fyn & Gating and/or endocytosis of $K_{v} 1.5$ and 2.1 channels & $\begin{array}{l}\text { Sobko et al., 1998; Peretz et al., } \\
\text { 1999; Tiran et al., } 2006\end{array}$ \\
\hline
\end{tabular}

Summary of some previously described activities of PrP (see main text) and the relevant molecular targets/events regulated by SFKs. The actual involvement of these pathways in the corresponding PrP phenotypes is hypothetical, except for those under "aß oligomer neurotoxicity" and "embryonic cell adhesion," which have been experimentally confirmed.

it at the ER, thus disrupting its delivery to the plasma membrane. Notably, while the molecular mechanisms of these two phenotypes seem unrelated, they are both consistent with the ability of SFKs to regulate the activity of ligand- and voltage-gated ion channels (Salter and Kalia, 2004). For instance, the spontaneous ionic currents induced by $\operatorname{PrP} \Delta \mathrm{CR}$ may be explained by alterations in SFK-mediated phosphorylation and trafficking of NMDAR subunits. Detailed biochemical analyses will be needed to distinguish between this scenario and one proposed by the authors, namely, that the mutant PrP molecule activates NMDARs via direct interaction (Biasini et al., 2013). For the PG14 phenotype, the data show that intracellular retention of VGCC $\alpha_{2} \delta-1$ during biosynthesis is the most likely explanation for its reduced levels at the plasma membrane (Senatore et al., 2012). However, here it also might be worthwhile considering that VGCCs are modulated via tyrosine phosphorylation by, among others, Src (Davis et al., 2001). Whether SFK regulation of VGCCs targets their trafficking or only their gating properties is presently unknown.

\section{PrP AND OLFACTION}

Unique among mouse PrP knockout phenotypes was the finding of impaired olfactory behavior (Le Pichon et al., 2009). In electrophysiological terms, the phenotype was attributed to olfactory bulb-specific alterations in the patterns of oscillatory activity and in the plasticity of the dendrodendritic synapse. No molecular basis was reported for these defects but the authors suggested that due to its localization at olfactory synaptic membranes and its interaction with Synapsin Ib (Spielhaupter and Schatzl, 2001), PrP may be a regulatory component of the synaptic machinery. Interestingly, several lines of evidence argue for a contribution of SFKs and their targets to this phenotype. First, phosphorylation of Synapsin I by Src increases its binding to synaptic vesicles (SVs) and the actin cytoskeleton, thereby limiting the number of recycled SVs available for exocytosis and neurotransmitter release (Messa et al., 2010). Second, Fyn-deficient mice exhibit defects related to the olfactory dysfunction described by Le Pichon et al., such as impaired suckling behavior, altered synaptic transmission via GABA and NMDA receptors in the olfactory bulb, and abnormal axon guidance and fasciculation in the olfactory nerve (Yagi et al., 1993; Kitazawa et al., 1998; Morse et al., 1998). Third, $\mathrm{K}_{\mathrm{v}} 1.3$ voltage-gated potassium channels are expressed along the dendrodendritic synapse and are negatively regulated by Src phosphorylation (Fadool and Levitan, 1998; Fadool et al., 2000). Remarkably, olfactory neurons from $\mathrm{K}_{\mathrm{V}} 1.3$ null mice have modified action potentials and deregulated potassium currents, resulting in structurally altered olfactory bulbs and a heightened sense of smell (Fadool et al., 2004). Fourth, NMDARs play a crucial role at the dendrodendritic synapse by generating the $\mathrm{Ca}^{2+}$ influx that triggers inhibitory GABA release (Chen et al., 2000; Halabisky et al., 2000). This essential component of olfactory learning is therefore also subject to modulation by $\operatorname{PrP}$ and SFKs. Hence, the combined, SFK-mediated deregulation of Synapsin $\mathrm{I}, \mathrm{K}_{\mathrm{v}} 1.3$ channels, and NMDARs provides testable explanations for the olfactory defects of PrP knockout mice. 


\section{PrP AND MYELINATION}

Re-examination of a mild, late-onset phenotype in PrP knockout mice led to the discovery of defects in the maintenance of peripheral myelin (Bremer et al., 2010). This chronic demyelinating polyneuropathy (CDP) was triggered by the loss of PrP in neurons but not in Schwann cells. The mechanistic basis of this phenotype remains unidentified, as the authors found no alterations in the phosphorylation of Akt, and Erk, two signaling molecules down the myelination pathway initiated with the cleavage of Neuregulin-1 (NRG1) by the BACE1 endopeptidase (Hu et al., 2006; Liu et al., 2007). Similarly, no differences were detected in the expression levels of NRG1, although, neither BACE1 activity nor BACE1-mediated cleavage of NRG1 was directly assessed in PrP knockout mice. Interestingly, Src is known to modulate several events along the BACE1/NRG1 pathway. Some of them, like Akt phosphorylation by Src (Chen et al., 2001; Jiang and Qiu, 2003), are probably not involved in the PrP phenotype, as implied by Bremer and colleagues. Others like BACE1 endocytosis and activation (Zou et al., 2007) or the mTORC1-induced transcription of the myelin basic protein (MBP) gene (Vojtechova et al., 2008; Ondrusova et al., 2013) would require further verification. Of note, BACE-null mice exhibit myelination defects reminiscent of those in PrP knockout mice, as well as increased levels of full-length NRG1 and-unlike PrP knockouts-reduced Akt phosphorylation (Hu et al., 2006, 2008).

As with the olfactory phenotype of Le Pichon et al., copious evidence suggests a potential involvement of SFKs in the PrP-CDP phenotype. Comprehensive reviews on the role of Fyn during myelination are available elsewhere (Kramer-Albers and White, 2011; White and Kramer-Albers, 2014) but for example, myelination requires Fyn activation by the myelin-associated glycoprotein (MAG), and activated Fyn promotes MBP gene transcription (Umemori et al., 1994, 1999). In addition, Fyn stimulates the localized translation of MBP mRNA at sites of axon-glia contact via phosphorylation of the heterogeneous nuclear ribonucleoprotein (hnRNP) A2 (White et al., 2008). Furthermore, Fyn-deficient mice show myelination defects similar to those of BACE- and PrPnull mice, albeit with some differences in the localization (PNS vs. CNS), onset (late vs. early) and severity of the phenotype (Umemori et al., 1994, 1999; Sperber et al., 2001). Interestingly, the presence of tyrosine-based endocytic motifs in MAG and the myelin/oligodendrocyte glycoprotein (MOG) strongly suggests that their cell surface expression is modulated by SFKs (Bo et al., 1995; Kroepfl and Gardinier, 2001a,b). In fact, the endocytic trafficking and sorting of myelin proteins is key to the establishment of membrane domains in oligodendroglial cells (Winterstein et al., 2008). Particularly relevant to the PrP-CDP phenotype, adult and aged MAG-null mice undergo degeneration of myelinated fibers in the PNS (Schachner and Bartsch, 2000).

Finally, voltage- and ligand-gated ion channels constitute further regulatory targets of SFKs during myelination. For instance, the phosphorylation state of $K_{v} 1.5$ and $K_{v} 2.1$ potassium channels in Schwann cells is controlled by the interplay between Src, Fyn, PTP $\alpha$, and PTPE (Sobko et al., 1998; Peretz et al., 1999; Tiran et al., 2006). This complex mechanism modulates the gating properties of the channels, influencing Schwann cell development and the onset of myelination. Likewise, NMDARs promote the maturation of oligodendrocyte precursor cells (OPCs) by enhancing the expression of myelin proteins ( $\mathrm{Li}$ et al., 2013). Nevertheless, experiments with NMDAR-deficient mice suggest that, in vivo, this regulation might be relevant for re-myelination but not for OPC development (De Biase et al., 2011; Li et al., 2013). Thus, although the molecular control of myelination is a rather intricate phenomenon, the PrP-CDP phenotype seems consistent with the alteration of multiple pathways downstream of SFKs.

Altogether, the common regulation of ion channels, olfaction and myelination by PrP and SFKs suggests that this phenomenon may extend to some of the other subtle PrP phenotypes mentioned above. For instance, it would be interesting to see if the role of $\mathrm{PrP}^{\mathrm{C}}$ in the proliferation and differentiation of various stem cell lineages (reviewed in Martin-Lannerée et al., 2014) requires the differential expression of SFKs and their targets at specific stages of stem cell maturation. Along these lines, the contribution of tissue-restricted SFKs to PrP signaling deserves further investigation, as most of the available data on the PrP/SFK pathway so far involve only the ubiquitously expressed Src, Fyn, and Yes.

\section{CONCLUSIONS}

Several key observations emerge from the present analysis. First, the ability of $\operatorname{PrP}^{\mathrm{C}}$ to elicit intracellular signals at the cell surface is central to its multiple roles in health and disease. Second, the specificity of these signals is largely determined by extrinsic factors such as the plasma membrane microenvironment and the availability of cell- and tissue-specific protein partners. Third, the ubiquitous expression and functional redundancy of SFKs, along with the diversity of their downstream targets offer plausible explanations for some of the striking facts of PrP biology, such as its functional promiscuity, the viability of PrP knockout mice, and the diversity of PrP transgenic/mutant phenotypes. Based on these considerations, we propose that $\operatorname{PrP}^{\mathrm{C}}$ acts as a gatekeeper between neuronal survival and toxicity by controlling the activity and/or endocytic trafficking of ion channels, synaptic proteins and cell adhesion molecules via SFKs. Testing these complex scenarios should prove a formidable but rewarding endeavor.

\section{ACKNOWLEDGMENTS}

Our warm gratitude to Florence Kranitz and the CJD Foundation for their kind support. Special thanks to Chuck for his dogged encouragement. Funded by the Deutsche Forschungsgemeinschaft (Grant MA 2525/1-1) and the University of Konstanz AFF.

\section{REFERENCES}

Aguzzi, A., Baumann, F., and Bremer, J. (2008). The prion's elusive reason for being. Annu. Rev. Neurosci. 31, 439-477. doi: 10.1146/annurev.neuro.31.060407.125620

Ahn, S., Kim, J., Lucaveche, C. L., Reedy, M. C., Luttrell, L. M., Lefkowitz, R. J., et al. (2002). Src-dependent tyrosine phosphorylation regulates dynamin self-assembly and ligand-induced endocytosis of the epidermal growth factor receptor. J. Biol. Chem. 277, 26642-26651. doi: 10.1074/jbc.M201499200

Ahn, S., Maudsley, S., Luttrell, L. M., Lefkowitz, R. J., and Daaka, Y. (1999). Srcmediated tyrosine phosphorylation of dynamin is required for beta2-adrenergic receptor internalization and mitogen-activated protein kinase signaling. J. Biol. Chem. 274, 1185-1188. doi: 10.1074/jbc.274.3.1185 
Biasini, E., Turnbaugh, J. A., Unterberger, U., and Harris, D. A. (2012). Prion protein at the crossroads of physiology and disease. Trends Neurosci. 35, 92-103. doi: 10.1016/j.tins.2011.10.002

Biasini, E., Unterberger, U., Solomon, I. H., Massignan, T., Senatore, A., Bian, H., et al. (2013). A mutant prion protein sensitizes neurons to glutamate-induced excitotoxicity. J. Neurosci. 33, 2408-2418. doi: 10.1523/JNEUROSCI.340612.2013

Bizat, N., Peyrin, J. M., Haik, S., Cochois, V., Beaudry, P., Laplanche, J. L., et al. (2010). Neuron dysfunction is induced by prion protein with an insertional mutation via a Fyn kinase and reversed by sirtuin activation in Caenorhabditis elegans. J. Neurosci. 30, 5394-5403. doi: 10.1523/JNEUROSCI.5831-09.2010

Bo, L., Quarles, R. H., Fujita, N., Bartoszewicz, Z., Sato, S., and Trapp, B. D. (1995). Endocytic depletion of L-MAG from CNS myelin in quaking mice. J. Cell Biol. 131, 1811-1820. doi: 10.1083/jcb.131.6.1811

Bremer, J., Baumann, F., Tiberi, C., Wessig, C., Fischer, H., Schwarz, P., et al. (2010). Axonal prion protein is required for peripheral myelin maintenance. Nat. Neurosci. 13, 310-318. doi: 10.1038/nn.2483

Chen, R., Kim, O., Yang, J., Sato, K., Eisenmann, K. M., Mccarthy, J., et al. (2001). Regulation of Akt/PKB activation by tyrosine phosphorylation. J. Biol. Chem. 276, 31858-31862. doi: 10.1074/jbc.C100271200

Chen, W. R., Xiong, W., and Shepherd, G. M. (2000). Analysis of relations between NMDA receptors and GABA release at olfactory bulb reciprocal synapses. Neuron 25, 625-633. doi: 10.1016/S0896-6273(00)81065-X

Chesebro, B., Trifilo, M., Race, R., Meade-White, K., Teng, C., Lacasse, R., et al. (2005). Anchorless prion protein results in infectious amyloid disease without clinical scrapie. Science 308, 1435-1439. doi: 10.1126/science.1110837

Chin, J., Palop, J. J., Puolivali, J., Massaro, C., Bien-Ly, N., Gerstein, H., et al. (2005). Fyn kinase induces synaptic and cognitive impairments in a transgenic mouse model of Alzheimer's disease. J. Neurosci. 25, 9694-9703. doi: 10.1523/JNEUROSCI.2980-05.2005

Davis, M. J., Wu, X., Nurkiewicz, T. R., Kawasaki, J., Gui, P., Hill, M. A., et al. (2001). Regulation of ion channels by protein tyrosine phosphorylation. Am. J. Physiol. Heart Circ. Physiol. 281, H1835-H1862.

De Biase, L. M., Kang, S. H., Baxi, E. G., Fukaya, M., Pucak, M. L., Mishina, M., et al. (2011). NMDA receptor signaling in oligodendrocyte progenitors is not required for oligodendrogenesis and myelination. J. Neurosci. 31, 12650-12662. doi: 10.1523/JNEUROSCI.2455-11.2011

Fadool, D. A., and Levitan, I. B. (1998). Modulation of olfactory bulb neuron potassium current by tyrosine phosphorylation. J. Neurosci. 18, 6126-6137.

Fadool, D. A., Tucker, K., Perkins, R., Fasciani, G., Thompson, R. N., Parsons, A. D., et al. (2004). Kv1.3 channel gene-targeted deletion produces "Super-Smeller Mice" with altered glomeruli, interacting scaffolding proteins, and biophysics. Neuron 41, 389-404. doi: 10.1016/S0896-6273(03)00844-4

Fadool, D. A., Tucker, K., Phillips, J. J., and Simmen, J. A. (2000). Brain insulin receptor causes activity-dependent current suppression in the olfactory bulb through multiple phosphorylation of Kv1.3. J. Neurophysiol. 83, 2332-2348.

Fujita, Y., Krause, G., Scheffner, M., Zechner, D., Leddy, H. E. M., Behrens, J., et al. (2002). Hakai, a c-Cbl-like protein, ubiquitinates and induces endocytosis of the E-cadherin complex. Nat. Cell Biol. 4, 222-231. doi: 10.1038/ncb758

Gyllberg, H., Löfgren, K., Lindegren, H., and Bedecs, K. (2006). Increased Src kinase level results in increased protein tyrosine phosphorylation in scrapie-infected neuronal cell lines. FEBS Lett. 580, 2603-2608. doi: 10.1016/j.febslet.2006.03.092

Halabisky, B., Friedman, D., Radojicic, M., and Strowbridge, B. W. (2000). Calcium influx through NMDA receptors directly evokes GABA release in olfactory bulb granule cells. J. Neurosci. 20, 5124-5134.

Hu, X., He, W., Diaconu, C., Tang, X., Kidd, G. J., Macklin, W. B., et al. (2008). Genetic deletion of BACE1 in mice affects remyelination of sciatic nerves. FASEB J. 22, 2970-2980. doi: 10.1096/fj.08-106666

Hu, X., Hicks, C. W., He, W., Wong, P., Macklin, W. B., Trapp, B. D., et al. (2006). Bacel modulates myelination in the central and peripheral nervous system. Nat. Neurosci. 9, 1520-1525. doi: 10.1038/nn1797

Ishiyama, N., Lee, S.-H., Liu, S., Li, G.-Y., Smith, M. J., Reichardt, L. F., et al. (2010). Dynamic and static interactions between p120 catenin and Ecadherin regulate the stability of cell-cell adhesion. Cell 141, 117-128. doi: 10.1016/j.cell.2010.01.017

Jiang, T., and Qiu, Y. (2003). Interaction between Src and a C-terminal proline-rich motif of Akt is required for Akt activation. J. Biol. Chem. 278, 15789-15793. doi: 10.1074/jbc.M212525200
Khosravani, H., Zhang, Y., Tsutsui, S., Hameed, S., Altier, C., Hamid, J., et al. (2008). Prion protein attenuates excitotoxicity by inhibiting NMDA receptors. J. Cell Biol. 181, 551-565. doi: 10.1083/jcb.200711002

Kitazawa, H., Yagi, T., Miyakawa, T., Niki, H., and Kawai, N. (1998). Abnormal synaptic transmission in the olfactory bulb of Fyn-kinase-deficient mice. J. Neurophysiol. 79, 137-142.

Kramer-Albers, E. M., and White, R. (2011). From axon-glial signalling to myelination: the integrating role of oligodendroglial Fyn kinase. Cell Mol. Life Sci. 68, 2003-2012. doi: 10.1007/s00018-010-0616-Z

Kroepfl, J. F., and Gardinier, M. V. (2001a). Identification of a basolateral membrane targeting signal within the cytoplasmic domain of myelin/oligodendrocyte glycoprotein. J. Neurochem. 77, 1301-1309. doi: 10.1046/j.1471-4159.2001.00343.x

Kroepfl, J. F., and Gardinier, M. V. (2001b). Mutually exclusive apicobasolateral sorting of two oligodendroglial membrane proteins, proteolipid protein and myelin/oligodendrocyte glycoprotein, in Madin-Darby canine kidney cells. J. Neurosci. Res. 66, 1140-1148. doi: 10.1002/jnr.10035

Lavezzari, G., Mccallum, J., Lee, R., and Roche, K. W. (2003). Differential binding of the AP-2 adaptor complex and PSD-95 to the C-terminus of the NMDA receptor subunit NR2B regulates surface expression. Neuropharmacology 45, 729-737. doi: 10.1016/S0028-3908(03)00308-3

Lee, G., Thangavel, R., Sharma, V. M., Litersky, J. M., Bhaskar, K., Fang, S. M., et al. (2004). Phosphorylation of tau by fyn: implications for Alzheimer's disease. J. Neurosci. 24, 2304-2312. doi: 10.1523/JNEUROSCI.4162-03.2004

Le Pichon, C. E., Valley, M. T., Polymenidou, M., Chesler, A. T., Sagdullaev, B. T., Aguzzi, A., et al. (2009). Olfactory behavior and physiology are disrupted in prion protein knockout mice. Nat. Neurosci. 12, 60-69. doi: 10.1038/nn.2238

Li, A., Christensen, H. M., Stewart, L. R., Roth, K. A., Chiesa, R., and Harris, D. A. (2007). Neonatal lethality in transgenic mice expressing prion protein with a deletion of residues 105-125. EMBO J. 26, 548-558. doi: 10.1038/sj.emboj.7601507

Li, C., Xiao, L., Liu, X., Yang, W., Shen, W., Hu, C., et al. (2013). A functional role of NMDA receptor in regulating the differentiation of oligodendrocyte precursor cells and remyelination. Glia 61, 732-749. doi: 10.1002/glia.22469

Linden, R., Martins, V. R., Prado, M. A., Cammarota, M., Izquierdo, I., and Brentani, R. R. (2008). Physiology of the prion protein. Physiol. Rev. 88, 673-728. doi: 10.1152/physrev.00007.2007

Liu, Y., Tao, Y. M., Woo, R. S., Xiong, W. C., and Mei, L. (2007). Stimulated ErbB4 internalization is necessary for neuregulin signaling in neurons. Biochem. Biophys. Res. Commun. 354, 505-510. doi: 10.1016/j.bbrc.2007.01.009

Lowell, C. A., and Soriano, P. (1996). Knockouts of Src-family kinases: stiff bones, wimpy $\mathrm{T}$ cells, and bad memories. Genes Dev. 10, 1845-1857. doi: 10.1101/gad.10.15.1845

Málaga-Trillo, E., and Sempou, E. (2009). PrPs: proteins with a purpose: lessons from the zebrafish. Prion 3, 129-133. doi: 10.4161/pri.3.3.9651

Málaga-Trillo, E., Solis, G. P., Schrock, Y., Geiss, C., Luncz, L., Thomanetz, V., et al. (2009). Regulation of embryonic cell adhesion by the prion protein. PLoS Biol. 7:e55. doi: 10.1371/journal.pbio.1000055

Maroteaux, L., Campanelli, J. T., and Scheller, R. H. (1988). Synuclein: a neuronspecific protein localized to the nucleus and presynaptic nerve terminal. J. Neurosci. 8, 2804-2815.

Martin-Lannerée, S., Hirsch, T. Z., Hernandez-Rapp, J., Halliez, S., Vilotte, J., Launay, J., et al. (2014). PrPC from stem cells to cancer. Front. Cell Dev. Biol. 2:55. doi: $10.3389 /$ fcell.2014.00055

Messa, M., Congia, S., Defranchi, E., Valtorta, F., Fassio, A., Onofri, F., et al. (2010). Tyrosine phosphorylation of synapsin I by Src regulates synaptic-vesicle trafficking. J. Cell Sci. 123, 2256-2265. doi: 10.1242/jcs.068445

Minami, S. S., Clifford, T. G., Hoe, H. S., Matsuoka, Y., and Rebeck, G. W. (2012). Fyn knock-down increases Abeta, decreases phospho-tau, and worsens spatial learning in 3xTg-AD mice. Neurobiol. Aging 33, 825.e815-825.e824. doi: 10.1016/j.neurobiolaging.2011.05.014

Miyashita, Y., and Ozawa, M. (2007). Increased internalization of p120-uncoupled E-cadherin and a requirement for a dileucine motif in the cytoplasmic domain for endocytosis of the protein. J. Biol. Chem. 282, 11540-11548. doi: 10.1074/jbc.M608351200

Morel, E., Fouquet, S., Chateau, D., Yvernault, L., Frobert, Y., Pincon-Raymond, M., et al. (2004). The cellular prion protein PrPc is expressed in human enterocytes in cell-cell junctional domains. J. Biol. Chem. 279, 1499-1505. doi: 10.1074/jbc.M308578200 
Morel, E., Fouquet, S., Strup-Perrot, C., Pichol Thievend, C., Petit, C., Loew, D., et al. (2008). The cellular prion protein $\operatorname{PrP}(c)$ is involved in the proliferation of epithelial cells and in the distribution of junction-associated proteins. PLoS ONE 3:e3000. doi: 10.1371/journal.pone.0003000

Morse, W. R., Whitesides, J. G. 3rd., Lamantia, A. S., and Maness, P. F. (1998). p59fyn and pp60c-src modulate axonal guidance in the developing mouse olfactory pathway. J. Neurobiol. 36, 53-63. doi: 10.1002/(SICI)10974695(199807)36:1<53::AID-NEU5>3.0.CO;2-9

Mouillet-Richard, S., Ermonval, M., Chebassier, C., Laplanche, J. L., Lehmann, S., Launay, J. M., et al. (2000). Signal transduction through prion protein. Science 289, 1925-1928. doi: 10.1126/science.289.5486.1925

Moya, K. L., Sales, N., Hassig, R., Creminon, C., Grassi, J., and Di Giamberardino, L. (2000). Immunolocalization of the cellular prion protein in normal brain. Microsc. Res. Tech. 50, 58-65. doi: 10.1002/1097-0029(20000701)50:1<58::AIDJEMT9>3.0.CO;2-5

Nixon, R. (2005). Prion-associated increases in Src-family kinases. J. Biol. Chem. 280, 2455. doi: 10.1074/jbc.M410883200

Ondrusova, L., Reda, J., Zakova, P., and Tuhackova, Z. (2013). Inhibition of mTORC1 by SU6656, the selective Src kinase inhibitor, is not accompanied by activation of Akt/PKB signalling in melanoma cells. Folia Biol. (Praha) 59, 162-167.

Pantera, B., Bini, C., Cirri, P., Paoli, P., Camici, G., Manao, G., et al. (2009). PrPc activation induces neurite outgrowth and differentiation in PC12 cells: role for caveolin-1 in the signal transduction pathway. J. Neurochem. 110, 194-207. doi: 10.1111/j.1471-4159.2009.06123.x

Passet, B., Halliez, S., Beringue, V., Laude, H., and Vilotte, J. L. (2013). The prion protein family: looking outside the central nervous system. Prion 7, 127-130. doi: $10.4161 /$ pri.22851

Peretz, A., Sobko, A., and Attali, B. (1999). Tyrosine kinases modulate K+ channel gating in mouse Schwann cells. J. Physiol. 519(Pt 2), 373-384. doi: 10.1111/j.1469-7793.1999.0373m.x

Reynolds, A. B. (2010). Exposing p120 catenin's most intimate affair. Cell 141, 20-22. doi: 10.1016/j.cell.2010.03.022

Roskoski, R. Jr. (2004). Src protein-tyrosine kinase structure and regulation. Biochem. Biophys. Res. Commun. 324, 1155-1164. doi: 10.1016/j.bbrc.2004.09.171

Roskoski, R. Jr. (2005). Src kinase regulation by phosphorylation and dephosphorylation. Biochem. Biophys. Res. Commun. 331, 1-14. doi: 10.1016/j.bbrc.2005.03.012

Salter, M. W., and Kalia, L. V. (2004). Src kinases: a hub for NMDA receptor regulation. Nat. Rev. Neurosci. 5, 317-328. doi: 10.1038/nrn1368

Santuccione, A., Sytnyk, V., Leshchyns'ka, I., and Schachner, M. (2005). Prion protein recruits its neuronal receptor NCAM to lipid rafts to activate p59fyn and to enhance neurite outgrowth. J. Cell Biol. 169, 341-354. doi: $10.1083 /$ jcb. 200409127

Sanz-Clemente, A., Nicoll, R. A., and Roche, K. W. (2013). Diversity in NMDA receptor composition: many regulators, many consequences. Neuroscientist 19, 62-75. doi: 10.1177/1073858411435129

Schachner, M., and Bartsch, U. (2000). Multiple functions of the myelin-associated glycoprotein MAG (siglec-4a) in formation and maintenance of myelin. Glia 29, 154-165. doi: 10.1002/(SICI) 1098-1136(20000115)29:2<154::AIDGLIA9>3.0.CO;2-3

Schubert, W., Prior, R., Weidemann, A., Dircksen, H., Multhaup, G., Masters, C. L., et al. (1991). Localization of Alzheimer beta A4 amyloid precursor protein at central and peripheral synaptic sites. Brain Res. 563, 184-194. doi: 10.1016/0006-8993(91)91532-6

Senatore, A., Colleoni, S., Verderio, C., Restelli, E., Morini, R., Condliffe, S. B., et al. (2012). Mutant PrP suppresses glutamatergic neurotransmission in cerebellar granule neurons by impairing membrane delivery of VGCC alpha(2)delta-1 Subunit. Neuron 74, 300-313. doi: 10.1016/j.neuron.2012.02.027

Shirazi, S. K., and Wood, J. G. (1993). The protein tyrosine kinase, fyn, in Alzheimer's disease pathology. Neuroreport 4, 435-437. doi: 10.1097/00001756199304000-00024

Silverman, L., Sudol, M., and Resh, M. D. (1993). Members of the src family of nonreceptor tyrosine kinases share a common mechanism for membrane binding. Cell Growth Differ. 4, 475-482.

Sobko, A., Peretz, A., and Attali, B. (1998). Constitutive activation of delayedrectifier potassium channels by a src family tyrosine kinase in Schwann cells. EMBO J. 17, 4723-4734. doi: 10.1093/emboj/17.16.4723
Solomon, I. H., Huettner, J. E., and Harris, D. A. (2010). Neurotoxic mutants of the prion protein induce spontaneous ionic currents in cultured cells. J. Biol. Chem. 285, 26719-26726. doi: 10.1074/jbc.M110.134619

Sperber, B. R., Boyle-Walsh, E. A., Engleka, M. J., Gadue, P., Peterson, A. C., Stein, P. L., et al. (2001). A unique role for Fyn in CNS myelination. J. Neurosci. 21, 2039-2047.

Spielhaupter, C., and Schatzl, H. M. (2001). PrPC directly interacts with proteins involved in signaling pathways. J. Biol. Chem. 276, 44604-44612. doi: 10.1074/jbc.M103289200

Steele, A. D., Emsley, J. G., Ozdinler, P. H., Lindquist, S., and Macklis, J. D. (2006). Prion protein $(\mathrm{PrPc})$ positively regulates neural precursor proliferation during developmental and adult mammalian neurogenesis. Proc. Natl. Acad. Sci. U.S.A. 103, 3416-3421. doi: 10.1073/pnas.0511290103

Steele, A. D., Lindquist, S., and Aguzzi, A. (2007). The prion protein knockout mouse: a phenotype under challenge. Prion 1, 83-93. doi: 10.4161/pri.1.2.4346

Thomas, S. M., and Brugge, J. S. (1997). Cellular functions regulated by Src family kinases. Annu. Rev. Cell Dev. Biol. 13, 513-609. doi: 10.1146/annurev.cellbio.13.1.513

Thoreson, M. A., Anastasiadis, P. Z., Daniel, J. M., Ireton, R. C., Wheelock, M. J., Johnson, K. R., et al. (2000). Selective uncoupling of p120(ctn) from Ecadherin disrupts strong adhesion. J. Cell Biol. 148, 189-202. doi: 10.1083/jcb. 148.1.189

Tiran, Z., Peretz, A., Sines, T., Shinder, V., Sap, J., Attali, B., et al. (2006). Tyrosine phosphatases epsilon and alpha perform specific and overlapping functions in regulation of voltage-gated potassium channels in Schwann cells. Mol. Biol. Cell 17, 4330-4342. doi: 10.1091/mbc.E06-02-0151

Um, J. W., Nygaard, H. B., Heiss, J. K., Kostylev, M. A., Stagi, M., Vortmeyer, A., et al. (2012). Alzheimer amyloid-beta oligomer bound to postsynaptic prion protein activates Fyn to impair neurons. Nat. Neurosci. 15, 1227-1235. doi: 10.1038/nn.3178

Umemori, H., Kadowaki, Y., Hirosawa, K., Yoshida, Y., Hironaka, K., Okano, H., et al. (1999). Stimulation of myelin basic protein gene transcription by Fyn tyrosine kinase for myelination. J. Neurosci. 19, 1393-1397.

Umemori, H., Sato, S., Yagi, T., Aizawa, S., and Yamamoto, T. (1994). Initial events of myelination involve Fyn tyrosine kinase signalling. Nature 367, 572-576. doi: $10.1038 / 367572 \mathrm{a} 0$

Vojtechova, M., Tureckova, J., Kucerova, D., Sloncova, E., Vachtenheim, J., and Tuhackova, Z. (2008). Regulation of mTORC1 signaling by Src kinase activity is Akt1-independent in RSV-transformed cells. Neoplasia 10, 99-107. doi: 10.1593/neo.07905

White, R., Gonsior, C., Kramer-Albers, E. M., Stohr, N., Huttelmaier, S., and Trotter, J. (2008). Activation of oligodendroglial Fyn kinase enhances translation of mRNAs transported in hnRNP A2-dependent RNA granules. J. Cell Biol. 181, 579-586. doi: 10.1083/jcb.200706164

White, R., and Kramer-Albers, E. M. (2014). Axon-glia interaction and membrane traffic in myelin formation. Front. Cell. Neurosci. 7:284. doi: 10.3389/fncel.2013.00284

Wilde, A., Beattie, E. C., Lem, L., Riethof, D. A., Liu, S. H., Mobley, W. C., et al. (1999). EGF receptor signaling stimulates SRC kinase phosphorylation of clathrin, influencing clathrin redistribution and EGF uptake. Cell 96, 677-687. doi: 10.1016/S0092-8674(00)80578-4

Winterstein, C., Trotter, J., and Kramer-Albers, E. M. (2008). Distinct endocytic recycling of myelin proteins promotes oligodendroglial membrane remodeling. J. Cell. Sci. 121, 834-842. doi: 10.1242/jcs.022731

Yagi, T., Aizawa, S., Tokunaga, T., Shigetani, Y., Takeda, N., and Ikawa, Y. (1993). A role for Fyn tyrosine kinase in the suckling behaviour of neonatal mice. Nature 366, 742-745. doi: 10.1038/366742a0

Zhang, C. C., Steele, A. D., Lindquist, S., and Lodish, H. F. (2006). Prion protein is expressed on long-term repopulating hematopoietic stem cells and is important for their self-renewal. Proc. Natl. Acad. Sci. U.S.A. 103, 2184-2189. doi: 10.1073/pnas.0510577103

Zimmerman, B., Simaan, M., Lee, M. H., Luttrell, L. M., and Laporte, S. A. (2009). c-Src-mediated phosphorylation of AP-2 reveals a general mechanism for receptors internalizing through the clathrin pathway. Cell Signal 21, 103-110. doi: 10.1016/j.cellsig.2008.09.013

Zou, L., Wang, Z., Shen, L., Bao, G. B., Wang, T., Kang, J. H., et al. (2007). Receptor tyrosine kinases positively regulate BACE activity and Amyloid-beta production through enhancing BACE internalization. Cell Res. 17, 389-401. doi: $10.1038 / \mathrm{cr} .2007 .5$ 
Conflict of Interest Statement: The authors declare that the research was conducted in the absence of any commercial or financial relationships that could be construed as a potential conflict of interest.

Received: 16 August 2014; paper pending published: 05 September 2014; accepted: 02 October 2014; published online: 28 October 2014.

Citation: Ochs K and Málaga-Trillo E (2014) Common themes in PrP signaling: the Src remains the same. Front. Cell Dev. Biol. 2:63. doi: 10.3389/fcell.2014.00063
This article was submitted to Cell Death and Survival, a section of the journal Frontiers in Cell and Developmental Biology.

Copyright (c) 2014 Ochs and Málaga-Trillo. This is an open-access article distributed under the terms of the Creative Commons Attribution License (CC BY). The use, distribution or reproduction in other forums is permitted, provided the original author(s) or licensor are credited and that the original publication in this journal is cited, in accordance with accepted academic practice. No use, distribution or reproduction is permitted which does not comply with these terms. 


\title{
Cellular prion protein and NMDA receptor modulation: protecting against excitotoxicity
}

\author{
Stefanie A. G. Black ${ }^{1,2}$, Peter K. Stys ${ }^{2,3}$, Gerald W. Zamponi ${ }^{1,2 *}$ and Shigeki Tsutsui ${ }^{2,3}$ \\ ' Department of Physiology and Pharmacology, University of Calgary, Calgary, AB, Canada \\ 2 Hotchkiss Brain Institute, University of Calgary, Calgary, AB, Canada \\ ${ }^{3}$ Department of Clinical Neurosciences, University of Calgary, Calgary, AB, Canada
}

Edited by:

Sophie Mouillet-Richard, INSERM

Unit 1124, France

Reviewed by:

Flavio Beraldo, Western University,

Canada

Federico Benetti, SISSA, Italy

*Correspondence:

Gerald W. Zamponi, Department of Physiology and Pharmacology,

Hotchkiss Brain Institute, University of Calgary, 3330 Hospital Drive NW,

Calgary, AB T2N 4N1, Canada

e-mail: zamponi@ucalgary.ca
Although it is well established that misfolding of the cellular prion protein $(\operatorname{Pr} P C)$ into the $\beta$-sheet-rich, aggregated scrapie conformation ( $\mathrm{PrPSc}^{\mathrm{Sc}}$ ) causes a variety of transmissible spongiform encephalopathies (TSEs), the physiological roles of $\operatorname{PrPC}^{\mathrm{C}}$ are still incompletely understood. There is accumulating evidence describing the roles of $\mathrm{PrPC}^{\mathrm{C}}$ in neurodegeneration and neuroinflammation. Recently, we identified a functional regulation of NMDA receptors by $\mathrm{PrP}^{\mathrm{C}}$ that involves formation of a physical protein complex between these proteins. Excessive NMDA receptor activity during conditions such as ischemia mediates enhanced $\mathrm{Ca}^{2+}$ entry into cells and contributes to excitotoxic neuronal death. In addition, NMDA receptors and/or PrPC play critical roles in neuroinflammation and glial cell toxicity. Inhibition of NMDA receptor activity protects against $\mathrm{PrPSc}_{\text {-induced }}$ neuronal death. Moreover, in mice lacking $\mathrm{PrPC}$, infarct size is increased after focal cerebral ischemia, and absence of $\operatorname{PrPC}$ increases susceptibility of neurons to NMDA receptor-dependent death. Recently, $\operatorname{PrPC}$ was found to be a receptor for oligomeric beta-amyloid $(A \beta)$ peptides, suggesting a role for $\operatorname{Pr}^{C} C$ in Alzheimer's disease (AD). Our recent findings suggest that $A \beta$ peptides enhance NMDA receptor current by perturbing the normal copper- and $\mathrm{PrP}^{\mathrm{C}}$-dependent regulation of these receptors. Here, we review evidence highlighting a role for $\mathrm{PrPC}^{\mathrm{C}}$ in preventing NMDA receptor-mediated excitotoxicity and inflammation. There is a need for more detailed molecular characterization of $\mathrm{PrP}^{\mathrm{C}}$-mediated regulation of NMDA receptors, such as determining which NMDA receptor subunits mediate pathogenic effects upon loss of $\mathrm{PrPC}^{\mathrm{C}}$-mediated regulation and identifying $\mathrm{PrPC}^{\mathrm{C}}$ binding site(s) on the receptor. This knowledge will allow development of novel therapeutic interventions for not only TSEs, but also for AD and other neurodegenerative disorders involving dysfunction of $\mathrm{PrPC}$.

Keywords: NMDA receptor, cellular prion protein, excitotoxicity, neuroinflammation, ischemia, beta-amyloid, Alzheimer's disease

\section{INTRODUCTION}

Misfolding of the cellular prion protein $\left(\mathrm{PrP}^{\mathrm{C}}\right)$ into the $\beta$-sheetrich, aggregate-prone scrapie conformation $\left(\mathrm{PrP}^{\mathrm{Sc}}\right)$ is well known to result in several progressive and often fatal diseases termed prionopathies. This group of disorders, also known as transmissible spongiform encephalopathies (TSEs), includes scrapie, bovine spongiform encephalopathy (BSE, or mad cow disease), and the human diseases Creutzfeld-Jakob disease, Gerstmann-StrausslerScheinker syndrome, fatal familial insomnia, and Kuru (Aguzzi et al., 2008). $\operatorname{PrP}^{\mathrm{Sc}}$ aggregation and formation of amyloid-like plaques disrupt neuronal physiology, and most TSEs involve eventual loss of neurons (Aguzzi et al., 2008). Although much work has been done investigating the deleterious effects of misfolded/aggregated prion proteins, the physiological roles of $\operatorname{PrP}^{\mathrm{C}}$ remain incompletely understood.

Mature $\operatorname{PrP}^{\mathrm{C}}$ is a glycoprotein that is anchored to the extracellular leaflet of the plasma membrane through a carboxyl (C)-terminal glycosylphosphatidylinositol (GPI) anchor. Initially,
$\operatorname{PrP}^{\mathrm{C}}$ is synthesized as a precursor polypeptide (254 amino acids for mouse $\operatorname{PrP}^{\mathrm{C}}$ ) containing an amino $(\mathrm{N})$-terminal signal sequence that directs $\operatorname{PrP}^{\mathrm{C}}$ to the endoplasmic reticulum and is post-translationally cleaved, and a C-terminal GPI anchor sequence that is removed and replaced with a GPI anchor (Figure 1; Biasini et al., 2012). The N-terminal portion of $\mathrm{PrP}^{\mathrm{C}}$ is intrinsically unstructured, contains the octarepeat region, and has multiple copper binding sites both within and outside of the octarepeat region (Figure 1; Klewpatinond et al., 2008; Stanyon et al., 2014). The $\operatorname{PrP}^{\mathrm{C}} \mathrm{N}$-terminus also contains sites for binding of oligomeric $\beta$-amyloid (A $\beta$ ) peptides (Figure 1; Lauren et al., 2009; Chen et al., 2010). In contrast to the N-terminus, the C-terminus of $\operatorname{PrP}^{\mathrm{C}}$ is globular in structure, with three $\alpha$-helical and two short $\beta$-strand regions, and is the location of two asparagine residues that undergo glycosylation (Figure 1; Biasini et al., 2012). In addition, $\operatorname{PrP}^{\mathrm{C}}$ can undergo physiological cleavage of different types: $\alpha$-cleavage in the vicinity of residue 109 (mouse sequence) generates $\mathrm{N} 1$ and $\mathrm{C} 1$ fragments; $\beta$-cleavage in 


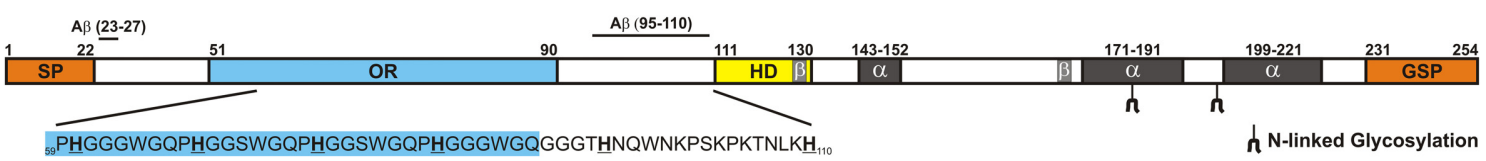

FIGURE 1 | Schematic representation of PrPC . Numbering of amino acid residues corresponds to the mouse $\mathrm{PrP}^{\mathrm{C}}$ sequence. Shown are the locations of histidine $(H)$ residues that bind copper ions (residues 60, 68, 76, 84, 95, 110), the amino (N)-terminal signal peptide (SP; residues $1-22$ ), $\beta$-amyloid oligomer $(A \beta)$ binding regions (residues 23-27, 95-110), the octapeptide repeat region (OR; residues 51-90), the central hydrophobic domain (HD; residues 111-130), $\alpha$-helical regions ( $\alpha$; residues 143-152, 171-191, 199-221), $\beta$-sheet regions ( $\beta$; residues 127-129, 166-168), sites of asparagine ( $N$ )-linked glycosylation (residues 180, 196), and the carboxyl (C)-terminal glycosylphosphatidylinositol (GPI) signal peptide (GSP; residues 231-254). the vicinity of residue 90 (mouse sequence) produces N2 and C2 fragments; and cleavage at the GPI anchor releases full-length $\mathrm{PrP}^{\mathrm{C}}$ into the extracellular environment (Altmeppen et al., 2013; McDonald et al., 2014). However, recent data from McDonald and co-workers using recombinant mouse $\mathrm{PrP}^{\mathrm{C}}$ reveal that cleavage of $\mathrm{PrP}^{\mathrm{C}}$ is quite complex, generating a number of different N1, C1, N2, and C2 fragments (McDonald et al., 2014), although the biological functions of these cleavage products remain to be determined.

$\operatorname{PrP}^{\mathrm{C}}$ interacts with and signals through many different cell surface proteins, including the $\alpha 7$ nicotinic acetylcholine receptor (Beraldo et al., 2010), metabotropic glutamate receptors mGluR1 (Beraldo et al., 2011) and mGluR5 (Beraldo et al., 2011; Um et al., 2013), kainate receptor GluR6/7 (Carulla et al., 2011), and $\alpha$-amino-3-hydroxy-5-methyl-4-isoxazole propionic acid (AMPA) receptor subunits GluA1 (Watt et al., 2012) and GluA2 (Kleene et al., 2007; Watt et al., 2012). Furthermore, A $\beta$ oligomers can bind to $\operatorname{PrP}^{\mathrm{C}}$ and signal through mGluR5 to activate Fyn kinase (Um et al., 2013), and an $\mathrm{A} \beta$-PrP $\mathrm{P}^{\mathrm{C}}$-mGluR5 pathway is also involved in facilitation of long-term depression (LTD) (Hu et al., 2014). The diversity of signaling mediated by $\mathrm{PrP}^{\mathrm{C}}$ highlights the need for a better understanding of how the interaction of $\mathrm{PrP}^{\mathrm{C}}$ with its binding partners is regulated in both physiological and pathological conditions. Work from our laboratory revealed that $\mathrm{PrP}^{\mathrm{C}}$ also interacts with $\mathrm{N}$-methyl-D-aspartate (NMDA) receptors; $\mathrm{PrP}^{\mathrm{C}}$-deficient mice display increased NMDA receptor-dependent neuronal excitability and are more susceptible to NMDA-induced excitotoxicity (Khosravani et al., 2008). Here, we briefly review properties of the NMDA receptor and focus on evidence supporting a role for $\mathrm{PrP}^{\mathrm{C}}$ in preventing NMDA receptor-mediated excitotoxicity, a process that may contribute to the pathogenesis of a variety of disorders including ischemic stroke, Alzheimer's disease (AD), Huntington's disease, and epilepsy (Lai et al., 2014; Parsons and Raymond, 2014). Similar mechanisms may be involved in $\mathrm{PrP}^{\mathrm{Sc}}$-induced toxicity (Müller et al., 1993; Riemer et al., 2008; Resenberger et al., 2011).

\section{NMDA RECEPTOR CHARACTERISTICS}

Glutamate is the major excitatory transmitter in the mammalian central nervous system (CNS), and it exerts its actions by binding to a variety of different receptor proteins. Glutamate receptors (GluRs) are divided into two families, ionotropic and metabotropic. Metabotropic GluRs are G protein-coupled receptors, while ionotropic GluRs are ion channels. There are three types of ionotropic GluRs, namely AMPA, kainate, and NMDA receptors (Mayer, 2005).
NMDA receptors are cation channels that mediate entry of $\mathrm{Na}^{+}$and $\mathrm{Ca}^{2+}$ ions and are activated by the co-agonists glutamate (or NMDA) and glycine or D-serine. Activation of NMDA receptors thus contributes to the excitatory postsynaptic potential (EPSP), as well as both long-term potentiation (LTP) and LTD (Bartlett and Wang, 2013). In addition to co-agonist binding, activation of NMDA receptors requires membrane depolarization to remove the $\mathrm{Mg}^{2+}$ ion block of the channel pore that occurs at resting membrane potentials. NMDA receptors are heterotetrameric channels formed by the assembly of two obligatory GluN1 and two GluN2/GluN3 subunits. GluN1 subunits contain the binding site for glycine, while glutamate binds to GluN2 subunits. To date, there are seven known NMDA receptor subunits: GluN1, GluN2A-GluN2D, and GluN3A-GluN3B, with alternative splicing of GluN1 and GluN3 subunits generating further diversity (Paoletti et al., 2013). GluN3 subunits also bind glycine, and thus NMDA receptors containing only GluN1 and GluN3 subunits give rise to "glycine-only" receptors that cannot be activated by glutamate or NMDA (Chatterton et al., 2002; Pina-Crespo et al., 2010). Identity of the GluN2 subunits that combine with GluN1 subunits to form the tetrameric channel dictates NMDA receptor properties, such as activation and deactivation kinetics, ion conductance, and affinity for glutamate (Cull-Candy and Leszkiewicz, 2004). Pharmacological characterization using ligands for specific GluN2 subunits allows differentiation of receptor subtypes (Wyllie et al., 2013).

NMDA receptor localization can be synaptic, perisynaptic, extrasynaptic, or even presynaptic, with receptor activity at each location coupling to specific cellular events (Corlew et al., 2008; Hardingham, 2009; Hardingham and Bading, 2010; Paoletti et al., 2013). In general, activation of synaptic NMDA receptors activates pro-survival signaling, while extrasynaptic NMDA receptor activity mediates pro-death signaling (Hardingham, 2009; Hardingham and Bading, 2010). Thus, while NMDA receptors mediate key physiological functions such as learning and memory under normal conditions, they also play a role in glutamate excitotoxicity, which can occur in response to ischemia (Lau and Tymianski, 2010) and is involved in many neurodegenerative conditions, including AD (Parsons and Raymond, 2014). In these abnormal situations, excessive glutamate can spill over from synaptic to extrasynaptic sites, thus activating not only the desired synaptically-localized NMDA receptors, but also those receptors located extrasynaptically. Because NMDA receptors are highly permeable to $\mathrm{Ca}^{2+}$ ions, this overstimulation leads to enhanced $\mathrm{Ca}^{2+}$ influx that ultimately can be fatal to cells (Lau and Tymianski, 2010). NMDA receptors are found not only in 
neurons, but also in oligodendrocytes and myelin, and ischemia can cause NMDA receptor-dependent damage to both myelin and oligodendrocyte processes (Karadottir et al., 2005; Salter and Fern, 2005; Micu et al., 2006). Hence, tight regulation of NMDA receptor activity is of extreme importance in maintaining physiological signaling while preventing excitotoxicity. NMDA receptor activity is regulated by a number of different mechanisms, one of which involves an intrinsic desensitization mechanism that results in termination of channel activity even in the prolonged presence of glutamate, a process that is potently regulated by the receptor co-agonist glycine (Mayer et al., 1989). Recently, we demonstrated that the absence of $\mathrm{PrP}^{\mathrm{C}}$ enhances NMDA receptor glycine affinity, leading to persistent NMDA receptor activity upon prolonged agonist application (You et al., 2012), which likely underlies the greater susceptibility of $\operatorname{PrP}^{\mathrm{C}}$-null neurons to NMDA receptor-mediated damage and dysfunction (Rangel et al., 2007; Khosravani et al., 2008; Gadotti and Zamponi, 2011; Gadotti et al., 2012; You et al., 2012; Fleisch et al., 2013).

\section{PrPC AS A REGULATOR OF NMDA RECEPTORS}

In support of a role for $\mathrm{PrP}^{\mathrm{C}}$ in preventing NMDA receptor hyperactivity, data from our and other laboratories reveal that NMDA receptor activity is enhanced when $\operatorname{PrP}^{C}$ is absent. Our work using mouse hippocampal slices showed that the enhanced neuronal excitability in $\mathrm{PrP}^{\mathrm{C}}$-null neurons can be reduced by the NMDA receptor blocker aminophosphonovaleric acid (APV), and that NMDA receptor-mediated miniature excitatory postsynaptic currents (mEPSCs) recorded from cultured hippocampal neurons from $\mathrm{PrP}^{\mathrm{C}}$-null mice had significantly larger amplitudes and longer decay times than those recorded from wildtype neurons (Khosravani et al., 2008). In this study we also showed that NMDA application resulted in whole-cell currents with a prolonged time course of deactivation in cultured $\mathrm{PrP}^{\mathrm{C}}$ null hippocampal neurons that could be restored to wild-type levels by ectopic expression of mouse $\mathrm{PrP}^{\mathrm{C}}$ and mimicked by reducing $\mathrm{PrP}^{\mathrm{C}}$ expression in cultured wild-type hippocampal neurons. Co-immunoprecipitation experiments demonstrated that $\mathrm{PrP}^{\mathrm{C}}$ and GluN2D subunits were found in the same protein complex, and immunofluorescent staining of hippocampal neurons showed co-localization of these two proteins. Indeed, the properties of the NMDA-evoked currents we observed in $\mathrm{PrP}^{\mathrm{C}}$-null neurons in this study appeared to resemble those of heterologously-expressed GluN2D-containing NMDA receptors (Cull-Candy and Leszkiewicz, 2004). Furthermore, siRNA knockdown of GluN2D expression dramatically accelerated NMDA receptor current deactivation kinetics and reduced current amplitude. Taken together, these observations point to an upregulation of GluN2D-containing NMDA receptor activity in the absence of $\mathrm{PrP}^{\mathrm{C}}$. However, it is also possible that activity of NMDA receptors containing other subunits is altered by the lack of $\mathrm{PrP}^{\mathrm{C}}$, producing GluN2D-like deactivation kinetics. Finally, in support of a role for $\mathrm{PrP}^{\mathrm{C}}$ in protecting against NMDA receptor-mediated toxicity, we observed significantly more cell death in response to NMDA treatment of $\mathrm{PrP}^{\mathrm{C}}$-null hippocampal cultures than in wild-type cultures, and that focal injection of NMDA into the hippocampus resulted in a lesion of significantly greater size in $\operatorname{PrP}^{\mathrm{C}}$-null mice than in wild-type mice (Khosravani et al., 2008). This increase in NMDA receptor activity not only gives rise to an increased susceptibility of neurons to cell death, but also affects other physiological processes that are linked to NMDA receptor function. For example, NMDA receptors are important for the transmission of pain signals at the spinal level. Consequently, in models of inflammatory and neuropathic pain, we found enhanced nociceptive responses in $\mathrm{PrP}^{\mathrm{C}}$-null mice that could be restored to control levels by MK-801 (Gadotti and Zamponi, 2011). It is also known that NMDA receptors play a role in depressive-like behavior at the level of the hippocampus. Consistent with this notion, we found that $\mathrm{PrP}^{\mathrm{C}}$-null mice displayed increased depressive-like behavior that could be abrogated by NMDA receptor blockers (Gadotti et al., 2012).

It is well established that $\operatorname{PrP}^{\mathrm{C}}$ is a copper-binding protein, with up to six copper ions binding to histidine residues in the $\mathrm{N}$-terminal region both within (mouse $\mathrm{PrP}^{\mathrm{C}}$ residues 60 , 68,76 , and 84 ) and outside of (mouse $\mathrm{PrP}^{\mathrm{C}}$ residues 95 and 110) the octarepeat region (Figure 1; Klewpatinond et al., 2008; Quintanar et al., 2013). In addition, copper may bind to histidine residues 176 and 186 (mouse sequence) in the C-terminus of $\operatorname{PrP}^{\mathrm{C}}$ (Quintanar et al., 2013), and recent evidence shows that copper can bind to the $\mathrm{N}$-terminal amino group of $\mathrm{PrP}^{\mathrm{C}}$ (Stanyon et al., 2014). Occupancy of these copper sites is known to alter $\operatorname{PrP}^{\mathrm{C}}$ structure (Qin et al., 2000; Thakur et al., 2011; Younan et al., 2011; Quintanar et al., 2013), and thus likely its interactions with other protein partners. The ability to examine NMDA receptor activity as an indirect readout of the interaction of the receptors with $\mathrm{PrP}^{\mathrm{C}}$ has provided interesting insights into the roles of the copper binding sites for $\operatorname{PrP}^{\mathrm{C}}$ function. Under normal circumstances, NMDA receptors undergo desensitization in the prolonged presence of glutamate or NMDA, and this process is modulated by the co-agonist glycine (Mayer et al., 1989). In cultured mouse hippocampal neurons lacking $\operatorname{PrP}^{\mathrm{C}}$, the desensitization kinetics appear to be slowed such that a non-desensitizing current is observed (You et al., 2012). In wild-type neurons, copper chelation using bathocuproine sulfonate (BCS) or cuprizone induced a persistent NMDA current similar to that seen in $\mathrm{PrP}^{\mathrm{C}}$-null neurons (You et al., 2012). Acute treatment with phosphatidylinositol-specific phospholipase C (PI-PLC), which enzymatically removes proteins such as $\mathrm{PrP}^{\mathrm{C}}$ that are linked to the extracellular leaflet of the plasma membrane via GPI anchors, also induced a persistent NMDA-dependent current in rat hippocampal neurons that was similar to both the current seen with copper chelation and to that recorded from $\mathrm{PrP}^{\mathrm{C}}$-null mouse hippocampal neurons (You et al., 2012). Moreover, PI-PLC treatment did not alter the steady-state NMDA current in $\operatorname{PrP}^{\mathrm{C}}$-null neurons, indicating that the enzymatic cleavage did not measurably affect other potential regulatory proteins (You et al., 2012). Experiments investigating the effect of glycine concentration on steady-state NMDA current revealed that at a given glycine concentration, a higher level of steady-state current was seen in neurons lacking $\mathrm{PrP}^{\mathrm{C}}$ than in wild-type neurons; a similar effect was seen upon copper chelation (You et al., 2012). In rat hippocampal cultures, copper chelation induced cell death that could be prevented by NMDA receptor inhibition or re-addition of excess copper (You et al., 2012). Taken together, these results indicate that copper ions modulate NMDA receptors by virtue of their interactions with 
$\operatorname{PrP}^{\mathrm{C}}$. Furthermore, these findings suggests that copper ions are key regulators of NMDA receptor function, thus adding another layer of metal ion regulation of these receptors in addition to the well described role of zinc ions.

Further support for $\mathrm{PrP}^{\mathrm{C}}$-mediated regulation of NMDA receptor activity comes from a study using zebrafish with a targeted mutation of the prp2 gene encoding the zebrafish prion protein PrP2, which has characteristics similar to mammalian $\mathrm{PrP}^{\mathrm{C}}$ (Fleisch et al., 2013). Consistent with observations in mammalian brain, these mutants displayed increased convulsantinduced seizure activity compared to wild-type animals. Analysis of mEPSCs recorded in vivo from intact zebrafish hindbrain neurons showed that the frequency of NMDA receptor-mediated mEPSCs was reduced in prp2 $2^{-/-}$fish compared to controls, and although NMDA receptor current amplitudes were the same in both groups, NMDA receptor currents had longer decay times in $p r p 2^{-/-}$zebrafish. These recent observations agree with the earlier findings of Walz and colleagues showing that mice lacking $\mathrm{PrP}^{\mathrm{C}}$ were more sensitive to convulsant-induced seizures, and significantly more $\mathrm{PrP}^{\mathrm{C}}$-null mice died than wild-type mice (Walz et al., 1999). However, a recent study found elevated thresholds for convulsant-induced epileptiform activity in hippocampal slices from $\mathrm{PrP}^{\mathrm{C}}$-null mice compared to wild-type controls (Ratte et al., 2011). The reason for this disparity in the literature remains to be determined.

The presence of misfolded prion proteins could induce NMDA receptor hyperfunction by preventing normal, $\operatorname{PrP}^{\mathrm{C}}$-mediated control of NMDA receptor activity. Indeed, there are several examples of augmented NMDA receptor function in the presence of mutant or scrapie forms of the prion protein. It has been demonstrated that NMDA receptor antagonists memantine and MK-801 prevented $\mathrm{PrP}^{\mathrm{Sc}}$-induced toxicity in cultured rat cortical neurons (Müller et al., 1993). Memantine also delayed death of scrapie-infected mice (Riemer et al., 2008) and blocked the $\mathrm{PrP}^{\mathrm{Sc}}$-induced increase in apoptosis of $\mathrm{PrP}^{\mathrm{C}}$-expressing $\mathrm{SH}-\mathrm{SY} 5 \mathrm{Y}$ neuroblastoma cells (Resenberger et al., 2011). Recently, Biasini and co-workers revealed a role for aberrant NMDA receptor activity in the toxic effects of a prion protein lacking residues 105-125 in the central region, termed $\triangle \mathrm{CR} \operatorname{PrP}$ (Biasini et al., 2013). In this study, organotypic cerebellar slice cultures from $\triangle \mathrm{CR} P r \mathrm{P}-$ expressing mice were more susceptible to glutamate-, kainate-, and NMDA-induced cell death compared to those from $\mathrm{PrP}^{+/-}$ controls, an effect that was rescued by overexpression of wild-type $\mathrm{PrP}^{\mathrm{C}}$. Notably, NMDA had a more marked effect on cell death compared to the other treatments. These authors also observed that $\triangle \mathrm{CR}$ PrP expression induces spontaneous inward currents, which may contribute to enhanced NMDA receptor activity via depolarization-induced relief of the $\mathrm{Mg}^{2+}$ ion block of these receptors. Importantly, the toxic NMDA receptor-dependent effects of $\triangle \mathrm{CR}$ PrP in this study were prevented by overexpression of wild-type $\mathrm{PrP}^{\mathrm{C}}$, again supporting a neuroprotective role of $\operatorname{PrP}^{\mathrm{C}}$ via prevention of NMDA receptor-mediated toxicity. In another recent study, the toxicity of the misfolded form of a prion protein fragment comprised of residues 90-231 was found to be mediated in part by NMDA receptor-dependent excitotoxicity (Thellung et al., 2013). In this study, treatment of cerebellar granule neuron cultures for 1-3 days with the misfolded prion protein 90-231 fragment augmented both intracellular $\mathrm{Ca}^{2+}$ levels and apoptosis compared to that measured in control cells, effects that were nearly completely abolished by NMDA receptor blockade.

Altogether, the data obtained from studies using $\operatorname{PrP}^{\mathrm{C}}$-null animals suggest that there is aberrant NMDA receptor activity in the absence of normal $\mathrm{PrP}^{\mathrm{C}}$ function, which is further supported by the fact that exogenous expression of $\mathrm{PrP}^{\mathrm{C}}$ can prevent the NMDA receptor-dependent toxic effects of misfolded or mutant prion proteins. This raises the possibility of restoring $\mathrm{PrP}^{\mathrm{C}}$ mediated regulation of NMDA receptors in pathologies where $\operatorname{PrP}^{\mathrm{C}}$ function is perturbed as a therapeutic intervention to control NMDA receptor-mediated toxicity. This could in theory be accomplished by mimicking the interaction of $\operatorname{PrP}^{\mathrm{C}}$ with NMDA receptors. To achieve this, more details regarding the molecular determinants governing the interaction of $\mathrm{PrP}^{\mathrm{C}}$ and NMDA receptor proteins are required. Additionally, if loss of physiological $\mathrm{PrP}^{\mathrm{C}}$ function results in augmented activity of certain NMDA receptor subtypes, such as those containing GluN2D subunits, a thorough molecular characterization of the $\operatorname{PrP}^{\mathrm{C}}$-NMDA receptor interaction will allow development of targeted pharmacotherapies to reduce hyperfunction of only those receptors affected whose activity is aberrantly upregulated. This approach could prevent undesired effects of blocking physiological NMDA receptor signaling.

\section{ABSENCE OF PrPC EXACERBATES ISCHEMIC INJURY-A ROLE FOR NMDA RECEPTOR HYPERACTIVITY?}

Given the neuroprotective effects of $\operatorname{PrP}^{\mathrm{C}}$, it may not be surprising that absence of $\mathrm{PrP}^{\mathrm{C}}$ can exacerbate the neuronal damage that ensues following an ischemic insult. Several studies have demonstrated increased ischemic brain damage in $\operatorname{PrP}^{\mathrm{C}}$-null mice (McLennan et al., 2004; Sakurai-Yamashita et al., 2005; Spudich et al., 2005; Weise et al., 2006; Mitteregger et al., 2007; Steele et al., 2009). However, ischemia can induce an upregulation of $\mathrm{PrP}^{\mathrm{C}}$ mRNA (McLennan et al., 2004; Mitsios et al., 2007; Mitteregger et al., 2007) and protein (McLennan et al., 2004; Weise et al., 2004; Shyu et al., 2005; Adle-Biassette et al., 2006; Mitsios et al., 2007; Mitteregger et al., 2007), presumably as a compensatory protective mechanism. The idea of compensatory upregulation of $\mathrm{PrP}^{\mathrm{C}}$ expression protecting against cell death in ischemia is supported by the findings that adenovirus-mediated overexpression of $\mathrm{PrP}^{\mathrm{C}}$ reduced ischemia-induced infarct volume in rats (Shyu et al., 2005) and $\mathrm{PrP}^{\mathrm{C}}$-overexpressing mice showed smaller infarct volumes in response to ischemia than wild-type controls (Weise et al., 2008). However, another showed no difference in infarct sizes between wild-type and $\mathrm{PrP}^{\mathrm{C}}$ overexpressing mice exposed to ischemia (Spudich et al., 2005). Of note, these studies used different $\mathrm{PrP}^{\mathrm{C}}$-overexpressing mouse models and times of ischemia, which could account for the observed differences. Currently, the role of NMDA receptors in the enhanced ischemic cell death seen in the absence of $\operatorname{PrP}^{\mathrm{C}}$ is unknown. However, because NMDA receptor hyperfunction contributes to cell death in ischemia (Lau and Tymianski, 2010; Lai et al., 2014), and since NMDA receptor desensitization is reduced in the absence of $\operatorname{PrP}^{\mathrm{C}}$ (You et al., 2012), enhanced NMDA receptor-mediated $\mathrm{Ca}^{2+}$ influx may very well contribute 
to the increased ischemia-induced cell death that is observed in $\operatorname{PrP}^{\mathrm{C}}$-null mice.

Increases in extracellular glutamate concentration, such as those seen in ischemic conditions, cause activation of both synaptic and extrasynaptic receptors (Hardingham and Bading, 2010; Parsons and Raymond, 2014). Extrasynaptic NMDA receptor activity can induce apoptotic signaling by promoting nuclear import of FOXO transcription factor proteins (Hardingham and Bading, 2010). FOXO3a has recently been identified as a negative regulator of the gene encoding $\operatorname{PrP}^{\mathrm{C}}$, prnp (Liu et al., 2013), and in this study it was shown that insulin-like growth factor-1 (IGF-1)-induced PI3K/Akt activity promoted prnp expression by preventing nuclear import of FOXO proteins, thus inhibiting their negative effect on prnp expression. Therefore, it is possible that conditions where extrasynaptic NMDA receptor activity is upregulated may lead to a down-regulation of $\mathrm{PrP}^{\mathrm{C}}$ protein expression, which may initiate a positive feedback loop of further dysregulation of NMDA receptor activity and thus toxicity. Hence, even if there is an initial protective upregulation of $\mathrm{PrP}^{\mathrm{C}}$, this may not be able to be sustained due to persistent activation of extrasynaptic NMDA receptors in the presence of prolonged elevation of glutamate levels.

Another important observation concerns increased shedding of $\mathrm{PrP}^{\mathrm{C}}$ in response to neurotoxic conditions (Wang et al., 2012). $\mathrm{PrP}^{\mathrm{C}}$ shedding results from cleavage of $\mathrm{PrP}^{\mathrm{C}}$ near the C-terminal GPI anchor, releasing full-length, soluble $\mathrm{PrP}^{\mathrm{C}}$ into the extracellular milieu (Altmeppen et al., 2013; McDonald et al., 2014). Wang and colleagues showed that upon treatment of cultured rat cortical neurons with NMDA, soluble $\mathrm{PrP}^{\mathrm{C}}$ was released into the culture medium, while total $\mathrm{PrP}^{\mathrm{C}}$ protein levels remained unchanged (Wang et al., 2012). As noted earlier, our data demonstrated that treatment with PI-PLC, which cleaves $\mathrm{PrP}^{\mathrm{C}}$ from its GPI anchor thus releasing it from the cell surface, resulted in persistent NMDA receptor-mediated current in cultured rat hippocampal neurons that was similar to those seen in $\mathrm{PrP}^{\mathrm{C}}$ null hippocampal neurons (You et al., 2012). If loss of cell surface anchored- $\mathrm{PrP}^{\mathrm{C}}$ results in aberrant NMDA receptor activity, one could envision a scenario where a positive feedback loop contributes to further shedding of $\mathrm{PrP}^{\mathrm{C}}$ and enhanced NMDA receptor currents, which would be of detriment to cells. However, it has been suggested that $\mathrm{PrP}^{\mathrm{C}}$ shedding could serve a protective role, especially in preventing $A \beta$-mediated toxicity (discussed in Altmeppen et al., 2013; Beland et al., 2014). A recent study by Beland and colleagues showed that shed $\mathrm{PrP}^{\mathrm{C}}$ co-immunoprecipitated with $\mathrm{A} \beta$ (Beland et al., 2014), suggesting that extracellular $\mathrm{A} \beta$ can be sequestered by shed $\mathrm{PrP}^{\mathrm{C}}$ to prevent $\mathrm{A} \beta$-induced cellular damage. As discussed below, we found that $\mathrm{A} \beta_{1-42}$ induced a $\mathrm{PrP}^{\mathrm{C}}$-dependent increase in steady-state NMDA receptor current (You et al., 2012). Shedding of $\operatorname{PrP}^{\mathrm{C}}$ may thus aid in preventing $A \beta_{1-42}$-induced dysregulation of NMDA receptor function. Hence, $\mathrm{PrP}^{\mathrm{C}}$ shedding may ultimately be protective in situations where $\operatorname{PrP}^{\mathrm{C}}$ function is compromised, for example by binding of $\mathrm{A} \beta$ peptides. On the other hand, shedding of $\mathrm{PrP}^{\mathrm{C}}$ may promote aberrant NMDA receptor activity by altering desensitization kinetics that could contribute to cell death in conditions such as ischemia where glutamate concentrations are elevated.
There is also evidence that ischemia induces cleavage of $\operatorname{PrP}^{\mathrm{C}}$ into its $\mathrm{N}$ - and $\mathrm{C}$-terminal fragments, and that these cleavage products can be neuroprotective. Mitteregger and coworkers also observed that ischemia caused increased cleavage of $\operatorname{PrP}^{\mathrm{C}}$, as detected by elevated levels of $\operatorname{PrP}^{\mathrm{C}} \mathrm{C} 1$ fragment on immunoblots of mouse brain homogenates (Mitteregger et al., 2007). In another study, oxygen glucose deprivation increased the secretion of the $\mathrm{PrP}^{\mathrm{C}} \mathrm{N} 1$ fragment from cultured retinal ganglion cells (GuillotSestier et al., 2009). Moreover, application of recombinant $\operatorname{PrP}^{\mathrm{C}}$ $\mathrm{N} 1$ ( $\mathrm{PrP}^{\mathrm{C}}$ residues 23-110) was able to prevent ischemia-induced death of retinal ganglion cells (Guillot-Sestier et al., 2009). The details of how $\mathrm{PrP}^{\mathrm{C}} \mathrm{N} 1$ protects against ischemic cell death were not fully explored, but the mechanism did involve a reduction of ischemia-induced caspase- 3 activation and p53 expression (Guillot-Sestier et al., 2009). An interesting possibility is that the $\mathrm{PrP}^{\mathrm{C}} \mathrm{N} 1$ fragment, which contains the octarepeat region that binds copper, binds to NMDA receptors, thus providing copper-dependent regulation of receptor desensitization. Of note, inhibition of NMDA receptor activity has been shown to attenuate death of retinal ganglion cells following ischemia-reperfusion injury (Li et al., 2014).

Further support of a role for $\operatorname{PrP}^{\mathrm{C}}$ in protecting against ischemic cell death comes from the work of Mitteregger and coworkers where $\mathrm{PrP}^{\mathrm{C}}$-null mice and mice expressing a prion protein lacking amino acid residues 32-93 had infarcts of similar volumes (Mitteregger et al., 2007), suggesting that this region of $\mathrm{PrP}^{\mathrm{C}}$ provides protection against ischemic injury. One reason for increased ischemic injury in mice expressing this form of prion protein could be that cleavage of this mutant would not produce the normal $\mathrm{PrP}^{\mathrm{C}} \mathrm{N} 1$ fragment. However, this deletion mutant lacks the copper-binding octarepeat region of $\operatorname{PrP}^{\mathrm{C}}$. As mentioned previously, we found a copper-dependent regulation of NMDA receptors that is mediated in large part through $\operatorname{PrP}^{\mathrm{C}}$, as demonstrated by no further augmentation of NMDA receptor currents by copper chelation in the absence of $\operatorname{PrP}^{\mathrm{C}}$ (You et al., 2012). Moreover, exogenous copper can protect neurons from NMDA receptor-mediated death (Schlief et al., 2006), whereas copper chelation induced cell death that could be prevented by NMDA receptor inhibition (You et al., 2012). Recently, data from in vitro experiments have revealed that copper enhances one type of $\alpha$-cleavage, termed $\alpha 2$-cleavage, of mouse $\operatorname{PrP}^{\mathrm{C}}$ (McDonald et al., 2014). Copper induced $\alpha 2$-cleavage such that the resultant $\mathrm{N}$-terminal $\operatorname{PrP}^{\mathrm{C}}$ fragments terminate at alanine residues 116 or 117 , in contrast to $\alpha 1$-cleavage observed in the absence of copper, which produces $\mathrm{PrP}^{\mathrm{C}} \mathrm{N} 1$ ending at lysine residue 109 (McDonald et al., 2014). These observations suggest that copper levels may regulate $\mathrm{PrP}^{\mathrm{C}}$ processing by influencing the amount and identity of the N1 fragment produced, although the biological outcomes of this copper-dependent differential $\mathrm{PrP}^{\mathrm{C}}$ cleavage are not yet known. Of further interest is the finding that the prion proteins carrying pathogenic mutations have decreased $\alpha 2$-cleavage upon addition of copper (McDonald et al., 2014), suggesting aberrant copper-dependent $\mathrm{PrP}^{\mathrm{C}}$ processing could be detrimental to the health of cells. These findings reveal the possibility of copper-dependent processing of $\mathrm{PrP}^{\mathrm{C}}$ as another mechanism contributing to regulation of NMDA receptor activity by copper. Thus, copper may alter the activity of NMDA receptors in 
multiple ways: $\mathrm{PrP}^{\mathrm{C}}$-independent control of receptor activity, as evidenced by restoration of NMDA receptor desensitization in $\mathrm{PrP}^{\mathrm{C}}$-null neurons by addition of excess copper ions (You et al., 2012); by mediating interaction of $\operatorname{PrP}^{\mathrm{C}}$ and NMDA receptors, as shown by a decrease in the amount of GluN1 subunit that coprecipitated with $\mathrm{PrP}^{\mathrm{C}}$ upon copper chelation (You et al., 2012); and by influencing $\mathrm{PrP}^{\mathrm{C}}$ cleavage to generate $\mathrm{PrP}^{\mathrm{C}} \mathrm{N} 1$ fragments, which could bind to NMDA receptors to modulate their function. Although evidence exists for the former two mechanisms, the latter remains to be investigated.

As mentioned previously, the activity of myelinic NMDA receptors is increased by ischemic conditions, resulting in damage to myelin (Micu et al., 2006). Thus, a loss of $\mathrm{PrP}^{\mathrm{C}}$-mediated regulation of NMDA current may not only be neurotoxic, but may also contribute to demyelination that has been observed in $\mathrm{PrP}^{\mathrm{C}}$-null mice and in mice expressing mutant prion proteins (Radovanovic et al., 2005; Baumann et al., 2007; Bremer et al., 2010).

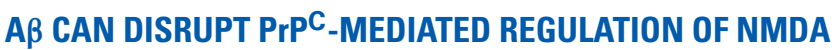 RECEPTOR ACTIVITY}

$\mathrm{PrP}^{\mathrm{C}}$ has been shown to be a receptor for oligomeric $\mathrm{A} \beta$ peptides (Lauren et al., 2009; Chen et al., 2010). Since these discoveries, many studies have investigated the role of $\mathrm{PrP}^{\mathrm{C}}$ in the pathological effects of $A \beta$ (reviewed in Lauren, 2014). Overall, these findings suggest a role for $\mathrm{PrP}^{\mathrm{C}}$ in protecting from the pathological effects of $\mathrm{A} \beta$ peptides that occur in $\mathrm{AD}$, although the requirement of $\operatorname{PrP}^{\mathrm{C}}$ for $\mathrm{A} \beta$-induced toxicity has been controversial, with some investigators finding that $\mathrm{PrP}^{\mathrm{C}}$ was not required for the pathological effects of A $\beta$ (Balducci et al., 2010; Calella et al., 2010; Kessels et al., 2010; Cisse et al., 2011). Recent findings by Nicoll and coworkers may help to reconcile these discrepancies. Their work showed that $\mathrm{A} \beta$ protofibrils, and not monomers or fibrils, bind with highest affinity to full-length $\operatorname{PrP}^{C}$ and the $\operatorname{PrP}^{C} \mathrm{~N} 1$ fragment (Nicoll et al., 2013). Furthermore, protofibril-rich A $\beta$ preparations blocked LTP in a $\mathrm{PrP}^{\mathrm{C}}$-dependent manner, whereas LTP inhibition by fibrillar $\mathrm{A} \beta$ was independent of $\operatorname{PrP}^{\mathrm{C}}$. These observations underscore the need for careful characterization of $\mathrm{A} \beta$ preparations in order to determine the nature of the $A \beta$ species used for experiments, which allow better interpretation of data resulting from these experiments.

Notably, many studies have demonstrated that $\mathrm{A} \beta$ can alter NMDA receptor function (reviewed in Rush and Buisson, 2014). Recently, we demonstrated that $\mathrm{PrP}^{\mathrm{C}}$ is required for $\mathrm{A} \beta$-induced alterations in NMDA receptor kinetics (You et al., 2012). Application of oligomerized $A \beta_{1-42}$, which is known to be a high-affinity copper chelator, to hippocampal neurons gave rise to a persistent (i.e., non-desensitizing) NMDA current, similar to what was observed in the presence of the copper chelator $\mathrm{BCS}$ or in the absence of $\operatorname{PrP}^{\mathrm{C}}$. Of note, the effects of $\mathrm{A} \beta_{1-42}$ and copper chelation on NMDA current were not additive, suggesting that they acted via the same mechanism. Finally, in neurons isolated from 5XFAD mice (a mouse model of AD), NMDA current displayed a qualitatively similar persistent component. Altogether, these data then suggest that $A \beta$-mediated perturbation of NMDA receptor activity depends on both $\mathrm{PrP}^{\mathrm{C}}$ and copper ions. Furthermore, the $A \beta_{1-42}$-induced upregulation of NMDA receptor activity may in part be responsible for the
$\mathrm{A} \beta_{1-42}$-mediated neurodegeneration observed in $\mathrm{AD}$. If this were the case, then why is neurodegeneration observed in 5XFAD mice, but relatively absent in $\operatorname{PrP}^{\mathrm{C}}$-null mice even though they both display similar non-desensitizing NMDA receptor currents? Slowed receptor desensitization can only manifest itself pathologically under conditions where there is a prolonged excess of glutamate. It has been shown that $A \beta_{1-42}$ prevents glutamate reuptake into neurons and glial cells (Danysz and Parsons, 2012), and induces release of glutamate from astrocytes (Talantova et al., 2013), which then would be expected to lead to just such an excess of glutamate. Then, together with the slowed desensitization kinetics of the receptor, this excess glutamate may damage neuronal structures such as spines. In $\mathrm{PrP}^{\mathrm{C}}$-null mice, this accumulation of glutamate would not be expected to occur, thus rendering the slowed desensitization kinetics physiologically inert (Figure 2). Nonetheless, as we discussed earlier, there are other pathophysiological events such as chemically-induced seizures or ischemia that are known to lead to an accumulation of glutamate that then causes increased brain damage in $\mathrm{PrP}^{\mathrm{C}}$-null mice (Walz et al., 1999; McLennan et al., 2004; Sakurai-Yamashita et al., 2005; Spudich et al., 2005; Weise et al., 2006; Mitteregger et al., 2007; Steele et al., 2009).

Work by Um and colleagues provides further evidence for the requirement of $\mathrm{PrP}^{\mathrm{C}}$ on the effects of $\mathrm{A} \beta$ on NMDA receptor function (Um et al., 2012). In their study, they found that phosphorylation of the GluN2B subunit of the NMDA receptor at tyrosine residue 1472 was transiently increased by $\mathrm{A} \beta$ oligomers in Fyn-overexpressing neuroblastoma cells and in cortical cultures; longer treatment with $A \beta$ oligomers ( $1-3 \mathrm{~h})$ resulted in decreased phospho-GluN2B levels, which correlated with an increase in the level of STEP protein phosphatase. Moreover, the $A \beta$ oligomer-induced increase in GluN2B phosphorylation was absent in $\mathrm{PrP}^{\mathrm{C}}$ - and Fyn-null cultures. Indeed, they found that $\mathrm{A} \beta$ oligomers activated Fyn kinase in a $\operatorname{PrP}^{\mathrm{C}}$-dependent manner. Furthermore, brain extract from $\mathrm{AD}$ patients induced Fyn activation in cultured mouse cortical neurons in a $\operatorname{PrP}^{\mathrm{C}}$ dependent manner, whereas extract from healthy controls did not activate Fyn. The initial GluN2B phosphorylation was paralleled by an increase in surface levels of GluN2B, and with longer $A \beta$ oligomer treatment a reduction in GluN2B surface expression was observed; again, both $\mathrm{PrP}^{\mathrm{C}}$ and Fyn were required for these $A \beta$ oligomer-mediated effects on GluN2B surface expression. In cultures from wild-type mice, pre-treatment for 15 min with $A \beta$ oligomers significantly enhanced the NMDA-induced increase in intracellular $\mathrm{Ca}^{2+}$ levels, whereas a $60 \mathrm{~min} \mathrm{~A} \beta$ oligomer pretreatment significantly reduced the NMDA-induced $\mathrm{Ca}^{2+}$ signal; in $\mathrm{PrP}^{\mathrm{C}}$-null cultures, $\mathrm{A} \beta$ oligomers had no effect on the $\mathrm{Ca}^{2+}$ signal induced by NMDA. Thus, $\mathrm{A} \beta$ oligomers, acting via $\operatorname{PrP}^{\mathrm{C}}$, induce a transient increase then a decrease in NMDA receptormediated $\mathrm{Ca}^{2+}$ influx into neurons. LDH release from cortical cultures was increased upon $90 \mathrm{~min} A \beta$ oligomer treatment and no further toxicity was observed with a $72 \mathrm{~h}$ treatment. This toxicity was NMDA receptor-dependent, as it was reduced by NMDA receptor inhibition with both APV and ifenprodil, the latter being a specific GluN2B antagonist. Thus, brief exposure to $A \beta$ oligomers causes toxicity, likely by $\mathrm{Ca}^{2+}$ influx mediated by the transient increase in surface localization of GluN2B-containing 


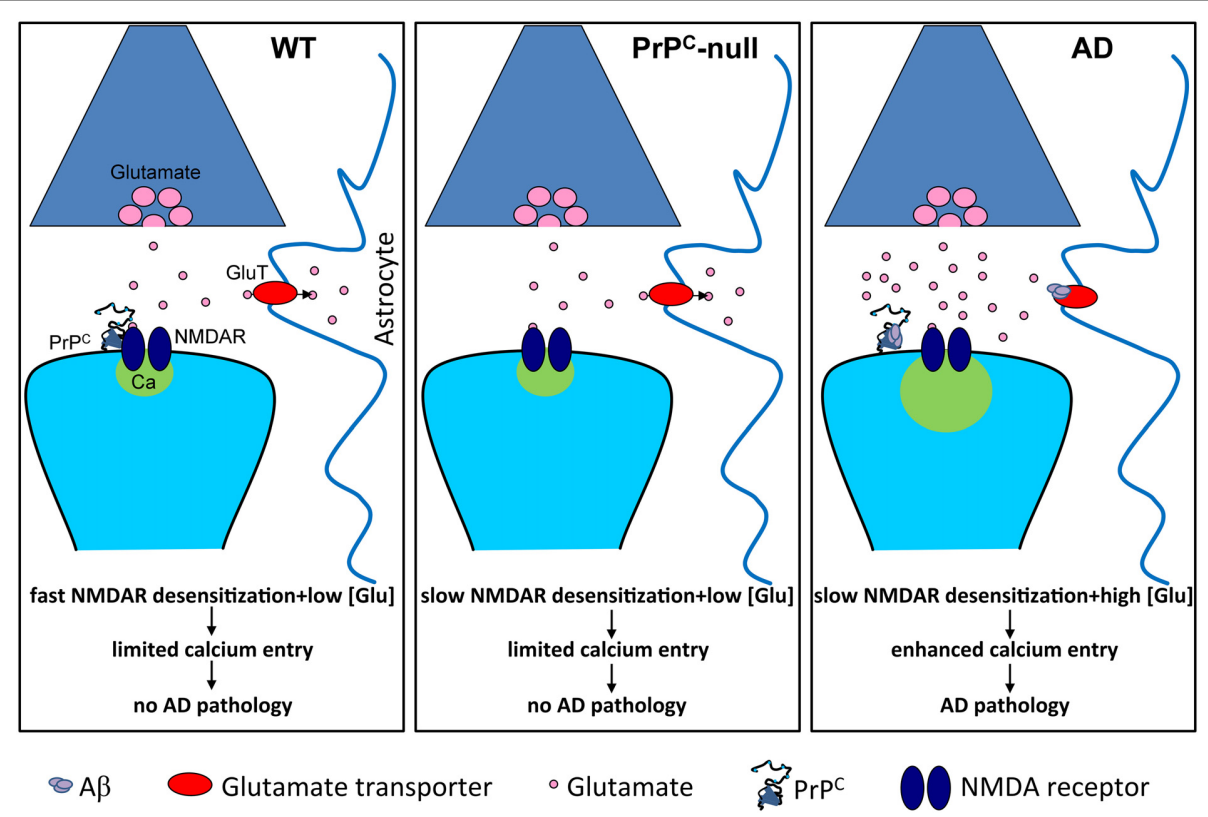

FIGURE 2 | Slowed NMDA receptor desensitization is pathological only in conditions of prolonged excess of glutamate. Under normal conditions (WT), glutamate homeostasis is unperturbed and prevents glutamate accumulation, and NMDA receptors (NMDAR) undergo fast desensitization, thus limiting calcium entry. In the absence of $\operatorname{PrPC}$ $\left(\mathrm{PrPC}^{\mathrm{C}}\right.$-null), NMDA receptor desensitization is slowed but glutamate homeostasis remains unperturbed, thus limited calcium entry occurs. However, in Alzheimer's disease (AD), A $\beta$ oligomers bind to $\operatorname{PrPC}$ and cause slowed NMDA receptor desensitization. This, in combination with $A \beta$-induced elevation of glutamate levels, for example by inhibiting glutamate re-uptake by astrocytic glutamate transporters, leads to enhanced calcium entry and pathology.
NMDA receptors. In this study, it was also shown that $\mathrm{A} \beta$ oligomers induced spine loss in a $\mathrm{PrP}^{\mathrm{C}}$ - and Fyn-dependent manner, and that the seizures and death due to status epilepticus in a mouse model of $\mathrm{AD}$ were prevented by genetic deletion of $\mathrm{PrP}^{\mathrm{C}}$. Taken together, these data suggest that $\mathrm{A} \beta$ oligomers signal through $\mathrm{PrP}^{\mathrm{C}}$ to induce aberrant Fyn activation, leading to first an increase then later a decrease in activity of GluN2Bcontaining receptors, which is ultimately deleterious to neurons. Altogether, the recent data indicate that $\mathrm{A} \beta$ oligomers, by interacting with $\mathrm{PrP}^{\mathrm{C}}$, can alter both NMDA receptor kinetics (You et al., 2012) and the signaling pathways that modulate NMDA receptor function (Um et al., 2012).

A study by Resenberger and colleagues showed that $\mathrm{A} \beta$ - and $\mathrm{PrP}^{\mathrm{Sc}}$-induced cell death of $\mathrm{PrP}^{\mathrm{C}}$-expressing $\mathrm{SH}-\mathrm{SY} 5 \mathrm{Y}$ neuroblastoma cells were not additive, suggesting that these species act via the same pathway (Resenberger et al., 2011). Furthermore, pre-treatment with the NMDA receptor blocker memantine prevented apoptosis of $\mathrm{PrP}^{\mathrm{C}}$-expressing $\mathrm{SH}-\mathrm{SY} 5 \mathrm{Y}$ neuroblastoma cells induced by $\operatorname{PrP}^{\mathrm{Sc}}, \mathrm{A} \beta$, and a synthetic peptide designed to be rich in $\beta$-sheet structure. This suggests that several types of $\beta$-sheet-containing proteins/peptides share a common mechanism of toxicity, aberrant NMDA receptor activity. Thus, $\mathrm{PrP}^{\mathrm{C}}$ could contribute to toxicity in disorders other than TSEs and AD, possibly by mediating aberrant NMDA receptor activity in the presence of $\beta$-sheet-rich peptides.

Of further interest is the finding that the toxicity induced by $\beta$-sheet-rich conformers was dependent upon the $\mathrm{N}$-terminal region of $\mathrm{PrP}^{\mathrm{C}}$ and was prevented by a soluble $\mathrm{N}$-terminal domain of $\mathrm{PrP}^{\mathrm{C}}$ (Resenberger et al., 2011). Similar protective effects of the $\mathrm{PrP}^{\mathrm{C}} \mathrm{N} 1$ fragment against $\mathrm{A} \beta$-induced toxicity have been observed in other studies (Beland et al., 2012, 2014; GuillotSestier et al., 2012; Nieznanski et al., 2012; Fluharty et al., 2013). This raises the possibility that increased $\mathrm{PrP}^{\mathrm{C}}$ cleavage to produce the $\mathrm{N} 1$ fragment is neuroprotective. Interestingly, cleavage of $\mathrm{PrP}^{\mathrm{C}}$ was increased in a mouse model of $\mathrm{AD}$ (Ostapchenko et al., 2013) and in post-mortem human AD brain (Beland et al., 2014). Furthermore, the recent findings from Beland and coworkers provide strong evidence for a protective role of the soluble $\mathrm{N} 1$ fragment that is produced by $\alpha$-cleavage of $\mathrm{PrP}^{\mathrm{C}}$. In this study, the binding of $\operatorname{PrP}^{\mathrm{C}} \mathrm{N} 1$ and $\mathrm{A} \beta$ induced a conformational change that produced amorphous aggregates, the amount of $\mathrm{PrP}^{\mathrm{C}} \mathrm{N} 1$ in guanidine hydrochloride extracts from insoluble amyloid deposits from $\mathrm{AD}$ brain was increased compared to non-demented controls, and there was a significant correlation between the amount of $\alpha$-cleavage, which generates the N1 fragment, and duration of AD (Beland et al., 2014). Altogether, these observations indicate that cleavage of $\mathrm{PrP}^{\mathrm{C}}$ may reduce $\mathrm{A} \beta$-mediated toxicity via N1-mediated neutralization of $\mathrm{A} \beta$ peptides, and $\mathrm{N}$-terminal fragments may be useful as a therapy to prevent pathological effects of $A \beta$ or other $\beta$-sheet-rich peptides, including alterations in NMDA receptor activity.

\section{NMDA RECEPTORS, PrPC, AND NEUROINFLAMMATION}

Recent evidence has emerged that glutamatergic mechanisms operate not only in the nervous system, but also in a wide variety of non-neuronal cells (reviews: Gill and Pulido, 2001; Skerry and 
Genever, 2001; Hinoi et al., 2004), including in the immune system (reviews: Boldyrev et al., 2005, 2012). GluRs, both ionotropic and metabotropic, are highly expressed in various immune cells, such as T cells, B cells, neutrophils, macrophages and dendritic cells, which are thought to subserve communication between the immune and nervous systems (review: Ganor and Levite, 2012). Interestingly, different GluRs, or different levels of certain GluRs, are expressed in resting and activated T cells (for review see Ganor and Levite, 2012). In particular, NMDA receptors expressed on T cells are involved in a wide variety of $\mathrm{T}$ cell functions, such as regulation of cytokine secretion (Kahlfu $\beta$ et al., 2014), proliferation (Kahlfuß et al., 2014), apoptosis (Affaticati et al., 2011), and induction of reactive oxygen species (Tuneva et al., 2003).

As described above, $\mathrm{PrP}^{\mathrm{C}}$ interacts with NMDA receptors on neurons and modulates NMDA receptor-dependent neuronal excitability and excitotoxicity (Khosravani et al., 2008). Although the precise functions of $\mathrm{PrP}^{\mathrm{C}}$ in immune cells remain unclear, $\mathrm{PrP}^{\mathrm{C}}$ expression is detected in the lymphoid system (Bendheim et al., 1992; Ford et al., 2002). Human T lymphocytes constitutively express $\operatorname{PrP}^{\mathrm{C}}$ and its surface expression is influenced by the activation state of the cells (Cashman et al., 1990; Mabbott et al., 1997). In addition, $\mathrm{PrP}^{\mathrm{C}}$ is upregulated on mouse T cells and dendritic cells after activation, and the lack of $\operatorname{PrP}^{\mathrm{C}}$ increases $\mathrm{T}$ cell proliferation and causes $\mathrm{T}$ cell over-activation in mouse (Tsutsui et al., 2008). Therefore, $\operatorname{PrP}^{\mathrm{C}}$ may play a role as a regulator of NMDA receptors in the immune system as we observed in the nervous system (Khosravani et al., 2008; You et al., 2012), with a common thread being "hyperfunction" when $\operatorname{PrP}^{\mathrm{C}}$ is absent and cannot restrain normal physiological mechanisms.

The CNS is conventionally recognized as being "immunologically privileged" (Bailey et al., 2006) and is anatomically separated from the peripheral immune system by the presence of the blood-brain barrier (BBB) (Xiao and Link, 1998; Weller et al., 2009). Despite the presence of the BBB, which limits the entry of cells and pathogens to the brain, lymphocytes can traffic into the CNS to surveil the local environment (Xiao and Link, 1998; Kivisakk et al., 2003). It is increasingly recognized that the CNS is capable of shaping the immune response (for review see Xiao and Link, 1998); it is now clear that neuroinflammation is a well-established hallmark of a number of neurodegenerative diseases, including $\mathrm{AD}$, and is frequently detrimental to neurological function (Akiyama et al., 2000; Rubio-Perez and Morillas-Ruiz, 2012; Solito and Sastre, 2012; Cappellano et al., 2013; Enciu and Popescu, 2013; Lynch, 2014). In the AD brain, the inflammatory response is thought to be a secondary response caused by an initial brain insult, which is provided by damaged neurons, neurites, insoluble $A \beta$ aggregates, and neurofibrillary tangles as stimuli (Akiyama et al., 2000). However, recent evidence suggests that inflammatory mediators may stimulate amyloid precursor protein processing, and therefore, play a role as a driving force to establish a deleterious cycle to $\mathrm{AD}$ progression (Heneka et al., 2010). As described above, $\operatorname{PrP}^{\mathrm{C}}$ is a receptor for oligomeric A $\beta$ peptides (Lauren et al., 2009; Chen et al., 2010; Lauren, 2014), and $\mathrm{A} \beta$ oligomers, acting via $\mathrm{PrP}^{\mathrm{C}}$, modulate NMDA receptor-mediated $\mathrm{Ca}^{2+}$ influx into neurons. Perhaps, even soluble forms of small oligomers, may directly stimulate $\mathrm{PrP}^{\mathrm{C}}$ and modulate NMDA receptor-mediated $\mathrm{Ca}^{2+}$ influx into immune cells to trigger signaling pathways to secrete cytokines, reactive oxygen species, and/or regulate T cell polarization at the early stage of $\mathrm{AD}$. Gaining more insight into the role of $\mathrm{PrP}^{\mathrm{C}}$-NMDA receptor interactions in neuroinflammation may reveal novel approaches to visualize early $\mathrm{AD}$ pathogenesis and diagnosis.

\section{CONCLUDING REMARKS}

It is becoming clear that loss of $\operatorname{PrP}^{\mathrm{C}}$ regulation of NMDA receptors can result in toxicity in a variety of pathological conditions, and that $A \beta$ can cause aberrant activation of NMDA receptors in a $\mathrm{PrP}^{\mathrm{C}}$-dependent manner. The possibility of restoring the NMDA receptor- $\mathrm{PrP}^{\mathrm{C}}$ interaction as a way to protect against excitotoxicity will need to be tested experimentally, and in order to accomplish this, elucidation of the molecular details of the interaction between $\mathrm{PrP}^{\mathrm{C}}$ and NMDA receptors is needed. In light of the recent findings regarding cleavage of $\mathrm{PrP}^{\mathrm{C}}$ and how this is altered in disease, there is a need for investigation of how physiological processing of $\mathrm{PrP}^{\mathrm{C}}$ impacts NMDA receptor activity in both health and disease. Overall, a better understanding of the molecular mechanisms that determine how $\operatorname{PrP}^{\mathrm{C}}$ regulates NMDA receptor function will open up new therapeutic avenues in situations where the regulation of NMDA receptors by $\operatorname{PrP}^{C}$ is perturbed, such as in $\mathrm{AD}$ and prion diseases.

\section{ACKNOWLEDGMENTS}

Stefanie A. G. Black is supported by a Postdoctoral Fellowship from the Multiple Sclerosis Society of Canada (MSSOC). Peter K. Stys is supported by an Alberta Innovates-Health Solutions (AIHS) Scientist Award; work in the lab of Peter K. Stys is supported by the Canadian Institutes of Health Research (CIHR), MSSOC, the Alberta Prion Research Institute (APRI), Canada Research Chairs. Gerald W. Zamponi is a Canada Research Chair and an AI-HS Scientist; work in the Gerald W. Zamponi lab is supported by funds from APRI and CIHR. Work in the lab of Shigeki Tsutsui is supported by APRI/Alzheimer Society of Alberta and Northwest Territories (ASANT).

\section{REFERENCES}

Adle-Biassette, H., Verney, C., Peoc'h, K., Dauge, M. C., Razavi, F., Choudat, L., et al. (2006). Immunohistochemical expression of prion protein (PrPC) in the human forebrain during development. J. Neuropathol. Exp. Neurol. 65, 698-706. doi: 10.1097/01.jnen.0000228137.10531.72

Affaticati, P., Mignen, O., Jambou, F., Potier, M., Klingel-Schmitt, I., Degrouard, J., et al. (2011). Sustained calcium signalling and caspase-3 activation involve NMDA receptors in thymocytes in contact with dendritic cells. Cell Death Differ. 18, 99-108. doi: 10.1038/cdd.2010.79

Aguzzi, A., Baumann, F., and Bremer, J. (2008). The prion's elusive reason for being. Annu. Rev. Neurosci. 31, 439-477. doi: 10.1146/annurev.neuro.31.060407. 125620

Akiyama, H., Barger, S., Barnum, S., Bradt, B., Bauer, J., Cole, G., et al. (2000). Inflammation and Alzheimer's disease. Neurobiol. Aging 21, 383-421. doi: 10.1016/S0197-4580(00)00124-X

Altmeppen, H. C., Prox, J., Puig, B., Dohler, F., Falker, C., Krasemann, S., et al. (2013). Roles of endoproteolytic alpha-cleavage and shedding of the prion protein in neurodegeneration. FEBS J. 280, 4338-4347. doi: 10.1111/febs. 12196

Bailey, S., Carpentier, P., McMahon, E., Begolka, W., and Miller, S. (2006). Innate and adaptive immune responses of the central nervous system. Crit. Rev. Immunol. 26, 149-188. doi: 10.1615/CritRevImmunol.v26.i2.40 
Balducci, C., Beeg, M., Stravalaci, M., Bastone, A., Sclip, A., Biasini, E., et al. (2010). Synthetic amyloid-beta oligomers impair long-term memory independently of cellular prion protein. Proc. Natl. Acad. Sci. U.S.A. 107, 2295-2300. doi: 10.1073/pnas.0911829107

Bartlett, T. E., and Wang, Y. T. (2013). The intersections of NMDAR-dependent synaptic plasticity and cell survival. Neuropharmacology 74, 59-68. doi: 10.1016/j.neuropharm.2013.01.012

Baumann, F., Tolnay, M., Brabeck, C., Pahnke, J., Kloz, U., Niemann, H. H., et al. (2007). Lethal recessive myelin toxicity of prion protein lacking its central domain. EMBO J. 26, 538-547. doi: 10.1038/sj.emboj.7601510

Beland, M., Bedard, M., Tremblay, G., Lavigne, P., and Roucou, X. (2014). Abeta induces its own prion protein N-terminal fragment (PrPN1)-mediated neutralization in amorphous aggregates. Neurobiol. Aging 35, 1537-1548. doi: 10.1016/j.neurobiolaging.2014.02.001

Beland, M., Motard, J., Barbarin, A., and Roucou, X. (2012). PrP(C) homodimerization stimulates the production of PrPC cleaved fragments PrPN1 and PrPC1. J. Neurosci. 32, 13255-13263. doi: 10.1523/JNEUROSCI.2236-12.2012

Bendheim, P., Brown, H., Rudelli, R., Scala, L., Goller, N., Wen, G., et al. (1992). Nearly ubiquitous tissue distribution of the scrapie agent precursor protein. Neurology 42, 149-156. doi: 10.1212/WNL.42.1.149

Beraldo, F. H., Arantes, C. P., Santos, T. G., Machado, C. F., Roffe, M., Hajj, G. N., et al. (2011). Metabotropic glutamate receptors transduce signals for neurite outgrowth after binding of the prion protein to laminin $\gamma 1$ chain. FASEB J. 25, 265-279. doi: 10.1096/fj.10-161653

Beraldo, F. H., Arantes, C. P., Santos, T. G., Queiroz, N. G., Young, K., Rylett, R. J., et al. (2010). Role of alpha7 nicotinic acetylcholine receptor in calcium signaling induced by prion protein interaction with stress-inducible protein 1. J. Biol. Chem. 285, 36542-36550. doi: 10.1074/jbc.M110.157263

Biasini, E., Turnbaugh, J. A., Unterberger, U., and Harris, D. A. (2012). Prion protein at the crossroads of physiology and disease. Trends Neurosci. 35, 92-103. doi: 10.1016/j.tins.2011.10.002

Biasini, E., Unterberger, U., Solomon, I. H., Massignan, T., Senatore, A., Bian, H., et al. (2013). A mutant prion protein sensitizes neurons to glutamate-induced excitotoxicity. J. Neurosci. 33, 2408-2418. doi: 10.1523/JNEUROSCI.340612.2013

Boldyrev, A., Bryushkova, E., and Vladychenskaya, E. (2012). NMDA receptors in immune competent cells. Biochemistry (Mosc.) 77, 128-134. doi: $10.1134 /$ S0006297912020022

Boldyrev, A., Carpenter, D., and Johnson, P. (2005). Emerging evidence for a similar role of glutamate receptors in the nervous and immune systems. J. Neurochem. 95, 913-918. doi: 10.1111/j.1471-4159.2005.03456.x

Bremer, J., Baumann, F., Tiberi, C., Wessig, C., Fischer, H., Schwarz, P., et al. (2010). Axonal prion protein is required for peripheral myelin maintenance. Nat. Neurosci. 13, 310-318. doi: 10.1038/nn.2483

Calella, A. M., Farinelli, M., Nuvolone, M., Mirante, O., Moos, R., Falsig, J., et al. (2010). Prion protein and Abeta-related synaptic toxicity impairment. EMBO Mol. Med. 2, 306-314. doi: 10.1002/emmm.201000082

Cappellano, G., Carecchio, M., Fleetwood, T., Magistrelli, L., Cantello, R., Dianzani, U., et al. (2013). Immunity and inflammation in neurodegenerative diseases. Am. J. Neurodegener. Dis. 2, 89-107.

Carulla, P., Bribián, A., Rangel, A., Gavín, R., Ferrer, I., Caelles, C., et al. (2011). Neuroprotective role of PrPC against kainate-induced epileptic seizures and cell death depends on the modulation of JNK3 activation by GluR6/7-PSD-95 binding. Mol. Biol. Cell 22, 3041-3054. doi: 10.1091/mbc.E11-04-0321

Cashman, N., Loertscher, R., Nalbantoglu, J., Shaw, I., Kascsak, R., Bolton, D., et al. (1990). Cellular isoform of the scrapie agent protein participates in lymphocyte activation. Cell 61, 185-192. doi: 10.1016/0092-8674(90)90225-4

Chatterton, J. E., Awobuluyi, M., Premkumar, L. S., Takahashi, H., Talantova, M., Shin, Y., et al. (2002). Excitatory glycine receptors containing the NR3 family of NMDA receptor subunits. Nature 415, 793-798. doi: 10.1038/ nature715

Chen, S., Yadav, S. P., and Surewicz, W. K. (2010). Interaction between human prion protein and amyloid-beta (Abeta) oligomers: role of N-terminal residues. J. Biol. Chem. 285, 26377-26383. doi: 10.1074/jbc.M110.145516

Cisse, M., Sanchez, P. E., Kim, D. H., Ho, K., Yu, G. Q., and Mucke, L. (2011). Ablation of cellular prion protein does not ameliorate abnormal neural network activity or cognitive dysfunction in the J20 line of human amyloid precursor protein transgenic mice. J. Neurosci. 31, 10427-10431. doi: 10.1523/JNEUROSCI.1459-11.2011
Corlew, R., Brasier, D. J., Feldman, D. E., and Philpot, B. D. (2008). Presynaptic NMDA receptors: newly appreciated roles in cortical synaptic function and plasticity. Neuroscientist 14, 609-625. doi: 10.1177/10738584083 22675

Cull-Candy, S. G., and Leszkiewicz, D. N. (2004). Role of distinct NMDA receptor subtypes at central synapses. Sci. STKE 2004:re16. doi: 10.1126/stke.2552004re16

Danysz, W., and Parsons, C. G. (2012). Alzheimer's disease, beta-amyloid, glutamate, NMDA receptors and memantine-searching for the connections. Br. J. Pharmacol. 167, 324-352. doi: 10.1111/j.1476-5381.2012. 02057.x

Enciu, A., and Popescu, B. (2013). Is there a causal link between inflammation and dementia? Biomed. Res. Int. 2013:316495. doi: 10.1155/2013/316495

Fleisch, V. C., Leighton, P. L., Wang, H., Pillay, L. M., Ritzel, R. G., Bhinder, G., et al. (2013). Targeted mutation of the gene encoding prion protein in zebrafish reveals a conserved role in neuron excitability. Neurobiol. Dis. 55, 11-25. doi: 10.1016/j.nbd.2013.03.007

Fluharty, B. R., Biasini, E., Stravalaci, M., Sclip, A., Diomede, L., Balducci, C., et al. (2013). An N-terminal fragment of the prion protein binds to amyloid-beta oligomers and inhibits their neurotoxicity in vivo. J. Biol. Chem. 288, 7857-7866. doi: 10.1074/jbc.M112.423954

Ford, M., Burton, L., Morris, R., and Hall, S. (2002). Selective expression of prion protein in peripheral tissues of the adult mouse. Neuroscience 113, 177-192. doi: 10.1016/S0306-4522(02)00155-0

Gadotti, V. M., Bonfield, S. P., and Zamponi, G. W. (2012). Depressive-like behaviour of mice lacking cellular prion protein. Behav. Brain. Res. 227, 319-323. doi: 10.1016/j.bbr.2011.03.012

Gadotti, V. M., and Zamponi, G. W. (2011). Cellular prion protein protects from inflammatory and neuropathic pain. Mol. Pain 7:59. doi: 10.1186/17448069-7-59

Ganor, Y., and Levite, M. (2012). "Glutamate in the immune system: glutamate receptors in immune cells, potent effects, endogenous production and involvement in disease," in Nerve-Driven Immunity, ed M. Levite (Wien: Springer-Verlag/Wien), 121-161. doi: 10.1007/978-3-7091-0888-8

Gill, S., and Pulido, O. (2001). Glutamate receptors in peripheral tissues: current knowledge, future research, and implications for toxicology. Toxicol. Pathol. 29, 208-223. doi: 10.1080/019262301317052486

Guillot-Sestier, M. V., Sunyach, C., Druon, C., Scarzello, S., and Checler, F. (2009). The alpha-secretase-derived N-terminal product of cellular prion, N1, displays neuroprotective function in vitro and in vivo. J. Biol. Chem. 284, 35973-35986. doi: 10.1074/jbc.M109.051086

Guillot-Sestier, M. V., Sunyach, C., Ferreira, S. T., Marzolo, M. P., Bauer C., Thevenet, A., et al. (2012). alpha-Secretase-derived fragment of cellular prion, N1, protects against monomeric and oligomeric amyloid beta (Abeta)-associated cell death. J. Biol. Chem. 287, 5021-5032. doi: 10.1074/jbc.M111.323626

Hardingham, G. E. (2009). Coupling of the NMDA receptor to neuroprotective and neurodestructive events. Biochem. Soc. Trans. 37, 1147-1160. doi: 10.1042/BST0371147

Hardingham, G. E., and Bading, H. (2010). Synaptic versus extrasynaptic NMDA receptor signalling: implications for neurodegenerative disorders. Nat. Rev. Neurosci. 11, 682-696. doi: 10.1038/nrn2911

Heneka, M., O'banion, M., Terwel, D., and Kummer, M. (2010). Neuroinflammatory processes in Alzheimer's disease. J. Neural Transm. 117, 919-947. doi: 10.1007/s00702-010-0438-z

Hinoi, E., Takarada, T., Ueshima, T., Tsuchihashi, Y., and Yoneda, Y. (2004) Glutamate signaling in peripheral tissues. Eur. J. Biochem. 271, 1-13. doi: 10.1046/j.1432-1033.2003.03907.x

Hu, N. W., Nicoll, A. J., Zhang, D., Mably, A. J., O’Malley, T., Purro, S. A., et al. (2014). mGlu5 receptors and cellular prion protein mediate amyloid- $\beta$ facilitated synaptic long-term depression in vivo. Nat. Commun. 5, 3374. doi: $10.1038 /$ ncomms4374

Kahlfuß, S., Simma, N., Mankiewicz, J., Bose, T., Lowinus, T., Klein-Hessling, S., et al. (2014). Immunosuppression by $\mathrm{N}$-methyl-D-aspartate receptor antagonists is mediated through inhibition of Kv1.3 and KCa3.1 channels in T cells. Mol. Cell. Biol. 34, 820-831. doi: 10.1128/MCB.01273-13

Karadottir, R., Cavelier, P., Bergersen, L. H., and Attwell, D. (2005). NMDA receptors are expressed in oligodendrocytes and activated in ischaemia. Nature 438 , 1162-1166. doi: 10.1038/nature04302 
Kessels, H. W., Nguyen, L. N., Nabavi, S., and Malinow, R. (2010). The prion protein as a receptor for amyloid-beta. Nature 466, E3-E4. discussion: E4-E5. doi: 10.1038 /nature09217

Khosravani, H., Zhang, Y., Tsutsui, S., Hameed, S., Altier, C., Hamid, J., et al. (2008). Prion protein attenuates excitotoxicity by inhibiting NMDA receptors. J. Cell Biol. 181, 551-565. doi: 10.1083/jcb.200711002

Kivisakk, P., Mahad, D., Callahan, M., Trebst, C., Tucky, B., Wei, T., et al. (2003). Human cerebrospinal fluid central memory CD4+ T cells: evidence for trafficking through choroid plexus and meninges via P-selectin. Proc. Natl. Acad. Sci. U.S.A. 100, 8389-8394. doi: 10.1073/pnas. 1433000100

Kleene, R., Loers, G., Langer, J., Frobert, Y., Buck, F., and Schachner, M. (2007). Prion protein regulates glutamate-dependent lactate transport of astrocytes. J. Neurosci. 27, 12331-12340. doi: 10.1523/JNEUROSCI.1358-07.2007

Klewpatinond, M., Davies, P., Bowen, S., Brown, D. R., and Viles, J. H. (2008). Deconvoluting the $\mathrm{Cu} 2+$ binding modes of full-length prion protein. J. Biol. Chem. 283, 1870-1881. doi: 10.1074/jbc.M708472200

Lai, T. W., Zhang, S., and Wang, Y. T. (2014). Excitotoxicity and stroke: identifying novel targets for neuroprotection. Prog. Neurobiol. 115, 157-188. doi: 10.1016/j.pneurobio.2013.11.006

Lau, A., and Tymianski, M. (2010). Glutamate receptors, neurotoxicity and neurodegeneration. Pflugers Arch. 460, 525-542. doi: 10.1007/s00424-010-0809-1

Lauren, J. (2014). Cellular prion protein as a therapeutic target in Alzheimer's disease. J. Alzheimers Dis. 38, 227-244. doi: 10.3233/JAD-130950

Lauren, J., Gimbel, D., Nygaard, H., Gilbert, J., and Strittmatter, S. (2009). Cellular prion protein mediates impairment of synaptic plasticity by amyloid-beta oligomers. Nature 457, 1128-1132. doi: 10.1038/nature07761

Li, J. B., Lu, Z. G., Xu, L., Wang, Q., Zhang, Z. H., and Fang, J. H. (2014) Neuroprotective effects of bis(7)-tacrine in a rat model of pressure-induced retinal ischemia. Cell Biochem. Biophys. 68, 275-282. doi: 10.1007/s12013-0139707-4

Liu, T., Yi, W., Feng, B., Zhou, Z., and Xiao, G. (2013). IGF-1-induced enhancement of PRNP expression depends on the negative regulation of transcription factor FOXO3a. PLoS ONE 8:e71896. doi: 10.1371/journal.pone.0071896

Lynch, M. (2014). The impact of neuroimmune changes on development of amyloid pathology; relevance to Alzheimer's disease. Immunology 141, 292-301. doi: 10.1111/imm. 12156

Mabbott, N., Brown, K., Manson, J., and Bruce, M. (1997). T-lymphocyte activation and the cellular form of the prion protein. Immunology 92, 161-165. doi: 10.1046/j.1365-2567.1997.00331.x

Mayer, M. L. (2005). Glutamate receptor ion channels. Curr. Opin. Neurobiol. 15 282-288. doi: 10.1016/j.conb.2005.05.004

Mayer, M. L., Vyklicky, L. Jr., and Clements, J. (1989). Regulation of NMDA receptor desensitization in mouse hippocampal neurons by glycine. Nature 338 , 425-427. doi: 10.1038/338425a0

McDonald, A. J., Dibble, J. P., Evans, E. G., and Millhauser, G. L. (2014). A new paradigm for enzymatic control of alpha-cleavage and beta-cleavage of the prion protein. J. Biol. Chem. 289, 803-813. doi: 10.1074/jbc.M113.502351

McLennan, N. F., Brennan, P. M., McNeill, A., Davies, I., Fotheringham, A., Rennison, K. A., et al. (2004). Prion protein accumulation and neuroprotection in hypoxic brain damage. Am. J. Pathol. 165, 227-235. doi: 10.1016/S00029440(10)63291-9

Micu, I., Jiang, Q., Coderre, E., Ridsdale, A., Zhang, L., Woulfe, J., et al. (2006). NMDA receptors mediate calcium accumulation in myelin during chemical ischaemia. Nature 439, 988-992. doi: 10.1038/nature04474

Mitsios, N., Saka, M., Krupinski, J., Pennucci, R., Sanfeliu, C., Miguel Turu, M., et al. (2007). Cellular prion protein is increased in the plasma and periinfarcted brain tissue after acute stroke. J. Neurosci. Res. 85, 602-611. doi: 10.1002/jnr.21142

Mitteregger, G., Vosko, M., Krebs, B., Xiang, W., Kohlmannsperger, V., Nolting, S., et al. (2007). The role of the octarepeat region in neuroprotective function of the cellular prion protein. Brain Pathol. 17, 174-183. doi: 10.1111/j.17503639.2007.00061.x

Müller, W. E., Ushijima, H., Schroder, H. C., Forrest, J. M., Schatton, W. F., Rytik, P. G., et al. (1993). Cytoprotective effect of NMDA receptor antagonists on prion protein (PrionSc)-induced toxicity in rat cortical cell cultures. Eur. J. Pharmacol. 246, 261-267. doi: 10.1016/0922-4106(93)90040-G

Nicoll, A. J., Panico, S., Freir, D. B., Wright, D., Terry, C., Risse, E., et al. (2013). Amyloid-beta nanotubes are associated with prion protein-dependent synaptotoxicity. Nat. Commun. 4, 2416. doi: 10.1038/ncomms3416
Nieznanski, K., Choi, J. K., Chen, S., Surewicz, K., and Surewicz, W. K. (2012). Soluble prion protein inhibits amyloid-beta (Abeta) fibrillization and toxicity. J. Biol. Chem. 287, 33104-33108. doi: 10.1074/jbc.C112.400614

Ostapchenko, V. G., Beraldo, F. H., Guimaraes, A. L., Mishra, S., Guzman, M., Fan, J., et al. (2013). Increased prion protein processing and expression of metabotropic glutamate receptor 1 in a mouse model of Alzheimer's disease. J. Neurochem. 127, 415-425. doi: 10.1111/jnc.12296

Paoletti, P., Bellone, C., and Zhou, Q. (2013). NMDA receptor subunit diversity: impact on receptor properties, synaptic plasticity and disease. Nat. Rev. Neurosci. 14, 383-400. doi: 10.1038/nrn3504

Parsons, M. P., and Raymond, L. A. (2014). Extrasynaptic NMDA receptor involvement in central nervous system disorders. Neuron 82, 279-293. doi: 10.1016/j.neuron.2014.03.030

Pina-Crespo, J. C., Talantova, M., Micu, I., States, B., Chen, H. S., Tu, S., et al. (2010). Excitatory glycine responses of CNS myelin mediated by NR1/NR3 "NMDA" receptor subunits. J. Neurosci. 30, 11501-11505. doi: 10.1523/JNEUROSCI.1593-10.2010

Qin, K., Yang, D. S., Yang, Y., Chishti, M. A., Meng, L. J., Kretzschmar, H. A., et al. (2000). Copper(II)-induced conformational changes and protease resistance in recombinant and cellular PrP. Effect of protein age and deamidation. J. Biol. Chem. 275, 19121-19131. doi: 10.1074/jbc.275.25.19121

Quintanar, L., Rivillas-Acevedo, L., Grande-Aztatzi, R., Gómez-Castro, C. Z. Arcos-López, T., and Vela, A. (2013). Copper coordination to the prion protein: insights from theoretical studies. Coordin. Chem. Rev. 257, 429-444. doi: 10.1016/j.ccr.2012.06.026

Radovanovic, I., Braun, N., Giger, O. T., Mertz, K., Miele, G., Prinz, M., et al. (2005) Truncated prion protein and Doppel are myelinotoxic in the absence of oligodendrocytic PrPC. J. Neurosci. 25, 4879-4888. doi: 10.1523/JNEUROSCI.032805.2005

Rangel, A., Burgaya, F., Gavin, R., Soriano, E., Aguzzi, A., and Del Rio, J. A. (2007). Enhanced susceptibility of Prnp-deficient mice to kainate-induced seizures, neuronal apoptosis, and death: role of AMPA/kainate receptors. J. Neurosci. Res. 85, 2741-2755. doi: 10.1002/jnr.21215

Ratte, S., Vreugdenhil, M., Boult, J. K., Patel, A., Asante, E. A., Collinge, J., et al. (2011). Threshold for epileptiform activity is elevated in prion knockout mice. Neuroscience 179, 56-61. doi: 10.1016/j.neuroscience.2011.01.053

Resenberger, U. K., Harmeier, A., Woerner, A. C., Goodman, J. L., Muller, V., Krishnan, R., et al. (2011). The cellular prion protein mediates neurotoxic signalling of beta-sheet-rich conformers independent of prion replication. EMBO J. 30, 2057-2070. doi: 10.1038/emboj.2011.86

Riemer, C., Burwinkel, M., Schwarz, A., Gultner, S., Mok, S. W., Heise, I., et al. (2008). Evaluation of drugs for treatment of prion infections of the central nervous system. J. Gen. Virol. 89, 594-597. doi: 10.1099/vir.0.83281-0

Rubio-Perez, J., and Morillas-Ruiz, J. (2012). A review: inflammatory process in Alzheimer's disease, role of cytokines. ScientificWorldJournal 2012:756357. doi: 10.1100/2012/756357

Rush, T., and Buisson, A. (2014). Reciprocal disruption of neuronal signaling and Abeta production mediated by extrasynaptic NMDA receptors: a downward spiral. Cell Tissue Res. 356, 279-286. doi: 10.1007/s00441-013-1789-1

Sakurai-Yamashita, Y., Sakaguchi, S., Yoshikawa, D., Okimura, N., Masuda, Y., Katamine, S., et al. (2005). Female-specific neuroprotection against transient brain ischemia observed in mice devoid of prion protein is abolished by ectopic expression of prion protein-like protein. Neuroscience 136, 281-287. doi: 10.1016/j.neuroscience.2005.06.095

Salter, M. G., and Fern, R. (2005). NMDA receptors are expressed in developing oligodendrocyte processes and mediate injury. Nature 438, 1167-1171. doi: 10.1038 /nature04301

Schlief, M. L., West, T., Craig, A. M., Holtzman, D. M., and Gitlin, J. D. (2006). Role of the Menkes copper-transporting ATPase in NMDA receptormediated neuronal toxicity. Proc. Natl. Acad. Sci. U.S.A. 103, 14919-14924. doi: 10.1073/pnas.0605390103

Shyu, W. C., Lin, S. Z., Chiang, M. F., Ding, D. C., Li, K. W., Chen, S. F., et al. (2005). Overexpression of PrPC by adenovirus-mediated gene targeting reduces ischemic injury in a stroke rat model. J. Neurosci. 25, 8967-8977. doi: 10.1523/JNEUROSCI.1115-05.2005

Skerry, T., and Genever, P. (2001). Glutamate signalling in non-neuronal tissues. Trends Pharmacol. Sci. 22, 174-181. doi: 10.1016/S0165-6147(00)01642-4

Solito, E., and Sastre, M. (2012). Microglia function in Alzheimer's disease. Front. Pharmacol. 3:14. doi: 10.3389/fphar.2012.00014 
Spudich, A., Frigg, R., Kilic, E., Kilic, U., Oesch, B., Raeber, A., et al. (2005). Aggravation of ischemic brain injury by prion protein deficiency: role of ERK-1/-2 and STAT-1. Neurobiol. Dis. 20, 442-449. doi: 10.1016/j.nbd.2005. 04.002

Stanyon, H. F., Patel, K., Begum, N., and Viles, J. H. (2014). Copper(II) sequentially loads onto the $\mathrm{N}$-terminal amino group of the cellular prion protein before the individual octarepeats. Biochemistry 53, 3934-3939. doi: 10.1021/bi500643b

Steele, A. D., Zhou, Z., Jackson, W. S., Zhu, C., Auluck, P., Moskowitz, M. A., et al. (2009). Context dependent neuroprotective properties of prion protein ( $\operatorname{PrP})$. Prion 3, 240-249. doi: 10.4161/pri.3.4.10135

Talantova, M., Sanz-Blasco, S., Zhang, X., Xia, P., Akhtar, M. W., Okamoto, S., et al. (2013). Abeta induces astrocytic glutamate release, extrasynaptic NMDA receptor activation, and synaptic loss. Proc. Natl. Acad. Sci. U.S.A. 110, E2518-E2527. doi: 10.1073/pnas. 1306832110

Thakur, A. K., Srivastava, A. K., Srinivas, V., Chary, K. V., and Rao, C. M. (2011), Copper alters aggregation behavior of prion protein and induces novel interactions between its N- and C-terminal regions. J. Biol. Chem. 286, 38533-38545. doi: 10.1074/jbc.M111.265645

Thellung, S., Gatta, E., Pellistri, F., Corsaro, A., Villa, V., Vassalli, M., et al. (2013). Excitotoxicity through NMDA receptors mediates cerebellar granule neuron apoptosis induced by prion protein 90-231 fragment. Neurotox. Res. 23, 301-314. doi: 10.1007/s12640-012-9340-9

Tsutsui, S., Hahn, J., Johnson, T., Ali, Z., and Jirik, F. (2008). Absence of the cellular prion protein exacerbates and prolongs neuroinflammation in experimental autoimmune encephalomyelitis. Am. J. Pathol. 173, 1029-1041. doi: 10.2353/ajpath.2008.071062

Tuneva, E., Bychkova, O., and Boldyrev, A. (2003). Effect of NMDA on production of reactive oxygen species by human lymphocytes. Bull. Exp. Biol. Med. 136, 159-161. doi: 10.1023/A:1026366907084

Um, J. W., Kaufman, A. C., Kostylev, M., Heiss, J. K., Stagi, M., Takahashi, H., et al. (2013). Metabotropic glutamate receptor 5 is a coreceptor for Alzheimer aß oligomer bound to cellular prion protein. Neuron 79, 887-902. doi: 10.1016/j.neuron.2013.06.036

Um, J. W., Nygaard, H. B., Heiss, J. K., Kostylev, M. A., Stagi, M., Vortmeyer, A., et al. (2012). Alzheimer amyloid-beta oligomer bound to postsynaptic prion protein activates Fyn to impair neurons. Nat. Neurosci. 15, 1227-1235. doi: 10.1038/nn.3178

Walz, R., Amaral, O. B., Rockenbach, I. C., Roesler, R., Izquierdo, I., Cavalheiro, E. A., et al. (1999). Increased sensitivity to seizures in mice lacking cellular prion protein. Epilepsia 40, 1679-1682. doi: 10.1111/j.1528-1157.1999.tb01583.x

Wang, K. K., Zoltewicz, J. S., Chiu, A., Zhang, Z., and Rubenstein, R. (2012). Release of full-length $\operatorname{PrP}(\mathrm{C})$ from cultured neurons following neurotoxic challenges. Front. Neurol. 3:147. doi: 10.3389/fneur.2012.00147

Watt, N. T., Taylor, D. R., Kerrigan, T. L., Griffiths, H. H., Rushworth, J. V., Whitehouse, I. J., et al. (2012). Prion protein facilitates uptake of zinc into neuronal cells. Nat. Commun. 3, 1134. doi: 10.1038/ncomms2135
Weise, J., Crome, O., Sandau, R., Schulz-Schaeffer, W., Bahr, M., and Zerr, I. (2004). Upregulation of cellular prion protein $(\mathrm{PrPc})$ after focal cerebral ischemia and influence of lesion severity. Neurosci. Lett. 372, 146-150. doi: 10.1016/j.neulet.2004.09.030

Weise, J., Doeppner, T. R., Muller, T., Wrede, A., Schulz-Schaeffer, W., Zerr, I., et al. (2008). Overexpression of cellular prion protein alters postischemic Erk1/2 phosphorylation but not Akt phosphorylation and protects against focal cerebral ischemia. Restor. Neurol. Neurosci. 26, 57-64.

Weise, J., Sandau, R., Schwarting, S., Crome, O., Wrede, A., Schulz-Schaeffer, W., et al. (2006). Deletion of cellular prion protein results in reduced Akt activation, enhanced postischemic caspase-3 activation, and exacerbation of ischemic brain injury. Stroke 37, 1296-1300. doi: 10.1161/01.STR.0000217262.03192.d4

Weller, R., Preston, S., Subash, M., and Carare, R. (2009). Cerebral amyloid angiopathy in the aetiology and immunotherapy of Alzheimer disease. Alzheimers Res. Ther. 1:6. doi: 10.1186/alzrt6

Wyllie, D. J., Livesey, M. R., and Hardingham, G. E. (2013). Influence of GluN2 subunit identity on NMDA receptor function. Neuropharmacology 74, 4-17. doi: 10.1016/j.neuropharm.2013.01.016

Xiao, B., and Link, H. (1998). Immune regulation within the central nervous system. J. Neurol. Sci. 157, 1-12. doi: 10.1016/S0022-510X(98)00049-5

You, H., Tsutsui, S., Hameed, S., Kannanayakal, T., Chen, L., Xia, P., et al. (2012). Abeta neurotoxicity depends on interactions between copper ions, prion protein, and N-methyl-D-aspartate receptors. Proc. Natl. Acad. Sci. U.S.A. 109, 1737-1742. doi: 10.1073/pnas.1110789109

Younan, N. D., Klewpatinond, M., Davies, P., Ruban, A. V., Brown, D. R., and Viles, J. H. (2011). Copper(II)-induced secondary structure changes and reduced folding stability of the prion protein. J. Mol. Biol. 410, 369-382. doi: 10.1016/j.jmb.2011.05.013

Conflict of Interest Statement: The authors declare that the research was conducted in the absence of any commercial or financial relationships that could be construed as a potential conflict of interest.

Received: 30 June 2014; paper pending published: 21 July 2014; accepted: 09 August 2014; published online: 28 August 2014.

Citation: Black SAG, Stys PK, Zamponi GW and Tsutsui S (2014) Cellular prion protein and NMDA receptor modulation: protecting against excitotoxicity. Front. Cell Dev. Biol. 2:45. doi: 10.3389/fcell.2014.00045

This article was submitted to Cell Death and Survival, a section of the journal Frontiers in Cell and Developmental Biology.

Copyright (๑) 2014 Black, Stys, Zamponi and Tsutsui. This is an open-access article distributed under the terms of the Creative Commons Attribution License (CC BY). The use, distribution or reproduction in other forums is permitted, provided the original author(s) or licensor are credited and that the original publication in this journal is cited, in accordance with accepted academic practice. No use, distribution or reproduction is permitted which does not comply with these terms. 


\title{
Lipid rafts: linking prion protein to zinc transport and amyloid- $\beta$ toxicity in Alzheimer's disease
}

\author{
Nicole T. Watt ${ }^{1}$, Heledd H. Griffiths ${ }^{2}$ and Nigel M. Hooper ${ }^{2 *}$ \\ ' Division of Cardiovascular and Diabetes Research, Multidisciplinary Cardiovascular Research Centre, University of Leeds, Leeds, UK \\ ${ }^{2}$ Faculty of Medical and Human Sciences, Institute of Brain, Behaviour and Mental Health, University of Manchester, Manchester, UK
}

\section{Edited by:}

Sophie Mouillet-Richard, INSERM

Unit 1124, France

\section{Reviewed by:}

NADIA ALFAIDY, INSERM, France Gerold Schmitt-Ulms, University of Toronto, Canada

\section{${ }^{*}$ Correspondence:}

Nigel M. Hooper, Faculty of Medical and Human Sciences, Institute of Brain, Behaviour and Mental Health, University of Manchester, Rm 2.015 AV Hill Building, Oxford Road, Manchester M13 9PT, UK e-mail: nigel.hooper@ manchester.ac.uk
Dysregulation of neuronal zinc homeostasis plays a major role in many processes related to brain aging and neurodegenerative diseases, including Alzheimer's disease (AD). Yet, despite the critical role of zinc in neuronal function, the cellular mechanisms underpinning its homeostatic control are far from clear. We reported that the cellular prion protein $(\operatorname{Pr} P C)$ is involved in the uptake of zinc into neurons. This $\mathrm{PrPC}^{\mathrm{C}}$-mediated zinc influx required the metal-binding octapeptide repeats in $\operatorname{PrP}^{\mathrm{C}}$ and the presence of the zinc permeable AMPA channel with which $\operatorname{PrPC}^{\mathrm{C}}$ directly interacted. Together with the observation that $\operatorname{PrP}^{\mathrm{C}}$ is evolutionarily related to the ZIP family of zinc transporters, these studies indicate that $\mathrm{PrPC}^{\mathrm{C}}$ plays a key role in neuronal zinc homeostasis. Therefore, $\mathrm{PrPC}^{\mathrm{C}}$ could contribute to cognitive health and protect against age-related zinc dyshomeostasis but $\operatorname{PrPC}^{\mathrm{C}}$ has also been identified as a receptor for amyloid- $\beta$ oligomers which accumulate in the brains of those with $A D$. We propose that the different roles that $\operatorname{PrPC}^{C}$ has are due to its interaction with different ligands and/or co-receptors in lipid raft-based signaling/transport complexes.

Keywords: Alzheimer's disease, AMPA receptor, amyloid, cholesterol, prion protein, zinc

\section{ZINC HOMEOSTASIS AND ALZHEIMER'S DISEASE}

Zinc is a trace element that is essential for life and whose importance to the function of the central nervous system is increasingly being appreciated. Zinc serves as a cofactor for $>300$ enzymes that regulate a variety of cellular processes and signaling pathways, and is also a key structural component of numerous other proteins (Frederickson et al., 2005; Sensi et al., 2009). In the brain, which has one of the highest zinc contents with respect to other organs, zinc-containing axons are particularly abundant in the hippocampus and cortex (Toth, 2011). Zinc is predominantly, but not exclusively, localized within synaptic vesicles at glutamatergic nerve terminals [sometimes referred to as gluzinergic neurons (Mocchegiani et al., 2005)]. During neuronal activity, zinc is released along with glutamate into the synaptic cleft where it affects the activity of various receptors. In addition, zinc is itself a signaling molecule, and within the neuron it regulates the activity of multiple enzymes and plays a critical role in the formation and stabilization of the postsynaptic density (Beyersmann and Haase, 2001; Grabrucker et al., 2011; Wilson et al., 2012). Both intracellular and extracellular zinc concentrations must be tightly maintained within narrow optimal ranges for the correct functioning of the nervous system. An excess influx of zinc can damage postsynaptic neurons (Plum et al., 2010) and zinc deficiency affects neurogenesis and increases neuronal apoptosis, which can lead to learning and memory deficits (Szewczyk, 2013). Under normal circumstances, zinc homeostasis is maintained by the coordinated actions of a range of different proteins involved in its uptake, efflux, and intracellular storage and trafficking. Zinc enters neurons through members of the ZIP (Zrt/Irt-like Protein; SLC39) family of zinc transporters, as well as through activated voltage-gated $\mathrm{Ca}^{2+}$ channels, $\alpha$-amino3-hydroxy-5-methyl-4-isoxazoleproprionate (AMPA) receptors, and N-methyl-D-aspartate (NMDA) receptors (Cousins et al., 2006; Sensi et al., 2009). Zinc exporters, members of the zinc transporter (ZnT; SLC30) family transport zinc from the cytosol to the lumen of intracellular organelles or out of the cell (Sensi et al., 2009).

Alzheimer's disease (AD) is the most prevalent form of dementia, affecting millions of individuals world-wide. With currently no cure, the economic and social costs associated with the disease are set to increase dramatically with our aging population. $\mathrm{AD}$ is characterized by the deposition in the brain of extracellular plaques of amyloid- $\beta$ (A $\beta$ ) peptide and intracellular inclusions of tau protein. $A \beta$ is proteolytically cleaved from the larger amyloid precursor protein (APP), and both A $\beta$ and APP have binding sites for zinc (Watt et al., 2010; Wong et al., 2014). Zinc, particularly that released from glutamatergic nerve terminals, has a crucial role to play in the aggregation of $A \beta$ into neurotoxic oligomers and fibrils (Bush et al., 1994; Esler et al., 1996; Deshpande et al., 2009), and is also co-localized with $A \beta$ in amyloid plaques (Dong et al., 2003). The activity of the zinc transporter ZnT-3 is required for the transport of zinc into the glutamate-containing presynaptic vesicles. Key evidence for a link between zinc and amyloid pathology in $\mathrm{AD}$ comes from the crossing of ZnT-3 knockout mice with Tg2576 mice, a commonly used transgenic mouse model of AD. The crossed mice had minimal synaptic zinc and as a consequence both brain plaque load and amyloid angiopathy were significantly reduced (Lee et al., 2002; Friedlich et al., 2004). Furthermore, in a separate study of aged ZnT-3 knockout mice, there were marked 
differences in learning and memory observed compared to wild type mice, supporting a requirement for zinc in memory function and the maintenance of synaptic health upon aging (Adlard et al., 2010).

\section{PrPC AND NEURONAL ZINC UPTAKE}

Recently we reported that $\operatorname{PrP}^{\mathrm{C}}$ facilitates the uptake of zinc into neuronal cells (Watt et al., 2012). $\operatorname{PrP}^{\mathrm{C}}$ is infamous because of its conformational conversion into $\mathrm{PrP}^{\mathrm{Sc}}$ being responsible for the fatal transmissible spongiform encephalopathies, such as Creutzfeldt-Jakob disease. $\mathrm{PrP}^{\mathrm{C}}$ is a glycosyl-phosphatidylinositol (GPI)-anchored protein located on the surface of neurons, at both pre- and post-synaptic sites. It is found throughout the central nervous system and is particularly abundant in the hippocampus and frontal cortex (Sales et al., 1998). Using two zinc specific fluorescent dyes (Newport green and Zinpyr-1) we showed that $\mathrm{PrP}^{\mathrm{C}}$ enhanced the uptake of zinc into human SH-SY5Y neuroblastoma cells and rat primary hippocampal neurons (Watt et al., 2012). This $\operatorname{PrP}^{\mathrm{C}}$-mediated zinc influx required the metalbinding octapeptide repeat region in $\mathrm{PrP}^{\mathrm{C}}$ but not its endocytosis. We then used selective channel antagonists to identify that AMPA receptors were involved in the $\operatorname{PrP}^{\mathrm{C}}$-mediated zinc uptake, and that $\mathrm{PrP}^{\mathrm{C}}$ interacted with both GluA1 and GluA2 AMPA receptor subunits as shown by co-immunoprecipitation. Intracellular protein tyrosine phosphatase activity, which is potently inhibited by zinc (Brautigan et al., 1981; Wilson et al., 2012), was increased in the brains of $\mathrm{PrP}^{\mathrm{C}}$ null mice, providing evidence of a physiological consequence of altered zinc uptake in the absence of $\operatorname{PrP}^{C}$. These observations provided the first mechanistic explanation for the reduced zinc in the hippocampus and other brain regions of $\operatorname{PrP}^{\mathrm{C}}$ null mice (Pushie et al., 2011) and indicate that $\operatorname{PrP}^{\mathrm{C}}$ is a key player in neuronal zinc uptake.
Interestingly, during the course of our work showing that $\operatorname{PrP}^{\mathrm{C}}$ mediates neuronal zinc uptake, the protein was reported to be evolutionarily related to a subset of the ZIP family of zinc transporters (Schmitt-Ulms et al., 2009). Bioinformatic analysis revealed that the $\mathrm{N}$-terminal extracellular domain of a distinct sub-branch of the LIV-1 subfamily of ZIPs that includes ZIPs 5,6 , and 10 had sequence similarity to the C-terminal globular domain of $\mathrm{PrP}^{\mathrm{C}}$. These three ZIPs are also equipped with histidine-rich sequences N-terminal to their "prion-like" domain, capable of divalent metal binding, which is reminiscent of the octapeptide repeat domain of $\operatorname{PrP}^{\mathrm{C}}$ (Figure 1A). Interestingly, the orientation and distance of the "prion-like" domain to the respective membrane attachment sites in both $\mathrm{PrP}^{\mathrm{C}}$ and the ZIPs are similar (Figure 1A), and the primary sequence of the first transmembrane domain in the ZIPs and the GPI anchor attachment sequence of $\mathrm{PrP}^{\mathrm{C}}$ are also comparable, providing further evidence that $\mathrm{PrP}^{\mathrm{C}}$ is evolutionarily related to members of the ZIP family (Schmitt-Ulms et al., 2009).

As $\mathrm{PrP}^{\mathrm{C}}$ is a GPI-anchored protein residing in the outer leaflet of the plasma membrane, in order to correlate a function for $\mathrm{PrP}^{\mathrm{C}}$ in the transport of zinc across the lipid bilayer, we proposed that $\mathrm{PrP}^{\mathrm{C}}$ requires the assistance of the channel properties of another protein(s), such as AMPA receptors, in order to achieve zinc transport (Figure 1B) (Watt et al., 2012). The octapeptide repeats in the GPI-anchored $\mathrm{PrP}^{\mathrm{C}}$ act as a zinc sensor/scavenger in the extracellular environment which then presents the metal to the transmembrane channel for uptake of the zinc into the cell (Watt et al., 2013). Interestingly, not all ZIP family members have an extracellular N-terminal extension that may function in zinc sensing: for example ZIPs 1, 2, 3, 9, and 11 have minimal N-terminal extensions on the first transmembrane domain. This raises the intriguing possibility that the two properties (zinc
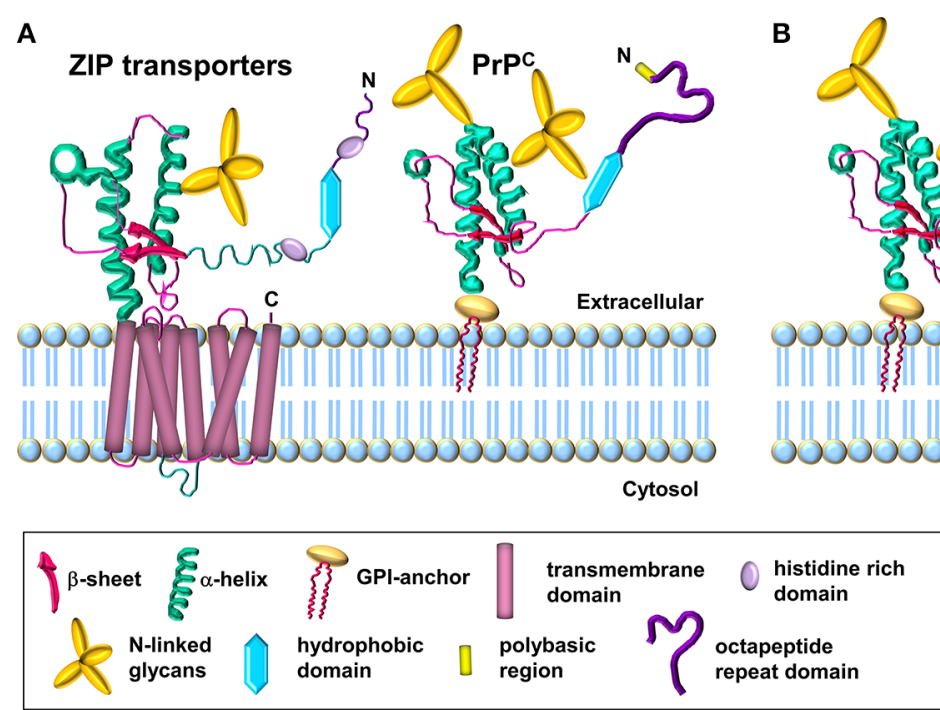

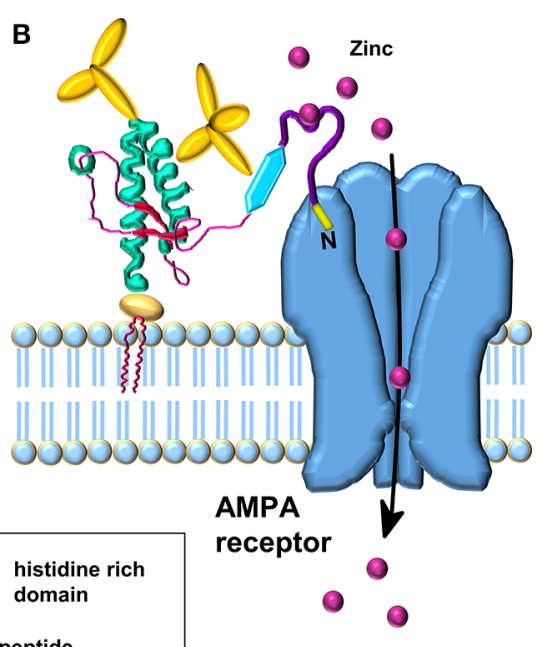

low affinity binding of zinc to the octapeptide repeats. The $\mathrm{N}$-terminal polybasic region of $\mathrm{Pr} P \mathrm{C}$ interacts with the AMPA receptor subunits; this interaction facilitates the transport of zinc through the AMPA receptor which forms a channel across the membrane for the uptake of zinc in a manner similar to the C-terminal region of the ZIP transporter. Modified from Watt et al. (2013). 
sensing and zinc channel) present together in certain ZIPs (e.g., ZIPs 6 and 10) reside in separate proteins in those ZIPs with minimal N-terminal extensions. It will be interesting to see if $\mathrm{PrP}^{\mathrm{C}}$ acts as the zinc sensor in combination with certain ZIPs, similar to the situation we have proposed for $\mathrm{PrP}^{\mathrm{C}}$ and the AMPA receptor (Figure 1B) (Watt et al., 2012, 2013). Such PrPC-based zinc sensing modules may be restricted to higher eukaryotes in which $\operatorname{PrP}^{\mathrm{C}}$ with the octapeptide metal binding repeats is present.

In addition to its role in zinc metabolism, $\operatorname{PrP}^{\mathrm{C}}$ also plays a role in the homeostasis of other metals such as iron and copper (Kozlowski et al., 2010; Singh et al., 2014). $\operatorname{PrP}^{\mathrm{C}}$ expression alters regional zinc, copper and iron content in the mouse brain (Pushie et al., 2011) and there appears to be crosstalk between the different metals, with zinc modulating copper coordination to the octapeptide repeats (Stellato et al., 2011). In addition, $\mathrm{PrP}^{\mathrm{C}}$ modulates NMDA receptor activity in a copper-dependent manner (Stys et al., 2012), suggesting that multiple receptors/channels may be regulated by $\mathrm{PrP}^{\mathrm{C}}$ in a ligand/metal-dependent manner.

\section{A CELL-SURFACE, LIPID RAFT-BASED COMPLEX INVOLVED IN THE REGULATION OF ZINC UPTAKE}

The GPI-anchored $\mathrm{PrP}^{\mathrm{C}}$ is localized in cholesterol-rich, detergent-resistant lipid rafts at the cell surface (Taylor et al., 2005) and it has been proposed that $\operatorname{PrP}^{\mathrm{C}}$ functions as a key scaffolding protein for the dynamic assembly of cell surface signaling modules (Linden et al., 2008). $\operatorname{PrP}^{\mathrm{C}}$, along with the microdomain-forming flotillin or caveolin proteins, may lead to the local assembly of membrane protein complexes at sites involved in cellular communication, such as cell-cell contacts, focal adhesions, the T-cell cap and synapses (Solis et al., 2010). Lipid rafts are essential for synapse development, stabilization and maintenance and caveolin-1 organizes and targets synaptic components to rafts (Hering et al., 2003; Willmann et al., 2006; Guirland and Zheng, 2007). Interestingly, when ZIP1 and ZIP3 were stably expressed in HEK293 cells, the punctate cell surface staining observed led the authors to suggest that they were localized to lipid rafts (although no experimental evidence for this was provided) (Wang et al., 2004). Furthermore, treatment of the HEK293 cells with methyl- $\beta$-cyclodextrin, which sequesters cholesterol and disrupts cholesterol-rich lipid rafts, resulted in a more diffuse surface staining (Wang et al., 2004), reminiscent of what is observed for $\mathrm{PrP}^{\mathrm{C}}$ and other GPI-anchored proteins (Parkin et al., 2003; Taylor et al., 2005). We also have disrupted rafts in neuronal cells using methyl- $\beta$-cyclodextrin and observed a reduction in zinc uptake, an effect exacerbated when the cells also expressed $\operatorname{PrP}^{\mathrm{C}}$ (Watt and Hooper, unpublished). In contrast, it has been reported that ZIP10 only partially colocalizes with $\mathrm{PrP}^{\mathrm{C}}$ in $\mathrm{N} 2 \mathrm{a}$ cells and is not detected in detergent-resistant rafts (Ehsani et al., 2012). These data raise the intriguing possibility that a cell-surface, lipid raft-based complex, possibly stabilized by $\operatorname{PrP}^{\mathrm{C}}$, regulates the cell surface expression of certain zinc transporters and thus zinc uptake.

\section{PrPC IS A CELL SURFACE RECEPTOR FOR A $\beta$ OLIGOMERS}

In $2009, \mathrm{PrP}^{\mathrm{C}}$ was identified as a high-affinity receptor for $\mathrm{A} \beta$ oligomers, the primary neurotoxic species in $\mathrm{AD}$ (Lauren et al., 2009). The presence of $\operatorname{PrP}^{C}$ in hippocampal slices was shown to be responsible for the $A \beta$ oligomer-mediated inhibition of long-term potentiation (LTP) (Lauren et al., 2009). $\operatorname{PrP}^{\mathrm{C}}$ was also required for the manifestation of memory impairments in an $\mathrm{AD}$ mouse model (Gimbel et al., 2010), which were reversed by intracerebral infusion of an anti- $\mathrm{PrP}^{\mathrm{C}}$ monoclonal antibody (Chung et al., 2010). Immuno-targeting of $\operatorname{PrP}^{\mathrm{C}}$ was shown to block completely the LTP impairments caused by A $\beta$ oligomers derived from human AD brain extracts (Barry et al., 2011; Freir et al., 2011). $\mathrm{A} \beta$ oligomers bound to $\mathrm{PrP}^{\mathrm{C}}$ activate the non-receptor tyrosine kinase Fyn (Um et al., 2012; Rushworth et al., 2013) and results in pathological changes in tau (Larson et al., 2012). Although there is general consensus that $\mathrm{PrP}^{\mathrm{C}}$ can bind oligomeric forms of $\mathrm{A} \beta$, some studies dispute a role for $\mathrm{PrP}^{\mathrm{C}}$ in mediating $\mathrm{A} \beta$ toxicity (Calella et al., 2010; Kessels et al., 2010).

It has been hypothesized that a putative transmembrane coreceptor is required to connect the binding of $A \beta$ to the GPIanchored $\mathrm{PrP}^{\mathrm{C}}$ on the outer surface of the plasma membrane with downstream effects inside the cell (Cisse and Mucke, 2009; Lauren et al., 2009). The transmembrane low-density lipoproteinreceptor related protein-1 (LRP1) is highly expressed in neuronal cells (Nykjaer and Willnow, 2002), facilitates the endocytosis of $\operatorname{PrP}^{\mathrm{C}}$ (Taylor and Hooper, 2007) and has been implicated in the neuronal uptake of $\mathrm{A} \beta$ (Fuentealba et al., 2010; Kanekiyo et al., 2011). We hypothesized, therefore, that LRP1 may play a role in the $\operatorname{PrP}^{\mathrm{C}}$-mediated action of $\mathrm{A} \beta$ oligomers (Figure 2 ). We showed that LRP1 is required for the binding of $A \beta$ oligomers to cells, as well as for their subsequent internalization and cytotoxicity (Rushworth et al., 2013). In parallel with our work on LRP1, Strittmatter and colleagues identified the metabotropic glutamate receptor, mGluR5, as a co-receptor with $\mathrm{PrP}^{\mathrm{C}}$ for $\mathrm{A} \beta$ oligomers and was required to activate Fyn (Um et al., 2013). Furthermore, antagonists of mGluR5 reversed the deficits in learning, memory and synapse density in AD transgenic mice (Um et al., 2013). In addition, the $\mathrm{A} \beta-\mathrm{PrP}^{\mathrm{C}}$-mGluR5 interplay is involved in mediating both long-term depression facilitation and LTP inhibition (Hu et al., 2014). Thus, both LRP1 and mGluR5 appear to be transmembrane co-receptors in the $\mathrm{A} \beta-\mathrm{PrP}^{\mathrm{C}}$ interaction, which are required for the $\mathrm{PrP}^{\mathrm{C}}$-mediated action of $\mathrm{A} \beta$ oligomers. Whether both LRP1 and mGluR5 reside in the same complex with $\mathrm{PrP}^{\mathrm{C}}$ or in separate signaling complexes is currently unclear.

\section{A CELL-SURFACE, LIPID RAFT-BASED SIGNALING COMPLEX INVOLVED IN A $\beta$ OLIGOMER ACTION}

Cell surface cholesterol-rich, detergent-resistant lipid rafts are intimately involved in the production, aggregation and toxicity of $\mathrm{A} \beta$ (Rushworth and Hooper, 2010; Di Paolo and Kim, 2011). For example, these membrane microdomains have been linked with $A \beta$ toxicity via Fyn, and rafts are involved in the neuronal internalization of $A \beta$ (Williamson et al., 2008; Lai and McLaurin, 2010). We investigated whether the integrity of lipid rafts is required for the binding of $A \beta$ oligomers and the subsequent activation of Fyn. Treatment of cells with methyl$\beta$-cyclodextrin caused the re-localization of $\mathrm{PrP}^{\mathrm{C}}$ and Fyn from detergent-resistant rafts to detergent-soluble, non-raft regions of the membrane as analyzed by sucrose density gradient centrifugation in the presence of Triton X-100. Surprisingly, disruption of the rafts with methyl- $\beta$-cyclodextrin significantly reduced (by 


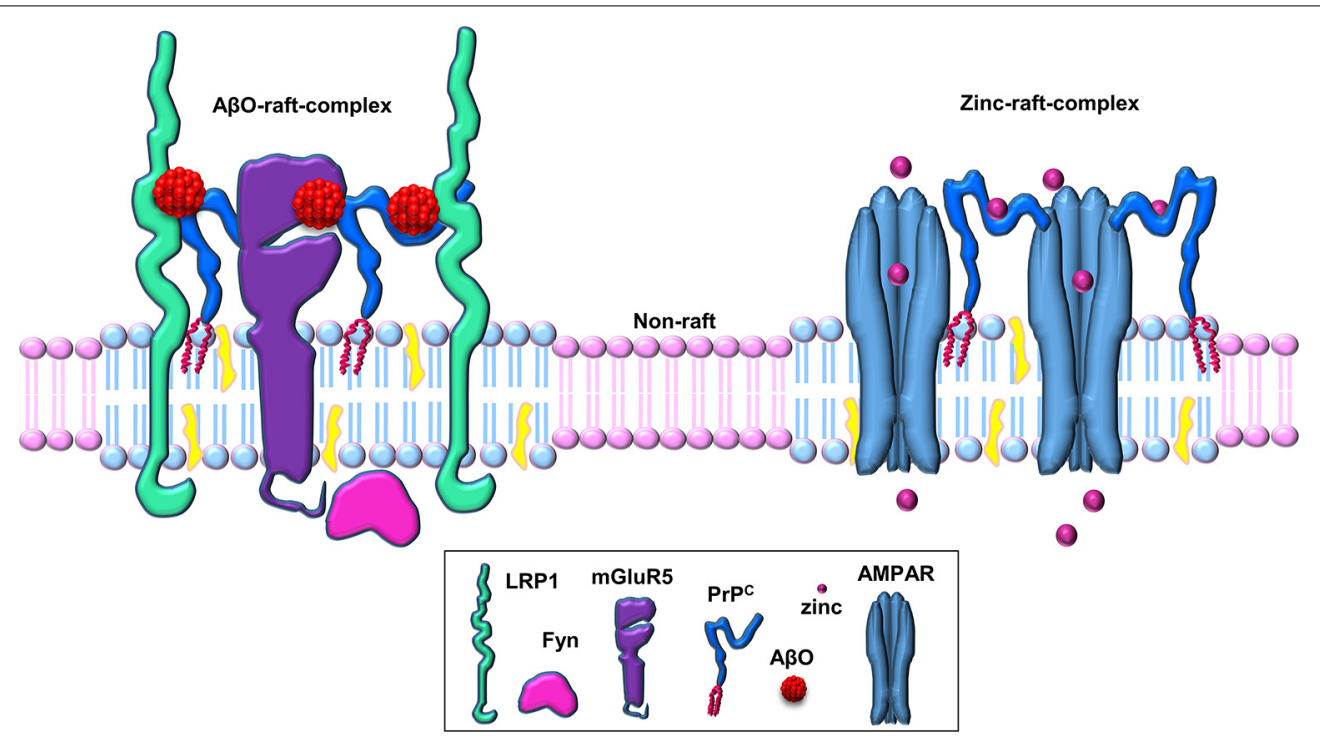

FIGURE 2 | Schematic of PrPC-based cell-surface, raft-based complexes involved in zinc uptake and $\mathbf{A} \boldsymbol{\beta}$ binding. $\mathrm{Pr}^{\mathrm{C}}$ acts as a hub for cell surface, lipid raft-based signaling/transport complexes. $\operatorname{PrPC}$ associates with various transmembrane proteins (such as AMPA receptors, LRP1, mGluR5, etc.) in these multi-protein complexes in a ligand-dependent manner (here shown for the ligands zinc and $A \beta$ oligomers within separate raft-based complexes).
$80.6 \%$ ) the cell surface binding of the $A \beta$ oligomers, even though the cell surface expression of $\operatorname{PrP}^{\mathrm{C}}$ was unaffected, and prevented the $A \beta$ oligomers from activating Fyn (Rushworth et al., 2013). Thus, raft localization of $\mathrm{PrP}^{\mathrm{C}}$ is required for the binding of $\mathrm{A} \beta$ oligomers, and the integrity of rafts and/or other raft-localized proteins are required for the $A \beta$-mediated activation of Fyn. These observations suggest that there is a cell-surface, raft-based signaling complex that is key to the binding of $A \beta$ oligomers and the subsequent generation of cellular responses.

$\mathrm{A} \beta$ oligomers caused mGluR5 receptors to manifest reduced lateral diffusion as they became aberrantly clustered (Renner et al., 2010). Antibodies against $\operatorname{PrP}^{\mathrm{C}}$ and the NR1 subunit of NMDA receptors had a similar inhibitory effect on $A \beta$ oligomer binding as the antibody against mGluR5, but there was not an additive effect of the individual antibodies, suggesting that mGluR5, PrPC , and NR1 may be in proximity to each other as well as the $\mathrm{A} \beta$ oligomer binding site (Renner et al., 2010). Interestingly, addition of $A \beta$ oligomers to neurons caused a large increase of mGluR5 in the Triton-resistant fraction (Renner et al., 2010), although no link to its possible redistribution into detergentresistant lipid rafts was made. In another study, disruption of lipid rafts by cholesterol depletion reduced the interaction of $A \beta$ with $\alpha$-7-nicotinic acetylcholine receptors (Khan et al., 2010). These observations are consistent with multiple (co)receptor proteins for $\mathrm{A} \beta$ oligomers residing in cell-surface, raft-based complex(es).

\section{PrPC AND RAFTS ARE DYSREGULATED IN AGING}

Zinc homeostasis plays a major role in many processes related to brain aging. For example, mouse models of accelerated aging, such as senescence-accelerated mouse prone 10 (SAMP10) mice display a low total zinc concentration in synaptic vesicles that is associated with brain atrophy and defects in learning and memory (Saito et al., 2000), and dietary zinc deficiency influences hippocampal learning and memory in an age-dependent manner (Mocchegiani et al., 2005; Szewczyk, 2013). ZIP6 expression has been reported to be decreased in an age-dependent manner (Wong et al., 2013), although nothing has been reported about the expression, subcellular localization or function of any other ZIP in the aged brain. Caveolin-1 has been identified as a novel control point for healthy neuronal aging, with the localization of caveolin-1, PSD95, and AMPA receptors in lipid rafts being decreased in aged ( $>18$ months) mice compared with young (3-6 month) mice (Head et al., 2010). Furthermore, in an aging series (age 20-88 years) of human brains we reported that $\operatorname{PrP}^{\mathrm{C}}$ was reduced in the hippocampus with increasing age (Whitehouse et al., 2010). Preliminary data indicate that there is a significant reduction of both ZIP1 and ZIP3 in the hippocampus of old (7988 years) compared with young (20-26 years) individuals (Watt and Hooper, unpublished). These observations suggest that alterations to the structure and function of the cell-surface, raft-based zinc transporter complex may occur in aging and contribute to the age-related dysregulated zinc homeostasis.

Aging is the greatest risk factor for $\mathrm{AD}$ and recently the REST protein was reported to have a central role in protecting aging neurons from degeneration (Lu et al., 2014). There is a close relationship between lipid rafts, cholesterol, and the age-associated decline and dysregulation of cellular signaling pathways (OhnoIwashita et al., 2010). A key component of a subset of rafts, caveolin-1, was identified as a novel control point for both $A \beta$ based neurodegeneration and healthy neuronal aging (Head et al., 2010), and caveolin-1 expression is altered in AD (Gaudreault et al., 2004). In addition, the level of $\mathrm{PrP}^{\mathrm{C}}$ is altered in both the AD and aging brain (Whitehouse et al., 2010, 2013; Larson et al., 2012). Thus, dysregulation of the structure and function of cell-surface, raft-based signaling complexes may occur in, and contribute to, both $\mathrm{AD}$ and aging. 


\section{CONCLUSION}

$\mathrm{PrP}^{\mathrm{C}}$ appears to be involved in multiple physiological and pathological processes, including as highlighted here, neuronal zinc uptake and $A \beta$ oligomer binding and toxicity. We propose that $\mathrm{PrP}^{\mathrm{C}}$ acts as a hub for cell surface, lipid raft-based signaling/transport complexes, and that the different roles that the protein has are due to the selective interaction of $\operatorname{PrP}^{\mathrm{C}}$ with different ligands (such as zinc or A $\beta$ oligomers) and/or co-receptors (such as AMPA receptors, LRP1, mGluR5) in these multi-protein complexes (Figure 2). It is likely that these complexes are relatively transient in nature, being stabilized upon binding of a particular ligand for a limited time period before dissociation or endocytosis terminates the signaling or transport process. The use of more sophisticated techniques, such as super resolution light microscopy, should enable the molecular details of these different lipid raft-based signaling/transport complexes to be determined and provide a clearer picture of the role of $\mathrm{PrP}^{\mathrm{C}}$ and lipid rafts in neuronal zinc transport and $\mathrm{A} \beta$ action in $\mathrm{AD}$. It will also be interesting to determine how the interplay between $\operatorname{PrP}^{\mathrm{C}}$, zinc, and $\mathrm{A} \beta$ may underlie aging and age-related diseases.

\section{ACKNOWLEDGMENTS}

The authors acknowledge the financial support of the Medical Research Council of Great Britain (G0802189).

\section{REFERENCES}

Adlard, P. A., Parncutt, J. M., Finkelstein, D. I., and Bush, A. I. (2010). Cognitive loss in zinc transporter-3 knock-out mice: a phenocopy for the synaptic and memory deficits of Alzheimer's disease? J. Neurosci. 30, 1631-1636. doi: 10.1523/JNEUROSCI.5255-09.2010

Barry, A. E., Klyubin, I., McDonald, J. M., Mably, A. J., Farrell, M. A., Scott, M., et al. (2011). Alzheimer's disease brain-derived amyloid- $\beta$-mediated inhibition of LTP in vivo is prevented by immunotargeting cellular prion protein. J. Neurosci. 31, 7259-7263. doi: 10.1523/JNEUROSCI.6500-10.2011

Beyersmann, D., and Haase, H. (2001). Functions of zinc in signaling, proliferation and differentiation of mammalian cells. Biometals 14, 331-341. doi: 10.1023/A:1012905406548

Brautigan, D. L., Bornstein, P., and Gallis, B. (1981). Phosphotyrosyl-protein phosphatase. Specific inhibition by Zn. J. Biol. Chem. 256, 6519-6522.

Bush, A. I., Pettingell, W. H., Multhaup, G., d Paradis, M., Vonsattel, J. P., Gusella, J. F., et al. (1994). Rapid induction of Alzheimer $A \beta$ amyloid formation by zinc. Science 265, 1464-1467. doi: 10.1126/science.8073293

Calella, A. M., Farinelli, M., Nuvolone, M., Mirante, O., Moos, R., Falsig, J., et al. (2010). Prion protein and A $\beta$-related synaptic toxicity impairment. EMBO Mol. Med. 2, 306-314. doi: 10.1002/emmm.201000082

Chung, E., Ji, Y., Sun, Y., Kascsak, R. J., Kascsak, R. B., Mehta, P. D., et al. (2010). Anti-PrPC monoclonal antibody infusion as a novel treatment for cognitive deficits in an Alzheimer's disease model mouse. BMC Neurosci. 11:130. doi: 10.1186/1471-2202-11-130

Cisse, M., and Mucke, L. (2009). Alzheimer's disease: a prion protein connection. Nature 457, 1090-1091. doi: 10.1038/4571090a

Cousins, R. J., Liuzzi, J. P., and Lichten, L. A. (2006). Mammalian zinc transport, trafficking, and signals. J. Biol. Chem. 281, 24085-24089. doi: 10.1074/jbc. R600011200

Deshpande, A., Kawai, H., Metherate, R., Glabe, C. G., and Busciglio, J. (2009). A role for synaptic zinc in activity-dependent $A \beta$ oligomer formation and accumulation at excitatory synapses. J. Neurosci. 29, 4004-4015. doi: 10.1523/JNEUROSCI.5980-08.2009

Di Paolo, G., and Kim, T.-W. (2011). Linking lipids to Alzheimer's disease: cholesterol and beyond. Nat. Rev. Neurosci. 12, 284-296. doi: 10.1038/nrn3012

Dong, J., Atwood, C. S., Anderson, V. E., Siedlak, S. L., Smith, M. A., Perry, G., et al. (2003). Metal binding and oxidation of amyloid- $\beta$ within isolated senile plaque cores: Raman microscopic evidence. Biochemistry 42, 2768-2773. doi: 10.1021/bi0272151
Ehsani, S., Salehzadeh, A., Huo, H., Reginold, W., Pocanschi, C. L., Ren, H., et al. (2012). LIV-1 ZIP ectodomain shedding in prion-infected mice resembles cellular response to transition metal starvation. J. Mol. Biol. 422, 556-574. doi: 10.1016/j.jmb.2012.06.003

Esler, W. P., Stimson, E. R., Jennings, J. M., Ghilardi, J. R., Mantyh, P. W., and Maggio, J. E. (1996). Zinc-induced aggregation of human and rat $\beta$ amyloid peptides in vitro. J. Neurochem. 66, 723-732. doi: 10.1046/j.14714159.1996.66020723.x

Frederickson, C. J., Koh, J. Y., and Bush, A. I. (2005). The neurobiology of zinc in health and disease. Nat. Rev. Neurosci. 6, 449-462. doi: 10.1038/nrn1671

Freir, D. B., Nicoll, A. J., Klyubin, I., Panico, S., McDonald, J. M., Risse, E., et al. (2011). Interaction between prion protein and toxic amyloid $\beta$ assemblies can be therapeutically targeted at multiple sites. Nat. Commun. 2, 336. doi: $10.1038 /$ ncomms 1341

Friedlich, A. L., Lee, J. Y., van Groen, T., Cherny, R. A., Volitakis, I., Cole, T. B., et al. (2004). Neuronal zinc exchange with the blood vessel wall promotes cerebral amyloid angiopathy in an animal model of Alzheimer's disease. J. Neurosci. 24, 3453-3459. doi: 10.1523/JNEUROSCI.0297-04.2004

Fuentealba, R. A., Liu, Q., Zhang, J., Kanekiyo, T., Hu, X., Lee, J. M., et al. (2010). Low-density lipoprotein receptor-related protein 1 (LRP1) mediates neuronal A $\beta 42$ uptake and lysosomal trafficking. PLOS ONE 5:e11884. doi: 10.1371/journal.pone.0011884

Gaudreault, S. B., Dea, D., and Poirier, J. (2004). Increased caveolin-1 expression in Alzheimer's disease brain. Neurobiol. Aging 25, 753-759. doi: 10.1016/j.neurobiolaging.2003.07.004

Gimbel, D. A., Nygaard, H. B., Coffey, E. E., Gunther, E. C., Lauren, J., Gimbel, Z. A., et al. (2010). Memory impairment in transgenic Alzheimer mice requires cellular prion protein. J. Neurosci. 30, 6367-6374. doi: 10.1523/JNEUROSCI.039510.2010

Grabrucker, A. M., Knight, M. J., Proepper, C., Bockmann, J., Joubert, M., Rowan, M., et al. (2011). Concerted action of zinc and ProSAP/Shank in synaptogenesis and synapse maturation. EMBO J. 30, 569-581. doi: 10.1038/emboj.2010.336

Guirland, C., and Zheng, J. Q. (2007). Membrane lipid rafts and their role in axon guidance. Adv. Exp. Med. Biol. 621, 144-155. doi: 10.1007/978-0-38776715-4_11

Head, B. P., Peart, J. N., Panneerselvam, M., Yokoyama, T., Pearn, M. L., Niesman, I. R., et al. (2010). Loss of caveolin-1 accelerates neurodegeneration and aging. PloS ONE 5:e15697. doi: 10.1371/journal.pone.0015697

Hering, H., Lin, C. C., and Sheng, M. (2003). Lipid rafts in the maintenance of synapses, dendritic spines, and surface AMPA receptor stability. J. Neurosci. 23, 3262-3271.

Hu, N.-W., Nicoll, A. J., Zhang, D., Mably, A. J., O’Malley, T., Purro, S. A., et al. (2014). mGlu5 receptors and cellular prion protein mediate amyloid- $\beta$ facilitated synaptic long-term depression in vivo. Nat. Commun. 5:3374. doi: $10.1038 /$ ncomms4374

Kanekiyo, T., Zhang, J., Liu, Q., Liu, C.-C., Zhang, L., and Bu, G. (2011). Heparan sulphate proteoglycan and the low-density lipoprotein receptor-related protein 1 constitute major pathways for neuronal amyloid- $\beta$ uptake. J. Neurosci. 31, 1644-1651. doi: 10.1523/JNEUROSCI.5491-10.2011

Kessels, H. W., Nguyen, L. N., Nabavi, S., and Malinow, R. (2010). The prion protein as a receptor for amyloid- $\beta$. Nature 466, E3-E4; discussion: E4-E5. doi 10.1038 /nature09217

Khan, G. M., Tong, M., Jhun, M., Arora, K., and Nichols, R. A. (2010). $\beta$-Amyloid activates presynaptic $\alpha 7$ nicotinic acetylcholine receptors reconstituted into a model nerve cell system: involvement of lipid rafts. Eur. J. Neurosci. 31, 788-796. doi: 10.1111/j.1460-9568.2010.07116.x

Kozlowski, H., Luczkowski, M., and Remelli, M. (2010). Prion proteins and copper ions. Biological and chemical controversies. Dalton Trans. 39, 6371-6385. doi: $10.1039 / \mathrm{c} 001267 \mathrm{j}$

Lai, A. Y., and McLaurin, J. (2010). Mechanisms of amyloid- $\beta$ peptide uptake by neurons: the role of lipid rafts and lipid raft-associated proteins. Int. J. Alzheimers Dis. 2011:548380. doi: 10.4061/2011/548380

Larson, M., Sherman, M. A., Amar, F., Nuvolone, M., Schneider, J. A., Bennett, D. A., et al. (2012). The complex PrPc-Fyn couples human oligomeric A $\beta$ with pathological Tau changes in Alzheimer's disease. J. Neurosci. 32, 16857-16871. doi: 10.1523/JNEUROSCI.1858-12.2012

Lauren, J., Gimbel, D. A., Nygaard, H. B., Gilbert, J. W., and Strittmatter, S. M. (2009). Cellular prion protein mediates impairment of synaptic plasticity by amyloid- $\beta$ oligomers. Nature 457, 1128-1132. doi: 10.1038/nature07761 
Lee, J. Y., Cole, T. B., Palmiter, R. D., Suh, S. W., and Koh, J. Y. (2002). Contribution by synaptic zinc to the gender-disparate plaque formation in human Swedish mutant APP transgenic mice. Proc. Natl. Acad. Sci. U.S.A. 99, 7705-7710. doi: 10.1073/pnas.092034699

Linden, R., Martins, V. R., Prado, M. A., Cammarota, M., Izquierdo, I., and Brentani, R. R. (2008). Physiology of the prion protein. Physiol. Rev. 88, 673-728. doi: 10.1152/physrev.00007.2007

Lu, T., Aron, L., Zullo, J., Pan, Y., Kim, H., Chen, Y., et al. (2014). REST and stress resistance in ageing and Alzheimer's disease. Nature 507, 448-454. doi: 10.1038 /nature 13163

Mocchegiani, E., Bertoni-Freddari, C., Marcellini, F., and Malavolta, M. (2005). Brain, aging and neurodegeneration: role of zinc ion availability. Prog. Neurobiol. 75, 367-390. doi: 10.1016/j.pneurobio.2005.04.005

Nykjaer, A., and Willnow, T. E. (2002). The low-density lipoprotein receptor gene family: a cellular Swiss army knife? Trends Cell Biol. 12, 273-280. doi: 10.1016/S0962-8924(02)02282-1

Ohno-Iwashita, Y., Shimada, Y., Hayashi, M., and Inomata, M. (2010). Plasma membrane microdomains in aging and disease. Geriatr. Gerontol. Int. 10 Suppl. 1, S41-S52. doi: 10.1111/j.1447-0594.2010.00600.x

Parkin, E. T., Tan, F., Skidgel, R. A., Turner, A. J., and Hooper, N. M. (2003). The ectodomain shedding of angiotensin-converting enzyme is independent of its localisation in lipid rafts. J. Cell Sci. 116, 3079-3087. doi: 10.1242/jcs.00626

Plum, L. M., Rink, L., and Haase, H. (2010). The essential toxin: impact of zinc on human health. Int. J. Environ. Res. Public health 7, 1342-1365. doi: 10.3390/ijerph7041342

Pushie, M. J., Pickering, I. J., Martin, G. R., Tsutsui, S., Jirik, F. R., and George, G. N. (2011). Prion protein expression level alters regional copper, iron and zinc content in the mouse brain. Metallomics 3, 206-214. doi: 10.1039/c0mt00037j

Renner, M., Lacor, P. N., Velasco, P. T., Xu, J., Contractor, A., Klein, W. L., et al. (2010). Deleterious effects of amyloid beta oligomers acting as an extracellular scaffold for mGluR5. Neuron 66, 739-754. doi: 10.1016/j.neuron.2010.04.029

Rushworth, J. V., Griffiths, H. H., Watt, N. T., and Hooper, N. M. (2013). Prion protein-mediated toxicity of amyloid- $\beta$ oligomers requires lipid rafts and the transmembrane LRP1. J. Biol. Chem. 288, 8935-8951. doi: 10.1074/jbc.M112.400358

Rushworth, J. V., and Hooper, N. M. (2010). Lipid rafts: linking Alzheimer's amyloid- $\beta$ production, aggregation, and toxicity at neuronal membranes. Int. J. Alzheimers Dis. 2011, 603052. doi: 10.4061/2011/603052

Saito, T., Takahashi, K., Nakagawa, N., Hosokawa, T., Kurasaki, M., Yamanoshita, O., et al. (2000). Deficiencies of hippocampal Zn and ZnT3 accelerate brain aging of Rat. Biochem. Biophys. Res. Commun. 279, 505-511. doi: $10.1006 /$ bbrc. 2000.3946

Sales, N., Rodolfo, K., Hassig, R., Faucheux, B., Di Giamberardino, L., and Moya, K. L. (1998). Cellular prion protein localization in rodent and primate brain. Eur. J. Neurosci. 10, 2464-2471. doi: 10.1046/j.1460-9568.1998.00258.x

Schmitt-Ulms, G., Ehsani, S., Watts, J. C., Westaway, D., and Wille, H. (2009). Evolutionary descent of prion genes from the ZIP family of metal ion transporters. PLoS ONE 4:e7208. doi: 10.1371/journal.pone.0007208

Sensi, S. L., Paoletti, P., Bush, A. I., and Sekler, I. (2009). Zinc in the physiology and pathology of the CNS. Nat. Rev. Neurosci. 10, 780-791. doi: 10.1038/nrn2734

Singh, N., Haldar, S., Tripathi, A. K., McElwee, M. K., Horback, K., and Beserra, A. (2014). Iron in neurodegenerative disorders of protein misfolding: a case of prion disorders and Parkinson's disease. Antioxid. Redox Signal. 21, 471-484. doi: 10.1089/ars.2014.5874

Solis, G. P., Malaga-Trillo, E., Plattner, H., and Stuermer, C. A. (2010). Cellular roles of the prion protein in association with reggie/flotillin microdomains. Front. Biosci. 15, 1075-1085. doi: 10.2741/3662

Stellato, F., Spevacek, A., Proux, O., Minicozzi, V., Millhauser, G., and Morante, S. (2011). Zinc modulates copper coordination mode in prion protein octa-repeat subdomains. Eur. Biophys. J. 40, 1259-1270. doi: 10.1007/s00249-011-0713-4

Stys, P. K., You, H., and Zamponi, G. W. (2012). Copper-dependent regulation of NMDA receptors by cellular prion protein: implications for neurodegenerative disorders. J. Physiol. 590, 1357-1368. doi: 10.1113/jphysiol.2011.225276

Szewczyk, B. (2013). Zinc homeostasis and neurodegenerative disorders. Front. Aging Neurosci. 5:33. doi: 10.3389/fnagi.2013.00033

Taylor, D. R., and Hooper, N. M. (2007). The low-density lipoprotein receptorrelated protein 1 (LRP1) mediates the endocytosis of the cellular prion protein. Biochem. J. 402, 17-23. doi: 10.1042/BJ20061736
Taylor, D. R., Watt, N. T., Perera, W. S., and Hooper, N. M. (2005). Assigning functions to distinct regions of the $\mathrm{N}$-terminus of the prion protein that are involved in its copper-stimulated, clathrin-dependent endocytosis. J. Cell Sci. 118, 5141-5153. doi: 10.1242/jcs.02627

Toth, K. (2011). Zinc in neurotransmission. Annu. Rev. Nutr. 31, 139-153. doi: 10.1146/annurev-nutr-072610-145218

Um, J. W., Kaufman, A. C., Kostylev, M., Heiss, J. K., Stagi, M., Takahashi, H., et al. (2013). Metabotropic glutamate receptor 5 is a coreceptor for Alzheimer A $\beta$ oligomer bound to cellular prion protein. Neuron 79, 887-902. doi: 10.1016/j.neuron.2013.06.036

Um, J. W., Nygaard, H. B., Heiss, J. K., Kostylev, M. A., Stagi, M., Vortmeyer, A., et al. (2012). Alzheimer amyloid- $\beta$ oligomer bound to postsynaptic prion protein activates Fyn to impair neurons. Nat. Neurosci. 15, 1227-1235. doi: 10.1038/nn.3178

Wang, F., Dufner-Beattie, J., Kim, B. E., Petris, M. J., Andrews, G., and Eide, D. J. (2004). Zinc-stimulated endocytosis controls activity of the mouse ZIP1 and ZIP3 zinc uptake transporters. J. Biol. Chem. 279, 24631-24639. doi: 10.1074/jbc.M400680200

Watt, N. T., Griffiths, H. H., and Hooper, N. M. (2013). Neuronal zinc regulation and the prion protein. Prion 7, 203-208. doi: 10.4161/pri.24503

Watt, N. T., Taylor, D. R., Kerrigan, T. L., Griffiths, H. H., Rushworth, J. V., Whitehouse, I. J., et al. (2012). Prion protein facilitates uptake of zinc into neuronal cells. Nat. Commun. 3, 1134. doi: 10.1038/ncomms 2135

Watt, N. T., Whitehouse, I. J., and Hooper, N. M. (2010). The role of zinc in Alzheimer's disease. Int. J. Alzheimers Dis. 2011:971021. doi: $10.4061 / 2011 / 971021$

Whitehouse, I. J., Jackson, C. D., Turner, A. J., and Hooper, N. M. (2010). Prion protein is reduced in aging and in sporadic but not in familial Alzheimer's disease. J. Alzheimers Dis. 22, 1023-1031. doi: 10.3233/JAD-2010-101071

Whitehouse, I. J., Miners, J. S., Glennon, E. B., Kehoe, P. G., Love, S., Kellett, K. A., et al. (2013). Prion protein is decreased in Alzheimer's brain and inversely correlates with BACE1 activity, amyloid- $\beta$ levels and Braak stage. PLoS ONE 8:e59554. doi: 10.1371/journal.pone.0059554

Williamson, R., Usardi, A., Hanger, D. P., and Anderton, B. H. (2008). Membranebound $\beta$-amyloid oligomers are recruited into lipid rafts by a Fyn-dependent mechanism. FASEB J. 22, 1552-1559. doi: 10.1096/fj.07-9766com

Willmann, R., Pun, S., Stallmach, L., Sadasivam, G., Santos, A. F., Caroni, P., et al. (2006). Cholesterol and lipid microdomains stabilize the postsynapse at the neuromuscular junction. EMBO J. 25, 4050-4060. doi: 10.1038/sj.emboj.7601288

Wilson, M., Hogstrand, C., and Maret, W. (2012). Picomolar concentrations of free zinc(II) ions regulate receptor protein-tyrosine phosphatase $\beta$ activity. J. Biol. Chem. 287, 9322-9326. doi: 10.1074/jbc.C111.320796

Wong, B. X., Hung, Y. H., Bush, A. I., and Duce, J. A. (2014). Metals and cholesterol: two sides of the same coin in Alzheimer's disease pathology. Front. Aging Neurosci. 6:91. doi: 10.3389/fnagi.2014.00091

Wong, C. P., Magnusson, K. R., and Ho, E. (2013). Increased inflammatory response in aged mice is associated with age-related zinc deficiency and zinc transporter dysregulation. J. Nutr. Biochem. 24, 353-359. doi: 10.1016/j.jnutbio.2012.07.005

Conflict of Interest Statement: The authors declare that the research was conducted in the absence of any commercial or financial relationships that could be construed as a potential conflict of interest.

Received: 25 June 2014; paper pending published: 08 July 2014; accepted: 05 August 2014; published online: 20 August 2014.

Citation: Watt NT, Griffiths HH and Hooper NM (2014) Lipid rafts: linking prion protein to zinc transport and amyloid- $\beta$ toxicity in Alzheimer's disease. Front. Cell Dev. Biol. 2:41. doi: 10.3389/fcell.2014.00041

This article was submitted to Cell Death and Survival, a section of the journal Frontiers in Cell and Developmental Biology.

Copyright (c) 2014 Watt, Griffiths and Hooper. This is an open-access article distributed under the terms of the Creative Commons Attribution License (CC BY). The use, distribution or reproduction in other forums is permitted, provided the original author(s) or licensor are credited and that the original publication in this journal is cited, in accordance with accepted academic practice. No use, distribution or reproduction is permitted which does not comply with these terms. 


\section{Prion protein and aging}

\section{Lisa Gasperini and Giuseppe Legname*}

Laboratory of Prion Biology, Department of Neuroscience, Scuola Internazionale Superiore di Studi Avanzati, Trieste, Italy

\section{Edited by:}

Sophie Mouillet-Richard, INSERM

Unit 1124, France

\section{Reviewed by:}

Mohammed Moudjou, Institut

National de la Recherche

Agronomique, France

Inga Zerr, University Medical Center

Göttingen, Germany

\section{${ }^{*}$ Correspondence:}

Giuseppe Legname, Laboratory of Prion Biology, Department of Neuroscience, Scuola Internazionale

Superiore di Studi Avanzati, Via

Bonomea 265, Trieste 34136, Italy

e-mail: legname@sissa.it
The cellular prion protein $\left(\mathrm{PrP}^{\mathrm{C}}\right)$ has been widely investigated ever since its conformational isoform, the prion (or $\mathrm{PrPSc}^{\text {) }}$, was identified as the etiological agent of prion disorders. The high homology shared by the $\mathrm{PrP}^{\mathrm{C}}$-encoding gene among mammals, its high turnover rate and expression in every tissue strongly suggest that $\operatorname{PrPC}^{C}$ may possess key physiological functions. Therefore, defining $\mathrm{PrPC}^{\mathrm{C}}$ roles, properties and fate in the physiology of mammalian cells would be fundamental to understand its pathological involvement in prion diseases. Since the incidence of these neurodegenerative disorders is enhanced in aging, understanding $\operatorname{PrP}^{\mathrm{C}}$ functions in this life phase may be of crucial importance. Indeed, a large body of evidence suggests that $\operatorname{PrP}^{C}$ plays a neuroprotective and antioxidant role. Moreover, it has been suggested that $\mathrm{PrPC}$ is involved in Alzheimer disease, another neurodegenerative pathology that develops predominantly in the aging population. In prion diseases, $\operatorname{PrPC}^{\mathrm{C}}$ function is likely lost upon protein aggregation occurring in the course of the disease. Additionally, the aging process may alter $\operatorname{PrPC}^{\mathrm{C}}$ biochemical properties, thus influencing its propensity to convert into $\mathrm{PrPSc}$. Both phenomena may contribute to the disease development and progression. In Alzheimer disease, PrPC has a controversial role because its presence seems to mediate $\beta$-amyloid toxicity, while its down-regulation correlates with neuronal death. The role of $\mathrm{PrPC}^{\mathrm{C}}$ in aging has been investigated from different perspectives, often leading to contrasting results. The putative protein functions in aging have been studied in relation to memory, behavior and myelin maintenance. In aging mice, $\operatorname{PrP}^{C}$ changes in subcellular localization and post-translational modifications have been explored in an attempt to relate them to different protein roles and propensity to convert into PrPSc. Here we provide an overview of the most relevant studies attempting to delineate $\operatorname{Pr} P C$ functions and fate in aging.

Keywords: PrP, aging, Alzheimer disease, prion diseases

\section{INTRODUCTION}

The conformational conversion of the cellular form of the prion protein $\left(\mathrm{PrP}^{\mathrm{C}}\right)$ into a $\beta$-sheet enriched isoform denoted as prion $\left(\mathrm{PrP}^{\mathrm{Sc}}\right)$ is central in neurodegenerative pathologies collectively know as prion diseases (Prusiner, 2001).

The $\mathrm{PrP}^{\mathrm{C}}$ is a sialoglycoprotein that is attached to the outer leaflet of the plasma membrane via a C-terminal glycosylphosphatidylinositol (GPI) anchor (Stahl et al., 1990). In the cell $\mathrm{PrP}^{\mathrm{C}}$ may be expressed in different glycosylated forms, corresponding to the variable occupancy of the residues Asn180 and Asn196 (Haraguchi et al., 1989). While the C-terminal domain is folded in ordered and distinctive secondary structures, the $\mathrm{N}$-terminal portion is flexible, unstructured and contains a unique octapeptide repeat (OR) region (Zahn et al., 2000). The OR confers $\operatorname{PrP}^{\mathrm{C}}$ one of its most salient features, i.e., the ability to bind divalent cations, prominently copper and to a lesser extent zinc, nickel, iron, and manganese (Stockel et al., 1998; Jackson et al., 2001; Singh et al., 2010; Arena et al., 2012). Indeed, at physiological $\mathrm{pH}$ copper shows the highest binding affinity (Chattopadhyay et al., 2005; Liu et al., 2011). The importance of copper binding for $\operatorname{PrP}^{\mathrm{C}}$ function is reflected in the high OR structural homology among different species (Hornshaw et al., 1995). Two of the most investigated putative functions for $\operatorname{PrP}^{\mathrm{C}}$ are neuroprotection and defense against oxidative stress, both relevant in neurodegeneration and cell aging (Vassallo and Herms, 2003; Roucou and LeBlanc, 2005; Aguzzi et al., 2008). In agreement with these findings, $\mathrm{PrP}^{\mathrm{C}}$ copper binding sites support the reduction of $\mathrm{Cu}^{2+}$ to $\mathrm{Cu}^{+}$, thus preventing reactive oxygen species (ROS) formation (Liu et al., 2011).

Although contrasting results are likely due to the different experimental protocols employed, $\mathrm{PrP}^{\mathrm{C}}$ is expressed in almost all body organs and tissues, from embryonic to aging stages (Fournier et al., 1998; Goldmann et al., 1999; Sales et al., 2002). However, the expression levels are differently regulated according to the age and tissue distribution. For instance, while $\mathrm{PrP}^{\mathrm{C}}$ shows a high expression in the central nervous system (CNS), where it is differently regulated during development and aging, it is present at very low levels in the liver (Horiuchi et al., 1995; Moudjou et al., 2001; Peralta et al., 2012). The broad homology conservation of the $\operatorname{PrP}^{\mathrm{C}}$-encoding gene among mammalian and avian species (Hornshaw et al., 1995), the expression of the protein in many tissues during the entire lifespan, and its high turnover rate strongly indicate that $\operatorname{PrP}^{\mathrm{C}}$ possesses key physiological roles. However, the definition of $\operatorname{PrP}^{\mathrm{C}}$ 's univocal function is still under debate. 
The $\mathrm{PrP}^{\mathrm{Sc}}$ isoform can form protein aggregates, known as prion deposits, often present as amyloid structures, which can propagate and possibly cause cell death. Despite continuous steps forward toward the definition of the conformational switch mechanism, the trigger of the posttranslational remodeling event is still obscure, especially in sporadic prion disorders. In the inherited forms of prion diseases, a genetic mutation in the openreading frame of the gene leads to amino acid substitutions, which in turn destabilizes the protein structure over time, promoting $\mathrm{PrP}^{\mathrm{C}}$ to $\mathrm{PrP}^{\mathrm{Sc}}$ conversion. In the infective forms, a preformed $\mathrm{PrP}^{\mathrm{Sc}}$-aggregate triggers the conversion of endogenous $\operatorname{PrP}^{\mathrm{C}}$. In the sporadic forms of the disease, several unknown factors may perturb the protein structure, thus favoring $\mathrm{PrP}^{\mathrm{Sc}}$ formation (Prusiner, 1991, 1994).

If a cause-effect relationship between prion deposits and cell death does not always exist (Lasmezas et al., 1997), a probable consequence of $\mathrm{PrP}^{\mathrm{C}}$ conversion into $\mathrm{PrP}^{\mathrm{Sc}}$ is the loss or alteration of its cellular function. Whether this impairment contributes or not to disease development is still under debate. Moreover, $\mathrm{PrP}^{\mathrm{C}}$ is also involved in Alzheimer disease (AD) (Kellett and Hooper, 2009). Whether in $\mathrm{AD} \operatorname{PrP}^{\mathrm{C}}$ mediates neuroprotection or $\beta$-amyloid toxicity is still under investigation.

All these observations, together with the fact that the highest incidence of prion disorders and $\mathrm{AD}$ is in the elderly population, have renewed the interest of scientists in investigating of the role of $\mathrm{PrP}^{\mathrm{C}}$ during aging. The two main topics under study have been: (i) $\mathrm{PrP}^{\mathrm{C}}$ physiological functions in aging models, and (ii) consequent changes in $\mathrm{PrP}^{\mathrm{C}}$ biochemical properties. The latter may be triggered by the cellular aging process and may promote prion aggregate formation. To date, studies into $\operatorname{PrP}^{\mathrm{C}}$ role in aging are contrasting, mostly due to different animal/cellular systems employed and the lack of consistency in defining aging in experimental models.

Here we provide a comprehensive overview of studies attempting to understand $\mathrm{PrP}^{\mathrm{C}}$ function and fate in aging and relate them to the neurodegenerative processes.

\section{AGING}

In mammals, aging is defined as the accumulation of changes in an individual over time and represents a multifaceted process of social, psychological, and physical alterations (Bowen and Atwood, 2004). Normal aging is associated with significant cognitive declines, such as decreased speed of information processing, working memory capacity, and long-term memory function (Hedden and Gabrieli, 2004). However, changes that occur in aging brains are less linked to chronological time than it was thought in the past. For instance, individual brains may grow old developing less alterations than others (Esiri, 2007).

The study of age-related changes in the human brain is challenging for two main reasons: (i) increasing improvement of nutrition during the last century limits our ability to directly compare human brain samples between generations; and (ii) most elderly brains show some pathological hallmarks, thus complicating the distinction between "normal aging" and "disease" (Esiri, 2007). In the past, it was thought that the main cause of agerelated cognitive decline was massive neuron loss (Brody, 1955) and deterioration of dendritic branches (Scheibel et al., 1976;
Scheibel, 1979). Now we know that alterations occurring in normal aging are more subtle and selective. In fact, it seems that most age-linked behavioral impairments are due to region-specific changes in dendritic morphology, cellular connectivity, calcium dysregulation, gene expression or other factors that affect plasticity and alter neuron network dynamics (Burke and Barnes, 2006). A crucial factor for brain aging is the enormous requirement that neurons have for oxidative metabolism required by energy consumption. Neurons need extraordinary amounts of energy because of: (i) the size and the ensuing energy-consumption system of transport for molecules and organelles; and (ii) the electrical activity for impulse transmission, implying ion gradient maintenance. The high degree of oxidative metabolism generates high amounts of ROS that damage proteins, nucleic acids and lipids, thus interfering with normal cell metabolism and resulting, for instance, in altered gene expression and abnormal protein generation (Esiri, 2007).

Mitochondrial efficiency decline, paralleled by oxidative stress, which occurs with aging, is connected to alterations in calcium homeostasis, in particular to higher calcium content in neuron cytosol after excitatory stimulation. Indeed, glutamate activation of N-methyl-D-aspartate (NMDA) receptors produces a transient elevation in intracellular calcium concentration, which is increased in normal aging. Disruption in calcium homeostasis predisposes aging neurons to more extended damage after stress and eventually leads to cell death by apoptosis (Cowan et al., 2001; Thibault et al., 2001; Esiri, 2007).

In this scenario, $\mathrm{PrP}^{\mathrm{C}}$ may possess different functions: (i) neuron protection from oxidative stress through antioxidant activity, by sensing copper and/or free radical stimuli (Vassallo and Herms, 2003); (ii) modulation of calcium entry through NMDA receptor pore by inhibition of the channel activity (Cowan et al., 2001; Lo et al., 2007); (iii) anti-apoptotic effect on Bax-mediated cell death (Bounhar et al., 2006; Lo et al., 2007).

\section{WHICH MOUSE AGE SHOULD BE CONSIDERED AS AN AGING MODEL?}

For many reasons, researchers often use terms as aged or old mice that may not be proper by definition. A wild-type mouse goes through the following life phases (http://research.jax.org/faculty/ harrison/ger1vLifespan1.html) (Flurkey et al., 2007):

- Mature adult [3-6 months old (mo) mouse]: this period is the reference for any age change; these mice are fully developed, but not senescent; after 6 months of age mice can show some agerelated changes, for instance females are retired from breeding because litter size begins to diminish.

- Middle age (10-15 mo mouse): senescent changes can be detected in some, but not all, biomarkers of aging; these mice are generally used to determine if an age-related change is progressive or occurs only in old age.

- Old (18-24 mo mouse, or older): senescent changes can be detected in almost all biomarkers in all animals.

Taking into account these categories, few studies claiming the use of old mice indeed employ a properly aged model. For the purposes of this manuscript, this point has to be carefully taken into account, especially in respect of studies on $\operatorname{PrP}^{\mathrm{C}}$ biochemical 
property changes in aging. On the other hand, studies on $\operatorname{PrP}^{\mathrm{C}}$ knockout mice (also noted as $\operatorname{Pr} n p^{0 / 0}$ ), when not performed on old animals, as defined above, can nevertheless reveal progressive age-related changes that start earlier because of $\operatorname{PrP}^{\mathrm{C}}$ absence. To let the reader critically consider reported results and conclusions, we will specify for each reviewed study the age of the animals used.

\section{PrPC ROLE IN AGING}

As previously mentioned, $\mathrm{PrP}^{\mathrm{C}}$ is highly conserved and expressed among mammals, and it may play important physiological roles. However, numerous efforts aimed at identifying $\operatorname{PrP}^{C}$ function have harbored contrasting results. Most of the work has focused on the nervous system, which is the organ with the highest $\mathrm{PrP}^{\mathrm{C}}$ expression and the site of prion disease pathology. Several results have linked $\mathrm{PrP}^{\mathrm{C}}$ to many cellular processes, such as neuronal survival, neurite outgrowth, synapse formation/maintenance/functionality, and myelinated fiber formation/maintenance (Aguzzi et al., 2008). However, its expression in many other tissues indicates that $\mathrm{PrP}^{\mathrm{C}}$ has either many different functions or a function compatible with diverse cellular types.

A large body of evidence suggests that $\mathrm{PrP}^{\mathrm{C}}$ plays a role in essential metal homeostasis, resulting in protection from oxidative stress. An overlap between systems controlling essential metal homeostasis and oxygen radical metabolism has been extensively documented (Avery, 2001). For instance, many antioxidant enzymes need metal ions as cofactors. $\mathrm{PrP}^{\mathrm{C}}$ has been associated with cellular systems that control redox balance and protect against oxidative stress (Brown and Sassoon, 2002). Indeed, $\mathrm{PrP}^{\mathrm{C}}$ null models show: (i) increased neuronal sensitivity to oxidative stress (Brown et al., 1997; Rachidi et al., 2003); (ii) alterations of superoxide dismutase 1 (SOD1) activity due to impairments in copper incorporation (Brown and Besinger, 1998; Kralovicova et al., 2009); (iii) higher levels of lipids and protein oxidation (Wong et al., 2001). Moreover, $\operatorname{PrP}^{\mathrm{C}}$ expression is increased by heat shock, hypoxia, ischemia, hypoglycemia, stroke, and knockdown of any SOD protein while shutting down $\mathrm{PrP}^{\mathrm{C}}$ increases extracellular-SOD expression and SOD2 activity (Brown and Besinger, 1998; Shyu et al., 2000, 2004, 2005; McLennan et al., 2004; Mitsios et al., 2007; Kralovicova et al., 2009). Furthermore, in vitro $\mathrm{PrP}^{\mathrm{C}}$ possesses $\mathrm{SOD}$-like activity with a dismutation constant rate similar to SOD2 (Brown et al., 1999, 2001; Cui et al., 2003; Treiber et al., 2007). A possible link between SOD and $\mathrm{PrP}^{\mathrm{C}}$ may be copper. Indeed, SOD activity depends on copper incorporation and probably involves $\mathrm{Cu}^{2+}$ reduction, characteristics shared with $\operatorname{PrP}^{\mathrm{C}}$ (Brown et al., 2001). It should also be noted that $\mathrm{PrP}^{\mathrm{C}}$ is cleaved at the end of the OR through the action of ROS, a process termed $\beta$-cleavage. $\beta$-cleavage is considered an early and critical event in the mechanism through which $\mathrm{PrP}^{\mathrm{C}}$ protects cells against oxidative stress. If a PrP construct lacks the $\mathrm{OR}$, the protein will fail to undergo ROS-mediated $\beta$-cleavage, as occurs with two mutant forms associated with prion diseases (Watt et al., 2005).

\section{PrPC $^{C}$ ROLE IN BEHAVIOR AND LEARNING AS A FUNCTION OF AGE}

Two main observations suggest that $\mathrm{PrP}^{\mathrm{C}}$ plays a role in behavior and learning mechanisms in aging: (i) $\mathrm{PrP}^{\mathrm{C}}$ is predominantly expressed in neurons, reaching the highest level in the hippocampus (DeArmond et al., 1987; Benvegnu et al., 2010); (ii) $\mathrm{PrP}^{\mathrm{C}}$ brain expression is increased in aging (Williams et al., 2004). However, studies carried out on $\mathrm{PrP}^{\mathrm{C}}$ knockout mice have sometimes produced contrasting results, likely due to differences in lines and age.

The behavioral characterization of the first $\operatorname{PrP}^{\mathrm{C}}$ knockout (ZurichI) mouse generation was performed in 7 mo mice (Bueler et al., 1992). At this age these mice cannot be considered aged. Nevertheless, the latter study represents a good starting point toward analyzing alterations triggered by $\mathrm{PrP}^{\mathrm{C}}$ ablation. In the swim test and in the Y-maze, $\operatorname{PrPC}^{C}$ knockout mice did not reveal learning impairments, although there were large individual differences within test and control groups. In the two-way avoidance test, in which animals have to avoid an electrical shock announced by a light by running to the opposite chamber of the box, thus involving also motorial ability, $\operatorname{PrP}^{\mathrm{C}}$ knockout mice showed a slightly lower performance, but the great variability in each group hid a possible significant difference. As Büeler and colleagues state, these results should be carefully considered because of the dissimilar loci surrounding $\operatorname{Prn} p^{0 / 0}$ and wild-type $\left(\operatorname{Prnp}{ }^{+/+}\right)$ alleles, due to different genetic background.

However, a follow-up study using the same mouse line showed that $\operatorname{Pr} n p^{0 / 0}$ mouse aging-related behavior alterations could not be ascribed to surrounding loci differences, but to $\operatorname{PrP}^{\mathrm{C}}$ ablation itself (Coitinho et al., 2003). Differently from Büeler and colleagues data, here statistically significant results were obtained by applying other behavioral tests and by increasing the animal age: 9 and 3 mo $\operatorname{Prnp}^{0 / 0}$ and $P r n p^{+/+}$mice were compared in regards to fear-motivated learning, locomotor activity, exploratory behavior and anxiety. Nine mo $\mathrm{PrP}^{\mathrm{C}}$ knockout mice showed impairments in short- and long-term memory and exploratory activity. With exception of the exploratory activity, 9 mo $\operatorname{Prn} p^{0 / 0}$ mouse performances were recapitulated in 9 mo rats injected in the hippocampus with anti-PrP $\mathrm{P}^{\mathrm{C}}$ antibody, thus ruling out the involvement of the surrounding loci in memory alterations in the aging $\operatorname{PrP}^{C}$ knockout line.

Another study concerning aging-related $\mathrm{PrP}^{\mathrm{C}}$ role in behavior control was performed on 3 and 11 mo mice from three lines (wild-type, $\operatorname{Prn} p^{0 / 0}$ and $\mathrm{PrP}^{\mathrm{C}}$ overexpressing Tga20 on a $\operatorname{Prn} p^{0 / 0}$ genetic background) (Rial et al., 2009). Collectively the data showed that $\mathrm{PrP}^{\mathrm{C}}$ overexpressing Tga20 mice were less susceptible to aging-caused alterations in locomotion, anxiety like responses and short-term social recognition memory in comparison with $\operatorname{Prnp}^{+/+}$and $P r n p^{0 / 0}$ mice. On the contrary, $\operatorname{PrP}^{\mathrm{C}}$ knockout mice resulted more susceptible to age-related decline in comparison with wild-type mice. Biochemical analyses revealed that Tga20 mice have lower neuron caspase 3 activation and serum acetylcholinesterase levels, and higher synaptic density. In light of these cognition-enhancing properties, Rial and colleagues suggest in particular the interaction of $\operatorname{PrP}^{\mathrm{C}}$ with the stress-inducible protein 1 as a target for pharmaceutical intervention to attenuate age-related cognitive impairments.

More recent results confirmed age-dependent behavioral abnormalities in ZurichI $\operatorname{PrP}^{\mathrm{C}}$ knockout mice (Schmitz et al., 2014). The following alterations were reported: (i) poor native nest building behavior in young ( $3 \mathrm{mo}$ ) and old (9 and $20 \mathrm{mo}$ ) 
$\operatorname{Pr}^{\mathrm{C}}$ knockout mice; (ii) higher latency in exploring a new environment only in young but not in old $\mathrm{PrP}^{\mathrm{C}}$ knockout mice; (iii) more pronounced drop in anxiety during aging in $\mathrm{PrP}^{\mathrm{C}}$ knockout mice; (iv) decline in associative learning in old $\mathrm{PrP}^{\mathrm{C}}$ knockout mice compared to age-matched wild-type. Schmitz and colleagues wanted to relate the observed behavioral abnormalities to neuron structural alterations in $\operatorname{PrP}^{\mathrm{C}}$ knockout mice. They found $\mathrm{PrP}^{\mathrm{C}}$-dependent alterations in cytoskeletal proteins that are responsible for morphology, structure, and stability of neurons, thus related to learning processes. Indeed, $\mathrm{PrP}^{\mathrm{C}}$ was previously reported to functionally interact with cytoskeletal proteins (Dong et al., 2008; Malaga-Trillo et al., 2009).

Telling's group performed a work on a slightly different line, the ZurichI crossed with wild-type FVB animals (Nazor et al., 2007). On the rotarod, $P r n p^{0 / 0}$ on FVB background mice showed an age-dependent motor behavior deficit in comparison to wildtype, suggesting a function for $\operatorname{PrP}^{\mathrm{C}}$ in maintaining sensorimotor coordination. This difference between wild-type and $\mathrm{PrP}^{\mathrm{C}}$ knockout mice was detected starting from 3 to 8 mo. Moreover, these mice at 6 mo revealed vacuolation in different brain regions. Although vacuolation has been rarely reported in $\operatorname{PrP}^{\mathrm{C}}$ knockout mice, Telling and coworkers parallel their findings, concerning both spongiosis and motor impairments, with results from a transgenic murine model expressing the PrP mutation linked to Gerstmann-Sträussler-Scheinker syndrome (GSS), thus suggesting the loss of $\mathrm{PrP}^{\mathrm{C}}$ function as disease mechanism.

Another study was performed by Massimino and colleagues using three groups of congenic mice: wild-type $\mathrm{FVB}, \mathrm{PrP}^{\mathrm{C}}$ knockout on FVB background and $\mathrm{Tg} 46$ mice in which $\mathrm{PrP}^{\mathrm{C}}$ expression was rescued over a $\operatorname{PrP}^{\mathrm{C}}$ knockout background (Massimino et al., 2013). While young ( $3 \mathrm{mo}) \operatorname{PrP}^{\mathrm{C}}$ knockout mice did not show any alteration, aged (15-18 mo) animals revealed perturbed behavioral pattern, in particular difficulties in adapting to new situations and in locomotor activity, likely due to a depressive syndrome. The authors suggest that $\operatorname{PrP}^{\mathrm{C}}$ absence affects emotional reactivity. The authors did not carry out histological analysis of old $\operatorname{Prn} p^{0 / 0}$ mice, therefore, it is not known whether the $\operatorname{PrP}^{\mathrm{C}}$ knockout colony employed showed the vacuolation phenotype observed by Telling's group studying the same mouse line. To our knowledge, the result obtained by Telling's and coworkers is the only one showing vacuolation in $\operatorname{Pr} n p^{0 / 0}$ mice. For instance, Aguzzi and colleagues did not detect any morphological anomaly in 14 mo ZurichI Prnp $p^{0 / 0}$ mice (Bremer et al., 2010).

Taken together, all these studies demonstrate that $\operatorname{PrP}^{\mathrm{C}}$ absence affects learning, cognitive and behavioral skills in aged mice. A possible cause of these alterations is the lack of $\mathrm{PrP}^{\mathrm{C}}$ mediated neuroprotection and reduction of oxidative stress, particularly important to preserve neuron functions in the aging brain milieu.

\section{PrPC ROLE IN MYELIN MAINTENANCE}

Alterations occurring during both normal aging and neurodegenerative pathologies largely involve maintenance and regeneration of myelin structure (Verdu et al., 2000; Peters, 2002; Bartzokis, 2011). Metal ions, in particular copper and iron, are necessary for both myelin formation and maintenance (Skripuletz et al., 2008; Benetti et al., 2010). Therefore, $\operatorname{PrP}^{\mathrm{C}}$ may influence myelin by maintaining copper and iron homeostasis, pathways in which $\mathrm{PrP}^{\mathrm{C}}$ has been involved (Pauly and Harris, 1998; Brown and Harris, 2003; Rachidi et al., 2003; Miura et al., 2005; Singh et al., 2009). By studying 14 mo (middle aged) mice, Aguzzi's group reported that $\mathrm{PrP}^{\mathrm{C}}$ knockout mouse sciatic nerve contains more digestion chambers, i.e., macrophages ingesting myelin debris of degenerating nerve fibers, compared to wild-type mice. Moreover, they showed that $\operatorname{PrP}^{\mathrm{C}}$ expression on neuronal cells, but not on Schwann's cells, is fundamental to preserve myelin fibers and prevent chronic demyelinating polyneuropathy $(\mathrm{CDP})$ in the peripheral nervous system. This finding suggests that neuronal $\operatorname{PrP}^{\mathrm{C}}$ in trans expression is required for a directional communication from axons to Schwann cells (Bremer et al., 2010).

As suggested in a study from our group (Benvegnu et al., 2011), $\operatorname{PrP}^{\mathrm{C}}$ may exert a direct role in myelin sheath formation and structural preservation through its modulation of $\beta$-secretase 1 (BACE1) (Parkin et al., 2007). Results obtained in sciatic nerves from 15 mo mice highlight that $\operatorname{PrP}^{\mathrm{C}}$ influences cleavage and processing of neuregulins. Neuregulins are a class of proteins crucial for myelin maintenance in the peripheral nervous system, and their cleavage by BACE1 is necessary for signaling functions. Hence, $\operatorname{PrP}^{\mathrm{C}}$ positively regulates neuregulin processing, thus affecting their function in myelin homeostasis, maybe by modulating BACE1 activity. Interestingly, in the previously mentioned work, Aguzzi's group showed that CDP is prevented by $\mathrm{PrP}^{\mathrm{C}}$ variants that are permissive for proteolytic amino-proximal cleavage, but not by variants that do not undergo cleavage. Indeed, all transgenic mice showing CDP lacked C1, i.e., the fragment generated by $\alpha$-cleavage, while all transgenic mice in which the CDP was rescued produced high $\mathrm{C} 1$ levels. Hence, the cleavage of $\operatorname{PrP}^{\mathrm{C}}$ seems to be functional for its myelinotrophic role (Bremer et al., 2010).

\section{AGING-RELATED MODIFICATION OF PrPC BIOCHEMICAL PROPERTIES}

The most common occurrence of human prion diseases (about $80 \%)$ is sporadic. This means that a trigger of prion pathologies may be neither a genetic mutation nor an infectious seed, but most likely an unknown alteration that provokes the switch from $\operatorname{PrP}^{\mathrm{C}}$ to $\mathrm{PrP}^{\mathrm{Sc}}$ (Prusiner, 2001). The aging process itself may modify $\operatorname{PrP}^{\mathrm{C}}$ biochemical properties, making the protein more prone to convert into $\mathrm{PrP}^{\mathrm{Sc}}$. For instance, loss of glycosylation in cell models favors $\mathrm{PrP}^{\mathrm{C}}$ acquisition of $\mathrm{Pr}^{\mathrm{Sc}}$-like features (Lehmann and Harris, 1997). Indeed, glycans regulate $\mathrm{PrP}^{\mathrm{C}}$ folding, intracellular trafficking, localization and function on the neuronal surface, thus their pattern modifications can be likely linked to the disease development. $\operatorname{PrP}^{\mathrm{C}}$ biochemical properties that may be altered by cellular changes occurring during the aging process are: expression levels, post-translational modifications, such as glycosylation and phosphorylation, as well as localization in cellular domains, such as inside/outside membrane lipid rafts.

As mentioned in a previous paragraph, analysis of both parenchyma and microvessels revealed higher levels of both glycosylated and unglycosylated $\operatorname{PrP}^{\mathrm{C}}$ in $\mathrm{C} 57 \mathrm{Bl} / 6 \mathrm{~J}$ old (18 and $24 \mathrm{mo}$ ) mice (Williams et al., 2004). Concerning $\operatorname{PrP}^{\mathrm{C}}$ diverse glycosylation isoforms, the three main bands appearing 
in one-dimensional immunoblots are commonly considered corresponding to di-glycosylated $(\sim 35 \mathrm{KDa})$, mono-glycosylated $(\sim 32 \mathrm{KDa})$ and un-glycosylated ( 28 KDa) (Collinge, 2001; Pan et al., 2002). However, by applying a panel of monoclonal antibodies, the presence of additional lower molecular weight bands representing $\mathrm{N}$-terminally truncated $\operatorname{PrP}^{\mathrm{C}}$ isoforms has been shown (Pan et al., 2002). Moreover, two-dimensional immunoblot analysis revealed in human brain more than 50 $\mathrm{PrP}^{\mathrm{C}}$ species which derive from several glycosylation and cleavage combinations. Interestingly, accumulation of aberrant full-length $\mathrm{PrP}^{\mathrm{C}}$ bound to immature N-linked glycans is indeed a common feature of prion disease (Pan et al., 2005a,b,c). Spurred by these findings, Goh and coworkers investigated N-linked glycans on $\mathrm{PrP}^{\mathrm{C}}$ during normal aging in mouse, providing the first glycan profile of full-length and truncated $\mathrm{PrP}^{\mathrm{C}}$ isoforms (Goh et al., 2007). The oldest mice they used were $15 \mathrm{mo}$. First, they found that different mouse lines (i.e., CD-1 and FVB) have different $\mathrm{PrP}^{\mathrm{C}}$ metabolism resulting in isoform heterogeneity. In general, they showed that the truncated form of $\mathrm{PrP}^{\mathrm{C}}$ undergoes a simplification in its glycosylation process during aging, while the amount of complex oligosaccharides on the full-length $\mathrm{PrP}^{\mathrm{C}}$ increases. This finding contrasts with what was observed in aging compared to young cattle (Yoshioka et al., 2010), but resembles what was previously detected in human brains affected by prion disorders (Pan et al., 2005b). It has been shown that $\operatorname{PrP}^{\mathrm{C}}$ glycosylation state may modulate affinity for copper binding (Moudjou et al., 2007). In particular, the nonglycosylated species showed stronger binding to divalent cations (copper and cobalt) in vitro. Therefore, decreasing $\operatorname{PrP}^{\mathrm{C}}$ glycosylation levels during aging may increase copper binding capacity, thus improving $\operatorname{PrP}^{\mathrm{C}}$ antioxidant function. Interestingly, galactose, which has been detected in this study on full-length $\operatorname{PrP}^{\mathrm{C}}$ in aging, is also highly present on $\operatorname{PrP}^{\mathrm{Sc}}$ (Safar et al., 1990). Moreover, sialic acid content increases with aging on the truncated $\operatorname{PrP}^{\mathrm{C}}$ but remains unchanged on the full-length $\operatorname{PrP}^{\mathrm{C}}$. As the authors observe, the presence of anionic residues may modulate $\mathrm{PrP}^{\mathrm{Sc}}$ mobility, thus facilitating its propagation in prion disorders.

As previously mentioned, aging can modify $\mathrm{PrP}^{\mathrm{C}}$ subcellular localization. Indeed, our group reported that $\mathrm{PrP}^{\mathrm{C}}$ moves from detergent soluble membrane fractions to lipid rafts in aged (20-21 mo) mouse hippocampus (Agostini et al., 2013). No differences in the total $\operatorname{PrP}^{\mathrm{C}}$ expression amount were detected, in contrast with what had been previously reported by another group that used the same mouse line and a very similar age but lacked repeated samples, normalization and statistical analysis (Williams et al., 2004). Changes in the cholesterol/sphingolipid ratio has been reported in normal brain aging, and in degenerative disorders, such as $\mathrm{AD}$ (Martin et al., 2010). As cholesterol and sphingolipids are the two main components of lipid rafts, their relative amount influences many cellular pathways, including protein localization (Martin et al., 2008; Trovo et al., 2011). $\operatorname{PrP}^{\mathrm{C}}$ is a GPI-anchored protein, thus bound to lipid rafts and likely affected by agingrelated alterations in membrane composition. $\mathrm{PrP}^{\mathrm{C}}$ shift toward lipid rafts triggered by changes in lipid composition was confirmed using model systems of lipid manipulation. Moreover, decreasing sphingolipids, thus mimicking a juvenile condition, reduced the formation of $\mathrm{PrP}^{\mathrm{Sc}}$ in a cell line model. This suggests that age-related changes influence $\operatorname{PrP}^{\mathrm{C}}$ localization and ensuing propensity to $\mathrm{PrP}^{\mathrm{Sc}}$ conversion (Agostini et al., 2013).

\section{PrPC AND AD}

The most prevalent form of dementia is AD (Burns and Iliffe, 2009). Various factors are conducive to the risk of late-onset AD, in particular old age, genetic factors, family history, a history of head trauma, midlife hypertension, obesity, diabetes, and hypercholesterolemia (Bendlin et al., 2010). AD is characterized by the misprocessing of two proteins: intraneuronal tau and extracellu$\operatorname{lar} \beta$-amyloid peptide (A $\beta$ ) (Querfurth and LaFerla, 2010). A $\beta$ is generated by the aberrant proteolytic processing of the amyloid precursor protein by BACE1. Several studies have been performed to understand if a toxic interaction between $A \beta$ and $\operatorname{PrP}$ exists, but the use of different in vitro or transgenic models has yielded contrasting results (Schwarze-Eicker et al., 2005; Lauren et al., 2009; Balducci et al., 2010; Calella et al., 2010; Chung et al., 2010; Kessels et al., 2010; Morales et al., 2010; Ordonez-Gutierrez et al., 2013). Thus, in this manuscript, we will consider only what has been found by analyzing $\mathrm{AD}$ patient brains. Whitehouse and colleagues found that $\operatorname{PrP}^{\mathrm{C}}$ levels are decreased in $\mathrm{AD}$ patient hippocampus, normal aging hippocampus, and temporal lobe, but not in AD patient temporal lobe (Whitehouse et al., 2010). With exception of $\mathrm{AD}$ patient temporal lobe data, these results are in contrast with what was reported by Saijo et al. (2011), but correlate with the $\mathrm{PrP}^{\mathrm{C}}$ decrease detected in the cerebrospinal fluid of patients affected by different neurological disorders including AD (Meyne et al., 2009). Since $\operatorname{PrP}^{\mathrm{C}}$ inhibits BACE1 (Parkin et al., 2007), $\operatorname{PrP}^{C}$ level reduction may elevate $A \beta$ production. Therefore, Whitehouse and colleagues suggest that $\operatorname{PrP}^{\mathrm{C}}$ decrease is not a secondary consequence, but a primary cause of $\mathrm{AD}$ and, by occurring also in normal aging, increases the incidence of $\mathrm{AD}$ in old individuals. Interestingly, individuals with mutations in the PrP encoding gene generating a truncated form of the protein developed clinical AD symptoms at relatively young age (Kitamoto et al., 1993). In aging, BACE1 activity strongly increases, thus enhancing $A \beta$ production and the possibility of deposit formation. The reduction of $\mathrm{PrP}^{\mathrm{C}}$-mediated BACE1 inhibition due to the decrease in $\operatorname{PrP}^{\mathrm{C}}$ levels may be a cause of the enzyme activity elevation (Whitehouse et al., 2010). Additionally, since $\mathrm{PrP}^{\mathrm{C}}$ is an antioxidant protein (Vassallo and Herms, 2003; Aguzzi et al., 2008), its downregulation likely increases neuron susceptibility to ROS, which rises in normal aging and in $\mathrm{AD}$ (Halliwell, 2006; Zhu et al., 2007), hence contributing to disease progression. However, a decrease in $\operatorname{PrP}^{\mathrm{C}}$ levels in $\mathrm{AD}$ does not exclude that the residual protein mediates some $A \beta$ toxic effects. Besides, it has been recently reported that $\mathrm{A} \beta$ and $\operatorname{PrP}^{\mathrm{C}}$ do interact specifically in AD patient brains (Dohler et al., 2014). This result was obtained by means of a $\operatorname{PrP}^{\mathrm{C}}-\mathrm{A} \beta$ binding assay and size exclusion chromatography, and no binding was detected in non-demented age-matched controls.

Taken together, these results indicate that $\mathrm{PrP}^{\mathrm{C}}$ may be involved in AD. Therefore, its fate in aging is likely related to the molecular mechanisms that induce neurodegeneration. 


\section{CONCLUSIONS}

As presented in this review, relatively few studies have been carried out on the role of aging in the expression and regulation of $\mathrm{PrP}^{\mathrm{C}}$. Nevertheless, these experiments suggest that there may be a correlation between the physiology of the cells in which $\mathrm{PrP}^{\mathrm{C}}$ is present and its localization and processing during aging. Particularly in the CNS, where it is abundantly expressed, $\mathrm{PrP}^{\mathrm{C}}$ plays a prominent role as the precursor of $\mathrm{PrP}^{\mathrm{Sc}}$ and thereby dictates the amount and extension of the conversion and accumulation process of prions. In aging, the physiology and the cellular localization of the protein may change concomitantly to different biochemical milieus in the cell membrane. Indeed, either membrane composition, in particular lipid raft composition, or additional protein complexes proximity to $\mathrm{PrP}^{\mathrm{C}}$, may influence its physiological functions. As indicated in the final paragraph, these changes may have a general relevance for more common causes of dementia such as AD. More work is necessary to define the precise role of $\mathrm{PrP}^{\mathrm{C}}$ in the progression of $\mathrm{AD}$ and perhaps in other neurodegenerative diseases.

\section{ACKNOWLEDGMENT}

The authors would like to thank Kate Pischke and Erica Sarnataro for editing and proofreading the manuscript.

\section{REFERENCES}

Agostini, F., Dotti, C. G., Perez-Canamas, A., Ledesma, M. D., Benetti, F., and Legname, G. (2013). Prion protein accumulation in lipid rafts of mouse aging brain. PLoS ONE 8:e74244. doi: 10.1371/journal.pone.0074244

Aguzzi, A., Baumann, F., and Bremer, J. (2008). The prion's elusive reason for being. Annu. Rev. Neurosci. 31, 439-477. doi: 10.1146/annurev.neuro.31.0604 07.125620

Arena, G., La Mendola, D., Pappalard, G., Sóvágód, I., and Rizzarelli, E. (2012). Interactions of $\mathrm{Cu} 2+$ with prion family peptide fragments: considerations on affinity, speciation and coordination. Coord. Chem. Rev. 256, 2202-2218. doi: 10.1016/j.ccr.2012.03.038

Avery, S. V. (2001). Metal toxicity in yeasts and the role of oxidative stress. Adv. Appl. Microbiol. 49, 111-142. doi: 10.1016/S0065-2164(01)49011-3

Balducci, C., Beeg, M., Stravalaci, M., Bastone, A., Sclip, A., Biasini, E., et al. (2010). Synthetic amyloid-beta oligomers impair long-term memory independently of cellular prion protein. Proc. Natl. Acad. Sci. U.S.A. 107, 2295-2300. doi: 10.1073/pnas.0911829107

Bartzokis, G. (2011). Alzheimer's disease as homeostatic responses to age-related myelin breakdown. Neurobiol. Aging 32, 1341-1371. doi: 10.1016/j.neurobiolaging.2009.08.007

Bendlin, B. B., Carlsson, C. M., Gleason, C. E., Johnson, S. C., Sodhi, A., Gallagher, C. L., et al. (2010). Midlife predictors of Alzheimer's disease. Maturitas 65, 131-137. doi: 10.1016/j.maturitas.2009.12.014

Benetti, F., Ventura, M., Salmini, B., Ceola, S., Carbonera, D., Mammi, S., et al. (2010). Cuprizone neurotoxicity, copper deficiency and neurodegeneration. Neurotoxicology 31, 509-517. doi: 10.1016/j.neuro.2010.05.008

Benvegnu, S., Gasperini, L., and Legname, G. (2011). Aged PrP null mice show defective processing of neuregulins in the peripheral nervous system. Mol. Cell. Neurosci. 47, 28-35. doi: 10.1016/j.mcn.2011.02.005

Benvegnu, S., Poggiolini, I., and Legname, G. (2010). Neurodevelopmental expression and localization of the cellular prion protein in the central nervous system of the mouse. J. Comp. Neurol. 518, 1879-1891. doi: 10.1002/cne.22357

Bounhar, Y., Mann, K. K., Roucou, X., and LeBlanc, A. C. (2006). Prion protein prevents Bax-mediated cell death in the absence of other Bcl-2 family members in Saccharomyces cerevisiae. FEMS Yeast Res. 6, 1204-1212. doi: 10.1111/j.15671364.2006.00122.x

Bowen, R. L., and Atwood, C. S. (2004). Living and dying for sex. A theory of aging based on the modulation of cell cycle signaling by reproductive hormones. Gerontology 50, 265-290. doi: 10.1159/000079125
Bremer, J., Baumann, F., Tiberi, C., Wessig, C., Fischer, H., Schwarz, P., et al. (2010). Axonal prion protein is required for peripheral myelin maintenance. Nat. Neurosci. 13, 310-318. doi: 10.1038/nn.2483

Brody, H. (1955). Organization of the cerebral cortex. III. A study of aging in the human cerebral cortex. J. Comp. Neurol. 102, 511-516. doi: 10.1002/cne.901020206

Brown, D. R., and Besinger, A. (1998). Prion protein expression and superoxide dismutase activity. Biochem. J. 334(Pt 2), 423-429.

Brown, D. R., Clive, C., and Haswell, S. J. (2001). Antioxidant activity related to copper binding of native prion protein. J. Neurochem. 76, 69-76. doi: 10.1046/j.1471-4159.2001.00009.x

Brown, D. R., and Sassoon, J. (2002). Copper-dependent functions for the prion protein. Mol. Biotechnol. 22, 165-178. doi: 10.1385/MB:22:2:165

Brown, D. R., Schulz-Schaeffer, W. J., Schmidt, B., and Kretzschmar, H. A. (1997). Prion protein-deficient cells show altered response to oxidative stress due to decreased SOD-1 activity. Exp. Neurol. 146, 104-112. doi: 10.1006/exnr.1997.6505

Brown, D. R., Wong, B. S., Hafiz, F., Clive, C., Haswell, S. J., and Jones, I. M. (1999) Normal prion protein has an activity like that of superoxide dismutase. Biochem. J. 344(Pt 1), 1-5. doi: 10.1042/0264-6021:3440001

Brown, L. R., and Harris, D. A. (2003). Copper and zinc cause delivery of the prion protein from the plasma membrane to a subset of early endosomes and the Golgi. J. Neurochem. 87, 353-363. doi: 10.1046/j.1471-4159.2003.01996.x

Bueler, H., Fischer, M., Lang, Y., Bluethmann, H., Lipp, H. P., DeArmond, S. J. et al. (1992). Normal development and behaviour of mice lacking the neuronal cell-surface PrP protein. Nature 356, 577-582. doi: 10.1038/356577a0

Burke, S. N., and Barnes, C. A. (2006). Neural plasticity in the ageing brain. Nat. Rev. Neurosci. 7, 30-40. doi: 10.1038/nrn1809

Burns, A., and Iliffe, S. (2009). Alzheimer's disease. BMJ 338, b158. doi: 10.1136/bmj.b158

Calella, A. M., Farinelli, M., Nuvolone, M., Mirante, O., Moos, R., Falsig, J., et al. (2010). Prion protein and Abeta-related synaptic toxicity impairment. EMBO Mol. Med. 2, 306-314. doi: 10.1002/emmm.201000082

Chattopadhyay, M., Walter, E. D., Newell, D. J., Jackson, P. J., Aronoff-Spencer, E., Peisach, J., et al. (2005). The octarepeat domain of the prion protein binds $\mathrm{Cu}$ (II) with three distinct coordination modes at pH 7.4. J. Am. Chem. Soc. 127, 12647-12656. doi: 10.1021/ja053254z

Chung, E., Ji, Y., Sun, Y., Kascsak, R. J., Kascsak, R. B., Mehta, P. D., et al. (2010). Anti-PrPC monoclonal antibody infusion as a novel treatment for cognitive deficits in an Alzheimer's disease model mouse. BMC Neurosci. 11:130. doi: 10.1186/1471-2202-11-130

Coitinho, A. S., Roesler, R., Martins, V. R., Brentani, R. R., and Izquierdo, I. (2003). Cellular prion protein ablation impairs behavior as a function of age. Neuroreport 14, 1375-1379. doi: 10.1097/01.wnr.0000078541.07662.90

Collinge, J. (2001). Prion diseases of humans and animals: their causes and molecular basis. Annu. Rev. Neurosci. 24, 519-550. doi: 10.1146/annurev.neuro. 24.1.519

Cowan, C. M., Thai, J., Krajewski, S., Reed, J. C., Nicholson, D. W., Kaufmann, S. H., et al. (2001). Caspases 3 and 9 send a pro-apoptotic signal from synapse to cell body in olfactory receptor neurons. J. Neurosci. 21, 7099-7109.

Cui, T., Daniels, M., Wong, B. S., Li, R., Sy, M. S., Sassoon, J., et al. (2003). Mapping the functional domain of the prion protein. Eur. J. Biochem. 270, 3368-3376. doi: 10.1046/j.1432-1033.2003.03717.x

DeArmond, S. J., Mobley, W. C., DeMott, D. L., Barry, R. A., Beckstead, J. H., and Prusiner, S. B. (1987). Changes in the localization of brain prion proteins during scrapie infection. Neurology 37, 1271-1280. doi: 10.1212/WNL.37.8.1271

Dohler, F., Sepulveda-Falla, D., Krasemann, S., Altmeppen, H., Schluter, H., Hildebrand, D., et al. (2014). High molecular mass assemblies of amyloid-beta oligomers bind prion protein in patients with Alzheimer's disease. Brain 137(Pt 3), 873-886. doi: 10.1093/brain/awt375

Dong, C. F., Shi, S., Wang, X. F., An, R., Li, P., Chen, J. M., et al. (2008). The Nterminus of $\operatorname{PrP}$ is responsible for interacting with tubulin and fCJD related PrP mutants possess stronger inhibitive effect on microtubule assembly in vitro. Arch. Biochem. Biophys. 470, 83-92. doi: 10.1016/j.abb.2007.11.007

Esiri, M. M. (2007). Ageing and the brain. J. Pathol. 211, 181-187. doi: 10.1002/path.2089

Flurkey, K., Currer, J. M., and Harrison, D. E. (2007). "The mouse in aging research," in The Mouse in Biomedical Research, Vol. 3, ed J. G. Fox (Burlington, MA: Elsevier), 637-672. 
Fournier, J. G., Escaig-Haye, F., Billette de Villemeur, T., Robain, O., Lasmezas, C. I., Deslys, J. P., et al. (1998). Distribution and submicroscopic immunogold localization of cellular prion protein $(\mathrm{PrPc})$ in extracerebral tissues. Cell Tissue Res. 292, 77-84. doi: 10.1007/s004410051036

Goh, A. X., Li, C., Sy, M. S., and Wong, B. S. (2007). Altered prion protein glycosylation in the aging mouse brain. J. Neurochem. 100, 841-854. doi: 10.1111/j.1471-4159.2006.04268.x

Goldmann, W., O’Neill, G., Cheung, F., Charleson, F., Ford, P., and Hunter, N. (1999). $\operatorname{PrP}$ (prion) gene expression in sheep may be modulated by alternative polyadenylation of its messenger RNA. J. Gen. Virol. 80(Pt 8), 2275-2283.

Halliwell, B. (2006). Oxidative stress and neurodegeneration: where are we now? J. Neurochem. 97, 1634-1658. doi: 10.1111/j.1471-4159.2006.03907.x

Haraguchi, T., Fisher, S., Olofsson, S., Endo, T., Groth, D., Tarentino, A., et al. (1989). Asparagine-linked glycosylation of the scrapie and cellular prion proteins. Arch. Biochem. Biophys. 274, 1-13. doi: 10.1016/0003-9861(89)90409-8

Hedden, T., and Gabrieli, J. D. (2004). Insights into the ageing mind: a view from cognitive neuroscience. Nat. Rev. Neurosci. 5, 87-96. doi: 10.1038/nrn1323

Horiuchi, M., Yamazaki, N., Ikeda, T., Ishiguro, N., and Shinagawa, M. (1995). A cellular form of prion protein (PrPC) exists in many non-neuronal tissues of sheep. J. Gen. Virol. 76(Pt 10), 2583-2587. doi: 10.1099/0022-1317-76-10-2583

Hornshaw, M. P., McDermott, J. R., and Candy, J. M. (1995). Copper binding to the N-terminal tandem repeat regions of mammalian and avian prion protein. Biochem. Biophys. Res. Commun. 207, 621-629. doi: 10.1006/bbrc.1995.1233

Jackson, G. S., Murray, I., Hosszu, L. L., Gibbs, N., Waltho, J. P., Clarke, A. R., et al. (2001). Location and properties of metal-binding sites on the human prion protein. Proc. Natl. Acad. Sci. U.S.A. 98, 8531-8535. doi: 10.1073/pnas.151038498

Kellett, K. A., and Hooper, N. M. (2009). Prion protein and Alzheimer disease. Prion 3, 190-194. doi: 10.4161/pri.3.4.9980

Kessels, H. W., Nguyen, L. N., Nabavi, S., and Malinow, R. (2010). The prion protein as a receptor for amyloid-beta. Nature 466, E3-E4. discussion: E-5. doi: 10.1038 /nature09217

Kitamoto, T., Iizuka, R., and Tateishi, J. (1993). An amber mutation of prion protein in Gerstmann-Straussler syndrome with mutant PrP plaques. Biochem. Biophys. Res. Commun. 192, 525-531. doi: 10.1006/bbrc.1993.1447

Kralovicova, S., Fontaine, S. N., Alderton, A., Alderman, J., Ragnarsdottir, K. V., Collins, S. J., et al. (2009). The effects of prion protein expression on metal metabolism. Mol. Cell. Neurosci. 41, 135-147. doi: 10.1016/j.mcn.2009.02.002

Lasmezas, C. I., Deslys, J. P., Robain, O., Jaegly, A., Beringue, V., Peyrin, J. M., et al. (1997). Transmission of the BSE agent to mice in the absence of detectable abnormal prion protein. Science 275, 402-405. doi: 10.1126/science.275.5298.402

Lauren, J., Gimbel, D. A., Nygaard, H. B., Gilbert, J. W., and Strittmatter, S. M. (2009). Cellular prion protein mediates impairment of synaptic plasticity by amyloid-beta oligomers. Nature 457, 1128-1132. doi: 10.1038/nature 07761

Lehmann, S., and Harris, D. A. (1997). Blockade of glycosylation promotes acquisition of scrapie-like properties by the prion protein in cultured cells. J. Biol. Chem. 272, 21479-21487. doi: 10.1074/jbc.272.34.21479

Liu, L., Jiang, D., McDonald, A., Hao, Y., Millhauser, G. L., and Zhou, F. (2011). Copper redox cycling in the prion protein depends critically on binding mode. J. Am. Chem. Soc. 133, 12229-12237. doi: 10.1021/ja2045259

Lo, R. Y., Shyu, W. C., Lin, S. Z., Wang, H. J., Chen, S. S., and Li, H. (2007). New molecular insights into cellular survival and stress responses: neuroprotective role of cellular prion protein (PrPC). Mol. Neurobiol. 35, 236-244. doi: 10.1007/s12035-007-8003-y

Malaga-Trillo, E., Solis, G. P., Schrock, Y., Geiss, C., Luncz, L., Thomanetz, V., et al. (2009). Regulation of embryonic cell adhesion by the prion protein. PLoS Biol. 7:e55. doi: 10.1371/journal.pbio. 1000055

Martin, M., Dotti, C. G., and Ledesma, M. D. (2010). Brain cholesterol in normal and pathological aging. Biochim. Biophys. Acta 1801, 934-944. doi: 10.1016/j.bbalip.2010.03.011

Martin, M. G., Perga, S., Trovo, L., Rasola, A., Holm, P., Rantamaki, T., et al. (2008). Cholesterol loss enhances TrkB signaling in hippocampal neurons aging in vitro. Mol. Biol. Cell 19, 2101-2112. doi: 10.1091/mbc.E07-09-0897

Massimino, M. L., Redaelli, M., Bertoli, A., Sorgato, M. C., and Mucignat-Caretta, C. (2013). Altered behavioral aspects of aged mice lacking the cellular prion protein. Physiol. Behav. 119, 86-91. doi: 10.1016/j.physbeh.2013.06.006

McLennan, N. F., Brennan, P. M., McNeill, A., Davies, I., Fotheringham, A., Rennison, K. A., et al. (2004). Prion protein accumulation and neuroprotection in hypoxic brain damage. Am. J. Pathol. 165, 227-235. doi: 10.1016/S00029440(10)63291-9

Meyne, F., Gloeckner, S. F., Ciesielczyk, B., Heinemann, U., Krasnianski, A., Meissner, B., et al. (2009). Total prion protein levels in the cerebrospinal fluid are reduced in patients with various neurological disorders. J. Alzheimers. Dis. 17, 863-873. doi: 10.3233/JAD-2009-1110

Mitsios, N., Saka, M., Krupinski, J., Pennucci, R., Sanfeliu, C., Miguel Turu, M., et al. (2007). Cellular prion protein is increased in the plasma and periinfarcted brain tissue after acute stroke. J. Neurosci. Res. 85, 602-611. doi: 10.1002/jnr.21142

Miura, T., Sasaki, S., Toyama, A., and Takeuchi, H. (2005). Copper reduction by the octapeptide repeat region of prion protein: $\mathrm{pH}$ dependence and implications in cellular copper uptake. Biochemistry 44, 8712-8720. doi: 10.1021/bi0501784

Morales, R., Estrada, L. D., Diaz-Espinoza, R., Morales-Scheihing, D., Jara, M. C., Castilla, J., et al. (2010). Molecular cross talk between misfolded proteins in animal models of Alzheimer's and prion diseases. J. Neurosci. 30, 4528-4535. doi: 10.1523/JNEUROSCI.5924-09.2010

Moudjou, M., Bernard, J., Sabuncu, E., Langevin, C., and Laude, H. (2007). Glycan chains modulate prion protein binding to immobilized metal ions. Neurochem. Int. 50, 689-695. doi: 10.1016/j.neuint.2007.01.001

Moudjou, M., Frobert, Y., Grassi, J., and La Bonnardière, C. (2001). Cellular prion protein status in sheep: tissue-specific biochemical signatures. J. Gen. Virol. 82(Pt 8), 2017-2024. doi: 10.1099/vir.0.17776-0

Nazor, K. E., Seward, T., and Telling, G. C. (2007). Motor behavioral and neuropathological deficits in mice deficient for normal prion protein expression. Biochim. Biophys. Acta 1772, 645-653. doi: 10.1016/j.bbadis.2007.04.004

Ordonez-Gutierrez, L., Torres, J. M., Gavin, R., Anton, M., Arroba-Espinosa, A. I., Espinosa, J. C., et al. (2013). Cellular prion protein modulates beta-amyloid deposition in aged APP/PS1 transgenic mice. Neurobiol. Aging 34, 2793-2804. doi: 10.1016/j.neurobiolaging.2013.05.019

Pan, T., Li, R., Kang, S. C., Pastore, M., Wong, B. S., Ironside, J., et al. (2005a). Biochemical fingerprints of prion diseases: scrapie prion protein in human prion diseases that share prion genotype and type. J. Neurochem. 92, 132-142. doi: 10.1111/j.1471-4159.2004.02859.x

Pan, T., Li, R., Wong, B. S., Kang, S. C., Ironside, J., and Sy, M. S. (2005b). Novel antibody-lectin enzyme-linked immunosorbent assay that distinguishes prion proteins in sporadic and variant cases of Creutzfeldt-Jakob disease. J. Clin. Microbiol. 43, 1118-1126. doi: 10.1128/JCM.43.3.1118-1126.2005

Pan, T., Li, R., Wong, B. S., Liu, T., Gambetti, P., and Sy, M. S. (2002). Heterogeneity of normal prion protein in two- dimensional immunoblot: presence of various glycosylated and truncated forms. J. Neurochem. 81, 1092-1101. doi: 10.1046/j.1471-4159.2002.00909.x

Pan, T., Wong, P., Chang, B., Li, C., Li, R., Kang, S. C., et al. (2005c). Biochemical fingerprints of prion infection: accumulations of aberrant full-length and $\mathrm{N}$ terminally truncated $\mathrm{PrP}$ species are common features in mouse prion disease. J. Virol. 79, 934-943. doi: 10.1128/JVI.79.2.934-943.2005

Parkin, E. T., Watt, N. T., Hussain, I., Eckman, E. A., Eckman, C. B., Manson, J. C., et al. (2007). Cellular prion protein regulates beta-secretase cleavage of the Alzheimer's amyloid precursor protein. Proc. Natl. Acad. Sci. U.S.A. 104, 11062-11067. doi: 10.1073/pnas.0609621104

Pauly, P. C., and Harris, D. A. (1998). Copper stimulates endocytosis of the prion protein. J. Biol. Chem. 273, 33107-33110. doi: 10.1074/jbc.273.50.33107

Peralta, O. A., Huckle, W. R., and Eyestone, W. H. (2012). Developmental expression of the cellular prion protein $(\operatorname{PrP}(\mathrm{C}))$ in bovine embryos. Mol. Reprod. Dev. 79, 488-498. doi: 10.1002/mrd.22057

Peters, A. (2002). The effects of normal aging on myelin and nerve fibers: a review. J. Neurocytol. 31, 581-593. doi: 10.1023/A:1025731309829

Prusiner, S. B. (1991). Molecular biology and transgenetics of prion diseases. Crit. Rev. Biochem. Mol. Biol. 26, 397-438. doi: 10.3109/10409239109086789

Prusiner, S. B. (1994). Biology and genetics of prion diseases. Annu. Rev. Microbiol. 48, 655-686. doi: 10.1146/annurev.mi.48.100194.003255

Prusiner, S. B. (2001). Shattuck lecture-neurodegenerative diseases and prions. N. Engl. J. Med. 344, 1516-1526. doi: 10.1056/NEJM200105173442006

Querfurth, H. W., and LaFerla, F. M. (2010). Alzheimer's disease. N. Engl. J. Med. 362, 329-344. doi: 10.1056/NEJMra0909142

Rachidi, W., Vilette, D., Guiraud, P., Arlotto, M., Riondel, J., Laude, H., et al. (2003). Expression of prion protein increases cellular copper binding and antioxidant enzyme activities but not copper delivery. J. Biol. Chem. 278, 9064-9072. doi: 10.1074/jbc.M211830200 
Rial, D., Duarte, F. S., Xikota, J. C., Schmitz, A. E., Dafre, A. L., Figueiredo, C. P., et al. (2009). Cellular prion protein modulates age-related behavioral and neurochemical alterations in mice. Neuroscience 164, 896-907. doi: 10.1016/j.neuroscience.2009.09.005

Roucou, X., and LeBlanc, A. C. (2005). Cellular prion protein neuroprotective function: implications in prion diseases. J. Mol. Med. (Berl.) 83, 3-11. doi: 10.1007/s00109-004-0605-5

Safar, J., Wang, W., Padgett, M. P., Ceroni, M., Piccardo, P., Zopf, D., et al. (1990). Molecular mass, biochemical composition, and physicochemical behavior of the infectious form of the scrapie precursor protein monomer. Proc. Natl. Acad. Sci. U.S.A. 87, 6373-6377. doi: 10.1073/pnas.87.16.6373

Saijo, E., Scheff, S. W., and Telling, G. C. (2011). Unaltered prion protein expression in Alzheimer disease patients. Prion 5, 109-116. doi: 10.4161/pri.5.2.16355

Sales, N., Hassig, R., Rodolfo, K., Di Giamberardino, L., Traiffort, E., Ruat, M., et al. (2002). Developmental expression of the cellular prion protein in elongating axons. Eur. J. Neurosci. 15, 1163-1177. doi: 10.1046/j.1460-9568.2002.01953.x

Scheibel, A. B. (1979). Dendritic changes in senile and presenile dementias. Res. Publ. Assoc. Res. Nerv. Ment. Dis. 57, 107-124.

Scheibel, M. E., Lindsay, R. D., Tomiyasu, U., and Scheibel, A. B. (1976). Progressive dendritic changes in the aging human limbic system. Exp. Neurol. 53, 420-430. doi: 10.1016/0014-4886(76)90082-0

Schmitz, M., Greis, C., Ottis, P., Silva, C. J., Schulz-Schaeffer, W. J., Wrede, A., et al. (2014). Loss of prion protein leads to age-dependent behavioral abnormalities and changes in cytoskeletal protein expression. Mol. Neurobiol. doi: 10.1007/s12035-014-8655-3. [Epub ahead of print].

Schwarze-Eicker, K., Keyvani, K., Gortz, N., Westaway, D., Sachser, N., and Paulus, W. (2005). Prion protein $(\mathrm{PrPc})$ promotes beta-amyloid plaque formation. Neurobiol. Aging 26, 1177-1182. doi: 10.1016/j.neurobiolaging.2004.10.004

Shyu, W. C., Chen, C. P., Saeki, K., Kubosaki, A., Matusmoto, Y., Onodera, T., et al. (2005). Hypoglycemia enhances the expression of prion protein and heat-shock protein 70 in a mouse neuroblastoma cell line. J. Neurosci. Res. 80, 887-894. doi: 10.1002/jnr.20509

Shyu, W. C., Kao, M. C., Chou, W. Y., Hsu, Y. D., and Soong, B. W. (2000). Heat shock modulates prion protein expression in human NT-2 cells. Neuroreport 11 , 771-774. doi: 10.1097/00001756-200003200-00023

Shyu, W. C., Lin, S. Z., Saeki, K., Kubosaki, A., Matsumoto, Y., Onodera, T., et al. (2004). Hyperbaric oxygen enhances the expression of prion protein and heat shock protein 70 in a mouse neuroblastoma cell line. Cell. Mol. Neurobiol. 24, 257-268. doi: 10.1023/B:CEMN.0000018620.41913.d2

Singh, A., Kong, Q., Luo, X., Petersen, R. B., Meyerson, H., and Singh, N. (2009) Prion protein (PrP) knock-out mice show altered iron metabolism: a functional role for PrP in iron uptake and transport. PLOS ONE 4:e6115. doi: 10.1371/journal.pone.0006115

Singh, N., Das, D., Singh, A., and Mohan, M. L. (2010). Prion protein and metal interaction: physiological and pathological implications. Curr. Issues Mol. Biol. 12, 99-107.

Skripuletz, T., Lindner, M., Kotsiari, A., Garde, N., Fokuhl, J., Linsmeier, F., et al. (2008). Cortical demyelination is prominent in the murine cuprizone model and is strain-dependent. Am. J. Pathol. 172, 1053-1061. doi: 10.2353/ajpath.2008.070850

Stahl, N., Baldwin, M. A., Burlingame, A. L., and Prusiner, S. B. (1990) Identification of glycoinositol phospholipid linked and truncated forms of the scrapie prion protein. Biochemistry 29, 8879-8884. doi: 10.1021/bi00490a001

Stockel, J., Safar, J., Wallace, A. C., Cohen, F. E., and Prusiner, S. B. (1998). Prion protein selectively binds copper(II) ions. Biochemistry 37, 7185-7193. doi: 10.1021/bi972827k
Thibault, O., Hadley, R., and Landfield, P. W. (2001). Elevated postsynaptic [Ca2+]i and L-type calcium channel activity in aged hippocampal neurons: relationship to impaired synaptic plasticity. J. Neurosci. 21, 9744-9756.

Treiber, C., Pipkorn, R., Weise, C., Holland, G., and Multhaup, G. (2007). Copper is required for prion protein-associated superoxide dismutase-I activity in Pichia pastoris. FEBS J. 274, 1304-1311. doi: 10.1111/j.1742-4658.2007.05678.x

Trovo, L., Van Veldhoven, P. P., Martin, M. G., and Dotti, C. G. (2011). Sphingomyelin upregulation in mature neurons contributes to TrkB activity by Rac1 endocytosis. J. Cell Sci. 124(Pt 8), 1308-1315. doi: 10.1242/jcs.078766

Vassallo, N., and Herms, J. (2003). Cellular prion protein function in copper homeostasis and redox signalling at the synapse. J. Neurochem. 86, 538-544. doi: 10.1046/j.1471-4159.2003.01882.x

Verdu, E., Ceballos, D., Vilches, J. J., and Navarro, X. (2000). Influence of aging on peripheral nerve function and regeneration. J. Peripher. Nerv. Syst. 5, 191-208. doi: 10.1046/j.1529-8027.2000.00026.x

Watt, N. T., Taylor, D. R., Gillott, A., Thomas, D. A., Perera, W. S., and Hooper, N. M. (2005). Reactive oxygen species-mediated beta-cleavage of the prion protein in the cellular response to oxidative stress. J. Biol. Chem. 280, 35914-35921. doi: 10.1074/jbc.M507327200

Whitehouse, I. J., Jackson, C., Turner, A. J., and Hooper, N. M. (2010). Prion protein is reduced in aging and in sporadic but not in familial Alzheimer's disease. J. Alzheimers. Dis. 22, 1023-1031. doi: 10.3233/JAD-2010-101071

Williams, W. M., Stadtman, E. R., and Moskovitz, J. (2004). Ageing and exposure to oxidative stress in vivo differentially affect cellular levels of PrP in mouse cerebral microvessels and brain parenchyma. Neuropathol. Appl. Neurobiol. 30, 161-168. doi: 10.1111/j.1365-2990.2003.00523.x

Wong, B. S., Liu, T., Li, R., Pan, T., Petersen, R. B., Smith, M. A., et al. (2001). Increased levels of oxidative stress markers detected in the brains of mice devoid of prion protein. J. Neurochem. 76, 565-572. doi: 10.1046/j.14714159.2001.00028.x

Yoshioka, Y., Ishiguro, N., and Inoshima, Y. (2010). Proteasome activity and biological properties of normal prion protein: a comparison between young and aged cattle. J. Vet. Med. Sci. 72, 1583-1587. doi: 10.1292/jvms.10-0149

Zahn, R., Liu, A., Luhrs, T., Riek, R., von Schroetter, C., Lopez Garcia, F., et al. (2000). NMR solution structure of the human prion protein. Proc. Natl. Acad. Sci. U.S.A. 97, 145-150. doi: 10.1073/pnas.97.1.145

Zhu, X., Su, B., Wang, X., Smith, M. A., and Perry, G. (2007). Causes of oxidative stress in Alzheimer disease. Cell. Mol. Life Sci. 64, 2202-2210. doi: 10.1007/s00018-007-7218-4

Conflict of Interest Statement: The authors declare that the research was conducted in the absence of any commercial or financial relationships that could be construed as a potential conflict of interest.

Received: 30 June 2014; paper pending published: 18 July 2014; accepted: 09 August 2014; published online: 29 August 2014.

Citation: Gasperini L and Legname G (2014) Prion protein and aging. Front. Cell Dev. Biol. 2:44. doi: 10.3389/fcell.2014.00044

This article was submitted to Cell Death and Survival, a section of the journal Frontiers in Cell and Developmental Biology.

Copyright (c) 2014 Gasperini and Legname. This is an open-access article distributed under the terms of the Creative Commons Attribution License (CC BY). The use, distribution or reproduction in other forums is permitted, provided the original author(s) or licensor are credited and that the original publication in this journal is cited, in accordance with accepted academic practice. No use, distribution or reproduction is permitted which does not comply with these terms. 


\section{Biochemical insight into the prion protein family}

\section{Danica Ciric and Human Rezaei *}

Virologie et Immunologie Moléculaires, Institut National de la Recherche Agronomique, Jouy-en-Josas, France

\section{Edited by:}

Jean-Luc Vilotte, National Institute of Agronomical Research, France

\section{Reviewed by:}

Franca Fraternali, King's College London, UK

Jose A. Del Rio, Institute for

Bioengineering of Catalonia, Spain

*Correspondence:

Human Rezaei, Institut National de la Recherche Agronomique, Bat.

Biotechnologies, Domaine de

Vilvert, 78350 Jouy-en-Josas, France

e-mail: human.rezaei@jouy.inra.fr
Prion protein family comprises proteins, which share not only similarity in their primary structure, but also similarity in their fold. These two groups of similarity presume a parceling in their respective biological function through the common biochemical properties. In this review, biochemical and structural similarities of PrP and two other proteins, Doppel and Shadoo, are evocated. Some evidence demonstrating respectively similarity between PrP N-terminal and C-terminal domain with respectively Shadoo and Doppel is presented. We extended primary structure similarity analysis to the other PrP subdomain as 166-176 polyNO domain and compare it to proteins using aggregation as a support for structural information transference and structural epigenetic. Finally, we questioned if prion protein family have conserved the PrP structural bistability, which should be at the origin of Prion phenomenon and if Prion pathology is not, ultimately, an exaptation of the physiological propensity of PrP to undergo a structural switch and polymerize.

Keywords: shadoo, doppel, PrP, prion protein, amyloid, evolution, dynamic systems

\section{PRNP AND ITS PARALOGS}

When prion gene was firstly identified it was named "sine," to indicate scrapie incubation period of the ME7 scrapie agent in mice (Dickinson et al., 1968), later it was shown that this gene corresponds to the murine prion gene, and is linked to the Prn-i gene, which determines incubation time in experimental scrapie (Oesch et al., 1985; Carlson et al., 1986). Human PRN gene locus contains three genes: PRNP, PRND, and a novel gene PRNT (Makrinou et al., 2002). Cellular prion protein $\left(\mathrm{PrP}^{\mathrm{C}}\right)$ is encoded by PRNP gene as a single copy. This last has been mapped on the mouse chromosome 2, and on chromosome 20 in the human, where it was mapped to band 20p12-3pte (Sparkes et al., 1986). Human and hamster PRNP consists of two exons, with open reading frame (ORF) located in exon 2. In contrast PRNP of mouse, sheep, and rat contain three exons, with the entire ORF located in exon 3 (Lee et al., 1998).

First prion-related gene, Doppel (Dpl) or "downstream prion protein-like gene," was discovered during sequencing of cosmid clones, isolated from a Prnp ${ }^{\mathrm{b} / \mathrm{b}}$ mouse (I/LnJ-4), due to the effort for characterization of the locus around PRNP (Moore et al., 1999). The gene encoding Dpl labeled PRND is located at the same locus with the PRNP gene. The PRND is a single copy gene and is located on the chromosome 2 in mouse $16 \mathrm{~kb}$ downstream from PRNP, and at chromosome 20 in human $27 \mathrm{~kb}$ downstream, and $52 \mathrm{~kb}$ downstream in ovine (Moore et al., 1999). PRND consists of two exons in human, or 4 and 5 exons in mouse depending on the different splicing. The two major transcripts are encoded by the part of exon 3 and exon 4 (Flicek et al., 2014). Current genomic evidence indicates that $\mathrm{Dpl}$ was present in the last common ancestor of tetrapods, but was lost in birds since there divergence from reptiles (Harrison et al., 2010). The third member of PRN locus, PRNT gene, was discovered $3 \mathrm{~kb}$ downstream from PRND. Even if these three gens are evolutionary related they show low primary structure homology which could suggest distinct biological function.

A new gene outside of PRN locus was discovered by Premzl in 2003 during an exploration for potential homolog of PrP in the in the NCBI non-redundant protein database. The gene coding for Shadoo protein was labeled SPRN and is located at the chromosome 7 in the mouse it has two exons, but the second exon has ORF. Unique transcript of $3374 \mathrm{bps}$ is translated in to the protein product of 147 residues in mouse (Watts and Westaway, 2007). In the Enseml database 16 ortholog sequences of mouse SPRN gene was published in four classes of Vertebtates from bony fishes (Osteichthyes), reptiles (Reptilia), birds (Aves), and mammals (Mammalia) (Flicek et al., 2014).

Comparison of predicted amino acid sequences of Sho orthologs showed highly conserved signal peptide responsible for exportation and one Arg-rich repetitive region containing up to six tetra-repeats of consensus XXRG. Moreover, Sho has a hydrophobic region of 20 residues, with strong homology to $\operatorname{PrP}$ 106-126 poly Ala segment. Sho's C-terminal domain contains a conserved NXT glycosylation motif and signal peptide predicated for glycophosphotidylinositol (GPI)-anchor attachment (Premzl et al., 2003).

\section{THE EVOLUTIONARY ORIGIN OF PRION GENES}

Bioinformatics analyses of PRN loci revealed the evolutionary descent of prion genes from an ancestral ZIP metal ion transporter (Ehsani et al., 2011). During the emergence of metazoa, a cysteine-flanked core domain was inserted, or de novo arose, in a pre-existing ZIP ancestor gene to generate a prion-like ectodomain in a sub-branch of ZIP genes. Approximately a halfbillion years later, a genomic insertion of a spliced transcript coding for such a prion-like ZIP ectodomain may have created the prion founder gene (Ehsani et al., 2011). Premzl and colleges were 
annotated the prion gene family (PrP-GF) in 42 complete eukaryotic genome assemblies, uncovering new genes and pseudo genes. According to this evidence it is likely that the Dpl gene was present in the last common ancestor of Tetrapoda, but it was lost in the bird lineage, since its divergence from reptiles. It has been suggested that PRNP and SPRN have evolved from the same ancestral gene into genes that may still share some functions, but may also have also gained new biological roles (Premzl et al., 2004). SPRN gene in mammals and fishes has conserved their genomic position. It is located close to the proximal adjacent gene, encoding a GTP-binding protein (GTP). This gene has tail-to-tail orientation relative to SPRN and it is conserved from fishes to mammals. The other most proximal gene encodes an amine oxidase (AO), is conserved between Fugu (Arothron sp.) and mammals, and it has also tail-to-tail orientation with SPRN. The block of three genes, with its conserved gene order (AO-GTP-SPRN) and orientation is an example of conserved contiguity between fishes and mammals, strongly indicates gene orthology. The genes distal to SPRN are not conserved between mouse and human indicating a chromosome rearrangement in either the mouse or human genome (Premzl et al., 2003). The proteins coded by PRNP and his two paralogs PRND and SPRN are grouped in the prion protein family (Prion, Dpl, and Shadoo protein respectively). In contrast, protein product of PRNT gene does not share any distinctive homology with any of proteins of PrP-GF excluding any functional relation (Harrison et al., 2010).

\section{THE PrP PROTEIN}

When PrP coding sequences were compared in 26 mammalian species it was found that part of sequence for glycosylation sites, positions of cysteines responsible for formation of disulfide bridge, and sequence for putative hydrophobic transmembrane region (Zhang et al., 1997) are perfectly conserved (Van Rheede et al., 2003). Human PrP precursor protein consists of 253 amino acids. It is processed in the ER and Golgi complex during the transport to the cell surface. In the ER its N-terminal signal sequence of 22 residues is cleaved, as well as 23 residues from C-terminal part, after addition of glycosyl phosphatidylinositol (GPI) anchor (Yusa et al., 2012). PrP is properly folded before transporting to the Golgi complex, where it can be differently glycosylated at N181 and N197 position. In cell surface, $\mathrm{PrP}^{\mathrm{C}}$ can exist in unglycosylated, monoglycosylated, and diglycosylated form (Meyer et al., 1986). Mature $\mathrm{PrP}^{\mathrm{C}}$ consists of 208 residues (human numbering). It is cell surface glycoprotein, attached to the membrane thought GPI anchor (Figure 1). The $\mathrm{N}$-terminal domain of PrP consists of positively charged amino acid sequences and an octapeptide repeat sequence, which can bind copper ions. Middle region between residues 106-126 constitute conserved hydrophobic domain (HD) rich with alanine and valine. This last segment has been reported to be involved in several regulatory processes (Rezaei-Ghaleh et al., 2011; Béland and Roucou, 2012) and have been reported to be able to span membrane (James et al., 1997).

Tertiary structure of PrP globular domain has been resolved by NMR in 1996 (Riek et al., 1996) (Figure 2A). Since this first 3D structure, PrP tertiary structure of several other mammalian species have been resolved (Lysek et al., 2005). All of them, revealed similar and highly conserved fold. Moreover, the comparison between extractive $\mathrm{PrP}^{\mathrm{C}}$, purified from bovine brain, and bovine recPrP, produced in E.coli, revealed similar fold, meaning

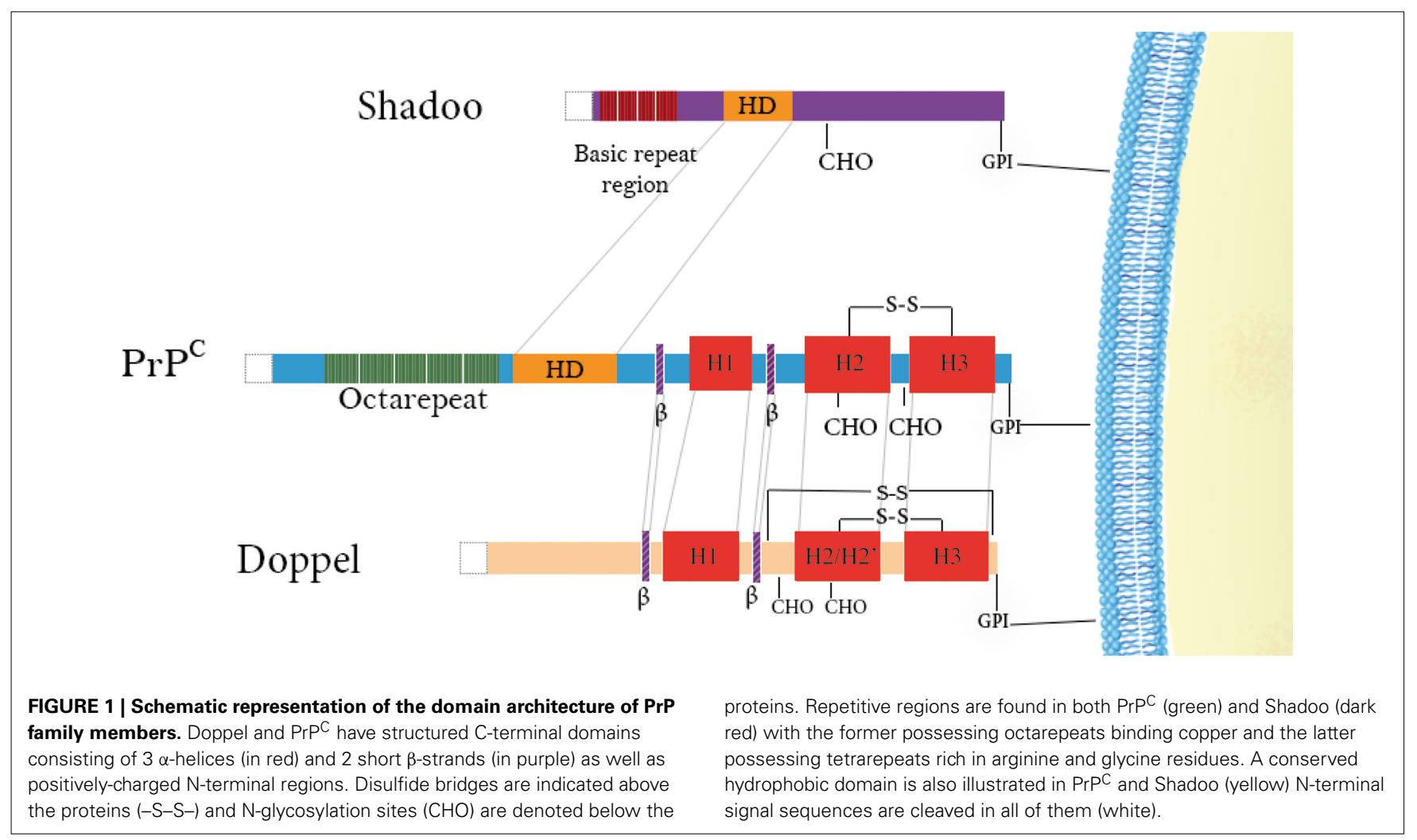


that glycosylation and GPI anchor did not affect general PrP fold (Hornemann et al., 2004). The PrP 3D structure reveals a globular domain, which contains three $\alpha$-helices comprising the residues 144-154 (H1), 173-194 (H2), and 200-228 (H3) and a short anti-parallel $\beta$-sheet comprising the residues 128-131 ( $\beta 1)$ and 161-164 $(\beta 2)$. Within the globular domain there is three loops, between residues $167-171$, at the end of $\mathrm{H} 2$ residues $187-$ 194, and in the C-terminal part of $\mathrm{H} 3$ residues 219-228. $\operatorname{PrP}$ have a disulfide bridge between $\mathrm{H} 2$ and $\mathrm{H} 3$ helixes. The reduction of this S-S bond in vitro has been reported to be at origin of structural switch and formation of amyloid fibrils (Jackson et al., 1999). Moreover, it was demonstrated that the H2H3 segment constitutes an independent folding unit (Adrover et al., 2010; Xu et al., 2011) (Figure 2B).

\section{DOPPEL PROTEIN}

PRND gene coding Dpl a 179 residues protein, sharing 25\% identity with PrP globular domain. As PrP, Dpl has a cell surface exportation amino acids signal sequence at its $\mathrm{N}$-terminus (1-27 residues) and GPI anchoring signal (from 156 to 179), at its Cterminal domain. Dpl is processed in the ER and Golgi as PrP and has two glycosylation sites, one at the 111 residues in the form $\mathrm{N}-\mathrm{X}-\mathrm{T}$ occurring and second non-conserved N-V-T Asn-linked glycosylation site at residue 99 (Figure 3A). The GPI anchor is predict to be attached at Gly155. The Dpl, as PrP, is attached to outer cell surface trough GPI anchored (Silverman et al., 2000). Despite the fact that both $\mathrm{Dpl}$ and $\mathrm{PrP}^{\mathrm{C}}$ are attached to the rafts, it was reported that they are attached to distinct microenvironments and not in the same raft domains. This observation

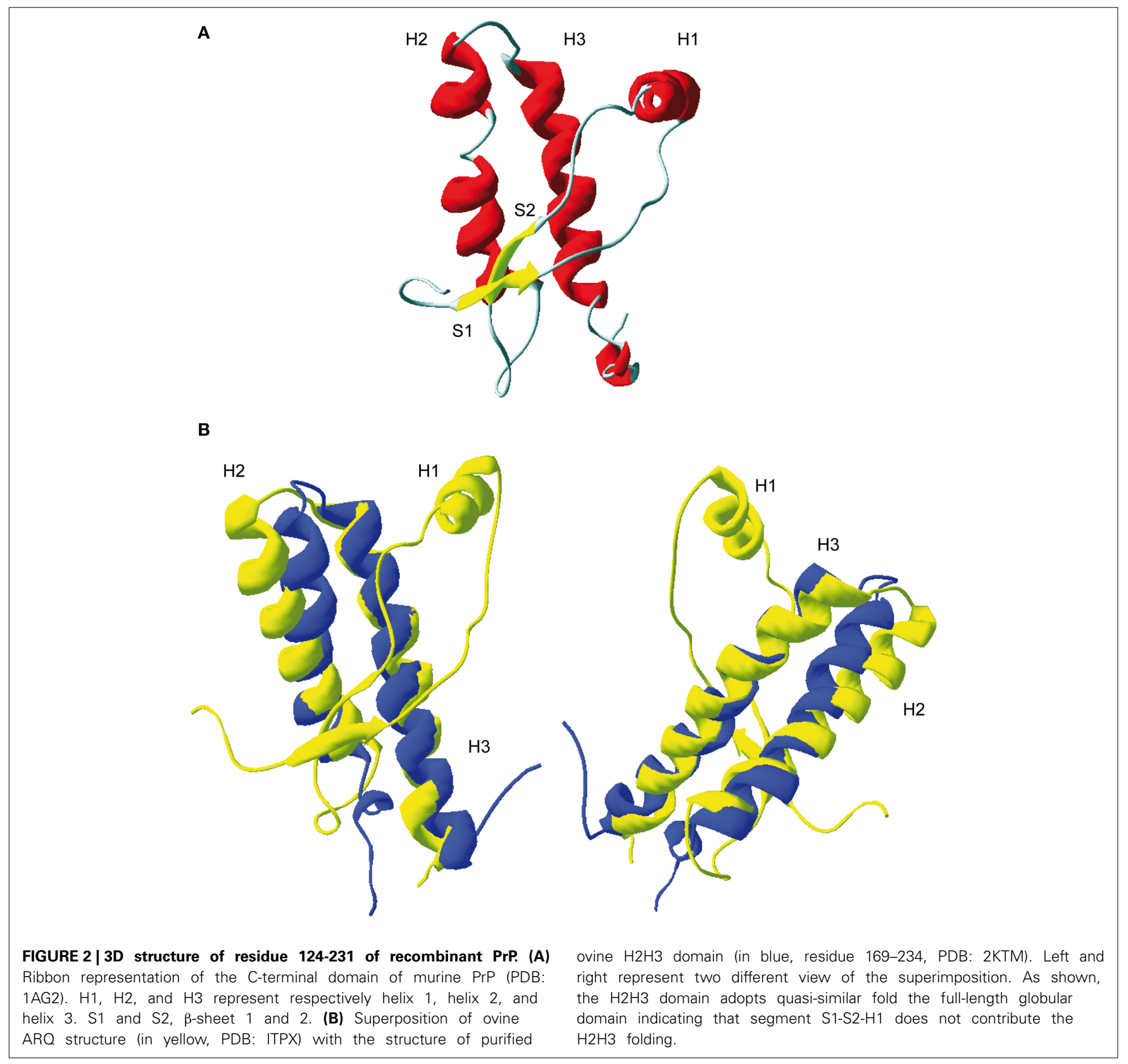




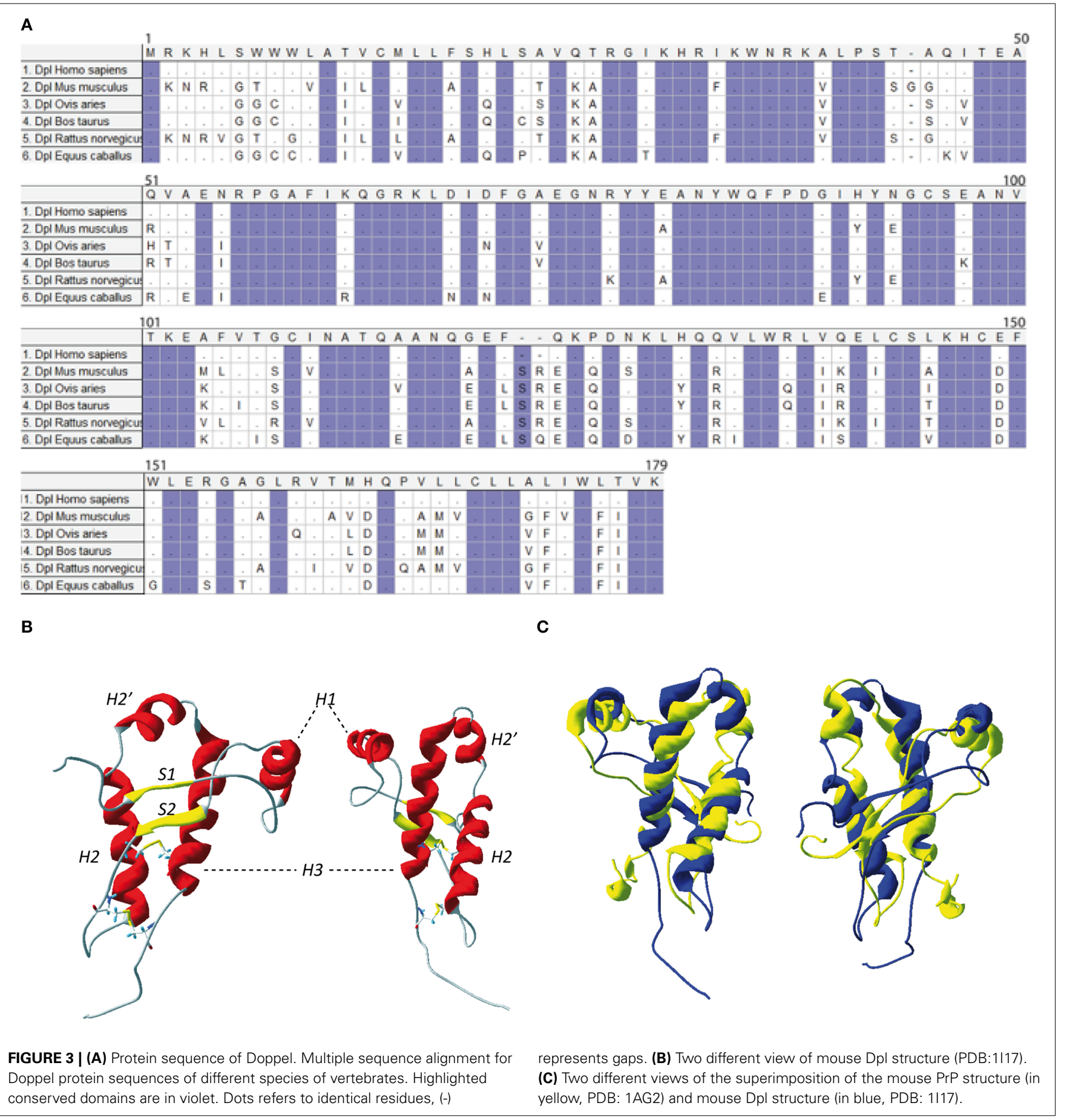

makes the authors to propose that even though PrP and Dpl share some identities they might have distinct functions (Shaked et al., 2002).

NMR structure of the recombinant human Dpl protein shows a short flexibly disordered $\mathrm{N}$-terminal domain comprising residues 24-51, and a globular domain extending from residues 52-149 (Figure 3B). The globular domain contains four $\alpha$-helices comprising residues 72-80 ( $\alpha 1), 101-115(\alpha 2 \mathrm{a})$, $117-121(\alpha 2 b)$, and $127-141(\alpha 3)$, and a short two-stranded

anti-parallel $\beta$-sheet comprising residues 58-60 ( $\beta 1)$ and 8890 ( $\beta 2$ ). The C-terminal peptide segment 144-149 folds back onto the loop connecting $\beta 2$ and $\alpha 2$ (Lührs et al., 2003). Dpl has two disulfide bonds (Cys95-Cys148 and Cys109-Cys143), in contrast to the $\operatorname{PrP}$ who has one. This additional disulfide bound could contribute to restriction of Dpl conformational dynamics, making it more rigid. Even if the $\operatorname{PrP}$ and Dpl present less than $25 \%$ of homology, their folds are similar (Figure 3C). 


\section{SHADOO PROTEIN}

Nascent protein product encoded by SPRN ORF is subjected to the similar type of processing events as the other members of PrP family. The mature mouse Sho consists of 98 amino acids it is a GPI-anchored protein (Premzl et al., 2003; Watts et al., 2007). Sho also has functional ER targeting signal sequence, and it can be modified with complex glycans and targeted to the outer leaflet of the plasma membrane (Miesbauer et al., 2006). Nterminal segment, from residues $25-42$ has very strictly conserved sequence (Figure 4A), with conserved methylation site at Arg27 (GGRGG). In human Sho the RGG repeats are consist of 15 residues: Arg residues are positively charged at physiological $\mathrm{pH}$ and 7 Gly residues, 6 of them grouped as dipeptides "GG" giving a high degree of flexibility to the backbone. The increased prevalence of Gly-Gly dipeptides, in the higher Eutherian mammals, could suggest evolutionary pressure for increased flexibility in this domain. In addition, proteins with an RGG-box motif can have RNA-binding function (Thandapani et al., 2013). It

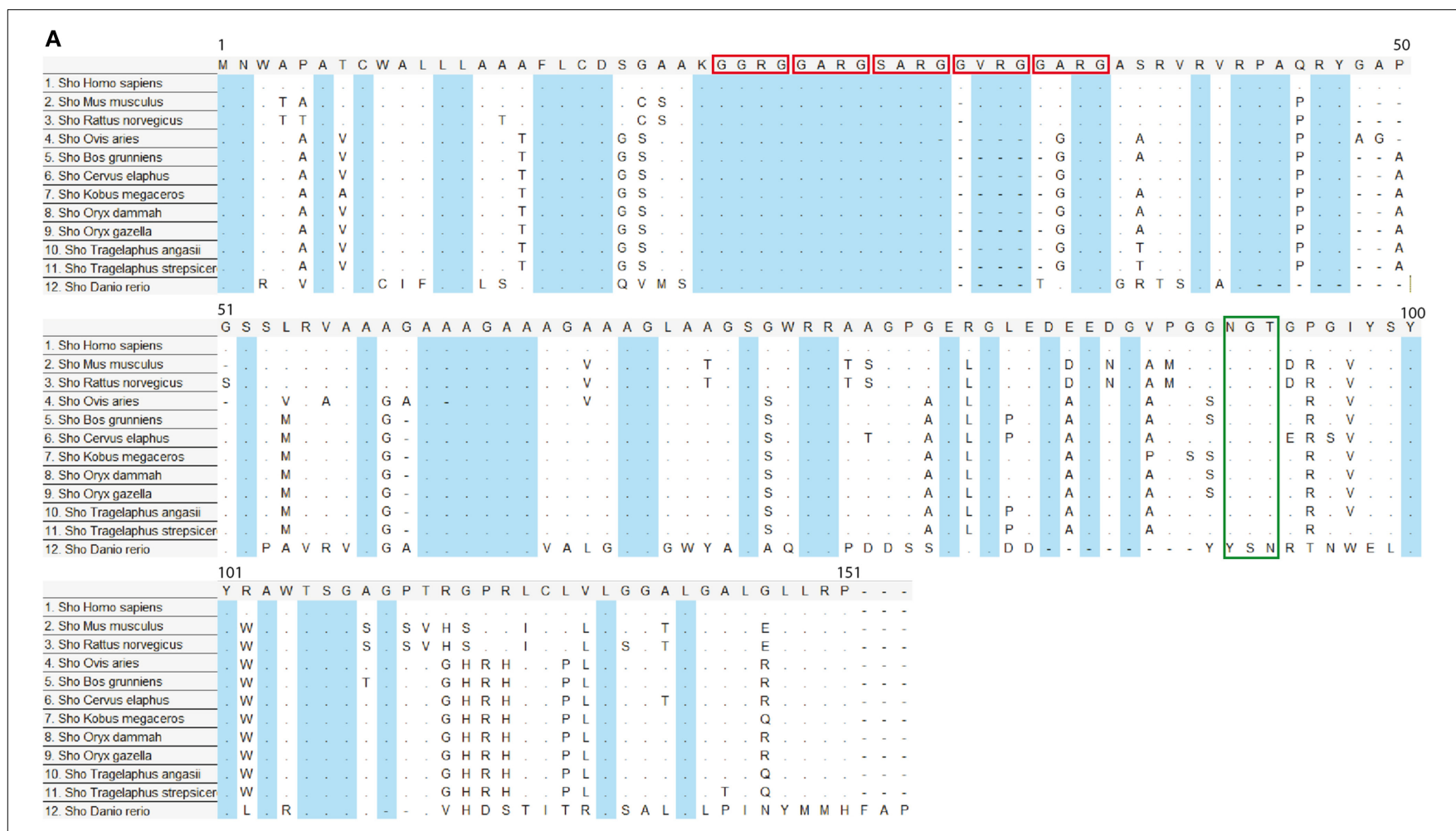

B

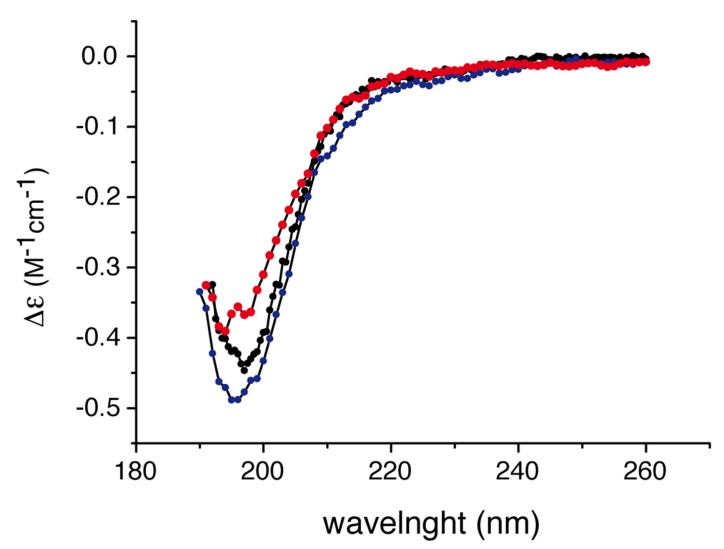

FIGURE 4 | (A) Conservation of Sho protein sequences. Alignment of Shadoo protein sequences in 12 species. Multiple alignments of protein referent sequences for Shadoo in vertebrates. In blue color are highlighted conserved domains. Red squares indicate the consensus XXRG repletion. The green box indicates the NXT N-glycosylation signal.
The alignment was obtained and color coded by MEGA5 software, dots refers to identical residues, (-) represents gaps, according to MEGA5 convention. (B) Circular dichroism (CD) spectra of Sho at $\mathrm{pH} 3.8,4.5$, and 7.0. $\mathrm{CD}$ spectra indicate that Sho adopts a random coil configuration for $3.8 \leq \mathrm{pH} \leq 7.0$. 
is suggested that Sho could bind mRNA directly (Corley and Gready, 2008) and thus play a role in neural plasticity as PrP, through his involvement in neural signaling pathways (Kanaani et al., 2005; Santuccione et al., 2005). HD in the middle of the protein is arranged in five tandem repeats (Figure 4), which consist of GxxxG motifs. These motifs can have a role in organization of transmembrane helixes and packaging of amyloidal fibers (Russ and Engelman, 2000). HD has a high degree of homology with PrP 106-126 domain. The primary structure analysis of Human Sho reveals the existence of a one putative N-glycosilation site (N111). Moreover, the different predication algorithms highly suggest that Sho could be devoid of secondary structure. The CD spectra of recombinant mouse Sho at different $\mathrm{pH}$ strongly suggest that Sho adopts a random coil structuration (Figure 4B). These observations strongly suggest that Sho belong to intrinsically disordered proteins (IDP) family.

\section{STRUCTURAL DYNAMIC OF PRION PROTEIN FAMILY}

In early 90th when conventional descriptions of prion pathology failed to describe prion disease, a new theory considering an infectious protein emerged (Griffith, 1967; Prusiner et al., 1982; Prusiner, 1998). The prion theory, now largely extended, stipulate an autonomous structural rearrangement of $\mathrm{PrP}^{\mathrm{C}}$ into $\mathrm{PrP}^{\mathrm{Sc}}$ conformer. The prion theory explicitly requires that PrP protein should exist, at least, in two conformations. However, the existence of several strains, for a given $\operatorname{PrP}$ primary structure, points out that PrP could exist not only in two conformations, but as plethora of conformations, each associated with a physiopathological state. The fact that $\operatorname{PrP}$ could adopt different conformations, in the quasi-similar environments, makes $\mathrm{PrP}$ a multi-stable protein, a hallmark of its plasticity. Therefore, one can question why PrP protein, in particular, kept all along the evolution such structural plasticity? The primary structure analysis of prion protein family, could highlight this point. Indeed, divergence of PRNP, PRND, and SPRN conduce to specific differences in $\mathrm{PrP}, \mathrm{Dpl}$, and Sho proteins. The existence of additional disulfide bridge in Dpl (Figure 3) highly reduces his plasticity, and therefore reduces Dpl's propensity to adopt several conformations. In terms of PrP-GF evolution, one can consider that additional disulfide bond has been selected to reduce Dpl conformational dynamic and hence, it's self-propensity to undergo a deleterious structural switch. A similar rational could be constructed for Sho. This last protein, during the selection process have discarded segments reported to be involved in the conformational switch of PrP, as it is the case of PrP globular part.

Another aspect of PRNP gene evolution, in relation with $\mathrm{PrP}$ structural landscape, should be also evocated. Compared to Sho and Dpl, the primary structure of PrP is highly conserved among the mammals (Figure 5). This high conservation could be either a hallmark of its folding, linked to its biological function, or linked to the fact that the amount of mutations and variation in the primary structure of PrP could lead to the appearance of deleterious

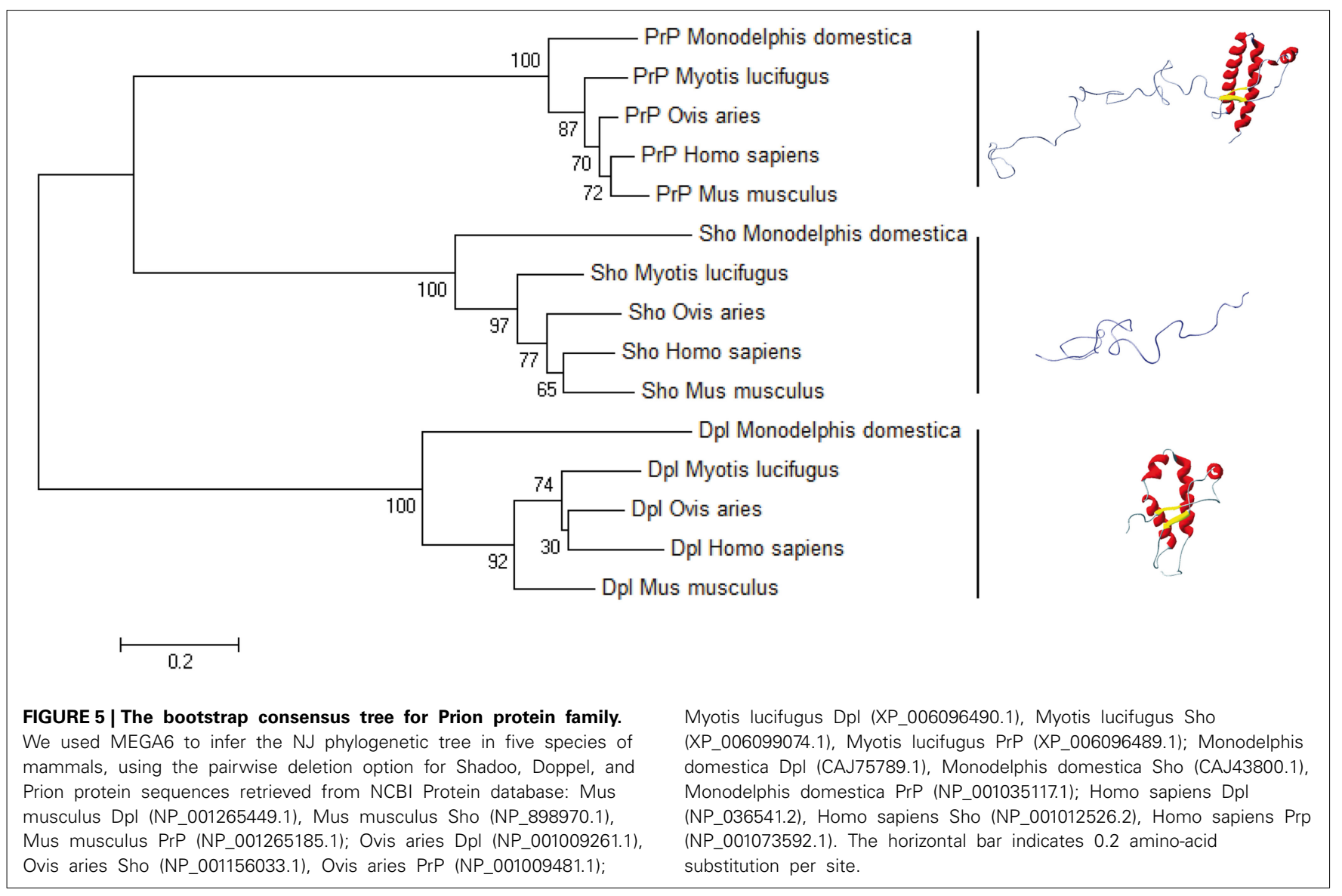


events, as it is the spontaneous conversion. This last phenomenon could be at the origin of PrP mutations responsible of the occurrence of GSS, FFI, and genetic CJD. To better understand this low variability of $\operatorname{PrP}$ primary structure we have to consider $\operatorname{PrP}$ primary structure in relation with its putative biological function. PrP protein could be segmented into two domains, the $\mathrm{N}$-terminal domain, highly flexible, binding $\mathrm{Cu}^{2+}$ ions and the globular domain. So far, most of the PrP biological functions are reported to involve only N-terminal segment. Contribution of the globular domain in the PrP physiological function is not well understood (Béland and Roucou, 2012). The question may arise: why during the mammalian evolution, the propensity of the PrP globular domain to misfold, has not been suppressed, if $\operatorname{PrP}$ biological function is only restricted to the N-terminal domain? The answer to this question could be an entanglement between PrP folding and biological function. Indeed, if we consider that PrP biological function is intertwined with its structural bistability in a highly controlled process, evolution should manage with both PrP bistability and the homeostasis of this bistability. One of direct consequences of this hypothesis is that highly controlled PrP conversion could have a physiological role, and that prion pathology could emerge as a breakdown of homeostasis of PrP physiological conversion process, induced by appearance $\operatorname{PrP}^{\mathrm{Sc}}$.

\section{REFERENCES}

Adrover, M., Pauwels, K., Prigent, S., de Chiara, C., Xu, Z., Chapuis, C., et al. (2010). Prion fibrillization is mediated by a native structural element that comprises helices $\mathrm{H} 2$ and H3. J. Biol. Chem. 285, 21004-21012. doi: 10.1074/jbc.M110.111815

Béland, M., and Roucou, X. (2012). The prion protein unstructured N-terminal region is a broad-spectrum molecular sensor with diverse and contrasting potential functions. J. Neurochem. 120, 853-868. doi: $10.1111 / \mathrm{j} .1471$ 4159.2011.07613.x

Carlson, G. A., Kingsbury, D. T., Goodman, P. A., Coleman, S., Marshall, S. T., DeArmond, S., et al. (1986). Linkage of prion protein and scrapie incubation time genes. Cell 46, 503-511. doi: 10.1016/0092-8674(86)90875-5

Corley, S. M., and Gready, J. E. (2008). Identification of the RGG box motif in Shadoo: RNA-binding and signaling roles? Bioinform. Biol. Insights 2, 383-400.

Dickinson, A. G., Meikle, V. M. H., and Fraser, H. (1968). Identification of a gene which controls the incubation period of some strains of scrapie agent in mice. J. Comp. Pathol. 78, 293-299. doi: 10.1016/0021-9975(68)90005-4

Ehsani, S., Tao, R., Pocanschi, C. L., Ren, H., Harrison, P. M., and Schmitt-Ulms, G. (2011). Evidence for retrogene origins of the prion gene family. PLoS ONE 6:e26800. doi: 10.1371/journal.pone.0026800

Flicek, P., Amode, M. R., Barrell, D., Beal, K., Billis, K., Brent, S., et al. (2014). Ensembl 2014. Nucleic Acids Res. 42, D749-D755. doi: 10.1093/nar/ gkt1196

Griffith, J. S. (1967). Self-replication and scrapie. Nature 215, 1043-1044. doi: 10.1038/2151043a0

Harrison, P. M., Khachane, A., and Kumar, M. (2010). Genomic assessment of the evolution of the prion protein gene family in vertebrates. Genomics 95, 268-277. doi: 10.1016/j.ygeno.2010.02.008

Hornemann, S., Schorn, C., and Wüthrich, K. (2004). NMR structure of the bovine prion protein isolated from healthy calf brains. EMBO Rep. 5, 1159-1164. doi: 10.1038/sj.embor.7400297

Jackson, G. S., Hosszu, L. L., Power, A., Hill, A. F., Kenney, J., Saibil, H., et al. (1999). Reversible conversion of monomeric human prion protein between native and fibrilogenic conformations. Science 283, 1935-1937. doi: 10.1126/science.283.5409.1935

James, T. L., Liu, H., Ulyanov, N. B., Farr-Jones, S., Zhang, H., Donne, D. G., et al. (1997). Solution structure of a 142-residue recombinant prion protein corresponding to the infectious fragment of the scrapie isoform. Proc. Natl. Acad. Sci. 94, 10086-10091. doi: 10.1073/pnas.94.19.10086
Kanaani, J., Prusiner, S. B., Diacovo, J., Baekkeskov, S., and Legname, G. (2005). Recombinant prion protein induces rapid polarization and development of synapses in embryonic rat hippocampal neurons in vitro. J. Neurochem. 95, 1373-1386. doi: 10.1111/j.1471-4159.2005.03469.x

Lee, I. Y., Westaway, D., Smit, A. F. A., Wang, K., Seto, J., Chen, L., et al. (1998). Complete genomic sequence and analysis of the prion protein gene region from three mammalian species. Genome Res. 8, 1022-1037.

Lührs, T., Riek, R., Güntert, P., and Wüthrich, K. (2003). NMR structure of the human doppel protein. J. Mol. Biol. 326, 1549-1557. doi: 10.1016/S00222836(02)01471-7

Lysek, D. A., Schorn, C., Nivon, L. G., Esteve-Moya, V., Christen, B., Calzolai, L., et al. (2005). Prion protein NMR structures of cats, dogs, pigs, and sheep. Proc. Natl. Acad. Sci. U.S.A. 102, 640-645. doi: 10.1073/pnas.04089 37102

Makrinou, E., Collinge, J., and Antoniou, M. (2002). Genomic characterization of the human prion protein (PrP) gene locus. Mamm. Genome 13, 696-703. doi: 10.1007/s00335-002-3043-0

Meyer, R. K., McKinley, M. P., Bowman, K. A., Braunfeld, M. B., Barry, R. A., and Prusiner, S. B. (1986). Separation and properties of cellular and scrapie prion proteins. Proc. Natl. Acad. Sci. U.S.A. 83, 2310-2314. doi: 10.1073/pnas.83.8.2310

Miesbauer, M., Bamme, T., Riemer, C., Oidtmann, B., Winklhofer, K. F., Baier, M., et al. (2006). Prion protein-related proteins from zebrafish are complex glycosylated and contain a glycosylphosphatidylinositol anchor. Biochem. Biophys. Res. Commun. 341, 218-224. doi: 10.1016/j.bbrc.2005.12.168

Moore, R. C., Lee, I. Y., Silverman, G. L., Harrison, P. M., Strome, R., Heinrich, C., et al. (1999). Ataxia in prion protein (PrP)-deficient mice is associated with upregulation of the novel PrP-like protein doppel. J. Mol. Biol. 292, 797-817. doi: 10.1006/jmbi.1999.3108

Oesch, B., Westaway, D., Wälchli, M., McKinley, M. P., Kent, S. B., Aebersold, R., et al. (1985). A cellular gene encodes scrapie PrP 27-30 protein. Cell 40, 735-746. doi: 10.1016/0092-8674(85)90333-2

Premzl, M., Gready, J. E., Jermiin, L. S., Simonic, T., Graves, J. A. M., and Marshall Graves, J. A. (2004). Evolution of vertebrate genes related to prion and Shadoo proteins-clues from comparative genomic analysis. Mol. Biol. Evol. 21, 2210-2231. doi: 10.1093/molbev/msh245

Premzl, M., Sangiorgio, L., Strumbo, B., Marshall Graves, J. A., Simonic, T., and Gready, J. E. (2003). Shadoo, a new protein highly conserved from fish to mammals and with similarity to prion protein. Gene 314, 89-102. doi: 10.1016/S0378-1119(03)00707-8

Prusiner, S. B. (1998). Nobel lecture: prions. Proc. Natl. Acad. Sci. U.S.A. 95, 13363-13383. doi: 10.1073/pnas.95.23.13363

Prusiner, S. B., Bolton, D. C., Groth, D. F., Bowman, K. A., Cochran, S. P., and McKinley, M. P. (1982). Further purification and characterization of scrapie prions. Biochemistry 21, 6942-6950. doi: 10.1021/bi00269a050

Rezaei-Ghaleh, N., Andreetto, E., Yan, L. M., Kapurniotu, A., and Zweckstetter, M. (2011). Interaction between amyloid beta peptide and an aggregation blocker peptide mimicking islet amyloid polypeptide. PLoS ONE 6: e20289. doi: 10.1371/journal.pone.0020289

Riek, R., Hornemann, S., Wider, G., Billeter, M., Glockshuber, R., and Wüthrich, K. (1996). NMR structure of the mouse prion protein domain $\operatorname{PrP}(121-231)$. Nature 382, 180-182. doi: 10.1038/382180a0

Russ, W. P., and Engelman, D. M. (2000). The GxxxG motif: a framework for transmembrane helix-helix association. J. Mol. Biol. 296, 911-919. doi: 10.1006/jmbi.1999.3489

Santuccione, A., Sytnyk, V., Leshchyns'ka, I., and Schachner, M. (2005). Prion protein recruits its neuronal receptor NCAM to lipid rafts to activate p59fyn and to enhance neurite outgrowth. J. Cell Biol. 169, 341-354. doi: 10.1083/jcb.200409127

Shaked, Y., Hijazi, N., and Gabizon, R. (2002). Doppel and $\operatorname{PrP}(C)$ do not share the same membrane microenvironment. FEBS Lett. 530, 85-88. doi: 10.1016/S00145793(02)03430-0

Silverman, G. L., Qin, K., Moore, R. C., Yang, Y., Mastrangelo, P., Tremblay, P., et al. (2000). Doppel is an N-glycosylated, glycosylphosphatidylinositol-anchored protein. Expression in testis and ectopic production in the brains of $\operatorname{Prnp}(0 / 0)$ mice predisposed to Purkinje cell loss. J. Biol. Chem. 275, 26834-26841. doi: 10.1074/jbc.M003888200

Sparkes, R. S., Simon, M., Cohn, V. H., Fournier, R. E., Lem, J., Klisak, I., et al. (1986). Assignment of the human and mouse prion protein genes 
to homologous chromosomes. Proc. Natl. Acad. Sci. 83, 7358-7362. doi: 10.1073/pnas.83.19.7358

Thandapani, P., O'Connor, T. R., Bailey, T. L., and Richard, S. (2013). Defining the RGG/RG motif. Mol. Cell 50, 613-623. doi: 10.1016/j.molcel.2013. 05.021

Van Rheede, T., Smolenaars, M. M. W., Madsen, O., and de Jong, W. W. (2003). Molecular evolution of the mammalian prion protein. Mol. Biol. Evol. 20, 111-121. doi: 10.1093/molbev/ msg014

Watts, J. C., Drisaldi, B., Ng, V., Yang, J., Strome, B., Horne, P., et al. (2007). The CNS glycoprotein Shadoo has $\operatorname{PrP}(C)$-like protective properties and displays reduced levels in prion infections. EMBO J. 26, 4038-4050. doi: 10.1038/sj.emboj.7601830

Watts, J. C., and Westaway, D. (2007). The prion protein family: diversity, rivalry, and dysfunction. Biochim. Biophys. Acta 1772, 654-672. doi: 10.1016/j.bbadis.2007.05.001

$\mathrm{Xu}$, Z., Prigent, S., Deslys, J.-P., and Rezaei, H. (2011). Dual conformation of H2H3 domain of prion protein in mammalian cells. J. Biol. Chem. 286, 40060-40068. doi: 10.1074/jbc.M111.275255

Yusa, S., Oliveira-Martins, J. B., Sugita-Konishi, Y., and Kikuchi, Y. (2012). Cellular prion protein: from physiology to pathology. Viruses 4, 3109-3131. doi: $10.3390 / \mathrm{v} 4113109$
Zhang, H., Stockel, J., Mehlhorn, I., Groth, D., Baldwin, M. A., Prusiner, S. B., et al. (1997). Physical studies of conformational plasticity in a recombinant prion protein. Biochemistry 36, 3543-3553. doi: 10.1021/bi961965r

Conflict of Interest Statement: The Associate Editor Jean-Luc Vilotte declares that, despite being affiliated to the same institution as the author Human Rezaei, the review process was handled objectively and no conflict of interest exists. The authors declare that the research was conducted in the absence of any commercial or financial relationships that could be construed as a potential conflict of interest.

Received: 15 October 2014; accepted: 09 January 2015; published online: 11 February 2015.

Citation: Ciric D and Rezaei H (2015) Biochemical insight into the prion protein family. Front. Cell Dev. Biol. 3:5. doi: 10.3389/fcell.2015.00005

This article was submitted to Cell Death and Survival, a section of the journal Frontiers in Cell and Developmental Biology.

Copyright (C) 2015 Ciric and Rezaei. This is an open-access article distributed under the terms of the Creative Commons Attribution License (CC BY). The use, distribution or reproduction in other forums is permitted, provided the original author(s) or licensor are credited and that the original publication in this journal is cited, in accordance with accepted academic practice. No use, distribution or reproduction is permitted which does not comply with these terms. 


\section{ADVANTAGES OF PUBLISHING IN FRONTIERS}
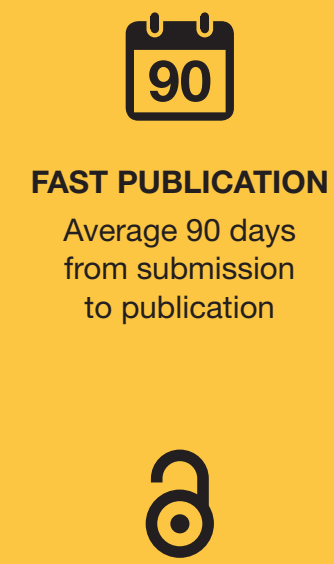

OPEN ACCESS

Articles are free to read, for greatest visibility

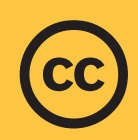

\section{COPYRIGHT TO AUTHORS}

No limit to article distribution and re-use

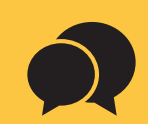

COLLABORATIVE

PEER-REVIEW

Designed to be rigorous yet also collaborative, fair and constructive

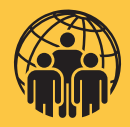

TRANSPARENT

Editors and reviewers acknowledged by name on published articles

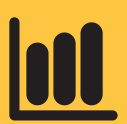

IMPACT METRICS

Advanced metrics track your article's impact

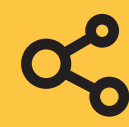

\section{RESEARCH NETWORK}

Our network increases readership

for your article

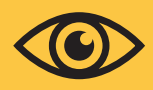

\section{GLOBAL SPREAD}

Six million monthly page views worldwide

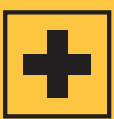

SUPPORT

By our Swiss-based editorial team 